EVANDRO JOSÉ DA SILVA

\title{
ANÁLISE DOS PADRÕES E RECOMENDAÇÕES DA ICAO E DA FAA PARA O PROJETO GEOMÉTRICO DE AERÓDROMOS
}

\author{
Dissertação apresentada à Escola \\ Politécnica da Universidade de São Paulo \\ para a obtenção do título de Mestre em \\ Engenharia.
}

São Paulo, 
EVANDRO JOSÉ DA SILVA

\section{ANÁLISE DOS PADRÕES E RECOMENDAÇÕES DA ICAO E DA FAA PARA O PROJETO GEOMÉTRICO DE AERÓDROMOS}

Dissertação apresentada à Escola Politécnica da Universidade de São Paulo para a obtenção do título de Mestre em Engenharia.

Área de Concentração:

Engenharia de Transportes

Orientador:

Prof. Dr. Nicolau Dionísio Fares Gualda

São Paulo, 2012 
Este exemplar foi revisado e alterado em relação à versão original, sob responsabilidade única do autor e com a anuência de seu orientador.

São Paulo, de abril de 2012.

Assinatura do autor

Assinatura do orientador

Silva, Evandro José da

Análise dos padrões e recomendações da ICAO e da FAA para o projeto geométrico de aeródromos / E.J. da Silva. -- ed. rev. -- São Paulo, 2012.

254 p.

Dissertação (Mestrado) - Escola Politécnica da Universidade de São Paulo. Departamento de Engenharia de Transportes.

1. Aeroportos (Planejamento; Projeto) 2. Terminais de transportes 3. Normas técnicas I. Universidade de São Paulo. Escola Politécnica. Departamento de Engenharia de Transportes II. t. 


\section{AGRADECIMENTOS}

Ao orientador Prof. Dr. Nicolau Dionísio Fares Gualda, pelos ensinamentos, discussões e apoio.

Aos professores da banca examinadora, Prof. Dr. Cláudio Jorge Pinto Alves e Prof. Dr. Carlos Müller, pelo interesse em participar da banca e pelas sugestões.

Aos professores do Departamento de Engenharia de Transportes da EPUSP, pela confiança depositada e pelos ensinamentos.

Aos professores e amigos da UNISC, pelas atividades de pesquisa durante a graduação.

Aos colegas do LPT e do curso, especialmente Auro, Daniel, Medau, Jorge, Renato e Wagner.

Aos amigos que encontrei em São Paulo, pelas horas descontraídas e pelas boas conversas, em especial, Ariadne, Carlos, Fabiano, Henrique e Paula, Inaê, Jaime e Adriana, Jansen e Cecília, Renan e Eliana, Thayne, Tiago e Walter.

Aos meus pais, Cláudio e Marlise, à minha irmã Deise, e a toda a minha família, pelo estímulo e incondicional apoio.

Ao CNPq, pela bolsa concedida.

E ainda, aos que eu tenha, por desatenção, esquecido de mencionar. 


\section{RESUMO}

Esta pesquisa de mestrado aborda o projeto geométrico de aeródromos a partir dos padrões e recomendações da ICAO (International Civil Aviation Organization) e da FAA (Federal Aviation Administration). Os padrões e recomendações da ICAO foram extraídos do documento Annex 14 to the Convention on International Civil Aviation e de documentos por ele referenciados. Para o caso da FAA, serviu de base o documento Airport Design: Advisory Circular 150/5300-13, incluindo-se aqueles nele referenciados e considerados pertinentes ao escopo do estudo. Seguindo-se uma estrutura de critérios de projeto proposta, os padrões e recomendações da ICAO e da FAA são comparados entre si, explicitando-se as diferenças nas especificações em si e também na forma como estas especificações são feitas por cada norma. Para o caso em que comparações diretas não são possíveis, as comparações são feitas a partir de um conjunto de aeronaves com características conhecidas. No caso dos critérios cuja avaliação é mais complexa, equacionamentos matemáticos são propostos. Apresenta-se também uma série de flexibilizações dos padrões, as quais são voltadas à acomodação das aeronaves A380-800 e B747-8 em aeroportos existentes. Estas flexibilizações provêm das conclusões do A380 Airport Compatibility Group (AACG) e do Boeing 747-8 Airport Compatibility Group (BACG), no caso dos padrões da ICAO. Para a as flexibilizações dos padrões da FAA, servem de base os Engineering Briefs (EBs) por ela emitidos. Finalmente, com base nos critérios de projeto considerados, é feita uma análise do Aeroporto Internacional de São Paulo/Guarulhos quanto à operação das aeronaves A380-800 e B747-8.

Palavras-Chave: Projeto de aeródromos. ICAO. FAA. Aeroportos. 


\begin{abstract}
This Master Thesis tackles aerodrome geometric design according to the standards and recommended practices from the ICAO (International Civil Aviation Organization) and the FAA (Federal Aviation Administration). ICAO standards and recommended practices are from the document Annex 14 to the Convention on International Civil Aviation and from the referred documents. In turn, FAA documents herein addressed are the Airport Design: Advisory Circular 150/5300-13 and others referred in this one. By following a proposed design criteria framework, ICAO and FAA standards and recommended practices are compared. From such comparison, it is shown the differences in specifications itself and also in the way by which ICAO and FAA specify their standards. For the cases where direct comparisons are not possible, it is used a set of aircrafts of known characteristics. For the most complex design criteria, mathematical equations are also proposed. Another addressed issue is the flexibilization of design standards, which aims the accommodation of A380-800 and B747-8 aircrafts at existing airports. The ICAO flexibilizations are made from conclusions of the A380 Airport Compatibility Group (AACG) and the Boeing 747-8 Airport Compatibility Group (BACG). FAA flexibilizations are from this same agency, namely through EBs (Engineering Briefs). Lastly, the addressed design criteria are applied to analyse the operation of $A 380-800$ and B747-8 aircrafts at São Paulo/Guarulhos International Airport.
\end{abstract}

Keywords: Aerodrome Design. ICAO. FAA. Airports. 


\section{LISTA DE ILUSTRAÇÕES}

Figura 4.3-1 - Exemplo de uma PTSR

Figura 4.3-2 - Geometria padrão da ICAO para uma PTSR que serve aos grupos dinâmicos 1 e 2 .

Figura 4.3-3 - Geometria padrão da ICAO para uma PTSR que serve aos grupos dinâmicos 3 e 4 . .50

Figura 4.3-4 - Geometria padrão da FAA para uma PTSR. 50

Figura 4.3-5 - Relação entre o raio de saída de uma PTSR e a velocidade de turnoff.

Figura 4.4-1 - Distâncias declaradas 59

Figura 4.5-1 - Geometria para análise da trajetória de aeronaves em curvas. 62

Figura 4.5-2 - Método gráfico para desenho de sobrelarguras. 66

Figura 4.5-3 - Método arco e tangente para desenho de sobrelarguras. 66

Figura 4.6-1- Recomendações para separação entre uma RW e uma TW. 72

Figura 4.6-2 - Rotas de táxi em um aeródromo. 74

Figura 4.6-3 - Separações FAA para as posições de estacionamento. .78

Figura 4.6-4 - BPRWs e BPs. .80

Figura 4.7-1 - Esquema das áreas de proteção da RW. .86

Figura 4.7-2 - Proposta de divisão da faixa da RW em três áreas. .87

Figura 4.7-3 -Área preparada da faixa da RW para os grupos dinâmicos 3 e 4 operando em pistas de aproximação de precisão. 89

Figura 4.7-4- Geometria da RPZ. .95

Figura 4.7-5 - Referencial longitudinal para as áreas de proteção da RW. .99

Figura 4.8-1 - Proposta de divisão da faixa da TW em duas áreas. 101

Figura 4.9-1 -Superfícies da OFZ conforme ICAO. 107

Figura 4.9-2 -Superfícies da OFZ conforme FAA, destinada a aeronaves de grande porte, com visibilidade de aproximação menor do que $1.200 \mathrm{~m}$ em uma RW com cabeceira deslocada. 
Figura 4.9-3 -Geometria da OFZ de transição interna da FAA.

Figura 4.9-4 - Vista superior da geometria utilizada para modelagem da OFZ de transição interna.

Figura 4.9-5 -OFZ de transição interna para uma aeronave que espera para entrar na RW.

Figura 4.9-6 - Geometria da OFZ de transição interna, conforme FAA para condições CAT I.

Figura 4.9-7 - Geometria da OFZ de transição interna, conforme FAA para condições CAT II e III.

Figura 5.2-1- Comparação dos critérios da ICAO e da FAA para o vento de través.

Figura 5.3-1- Comparação dos critérios da ICAO e da FAA para a largura da RW.

Figura 5.3-2- Comparação dos critérios da ICAO e da FAA para a largura combinada entre a RW e seus acostamentos. Dados disponíveis no ANEXO B...135

Figura 5.3-3- Comparação dos critérios da ICAO e da FAA para o comprimento de blast pads.

Figura 5.6-1- Comparação entre as especificações da ICAO e da a FAA para a separação entre RWs paralelas, em pistas para aproximação visual, com base nas aeronaves da Tabela 5.1-1....

Figura 5.6-2- Comparação entre as especificações da ICAO e da a FAA para separação entre RWs e TWs paralelas com base nas aeronaves da Tabela 5.1-1. Cenários 1 e 2 para o caso em que a aeronave espera para entrar na RW.

Figura 5.6-3- Comparação entre as especificações da ICAO e da a FAA para separação entre RWs e TWs paralelas com base nas aeronaves da Tabela 5.1-1. Cenários 3 e 4 para o caso em que a aeronave espera para entrar na RW.

Figura 5.6-4- Comparação entre as especificações da ICAO e da a FAA para separação entre RWs e TWs paralelas, com base nas aeronaves da Tabela 5.1-1. Cenários 5 e 6 para o caso em que a aeronave espera para entrar na RW.

Figura 5.7-1- Comparação entre as especificações da ICAO e da a FAA para a largura das áreas de proteção da RW, com base nas aeronaves da Tabela 5.1-1. Cenário 1. 
Figura 5.7-2- Comparação entre as especificações da ICAO e da FAA para a largura das áreas de proteção da RW, com base nas aeronaves da Tabela 5.1-1. Cenário 2.

Figura 5.7-3- Comparação entre as especificações da ICAO e da FAA para o comprimento das áreas de proteção da RW desde o final da RW, com base nas aeronaves da Tabela 5.1-1. Cenário 1.

Figura 5.7-4- Comparação entre as especificações da ICAO e da FAA para o comprimento das áreas de proteção da RW desde o final da RW, com base nas aeronaves da Tabela 5.1-1. Cenário 2

Figura 5.8-1- Comparação entre as especificações da ICAO e da FAA para a largura das áreas de proteção da TW.

Figura 5.9-1- Comparação entre as especificações da ICAO e da FAA para as superfícies da OFZ.

Figura 5.9-2- Comparação entre as especificações da ICAO e da FAA para OFZs de transição interna. 164

Figura 6.1-1- Nível de gravidade (severity level). 177

Figura 7.2-1 - Dispersão lateral máxima do jet blast de $\mathbf{3 5 m p h}$. 186

Figura 7.2-2 - Dispersão longitudinal máxima do jet blast a $\mathbf{3 5 m p h}$, desde a bequilha.

Figura 7.2-3 - Dispersão longitudinal máxima do jet blast a 35mph, desde a cauda.

Figura 7.5-1 - Comparação entre as aeronaves A380-800 e A340-600 quando estas encontram-se inicialmente desviadas em $90^{\circ}$ em relação a uma linha guia retilínea. .194

Figura 7.5-2 -Trajetória para as aeronaves A340-600 e A380-800 durante manobra associada ao caso ii . 194

Figura 7.5-3 - Trajetória para as aeronaves A340-600 e A380-800 durante manobra associada ao caso iii 195

Figura 7.6-1 - Posição das barras de parada. 199 


\section{LISTA DE TABELAS}

Tabela 4.1-1 - Código de referência do aeródromo (ARC), conforme ICAO .38

Tabela 4.1-2 - Código de referência do aeródromo (ARC), conforme FAA . .39

Tabela 4.3-1 - Largura padrão para a pista de pouso e decolagem, conforme ICAO

Tabela 4.3-2 - Largura padrão da pista de pouso e decolagem, conforme FAA ......43

Tabela 4.3-3 - Larguras recomendadas para acostamentos da RW, conforme ICAO

Tabela 4.3-4 - Largura padrão dos acostamentos de uma pista de pouso e

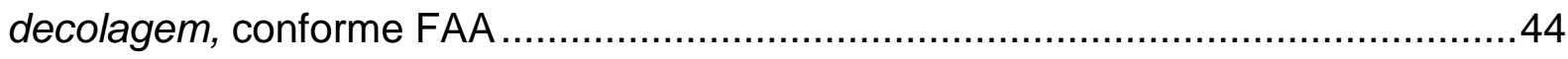

Tabela 4.3-5 - Dimensões da blast pad, conforme FAA …...................................45

Tabela 4.3-6 - Padrão ICAO para a folga do pavimento e para a largura da pista de táxi.

Tabela 4.3-7 - Padrão FAA para a folga do pavimento e para a largura da pista de táxi......

Tabela 4.3-8 - Padrão ICAO para a largura combinada entre pistas de táxi e seus acostamentos.

Tabela 4.3-9 - Padrão FAA para os acostamentos das TWs. .48

Tabela 4.3-10 - Relação entre o raio de saída de uma PTSR e a velocidade de turnoff

Tabela 4.6-1 - Separação padrão da ICAO entre RWs e TWs paralelas .71

Tabela 4.6-2 - Padrão FAA para a separação entre RWs e TWs / TLs. .72

Tabela 4.6-3 - Padrão ICAO para separação entre pistas de táxi e entre estas e objetos. .75

Tabela 4.6-4 - Padrão FAA para separação entre pistas de táxi e entre estas e objetos. .76

Tabela 4.6-5 - Padrão ICAO para separação entre a aeronave e: outras aeronaves; terminais; e outros objetos fixos .77

Tabela 4.6-6 - Padrão ICAO para a separação entre a BPRW e o centro da RW....80 Tabela 4.6-7 - Padrão FAA para separação entre a BPRW e o centro da RW .82 
Tabela 4.6-8 - Distância entre uma RW e uma BPRW, considerando-se as especificações da área restrita da faixa da RW, para RWs para aproximação de

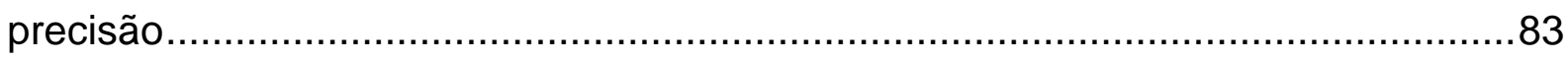

Tabela 4.6-9 - Altura da OFZ de transição interna na BPRW $(\mathrm{m})$..........................85

Tabela 4.7-1 - Padrão FAA para a ROFA .................................................... 92

Tabela 4.7-2 - Dimensões padrão da FAA para a RSA ..................................93

Tabela 4.7-3 - RPZ de aproximação e saída para RW utilizada em toda a extensão

Tabela 4.7-4 - RPZ de saída para distâncias declaradas

Tabela 4.7-5 - Referencial longitudinal paras as áreas de proteção da RW 100

Tabela 4.8-1 - Largura padrão ICAO para a área preparada da faixa da TW.........102

Tabela 4.8-2 - Largura padrão da OFA da TW ..........................................103

Tabela 4.8-3 - Padrão de folga OFA da TW ...............................................103

Tabela 4.8-4 - Largura padrão da OFA da TL $(\mathrm{m})$......................................104

Tabela 4.8-5 - Largura padrão da FAA para a TSA ....................................104

Tabela 4.9-1 - Padrões ICAO para as superfícies da OFZ ...............................109

Tabela 4.9-2 - Resumo das equações utilizadas para modelagem da OFZ de transição interna......................................................................................... 121

Tabela 5.1-1 - Dados utilizados como base de especificação pela ICAO e pela FAA relativos a um conjunto de aeronaves selecionadas

Tabela 5.1-2 -Grupos dinâmicos da ICAO e da FAA para as aeronaves da Tabela 5.1-1

Tabela 5.1-3 -Grupos geométricos da ICAO e da FAA para as aeronaves da Tabela 5.1-1 128

Tabela 5.1-4 -Dominância entre os dois critérios do grupo geométrico da ICAO e da FAA para as aeronaves da Tabela 5.1-1. 128

Tabela 5.3-1 - Comparação entre os padrões da ICAO e da FAA para largura da pista de táxi e para a folga do pavimento

Tabela 5.3-2 - Comparação dos padrões de largura combinada entre a TW e seus acostamentos, para a ICAO e para a FAA $(\mathrm{m})$

Tabela 5.6-1 - Cenários para comparação entre os padrões da ICAO e da FAA quanto à separação entre RWs e TWs 
Tabela 5.6-2 - Comparação entre os padrões da ICAO e da FAA quanto a separações em TWs

Tabela 5.6-3 - Comparação entre os padrões da ICAO e da FAA quanto separações em TLS

Tabela 5.6-4 - Comparação entre as separações padrão da ICAO e da FAA para o pátio de aeronaves 146

Tabela 5.6-5 - Cenários para as comparações entre os padrões da ICAO e da FAA quanto a BPRWs e OFZs de transição interna. 148

Tabela 5.6-6 - Comparação entre os padrões da ICAO e da FAA para BPRWs e OFZs de transição interna 150

Tabela 5.7-1 - Comparação quanto ao uso e preparação das áreas de proteção da RW

Tabela 5.8-1 - Comparação das especificações quanto ao uso e preparação das áreas de proteção da TW

Tabela 6.2-1 - EBs da FAA relacionados à acomodação das aeronaves A380 e B747-8. 178

Tabela 7.2-1 - Distâncias laterais de sucção, semi-larguras padrão das RWs e TWs e posição do centro das turbinas, tomando-se como referência o eixo longitudinal da aeronave 184

Tabela 7.2-2 - Folgas quanto à distância de sucção e quanto à posição da turbina desde a linha de centro longitudinal da aeronave 185

Tabela 7.2-3 - Variação entre a dispersão lateral máxima do contorno jet blast a 35 mph 186

Tabela 7.2-4 - Variação da dispersão lateral e longitudinal do jet blast: A380-800 e B747-8 versus A340-600 e B747-400 188

Tabela 7.5-1 - Dimensões WS, $d_{\text {beq }}$ e $d$ de aeronaves selecionadas. 192

Tabela 7.6-1 - Distância máxima possível entre a RW 09L/27R e a BPRW que the dá acesso desde a TW B 197

Tabela 7.6-2 - Posição das barras de parada. 199

Tabela 7.9-1 - Avaliação da OFZ de transição interna nas BPRWs do SBGR .203 


\section{LISTA DE ABREVIATURAS E SIGLAS}

AACG: Airbus A380 Airport Compatibility Group.

AGFRW: Área Geral da Faixa da RW (sigla proposta).

AGFTW: Área Geral da Faixa da TW (sigla proposta).

Alt.: Altitude.

APFRW: Área Preparada da Faixa da RW (sigla proposta).

APFTW: Área Preparada da Faixa da TW (sigla proposta).

Aprox.: Aproximação.

ARFRW: Área Restrita da Faixa da RW (sigla proposta).

ANAC: Agência Nacional de Aviação Civil.

AOPG: Aerodrome Operations Planning Group.

APM: Airport Planning Manual; aircraft characteristics for airport planning.

ARC: Código de referência do aeródromo/aeroporto; Airport/Aerodrome Reference Code.

ASDA: Distância disponível para aceleração e parada; Accelerate Stop Distance Available.

ATC: Controle de tráfego aéreo; Air Traffic Control.

BACG: Boeing 747-8 Airport Compatibility Group.

BP: Barra de Parada em intersecções entre pistas de táxi.

BPRW: Barra de Parada da pista de pouso e decolagem; Holdline (sigla proposta).

BRL: Building Restriction Line; Linha de restrição predial.

C: a) Coluna; e b) Cenário (sigla proposta).

CAT I, II ou III: Categoria de aproximação de precisão I, II ou III; Precision Approach Category.

CBP: Comprimento Básico de Pista da aeronave; aeroplane reference field length.

CR: Critério (sigla proposta).

CRM: Collision Risk Model.

CWY: Zona desimpedida; Clea.rway .

EB: Engineering Brief.

e-CFR: electronic Code of Federal Regulations.

EAM Efeito do Arremesso de Materiais (sigla proposta).

EE: Efeito de Erosão (sigla proposta).

EFA: Efeito do Fluxo de Ar (sigla proposta).

EUA: Estados Unidos da América.

FAA: Federal Aviation Administration. 
FOD: Dano devido a um objeto estranho; Foreign Object Damage.

ICAO: International Civil Aviation Organization.

IFR: Regras de vôo por instrumentos; Instrument Flight Rules.

ILS: Instrument Landing System.

LDA: Distância disponível para pouso; Landing Distance Available.

MLS: Microwave Landing System.

MoSs: Modification of Standards (FAA).

MTOW: Peso máximo de decolagem; Maximum Take-Off Weight.

Navaid: Navigational aid.

NLA: New Large Aeroplane.

OAS: Obstacle Assessment Surface.

OCA I OCH: Obstacle Clearance Altitude / Obstacle Clearance Height.

OCP: Obstacle Clearance Panel (ICAO).

OFA: Área livre de objetos ; Object Free Area.

OFZ: Zona livre de objetos; Object Free Zone.

PANS-ATM: Procedures for Air Navigation Services: Air Traffic Management.

PANS-OPS: Procedures for Air Navigation Services - Aircraft Operations.

POFZ: Precision Object Free Zone.

PTSR: Pista de Táxi de Saída Rápida (sigla proposta).

RESA: Runway End Safety Area.

ROFA: Área livre de objetos da RW; Runway Object Free Area (FAA).

RPZ: Runway Protection Zone (FAA).

RSA: Runway Safety Area (FAA).

RVR: Runway Visual Range.

RW: Pista de pouso e decolagem; Runway.

SWY: Zona de parada da pista de pouso e decolagem; Stopway.

TL: Pista de táxi de acesso ao estacionamento de aeronaves; Aircraft Stand Taxilane (ICAO); Taxilane (FAA).

TLS: Target Level of Safety.

TODA: Distância disponível para decolagem; Take-Off Distance Available.

TORA Distância disponível para corrida de decolagem: Take-Off Run Available.

TOFA: Taxiway Object Free Area (FAA).

TW: Pista de táxi; Taxiway.

VFR: Regras de vôo visual; Visual Flight Rules.

WS: Wheel span (sigla proposta). 


\section{LISTA DE SÍMBOLOS}

ang: posição relativa da aeronave em relação à $\mathrm{RW}$ sob análise variando entre $0^{\circ} \mathrm{e}$ $+90^{\circ}$.

C: Coluna.

d: Comprimento de referência da aeronave (aircraft datum length).

dec, dec1, dec2: Declividade (horizontal:vertical) da OFZ de transição interna.

$\mathbf{d}_{\mathbf{x}}$ : Distância longitudinal absoluta entre N e P.

$\mathbf{d}_{\mathrm{y}}$ : Distância transversal absoluta entre N e P.

E: Elevação em relação ao nível do mar.

env: envergadura da aeronave.

env taxia: envergadura da aeronave que taxia.

f: Fator de carga lateral.

folga $_{\text {taxia: }}$ folga de ponta de asa associada à aeronave que taxia

g: Aceleração da gravidade $\left(9,81 \mathrm{~m} / \mathrm{s}^{2}\right)$.

GD: Grupo dinâmico.

GG: Grupo geométrico.

H1: Variável utilizada para a construção da OFZ de transição interna pelos critérios da FAA em condições CAT I.

$\mathbf{H}_{2}$ : Variável utilizada para a construção da OFZ de transição interna pelos critérios da FAA em condições CAT II e III.

L: a) Dimensão utilizada para o desenho de uma sobrelargura pelo método arco e tangente, representando o comprimento ao longo do eixo da TW, desde o ponto em que a aeronave inicia a taxiar sobre a linha guia retilínea até o ponto em que a reta tangente ao arco intercepta a borda da TW. b) Linha.

$\mathbf{L}_{\mathbf{R W}}$ : Comprimento da pista de pouso e decolagem.

lasa: distância longitudinal entre o nariz da aeronave e a ponta da asa.

lest: distância longitudinal entre o nariz da aeronave e o estabilizador.

$l_{\text {espera: }}$ comprimento da aeronave que espera.

$\mathbf{L}_{1}$ : Comprimento da RSA anterior ao início da RW.

$\mathbf{L}_{2}$ : Comprimento da RSA posterior ao final da RW.

M: Folga do pavimento. 
N: Ponto de referência da aeronave, assumido a seguir a linha guia.

P: Ponto de interesse para uma dada análise.

R: Raio.

r: Dimensão utilizada para o desenho de uma sobrelargura pelo método arco e tangente, representando o raio do arco da sobrelargura, concêntrico ao arco de círculo da linha guia.

S: Envergadura de uma aeronave.

TP: Tipo de RW. Trata-se de uma classificação conforme os auxílios à aproximação ou mínimo de visibilidade permitido. Conforme os conceitos da ICAO, os tipos de RW são: RW para aproximação visual; RW para aproximação de não precisão; e RW para aproximação de precisão. Já para a FAA pode significar: RW para aproximação com visibilidade maior ou igual a $1.200 \mathrm{~m}$; RW para aproximação com visibilidade menor do que $1.200 \mathrm{~m}$, CAT I; e RW para aproximação com visibilidade menor do que $1.200 \mathrm{~m}$, CAT II ou III.

U: Centroide das rodas do trem principal.

V: Velocidade.

$\mathbf{V}_{\text {ap: }}$ Velocidade de aproximação que corresponde a 1,3 vezes a velocidade de estol com os flapes na configuração máxima certificada para pouso, no MTOW, em condições ISA, ao nível do mar.

$\mathbf{V}_{\text {des }}$ : Velocidade de saída de projeto (design exit speed), compatível com um fator de carga de $0,133 \mathrm{~g}$.

$\mathbf{V}_{\mathbf{o p}}$ : Velocidade operacional de saída (operational turn-off speed), que é menor do que a velocidade de saída de projeto $\left(\mathrm{V}_{\text {des }}\right)$ de forma a melhorar a aceitação dos pilotos em utilizar uma PTSR.

$\mathbf{V}_{1}, \mathbf{V}_{2}, \mathbf{V}_{3}$ : a) Folga ICAO entre TWs e objetos; e b) $\mathrm{V}_{1}$ significa velocidade de decisão.

W: Qualquer largura ou semi-largura.

Wacostamento_tw: Largura do acostamento da pista de táxi.

$\mathbf{W}_{\mathbf{b}}$ : Base de rodas, ou seja, a distância entre o centroide do trem principal e a bequilha (Wheel Base).

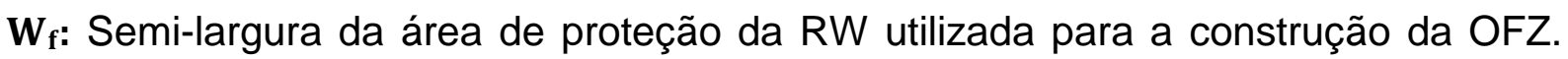
Para a ICAO esta área é a área restrita da faixa da RW e para a ICAO é a ROFZ.

$\mathbf{W}_{\text {folga_TL: }}$ Folga entre objetos e um aeronave que taxia em uma TL. 
$\mathbf{W}_{\text {folga_Tw: }}$ Folga entre objetos e um aeronave que taxia em uma TW.

WOFA_TL: Largura da OFA da TL.

WofA_tw: Largura da OFA da TW.

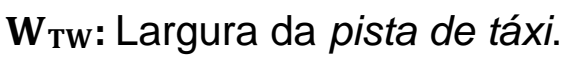

$\mathbf{X}_{\mathrm{N}}$ : Coordenada retangular do ponto $\mathrm{N}$ no eixo $\mathrm{x}$.

$\mathbf{X}_{1}, \mathbf{X}_{2}, \mathbf{X}_{3}$ : Desvio lateral máximo em uma TW, para fins de cálculo da folga ICAO entre TWs e objetos. Possui a mesma dimensão que a folga do pavimento.

$\mathbf{Y}_{\mathrm{N}}$ : Coordenada retangular do ponto $\mathrm{N}$ no eixo y.

Y: Variável utilizada para a construção da OFZ de transição interna pelos critérios da FAA em condições CAT II e III.

$\mathbf{Y}_{1}, \mathbf{Y}_{2}, \mathbf{Y}_{3}$ : semi-envergadura da aeronave.

Yasa: distância entre a ponta da asa e o eixo da RW.

yest: distância entre o estabilizador e o eixo da RW.

$\mathbf{y}_{\text {nar: }}$ distância entre a nariz da aeronave e o eixo da RW.

$\mathbf{Z}_{1}, \mathbf{Z}_{2}, \mathbf{Z}_{3}$ : Incremento ao desvio máximo em uma TW, para fins de cálculo da folga ICAO entre TWs e objetos.

zasa: altura da ponta da asa.

Zest: altura do estabilizador.

$\mathbf{z}_{\text {nar: }}$ altura do nariz.

\section{SÍMBOLOS GREGOS:}

$\boldsymbol{\alpha}$ : Ângulo formado entre a linha tangente à linha guia, no ponto $\mathrm{N}$, e o eixo $\mathrm{x}$.

$\boldsymbol{\beta}$ : Ângulo de esterçamento da aeronave.

$\boldsymbol{\beta}_{\text {beq }}$ : Ângulo de esterçamento da bequilha.

$\Delta$ : folga vertical entre o ponto de interesse da aeronave e a OFZ de transição interna. $\triangle$ ASA: folga vertical entre a ponta da asa e a OFZ de transição interna.

$\Delta$ EST: folga vertical entre o estabilizador e a OFZ de transição interna.

$\triangle$ NAR: folga vertical entre o nariz da aeronave e a OFZ de transição interna.

$\varphi 1$ e $\varphi 2$ : coeficientes utilizados para seleção da posição relativa entre P e N: para a porção da aeronave posicionada à frente de $\mathrm{N}$, deve-se utilizar $\varphi 1=-1$; para o lado direito da aeronave deve-se utilizar $\varphi 2=-1$; e para as demais situações utilizar valores positivos desses coeficientes. 


\section{SUMÁRIO}

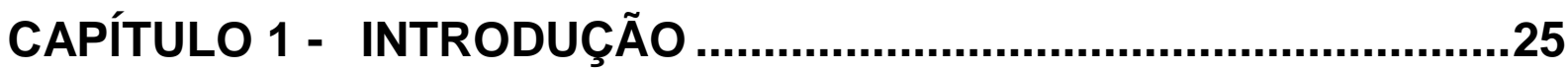

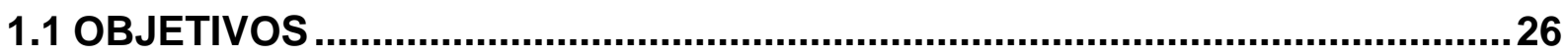

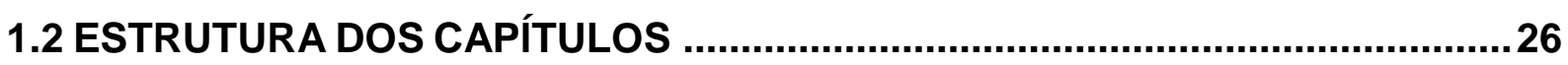

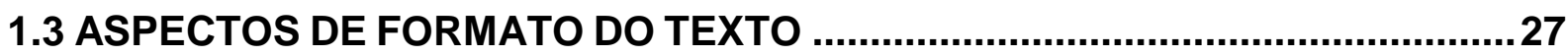

CAPÍTULO 2 - O PROJETO GEOMÉTRICO DE AERÓDROMOS NA

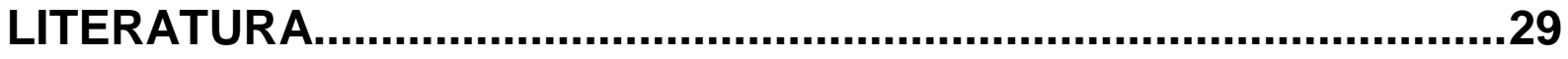

2.1 ICAO

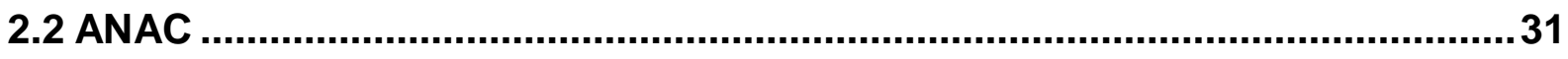

2.3 FAA

CAPÍTULO 3 - METODOLOGIA PROPOSTA...................................33

3.1 TERMOS PROPOSTOS PARA O TRABALHO ................................................33

3.2 ESTRUTURA DE CRITÉRIOS, METODOLOGIAS E CONSIDERÇAÕES DE

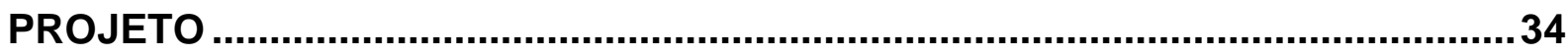

3.3 OUTROS ASPECTOS METODOLÓGICOS....................................................35

CAPÍTULO 4 - PADRÕES E RECOMENDAÇÕES DA ICAO E DA FAA PARA O PROJETO GEOMÉTRICO DE AERÓDROMOS .............37 4.1 CÓDIGO DE REFERÊNCIA DO AERÓDROMO (ARC) …..................................37

4.2 CONSIDERAÇÕES DE PROJETO

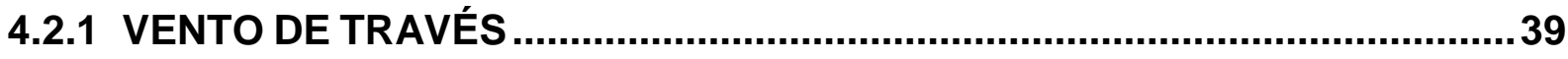

4.2.1.1 Relação entre os padrões para vento de través e outros componentes, metodologias e considerações de projeto ............................................................ 40

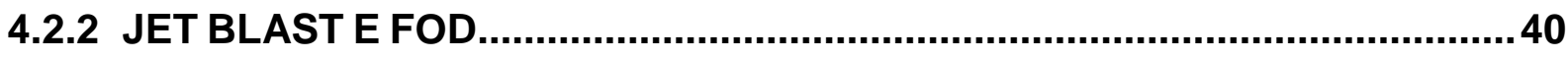

4.2.2.1 Relação entre o jet blast e outros componentes, metodologias e

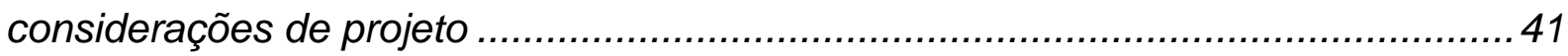

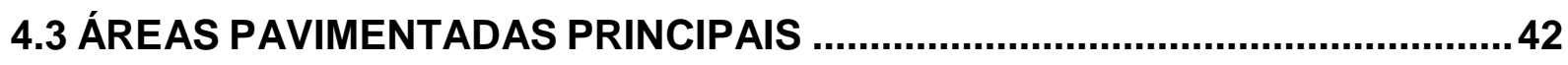

4.3.1 LARGURA DA PISTA DE POUSO E DECOLAGEM .....................................42

4.3.1.1 Relação entre a largura da RW e outros componentes, metodologias $e$

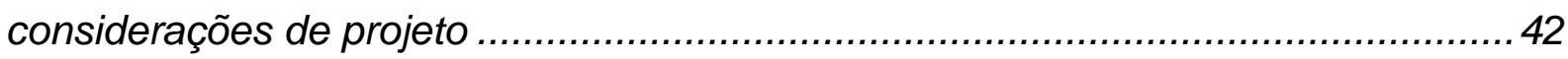


4.3.2.1 Relação entre a largura dos acostamentos da RW e outros componentes, metodologias e considerações de projeto ................................................. 43

4.3.3 BLAST PADS. .44

4.3.3.1 Relação entre as dimensões da blast pad e outros componentes, metodologias e considerações de projeto 45

4.3.4 LARGURA DAS PISTAS DE TÁXI 45

4.3.4.1 Relação entre a largura da TW e outros componentes, metodologias e considerações de projeto 46

4.3.5 ACOSTAMENTOS DA TW. .46

4.3.5.1 Relação entre a largura dos acostamentos da TW e outros componentes, metodologias e considerações de projeto .................................................47

4.3.6 PISTAS DE TÁXI DE SAÍDA RÁPIDA (PTSRS) ........................................48

4.3.6.1 Geometria de uma PTSR .......................................................... 49

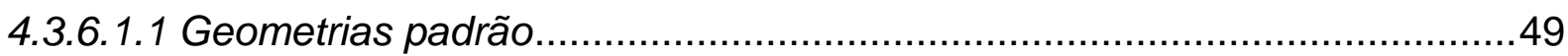

4.3.6.1.2 Princípios e Recomendações da ICAO para o projeto de PTSRs ..............51

4.3.6.2 Posição e número de PTSRs .................................................... 51

4.3.6.3 Relação entre PTSRs e outros componentes, metodologias e considerações de projeto .54

4.3.7 PISTAS DE TÁXI SOBRE PONTES 54

4.3.7.1 Relação entre TWs sobre pontes e outros componentes, metodologias e considerações de projeto 55

4.4 DISTÂNCIAS DECLARADAS. 55

4.4.1 ZONA DESIMPEDIDA (CLEARWAY - CWY) ............................................ 57

4.4.2 ZONA DE PARADA (STOPWAY - SWY) .58

4.4.3 RELAÇÃO ENTRE DISTÂNCIAS DECLARADAS E OUTROS COMPONENTES, METODOLOGIAS E CONSIDERAÇÕES DE PROJETO .............59

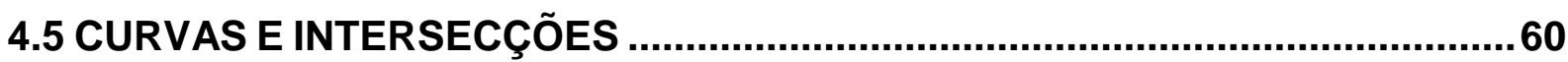

4.5.1 FATOR DE CARGA LATERAL ..............................................................61

4.5.2 TRAJETÓRIA DA AERONAVE ..............................................................61

4.5.2.1 Ângulo de esterçamento da aeronave............................................ 62

4.5.2.2 Ângulo de esterçamento das rodas .................................................. 63

4.5.2.3 Trajetória de pontos de interesse ................................................. 64 
4.5.3 SOBRELARGURAS

4.5.4 RELAÇÃO ENTRE CURVAS E INTERSECÇÕES E OUTROS COMPONENTES, METODOLOGIAS E CONSIDERAÇÕES DE PROJETO. 67

4.6 SEPARAÇÕES 67

4.6.1 SEPARAÇÃO ENTRE RWS PARALELAS 67

4.6.1.1 Especificações da ICAO para separações entre RWs paralelas 67

4.6.1.2 Especificações da FAA para separações entre RWs paralelas. 69

4.6.1.2.1 Separação entre RWs paralelas para operações VFR simultâneas.... 69

4.6.1.2.2 Separação entre RWs paralelas para operações IFR simultâneas 69 4.6.1.3 Relação entre separações em RWs paralelas e outros componentes, metodologias e considerações de projeto. 70

4.6.2 SEPARAÇÃO ENTRE RWs E TWS PARALELAS .70

4.6.2.1 Relação entre separações RW/TW e outros componentes, metodologias e considerações de projeto .73

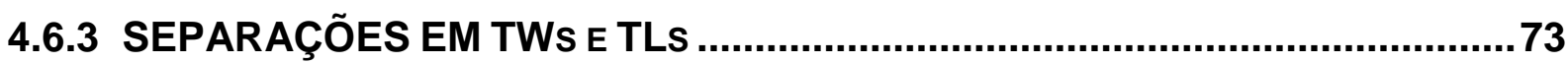

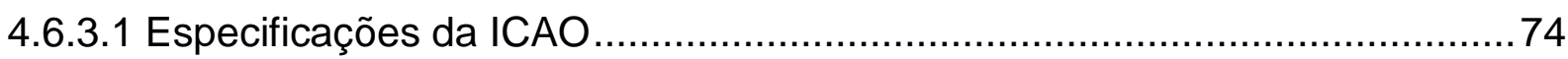

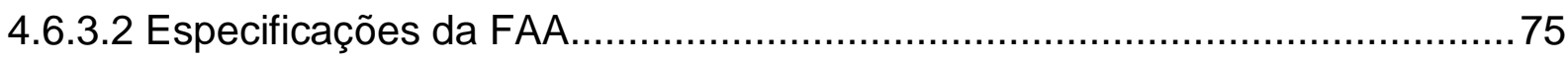

4.6.3.3 Relação entre separações em TWs e TLs e outros componentes, metodologias e considerações de projeto .................................................. 76

4.6.4 SEPARAÇÕES NAS POSIÇÕES DE ESTACIONAMENTO .......................... 76

4.6.4.1 Relação entre separações no pátio e outros componentes, metodologias e

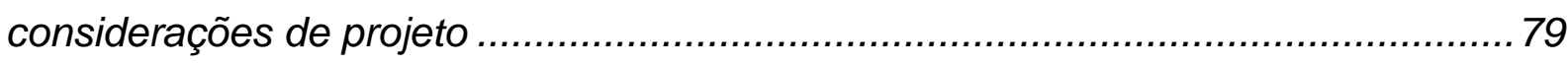

4.6.5 POSIÇÃO DAS BARRAS DE PARADA DA RW ....................................... 79

4.6.5.1 Padrões da ICAO para BPRWS ................................................... 80

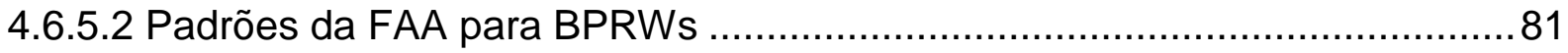

4.6.5.3 Relação entre os padrões para a posição da BPRW e outros componentes, metodologias e considerações de projeto .................................................. 82

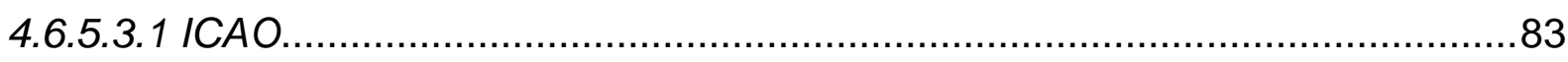

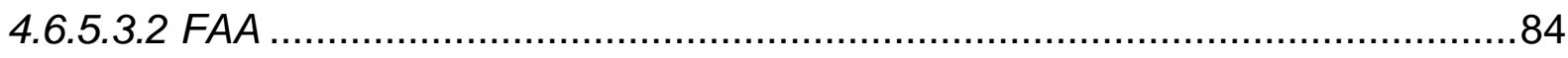

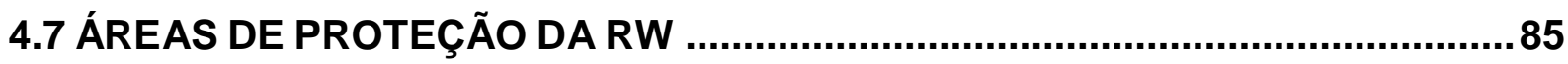

4.7.1 ESPECIFICAÇÕES DA ICAO PARA A FAIXA DA RW............................... 86

4.7.1.1 Área geral da faixa da RW (AGFRW) ............................................. 87

4.7.1.2 Área preparada (graded area) da faixa da RW (APFRW) ......................... 88 
4.7.1.3 Área restrita da faixa da RW (ARFRW). 89

4.7.1.4 Relação entre a faixa da RW e outros componentes, metodologias e considerações de projeto 90

4.7.2 ESPECIFICAÇÕES DA ICAO PARA A RESA (RUNWAY END SAFETY AREA) .90

4.7.2.1 Relação entre a RESA e outros componentes, metodologias e considerações de projeto

4.7.3 ESPECIFICAÇÕES DA FAA PARA A ROFA (RUNWAY OBJECT FREE AREA) .91

4.7.3.1 Relação entre a ROFA e outros componentes, metodologias e considerações de projeto 91

4.7.4 ESPECIFICAÇÕES DA FAA PARA A RSA (RUNWAY SAFETY AREA) .......92 4.7.4.1 Relação entre a RSA e outros componentes, metodologias e considerações de projeto 93

4.7.5 ESPECIFICAÇÕES DA FAA PARA A RPZ (RUNWAY PROTECTION ZONE)94 4.7.5.1 Relação entre a RPZ e outros componentes, metodologias e considerações de projeto .95

4.7.6 USO DE DISTÂNCIAS DECLARADAS PARA ROFA E RSA ........................96

4.7.7 REFERENCIAL LONGITUDINAL DAS ÁREAS DE PROTEÇÃO DA RW ......96 4.8 ÁREAS DE PROTEÇÃO DA TW ............................................................ 101

4.8.1 ESPECIFICAÇÕES DA ICAO PARA A FAIXA DA TW ..............................101

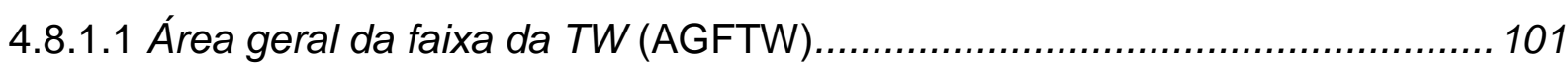

4.8.1.2 Área preparada (graded area) da faixa da TW (APFTW) .......................... 102 4.8.1.3 Relação entre a faixa da TW e outros componentes, metodologias e considerações de projeto 102

4.8.2 ESPECIFICAÇÕES DA FAA PARA A ÁREA LIVRE DE OBJETOS DA TW (TAXIWAY OBJECT FREE AREA - TOFA) E DA TL 102

4.8.2.1 Relação entre a OFA da TW e da TL e outros componentes, metodologias e considerações de projeto 104

4.8.3 ESPECIFICAÇÕES DA FAA PARA A ÁREA DE SEGURANÇA DA TW (TSA)104 4.8.3.1 Relação entre a TSA e outros componentes, metodologias e considerações de projeto 105

4.9 OFZ 105 
4.9.1 ESPECIFICAÇÕES DA ICAO E DA FAA PARA A OFZ...............................106

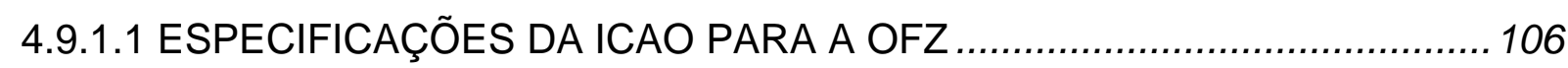

4.9.1.1.1 SUPERFÍCIE DE APROXIMAÇÃO INTERNA...................................... 107

4.9.1.1.2 SUPERFÍCIE DE TRANSIÇÃO INTERNA ........................................ 107

4.9.1.1.3 SUPERFÍCIE DE POUSO INTERROMPIDO ................................... 108

4.9.1.2 ESPECIFICAÇÕES DA FAA PARA A OFZ ....................................... 110

4.9.1.2.1 OFZ DA RW (RUNWAY OFZ - ROFZ) ........................................ 111

4.9.1.2.2 OFZ DE APROXIMAÇÃO INTERNA (INNER-APPROACH OFZ) ............111

4.9.1.2.3 OFZ DE TRANSIÇÃO INTERNA (INNER-TRANSITIONAL OFZ)...........111

4.9.1.2.4 OFZ DE PRECISÃO (PRECISION OFZ - POFZ).................................113

4.9.2 RELAÇÃO ENTRE A OFZ E OUTROS COMPONENTES, METODOLOGIAS E CONSIDERAÇÕES DE PROJETO ..................................................................114

4.9.3 METODOLOGIA PARA ANÁLISE DA OFZ DE TRANSIÇÃO INTERNA......114

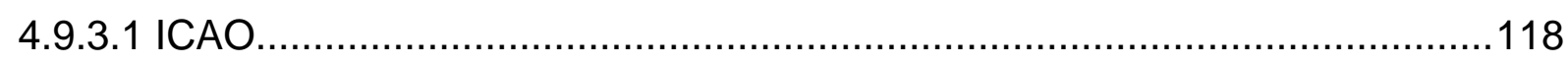

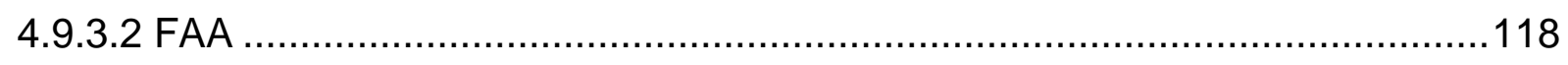

4.10 CONCLUSÕES DO CAPÍTULO ......................................................... 122

CAPÍTULO 5 - COMPARAÇÃO ENTRE OS PADRÕES E RECOMENDAÇÕES DA ICAO E FAA ......................................124

5.1 CÓDIGO DE REFERÊNCIA DO AERÓDROMO (ARC) ................................. 124

5.1.1 COMPARAÇÃO ENTRE OS GRUPOS DINÂMICOS.................................127

5.1 .2 COMPARAÇÃO ENTRE OS GRUPOS GEOMÉTRICOS ............................128

5.2 CONSIDERAÇÕES DE PROJETO .......................................................... 129

5.2.1 VENTO DE TRAVÉS ............................................................................... 129

5.2 .2 JET BLAST E FOD......................................................................... 130

5.2 .2 .1 Considerações gerais ................................................................ 130

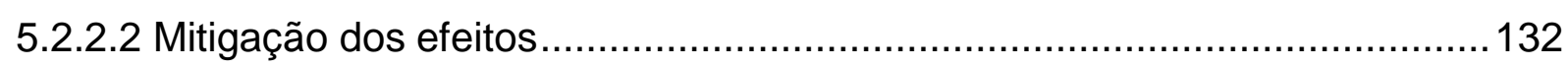

5.2 .2 .3 Especificações e métodos....................................................... 133

5.3 ÁREAS PAVIMENTADAS PRINCIPAIS .................................................... 133

5.3.1 LARGURA DA PISTA DE POUSO E DECOLAGEM..................................134

5.3.2 ACOSTAMENTOS DA PISTA DE POUSO E DECOLAGEM ..........................134

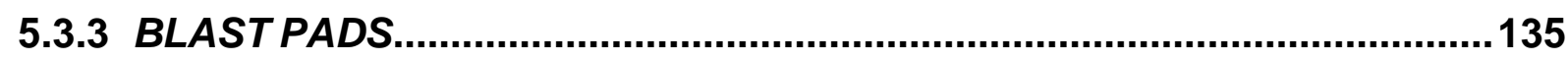

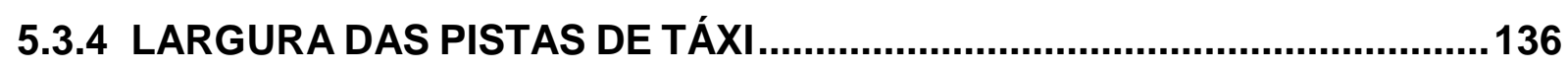

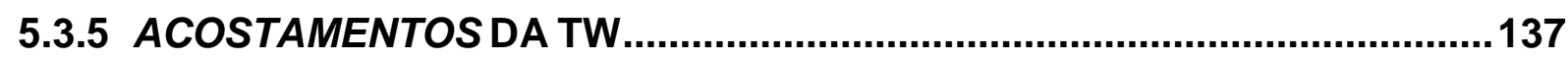




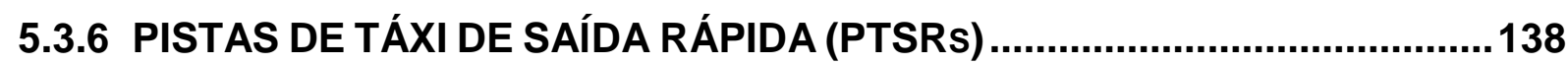

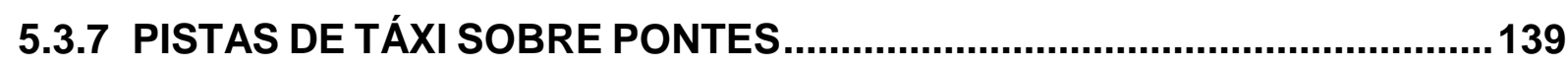

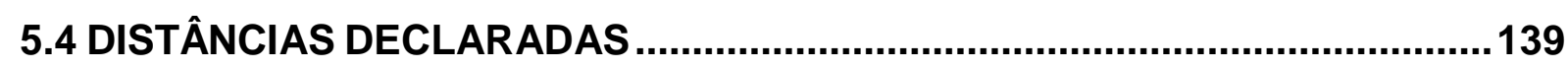

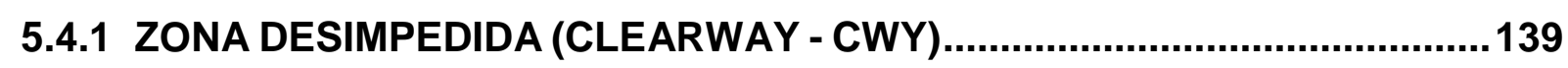

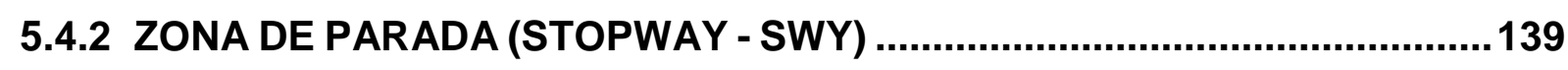

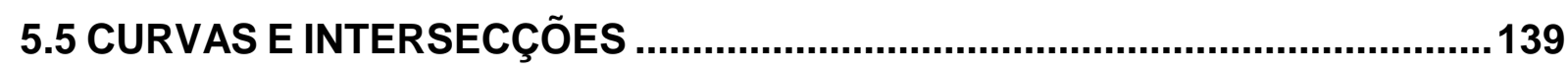

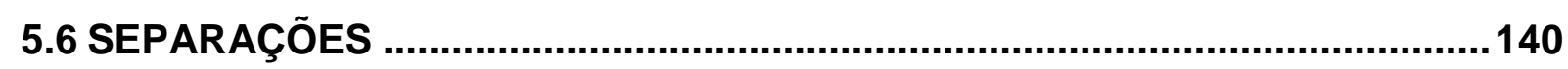

5.6.1 SEPARAÇÃO ENTRE RWS PARALELAS ...........................................140

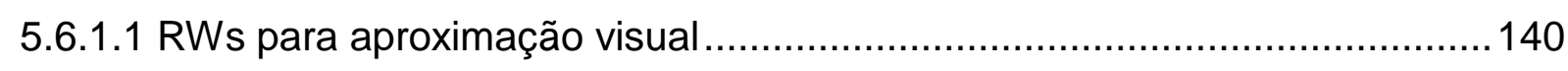

5.6.1.1 RWs para aproximação por instrumentos ..............................................141

5.6.2 SEPARAÇÃO ENTRE RWs E TWs PARALELAS .....................................142

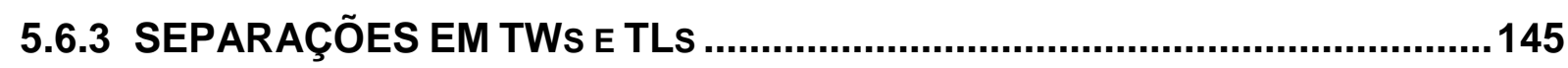

5.6.3.1 SEPARAÇÕES TW/TW E TW/OBJETOS .............................................145

5.6.3.2 SEPARAÇÕES TL/TL E TL/OBJETOS ...............................................145

5.6.4 SEPARAÇÕES NAS POSIÇÕES DE ESTACIONAMENTO ........................146

5.6.5 POSIÇÃO DAS BARRAS DE PARADA DA RW (BPRWs) ..........................147

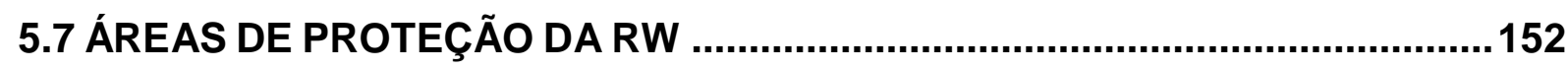

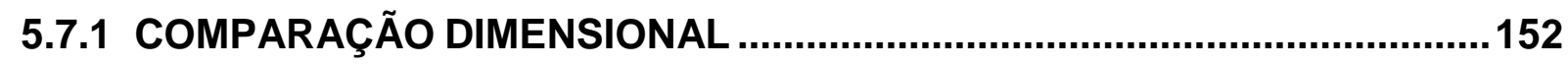

5.7.2 COMPARAÇÃO QUANTO AO USO E PREPARAÇÃO..............................156

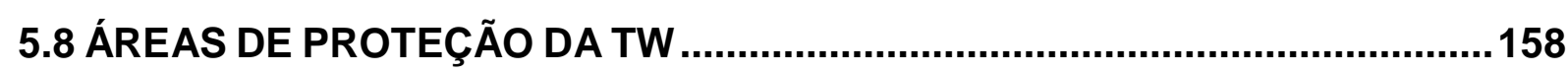

5.9 OFZ

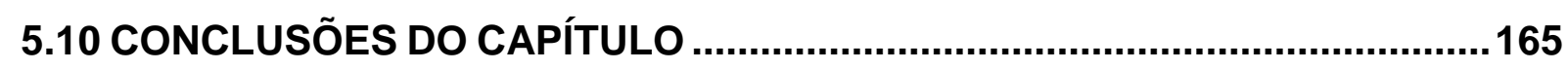

CAPÍTULO 6 - ACOMODAÇÃO DE AERONAVES DO $6^{\circ}$ GRUPO GEOMÉTRICO EM AEROPORTOS EXISTENTES ...........................168

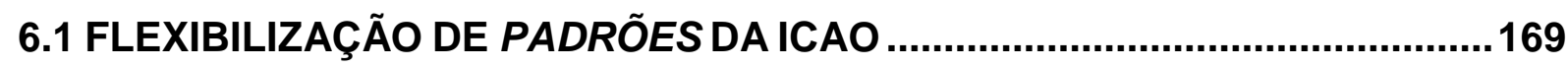

6.1.1 A380 COMMON AGREEMENT DOCUMENT - AACG ..............................169

6.1.2 B747-8 COMMON AGREEMENT DOCUMENT - BACG ............................170

6.1.3 FLEXIBILIZAÇÃO DA OFZ CONFORME ICAO CIR301 (2005B) ..................172

6.1.4 METODOLOGIA PARA ESTUDOS QUE SUPORTAM FLEXIBILIZAÇÕES CONFORME ICAO CIR305 (2004C)..............................................................174

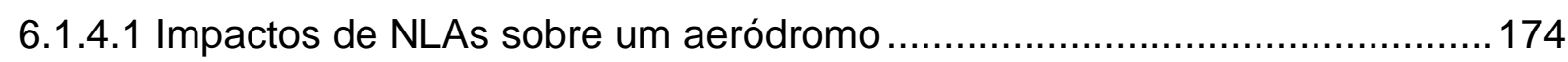

6.1.4.2 Metodologia para estudos aeronáuticos.................................................176 
6.1.5 ESTUDOS SOBRE MODIFICAÇÕES DE PADRÕES DA ICAO …................178

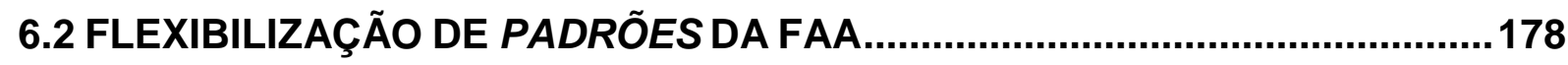

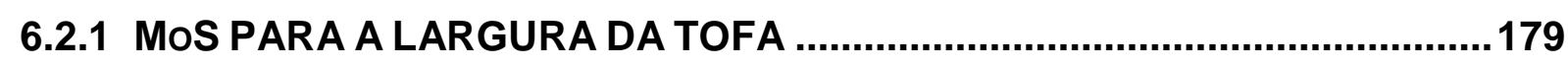

6.3 CONCLUSÕES DO CAPÍTULO ...............................................................180

CAPÍTULO 7 - ANÁLISE DO LADO AÉREO DO AEROPORTO DE GUARULHOS QUANTO À OPERAÇÃO DO A380-800 E DO B747-8181 7.1 ARC

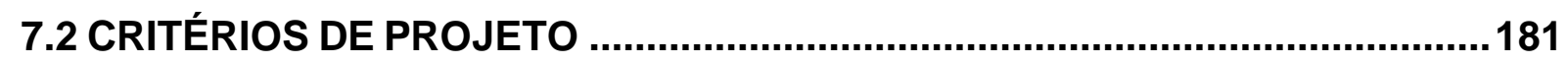

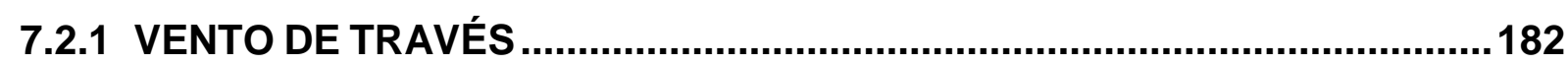

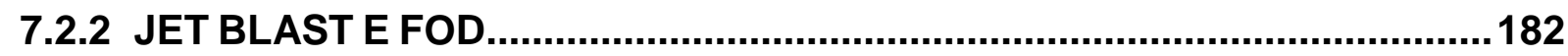

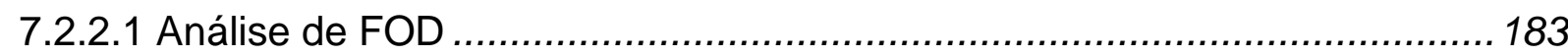

7.2.2.1.1 Análise da dispersão lateral do contorno de 35mph...............................185

7.2.2.1.2 Análise da dispersão longitudinal do contorno de $35 \mathrm{mph}$........................186

7.2.2.1.3 Análise da dispersão de velocidades maiores do que $35 \mathrm{mph}$..................187

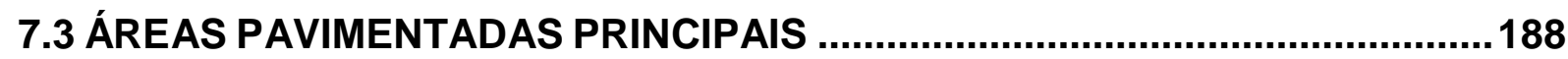

7.3.1 LARGURA DA PISTA DE POUSO E DECOLAGEM..................................188

7.3.2 ACOSTAMENTOS DA PISTA DE POUSO E DECOLAGEM .......................189

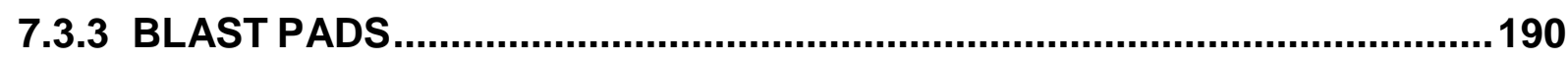

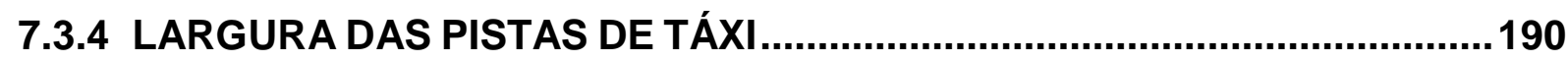

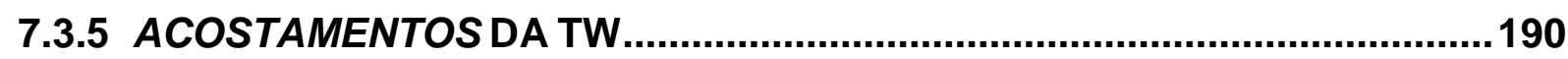

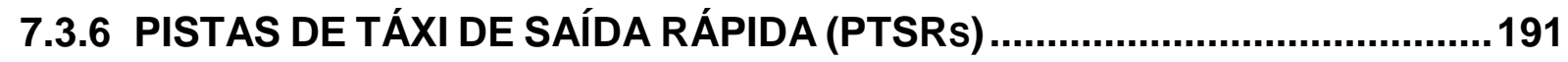

7.3.7 PISTAS DE TÁXI SOBRE PONTES .........................................................191

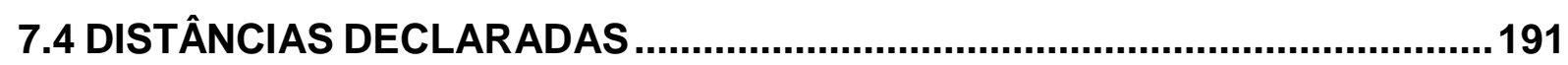

7.4.1 ZONA DESIMPEDIDA (CLEARWAY-CWY) …...........................................191

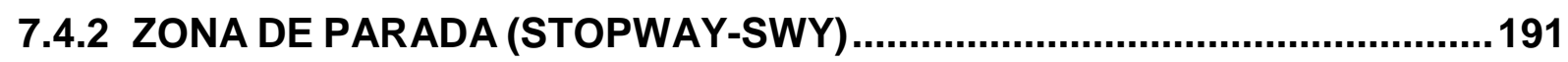

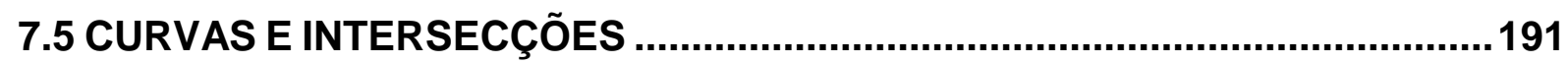

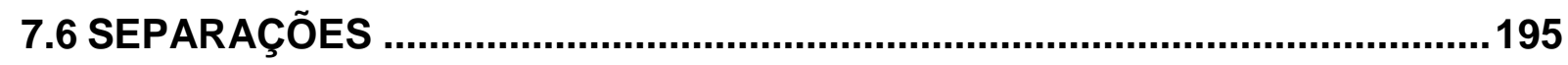

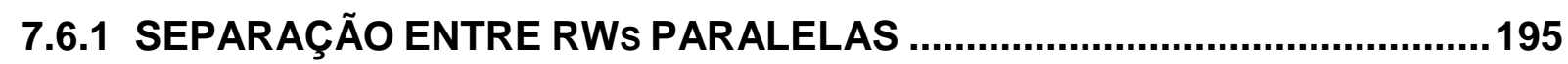

7.6.2 SEPARAÇÃO ENTRE RWS E TWS PARALELAS ...................................195

7.6.2.1 Análise da separação entre os eixos da RW e da TW ...............................195

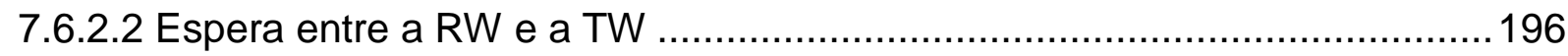

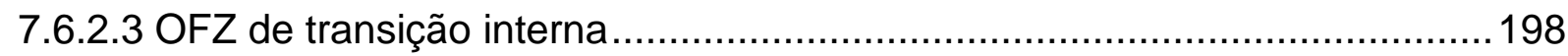


7.6.3 SEPARAÇÃO ENTRE TWS PARALELAS 198

7.6.4 SEPARAÇÕES NAS POSIÇÕES DE ESTACIONAMENTO .........................198

7.6.5 POSIÇÃO DAS BARRAS DE PARADA DA RW (BPRWS) ..........................199

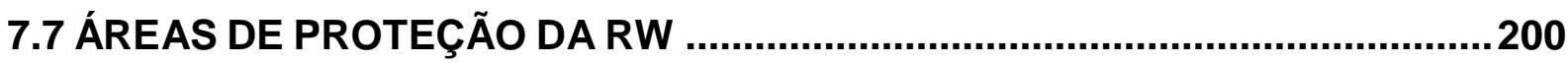

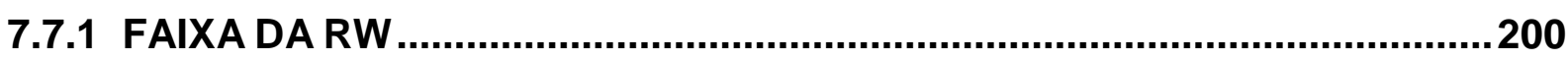

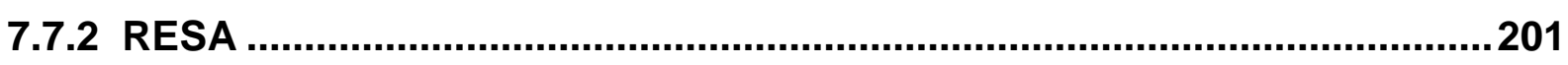

7.8 ÁREAS DE PROTEÇÃO DA TW ...........................................................201

7.9 OFZ

7.9.1 UM A380-800 OU B747-8 ENCONTRA-SE SOBRE UMA DAS RWS DURANTE APROXIMAÇÃO DE PRECISÃO NA RW PARALELA........................202

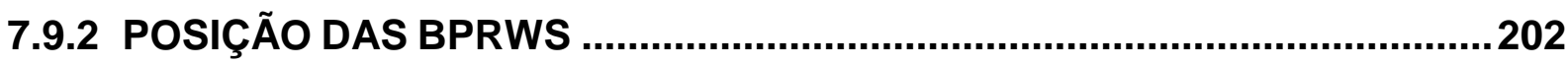

7.9.3 UM A380-800 OU UM B747-8 TAXIA NA TW B E UM A380-800 OU UM B7478 PERFAZ UMA APROXIMAÇÃO DE PRECISÃO NA RW 09L/27R......................204

7.10 CONCLUSÕES DO CAPÍTULO .............................................................205

CAPÍTULO 8 - CONCLUSÕES E RECOMENDAÇÕES....................208

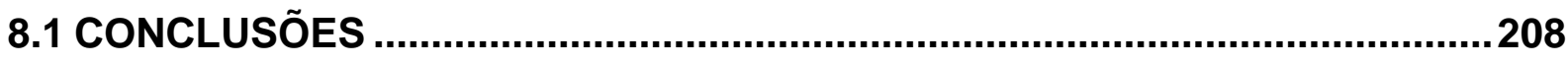

8.2 RECOMENDAÇÕES PARA PESQUISAS FUTURAS...................................211

REFERÊNCIAS.........................................................................213

GLOSSÁRIO...........................................................................218

ANEXO A - DADOS RELATIVOS À LARGURA DA RW ..........................232

ANEXO B - DADOS RELATIVOS À LARGURA COMBINADA ENTRE RW E ACOSTAMENTOS..........................................................................233

ANEXO C - DADOS RELATIVOS AO COMPRIMENTO DA BLAST

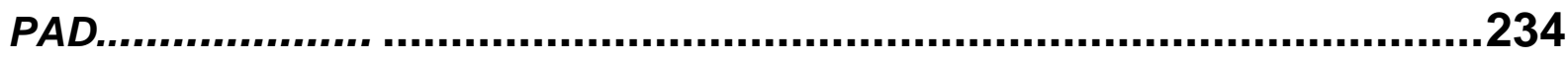

ANEXO D - DADOS RELATIVOS AOS CENÁRIOS 1 E 2 PARA AVALIAÇÃO DOS PADRÕES DAS BPRWS E DA OFZ DE TRANSIÇÃO INTERNA ...............235

ANEXO E - DADOS RELATIVOS AOS CENÁRIOS 3 E 4 PARA AVALIAÇÃO DOS PADRÕES DAS BPRWS E DA OFZ DE TRANSIÇÃO INTERNA ..............237

ANEXO F - DADOS RELATIVOS AOS CENÁRIOS 5 E 6 PARA AVALIAÇÃO DOS PADRÕES DAS BPRWS E DA OFZ DE TRANSIÇÃO INTERNA 239 
ANEXO G - DADOS RELATIVOS AOS CENÁRIOS 7 E 8 PARA AVALIAÇÃO DOS PADRÕES DAS BPRWS E DA OFZ DE TRANSIÇÃO INTERNA

ANEXO H - DADOS RELATIVOS AOS CENÁRIOS 9, 10, 11 e 12 PARA AVALIAÇÃO DOS PADRÕES DAS BPRWS .243

ANEXO I - DADOS RELATIVOS À SEPARAÇÃO ENTRE RWS PARALELAS. 245

ANEXO J - DADOS RELATIVOS À SEPARAÇÃO ENTRE RWS E TWS PARALELAS PARA OS CENÁRIOS 1 E 2 246

ANEXO K - DADOS RELATIVOS À SEPARAÇÃO ENTRE RWS E TWS PARALELAS PARA OS CENÁRIOS 3 E 4 247

ANEXO L - DADOS RELATIVOS À SEPARAÇÃO ENTRE RWS E TWS PARALELAS PARA OS CENÁRIOS 5 E 6 248

ANEXO L - DADOS RELATIVOS Às ÁREAS DE PROTEÇÃO DA RW, CENÁRIO 1. 249

ANEXO N - DADOS RELATIVOS ÀS ÁREAS DE PROTEÇÃO DA RW, CENÁRIO 2. 251

ANEXO O - DADOS RELATIVOS À AVALIAÇÃO DA OFZ DE TRANSIÇÃO INTERNA NAS BPRWS DO SBGR COM BASE NOS PADRÕES DO GRUPO GEOMÉTRICO F PARA ICAO E NOS PADRÕES CAT IIIIII PARA AERONAVES DE GRANDE PORTE NO CASO DA FAA.. . 253

ANEXO P - DADOS RELATIVOS À AVALIAÇÃO DA OFZ DE TRANSIÇÃO INTERNA NAS BPRWS DO SBGR COM BASE NOS PADRÕES DO GRUPO GEOMÉTRICO E PARA ICAO E NOS PADRÕES CAT IIIIII PARA AERONAVES DE GRANDE PORTE NO CASO DA FAA.. 


\section{CAPÍTULO 1 - INTRODUÇÃO}

A indústria da aviação civil é baseada no equacionamento de dois importantes fatores: o desenvolvimento tecnológico e a padronização. Enquanto o primeiro é importante do ponto de vista da eficácia, o segundo é essencial à eficiência econômica e operacional. Por desenvolvimento tecnológico, entende-se as possibilidades em termos de aeronaves, aeroportos, controle de tráfego aéreo e assim por diante, enquanto a padronização é uma estratégia que faz frente às limitações dos recursos, entre os quais os custos operacionais, os altos investimentos necessários, os longos tempos de desenvolvimento, além dos interesses nacionais e corporativos e tantos outros.

No entanto, por mais que a padronização busque harmonizar-se com a tecnologia, existirá um atraso da primeira em relação à segunda, pois os padrões criados à luz de um contexto tecnológico serão vigentes em um período posterior, ao longo do qual os avanços tecnológicos seguirão seu curso. E assim, a adoção de novas tecnologias ficará sujeita ao cenário criado pela padronização existente.

Isso cria a necessidade de uma constante atualização dos padrões, para que eles não comprometam o desenvolvimento tecnológico do setor, e também, para fins de adequação, tendo-se em vista a validade dos modelos e premissas que suportam os padrões ao longo do tempo.

Aliás, as premissas serão mais ocultas, quanto mais empírico for o modelo que suporta os padrões, como é o caso dos estudos observacionais. Já em modelos analíticos, as variáveis serão conhecidas, mas ainda assim, a validade do modelo estará sujeita a um dado contexto, para o qual foi validado.

Assim, justifica-se a investigação a cerca dos modelos e premissas que suportam os padrões, de forma a contribuir-se para uma maior integração entre a tecnologia e a padronização, bem como para os aspectos de eficiência e segurança envolvidos.

Esta dissertação aborda o projeto geométrico de aeródromos a partir dos padrões e recomendações da ICAO (International Civil Aviation Organization) e da FAA (Federal Aviation Administration), limitando-se a comparar os padrões emitidos por cada um destas instituições, para um conjunto selecionado de critérios. Isso permite uma explicitação tanto das diferenças nos padrões em si, quanto das 
variáveis e condições utilizadas para defini-los, e das metodologias sugeridas para avaliá-los. Estes dois conjuntos de padrões (da ICAO e da FAA) foram selecionados com base na idéia de que cumprem objetivos similares, os quais incluem a proteção das operações de decolagem, pouso, táxi, e estacionamento em um aeródromo.

Outro ponto abordado na presente dissertação é a operação de aeronaves como o A380-800 e o B747-8 em aeroportos existentes, onde não é possível atender-se aos padrões de projeto. A abordagem ao tema consiste em uma revisão bibliográfica das flexibilizações dos padrões de projeto para estas duas aeronaves, considerando-se os padrões da ICAO e da FAA. E, a partir da revisão dos padrões, recomendações e flexibilizações, é feita uma aplicação ao caso do Aeroporto Internacional de São Paulo/Guarulhos, avaliando-se impactos da operação do A380800 e do B747-8 sobre o lado aéreo.

\subsection{OBJETIVOS}

Os objetivos desta dissertação são:

- Apresentar uma revisão dos padrões e recomendações da ICAO e da FAA para o projeto geométrico de aeródromos para um conjunto selecionado de critérios de projeto, propondo-se uma nomenclatura comum à ICAO e à FAA, apontando-se relações entre os critérios de projeto, apresentando-se as metodologias de projeto e análise introduzidas pelas normas e propondo-se modelagens pontuais.

- Comparar as especificações da ICAO e da FAA quanto a um conjunto selecionado de critérios de projeto geométrico do aeródromo, a partir dos padrões e recomendações publicados por cada uma das instituições, explicitando-se as diferenças na base de especificação e nas especificações em si.

- Apresentar uma revisão das flexibilizações dos padrões de projeto para acomodação de aeronaves como A380-800 e o B747-8 em aeroportos existentes, onde não é possível o atendimento aos padrões.

- Analisar, a partir da revisão de padrões e flexibilizações, a operação das aeronaves A380-800 e o B747-8 no Aeroporto Internacional de São Paulo/Guarulhos.

\subsection{ESTRUTURA DOS CAPÍTULOS}

Os capítulos estão organizados como a seguir discutido. 
O Capítulo 1 faz uma introdução à pesquisa, explicitando os objetivos e a estrutura do trabalho.

O Capítulo 2 apresenta uma revisão de literatura, focada nas normas utilizadas no trabalho.

O Capítulo 3 apresenta os aspectos metodológicos da pesquisa, propondo-se uma estrutura de critérios de projeto.

O Capítulo 4 compõe-se de uma revisão dos padrões e recomendações da ICAO e da FAA a partir da estrutura de critérios de projeto introduzida no Capítulo 3. Ainda, no Capítulo 4 propõe-se uma padronização da nomenclatura utilizada, e também modelagens pontuais para alguns critérios de projeto.

No Capítulo 5 apresentam-se comparações entre as especificações da ICAO e da FAA, com base na estrutura de critérios de projeto introduzida no Capítulo 3 e nas especificações e modelagens do Capítulo 4.

O Capítulo 6 apresenta uma revisão bibliográfica das flexibilizações dos padrões de projeto da ICAO e da FAA que visam à acomodação das aeronaves A380-800 e B747-8 em aeroportos existentes, onde não é possível o atendimento aos padrões.

O Capítulo 7 apresenta uma avaliação da introdução das aeronaves A380-800 e B747-8 no Aeroporto Internacional de São Paulo/Guarulhos, levando-se em consideração a estrutura de critérios de projeto proposta no Capítulo 3, os padrões e modelagens apresentados no Capítulo 4 e as flexibilizações dos padrões apresentadas no Capítulo 6.

Já o Capítulo 8 apresenta as conclusões e recomendações para pesquisas futuras.

O texto ainda inclui um glossário e um conjunto de anexos, contendo os dados oriundos das comparações apresentadas no Capítulo 5.

\subsection{ASPECTOS DE FORMATO DO TEXTO}

A apresentação das especificações da ICAO e da FAA no Capítulo 4 busca uma harmonização entre o formato de cada norma e a necessidade de uma uniformização dos conceitos, para que as comparações do Capítulo 5 possam ser feitas em condições equivalentes. Nessa mesma linha, a estrutura de critérios de projeto proposta no Capítulo 3 é utilizada nos Capítulos 4, 5 e 7. 
No caso de conceitos definidos por termos diferentes nos documentos da ICAO e da FAA, utiliza-se preferencialmente o termo da ICAO. Para a tradução à língua portuguesa, procurou-se seguir a ANAC RBAC 154 (2009a). Ainda, é feito um amplo uso de palavras em língua inglesa, entre parênteses, como sinônimo.

Recorre-se também ao uso de siglas, preferencialmente aquelas já utilizadas na literatura, embora algumas tenham sido propostas nesta dissertação. Na lista de abreviaturas e siglas indicam-se, entre parênteses, aquelas que são exclusivas da FAA e também aquelas propostas pelo autor.

Grifo em itálico é utilizado para palavras estrangeiras, termos com definição técnica, e para os títulos de nível 5. As palavras em itálico, denotando um conceito específico, são definidas no glossário ou ao longo do texto.

Aliás, é apresentado um amplo glossário, dividido em três partes: termos comuns à ICAO e à FAA; termos da FAA; e termos cujos significados diferem para a ICAO e para a FAA.

As legendas das figuras, tabelas e equações seguem a numeração dos títulos de nível 2, segundo os quais os critérios de projeto são tratados. Ainda, as legendas das figuras do Capítulo 5 fazem referência ao anexo que contém os dados originais. 


\section{CAPÍTULO 2 - O PROJETO GEOMÉTRICO DE AERÓDROMOS NA LITERATURA}

O conhecimento e a pesquisa na área de projeto de aeródromos são muito restritos a organizações não acadêmicas como órgãos de governo, fabricantes de aeronaves, operadores aeroportuários, consultorias e afins. Disso resulta um contraste entre a complexidade do tema e a falta de uma sistematização das metodologias e dos princípios de projeto, à luz da estrutura acadêmica encontrada em outras áreas do conhecimento. Outro fator a considerar-se é o baixo grau de divulgação dos materiais relacionados ao conhecimento e à prática no tema.

Como o projeto de aeródromos deve atender a uma série de normas técnicas, este tipo de material se torna a principal referência para o assunto. De forma coerente com esta ideia, livros texto, como Horonjeff e McKelvey (1994) e Kazda e Caves (2008), se limitam a apresentar exigências normativas, sem dar atenção aos princípios que suportam estas exigências e sem explorar outras possibilidades de projeto, do ponto de vista tecnológico.

Por sua abordagem científica, cabe citar a dissertação de Weissmann (1983), que apresenta uma análise dos padrões de projeto para pistas de pouso e decolagem, comparando os padrões especificados pelo Ministério da Aeronáutica, então encarregado deste assunto no Brasil, e os padrões da ICAO (International Civil Aviation Organization). A partir desta comparação, o trabalho apontou discrepâncias entre as duas normas, no padrão de largura da pista de pouso e decolagem. Discrepâncias também apareceram entre os padrões da ICAO e as dimensões obtidas pela autora, a partir da análise estatística de dados de dispersão em pistas de pouso e decolagem. Estas dimensões foram obtidas com base na mesma metodologia utilizada pela ICAO para elaboração dos padrões. Um ponto que a pesquisa questiona diz respeito à forma como os padrões são especificados, ao utilizar características das aeronaves que, pelas análises, não podem ser correlacionadas às dispersões observadas. Além das questões geométricas, o trabalho aborda o projeto de pavimentos, a partir da relação deste com as características de dispersão das aeronaves em pistas de pouso e decolagem.

Atualmente existem dois conjuntos razoavelmente independentes de normas para projeto de aeródromos, que são as normas da ICAO e as normas da FAA (Federal Aviation Administration). A ICAO é o braço da ONU (Organização das Nações Unidas) para aviação civil, emitindo padrões e recomendações para projeto 
e operação nos aeroportos internacionais localizados nos países membros da organização. Pela presente data, a ICAO possui 191 Estados (países) membros. Nos aeroportos domésticos, os Estados possuem autonomia para definir seus próprios padrões de projeto. Neste contexto, se destaca a FAA, cujos padrões devem ser seguidos nos aeroportos dos Estados Unidos. Estes padrões diferem daqueles da ICAO, conforme é demonstrado no Capítulo 5 desta dissertação, através de comparações para uma série de critérios de projeto selecionados.

No Brasil, a ANAC (Agência Nacional de Aviação Civil) é responsável por estabelecer as exigências a serem observadas no projeto de aeródromos, o que é feito com base nos documentos publicados pela ICAO, mesmo para os aeródromos domésticos.

Os itens seguintes apresentam uma descrição sucinta dos principais documentos da ICAO, da ANAC e da FAA relacionados ao projeto de aeródromos.

\subsection{ICAO}

A norma principal da ICAO para o projeto de aeródromos é a ICAO Annex 14 (2004a). E especificamente sobre o projeto geométrico de aeródromos tratam os Capítulos 3 e 4 desta norma, que apresentam, respectivamente, componentes físicos de um aeródromo e critérios de restrição de obstáculos. A ICAO Annex 14 (2004a) faz referência a uma série de normas e manuais complementares, tratados a seguir.

A ICAO Doc 9157 Parte 1 (2006a) é um manual complementar à ICAO Annex 14 (2004a), que trata de pistas de pouso e decolagem, sendo bastante redundante em relação a esta. No entanto, em termos de padrões de projeto, este manual acrescenta: i) correções de declividade, temperatura e elevação para o cálculo do comprimento da pista de pouso e decolagem, quando tais condições não são consideradas no APM (Airport Planning Manual); ii) exemplos de áreas de giro da RW (Pista de pouso e decolagem); iii) uma lista de aeronaves com suas características básicas e ARC (Aerodrome Reference Code); e iv) um estudo sobre o efeito da declividade da RW sobre o desempenho das aeronaves.

De forma similar, a ICAO Doc 9157 Parte 2 (2005a) é um manual complementar à ICAO Annex 14 (2004a), tratando de pistas de táxi e áreas de espera e ultrapassagem. Este documento acrescenta metodologias de projeto importantes, especialmente em relação às sobrelarguras e às pistas de táxi de saída rápida. Além disso, o documento apresenta uma série de considerações de projeto, em relação a aspectos de segurança e eficiência de aeródromos. 
O PANS-OPS, por sua vez, é composto por dois documentos, a ICAO PANSOPS Volume I (2006c) e a ICAO PANS-OPS Volume II (2006d), que apresentam diversos procedimentos de voo por instrumentos, a dispersão de trajetória a eles associada e as áreas que devem ser protegidas para a construção dos procedimentos.

Já a ICAO Doc 9137 (1983a) trata do controle de obstáculos em aeródromos, do ponto de vista do projeto e da operação. O documento é complementar à ICAO Annex 14 (2004a) ao descrever a função de cada uma das superfícies de proteção do espaço aéreo especificadas no Capítulo 4 desta norma. Além disso, o documento compara a função das superfícies da ICAO Annex 14 (2004a) com as superfícies de proteção especificadas no PANS-OPS. O documento também apresenta informações sobre o CRM (Collision Risk Model) e sobre a utilização do princípio de shielding ${ }^{1}$.

A ICAO PANS-ATM (2007a) trata de controle de tráfego aéreo, incluindo regras de separação entre aeronaves, o que impacta sobre a separação e a disposição de duas ou mais pistas de pouso e decolagem em um aeródromo.

A ICAO Cir 301 (2005b) trata da utilização de uma OFZ (Object Free Zone) projetada conforme os critérios do grupo geométrico $E$, por aeronaves do grupo geométrico $F$. Esta circular apresenta a metodologia e as conclusões de estudos aeronáuticos conduzidos pela FAA e por instituições europeias. O material serve de base aos Estados que desejam permitir tal flexibilização dos padrões de projeto. $O$ item 6.1.3 resume as principais conclusões dos estudos apresentados neste documento.

A ICAO Cir 305 (2004c) apresenta uma metodologia de análise de riscos a ser utilizada para a flexibilização de critérios de projeto para a introdução de NLAs (New Large Aeroplanes) em aeroportos existentes. A circular apresenta também as características de NLAs e suas implicações sobre componentes do aeródromo, bem como os principais riscos associados. O item 6.1.4 resume este documento.

\subsection{ANAC}

A norma brasileira relacionada ao projeto de aeródromos é a ANAC RBAC 154 (2009a). Esta é muito similar à ICAO Annex 14 (2004a), sendo basicamente uma

\footnotetext{
${ }^{1}$ Quando objetos que penetram superfícies de proteção ao espaço aéreo estão a certa distância do aeródromo e de obstáculos considerados irremovíveis, o princípio de shielding pode ser utilizado para justificar sua não remoção.
} 
tradução desta para a língua portuguesa. No entanto, certas recomendações da ICAO foram transformadas em padrões.

\subsection{FAA}

A principal norma da FAA para o projeto de aeródromos é a FAA AC 150/530013 (1989), apresentando critérios de projeto e diversas considerações quanto à segurança e eficiência do aeródromo. A seguir apresenta-se uma série de documentos complementares a esta norma, quanto ao projeto geométrico de aeródromos.

A EUA e-CFR Title 14 (2010) compreende um conjunto de normas dos EUA para aeronáutica e espaço, disponíveis eletronicamente através do portal GPO Access. Em especial, a Parte 1 desta legislação reúne definições e abreviações e a Parte 77 trata de obstruções ao espaço aéreo, de forma semelhante ao Capítulo 4 da ICAO Annex 14 (2004a). No entanto, a Parte 77 não trata de OFZs, sendo este assunto tratado na própria FAA AC 150/5300-13 (1989).

A FAA AC 150/5325-4B (2005b), por sua vez, trata do cálculo do comprimento de pistas de pouso e decolagem. Para tanto, a norma propõe uma divisão das aeronaves em diferentes grupos com base no MTOW (Maximum Take-off Weight), no fato dela ser ou não um jato regional e na velocidade de aproximação. Para aeronaves com $27.200 \mathrm{~kg}$ ou mais, e jatos regionais, a norma determina a utilização do APM para cálculo do comprimento da pista de pouso e decolagem. Para as demais aeronaves, existem 5 metodologias distintas para cálculo do comprimento da RW, agrupando-se as aeronaves conforme seu MTOW e velocidade de aproximação.

Em relação à flexibilização de padrões de projeto, a FAA tem emitido Engineering Briefs (EBs). Estes documentos apresentam flexibilizações dos padrões de projeto de componentes específicos do aeródromo, para as aeronaves A380-800 e B747-8. Além disso, a FAA disponibiliza em seu sítio eletrônico uma série de documentos sobre acomodação destas aeronaves em aeroportos existentes que não atendem aos critérios do grupo geométrico VI. Tais documentos contêm flexibilizações autorizadas pela FAA e restrições operacionais necessárias. O item 6.2 apresenta estas questões. 


\section{CAPÍTULO 3 - METODOLOGIA PROPOSTA}

Este trabalho aborda o projeto geométrico de aeródromos a partir dos padrões e recomendações da ICAO e da FAA, comparando-os. Além disso, é feita uma avaliação da introdução das aeronaves A380-800 e B747-8 no aeroporto de São Paulo/Guarulhos, à luz das exigências da ICAO e da FAA e também de flexibilizações dos padrões de projeto. Tais flexibilizações, por sua vez, são organizadas em um capítulo próprio.

Este capítulo, especificamente, apresenta os aspectos metodológicos da pesquisa, introduzindo uma série de termos propostos, uma estrutura de critérios, metodologias e considerações de projeto e os métodos utilizados para as comparações e análises.

\subsection{TERMOS PROPOSTOS PARA O TRABALHO}

Algumas expressões são amplamente empregadas ao longo do texto. São elas: padrões e recomendações; critérios, metodologias e recomendações de projeto; especificação; base de especificação; e referencial. Embora nem todas sejam utilizadas nos documentos consultados, considera-se importante utilizá-las, para fins de padronização do texto. A seguir estas expressões são definidas.

Padrões e recomendações se referem às especificações feitas pelas normas em relação a um determinado critério ou consideração de projeto. A título de exemplo, serve o caso da especificação de que a pista de pouso e decolagem deva possuir $45 \mathrm{~m}$ de largura. Neste caso, a largura da pista de pouso e decolagem é um critério de projeto, e a especificação da largura em $45 \mathrm{~m}$ é um padrão de projeto. Por sua vez, padrões e recomendações diferem quanto ao grau de exigência: um padrão é uma exigência mínima, a menos que devidamente flexibilizado. Uma recomendação tem caráter opcional aos Estados. Em alguns casos, os Estados adotam recomendações como padrões, de forma a aumentar a segurança operacional.

Critério, metodologia e recomendação de projeto diferem entre si. Por exemplo, a largura da pista de pouso e decolagem é um critério de projeto, cabendo especificações. O método de projeto de uma sobrelargura é o exemplo de uma metodologia de projeto, não cabendo especificações à metodologia em si. Já o jet blast é uma consideração de projeto, à qual cabe uma metodologia de avaliação, e especificações para critérios de projeto que compõem a consideração, como por exemplo, o limite da velocidade do fluxo sobre pessoas e veículos. 
Base de especificação se refere às variáveis utilizadas para estabelecer-se os padrões e recomendações. No exemplo do critério de projeto largura da pista de pouso e decolagem, para a ICAO, a base de especificação inclui: o ARC (Aerodrome Reference Code), que, por sua vez, é definido com base em características da aeronave) de uma dada aeronave e o fato de a pista de pouso e decolagem se destinar a aproximações de precisão ou não.

Referencial se refere a um ponto ou conjunto de pontos a partir do(s) qual(is) algum critério, metodologia ou consideração de projeto é especificada. Serve de exemplo o comprimento da faixa da RW após as extremidades da pista de pouso e decolagem, que é especificada com base em duas distâncias: distância antes da cabeceira e distância após o final de pista ou stopway. Neste caso, a cabeceira é um dos referenciais para o comprimento da faixa da RW.

Outras expressões e termos são apresentados no Capítulo 4, concomitantemente à revisão dos padrões e recomendações a eles associados.

\subsection{ESTRUTURA DE CRITÉRIOS, METODOLOGIAS E CONSIDERÇAÕES DE PROJETO}

A estrutura proposta para o trabalho consiste em um agrupamento, por função, de um conjunto selecionado de critérios, metodologias e considerações de projeto. Este agrupamento permite uma abordagem uniformizada aos padrões e recomendações da ICAO e da FAA, facilitando as comparações pretendidas. Tal estrutura é utilizada nos Capítulos 4, 5 e 7 desta dissertação.

Optou-se pelo seguinte agrupamento: ARC (Aerodrome Reference Code); considerações de projeto; áreas pavimentadas principais; distâncias declaradas; curvas e intersecções; separações; áreas de proteção da RW (pista de pouso e decolagem); áreas de proteção da TW (pista de táxi); e OFZ (object free zone).

O grupo ARC cobre a categorização das aeronaves, com base nas suas características frente às necessidades de infraestrutura no aeródromo, uma vez que o ARC costuma fazer parte da base de especificação de muitos critérios de projeto.

O grupo considerações de projeto é composto por especificações e metodologias relacionadas ao vento de través de projeto, o qual influencia a orientação da pista de pouso e decolagem, e relacionadas ao jet blast, que influencia o projeto de áreas pavimentadas e separações.

O grupo áreas pavimentadas principais é composto por componentes físicos do aeródromo sobre os quais as aeronaves decolam, pousam, taxiam, esperam e 
estacionam. Os critérios de projeto associados a estes componentes físicos são: largura da pista de pouso e decolagem; largura combinada entre a pista de pouso e decolagem e seus acostamentos; dimensões de uma blast pad; largura da pista de táxi; largura combinada entre uma pista de táxi e seus acostamentos; pistas de táxi de saída rápida; e pistas de táxi sobre pontes.

As distâncias declaradas agrupam stopways e clearways.

O grupo curvas e intersecções apresenta princípios de projeto e metodologias a serem empregados no projeto dos raios das curvas, das sobrelarguras e de folgas em áreas de proteção.

Separações agrupam critérios de distância entre áreas pavimentadas, e de folga, entre aeronaves e objetos. São eles: separações entre pistas de pouso e decolagem; separações entre pistas de pouso e decolagem e pistas de táxi paralelas; separações entre pistas de táxi e pistas de táxi de acesso ao estacionamento de aeronaves, e entre estas e objetos; separações nas posições de estacionamento; e posição das barras de parada da pista de pouso e decolagem.

Áreas de proteção da pista de pouso e decolagem agrupam áreas destinadas a proteger as operações na pista de pouso e decolagem. São elas: faixa da pista de pouso e decolagem, RESA (Runway End Safety Area), ROFA (Runway Object Free Area), RSA (Runway Safety Area) e RPZ (Runway Protection Zone).

Áreas de proteção da pista de táxi agrupam áreas destinadas a proteger pistas de táxi. São elas: faixa da pista de táxi; OFA (Object Free Area) da pista de táxi; OFA (Object Free Area) da pista de táxi de acesso ao estacionamento de aeronaves; e TSA (Taxiway Safety Area).

Finalmente, o grupo OFZ reúne superfícies que delimitam a presença de objetos na proximidade imediata das pistas de pouso e decolagem, de forma a proteger aeronaves abaixo da altura de decisão, durante aproximações de precisão.

Esta mesma estrutura de critérios, metodologias e considerações de projeto é utilizada para apresentar as especificações das normas (Capítulo 4), para comparar os padrões da ICAO e da FAA (Capítulo 5) e para a análise da operação das aeronaves A380-800 e B747-8 no Aeroporto Internacional de São/Paulo Guarulhos (Capítulo 7).

\subsection{OUTROS ASPECTOS METODOLÓGICOS}

Tendo-se em vista as comparações pretendidas entre os critérios da ICAO e da FAA, busca-se uma uniformização da nomenclatura e da apresentação das 
especificações das normas, explicitando-se as diferenças quando uma uniformização não é possível.

Aliás, para as comparações entre os padrões da ICAO e da FAA, nos casos em que a base de especificação varia entre as normas, recorre-se a um grupo de aeronaves para as quais as variáveis da base de especificação de cada norma são conhecidas.

Finalmente, a análise da operação das aeronaves A380-800 e B747-8 no aeroporto de São Paulo/Guarulhos é feita com base nos padrões de projeto, nas suas flexibilizações e na análise comparativa entre aeronaves que operam atualmente no aeródromo. 


\section{CAPÍTULO 4 - PADRÕES E RECOMENDAÇÕES DA ICAO E DA FAA PARA O PROJETO GEOMÉTRICO DE AERÓDROMOS}

Este capítulo apresenta uma revisão bibliográfica dos padrões e recomendações da ICAO (International Civil Aviation Organization) e da FAA (Federal Aviation Administration) para o projeto geométrico de aeródromos, com base em um conjunto selecionado de critérios, metodologias e considerações de projeto, conforme a estrutura apresentada no Capítulo 3.

Ao longo deste Capítulo, nomenclaturas, referenciais e modelagens são propostos, de forma a permitir-se uma abordagem uniforme e facilitada aos padrões e recomendações da ICAO e da FAA.

As nomenclaturas propostas ao longo do Capítulo são: grupo dinâmico; grupo geométrico; folga do pavimento; área geral da faixa da $R W$; área preparada da faixa da RW; área restrita da faixa da RW; área geral da faixa da TW; e área preparada da faixa da TW.

As modelagens propostas ao longo do Capítulo dizem respeito à trajetória de pontos de interesse da aeronave durante curvas (item 4.5.2.3) e também à $O F Z$ de transição interna (item 4.9.3).

Ainda, para as áreas de proteção da $R W$, no item 4.7.7, propõe-se uma apresentação didática dos referenciais segundo os quais as especificações são feitas.

Além disso, explicitam-se as inter-relações entre critérios, metodologias e considerações de projeto tratadas ao longo do Capítulo.

\subsection{CÓDIGO DE REFERÊNCIA DO AERÓDROMO (ARC)}

Muitos dos critérios de projeto de aeródromos são especificados com base no chamado código de referência do aeródromo (ARC - Aerodrome Reference Code). Para estes critérios, o ARC é uma medida de compatibilidade entre o aeródromo e a aeronave que ele acomoda. Isso porque o ARC é composto por dois termos, onde o primeiro se refere a uma característica de desempenho da aeronave e o segundo advém de características geométricas da mesma.

Caso uma única aeronave possua as características mais demandantes para os dois termos do ARC, esta será a aeronave crítica, considerando-se critérios cuja base de especificação contenha somente o ARC. Alternativamente, duas aeronaves 
poderiam mesclar as características mais demandantes para os dois termos do código.

Por questões de padronização entre a nomenclatura da ICAO e da FAA, o primeiro termo do ARC é doravante denominado grupo dinâmico e para o segundo termo utiliza-se a expressão grupo geométrico. Para a ICAO as nomenclaturas originais são code number e code letter, respectivamente. Já no caso da FAA, os nomes originais são aircraft approach category e airplane design group, respectivamente.

Para a ICAO, o grupo dinâmico é baseado no comprimento básico de pista da aeronave $^{2}$ (aeroplane reference field length- CBP). Já o grupo geométrico depende de duas características: envergadura e wheel span (largura do trem principal desde as extremidades das rodas), valendo a mais demandante. A Tabela 4.1-1 relaciona o ARC com intervalos das características das aeronaves, conforme estabelecido pela ICAO:

Tabela 4.1-1 - Código de referência do aeródromo (ARC), conforme ICAO

\begin{tabular}{|c|c|c|c|c|}
\hline \multicolumn{2}{|c|}{ Elemento 1 do código } & \multicolumn{3}{|c|}{ Elemento 2 do código } \\
\hline $\begin{array}{c}\text { Grupo } \\
\text { dinâmico }\end{array}$ & $\begin{array}{c}\text { Comprimento } \\
\text { básico de pista } \\
\text { da aeronave }\end{array}$ & $\begin{array}{c}\text { Grupo } \\
\text { geométrico }\end{array}$ & Envergadura & Wheel span \\
\hline 1 & Inferior a 800m & $A$ & $\begin{array}{c}\text { Inferior a } \\
15 \mathrm{~m}\end{array}$ & $\begin{array}{c}\text { Inferior a } \\
4,5 \mathrm{~m}\end{array}$ \\
\hline 2 & $\begin{array}{c}\text { De } 800 \mathrm{~m} \text { a } \\
1.200 \mathrm{~m} \\
\text { exclusive } \\
\end{array}$ & $\mathrm{B}$ & $\begin{array}{c}\text { De } 15 \mathrm{~m} \text { a } \\
24 \mathrm{~m} \\
\text { exclusive }\end{array}$ & $\begin{array}{c}\text { De } 4,5 \mathrm{~m} \text { a } \\
6 \mathrm{~m} \\
\text { exclusive }\end{array}$ \\
\hline 3 & $\begin{array}{c}\text { De } 1.200 \mathrm{~m} \text { a } \\
1.800 \mathrm{~m} \\
\text { exclusive } \\
\end{array}$ & C & $\begin{array}{c}\text { De } 24 \mathrm{~m} \text { a } \\
36 \mathrm{~m} \\
\text { exclusive }\end{array}$ & $\begin{array}{c}\text { De } 6 \mathrm{~m} \text { a } 9 \mathrm{~m} \\
\text { exclusive }\end{array}$ \\
\hline \multirow{3}{*}{4} & \multirow{3}{*}{$1.800 \mathrm{~m}$ e acima } & $\mathrm{D}$ & $\begin{array}{c}\text { De } 36 \mathrm{~m} \text { a } \\
52 \mathrm{~m} \\
\text { exclusive }\end{array}$ & $\begin{array}{l}\text { De } 9 \mathrm{~m} \text { a } \\
14 \mathrm{~m} \\
\text { exclusive }\end{array}$ \\
\hline & & $E$ & $\begin{array}{c}\text { De } 52 \mathrm{~m} \text { a } \\
65 \mathrm{~m} \\
\text { exclusive }\end{array}$ & $\begin{array}{c}\text { De } 9 \mathrm{~m} \text { a } \\
14 \mathrm{~m} \\
\text { exclusive }\end{array}$ \\
\hline & & $\mathrm{F}$ & $\begin{array}{c}\text { De } 65 \mathrm{~m} \text { a } \\
80 \mathrm{~m} \\
\text { exclusive }\end{array}$ & $\begin{array}{c}\text { De } 14 \mathrm{~m} \text { a } \\
16 \mathrm{~m} \\
\text { exclusive }\end{array}$ \\
\hline
\end{tabular}

FONTE: ICAO Annex 14 (2004a, p.1-8)

Para a FAA o grupo dinâmico é baseado no categoria de aproximação da aeronave (aircraft approach category). Já o grupo geométrico depende de duas características: envergadura e altura do estabilizador, valendo a mais demandante. A Tabela 4.1-2 apresenta a categorização da FAA para o ARC.

${ }^{2}$ Nomenclatura conforme ANAC RBAC 154 (2009a). Ver glossário para definição. 
Tabela 4.1-2 - Código de referência do aeródromo (ARC), conforme FAA

\begin{tabular}{|c|c|c|c|c|}
\hline \multicolumn{2}{|c|}{ Elemento 1 do código } & \multicolumn{3}{|c|}{ Elemento 2 do código } \\
\hline $\begin{array}{c}\text { Grupo } \\
\text { dinâmico }\end{array}$ & $\begin{array}{l}\text { Velocidade de } \\
\text { aproximação }\end{array}$ & $\begin{array}{c}\text { Grupo } \\
\text { geométrico }\end{array}$ & Envergadura & $\begin{array}{c}\text { Altura do } \\
\text { estabilizador } \\
\text { | a }\end{array}$ \\
\hline$A$ & $V_{A}<91$ nós & I & $\begin{array}{c}\text { Inferior a } \\
15 \mathrm{~m}\end{array}$ & Inferior a $6,1 \mathrm{~m}$ \\
\hline \multirow[t]{2}{*}{$B$} & \multirow{2}{*}{$\begin{array}{c}\text { 91nós } \leq \mathrm{V}_{\mathrm{B}}< \\
\text { 121nós }\end{array}$} & \multirow[t]{2}{*}{ II } & \multirow{2}{*}{$\begin{array}{c}\text { De } 15 \mathrm{~m} \text { a } \\
24 \mathrm{~m} \\
\text { exclusive }\end{array}$} & $\begin{array}{c}\text { De } 6,1 \mathrm{~m} \text { a } \\
9,1 \mathrm{~m}\end{array}$ \\
\hline & & & & exclusive \\
\hline C & $\begin{array}{c}\text { 121nós } \leq \mathrm{V}_{\mathrm{C}}< \\
\text { 141nós }\end{array}$ & III & $\begin{array}{l}\text { De } 24 \mathrm{~m} \text { a } \\
36 \mathrm{~m} \\
\text { exclusive }\end{array}$ & $\begin{array}{c}\text { De } 9,1 \mathrm{~m} \text { a } \\
13,7 \mathrm{~m} \\
\text { exclusive }\end{array}$ \\
\hline $\mathrm{D}$ & $\begin{array}{c}\text { 141nós } \leq \mathrm{V}_{\mathrm{D}}< \\
\text { 166nós }\end{array}$ & IV & $\begin{array}{c}\text { De } 36 \mathrm{~m} \text { a } \\
52 \mathrm{~m} \\
\text { exclusive }\end{array}$ & $\begin{array}{c}\text { De } 13,7 \mathrm{~m} \text { a } \\
18,3 \mathrm{~m} \\
\text { exclusive } \\
\end{array}$ \\
\hline \multirow{2}{*}{$E$} & \multirow{2}{*}{ 166nós $\leq V_{E}$} & V & $\begin{array}{l}\text { De } 52 \mathrm{~m} \text { a } \\
65 \mathrm{~m} \\
\text { exclusive }\end{array}$ & $\begin{array}{c}\text { De } 18,3 \mathrm{~m} \text { a } \\
20,1 \mathrm{~m} \\
\text { exclusive }\end{array}$ \\
\hline & & VI & $\begin{array}{l}\text { De } 60 \mathrm{~m} \text { a } \\
80 \mathrm{~m} \\
\text { exclusive }\end{array}$ & $\begin{array}{c}\text { De } 20,1 \mathrm{~m} \text { a } \\
24,4 \mathrm{~m} \\
\text { exclusive }\end{array}$ \\
\hline
\end{tabular}

a: Valores convertidos a partir da unidade pé (foot) com arredondamento em uma casa decimal.

FONTE: FAA AC 150/5300-13 (1989, p.1)

\subsection{CONSIDERAÇÕES DE PROJETO}

Nesta seção são apresentados os critérios da ICAO e da FAA quanto ao vento de través máximo de projeto, para fins de orientação da pista de pouso e decolagem (RW), e quanto ao jet blast.

\subsubsection{VENTO DE TRAVÉS}

A combinação entre a direção e a intensidade dos ventos em um dado sítio aeroportuário influencia a orientação da pista de pouso e decolagem. A ICAO e a FAA estabelecem limites para o vento de través, e, além disso, recomendam o provimento de um fator de utilização (usability factor) mínimo de 95\%.

O fator de utilização corresponde ao percentual de tempo durante o qual uma dada RW é esperada a apresentar um vento de través menor do que os limites recomendados para cada tipo de aeronave. Pistas secundárias podem ser necessárias onde uma única RW não for capaz de prover um fator de utilização mínimo de 95\%, para todas as aeronaves que utilizem o aeródromo regularmente.

A ICAO Doc 9184 (1987, p.1-36) apresenta uma metodologia para preparação e análise de dados sobre ventos, para o propósito de planejamento de aeródromos. 
A FAA AC 150/5300-13 (1989, p.87) também apresenta uma metodologia para análise de dados sobre ventos, para o propósito de planejamento da orientação da RW.

A ICAO Annex 14 (2004a, p.3-1) estabelece as seguintes velocidades máximas admissíveis para o vento de través (crosswind) de projeto:

- $19 \mathrm{~km} / \mathrm{h}$ (10nós): no caso de aeronaves cujo CBP é menor que $1.200 \mathrm{~m}$;

- 24km/h(13nós): no caso de aeronaves cujo CBP é maior ou igual a $1.200 \mathrm{~m}$ e menor do que $1.500 \mathrm{~m}$; e

- $37 \mathrm{~km} / \mathbf{h}$ (20nós): no caso de aeronaves cujo CBP é maior ou igual a $1.500 \mathrm{~m}$, exceto quando houver, com certa frequência, uma baixa ação de frenagem na RW devido a um coeficiente de atrito longitudinal insuficiente, quando, então, deve ser assumido um componente de vento de través que não exceda $24 \mathrm{~km} / \mathrm{h}$ (13nós).

A FAA AC 150/5300-13 (1989, p.10) também especifica limites de projeto para o vento de través:

- 19, $4 \mathrm{~km} / \mathrm{h}(10,5 n o ́ s):$ ARCs A-l e B-l;

- 24,1 km/h (13knós): ARCs A-ll e B-Il;

- 29,6km/h (16nós): grupo geométrico III além dos ARCs C-I, C-II, D-I e D-II;

- 37,0km/h (20nós): grupos geométricos $I V, V$ e VI.

4.2.1.1 Relação entre os padrões para vento de través e outros componentes, metodologias e considerações de projeto

O vento de través influencia as características de controle das aeronaves durante pouso, decolagem e táxi. Embora o vento de través não componha a base de especificação de padrões para RWs e TWs (pistas de táxi), a operação em níveis mais elevados do vento de través pode exigir ações mitigatórias como aumento de largura da RW e maior treinamento dos pilotos, por exemplo.

\subsubsection{JET BLAST E FOD}

O jet blast representa riscos às aeronaves, pessoal, veículos, equipamentos e estruturas dentro e fora do aeródromo, além de impactar sobre a erosão do solo. Assim, o jet blast deve ser considerado no projeto de áreas pavimentadas, como acostamentos e blast pads; áreas de proteção de RWs e TWs (pistas de táxi); separações entre RWs, TWs e TLs (pistas de táxi de acesso ao estacionamento de aeronaves) e áreas de estacionamento, e entre estas e pessoal, veículos, 
equipamentos e estruturas; posição da sinalização vertical do aeródromo; posição das barreiras contra jet blast (blast fences); entre outros.

Três níveis de empuxo são geralmente considerados para determinar-se os efeitos e ações mitigatórias quanto ao jet blast: empuxo à marcha lenta (idle thrust), empuxo de partida (breakaway thrust) e empuxo máximo contínuo (take-off thrust). Quase todas as instalações adjacentes às áreas de movimento estarão sujeitas, no mínimo, ao empuxo à marcha lenta, considerando-se a aeronave crítica de projeto. Já o empuxo de partida é aquele necessário ao início do movimento de táxi, situando-se entre 50 e $60 \%$ do empuxo máximo contínuo. Áreas tipicamente projetadas para este nível de empuxo podem incluir os prédios do terminal, pátio e acostamentos das pistas de táxi, baías de espera e todos os pavimentos, com exceção da pista de pouso e decolagem. Por último, o empuxo máximo contínuo é aquele associado à decolagem, sendo de especial consideração para o projeto do pavimento da pista de pouso e decolagem, seus acostamentos e extremidades (blast pads).

A análise dos efeitos do jet blast deve considerar a trajetória das aeronaves no aeródromo e o nível de propulsão utilizado em cada parte. Deve levar em consideração também a mudança de direção do fluxo durante as curvas, quando a aeronave taxia. Elevações de terreno, vegetação e cercas vivas podem também ajudar a minimizar os efeitos do jet blast. Barreiras especialmente projetadas para contenção do jet blast podem ser necessárias (blast fences).

Os fabricantes de aeronaves fornecem as curvas de contorno de velocidade e temperatura do fluxo de ar emanado do sistema propulsor, através do APM (Airport Planning Manual).

A ICAO Doc 9157 Parte 2 (2005a, p. APP 2-1) estabelece 56km/h (35mph) como limite máximo para o jet blast sobre pessoal, veículos e outros equipamentos na área de movimento.

Já a FAA AC 150/5300-13 (1989, p. 77) estabelece 48km/h (30mph), como limite do fluxo sobre pessoas, equipamentos e veículos. Além disso, a FAA coloca que rajadas a partir de $31 \mathrm{~km} / \mathrm{h}(19 \mathrm{mph})$ são mais perigosas do que velocidades contínuas ao atingir veículos e aeronaves, afetando sua estabilidade.

\subsubsection{Relação entre o jet blast e outros componentes, metodologias e considerações de projeto}

Os efeitos do jet blast e da sucção das turbinas não faz parte da base de especificação de critérios para áreas pavimentadas ou separações, embora seja de 
especial consideração para o projeto do pátio de aeronaves e do estabelecimento de áreas a serem evitadas pelo público, como nas cabeceiras da RW, por exemplo. Quando flexibilizações aos padrões para áreas pavimentadas, áreas de proteção e separações são avaliadas, os efeitos do jet blast e da sucção dos motores devem ser considerados.

\section{3 ÁREAS PAVIMENTADAS PRINCIPAIS}

Nesta seção apresenta-se os padrões e recomendações da ICAO e da FAA quanto à: largura da pista de pouso e decolagem (RW); largura combinada entre a RW e acostamentos; dimensões de blast pads; largura de uma pista de táxi (TW); largura combinada entre TWs e acostamentos, pistas de táxi de saída rápida (PTSRs); e TWs sobre pontes.

\subsubsection{LARGURA DA PISTA DE POUSO E DECOLAGEM}

A largura recomendada pela ICAO para a pista de pouso e decolagem obedece à Tabela 4.3-1:

Tabela 4.3-1 - Largura padrão para a pista de pouso e decolagem, conforme ICAO

\begin{tabular}{|c|c|c|c|c|c|c|}
\hline \multirow{2}{*}{ Grupo dinâmico } & \multicolumn{6}{|c|}{ Grupo geométrico } \\
\hline & A & B & C & D & $\mathbf{E}$ & $\mathbf{F}$ \\
\hline 1 & $18 \mathrm{~m}$ & $18 \mathrm{~m}$ & $23 m$ & - & - & - \\
\hline $\begin{array}{c}1, \\
\text { RWs para aprox. } \\
\text { de precisão }\end{array}$ & $30 m$ & $30 \mathrm{~m}$ & $30 m$ & - & - & - \\
\hline 2 & $23 m$ & $23 m$ & $30 m$ & - & - & - \\
\hline $\begin{array}{c}2, \\
\text { RWs para aprox. } \\
\text { de precisão }\end{array}$ & $30 m$ & $30 \mathrm{~m}$ & $30 m$ & - & - & - \\
\hline 3 & $30 \mathrm{~m}$ & $30 \mathrm{~m}$ & $30 \mathrm{~m}$ & $45 \mathrm{~m}$ & - & - \\
\hline 4 & - & - & $45 m$ & $45 m$ & $45 m$ & $60 \mathrm{~m}$ \\
\hline
\end{tabular}

FONTE: ICAO Annex 14 (2004a, p.3-2)

Já a largura exigida pela FAA para a pista de pouso e decolagem é mostrada na Tabela 4.3-2.

\subsubsection{Relação entre a largura da RW e outros componentes, metodologias e considerações de projeto}

A largura da RW guarda relação com a largura dos acostamentos, à medida que uma maior largura daquela pode justificar uma menor largura destes. E ambos guardam relação com a largura da blast pad. 
Tabela 4.3-2 - Largura padrão da pista de pouso e decolagem, conforme FAA

\begin{tabular}{c|c|c|c}
\hline \multirow{2}{*}{$\begin{array}{c}\text { Grupo } \\
\text { geométrico }\end{array}$} & $\begin{array}{c}\text { GWs visuais ou RWs com visibilidade } \\
\text { de aproximação não menor do que } \\
\mathbf{1 . 2 0 0 m}\end{array}$ & $\begin{array}{c}\text { RWs com visibilidade de } \\
\text { aproximação menor do que } \\
\mathbf{1 . 2 0 0 m} \\
\text { [b }\end{array}$ & $\begin{array}{c}\text { Grupos } \\
\text { dinâmicos } \\
\text { C e D }\end{array}$ \\
\hline I |a & $18 \mathrm{~m}$ & $23 \mathrm{~m}$ & \\
II & $18 \mathrm{~m}$ & $30 \mathrm{~m}$ & - \\
II & $23 \mathrm{~m}$ & $30 \mathrm{~m}$ & $30 \mathrm{~m}$ \\
III & $30 \mathrm{~m}$ & $30 \mathrm{~m}$ & $30 \mathrm{~m}$ \\
IV & $45 \mathrm{~m}$ & $45 \mathrm{~m}$ & $30 \mathrm{~m} \mid \mathbf{c}$ \\
V & - & - & $45 \mathrm{~m}$ \\
VI & - & - & $45 \mathrm{~m}$ \\
\hline
\end{tabular}

|a: aeronaves de pequeno porte

lb: adotar as dimensões correspondentes à cabeceira com a menor visibilidade permitida.

|c: Para aeronaves com peso máximo certificado de decolagem maior do que $68.100 \mathrm{~kg}$, pertencendo ao grupo geométrico III, a largura é de $45 \mathrm{~m}$.

FONTE: FAA AC 150/5300-13 (1989, p.de 25 até 26-1)

\subsubsection{ACOSTAMENTOS DA PISTA DE POUSO E DECOLAGEM}

Os acostamentos da RW são uma superfície de transição entre o pavimento e a superfície adjacente, que tem as funções de: reduzir o risco de FOD (Foreign Object Damage); proteger o solo contra a erosão; e acomodar a aeronaves durante desvios eventuais destas, permitindo que retornem para a superfície da RW em segurança. Uma superfície natural, como grama, normalmente reduz a possibilidade de erosão do solo e a ingestão de objetos estranhos. Solo coberto por vegetação não adequado ao propósito de um acostamento requer sua estabilização, ou mesmo uma superfície pavimentada de baixo custo.

A ICAO Annex 14 (2004a, p.3-5) recomenda larguras mínimas combinadas entre RWs e acostamentos, para RWs destinadas a aeronaves dos grupos geométricos D, E e F. Observando-se isso e descontado-se a largura padrão da RW, encontra-se a largura mínima para os acostamentos, conforme a Tabela 4.3-3.

Já os padrões para acostamentos da RW, contidos na FAA 150/5300-13 (1989, p.de 25 até 26-1), são mostrados na Tabela 4.3-4.

\subsubsection{Relação entre a largura dos acostamentos da RW e outros componentes, metodologias e considerações de projeto}

A largura dos acostamentos da RW guarda relação com a largura da RW, à medida que uma maior largura desta pode justificar uma menor largura dos acostamentos. E ambos guardam relação com a largura da blast pad. 
Tabela 4.3-3 - Larguras recomendadas para acostamentos da RW, conforme ICAO

\begin{tabular}{cccccccccc}
\hline \multicolumn{10}{c|}{ Grupo geométrico } \\
\hline \multicolumn{2}{c|}{ Largura da RW } & \multicolumn{2}{c}{ Largura combinada entre } & \multicolumn{3}{c}{ Largura de cada } \\
(conforme Tabela 4.3-1) & \multicolumn{2}{c}{ RW e acostamentos } & \multicolumn{3}{c}{ acostamento } \\
D & E & F & D & E & F & D & E & F \\
\hline 45m & $45 \mathrm{~m}$ & $60 \mathrm{~m}$ & $60 \mathrm{~m}$ & $60 \mathrm{~m}$ & $75 \mathrm{~m}$ & $7,5 \mathrm{~m}$ & $7,5 \mathrm{~m}$ & $7,5 \mathrm{~m}$ \\
\hline
\end{tabular}

FONTE: ICAO Annex 14 (2004a, p.3-2, 3-5)

Tabela 4.3-4 - Largura padrão dos acostamentos de uma pista de pouso e decolagem, conforme FAA

\begin{tabular}{c|c|c|c}
\hline \multirow{2}{*}{$\begin{array}{c}\text { Grupo } \\
\text { geométrico }\end{array}$} & $\begin{array}{c}\text { GWs de aproximação visual ou RWs } \\
\text { com visibilidade de aproximação não } \\
\text { menor do que 1.200m } \\
\text { |b }\end{array}$ & $\begin{array}{c}\text { RWs com visibilidade de } \\
\text { aproximação menor do que } \\
\mathbf{1 . 2 0 0 m} \\
\text { |b }\end{array}$ & $\begin{array}{c}\text { Grupos } \\
\text { dinâmicos } \\
\text { C e D }\end{array}$ \\
\hline I|a & $3 \mathrm{~m}$ & $3 \mathrm{~m}$ & \\
II & $3 \mathrm{~m}$ & $3 \mathrm{~m}$ & - \\
II & $3 \mathrm{~m}$ & $3 \mathrm{~m}$ & $3 \mathrm{~m}$ \\
III & $6 \mathrm{~m}$ & $6 \mathrm{~m}$ & $3 \mathrm{~m}$ \\
IV & $7,5 \mathrm{~m}$ & $7,5 \mathrm{~m}$ & $6 \mathrm{~m} \mid \mathbf{c}$ \\
V|d & - & - & $7,5 \mathrm{~m}$ \\
VI |d & - & - & $10,5 \mathrm{~m}$ \\
\hline
\end{tabular}

a: aeronaves de pequeno porte

b: adotar as dimensões correspondentes à cabeceira com a menor visibilidade permitida.

|c: Para aeronaves com peso máximo certificado de decolagem maior do que $68.100 \mathrm{~kg}$, pertencendo ao grupo geométrico III, a largura do acostamento é de 7,5m.

|d: Aeronaves dos grupos geométricos $V$ e VI normalmente exigem acostamentos com superfície estabilizada ou pavimentada.

FONTE: FAA AC 150/5300-13 (1989, p.de 25 até 26-1)

\subsubsection{BLAST PADS}

A blast pad é uma superfície retangular adjacente à extremidade da pista de pouso e decolagem, sendo destinada a proteger o solo contra erosão.

O apêndice 2 da ICAO Doc 9157 Parte 2 (2005a, p. APP 2-5) recomenda que a largura da blast pad deve ser igual à largura combinada entre a pista de pouso e decolagem e seus acostamentos. Já o comprimento da blast pad depende do tamanho da aeronave: para aeronaves como o B747 e o A380, recomenda-se um comprimento de $120 \mathrm{~m}$; e para aeronaves menores recomenda-se $60 \mathrm{~m}^{3}$. Tal recomendação gera dúvidas uma vez que o texto não é estrito ao citar o B747 e o A380. Para o propósito das comparações do Capítulo 5, admite-se um comprimento de $120 \mathrm{~m}$ somente para aeronaves B747 e A380.

\footnotetext{
${ }^{3}$ Trecho do texto original: For aircraft such as Boeing 747 and A380, a blast pad length of at least $120 \mathrm{~m}$ is recommended; For smaller aircraft, a blast pad length of $60 \mathrm{~m}$ is recommended.
} 
Já a Tabela 4.3-5 apresenta as dimensões padrão para a blast pad conforme a FAA AC 150/5300-13 (1989, p. de 25 até 26-1):

Tabela 4.3-5 - Dimensões da blast pad, conforme FAA

\begin{tabular}{|c|c|c|c|c|c|c|}
\hline \multirow{3}{*}{$\begin{array}{l}\text { Grupo } \\
\text { geomé } \\
\text { trico }\end{array}$} & \multicolumn{4}{|c|}{ Grupos dinâmicos A e B } & & \\
\hline & \multicolumn{2}{|c|}{$\begin{array}{l}\text { RWs visuais ou RWs com } \\
\text { visibilidade de } \\
\text { aproximação não menor } \\
\text { do que } 1.200 \mathrm{~m} \\
\text { |b }\end{array}$} & \multicolumn{2}{|c|}{$\begin{array}{c}\text { RWs com visibilidade de } \\
\text { aproximação menor do } \\
\text { que } 1.200 \mathrm{~m} \\
\text { |b }\end{array}$} & \multicolumn{2}{|c|}{$\begin{array}{c}\text { Grupos dinâmicos } \\
\text { C e D }\end{array}$} \\
\hline & Comprimento & Largura & Comprimento & Largura & Comprimento & Largura \\
\hline I |a & $18 \mathrm{~m}$ & $24 \mathrm{~m}$ & $18 \mathrm{~m}$ & $29 m$ & - & - \\
\hline I & $30 m$ & $24 m$ & $30 \mathrm{~m}$ & $36 m$ & $30 m$ & $36 m$ \\
\hline II & $45 m$ & $29 m$ & $45 \mathrm{~m}$ & $36 m$ & $45 m$ & $36 m$ \\
\hline III & $60 m$ & $42 m$ & $60 \mathrm{~m}$ & $42 m$ & $60 \mathrm{~m}$ & $42 \mathrm{~m} \mid \mathrm{c}$ \\
\hline IV & $60 \mathrm{~m}$ & $60 \mathrm{~m}$ & $60 \mathrm{~m}$ & $60 m$ & $60 \mathrm{~m}$ & $60 \mathrm{~m}$ \\
\hline V & - & - & - & - & $120 m$ & $66 m$ \\
\hline VI & - & - & - & - & $120 \mathrm{~m}$ & 84 \\
\hline
\end{tabular}

a: Somente aeronaves de pequeno porte.

lb: adotar as dimensões correspondentes à cabeceira com a menor visibilidade permitida.

|c: Para aeronaves com peso máximo certificado de decolagem maior do que $68.100 \mathrm{~kg}$, pertencendo grupo geométrico III, a largura da blast pad é de $60 \mathrm{~m}$.

FONTE: FAA AC 150/5300-13 (1989, p. de 25 até 26-1)

\subsubsection{Relação entre as dimensões da blast pad e outros componentes, metodologias} e considerações de projeto

A blast pad deve possuir a largura combinada entre a RW e seus acostamentos.

\subsubsection{LARGURA DAS PISTAS DE TÁXI}

O dimensionamento da TW (pista de táxi) deve observar o padrão especificado para o critério folga do pavimento. Assim, para os trechos retilíneos de uma pista de táxi, a largura mínima desta será a soma entre o wheel span e o dobro da folga do pavimento. Para os trechos curvos das TWs, deve-se considerar o desvio das rodas, induzido pelo ângulo de esterçamento da aeronave. A metodologia apresentada pela norma para o projeto de TWs em trechos curvos é discutida no item 4.5.2.

Os padrões da ICAO para a folga do pavimento e para a largura de uma pista de táxi em um trecho retilíneo, contidos na ICAO Annex 14 (2004a, p.3-11), são mostrados na Tabela 4.3-6.

Os padrões da FAA para a folga do pavimento e para a largura de uma pista de táxi em um trecho retilíneo, contidos na FAA AC 150/5300-13 (1989, p.38), são mostrados na Tabela 4.3-7. 
Tabela 4.3-6 - Padrão ICAO para a folga do pavimento e para a largura da pista de táxi

\begin{tabular}{c|c|c}
\hline Grupo geométrico & Folga do pavimento & Largura da pista de táxi \\
\hline A & $1,5 \mathrm{~m}$ & $7,5 \mathrm{~m}$ \\
\hline B & $2,25 \mathrm{~m}$ & $10,5 \mathrm{~m}$ \\
\hline C, com base de rodas menor do que $18 \mathrm{~m}$ & $3 \mathrm{~m}$ & $15 \mathrm{~m}$ \\
\hline C, com base de rodas igual ou maior a $18 \mathrm{~m}$ & $4,5 \mathrm{~m}$ & $18 \mathrm{~m}$ \\
\hline D, com wheel span menor do que $9 \mathrm{~m}$ & $4,5 \mathrm{~m}$ & $18 \mathrm{~m}$ \\
\hline D, com wheel span maior ou igual a $9 \mathrm{~m}$ & $4,5 \mathrm{~m}$ & $23 \mathrm{~m}$ \\
\hline $\mathrm{E}$ & $4,5 \mathrm{~m}$ & $23 \mathrm{~m}$ \\
\hline $\mathrm{F}$ & $4,5 \mathrm{~m} \mathrm{|a}$ & $25 \mathrm{~m} \mid \mathbf{a}$ \\
\hline
\end{tabular}

|a: Para aeronaves do grupo geométrico $F$, em condições de tráfego elevado, a adoção de uma folga do pavimento maior torna-se interessante para permitir velocidades maiores de taxiamento, à medida que isso influencia o comportamento dos pilotos.

FONTE: ICAO Annex 14 (2004a, p.3-11)

Tabela 4.3-7 - Padrão FAA para a folga do pavimento e para a largura da pista de táxi

\begin{tabular}{c|c|c}
\hline Grupo geométrico & Folga do pavimento & Largura da pista de táxi \\
\hline $\mathrm{I}$ & $1,5 \mathrm{~m}$ & $7,5 \mathrm{~m}$ \\
\hline $\mathrm{II}$ & $2,25 \mathrm{~m}$ & $10,5 \mathrm{~m}$ \\
\hline III, com base de rodas menor do que $18 \mathrm{~m}$ & $3 \mathrm{~m}$ & $15 \mathrm{~m}$ \\
\hline III, com base de rodas igual ou maior a $18 \mathrm{~m}$ & $4,5 \mathrm{~m}$ & $18 \mathrm{~m}$ \\
\hline $\mathrm{IV}$ & $4,5 \mathrm{~m}$ & $23 \mathrm{~m}$ \\
\hline $\mathrm{V}$ & $4,5 \mathrm{~m}$ & $23 \mathrm{~m}$ \\
\hline $\mathrm{VI}$ & $6 \mathrm{~m}$ & $30 \mathrm{~m}$ \\
\hline
\end{tabular}

FONTE: FAA AC 150/5300-13 (1989, p.38)

4.3.4.1 Relação entre a largura da TW e outros componentes, metodologias e considerações de projeto

A largura da TW guarda relação com a largura dos seus acostamentos, à medida que uma maior largura daquela pode justificar uma menor largura destes.

\subsubsection{ACOSTAMENTOS DA TW}

As funções dos acostamentos da TW e da RW são similares, sendo basicamente: acomodação das rodas das aeronaves durante desvios eventuais, permitindo que estas voltem à TW; proteção contra FOD (Foreign Object Damage); e proteção contra erosão da área adjacente à TW. No entanto, as especificações para os acostamentos da TW e RW diferem. Isso é de se esperar, a partir da diferença: nos desvios das aeronaves; nos níveis de empuxo praticados; e nas larguras, das RWs e TWs. 
Os acostamentos devem se estender de forma simétrica na direção das laterais da pista de táxi, iniciando na borda desta.

A ICAO Annex 14 (2004a, p.3-15), recomenda larguras mínimas combinadas entre TWs e seus acostamentos. Tais especificações são mostradas na Tabela 4.3-8, bem como a largura resultante para os acostamentos, a partir das especificações de largura da TW, mostradas na Tabela 4.6-3.

A norma recomenda também que nas curvas e interseções das pistas de táxi, onde existe um aumento da área pavimentada (sobrelarguras ou fillets), os acostamentos não devem ser menores do que nos trechos retilíneos das pistas de táxi.

Tabela 4.3-8 - Padrão ICAO para a largura combinada entre pistas de táxi e seus acostamentos

\begin{tabular}{|c|c|c|c|}
\hline Grupo geométrico & $\begin{array}{c}\text { Padrão de } \\
\text { largura da } \\
T W \\
\text { (conforme } \\
\text { Tabela } \\
4.3-6 \text { ) } \\
\end{array}$ & $\begin{array}{c}\text { Padrão para } \\
\text { largura } \\
\text { combinada } \\
\text { entre TWs e } \\
\text { seus } \\
\text { acostamentos }\end{array}$ & $\begin{array}{l}\text { Largura } \\
\text { resultante } \\
\text { para } \\
\text { cada } \\
\text { acostamento }\end{array}$ \\
\hline A & $7,5 \mathrm{~m}$ & - & - \\
\hline $\mathrm{B}$ & $10,5 \mathrm{~m}$ & - & - \\
\hline $\mathrm{C}$, com base de rodas menor do que $18 \mathrm{~m}$ & $15 \mathrm{~m}$ & $25 m$ & $5 \mathrm{~m}$ \\
\hline $\mathrm{C}$, com base de rodas igual ou maior a $18 \mathrm{~m}$ & $18 \mathrm{~m}$ & $25 m$ & $3,5 \mathrm{~m}$ \\
\hline $\mathrm{D}$, com wheel span menor do que $9 \mathrm{~m}$ & $18 \mathrm{~m}$ & $38 m$ & $10 \mathrm{~m}$ \\
\hline $\mathrm{D}$, com wheel span maior ou igual a $9 \mathrm{~m}$ & $23 m$ & $38 m$ & $7,5 \mathrm{~m}$ \\
\hline$E$ & $23 m$ & $44 \mathrm{~m}$ & $10,5 \mathrm{~m}$ \\
\hline $\mathrm{F}$ & $25 m$ & $60 \mathrm{~m}$ & $17,5 \mathrm{~m}$ \\
\hline
\end{tabular}

FONTE: ICAO Annex 14 (2004a, p.3-11, 3-15)

A FAA 150/5300-13 (1989, p.38) especifica diretamente a largura mínima para cada um dos acostamentos em uma pista de táxi, conforme a Tabela 4.3-9. A mesma tabela também apresenta o padrão FAA para a largura da TW e a largura combinada resultante entre a TW e seus acostamentos.

4.3.5.1 Relação entre a largura dos acostamentos da TW e outros componentes, metodologias e considerações de projeto

A largura dos acostamentos da TW guarda relação com a largura da TW, à medida que uma maior largura desta pode justificar uma menor largura daqueles. 
Tabela 4.3-9 - Padrão FAA para os acostamentos das TWs

\begin{tabular}{c|c|c|c}
\hline Grupo geométrico & $\begin{array}{c}\text { Padrão de } \\
\text { largura } \\
\text { da TW } \\
\text { (conforme } \\
\text { Tabela 4.3-7) }\end{array}$ & $\begin{array}{c}\text { Largura } \\
\text { combinada } \\
\text { entre TWs e } \\
\text { seus } \\
\text { acostamentos }\end{array}$ & $\begin{array}{c}\text { Padrão para } \\
\text { cada } \\
\text { acostamento }\end{array}$ \\
\hline I & $7,5 \mathrm{~m}$ & $13,5 \mathrm{~m}$ & $3 \mathrm{~m}$ \\
II & $10,5 \mathrm{~m}$ & $16,5 \mathrm{~m}$ & $3 \mathrm{~m}$ \\
III, com base de rodas menor do que 18m & $15 \mathrm{~m}$ & $27 \mathrm{~m}$ & $6 \mathrm{~m}$ \\
III, com base de rodas igual ou maior a 18m & $18 \mathrm{~m}$ & $30 \mathrm{~m}$ & $6 \mathrm{~m}$ \\
IV & $23 \mathrm{~m}$ & $38 \mathrm{~m}$ & $7,5 \mathrm{~m}$ \\
V & $23 \mathrm{~m}$ & $44 \mathrm{~m}$ & $10,5 \mathrm{~m} \mathrm{|a}$ \\
VI & $30 \mathrm{~m}$ & $54 \mathrm{~m}$ & $12 \mathrm{~m} \mathrm{|a}$ \\
\hline
\end{tabular}

FONTE: FAA AC 150/5300-13 (1989, p.38)

la: Aeronaves dos grupos geométricos V e VI normalmente exigem acostamentos pavimentados ou, pelo menos, estabilizados. Deve também ser considerado o efeito do jet blast no caso de intersecções.

\subsubsection{PISTAS DE TÁXI DE SAÍDA RÁPIDA (PTSRS)}

Pistas de táxi de saída rápida (PTSRs) servem ao propósito de aumentar a capacidade da pista de pouso e decolagem, acelerando a saída das aeronaves que acabam de pousar. Isso é atingido através de um ângulo agudo de intersecção entre a PTSR e a RW, o qual permite um aumento do raio da curva de saída e, consequentemente, da velocidade. A Figura 4.3-1 ilustra a geometria de uma PTSR e alguns parâmetros de projeto destas pistas de táxi.

Do ponto de vista operacional, cabe à tripulação decidir qual pista de táxi de saída da RW será utilizada. A aceitação de PTSRs diminui em situações adversas, como pista molhada e vento de través.

O projeto de uma PTSR consiste de dois elementos chave: geometria; e posição a partir da cabeceira. Estes elementos relacionam-se através da velocidade, que decai desde a cabeceira até o ponto de turn-off, no qual a aeronave inicia a curva de saída da RW.

Os assuntos geometria e posição foram tratados separadamente nos itens 4.3.6.1 e 4.3.6.2. Para tanto, serviu de base o conteúdo dos seguintes trechos de documentos: ICAO Doc 9157 Parte 2 (2005a, p. de 1-30 até 1-36); apêndice 5 da ICAO Doc 9157 Parte 2 (2005a); FAA AC 150/5300-13 (1989, p.36, 48); apêndice 9 da FAA AC 150/5300-13 (1989, p.142); e FAA AC 150/5060-5 (1983). 


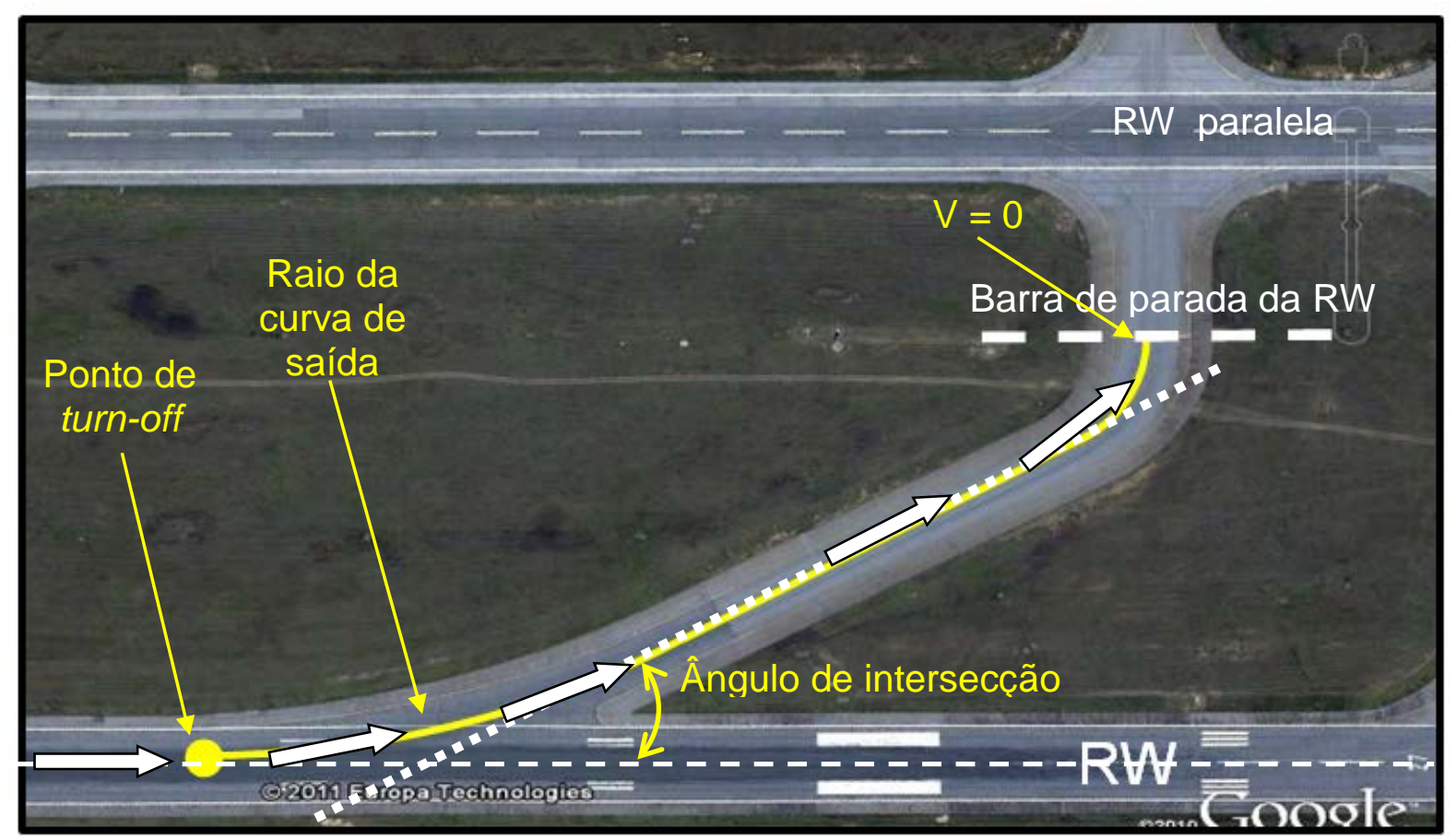

Figura 4.3-1 - Exemplo de uma PTSR. FONTE: Adaptado a partir do Google Earth

\subsubsection{Geometria de uma PTSR}

A ICAO e a FAA apresentam PTSRs padrão. A ICAO apresenta também princípios e recomendações para o projeto de PTSRs. Estas duas possibilidades são discutidas nos itens seguintes.

\subsection{Geometrias padrão}

A ICAO Doc 9157 Parte 2 (2005a, p. de 1-32 até 1-33) apresenta PTSRs padrão para os grupos dinâmicos 1 e 2 e para os grupos dinâmicos 3 e 4, conforme ilustram a Figura 4.3-2 e a Figura 4.3-3.

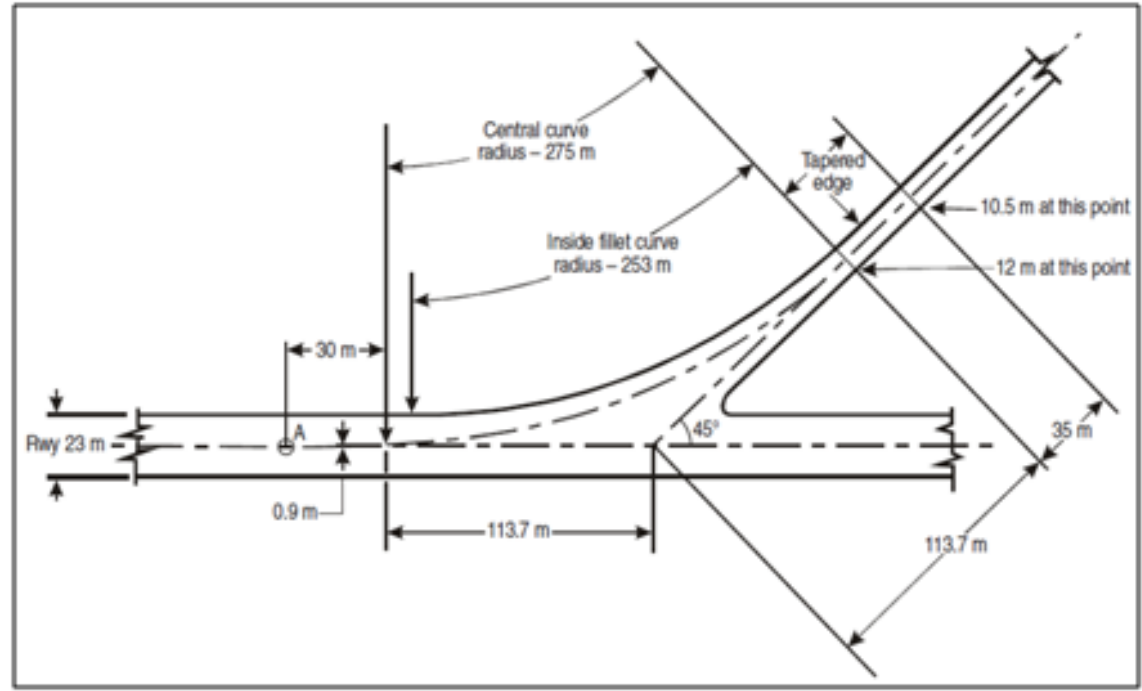

Figura 4.3-2 - Geometria padrão da ICAO para uma PTSR que serve aos grupos dinâmicos 1 e 2. FONTE: ICAO Doc 9157 (2005a, p.1-32) 


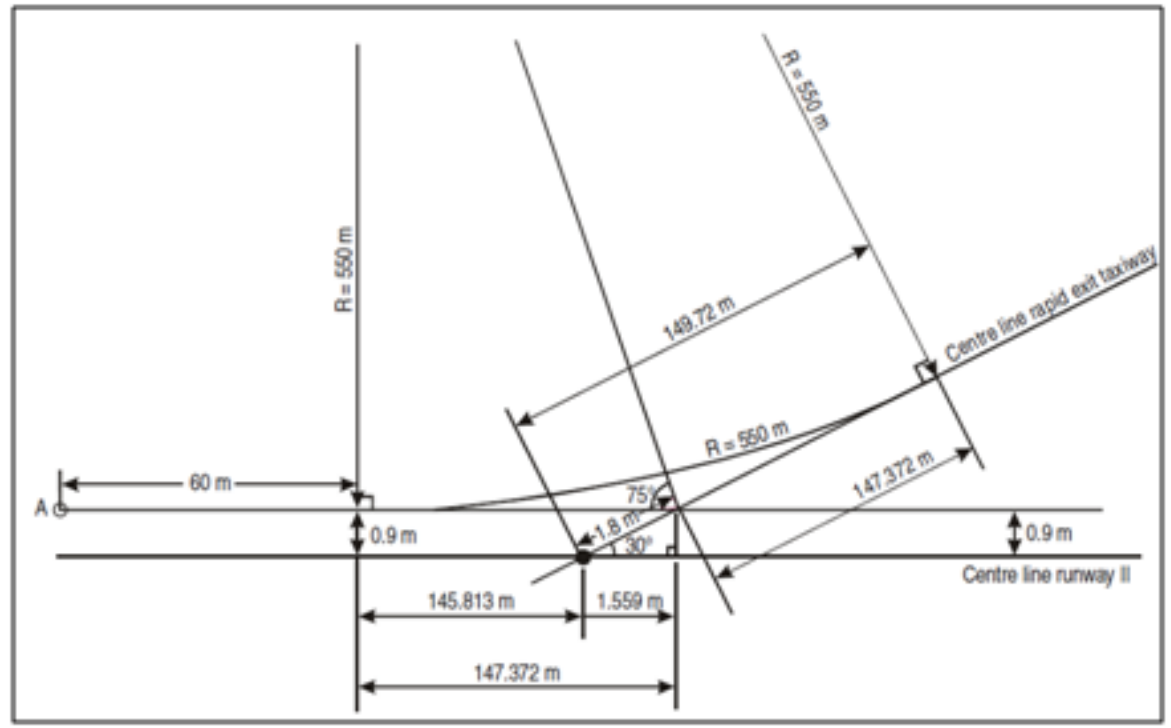

Figura 4.3-3 - Geometria padrão da ICAO para uma PTSR que serve aos grupos dinâmicos 3 e 4. FONTE: ICAO Doc 9157 Parte 2 (2005a, p.1-33)

Como pode ser observado nestas figuras, a ICAO detalha: o raio da curva de saída da RW; o ângulo de intersecção entre a PTSR e a RW; o comprimento do trecho de desaceleração, entre outros.

Já a FAA AC 150/5300-13 (1989, p.48) apresenta uma PTSR padrão, mostrada Figura 4.3-4. No entanto, esta figura precisa ser complementada com informações apresentadas em outras páginas da norma, de forma a constituir-se uma PTSR minimamente definida. Na página 36 esta norma coloca que a espiral de entrada (entrance spiral) é de $420 \mathrm{~m}$. E na página 12, esta norma recomenda separações mínimas entre os eixos de RWs e TWs paralelas de forma a acomodar-se uma PTSR entre as mesmas. Estas distâncias são: 120m para os grupos de projeto / e II; $150 \mathrm{~m}$ para o grupo de projeto III; e $180 \mathrm{~m}$ para os grupos de projeto IV, V e VI.

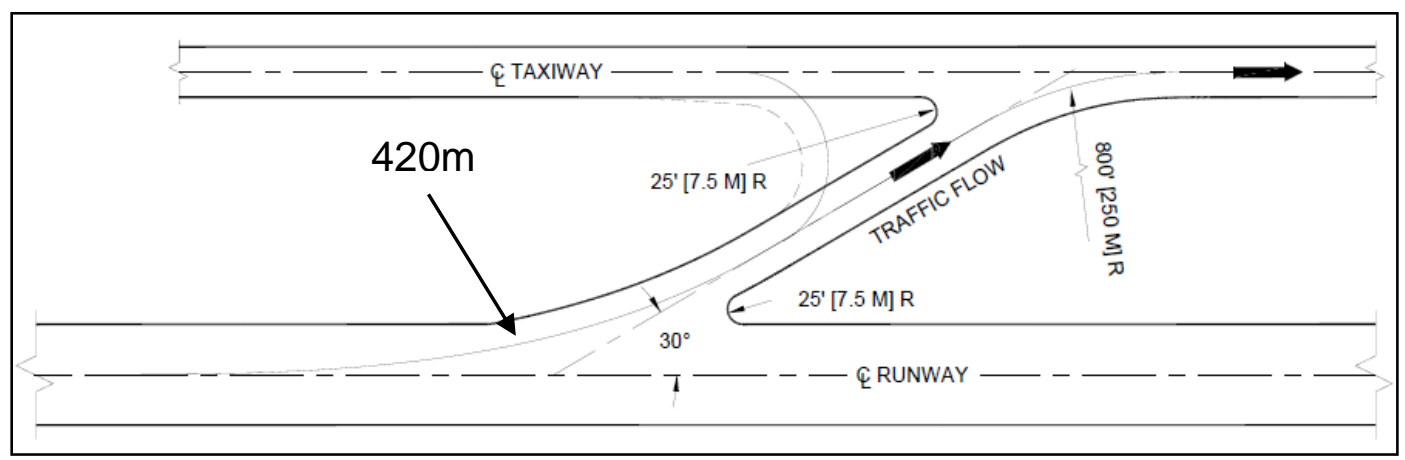

Figura 4.3-4 - Geometria padrão da FAA para uma PTSR. FONTE: Adaptada a partir da FAA AC 150/5300-13 (1989, p.36 e 48) 


\subsection{Princípios e Recomendações da ICAO para o projeto de PTSRs}

O ICAO Doc 9157 Parte 2 (2005a, p. de 1-30 até 1-36) apresenta alguns princípios e recomendações para o projeto de PTSRs:

- O raio de saída (radius of turn-off curve) deve ser compatível com a velocidade de saída ${ }^{4}$. O item 4.3.6.2 trata sobre a relação entre raio e velocidade;

- Deve-se garantir que o comprimento da PTSR seja suficiente para uma parada completa das aeronaves que a utilizam, antes de qualquer intersecção que assim exigir. Para tanto, a norma recomenda a adoção de uma desaceleração de $0,76 \mathrm{~m} / \mathrm{s}^{2}$ no trecho curvo e de $1,52 \mathrm{~m} / \mathrm{s}^{2}$ no trecho retilíneo da PTSR;

- O ângulo de intersecção entre a pista de pouso e decolagem e a PTSR deve estar entre $25^{\circ}$ e $45^{\circ}$, devendo ser preferencialmente de $30^{\circ}$; e

- A sobrelargura provida no interior da curva da PTSR deve ser maior do que em TWs comuns, de forma a facilitar-se o reconhecimento da entrada por parte dos pilotos.

O apêndice 5 da ICAO Doc 9157 Parte 2 (2005a) apresenta um método alternativo para a geometria de PTSRs, no qual o raio da curva diminui à medida que a aeronave se afasta da RW, formando uma espiral. Tal geometria é especialmente atrativa nos casos em que o espaço entre a RW e a TW paralela não permite uma PTSR padrão.

\subsubsection{Posição e número de PTSRs}

O ICAO Doc 9157 Parte 2 (2005a, p. 1-36) recomenda a adoção de um raio de mínimo de 550m para aeronaves dos grupos dinâmicos 3 e 4 e de $275 \mathrm{~m}$ para aeronaves dos grupos dinâmicos 1 e 2. O documento coloca que as velocidades compatíveis com estes raios são de $93 \mathrm{~km} / \mathrm{h}$ e $65 \mathrm{~km} / \mathrm{h}$, respectivamente, o que corresponde a um fator de carga lateral de 0,133g, aplicando-se a Equação 4.5-1. No entanto, no parágrafo 1.3.4 do ICAO Doc 9157 Parte 2 (2005a, p. 1-30) cita-se a adoção de $93 \mathrm{~km} / \mathrm{h}$ como limite de velocidade na qual os pilotos optam por utilizar uma PTSR, no caso dos grupos dinâmicos 3 e 4. Disso se intui que estes raios mínimos especificados estão de acordo com a velocidade máxima esperada para utilização da PTSR. Esta é a velocidade de saída de projeto (design exit speed), simbolizada por $\mathrm{V}_{\text {des. }}$

\footnotetext{
${ }^{4}$ O ICAO Doc 9157 (2005a, p. de 1-36) recomenda a adoção de um raio de mínimo de 550m para aeronaves dos grupos dinâmicos 3 e 4 e de $275 \mathrm{~m}$ para aeronaves dos grupos dinâmicos 1 e 2 .
} 
No entanto, a posição da PTSR desde a cabeceira é estabelecida com base em uma velocidade mais baixa que $V_{\text {des }}$, de forma a aumentar-se a aceitação dos pilotos. Esta é a velocidade operacional de turn-off (operational turn-off speed), simbolizada por $\mathrm{V}_{\mathrm{op}}$.

Para o caso de PTSRs não padrão, deve-se utilizar as relações entre raios e velocidades que constam na Tabela 4.3-10. Desta tabela, $V_{\text {des }}$ é a velocidade a ser utilizada para a escolha do raio e $V_{\text {op }}$ é a velocidade que serve para posicionamento da PTSR.

Tabela 4.3-10 - Relação entre o raio de saída de uma PTSR e a velocidade de turn-off

\begin{tabular}{c|cc|cc}
\hline Raio (m) & \multicolumn{2}{|c|}{$\mathbf{V}_{\text {des }}$} & \multicolumn{2}{c}{$\mathbf{V}_{\text {op }}$} \\
& nós & $\mathbf{k m} / \mathbf{h}$ & nós & $\mathbf{~ k m / h}$ \\
\hline 40 & 14 & 25,93 & 13 & 24,08 \\
60 & 17 & 31,48 & 16 & 29,63 \\
120 & 24 & 44,45 & 22 & 40,74 \\
160 & 28 & 51,86 & 24 & 44,45 \\
240 & 34 & 62,97 & 27 & 50,00 \\
375 & 43 & 79,64 & 30 & 55,56 \\
550 & 52 & 96,30 & 33 & 61,12 \\
\hline
\end{tabular}

Obs.: $V_{\text {des }}$ representa a velocidade compatível com um fator de carga lateral de $0,133 g$ e $V_{\text {op }}$ representa a velocidade de projeto, a qual é empírica e serve ao propósito de otimização do local da PTSR. Os valores originais de velocidade são apresentados na norma em nós (1 nó $=1,852 \mathrm{~km} / \mathrm{h}$ ).

FONTE: ICAO Doc 9157 Parte 2 (2005a, p.1-35)

O mesmo documento apresenta também um gráfico, destinado ao mesmo fim, mostrado na Figura 4.3-5.

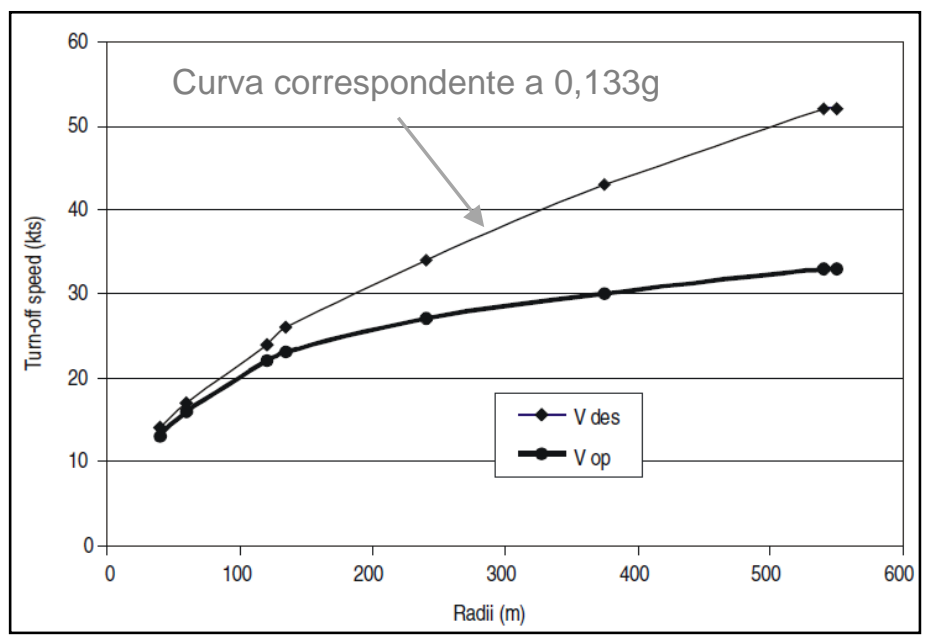

Figura 4.3-5 - Relação entre o raio de saída de uma PTSR e a velocidade de turn-off. FONTE: ICAO Doc 9157 Parte 2 (2005a, p.1-35) 
Conforme o ICAO Doc 9157 Parte 2 (2005a, p. de 1-34), para as PTSRs padrão (da Figura 4.3-2 e da Figura 4.3-3), a velocidade de turn-off ( $\mathrm{V}_{\mathrm{op}}$ ) valerá: 30nós para os grupos dinâmicos 3 e 4; e 15nós para os grupos dinâmicos 1 e 2. No entanto, uma rápida consulta à Tabela 4.3-10 ou à Figura 4.3-5, mostra que, para as geometrias padrão (raios de $550 \mathrm{~m}$ e $275 \mathrm{~m}$ ), $\vee_{\text {op }}$ valerá: 33nós para os grupos dinâmicos 3 e 4; e 28nós para os grupos dinâmicos 1 e 2. Não se conseguiu apurar a razão destas diferenças.

Para o cálculo da distância entre a cabeceira e o ponto de turn-off que coincida com a velocidade operacional de turn-off $\left(\mathrm{V}_{\mathrm{op}}\right)$, o ICAO Doc 9157 Parte 2 (2005a, p. de 1-31 até 1-34) apresenta a metodologia Three Segment Method. Segundo este método, a distância entre a cabeceira e o ponto de turn-off é dividido em três partes, sendo a primeira parte destinada ao flare, a segunda parte à transição (durante a qual a roda dianteira toca o solo), e a terceira parte compreende a desaceleração até $\mathrm{V}_{\mathrm{op}}$. Para esta metodologia, as variáveis de entrada são a velocidade de turn-off $\left(\mathrm{V}_{\mathrm{op}}\right)$, a velocidade de cruzamento da cabeceira (threshold crossing speed), o vento de cauda e a declividade da RW.

Como visto anteriormente, a velocidade operacional de turn-off é fixa para PTSRs padrão. Para as demais, basta conhecer-se o raio da curva de saída da RW, o qual, fornece $\mathrm{V}_{\text {op }}$ a partir da Tabela 4.3-10 ou da Figura 4.3-5.

A velocidade de cruzamento da cabeceira pode ser obtida no APM (Airport Planning Manual). Conforme o ICAO Doc 9157 Parte 2 (2005a, p. 1-34) esta velocidade é definida como: 1,3 vezes a velocidade de estol assumindo-se uma massa de pouso igual a $85 \%$ da massa máxima de pouso. Deve-se corrigir esta velocidade para a temperatura e altitude do aeródromo. ${ }^{5} \mathrm{O}$ mesmo documento propõe um agrupamento de aeronaves em quatro grupos de intervalos da velocidade de cruzamento da cabeceira, considerando-se o nível do mar ${ }^{6}$. No Three Segment Method, considera-se esta divisão em grupos para o estabelecimento de algumas regras de cálculo, mas considera-se a velocidade de cruzamento de cabeceira específica para cada aeronave. Assim, a cada aeronave e condição de vento corresponde uma posição ótima da PTSR. Os grupos são:

- Grupo A: menos de 169km/h (91nós);

- Grupo B: entre $169 \mathrm{~km} / \mathrm{h}$ (91nós) e $222 \mathrm{~km} / \mathrm{h}$ (120nós) ;

\footnotetext{
${ }^{5}$ Nota-se que esta velocidade difere ligeiramente da velocidade de aproximação da FAA, a qual considera a massa máxima de pouso, além de condições atmosféricas padrão ao nível do mar.

${ }^{6}$ Aparentemente a norma se refere a condições atmosféricas padrão e nível do mar, ao mencionar somente o nível do mar na p.1-31 de ICAO Doc 9157 (2005a).
} 
- Grupo C: entre $224 \mathrm{~km} / \mathrm{h}$ (121nós) e 259km/h (140nós); e

- Grupo D: entre $261 \mathrm{~km} / \mathrm{h}$ (141nós) e 306km/h (165nós).

Já a declividade é um fator específico da RW, devendo ser utilizada a declividade da extensão da RW compreendida entre a cabeceira e a PTSR.

O Apêndice 5 da ICAO Doc 9157 Parte 2 (2005a) apresenta um metodologia de cálculo da posição ótima da PTSR em relação à cabeceira, considerando diversas condições de ventos de cauda, bem como o conjunto de aeronaves esperados a utilizar a RW. A metodologia deste apêndice é baseada no Three Segment Method.

Uma forma mais simples de avaliar-se a posição de uma PTSR é através de tabelas e gráficos acumulativos, oriundos de estudos estatísticos. Através desses meios é possível estimar-se a taxa de utilização de uma determinada saída, por parte de aeronaves ou grupos de aeronaves, com base na posição de uma dada pista de táxi de saída. Nesse sentido, o ICAO Doc 9157 Parte 2 (2005a, p.de 1-34 até 1-36) apresenta um estudo no qual as aeronaves são agrupadas conforme a velocidade de cruzamento da cabeceira. O apêndice 9 da FAA AC 150/5300-13 (1989, p.142) também apresenta uma tabela desse tipo, onde as aeronaves são agrupadas em quatro categorias: aeronave de pequeno porte, monomotor; aeronave de pequeno porte, bimotor; aeronave de grande porte, com menos de $136.000 \mathrm{~kg}$; e aeronaves pesadas (heavy), com mais de $136.000 \mathrm{~kg}$.

Ainda em relação à posição de uma PTSR, a FAA AC 150/5060-5 (1983) discorre sobre a influência de PTSRs sobre a capacidade de uma pista de pouso e decolagem.

\subsubsection{Relação entre PTSRs e outros componentes, metodologias e considerações de projeto}

A distância entre uma RW e uma RW ou TW paralela deve ser tal a acomodar a parada e espera da aeronave que utiliza a PTSR.

\subsubsection{PISTAS DE TÁXI SOBRE PONTES}

Nos casos onde modos de superfície (rodovias, hidrovias, ferrovias, etc.) precisam passar pelo local designado como rota de táxi em um aeródromo, a utilização de pistas de táxi sobre pontes é uma solução.

A ICAO Annex 14 (2004a, p. 3-15) preconiza que pelo menos uma largura igual à da área preparada da faixa da pista de táxi (largura conforme item 4.8.1.2) seja capaz de suportar as aeronaves à qual a ponte se destina. No entanto, esta largura 
pode ser diminuída, caso seja oferecido um meio de retenção lateral que, provadamente, não coloque as aeronaves em perigo. Segundo a mesma norma, de especial preocupação é o acesso dos veículos de emergência à ponte e, ainda, o jet blast que pode representar riscos nas áreas adjacentes, abaixo da ponte.

A ICAO Doc 9157 Parte 2 (2005a, p. 1-37) recomenda que o comprimento do trecho retilíneo adjacente à ponte deve ser de pelo menos o dobro do parâmetro base de rodas e nunca ser menor do que:

- $15 m$ se o grupo geométrico for $A$;

- $20 \mathrm{~m}$ se o grupo geométrico for $B$;

- $50 \mathrm{~m}$ se o grupo geométrico for $C, D$ ou $E$;

- $70 \mathrm{~m}$ se o grupo geométrico for $F$.

A FAA, através do Capítulo 7 da FAA AC 150/5300-13 (1989) trata as pistas de táxi sobre pontes e também as pistas de pouso e decolagem sobre pontes. Em termos dimensionais, a norma coloca que o comprimento da ponte deve ser paralelo com a linha de centro da RW ou da TW. Já a largura recomendada, com capacidade plena de suporte, é a largura da TW ou RW mais as áreas de segurança ${ }^{7}$. Em condições excepcionais, a largura da ponte pode ser igual à largura da TW, mais a largura dos acostamentos. Uma pista de táxi com largura mínima deve prover: restrição lateral, folga vertical entre asa e motores, proteção contra efeitos do jet blast sobre pessoas e veículos sob a ponte, espaço suficiente para a manobra de veículos de emergência e espaço suficiente para as escadas de emergência das aeronaves.

\subsubsection{Relação entre TWs sobre pontes e outros componentes, metodologias e considerações de projeto}

Para a ICAO, por padrão, a largura da área com capacidade plena de suporte deve ser, no mínimo, da largura da área preparada da faixa da TW.

Para a FAA, por padrão, a largura da área com capacidade plena de suporte deve ser, no mínimo, da largura da TSA ( Taxiway Safety Area).

\subsection{DISTÂNCIAS DECLARADAS}

O comprimento de uma pista de pouso e decolagem (RW) em conjunto com a zona de parada (stopway - SWY), com a zona desimpedida (clearway - CWY) e com a posição da cabeceira definem um conjunto de quatro distâncias, as quais são

${ }^{7}$ TSA (taxiway safety area) RSA (runway safety area), respectivamente. 
utilizadas pelos operadores para determinação do peso máximo de pouso e decolagem, influenciando diretamente a carga paga e o alcance a partir de um dado aeródromo. As distâncias mencionadas são: a TORA (take-off run available); a TODA (take-off distance available); a ASDA (accelerate-stop distance available); e a LDA (landing distance available). A função de cada uma destas distâncias é discutida a seguir.

A TORA é o comprimento de pista disponível e adequado para a corrida em solo de uma aeronave que decola. O deslocamento de cabeceiras não influencia o comprimento da TORA porque a corrida de decolagem inicia no começo da RW e não na cabeceira.

A TODA é a soma entre a TORA e uma CWY, caso esta estrutura seja provida. Durante o comprimento da TODA a aeronave perfaz a corrida de decolagem, desde o repouso, deixa o solo e atinge uma determinada altura. Em relação à presença de CWYs, cabe explorar alguns casos, onde serve de exemplo a hipotética RW 09R/27L ${ }^{8}$ :

- Não existem CWYs: a TODA é igual ao comprimento da TORA nos dois sentidos;

- Existe uma CWY no sentido 09R': no sentido 09R a TODA será a soma entre o comprimento da TORA e a CWY. No sentido 27L a TODA será igual ao comprimento da RW; ou

- Existem CWYs nos dois sentidos: em ambos os sentidos a TODA possui o comprimento da TORA mais o comprimento da respectiva CWY.

A ASDA, por sua vez, corresponde ao comprimento da TORA com a SWY, se esta estrutura estiver disponível. A ASDA representa o comprimento disponível para aceleração, desde o repouso, desaceleração e parada, no caso de uma decolagem abortada. A decolagem abortada ocorre quando o piloto reconhece e reage a uma falha de motor antes de a aeronave atingir a $V_{1}$ (velocidade de decisão). A velocidade de decisão é selecionada pelo operador de acordo com as condições locais e no manual de voo da aeronave, podendo influenciar o peso máximo de decolagem. Em relação à presença de SWYs, cabe explorar alguns casos, onde serve de exemplo a hipotética RW 09R/27L:

809 e 27 se referem à orientação magnética da aeronave que utiliza a RW. Ver http://en.wikipedia.org/wiki/Runway para uma abordagem simplificada ao conceito.

${ }^{9}$ Neste caso a CWY está próxima na cabeceira $27 \mathrm{~L}$ e a aeronave inicia a corrida de decolagem na extremidade mais próxima à cabeceira 09R. 
- Não existem SWYs: a ASDA é igual ao comprimento da TORA nos dois sentidos;

- Existe uma SWY no sentido $09 \mathrm{R}^{10}$ : no sentido 09R a ASDA será a soma entre o comprimento da TORA e a SWY. No sentido 27L a ASDA será igual ao comprimento da TORA; ou

- Existem SWYs nos dois sentidos: em ambos os sentidos a ASDA possui o comprimento da TORA mais o comprimento da respectiva SWY.

Já a LDA corresponde à distância declarada disponível e adequada para a corrida em solo de uma aeronave que pousa. A LDA inicia na cabeceira e se estende até o final da RW considerado adequado para a corrida em solo. Em RWs com cabeceira deslocada (displaced threshold), a LDA será menor do que o comprimento da RW.

A decisão de prover-se CWYs e SWYs depende do desempenho da(s) aeronaves(s) consideradas críticas em relação às distâncias declaradas. Estas questões de desempenho não costumam ser tratadas nos APMs (Airport Planning Manuals), o que traz a necessidade de consulta a manuais de vôo, operadores e/ou fabricantes.

A CWY e a SWY aumentam, respectivamente a TODA e a ASDA, dado um comprimento da RW. Do ponto de vista econômico, a CWY tem a vantagem de exigir uma preparação menor do que a RW, dispensando pavimentação. A SWY também requer menor preparação do que a RW, pela natureza eventual de sua utilização. Como desvantagem das SWYs, cita-se o caso de RWs equipadas com uma SWY em cada extremidade, no qual somente uma delas cumprirá função durante a corrida de decolagem.

Os padrões de projeto de CWYs e SWYs são tratados nos tópicos seguintes. A Figura 4.4-1 ilustra as distâncias declaradas.

\subsubsection{ZONA DESIMPEDIDA (CLEARWAY - CWY)}

A CWY é uma área retangular definida sobre solo ou água, controlada pela respectiva autoridade, a qual é selecionada ou preparada para que uma aeronave possa perfazer uma parte de sua subida de decolagem até uma dada altura, portanto situa-se na extremidade da pista de pouso e decolagem. Durante a decolagem, a aeronave não deve tocar a CWY.

\footnotetext{
${ }^{10}$ Neste caso a SWY está próxima na cabeceira $27 \mathrm{~L}$ e a aeronave inicia a corrida de decolagem na extremidade mais próxima à cabeceira 09R.
} 
A ICAO Annex 14 (2004a, p. 3-9) faz algumas recomendações sobre o projeto de CWYs:

- LOCALIZAÇÃO: deve iniciar no final da TORA, na elevação do eixo da RW neste ponto.

- COMPRIMENTO: não deve exceder mais do que metade do comprimento da TORA.

- LARGURA: deve possuir pelo menos $150 \mathrm{~m}$ de largura, distribuídos simetricamente em relação ao eixo estendido da RW.

- OBSTÁCULOS: deve ser livre de objetos acima de um plano cuja declividade é de 1,25\% (1vertical:80horizontal) e se inicia no final da TORA.

Os parágrafos 3.6.4, 3.6.5 e 3.6.6 da norma apresentam informações sobre a preparação da superfície de uma CWY.

A FAA AC 150/5300-13 (1989, p.23) também apresenta padrões para o projeto de CWYs. Os critérios para localização, largura e obstáculos são idênticos aos da ICAO. Para o comprimento, no entanto, a norma coloca $300 \mathrm{~m}$ como limite prático.

Ainda, em relação ao comprimento para a CWY, este deve levar em conta as características de desempenho das aeronaves críticas esperadas para o aeródromo, tendo-se em vista o comprimento necessário para a decolagem de uma dada aeronave, considerando-se a altitude-densidade, o peso de decolagem e também, o fato de a pista estar molhada ou não. O parágrafo 25.113 da ANAC RBAC 25 (2009b, p.26) relaciona as exigências de certificação de uma aeronave com o comprimento de um CWY, explicitando o comprimento da trajetória de decolagem (take-off distance) que pode ser completado sobre uma CWY, ao invés de uma superfície com capacidade de suporte.

\subsubsection{ZONA DE PARADA (STOPWAY - SWY)}

É uma área adjacente à extremidade da pista de pouso e decolagem a ser utilizada para desaceleração e parada de aeronaves que tenham abortado a decolagem. Assim, a superfície de uma SWY deve suportar a aeronave crítica esperada a utilizá-la, sem causar-lhe danos, e provendo um coeficiente de friç̧ão compatível com aquele da $\mathrm{RW}^{11}$.

\footnotetext{
${ }^{11}$ A superfície da SWY pode também ser construída de forma a aumentar a taxa de desaceleração das aeronaves, através da utilização de um sistema conhecido como EMAS (Engineering Materials Arresting System).
} 
A ICAO Annex 14 (2004a, p. 3-10) coloca que a largura de uma SWY deve ser a mesma da RW a ela associada. Além disso, esta norma especifica detalhes para as declividades na SWY e na transição desta com a RW.

A FAA AC 150/5300-13 (1989, p.23) coloca que a SWY deve ser tão larga quanto a RW a ela associada e oferecer uma capacidade de suporte suficiente para não induzir danos às aeronaves. A norma também coloca que os custos de construção de SWYs prejudicam seu custo-benefício quando comparadas à RW com capacidade plena de suporte, a qual permite operações nos dois sentidos.

Chama a atenção o fato de que as duas normas não exigem, explicitamente, acostamentos para as stopways.

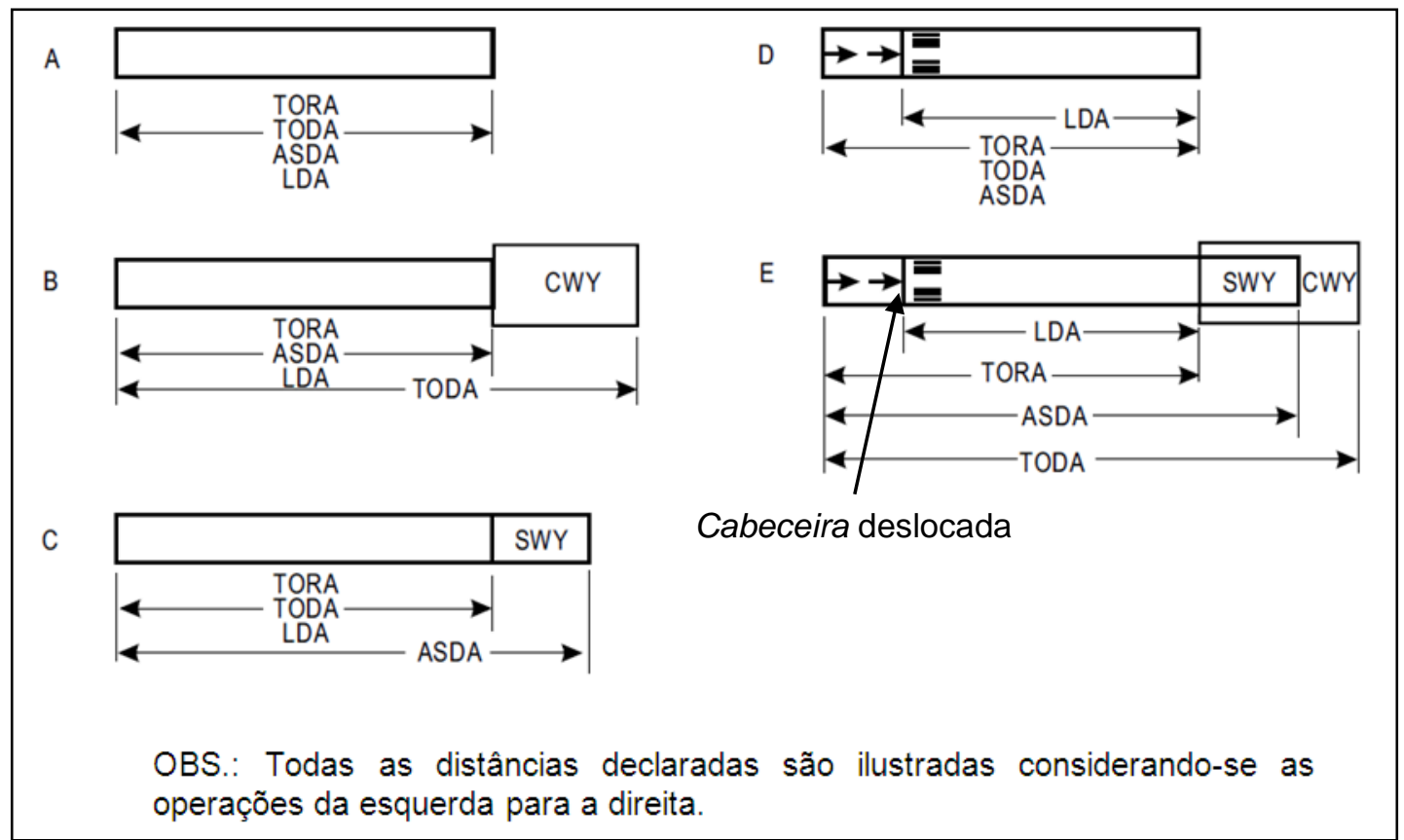

Figura 4.4-1 - Distâncias declaradas. FONTE: Adaptado a partir da ICAO Annex 14 (2004a, p. ATT A-4)

\subsubsection{RELAÇÃO ENTRE DISTÂNCIAS DECLARADAS E OUTROS COMPONENTES, METODOLOGIAS E CONSIDERAÇÕES DE PROJETO}

As stopways, clearways e cabeceiras deslocadas (displaced threshold) modificam os inícios e finais de pista, podendo alterar os referenciais para a posição de áreas de proteção e superfícies de proteção a obstáculos.

Pelos padrões da ICAO, componentes afetados são: faixa da RW; RESA e OFZ.

Pelos padrões da FAA, componentes afetados são: ROFA, RSA, RPZ e OFZ.

Ainda, a largura de uma stopway deve ser a mesma da RW, para a ICAO e para a FAA. 


\subsection{CURVAS E INTERSECÇÕES}

Em um aeródromo, as aeronaves perfazem curvas desde a posição de estacionamento até a pista de pouso e decolagem, passando pelo pátio, pistas de táxi, baías de espera, áreas de giro, entre outros. O projeto destes componentes deve levar em conta critérios de segurança e eficiência, sendo muitos deles apresentados ao longo do presente Capítulo. Mas, além disso, as curvas e intersecções acrescentam especificidades ao projeto de tais componentes.

Isso porque, durante as curvas, as rodas e outras partes da aeronave como nariz, pontas de asa e estabilizadores se desviam das linhas de centro. Isso exige uma análise cuidadosa das áreas pavimentadas, das áreas de segurança e das folgas de projeto, o que exige uma metodologia capaz de fornecer a correspondência entre a trajetória de um ponto de referência da aeronave, que geralmente é a cabine ou a bequilha (roda dianteira da aeronave), e as partes de interesse. Para as áreas pavimentadas, as partes de interesse são as rodas, devendo existir uma margem ${ }^{12}$ de segurança, entre estas e a borda do pavimento. As áreas de segurança ${ }^{13}$, por sua vez, são centradas nas RWs e TWs, sendo, neste caso, de especial interesse os pontos extremos da aeronave, como nariz, pontas de asa e estabilizadores. Estes mesmos pontos devem ter sua trajetória avaliada de forma a manterem-se as folgas especificadas para o pátio e outros componentes. Além disso, as curvas devem ser adequadas à capacidade de manobra das aeronaves, em termos do ângulo de esterçamento da bequilha e do fator de carga lateral, o qual limita a velocidade máxima praticável para um dado raio.

As intersecções também introduzem especificidades ao projeto de alguns componentes, de forma a atender-se às áreas de segurança e às folgas. Nas intersecções entre pistas de táxi, cria-se uma situação na qual uma dada TW vira área de segurança daquela que a intercepta, exigindo barras de parada (BPs). Já para a intersecção entre RWs e TWs, devem ser providas barras de parada da RW (BPRWs) para as aeronaves que entram na RW. A Figura 4.6-4 ilustra essas intersecções.

Dada uma visão geral dos aspectos relacionados às curvas e intersecções, cabe neste ponto dividir o assunto para abordá-lo com mais profundidade. Os itens 4.5.1, 4.5.2 e 4.5.3 apresentam os assuntos fator de carga lateral, trajetória da aeronave e sobrelarguras, respectivamente.

\footnotetext{
${ }^{12}$ Ao longo desta dissertação, esta margem é chamada de folga do pavimento.

${ }^{13}$ Áreas de segurança por vezes, são especificadas com base em folgas de ponta de asa, mas isso não é uma regra.
} 


\subsubsection{FATOR DE CARGA LATERAL}

A ICAO Doc 9157 Parte 2 (2005a, p. 1-9) apresenta um fator de carga lateral (f) máximo de 0,133g a ser utilizado para o cálculo do raio de curvas em TWs. O equacionamento entre as variáveis $\mathrm{f}$, raio e velocidade é dada na p. 1-13 da mesma norma:

$\mathrm{V}=\sqrt{\mathrm{f} \times \mathrm{R}}=\sqrt{0,133 \times \mathrm{g} \times \mathrm{R}}$

Onde f é o fator de carga lateral $\left(\mathrm{m} / \mathrm{s}^{2}\right), g$ a aceleração da gravidade $\left(\mathrm{m} / \mathrm{s}^{2}\right)$, $V$ a velocidade $(\mathrm{m} / \mathrm{s})$, e $R$ o raio da curva $(\mathrm{m})$. A norma, no entanto, não apresenta uma velocidade mínima a ser adotada para o projeto das curvas, a não ser para PTSRs, conforme as informações do item 4.3.6.

A FAA AC 150/5300-13 (1989) não apresenta nenhum fator de carga lateral para o projeto de TWs, mas, na p. 34, esta norma recomenda que o sistema de TWs possibilite uma velocidade mínima de $20 \mathrm{mph}(30 \mathrm{~km} / \mathrm{h})$ e, ao mesmo tempo, cita $60 \mathrm{~m}$ como raio mínimo para a curva em uma TW. Esses valores são consistentes com a Equação 4.5-1 apresentada pela ICAO, o que implica um fator de carga lateral de $0,133 \mathrm{~g}$.

\subsubsection{TRAJETÓRIA DA AERONAVE}

As aeronaves comerciais apresentam trens de pouso sob a configuração triciclo, na qual o esterçamento da bequilha (roda do nariz) é utilizado para controle em solo e o trem principal é fixo. Em algumas aeronaves, como é o caso do B747, por exemplo, algumas rodas do trem principal também se esterçam.

Quando a cabine ou outro ponto de referência da aeronave (N) segue a sinalização horizontal, será criado um ângulo entre o eixo longitudinal da aeronave e a sinalização horizontal, no ponto N. Esse é o chamado ângulo de esterçamento da aeronave ( $\beta$ ). A Figura 4.5-1 ilustra a geometria envolvida.

O ângulo de esterçamento da aeronave $(\beta)$ será diferente do ângulo de esterçamento da bequilha $\left(\beta_{\text {beq }}\right)$ caso a bequilha não coincida com o ponto de referência da aeronave $(\mathrm{N})$. Isso porque a bequilha descreverá uma trajetória diferente daquela do ponto $\mathrm{N}$. No caso do B747, cada uma das rodas com capacidade de esterçamento estará sujeita a uma trajetória e a um ângulo de esterçamento diferente ${ }^{14}$. Já o ponto $\mathrm{U}$ é convencionado como o centroide das rodas desprovidas de capacidade de esterçamento.

\footnotetext{
${ }^{14} \mathrm{O}$ ângulo de esterçamento de uma roda é medido entre o eixo longitudinal da aeronave e a trajetória instantânea da roda.
} 


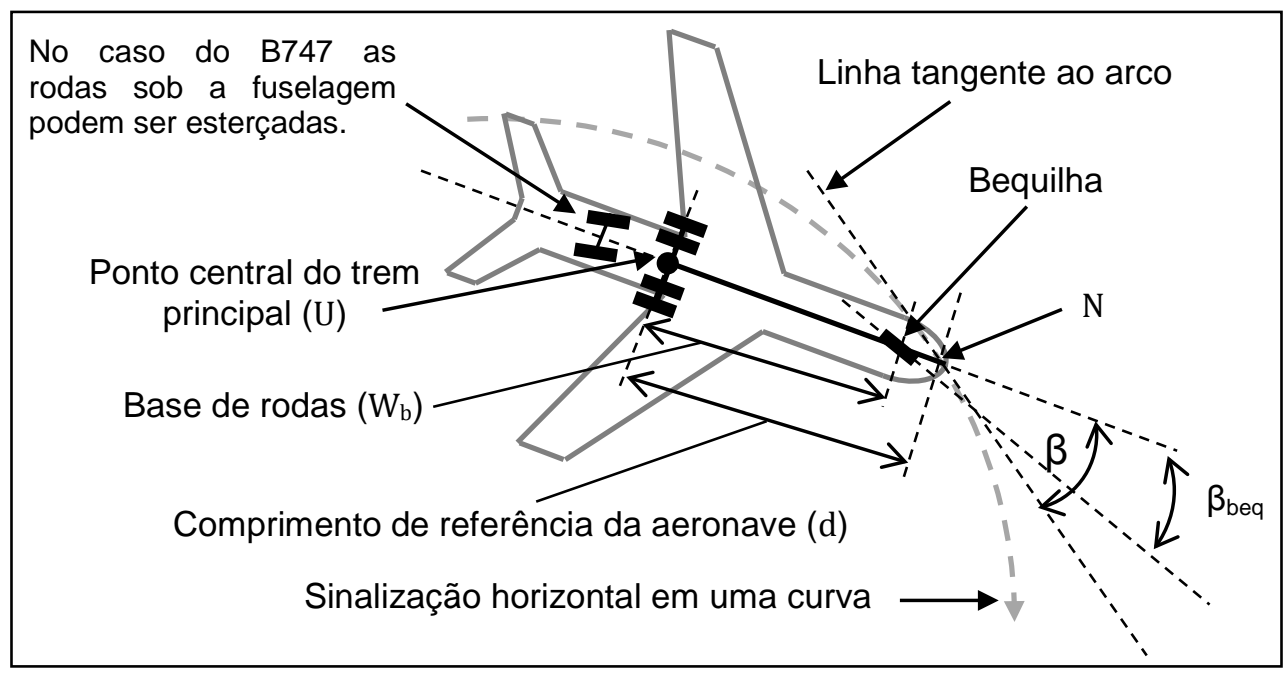

Figura 4.5-1 - Geometria para análise da trajetória de aeronaves em curvas. FONTE: Adaptado a partir da metodologia apresentada pela ICAO Doc 9157 (2005a, p. 1-40)

Como a aeronave constitui um conjunto rígido sujeito ao ângulo $\beta$, a trajetória de cada ponto da mesma será descrito com base em $\beta$ e na posição de $\mathrm{N}$. Assim, o assunto pode ser dividido novamente em três partes: ângulo de esterçamento da aeronave; ângulo de esterçamento das rodas; e trajetória dos pontos de interesse (rodas, nariz, pontas de asa, etc.). Isso é feito nos itens 4.5.2.1, 4.5.2.2 e 4.5.2.3.

\subsubsection{1 Ângulo de esterçamento da aeronave}

A ICAO e a FAA apresentam metodologias para avaliação do ângulo $\beta$, considerando apenas duas geometrias para a linha guia (guideline): arco de círculo e linha reta. A utilização combinada destas duas geometrias permite um desenho razoavelmente flexível do percurso das aeronaves, alternando-se retas, arcos de círculo e espirais (compostas por arcos de diferentes raios). A ICAO Doc 9157 Parte 2 (2005a, p. 1-40) e a FAA AC 150/5300-13 (1989, p. de 33 até 34$)^{15}$ citam a possibilidade de deslocar-se a linha guia para fora da curva (offsetting), de forma a prover-se maior folga para o pavimento ou para as pontas de asa. No entanto, existem várias desvantagens oriundas dessa prática, pois a mesma linha guia deve ser utilizada por vários tipos de aeronaves e nos dois sentidos do tráfego. Além disso, o deslocamento da linha guia em relação ao arco, tem o efeito antagônico de aumentar a folga em um lado e diminuir do outro. Como nenhuma das normas fornece uma metodologia para avaliação do ângulo $\beta$ para geometrias diferentes de

${ }^{15}$ Para a FAA esta é uma medida temporária, não devendo ser aplicada no projeto de instalações novas. A norma oferece uma fórmula para o cálculo no novo raio a ser adotado para o arco, com base no raio atual e no comprimento de referência da aeronave. 
uma reta e de um arco de círculo, surge como solução o método numérico apresentado por Horonjeff e McKelvey (1994).

Para a avaliação de geometrias sucessivas, compostas pela união de retas e arcos de diversos raios, o ângulo de esterçamento final de uma dada geometria será utilizado como ângulo de esterçamento inicial da geometria sucessora. As variáveis de entrada para cálculo da variação de $\beta$ quando $\mathrm{N}$ segue uma reta ou arco de círculo são: o comprimento de referência da aeronave (d); o ângulo $\beta$ no início da manobra ${ }^{16}$; e o raio (R), no caso de arcos. Quando $N$ segue uma linha reta, a variável independente é a distância em linha reta, desde o início da manobra, nas metodologias da ICAO e da FAA. Já para a avaliação da manobra ao longo de um arco, a metodologia da ICAO utiliza o ângulo polar $^{17}$ e a metodologia da FAA utiliza a distância percorrida sobre o arco. Feitos os devidos ajustes, as variáveis independentes das duas metodologias são equivalentes.

O apêndice 1 da ICAO Doc 9157 Parte 2 (2005a) apresenta equações e ábacos para a avaliação de $\beta$ quando $\mathrm{N}$ segue retas ou arcos. Já a metodologia equivalente da FAA é apresentada no apêndice 10 da FAA AC 150/5300-13 (1989).

\subsubsection{2 Ângulo de esterçamento das rodas}

Caso uma roda com capacidade de esterçamento esteja posicionada fora do ponto $\mathrm{N}$, o ângulo de esterçamento dessa roda será diferente de $\beta$. O apêndice 10 FAA AC 150/5300-13 (1989) apresenta a Equação 4.5-2, que relaciona $\beta$ e o ângulo de esterçamento da bequilha $\left(\beta_{\text {beq }}\right)$ a partir da base de rodas $\left(\mathrm{W}_{\mathrm{b}}\right)$ e do comprimento de referência da aeronave (d). O apêndice 1 da ICAO Doc 9157 Parte 2 (2005a) apresenta uma tabela que relaciona $\beta$ e $\beta_{\text {beq }}$ para diversas razões $\left(d / W_{b}\right)$, cujos valores são equivalentes ao da Equação 4.5-2.

$\beta_{b e q}=\operatorname{atan}\left[\frac{\mathrm{W}_{\mathrm{b}} \times \tan (\beta)}{\mathrm{d}}\right]$

Caso uma dada trajetória da aeronave exija um $\beta_{\text {beq }}$ muito elevado, a geometria deve ser alterada. Para o caso de arcos, deve-se aumentar o raio. O apêndice 10 da FAA AC 150/5300-13 (1989) coloca que o limite máximo de projeto para o $\beta_{\text {beq é de }}$

\footnotetext{
${ }^{16}$ O apêndice 1 da ICAO Doc 9157 (2005a) apresenta a correspondência matemática entre $\beta$ e o desvio do ponto $U(\lambda)$ o qual é medido entre o ponto $U$ e a reta ou arco, de forma que a reta desde $U$ intercepte $\mathrm{o}$ arco ou reta de forma tangente. A norma também apresenta ábacos onde $\lambda$ e $\beta$ estão relacionados.

${ }^{17} \mathrm{O}$ ângulo polar que aparece na metodologia da ICAO inicia em $0^{\circ}$ e vai até a convergência da manobra, quando $\beta$ torna-se constante ao longo do arco. No ponto $0^{\circ}$ a aeronave encontra-se posicionada a $90^{\circ}$ em relação à reta tangente ao arco.
} 
$50^{\circ}$. Apurou-se que a ICAO coloca limite para $\beta_{\text {beq }}$ somente no caso de áreas de giro, através da ICAO Annex 14 (2004a, p. 3-6), que limita $\beta_{\text {beq }} a 4^{\circ}$.

\subsubsection{Trajetória de pontos de interesse}

De forma a atender-se às folgas do pavimento, folgas de ponta de asa e às áreas de segurança, é necessário conhecer-se as trajetórias de pontos extremos da aeronave como nariz, pontas de asa, estabilizadores e rodas. Para o cálculo das coordenadas retangulares dos pontos de interesse da aeronave, pode-se utilizar a Equação 4.5-3 e a Equação 4.5-4, as quais foram adaptadas pelo autor a partir das equações apresentadas na FAA AC 150/5300-13 (1989, p. 146).

$X_{P}=x_{N}-\varphi_{1} \times d_{x} \times \cos (\alpha-\beta)+\varphi_{2} \times \frac{d_{y} \times \sin (\alpha-\beta)}{2}$

$Y_{P}=y_{N}+\varphi_{1} \times d_{x} \times \cos (\alpha-\beta)+\varphi_{2} \times \frac{d_{y} \times \sin (\alpha-\beta)}{2}$

Onde:

- $X_{\mathrm{p}}$ e $Y_{\mathrm{p}}$ são as coordenadas retangulares do ponto de interesse (P);

- $X_{\mathrm{N}}$ e $Y_{\mathrm{N}}$ são as coordenadas retangulares do ponto de referência da aeronave $(\mathrm{N})$, posicionado sobre a trajetória;

- $\varphi_{1}$ e $\varphi_{2}$ são coeficientes utilizados para seleção da posição relativa entre P e $\mathrm{N}$ : para a porção da aeronave posicionada à frente de $\mathrm{N}$, deve-se utilizar $\varphi_{1}=-1$; para o lado direito da aeronave deve-se utilizar $\varphi_{2}=-1$; e para as demais situações utilizar valores positivos desses coeficientes;

- $d_{x}$ é a distância longitudinal absoluta entre $\mathrm{N}$ e P;

- $d_{y}$ é a distância transversal absoluta entre $\mathrm{N}$ e P;

- $\alpha$ é o ângulo formado entre a linha tangente à linha guia, no ponto $\mathrm{N}$, e o eixo x; e

- $\beta$ é o ângulo de esterçamento da aeronave.

\subsubsection{SOBRELARGURAS}

De forma a atender-se às folgas do pavimento especificadas no item 4.3.4, e tendo-se em vista o desvio das rodas das aeronaves durante as curvas, sobrelarguras (fillets) podem ser necessárias nas TWs. O pavimento da sobrelargura deve possuir capacidade plena de suporte. 
As variáveis envolvidas na decisão de prover-se ou não sobrelarguras são as seguintes: wheel span e comprimento de referência (d) da aeronave crítica ${ }^{18}$; largura da TW; raio do arco (R); posição inicial da aeronave antes de iniciar a curva; e folga do pavimento. A utilização de mudanças de direção mais gradativas e de raios mais avantajados ao longo do caminho de táxi pode eliminar a necessidade de prover-se sobrelarguras. Cabe lembrar-se que a análise dos desvios deve considerar o tráfego nos dois sentidos.

Para o dimensionamento de sobrelarguras, o apêndice 1 da ICAO Doc 9157 Parte 2 (2005a) apresenta três métodos diferentes: método gráfico; método arco e tangente; e uma variação do método arco e tangente (variant of arc and tangent method).

O método gráfico consiste em: i) desenho das linhas de centro e das bordas das TWs que se interceptam; ii) cálculo do ângulo $\beta$ ao longo da curva; iii) desenho da trajetória das rodas ao longo da manobra; e iv) desenho de uma sobrelargura, considerando-se a folga do pavimento (M), caso esta margem não possa ser atendida dentro da largura da TW. Os passos iii) e iv) podem ser realizados através da Equação 4.5-3 e da Equação 4.5-4. E a Figura 4.5-2 ilustra o método gráfico.

O método arco e tangente é uma simplificação geométrica, onde um arco concêntrico à curva e duas retas tangentes ao arco formam a sobrelargura. Neste caso existem apenas dois parâmetros geométricos a serem definidos: o raio da sobrelargura (r) e comprimento (L) ao longo do eixo da TW, desde o ponto em que a aeronave inicia a taxiar sobre a linha guia retilínea até o ponto em que a reta tangente ao arco intercepta a borda da TW. A geometria do método arco e tangente é mostrada na Figura 4.5-3. No apêndice 1 da ICAO Doc 9157 Parte 2 (2005a) são apresentadas equações e ábacos para cálculo dos parâmetros $\mathrm{r}$ e L.

A ICAO apresenta também uma variação do método arco e tangente que consiste em utilizar quatro linhas retas ao invés de duas, diminuindo a área total do pavimento da sobrelargura. Para maiores detalhes, ver o apêndice 1 da ICAO Doc 9157 Parte 2 (2005a).

O apêndice 10 da FAA AC 150/5300-13 (1989) apresenta um método simplificado para o projeto de sobrelarguras, muito similar ao método arco e tangente. Equações são fornecidas para o cálculo de r e L.

\footnotetext{
${ }^{18}$ No caso do B747 as rodas posicionadas sob a fuselagem, não são computadas no comprimento de referência da aeronave (d), pois possuem capacidade de esterçamento. Com isso, para a análise da folga do pavimento e para o projeto de sobrelarguras, d será menor do que $\mathrm{d}_{\mathrm{x}}$.
} 


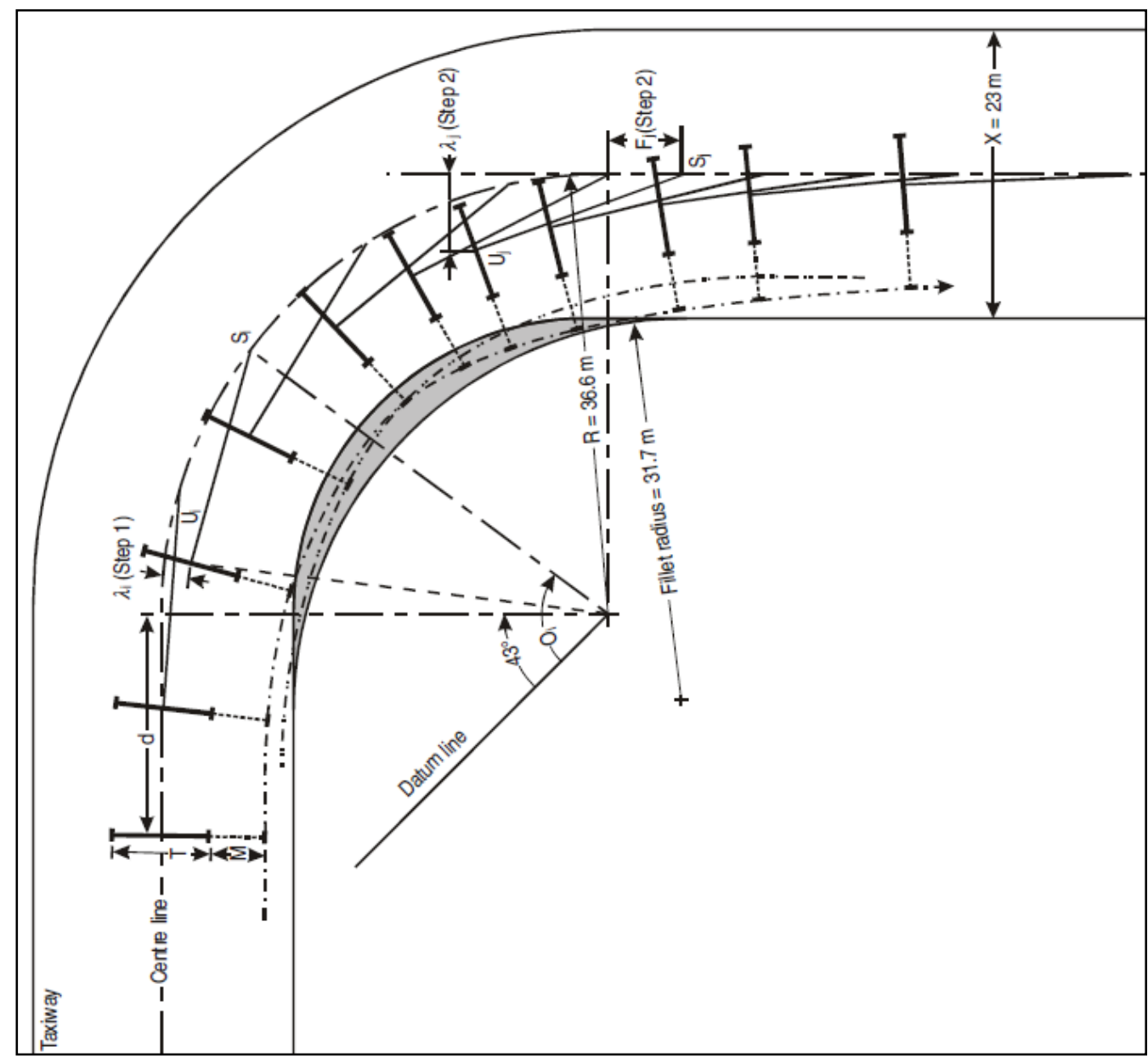

Figura 4.5-2 - Método gráfico para desenho de sobrelarguras. FONTE: ICAO Doc 9157 Parte 2 (2005a, p. APP 1-22)

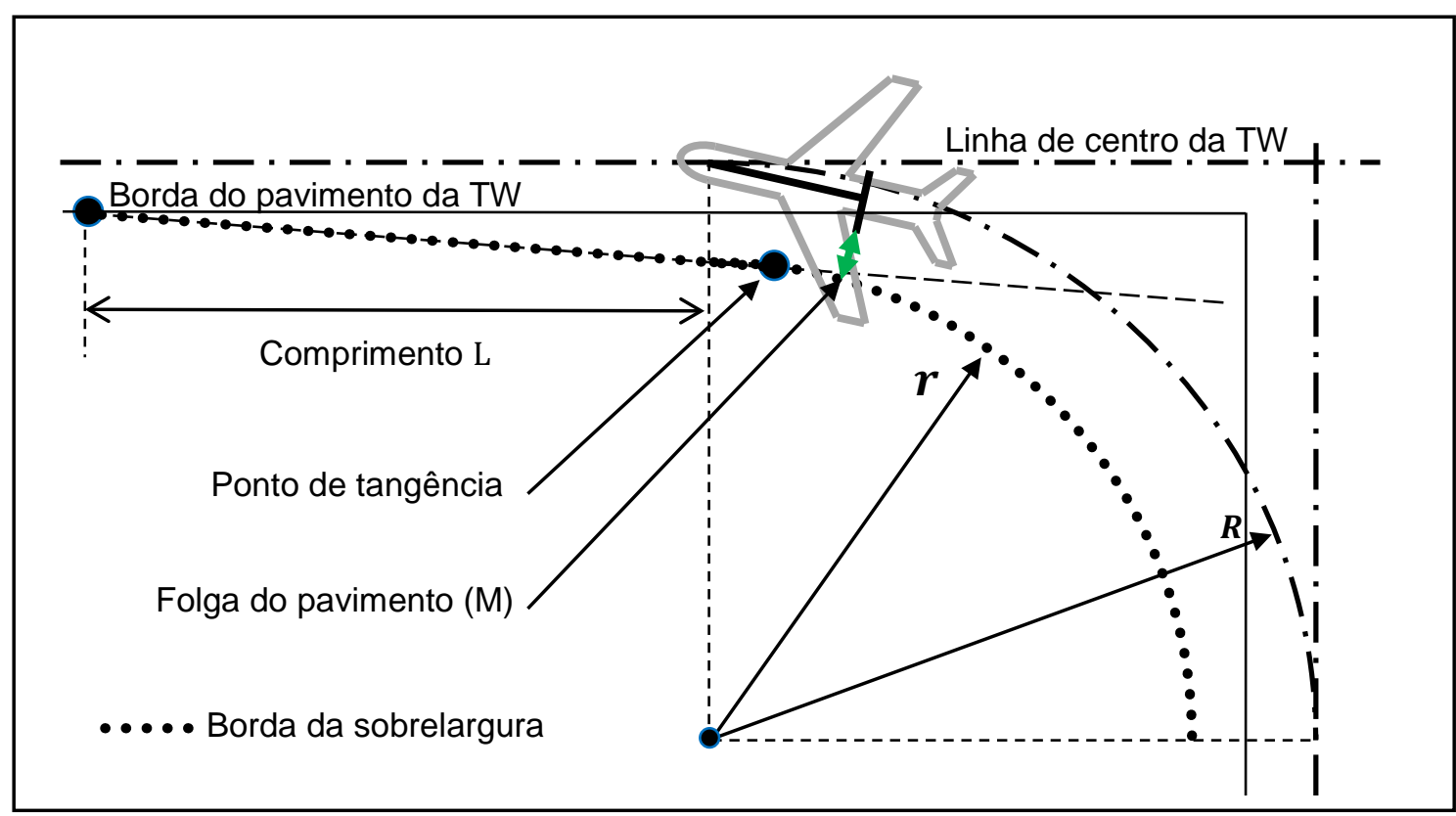

Figura 4.5-3 - Método arco e tangente para desenho de sobrelarguras. FONTE: Adaptado a partir da metodologia apresentada pela ICAO Doc 9157 Parte 2 (2005a, p. 1-40) 


\subsubsection{RELAÇÃO ENTRE CURVAS E INTERSECÇÕES E OUTROS COMPONENTES, METODOLOGIAS E CONSIDERAÇÕES DE PROJETO}

O deslocamento de partes da aeronave como rodas, nariz, pontas de asa e estabilizadores exige a devida consideração quanto às folgas e áreas de proteção.

Para a ICAO os componentes afetados são: sobrelarguras, faixa da TW, folgas entre aeronaves e objetos, folgas no pátio e BPs (barras de parada no sistema de pistas de táxi.

Para a FAA os componentes afetados são: sobrelarguras, OFAs das TWs, OFAs das TLs, TSA, folgas no pátio e BPs.

\subsection{SEPARAÇÕES}

Separações são distâncias mínimas a serem observadas entre componentes como RWs, TWs, TLs e posições do pátio de aeronaves. Folgas entre aeronaves e objetos ou outras aeronaves estão também relacionadas às separações. Os itens seguintes apresentam os padrões da ICAO e da FAA quanto às separações em um aeródromo.

\subsubsection{SEPARAÇÃO ENTRE RWs PARALELAS}

A ICAO e a FAA apresentam separações mínimas entre os eixos de RWs paralelas, dependendo de até três informações: i) nível de visibilidade/instrumentação; ii) natureza das operações nas RWs: uso simultâneo das RWs, operações segregadas, etc.; e iii) grupo dinâmico.

Os tópicos 4.6.1.1 e 4.6.1.2 apresentam as especificações da ICAO e da FAA, respectivamente.

\subsubsection{Especificações da ICAO para separações entre RWs paralelas}

A ICAO Annex 14 (2004a, p. 3-2) recomenda, para pistas para aproximação visual, destinadas ao uso simultâneo, as seguintes separações mínimas:

- 210m: para os grupos dinâmicos 3 ou 4;

- 150m: para o grupo dinâmico 2; e

- 120m: para o grupo dinâmico 1.

Procedimentos para categorização de esteira de turbulência de aeronaves e para separações mínimas devido à turbulência são fornecidas na ICAO PANS-ATM (2007a), respectivamente no item 4.9 e no item 5.8 desta norma. 
Já para o caso de operações por instrumentos, quando o uso simultâneo está sujeito às condições especificadas na ICAO PANS-ATM (2007a) e na ICAO PANSOPS Volume I (2006c), a ICAO Annex 14 (2004a, p. 3-2) recomenda as seguintes distâncias entre os eixos das pistas:

- 1.035m: para aproximações paralelas independentes ${ }^{19}$;

- 915m: para aproximações paralelas dependentes ${ }^{20}$;

- 760m: para decolagens paralelas independentes ${ }^{21}$; e

- 760m: para operações paralelas segregadas ${ }^{22}$.

Uma exceção à distância especificada acima para operações paralelas segregadas fica por conta do caso onde as pistas são decaladas (staggered) ${ }^{23}$, ou seja, as extremidades são deslocadas longitudinalmente. Neste caso a separação de $760 \mathrm{~m}$ :

- pode ser diminuída em $30 m$ para cada $150 m$ de decalagem favorável ${ }^{24}$, até um mínimo de $300 \mathrm{~m}$; e

- deve ser aumentada em $30 \mathrm{~m}$ para cada $150 \mathrm{~m}$ de decalagem desfavorável.

Para aproximações paralelas independentes, combinações de distâncias mínimas e outras condições relacionadas que não as especificadas na ICAO PANSATM (2007a) podem ser aplicadas quando for determinado que estas combinações não irão afetar adversamente a segurança operacional das aeronaves.

Exigências quanto a procedimentos e instalações para operações simultâneas em pistas de aproximação de precisão paralelas ou quase-paralelas são apresentadas no: Capítulo 6 da ICAO PANS-ATM Doc 4444 (2007); na parte VI da ICAO PANS-OPS Doc 8168 Volume I (2006c); nas partes II e III da ICAO PANSOPS Doc 8168, Volume II (2006d); e na ICAO Doc 9643 (2004b).

\footnotetext{
${ }^{19}$ Aproximações simultâneas em pistas paralelas, ou quase paralelas, por instrumento, onde não são prescritas as separações radar mínimas entre aeronaves nos prolongamentos dos eixos de pistas adjacentes.

${ }^{20}$ Aproximações simultâneas em pistas paralelas, ou quase paralelas, por instrumento, onde são prescritas as separações radar mínimas entre aeronaves nos prolongamentos dos eixos de pistas adjacentes.

${ }^{21}$ decolagens simultâneas a partir de pistas paralelas ou quase paralelas operando por instrumentos.

${ }^{22}$ Operações simultâneas, em pistas de operação por instrumento paralelas ou quase paralelas, nas quais uma pista é utilizada exclusivamente para aproximações e a outra pista é utilizada exclusivamente para decolagens.

${ }^{23}$ Decalagem é a tradução adotada para a palavra stagger, que se refere à distância longitudinal entre as cabeceiras de mesmo heading de duas RWs paralelas.

${ }^{24}$ A decalagem será favorável quando a aeronave em aproximação estiver mais próxima da primeira cabeceira e a que decola, o faz da cabeceira mais distante.
} 


\subsubsection{Especificações da FAA para separações entre RWs paralelas}

As especificações são divididas entre operações VFR e IFR, conforme os itens 4.6.1.2.1 e 4.6.1.2.2.

\subsection{Separação entre RWs paralelas para operações VFR simultâneas}

A separação mínima padrão é de $214 \mathrm{~m}$. Mas a norma recomenda que para aeronaves dos grupos geométricos V e VI uma separação de $366 \mathrm{~m}$ seja utilizada. No entanto, pode ser necessário aumentar-se essas distâncias devido à necessidade de acomodarem-se aeronaves em espera entre as duas pistas de pouso e decolagem. Pistas paralelas separadas em menos de $762 \mathrm{~m}$ são tratadas como uma pista única pelo ATC quando a esteira de turbulência é considerada.

\subsection{Separação entre RWs paralelas para operações IFR simultâneas}

A separação longitudinal das aeronaves nas operações de pouso e decolagem pode ser reduzida ou substituída pelo uso de separação entre os eixos de duas RWs paralelas. Quando possível deve prover-se uma separação de $1.525 \mathrm{~m}$, o que permite operações totalmente independentes. Quando esta separação não é provida, valem as seguintes distâncias:

\section{Aproximações simultâneas:}

Aproximações de precisão requerem auxílios eletrônicos à navegação área e equipamentos de monitoramento, controle de tráfego aéreo e procedimentos de aproximação. As seguintes divisões se aplicam:

- Aproximações duplas simultâneas de precisão: normalmente a separação exigida é de $1.310 \mathrm{~m}$. Em uma análise caso-a-caso é possível reduzir-se esta separação para até $915 \mathrm{~m}$, mas isso exige ações mitigatórias como a melhoria dos equipamentos de monitoramento, etc.

- Aproximações triplas simultâneas de precisão: para aeroportos abaixo de $305 m$ de elevação é normalmente requerida uma separação de $1.525 m$. Operações em elevações maiores do que $305 \mathrm{~m}$ e/ou uso de separações menores do $1.525 m$ estão sendo estudadas pela FAA. De forma provisória a FAA pode autorizar, caso-a-caso, a operação em separações tão baixas quanto $1.310 \mathrm{~m}$ quando separações maiores não são possíveis e 0 aeródromo está a uma elevação menor do que $305 \mathrm{~m}$. Separações menores do que $1.525 \mathrm{~m}$ podem exigir ações mitigatórias como melhoria dos equipamentos de monitoramento, etc. 
- Aproximações quádruplas simultâneas de precisão: este tipo de aproximação está sob estudo. De forma provisória pode-se autorizar separações mínimas de até $1.525 m$, o que pode exigir ações mitigatórias, como melhoria dos equipamentos de monitoramento, etc.

\section{Aproximações e saídas simultâneas:}

As seguintes condições se aplicam:

- Saídas simultâneas: nem sempre exigem instalações de controle radar do tráfego.

- Saídas simultâneas não radar: requerem uma separação de pelo menos $1.067 \mathrm{~m}$;

- Saídas simultâneas radar: requerem uma separação de 762m;

- Saídas e aproximações simultâneas (operações segregadas):

- Cabeceiras não decaladas: requerem uma separação de pelo menos $762 m$;

- Cabeceiras favoravelmente decaladas: a separação de $762 m$ pode ser reduzida até $305 m$ a uma razão de $30 \mathrm{~m}$ para cada $150 \mathrm{~m}$ de decalagem. Para aeronaves dos grupos geométricos $V$ e $V I$ recomenda-se uma separação mínima não menor do que $366 \mathrm{~m}$.

- Cabeceiras desfavoravelmente decaladas: Neste caso a distância mínima de $762 \mathrm{~m}$ precisa ser aumentada em $30 \mathrm{~m}$ para cada $152 \mathrm{~m}$ de decalagem.

4.6.1.3 Relação entre separações em RWs paralelas e outros componentes, metodologias e considerações de projeto

Além dos efeitos sobre as operações de pouso e decolagem, a separação entre RWs paralelas merece consideração quanto à $O F Z$ de transição interna, quando à posição das BPRWs entre as RWs e quanto à possibilidade de acomodarse PTSRs.

\subsubsection{SEPARAÇÃO ENTRE RWs e TWs PARALELAS}

A ICAO Annex 14 (2004a, p. 3-13) recomenda separações mínimas entre os eixos de RWs e TWs paralelas, conforme a Tabela 4.6-1. De acordo com o parágrafo 1.2.19 da ICAO Doc 9157 Parte 2 (2005a), estas distâncias são tais a proteger a área geral da faixa da RW (AGFRW). Assim, as distâncias da Tabela 4.6-1 correspondem à soma da metade da envergadura máxima de cada grupo 
geométrico com a AGFRW de cada grupo dinâmico. Segundo a norma, estas distâncias mínimas podem ser flexibilizadas em condições especiais de operação, mediante estudo aeronáutico. A ICAO Doc 9157 Parte 2 (2005a, p.de 1-13 até 1-28) apresenta uma série de fatores a serem considerados para a flexibilização do padrão.

Tabela 4.6-1 - Separação padrão da ICAO entre RWs e TWs paralelas

\begin{tabular}{c|c|c|c|c|c|c|c|c}
\hline \multirow{2}{*}{$\begin{array}{c}\text { Grupo } \\
\text { geométrico }\end{array}$} & \multicolumn{4}{|c|}{$\begin{array}{c}\text { Pistas para aproximação por } \\
\text { instrumentos }\end{array}$} & \multicolumn{4}{c}{ Pistas para aproximação visual } \\
\cline { 2 - 9 } & \multicolumn{3}{|c|}{ Grupo dinâmico } & \multicolumn{4}{c}{ Grupo dinâmico } \\
\cline { 2 - 9 } & $\mathbf{1}$ & $\mathbf{2}$ & $\mathbf{3}$ & $\mathbf{4}$ & $\mathbf{1}$ & $\mathbf{2}$ & $\mathbf{3}$ & $\mathbf{4}$ \\
\hline A & $82,5 \mathrm{~m}$ & $82,5 \mathrm{~m}$ & - & - & $37,5 \mathrm{~m}$ & $47,5 \mathrm{~m}$ & - & - \\
B & $87 \mathrm{~m}$ & $87 \mathrm{~m}$ & - & - & $42 \mathrm{~m}$ & $52 \mathrm{~m}$ & - & - \\
C & - & - & $168 \mathrm{~m}$ & - & - & - & $93 \mathrm{~m}$ & - \\
D & - & - & $176 \mathrm{~m}$ & $176 \mathrm{~m}$ & - & - & $101 \mathrm{~m}$ & $101 \mathrm{~m}$ \\
E & - & - & - & $182,5 \mathrm{~m}$ & - & - & - & $107,5 \mathrm{~m}$ \\
F & - & - & - & $190 \mathrm{~m}$ & - & - & - & $115 \mathrm{~m}$ \\
\hline
\end{tabular}

FONTE: ICAO Annex 14 (2004a, p.3-13)

Ainda, segundo a ICAO Annex 14 (2004a, p. 3-13), alguns fatores devem ser levados em consideração para a separação entre RWs e TWs, como: a) possibilidade de aeronaves aguardarem entre a RW e a TW; $b$ ) interferência sobre os sistemas ILS (Instrument Landing System) e MLS (Microwave Landing System); c) presença de PTSRs entre a RW e a TW; e d) possibilidade de as aeronaves manobrarem entre a RW e a TW paralela. A seguir estes fatores são discutidos:

a) Neste caso a separação entre a pista de táxi e a pista de pouso e decolagem paralela não poderá ser menor do que a soma entre: i) a separação mínima entre o centro da TW e um objeto; ii) o comprimento da aeronave mais demandante; e iii) a distância da barra de parada da RW até o centro da RW.

b) A ICAO Annex 14 (2004a, p. 3-13) cita ANEXOS C e D da ICAO Annex 10 Volume I (2006b) como fonte para a avaliação da interferência sobre o ILS e o MLS, respectivamente;

c) Para o projeto de PTSRs ver item 4.3.6; e

d) Para a possibilidade de as aeronaves manobrarem entre a RW e a TW ver item 4.5.

A FAA AC 150/5300-13 (1989, p. 139) coloca que seus padrões de separação entre a RW e a TW paralela, mostrados na Tabela 4.6 2, são tais a proteger a RSA e a OFZ. A RSA será protegida desde que a soma entre a semi-envergadura máxima 
de cada grupo geométrico e a semi-largura da RSA seja menor do que a separação entre a RW e a TW.

Comparando-se as especificações da Tabela 4.6-2 e da Tabela 4.7-2, verificase que a RSA é protegida pelo padrão de separação entre RWs e TWs. Já em relação à OFZ de transição interna não se pode dizer o mesmo, tendo-se em vista que as dimensões desta variam com a altitude. Verificou-se que a OFZ de transição interna só é garantida ao nível do mar. Conforme a altitude aumenta, deve-se avaliar a OFZ e se necessário, deve-se aumentar a separação. Ainda, verificou-se que o padrão de separação entre RWs e TWs não pode ser explicado somente pelo atendimento à RSA e OFZ de transição interna. As dimensões padrão especificadas sugerem que outros fatores tenham sido levados em conta para a elaboração do padrão.

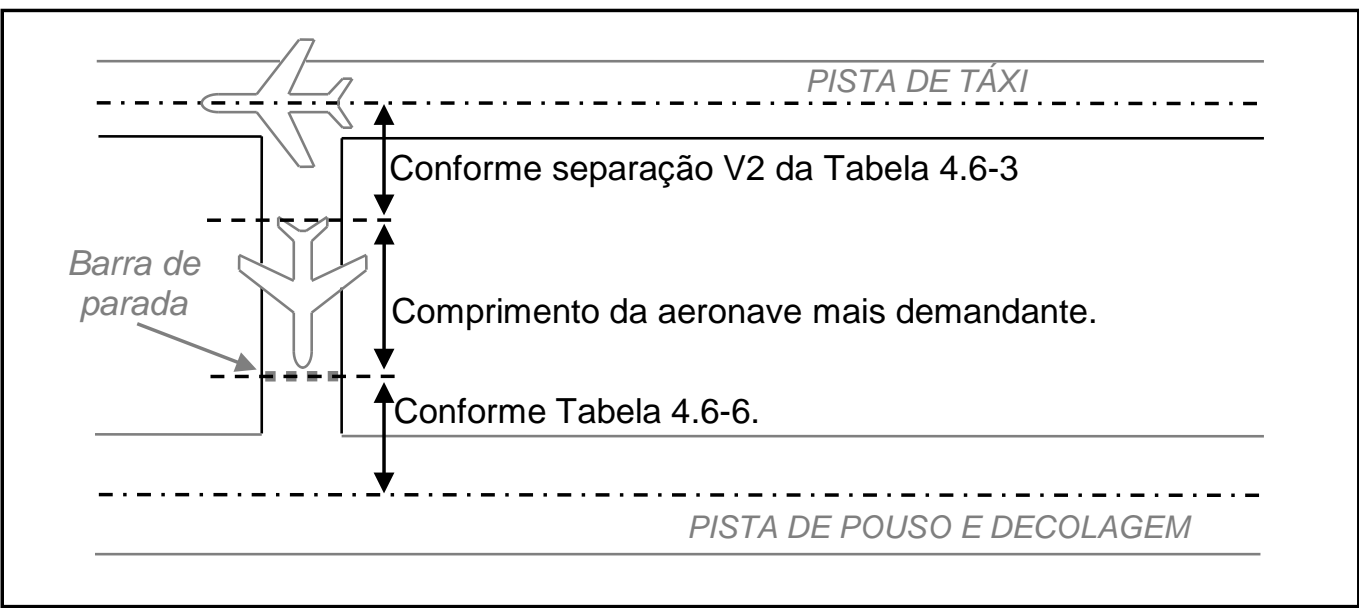

Figura 4.6-1- Recomendações para separação entre uma RW e uma TW. FONTE: Criado a partir das recomendações da ICAO e da FAA sobre RWs e TWs paralelas

Tabela 4.6-2 - Padrão FAA para a separação entre RWs e TWs / TLs

\begin{tabular}{|c|c|c|c|c|}
\hline \multirow[t]{2}{*}{$\begin{array}{c}\text { Grupo } \\
\text { geométrico }\end{array}$} & \multicolumn{2}{|c|}{$\begin{array}{l}\text { RWs visuais ou RWs com visibilidade } \\
\text { de aproximação não menor do que } \\
1.200 \mathrm{~m}|\mathrm{~b}| \mathrm{c}\end{array}$} & \multicolumn{2}{|c|}{$\begin{array}{l}\text { RWs com visibilidade de } \\
\text { aproximação menor do que } \\
1.200 \mathrm{~m}|\mathrm{~b}| \mathrm{c}\end{array}$} \\
\hline & $A$ e $B$ & C e D & $A$ e $B$ & C e D \\
\hline $\mathrm{I} \mid \mathrm{a}$ & $45 m$ & - & $60 m$ & - \\
\hline 1 & $67,5 \mathrm{~m}$ & $90 \mathrm{~m}$ & $75 \mathrm{~m}$ & $120 \mathrm{~m}$ \\
\hline II & $72 m$ & $90 \mathrm{~m}$ & $90 \mathrm{~m}$ & $120 \mathrm{~m}$ \\
\hline III & $90 \mathrm{~m}$ & $120 \mathrm{~m}$ & $105 \mathrm{~m}$ & $120 \mathrm{~m}$ \\
\hline IV & $120 \mathrm{~m}$ & $120 \mathrm{~m}$ & $120 \mathrm{~m}$ & $120 \mathrm{~m}$ \\
\hline V & - & |d & - & $|d| e$ \\
\hline VI & - & $150 \mathrm{~m}$ & - & If \\
\hline
\end{tabular}

FONTE: FAA AC 150/5300-13 (1989, p. de 14 até 15)

|a: aeronaves de pequeno porte somente. 
|b: estas separações são para o nível do mar. Em elevações maiores deve-se considerar o efeito da OFZ.

|c: separações existentes que não atendam a esses padrões podem ser autorizadas pela FAA.

|d: para o grupo geométrico $\mathrm{V}$ o padrão depende da altitude: $120 \mathrm{~m}$ (para altitudes menores do que $410 \mathrm{~m}$ ); $135 \mathrm{~m}$ (para altitudes entre $410 \mathrm{~m}$ e $2.000 \mathrm{~m}$ ) e $150 \mathrm{~m}$ (para altitudes maiores do que $2.000 \mathrm{~m}$ ).

|e: para aproximações com visibilidade menor do que $800 \mathrm{~m}$, a separação aumenta para $150 \mathrm{~m}$ mais a correção necessária para OFZ.

|f: para aproximações com visibilidade maior do que $800 \mathrm{~m}$, a separação é de $150 \mathrm{~m}$ mais a correção de elevação necessária para a OFZ. Para visibilidade menor do que $800 \mathrm{~m}$, a separação aumenta para $168 \mathrm{~m}$ mais a correção necessária para OFZ.

Ainda, a FAA AC 150/5300-13 (1989, p. 12) destaca a importância de prover-se espaço para a construção de PTSRs entre a RW e a TW paralela. Neste caso, as seguintes distâncias são recomendadas:

- $120 m$ para os grupos geométricos / e II;

- $150 m$ para o grupo geométrico III; e

- $180 m$ para os grupos geométricos IV, $\mathrm{V}$ e $\mathrm{VI}$.

\subsubsection{Relação entre separações RW/TW e outros componentes, metodologias e considerações de projeto}

A separação RW/TW deve considerar a OFZ de transição interna, a possibilidade de as aeronaves aguardarem entre a RW e a TW, o que por sua vez está relacionado ao padrão de folga entre aeronave e objetos em TWs. Outra questão é a possibilidade de construir-se uma PTSR entre a RW e a TW.

Para o caso da ICAO, o padrão de separação entre RWs e TWs segue o princípio de que aeronaves taxiando não podem invadir a área geral da faixa da $R W$. Para o caso da FAA o padrão de separação entre RWs e TWs segue o princípio de que aeronaves taxiando não podem invadir a RSA.

\subsubsection{SEPARAÇÕES EM TWs e TLS}

Diferentemente da pista de pouso e decolagem, onde as separações são derivadas do perfil de voo das aeronaves, nas pistas de táxi, os fatores mais importantes são a geometria das aeronaves e os desvios que estas apresentam ao taxiar.

Dependo da parte do aeródromo em que a aeronave se encontra, a velocidade de táxi varia, bem como os componentes adjacentes à rota de táxi. Isso faz com que 
os riscos e os danos potenciais também variem. Daí a necessidade de diferenciar-se as pistas de táxi entre si e exigir-se margens diferentes.

Para a ICAO e para a FAA as aeronaves taxiam em pelos menos 4 tipos de vias: pistas de táxi, pistas de táxi do pátio, pistas de táxi de acesso ao estacionamento de aeronaves, e nas posições de estacionamento. A Figura 4.6-2 ilustra os diversos tipos de caminhos de táxi em um aeródromo.

As pistas de táxi e as pistas de táxi do pátio (taxiways - TWs) estão sujeitas aos mesmos padrões. As pistas de táxi do pátio diferenciam-se das demais TWs apenas por situar-se na borda do pátio.

As pistas de táxi de acesso ao estacionamento de aeronaves (aircraft stand taxilanes ou simplesmente taxilanes - TLs) possuem critérios de separação menos exigentes do que TWs, devido à menor velocidade nelas praticadas. As TLs têm a função de conectar as TWs com as posições de estacionamento.

Já os caminhos de táxi das posições de estacionamento obedecem aos critérios de separação discutidos no item 4.6.4.

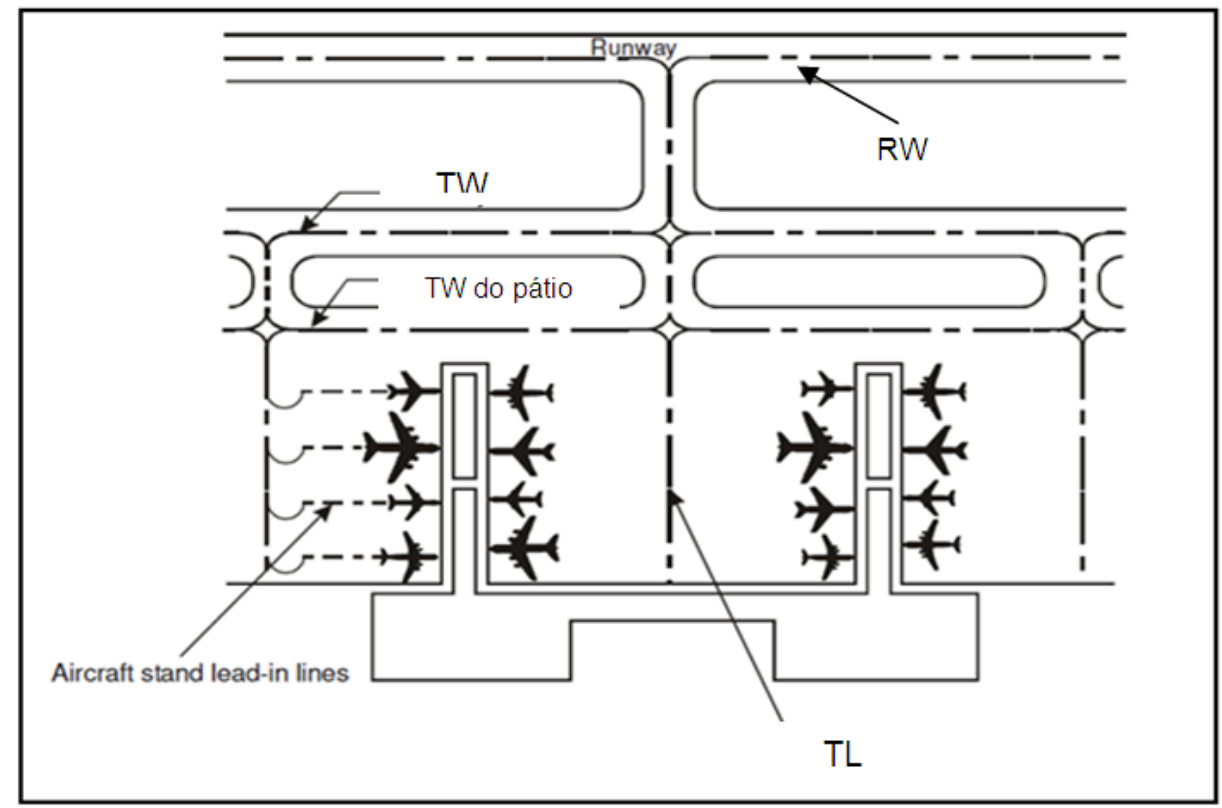

Figura 4.6-2 - Rotas de táxi em um aeródromo. FONTE: Adaptado a partir de ICAO Doc 9157 Parte 2 (2005a, p.1-4)

\subsubsection{Especificações da ICAO}

A ICAO Doc 9157 Parte 2 (2005a, p. 1-11) apresenta as separações entre os eixos de TWs paralelas, TWs e objetos e entre TLs e objetos, conforme a Tabela 4.6-3. A partir desta tabela, nota-se que as separações mínimas são compostas da 
soma de três distâncias: envergadura ou semi-envergadura, folga do pavimento e uma margem adicional, referida como incremento.

Ainda, na Tabela 4.6-3 nota-se que X1 e X2 são iguais entre si, bem como Z1 e Z2. Aliás, os valores X1 e X2 correspondem ao critério folga do pavimento para pistas de táxi, discutido no item 4.3.4. Com isso, Z1 e Z2 tornam-se uma margem adicional de segurança, evitando colisões mesmo no caso de uma das aeronaves acidentalmente sair da sua pista de táxi. Esta margem serve também para facilitar o táxi, ao prover espaço extra. Já as margens X3 e Z3 são menores, com base na idéia de que as velocidades praticadas na pista de táxi de acesso ao estacionamento de aeronaves (TLs) são menores, e de que o nível de atenção é maior.

Tabela 4.6-3 - Padrão ICAO para separação entre pistas de táxi e entre estas e objetos

\begin{tabular}{|c|c|c|c|c|c|c|}
\hline \multirow{2}{*}{ Separações } & \multicolumn{6}{|c|}{ Grupo geométrico } \\
\hline & A & B & C & D & E & $\mathbf{F}$ \\
\hline \multicolumn{7}{|l|}{$\begin{array}{l}\text { ENTRE AS LINHAS DE CENTRO DE DUAS PISTAS DE } \\
\text { TÁXI OU PISTA DE TÁXI DO PÁTIO: }\end{array}$} \\
\hline Envergadura (Y1) & $15 \mathrm{~m}$ & $24 m$ & $36 m$ & $52 m$ & $65 \mathrm{~m}$ & $80 m$ \\
\hline + desvio lateral máximo (X1) & $1,5 \mathrm{~m}$ & $2,25 \mathrm{~m}$ & $3 m$ & $4,5 \mathrm{~m}$ & $4,5 \mathrm{~m}$ & $4,5 \mathrm{~m}$ \\
\hline + incremento (Z1) & $7,25 \mathrm{~m}$ & $7,25 m$ & $5 m$ & $10 m$ & $10,5 \mathrm{~m}$ & $13 m$ \\
\hline Total (V1) & $23,75 \mathrm{~m}$ & $33,5 \mathrm{~m}$ & $44 m$ & $66,5 \mathrm{~m}$ & $80 \mathrm{~m}$ & $97,5 \mathrm{~m}$ \\
\hline \multicolumn{7}{|l|}{$\begin{array}{l}\text { ENTRE O CENTRO DE UMA PISTA DE TÁXI QUALQUER } \\
\text { A NÃO SER UMA STAND TAXILANE E UM OBJETO }\end{array}$} \\
\hline 1/2 Envergadura (Y2) & $7,5 \mathrm{~m}$ & $12 m$ & $18 m$ & $26 \mathrm{~m}$ & $32,5 \mathrm{~m}$ & $40 \mathrm{~m}$ \\
\hline + desvio lateral máximo (X2) & $1,5 \mathrm{~m}$ & $2,25 \mathrm{~m}$ & $3 m$ & $4,5 \mathrm{~m}$ & $4,5 \mathrm{~m}$ & $4,5 \mathrm{~m}$ \\
\hline + incremento (Z2) & $7,25 \mathrm{~m}$ & $7,25 \mathrm{~m}$ & $5 m$ & $10 m$ & $10,5 \mathrm{~m}$ & $13 m$ \\
\hline Total (V2) & $16,25 \mathrm{~m}$ & $21,5 \mathrm{~m}$ & $26 \mathrm{~m}$ & $40,5 \mathrm{~m}$ & $47,5 \mathrm{~m}$ & $57,5 \mathrm{~m}$ \\
\hline \multicolumn{7}{|l|}{$\begin{array}{l}\text { ENTRE A LINHA DE CENTRO DE UMA PISTA DE TÁXI DE } \\
\text { ACESSO AO ESTACIONAMENTO DE AERONAVES E } \\
\text { OBJETOS }\end{array}$} \\
\hline 1/2 Envergadura (Y3) & $7,5 \mathrm{~m}$ & $12 m$ & $18 m$ & $26 m$ & $32,5 \mathrm{~m}$ & $40 m$ \\
\hline + desvio lateral máximo (X3) & $1,5 \mathrm{~m}$ & $1,5 \mathrm{~m}$ & $2 m$ & $2,5 \mathrm{~m}$ & $2,5 \mathrm{~m}$ & $3 m$ \\
\hline + incremento (Z3) & $3 m$ & $3 m$ & $4,5 \mathrm{~m}$ & $7,5 \mathrm{~m}$ & $7,5 \mathrm{~m}$ & $7,5 \mathrm{~m}$ \\
\hline Total (V3) & $12 m$ & $16,5 \mathrm{~m}$ & $24,5 \mathrm{~m}$ & $36 m$ & $42,5 \mathrm{~m}$ & $50,5 \mathrm{~m}$ \\
\hline
\end{tabular}

FONTE: ICAO Doc 9157 Parte 2 (2005a, p. 1-11)

\subsubsection{Especificações da FAA}

A FAA AC 150/5300-13 (1989, p. 16) especifica separações mínimas entre TWs, TLs e entre estas e objetos. De forma coerente com estas separações, a norma coloca a OFA (object free area) como critério de separação. 
Tabela 4.6-4 - Padrão FAA para separação entre pistas de táxi e entre estas e objetos

\begin{tabular}{c|c|c|c|c|c|c}
\hline \multirow{2}{*}{ Padrão } & \multicolumn{7}{c}{ Grupo geométrico } \\
\cline { 2 - 7 } & I & II & III & IV & V & VI \\
\hline Separação TW/TW & $21 \mathrm{~m}$ & $34,8 \mathrm{~m}$ & $46,2 \mathrm{~m}$ & $65,4 \mathrm{~m}$ & $81 \mathrm{~m}$ & $99 \mathrm{~m}$ \\
\hline Folga de ponta de asa para TW & $6 \mathrm{~m}$ & $10,8 \mathrm{~m}$ & $10,2 \mathrm{~m}$ & $13,4 \mathrm{~m}$ & $16 \mathrm{~m}$ & $19 \mathrm{~m}$ \\
\hline Separação TL/TL & $19,5 \mathrm{~m}$ & $29,5 \mathrm{~m}$ & $42,5 \mathrm{~m}$ & $60 \mathrm{~m}$ & $74,5 \mathrm{~m}$ & $91 \mathrm{~m}$ \\
\hline Folga de ponta de asa para TL & $4,5 \mathrm{~m}$ & $5,5 \mathrm{~m}$ & $6,5 \mathrm{~m}$ & $8 \mathrm{~m}$ & $9,5 \mathrm{~m}$ & $11 \mathrm{~m}$ \\
\hline
\end{tabular}

FONTE: FAA AC 150/5300-13 (1989, p.16)

4.6.3.3 Relação entre separações em TWs e TLs e outros componentes, metodologias e considerações de projeto

Para a ICAO, a área geral da faixa da TW é especificada com base na folga entre a aeronave e objetos. Para a FAA, a folga entre a aeronave e objetos em TWs e TLs deve ser tal a proteger a OFA da TW ou OFA da TL, respectivamente.

\subsubsection{SEPARAÇÕES NAS POSIÇÕES DE ESTACIONAMENTO}

De forma a proteger-se aeronaves que ingressam, permanecem ou deixam as posições de estacionamento, a ICAO e a FAA estabelecem folgas em relação ao terminal, outras aeronaves e objetos. Estas folgas devem também ser mantidas durante as manobras, o que exige uma análise das curvas descritas por pontas de asas, nariz e estabilizadores. ${ }^{25} \mathrm{~A}$ área de estacionamento não deve ser confundida com as demais áreas do pátio onde se situam as TLs e TWs. A Figura 4.6-2 ilustra as diferenças entre TWs, TLs e a área de estacionamento.

A ICAO Annex 14 (2004a, p. 3-18) recomenda as separações mostradas na Tabela 4.6-5, a serem observadas entre as aeronaves, prédios e outros objetos fixos. Para posições de docagem do tipo nose-in ,quando circunstâncias especiais assim justificarem, as seguintes separações podem ser reduzidas, onde o grupo geométrico é $\mathrm{D}, \mathrm{E}$ ou $\mathrm{F}$ :

- Separação entre o nariz da aeronave e o terminal, incluindo qualquer ponte de passageiros fixa;

- Separação entre qualquer parte da aeronave e o estacionamento, na área equipada com orientação por azimute através de um sistema de docagem visual.

${ }^{25} \mathrm{O}$ item 4.5.2 trata da metodologia de cálculo de manobras. 
Tabela 4.6-5 - Padrão ICAO para separação entre a aeronave e: outras aeronaves; terminais; e outros objetos fixos

\begin{tabular}{cccccc}
\hline \multicolumn{7}{c}{ Grupo geométrico } \\
\hline A & B & C & D & E & F \\
\hline $3 m$ & $3 m$ & $4,5 \mathrm{~m}$ & $7,5 \mathrm{~m}$ & $7,5 \mathrm{~m}$ & $7,5 \mathrm{~m}$ \\
\hline
\end{tabular}

FONTE: ICAO Annex 14 (2004a, p.3-18)

Já a FAA AC 150/5360-13 (1988a, p.29) propõe uma classificação das aeronaves em quatro grupos, a partir dos quais o documento apresenta orientações de projeto de terminais aeroportuários, inclusive para as posições de estacionamento. Estes grupos são:

- Gate Type A: aeronaves do grupo geométrico III;

- Gate Type B: aeronaves do grupo geométrico IV, cujo comprimento da fuselagem é menor do que $49 \mathrm{~m}$;

- Gate Type C: aeronaves do grupo geométrico IV, cujo comprimento da fuselagem supera $49 \mathrm{~m}$; e

- Gate Type D: aeronaves do grupo geométrico $\mathrm{V}$.

Com base nestes grupos, a FAA AC 150/5360-13 (1988a, p. 30, 36, 41) apresenta separações para posições de estacionamento, ilustradas na Figura 4.6-3.

- Separação nariz/terminal (nose to building clearance): esta separação se aplica ao caso no qual as aeronaves taxiam até a posição de estacionamento e deixam-na com auxílio de trator rebocador (taxi-in, pushout/power-out parking). Este é o procedimento de estacionamento mais utilizado em aeroportos com grande movimentação, de forma a diminuir-se a área de pátio necessária para a manobra das aeronaves até o portão de embarque. No caso típico em que o nariz da aeronave fica próximo ao terminal (nose-in), a folga a ser adotada depende: da distância entre a bequilha e o nariz; do comprimento do trator rebocador; e da configuração do prédio. Caso o trator possa operar abaixo da aeronave e/ou abaixo do segundo piso, a folga entre o nariz e a parte mais saliente do prédio poderá ser menor. Para propósito de planejamento, as seguintes folgas são recomendadas: $9 \mathrm{~m}$ para gate type $A ; 6 \mathrm{~m}$ para gate type $B$ e gate type $C$; $e$ 4,5m para gate type $D$;

- Separação entre a cauda e o terminal (nose to tail clearance): esta separação é recomendada para o caso em que a aeronave movimenta-se por conta própria para chegar e sair da posição de estacionamento (taxi- 
in/taxi-out parking), projetando o escape do sistema propulsor sobre o terminal. Devido aos efeitos adversos do jet blast, as separações necessárias entre a aeronave e o terminal serão maiores. Considerando uma velocidade de $50 \mathrm{mph}(80 \mathrm{~km} / \mathrm{h})$, o documento recomenda a utilização de uma separação entre a aeronave e o terminal de: $149 \mathrm{~m}$ para gate type $D$; $113 \mathrm{~m}$ para gate type $C$; e $37 \mathrm{~m}$ para gate type $A$ e gate type $B$. $O$ uso de blast fences e utilização de baixos níveis de empuxo no pátio podem reduzir estas separações.

- Separação entre as extremidades da aeronave e prédios (aircraft extremity to building clearances): deve ser de $6 \mathrm{~m}$, exceto para inner pier gates, onde a separação mínima é de $14 \mathrm{~m}$.

- Separação entre as pontas das asas (wingtip clearances): varia entre $6 \mathrm{~m}$ e 7,5m, conforme a Figura 4-10 da FAA AC 150/5360-13 (1988a, p. 41).

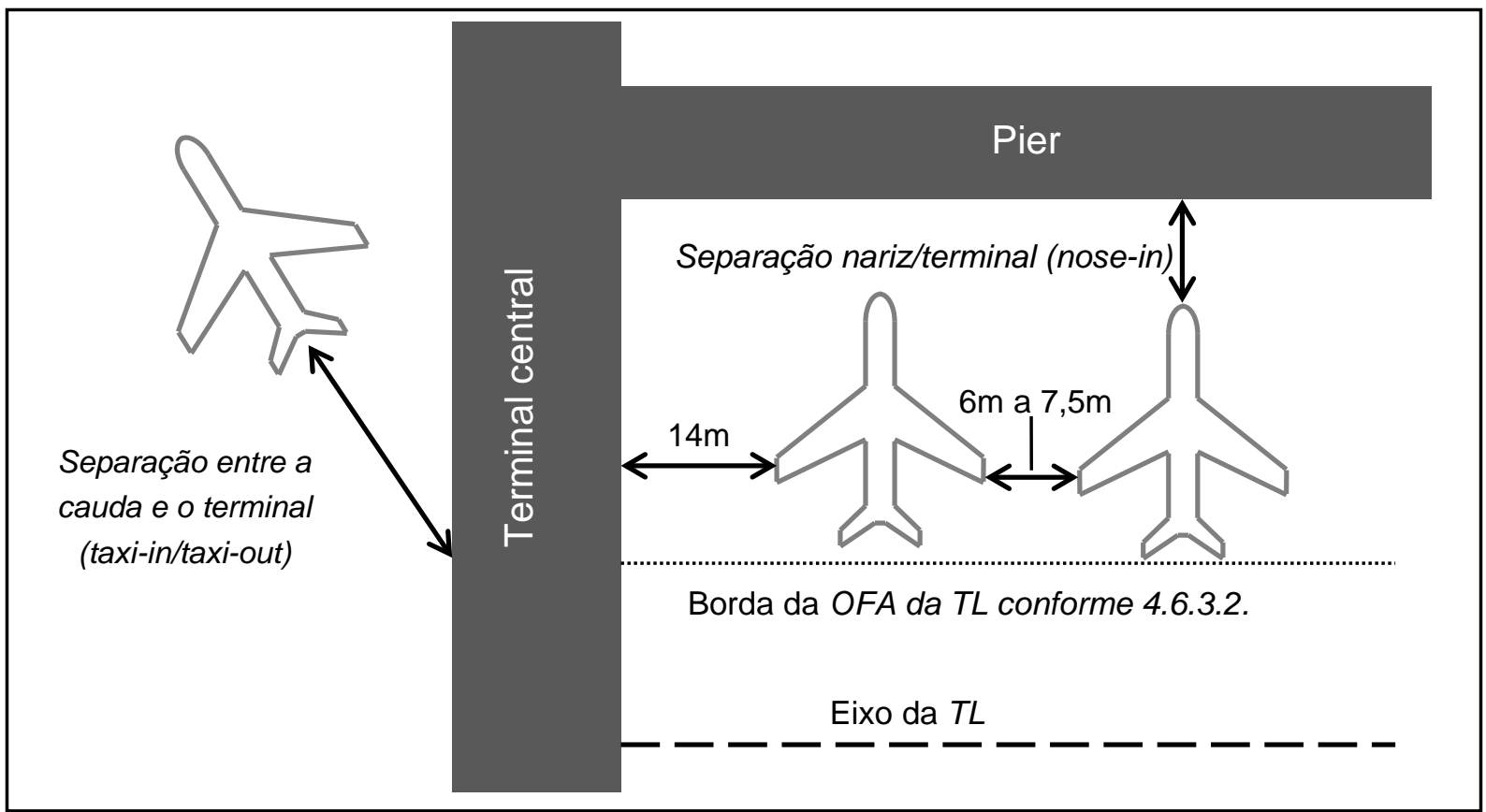

Figura 4.6-3 - Separações FAA para as posições de estacionamento. Adaptado a partir de informações da FAA AC 150/5360-13 (1988a, p. 30, 36, 41)

Percebe-se, no entanto, que os textos citados da ICAO e da FAA não apresentam folgas em relação a vias de serviço, veículos, equipamentos de serviço e pessoal, os quais são comuns entre o terminal e a aeronave estacionada. Portanto, para fins de planejamento e projeto desta área do aeródromo, as folgas fornecidas entre o terminal e a aeronave podem não ser suficientes. 


\subsubsection{Relação entre separações no pátio e outros componentes, metodologias e considerações de projeto}

As folgas especificadas para o pátio devem considerar a trajetória induzida pelo ângulo de esterçamento da aeronave. Devem seguir também as considerações referentes ao jet blast.

\subsubsection{POSIÇÃO DAS BARRAS DE PARADA DA RW}

Uma barra de parada da RW (BPRW) delimita a posição horizontal mais próxima do eixo da RW que pode ser ocupada por objetos móveis durante pousos e decolagens. BPRWs servem ao propósito de manter o entorno da pista de pouso e decolagem livre de outras aeronaves, veículos ou quaisquer objetos durante as operações de pouso e decolagem. Tendo-se em vista uma aeronave que taxia na direção da RW, esta deverá aguardar permissão de decolagem atrás da BPRW. E tendo-se em vista uma aeronave que acaba de pousar, a RW só será considerada livre para pouso quando esta aeronave já tiver passado completamente pela BPRW $^{26}$.

Barras de parada (BPs) também podem ser necessárias fora das proximidades da RW, em qualquer ponto do sistema de pistas de táxi, onde pontos de espera forem necessários. A Figura 4.6-4 ilustra BPs e BPRWs.

As normas apresentam especificações somente para as BPRWs. Na falta de critérios para BPs, conclui-se que sejam utilizadas as separações previstas para pistas de táxi e pistas de táxi do pátio.

Os padrões e recomendações para BPRWs são especificados com base em diversos fatores como o tipo de aproximação previsto, grupo geométrico, grupo dinâmico, elevação do aeródromo e elevação da cabeceira. Os itens 4.6.5.1 e 4.6.5.2 apresentam, respectivamente, os padrões da ICAO e da FAA para a posição de BPRWs.

\footnotetext{
${ }^{26}$ Isso está de acordo com os procedimentos da ICAO e da FAA. Para o caso da ICAO ver: o parágrafo 7.10.2 da ICAO Doc 4444 (2007). Para o caso da FAA ver: Aeronautical Information Manual: Official Guide to Basic Flight Information and ATC Procedures (Disponível em: http://www.faa.gov/air traffic/publications/atpubs/aim/Chap4/aim0403.html), parágrafo 4-3-20.
} 


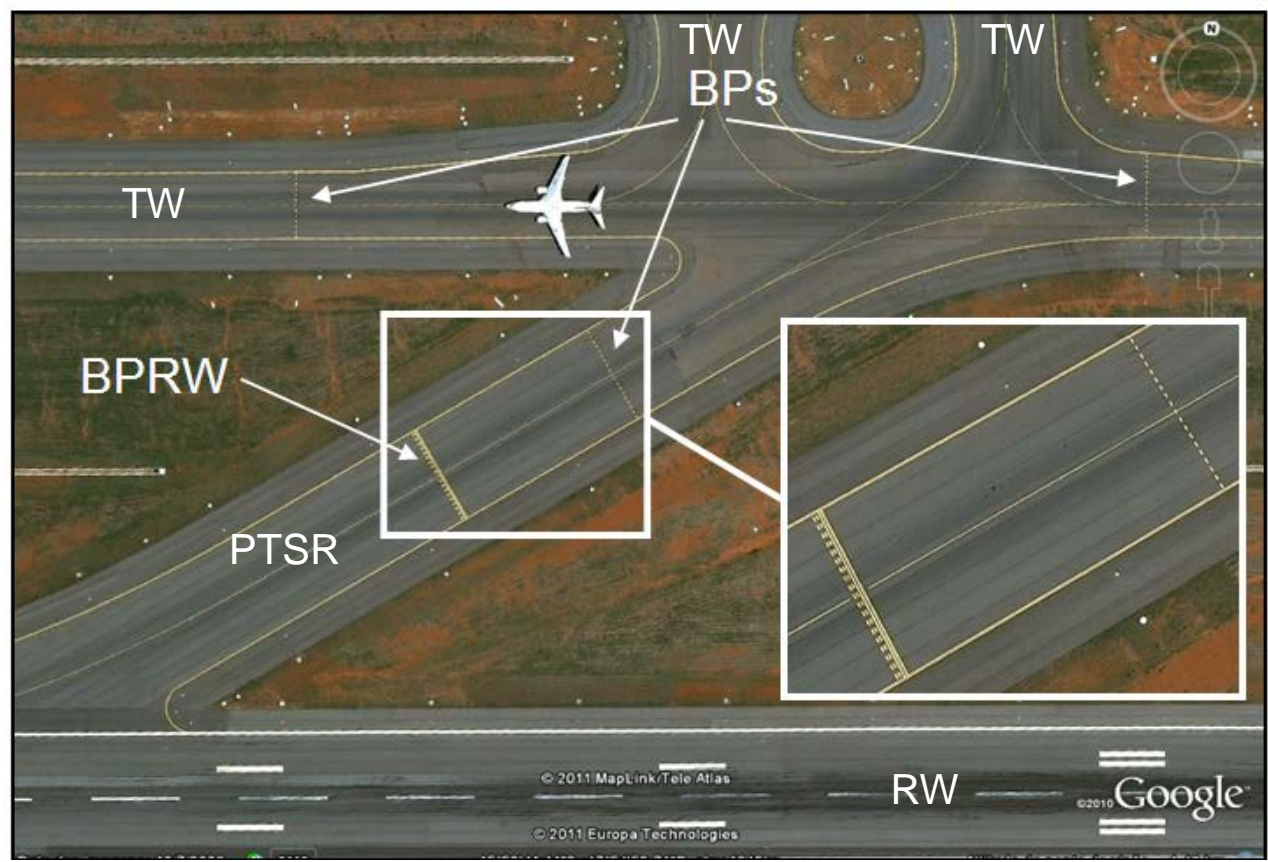

Figura 4.6-4 - BPRWs e BPs. FONTE: Adaptado a partir do Google Earth

\subsubsection{Padrões da ICAO para BPRWS}

A posição das BPRWs deve obedecer aos padrões dimensionais da Tabela 4.6-6 e ainda, de forma a garantir-se que veículos e aeronaves não interfiram nos auxílios rádio à navegação aérea nem infrinjam: a OFZ; a superfície de aproximação; a superfície de saída (take-off climb surface); ou uma área crítica/sensível do ILS/MLS.

Tabela 4.6-6 - Padrão ICAO para a separação entre a BPRW e o centro da RW

\begin{tabular}{l|ccccc}
\hline \multicolumn{1}{c|}{ Tipo de pista } & \multicolumn{5}{c}{ Grupo dinâmico / } \\
& $\mathbf{1}$ & $\mathbf{2}$ & $\mathbf{3}$ & $\mathbf{4}$ & $\mathbf{4 - F}$ \\
\hline Visual & $30 \mathrm{~m}$ & $40 \mathrm{~m}$ & $75 \mathrm{~m}$ & $75 \mathrm{~m}$ & $75 \mathrm{~m}$ \\
Não precisão & $40 \mathrm{~m}$ & $40 \mathrm{~m}$ & $75 \mathrm{~m}$ & $75 \mathrm{~m}$ & $75 \mathrm{~m}$ \\
Precisão, categoria I & $60 \mathrm{~m} \mid \mathbf{b}$ & $60 \mathrm{~m} \mid \mathbf{b}$ & $90 \mathrm{~m} \mid \mathbf{a}, \mathbf{b}$ & $90 \mathrm{~m} \mid \mathbf{a}, \mathbf{b}$ & $107,5 \mathrm{~m}$ \\
& & & & & $\mathbf{a}, \mathbf{b}, \mathbf{c}$ \\
Precisão, categorias II e III & - & - & $90 \mathrm{~m} \mid \mathbf{a}, \mathbf{b}$ & $90 \mathrm{~m} \mid \mathbf{a}, \mathbf{b}$ & $107,5 \mathrm{~m}$ \\
& & & & & $\mathbf{a}, \mathbf{b}, \mathbf{c}$ \\
Pista exclusiva de decolagem & $30 \mathrm{~m}$ & $40 \mathrm{~m}$ & $75 \mathrm{~m}$ & $75 \mathrm{~m}$ & $75 \mathrm{~m}$ \\
\hline
\end{tabular}

|a: Caso a baía de espera (holding bay), BP da RW (runway-holding position) ou BP da via de serviço (road-holding position) estiverem em uma elevação menor que a cabeceira, a distância pode ser diminuída em $5 \mathrm{~m}$ para cada metro de diferença de elevação, e desde que a superfície de transição interna (inner-transitional surface) não seja infringida.

|b: Esta distância pode necessitar de aumento, para evitar a interferência com auxílios-rádio à navegação aérea, particularmente com o indicador de trajetória de planeio (glide path indicator) e os localizadores (localizer). Informações sobre áreas críticas e de sensibilidade do ILS e MLS são providas, respectivamente, pelos apêndices C e G da ICAO Annex 10 (2006b). 
Nota 1: a distância de $90 \mathrm{~m}$ dos grupos dinâmicos 3 e 4 é baseada em uma aeronave com um estabilizador de altura $20 \mathrm{~m}$, com uma distância de $52,7 \mathrm{~m}$ entre o nariz e parte mais alta do estabilizador e um nariz com altura de $10 \mathrm{~m}$. Sendo que essa aeronave fica na posição de espera com um ângulo de $45^{\circ}$ ou mais em relação ao eixo da pista, estando fora da OFZ e sem ter que considerála para o cálculo da OCA/H.

Nota 2: a distância de $60 \mathrm{~m}$ para o grupo dinâmico 2 baseia-se em uma aeronave com um estabilizador de $8 \mathrm{~m}$ de altura, uma distância de $24,6 \mathrm{~m}$ entre o nariz e o ponto mais alto de estabilizador, uma altura do nariz de $5,2 \mathrm{~m}$. Esta aeronave está na linha de espera com um ângulo de $45^{\circ}$ ou mais em relação ao eixo da pista, não infringindo a OFZ.

|c: Esta distância é baseada em uma aeronave com um estabilizador de $24 \mathrm{~m}$ de altura, uma distância de $62,2 \mathrm{~m}$ entre o ponto mais alto do estabilizador e o nariz, tendo o nariz $10 \mathrm{~m}$ de altura. Esta aeronave está na linha de espera em um ângulo de $45^{\circ}$ ou mais em relação ao eixo da pista, não infringindo a OFZ.

FONTE: ICAO Annex 14 (2004a, p.3-17)

A ICAO Annex 14 (2004a, p. 3-16) recomenda que em elevações maiores do que $700 \mathrm{~m}$ (2.300pés) a distância de $90 \mathrm{~m}$ ou 107,5m, especificada na Tabela 4.6-6 para uma pista de aproximação de precisão com grupo dinâmico 4, precisa aumentar da seguinte forma:

- até uma elevação de $2.000 \mathrm{~m}$ (6.600pés); $1 \mathrm{~m}$ para cada $100 \mathrm{~m}$ (330pés) em excesso de $700 \mathrm{~m}$ (2.300pés);

- elevação em excesso de $2.000 m$ (6.600pés) e até $4.000 m$ (13.320pés); $13 \mathrm{~m}$ mais $1,5 \mathrm{~m}$ para cada $100 \mathrm{~m}$ (330pés) em excesso de $2.000 \mathrm{~m}$ (6.600pés); e

- elevação em excesso de $4.000 m$ (13.320pés) e até $5.000 m$ (16.650pés); $43 m$ mais $2 m$ para cada $100 m$ (330pés) em excesso de $4.000 m$ (13.320pés).

Para pistas para aproximação de precisão atendendo a aeronaves do grupo dinâmico 4, caso a BPRW estiver em uma elevação maior do que a da cabeceira, a distância indicada na Tabela 4.6-6 deve ser aumentada em 5m para cada metro de diferença de elevação, e ainda observando-se a superfície de transição interna.

\subsubsection{Padrões da FAA para BPRWs}

O padrão para a BPRW é mostrado na Tabela 4.6-7, sendo estas distâncias medidas perpendicularmente em relação ao centro da RW. BPRWs adicionais podem ser necessárias para prevenir que as aeronaves interfiram com o ILS.

Conforme a FAA AC 150/5300-13 (1989, p.139) os padrões de separação entre o centro da RW e uma BPRW são tais a excluir qualquer parte da aeronave que espera (nariz, ponta de asa, estabilizador etc.) da RSA e da OFZ. 
Tabela 4.6-7 - Padrão FAA para separação entre a BPRW e o centro da RW

\begin{tabular}{|c|c|c|c|c|}
\hline \multirow[t]{2}{*}{$\begin{array}{c}\text { Grupo } \\
\text { geométrico }\end{array}$} & \multicolumn{2}{|c|}{$\begin{array}{l}\text { RWs para aprox. visual ou RWs com } \\
\text { visibilidade de aproximação não } \\
\text { menor do que } 1.200 \mathrm{~m}\end{array}$} & \multicolumn{2}{|c|}{$\begin{array}{l}\text { RWs com visibilidade de } \\
\text { aproximação menor do que } \\
1.200 \mathrm{~m}\end{array}$} \\
\hline & $A e B$ & $C$ e D If & $A$ e B & $C$ e $D$ |f \\
\hline $\mathrm{I} \mid \mathrm{a}$ & $38 m$ & - & $53 m$ & - \\
\hline 1 & $60 \mathrm{~m} \mid \mathrm{b}$ & $75 m$ & $75 \mathrm{~m} \mid \mathrm{c}$ & $75 m$ \\
\hline II & $60 \mathrm{~m} / \mathrm{b}$ & $75 m$ & $75 \mathrm{~m} \mid \mathrm{c}$ & $75 m$ \\
\hline III & $60 \mathrm{~m} \mid \mathbf{d}$ & $75 m$ & $75 \mathrm{~m} / \mathbf{d}$ & $75 \mathrm{~m}$ \\
\hline IV & $75 m$ & $75 m$ & $75 \mathrm{~m}$ le & $75 \mathrm{~m} / \mathbf{g}$ \\
\hline V & - & $75 \mathrm{~m} / \mathbf{g}$ & - & $85 \mathrm{~m} / \mathrm{g}$ \\
\hline VI & - & $85 \mathrm{~m} \mid \mathbf{g}$ & - & $85 \mathrm{~m} / \mathbf{g}$ \\
\hline
\end{tabular}

a: somente aeronaves de pequeno porte

|b: para aeronaves de pequeno porte esta separação vale $38 \mathrm{~m}$.

|c: para aeronaves de pequeno porte esta separação vale $53 \mathrm{~m}$.

|d: esta distância aumentada em $1 \mathrm{~m}$ para cada $100 \mathrm{~m}$ após a altitude de $1.554,5 \mathrm{~m}$.

|e: esta distância é aumentada em $1 \mathrm{~m}$ para cada $100 \mathrm{~m}$ acima do nível do mar.

|f: para todas as aeronaves do grupo dinâmico $D$ estas distâncias aumentam em $1 \mathrm{~m}$ para cada $100 \mathrm{~m}$ acima do nível do mar.

lg para todas as aeronaves do grupo dinâmico C estas distâncias aumentam em $1 \mathrm{~m}$ para cada $100 \mathrm{~m}$ acima do nível do mar.

FONTE: FAA AC 150/5300-13 (1989, p.de 14 até 15)

\subsubsection{Relação entre os padrões para a posição da BPRW e outros componentes, metodologias e considerações de projeto}

A BPRW representa o limite para a presença de aeronaves na proximidade da $\mathrm{RW}$, de modo que esta possa ser considerada livre pela torre de controle. De forma a tornar seguras as operações de pouso e decolagem, a posição da BPRW deve ser tal a proteger: i) as aeronaves que acidentalmente saiam lateralmente da RW (veering-off); ii) aquelas em vôo, próximas do solo, que tenham se desviado do centro da RW; e iii) contra a interferência que a aeronave que espera desempenha sobre os equipamentos de navegação, tendo-se em vista uma aproximação em curso na RW. A seguir trata-se da relação entre BPRW e outros componentes do aeródromo, tendo-se por base os tópicos $i$ e ii.

Com base nas funções que cumprem os diversos componentes detalhados neste Capítulo, nota-se que os veering-offs são protegidos através do provimento das áreas de proteção que envolvem a RW. Já a OFZ protege as aeronaves em voo, próximas do solo, abaixo da altura de decisão. E de especial interesse é a OFZ de transição interna, que considera os objetos posicionados na área lateral à RW. Logo, 
é de se esperar que as especificações quanto às BPRWs estejam relacionadas às especificações desses componentes.

\subsection{ICAO}

A OFZ de transição interna é exigida pela ICAO somente para pistas para aproximação de precisão. Já a faixa da RW é exigida, ou no mínimo recomendada, para todos os tipos de RWs. Analisando-se a Tabela 4.6-6, e tendo-se em vista a relação funcional recém discutida, chamam a atenção os seguintes apontamentos:

- RWs para aproximação visual: a posição da BPRW coincide com a semilargura da área geral da faixa da RW;

- RWs destinadas exclusivamente à decolagem: a posição da BPRW coincide com a semi-largura da área geral da faixa da RW. No entanto, a ICAO especifica também separações mínimas entre o centro de uma RW e objetos móveis durante pouso e decolagem em RWs para aproximação de precisão. O atendimento a estes critérios leva à necessidade de aumento das distâncias previstas na Tabela 4.6-6, conforme os valores entre parênteses mostrados na Tabela 4.6-8;

- RWs para aproximação de não precisão: a posição da BPRW coincide com a semi-largura da área geral da faixa da RW, com exceção do grupo dinâmico 1, que apresenta um acréscimo de 10m; e

- RWs para aproximação de precisão, CAT I, II e III: para os grupos dinâmicos 2, 3 4, a posição da BPRW coincide com a OFZ de transição interna, tendo-se por base as aeronaves padrão citadas nas notas 1, 2 e $c$ da Tabela 4.6-6. No entanto, para o grupo dinâmico 1 não existe nenhuma observação descrevendo a geometria da aeronave considerada. Ainda, a área geral da faixa da RW não é atendida.

Tabela 4.6-8 - Distância entre uma RW e uma BPRW, considerando-se as especificações da área restrita da faixa da $R W$, para RWs para aproximação de precisão

\begin{tabular}{c|ccccc}
\hline \multirow{2}{*}{ Tipo de pista } & \multicolumn{5}{|c}{ Grupo dinâmico/ARC } \\
& $\mathbf{1}$ & $\mathbf{2}$ & $\mathbf{3}$ & $\mathbf{4}$ & 4-F \\
\hline Pista exclusiva de decolagem & $30 \mathrm{~m}(+15 \mathrm{~m})$ & $40 \mathrm{~m}(+5 \mathrm{~m})$ & $75 \mathrm{~m}(+0 \mathrm{~m})$ & $75 \mathrm{~m}(+0 \mathrm{~m})$ & $75 \mathrm{~m}(+2,5 \mathrm{~m})$ \\
\hline
\end{tabular}

FONTE: Adaptado a partir de ICAO Annex 14 (2004a, p.3.17 e p.3.7)

Lembra-se que as especificações para a BPRW possuem uma série de exceções e recomendações apresentadas no item 4.6.5, as quais incluem aumento da distância entre uma BPRW e a RW, com base no aumento da altitude do 
aeródromo. Tais aumentos se aplicam a pistas para aproximação de precisão servindo aeronaves do grupo dinâmico 4. Como a OFZ de transição interna não é função da altitude, a OFZ não pode ser utilizada para justificar as maiores separações entre a BPRW e a RW. Por outro lado, como a área geral da faixa da $R W$ não é atendida em pistas para aproximação de precisão, faria sentido uma maior proteção contra veering-offs em altitudes maiores, à medida que as aeronaves pousam e decolam a velocidades mais elevadas. Na mesma linha, faz sentido que a maior separação se aplique somente ao grupo dinâmico 4, também pela justificativa da maior velocidade praticada.

\subsection{FAA}

Os critérios para BPRWs são tais a proteger a RSA, a OFZ e os auxílios rádio à navegação aérea, conforme FAA AC 150/5300-13 (1989, p. 139).

A FAA exige a observação da superfície de transição interna somente para RWs com visibilidade de aproximação menor do que $1.200 \mathrm{~m}$. Como discutido no item 4.7, as áreas estabelecidas pela FAA para proteção da RW são a RSA (Runway Safety Area) e a ROFA (Runway Object Free Area). Ambas as áreas são especificadas para todos os tipos de RWs.

Comparando-se as especificações, verifica-se diretamente que a separação entre a BPRW e a RW é igual ou maior que a semi-largura da RSA para todos os casos enumerados na Tabela 4.6-7 e na Tabela 4.7-2.

Uma análise semelhante mostra que os padrões para a ROFA não são atendidos, ou seja, uma BPRW pode estar contida na ROFA. Já o atendimento à OFZ de transição interna exige uma análise um pouco mais complexa, realizada a partir: i) da modelagem proposta no item 4.9.3.2, para a OFZ de transição interna; ii) da posição da BPRW, dada na Tabela 4.6-7; e iii) de dois cenários para a altitude do aeródromo. A partir dos cálculos obteve-se a altura da OFZ de transição interna sobre a BPRW, o que é mostrado na Tabela 4.6-9.

Caso o ponto mais alto de uma aeronave que espera para entrar na RW ou que tenha saído dela, seja mais baixo do que os valores da Tabela 4.6-9, então o padrão da BPRW é suficiente para garantir o atendimento da OFZ de transição interna, para um dado cenário de altitude e tipo de pista (CAT I ou CAT II e III). Para as células grifadas da Tabela 4.6-9, os valores apresentados são maiores do que a altura máxima do estabilizador de cada grupo de projeto, o que garante o atendimento da OFZ para as aeronaves posicionadas atrás da BPRW, esperando para entrar na RW ou deixando-a. Para as demais células, seria necessária a proposição de cenários 
para a geometria da aeronave ${ }^{27}$, bem como para posição da mesma em relação à RW (esperando perpendicular, esperando a $45^{\circ}$, deixando a RW, etc.).

Tabela 4.6-9 - Altura da OFZ de transição interna na BPRW (m)

\begin{tabular}{|c|c|c|c|c|c|c|c|c|c|c|c|c|}
\hline \multirow{4}{*}{$\begin{array}{c}\text { Grupo } \\
\text { geométrico }\end{array}$} & \multicolumn{12}{|c|}{ Elevação da cabeceira em relação ao nível do mar } \\
\hline & \multicolumn{3}{|c|}{$0 \mathrm{~m}$} & \multicolumn{3}{|c|}{$3.500 \mathrm{~m}$} & \multicolumn{3}{|c|}{$\mathbf{0 m}$} & \multicolumn{3}{|c|}{$3.500 \mathrm{~m}$} \\
\hline & \multicolumn{3}{|c|}{ CAT I } & \multicolumn{3}{|c|}{ CAT I } & \multicolumn{3}{|c|}{ CAT II e III } & \multicolumn{3}{|c|}{ CAT II e III } \\
\hline & $A$ e $B$ & C & $\mathrm{D}$ & $A$ e $B$ & $\mathrm{C}$ & $\mathrm{D}$ & $A$ e $B$ & C & $\mathrm{D}$ & $A$ e $B$ & C & $\mathrm{D}$ \\
\hline I |a & 2,7 & - & - & 2,7 & - & - & 2,7 & - & - & 2,7 & - & - \\
\hline II $\mid \mathbf{a}$ & 2,7 & - & - & 2,7 & - & - & 2,7 & - & - & 2,7 & - & - \\
\hline I & 19,5 & 19,5 & 19,5 & 9,0 & 9,0 & 14,8 & 17,1 & 17,1 & 17,1 & 9,0 & 9,0 & 14,8 \\
\hline II & 18,6 & 18,6 & 18,6 & 8,1 & 8,1 & 14,0 & 15,9 & 15,9 & 15,9 & 8,1 & 8,1 & 14 \\
\hline III & 17,5 & 17,5 & 17,5 & 10,3 & 7,0 & 12,8 & 14,3 & 14,3 & 14,3 & 10,2 & 6,6 & 12,8 \\
\hline IV & 16,0 & 16,0 & 16,0 & 11,3 & 11,3 & 11,3 & 12,2 & 12,2 & 12,2 & 11,3 & 11,3 & 11,3 \\
\hline V & - & 16,5 & 16,5 & - & 11,8 & 11,8 & - & 12,6 & 12,6 & - & 11,8 & 11,8 \\
\hline VI & - & 15,0 & 15,0 & - & 10,4 & 10,4 & - & 10,6 & 10,6 & - & 9,9 & 9,9 \\
\hline
\end{tabular}

la: aeronave de pequeno porte.

FONTE: adaptado a partir da FAA AC 150/5300-13 (1989, p.14, 15 e 22)

Outra questão não tratada pela FAA é diferença de altura entre a BPRW e a cabeceira, a não ser pela exigência de atendimento à $O F Z$ de transição interna.

Com base nos fatores apontados, percebe-se que pode ser necessária uma análise caso-a-caso para avaliar-se a violação da OFZ de transição interna, de forma que os padrões para BPRWs, mostrados na Tabela 4.6-7 podem necessitar de aumento.

\section{7 ÁREAS DE PROTEÇÃO DA RW}

Em adição à proteção do espaço aéreo vizinho a um aeródromo, as normas especificam áreas em solo que circundam a RW e se prolongam para fora, desde suas extremidades.

Para a ICAO, estas áreas são a faixa da RW e a área de segurança de fim de pista (Runway End Safety Area - RESA). Enquanto a primeira área forma um retângulo que envolve a RW e se estende até uma certa distância desde o final de pista ou cabeceira, a segunda inicia nas bordas da primeira e segue para fora, na direção do eixo estendido da RW, constituindo um retângulo em cada cabeceira. Para a FAA, as áreas de proteção da RW são a ROFA (Runway Object Free Area), a RSA (Runway Safety Area) e a RPZ (Runway Protection Zone). A Figura 4.7-1 ilustra essas áreas.

\footnotetext{
${ }^{27}$ altura do nariz, da ponta da asa, ou qualquer ponto crítico da aeronave, e da distância desse ponto em relação a um ponto de referência da aeronave
} 


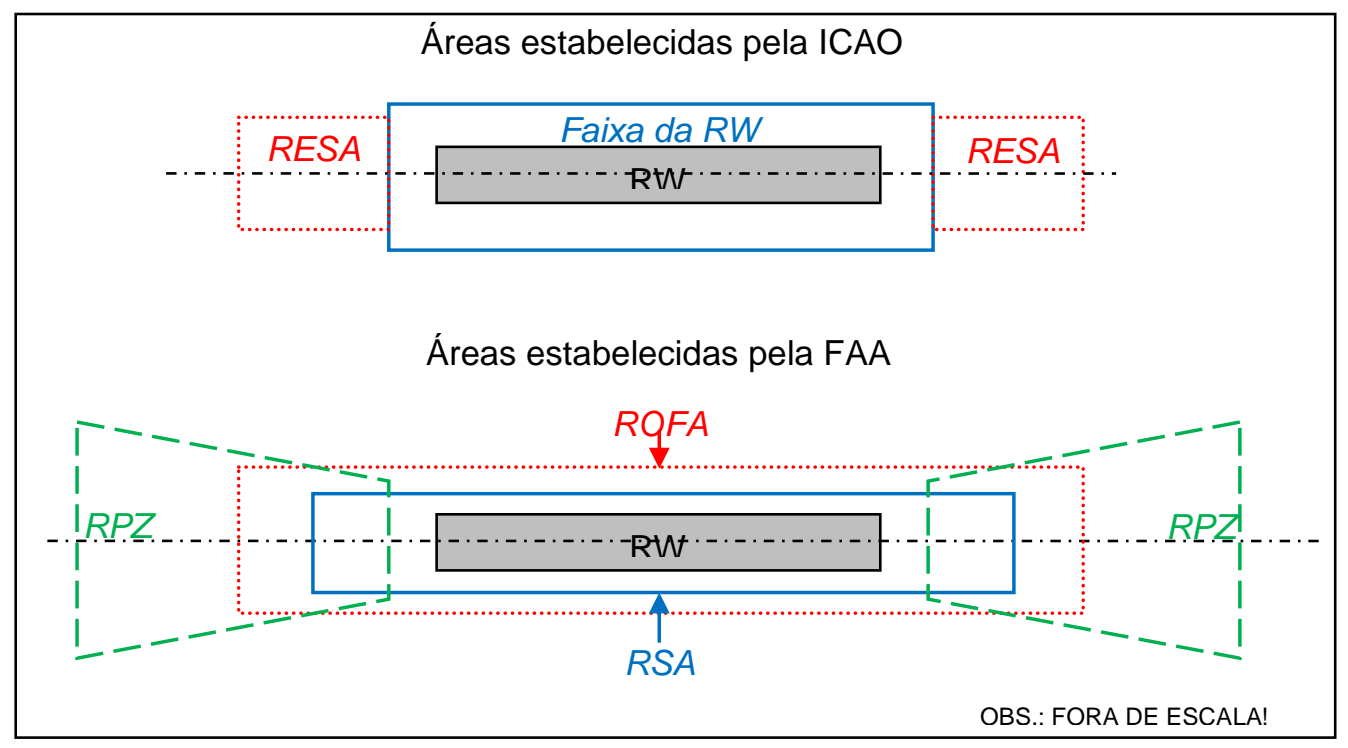

Figura 4.7-1 - Esquema das áreas de proteção da RW. FONTE: Modificado a partir das especificações da ICAO Annex 14 (2004a) e da FAA AC 150/5300-13 (1989)

A seguir são apresentadas as especificações da ICAO e da FAA para cada uma das áreas de proteção da RW.

\subsubsection{ESPECIFICAÇÕES DA ICAO PARA A FAIXA DA RW}

A ICAO Annex 14 (2004a, p. de 3-6 até 3-8) especifica padrões para a faixa da $R W$ em relação a comprimento, largura, preparação (grading) e também quanto à presença de objetos.

Embora a norma não faça uma divisão explícita da faixa da $R W$, propõe-se a divisão desta área em três partes, com base nas diferenças de especificação. Além disso, a divisão aqui proposta facilita a especificação de outros critérios de projeto, à medida que certos componentes (como a OFZ de transição interna e a posição das barras de parada da $\mathrm{RW}$ ) guardam relações com a faixa da RW. A divisão proposta consiste em: área geral da faixa da RW (AGFRW); área preparada da faixa da RW (APFRW); e área restrita da faixa da RW (ARFRW). O comprimento destas três áreas é igual, obedecendo às especificações do próximo parágrafo. A Figura 4.7-2 ilustra a posição destas três áreas dentro da faixa da RW.

Longitudinalmente, a faixa da RW deve conter a RW e qualquer zona de parada (stopway) associada. O comprimento desta faixa deve ser tal que a distância antes da cabeceira e depois do final de pista ou stopway (se disponível) seja de: 
- $60 m$ para o grupo dinâmico 1, caso a pista de pouso e decolagem seja operada por instrumentos;

- $30 \mathrm{~m}$ para o grupo dinâmico 1 caso trate-se de uma pista para aproximação visual; ou

- $60 m$ para os grupos dinâmicos 2, 3 e 4.

Os itens 4.7.1.1, 4.7.1.2 e 4.7.1.3 estabelecem os demais padrões para cada uma das três áreas da faixa da RW. Cabe lembrar que cada uma das áreas inicia na borda da RW, acostamento ou stopway, se disponível. Assim, uma dada área deve atender aos critérios especificados para a área que a contém. Ainda, cabe mencionar que, não necessariamente, a largura da área restrita da faixa RW é menor do que a largura da área preparada da faixa da RW.

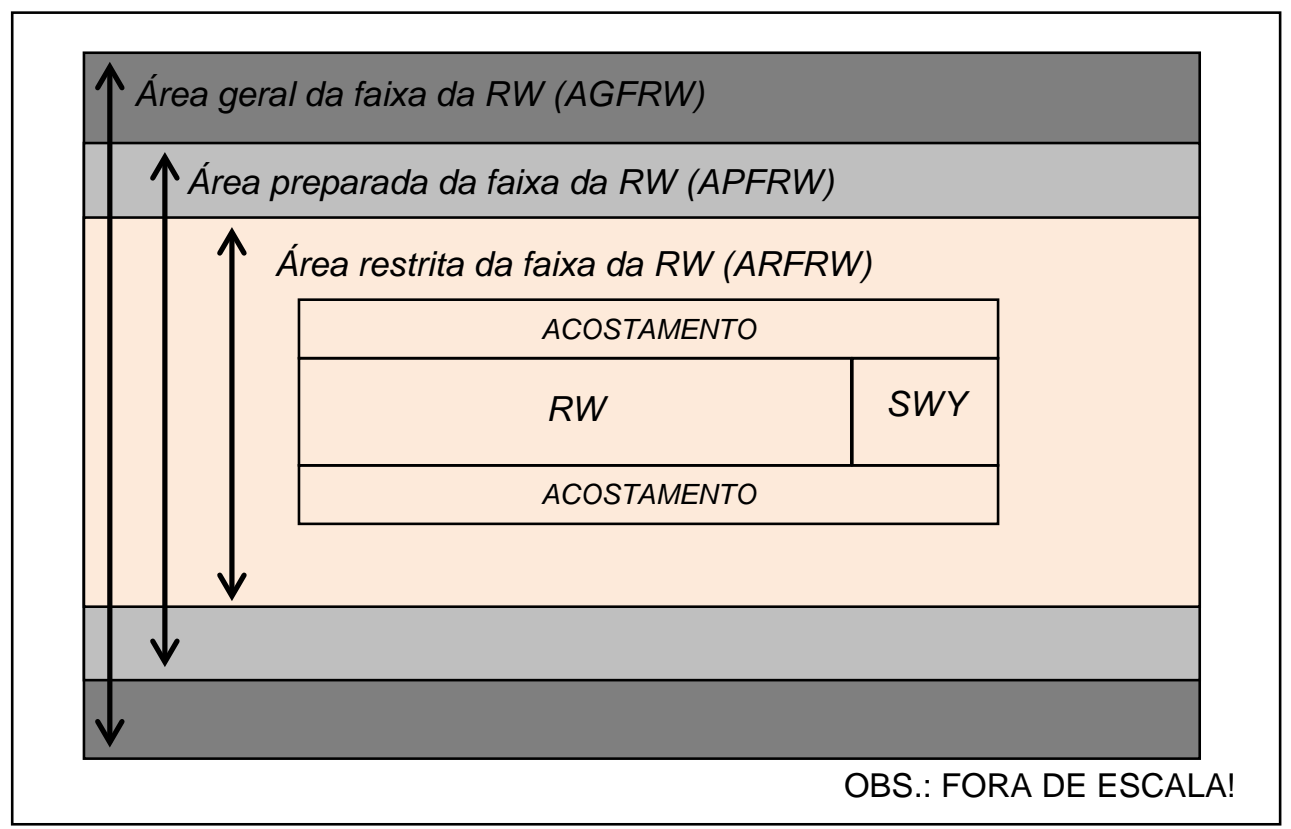

Figura 4.7-2 - Proposta de divisão da faixa da RW em três áreas. FONTE: Proposto pelo Autor

\subsubsection{1 Área geral da faixa da RW (AGFRW)}

A norma recomenda que objetos que não sejam estritamente necessários às operações sejam removidos da faixa da $R W$, formando-se uma área livre de objetos. Equipamentos indispensáveis devem ser montados sobre bases frangíveis ${ }^{28}$. $O$ parágrafo 9.9 da ICAO Annex 14 (2004a) apresenta detalhes sobre equipamentos e instalações localizados na faixa da RW.

${ }^{28}$ Em caso de impacto, a base frangível quebra ou deforma-se, protegendo a aeronave. Essa base deve ser mais baixa o quanto possível, de forma a amenizar as consequências do eventual impacto com a aeronave. 
A largura da área geral da faixa $R W$ deverá estender-se simetricamente em relação ao eixo da RW e por todo o comprimento da faixa da $R W$, conforme as seguintes larguras, para pistas para aproximação de precisão:

- $300 m$ para os grupos dinâmicos 3 e 4; e

- $150 \mathrm{~m}$ para os grupos dinâmicos 1 e 2;

Para pistas de aproximação de não-precisão a norma recomenda essas mesmas larguras.

Para pistas de aproximação visual a norma recomenda as seguintes larguras:

- $150 \mathrm{~m}$ para os grupos dinâmicos 3 e 4;

- $80 \mathrm{~m}$ para o grupo dinâmico 2; ou

- $60 \mathrm{~m}$ para o grupo dinâmico 1.

A norma coloca que deve-se proteger as aeronaves considerando-se a possibilidade de suas rodas afundarem no solo. Para tanto, deve-se evitar estruturas situadas a uma profundidade menor do que $30 \mathrm{~cm}$. Como a superfície da faixa da $R W$ deve estar em um nível similar àquele das áreas pavimentadas ( $R W$, acostamentos, stopways), aconselha-se o uso de chanfros, de forma a oferecer-se uma transição na borda da área pavimentada, abaixo do nível do solo.

O parágrafo 3.4.15 da ICAO Annex 14 (2004a) recomenda que a declividade transversal da área geral da faixa da $R W$ não exceda $5 \%$, tomando-se a medida desde a RW.

\subsubsection{2 Área preparada (graded area) da faixa da RW (APFRW)}

Consiste em uma área preparada em termos de declividades e capacidade de suporte, destinada a reduzir os danos às aeronaves que acidentalmente saiam da RW (veering-off).

Para pistas de aproximação por instrumentos, a norma recomenda seguinte largura para a área preparada da faixa da RW:

- $150 m$ para os grupos dinâmicos 3 e 4; ou

- $80 \mathrm{~m}$ para os grupos dinâmicos 1 e 2;

Para os grupos dinâmicos 3 e 4 operando em pistas para aproximação de precisão, a norma recomenda um aumento da área preparada da faixa da RW, conforme a Figura 4.7-3. 


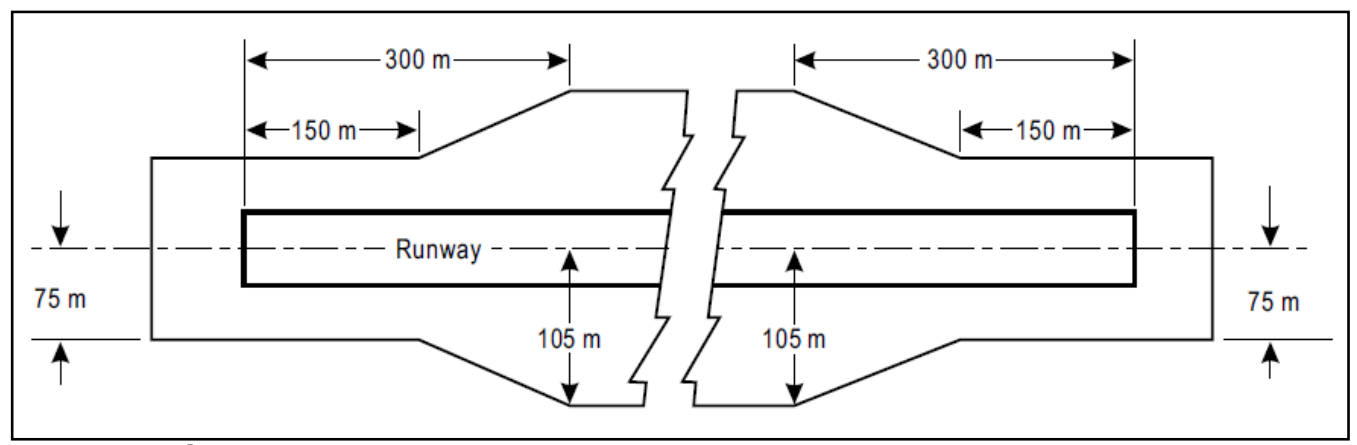

Figura 4.7-3 -Área preparada da faixa da RW para os grupos dinâmicos 3 e 4 operando em pistas de aproximação de precisão. FONTE: ICAO Annex 14 (2004a, p. ATT A-9)

Para pistas para aproximação visual, a norma recomenda a seguinte largura para a área preparada da faixa da RW:

- $150 m$ para os grupos dinâmicos 3 e 4;

- $80 m$ para o grupo dinâmico 2; e

- $60 m$ para o grupo dinâmico 1;

A superfície daquela porção da área preparada da faixa da RW adjacente à RW, acostamento ou stopway deve ser nivelada com a superfície da $R W$, acostamento ou stopway ${ }^{29}$.

A norma recomenda que a porção da faixa da RW situada a 30m da cabeceira seja protegida contra a erosão, de forma a evitar-se os riscos que bordas expostas representam às aeronaves.

Os parágrafos 3.4.12, 3.4.13 e 3.4.14 da ICAO Annex 14 (2004a) apresentam recomendações para os limites máximos das declividades longitudinais e transversais na área preparada da faixa da RW.

Em relação à capacidade de suporte, a área preparada da faixa da $R W$ deve ser tal a minimizar os riscos oriundos da diferença de capacidade de suporte.

\subsubsection{3 Área restrita da faixa da RW (ARFRW)}

Aplica-se a pistas para aproximação de precisão. A norma estabelece que nenhum objeto fixo, com exceção de auxílios visuais, é permitido dentro de uma área centrada na RW, com a seguinte largura:

- $155 m$ em uma RW de aproximação de precisão, de categorias I, II ou III, caso o ARC seja $4-F$;

- $120 m$ em uma RW de aproximação de precisão, de categorias I, II ou III caso o grupo dinâmico seja 3 ou 4; ou

${ }^{29}$ Texto original: The surface of that portion of a strip that abuts a runway, shoulder or stopway shall be flush with the surface of the runway, shoulder or stopway. Parágrafo 3.4.10 da ICAO Annex 14 (2004a). 
- $90 m$ em uma RW de aproximação de precisão, categoria I caso o grupo dinâmico seja 1 ou 2;

Nenhum objeto móvel pode ocupar a área restrita da faixa da $R W$ durante pouso ou decolagem de uma aeronave.

\subsubsection{Relação entre faixa da $R W$ e outros componentes, metodologias e considerações de projeto}

A área geral da faixa da RW (AGFRW) exclui aeronaves taxiando, sendo utilizada como critério para definir a separação entre uma RW e uma TW.

A área restrita da faixa da RW (ARFRW) é utilizada para especificação das superfícies da OFZ e também para limitar objetos móveis na proximidade de uma pista para aproximação de precisão, mesmo quando uma decolagem é conduzida.

A faixa da RW guarda relação também com as distâncias declaradas, que definem seu início e fim nas extremidades da RW. Além disso, define a posição de início da RESA.

\subsubsection{ESPECIFICAÇÕES DA ICAO PARA A RESA (RUNWAY END SAFETY AREA)}

A RESA é uma área retangular situada na extremidade da RW, sendo adjacente à faixa da $R W$. Sua função é minimizar os riscos às aeronaves que pousem antes ou depois da cabeceira (undershooting e overruning).

A ICAO Annex 14 (2004a, p. 3-8) exige que uma área de segurança de fim de pista (runway end safety area - RESA) seja provida para o grupo dinâmico 3 ou 4 ou ainda para os grupos dinâmicos 1 e 2, caso a RW seja provida de aproximação por instrumentos. Esta área inicia na faixa da pista de pouso e decolagem e deve se estender por pelo menos $90 \mathrm{~m}$.

A norma encoraja a utilização de um comprimento maior, que é de $240 \mathrm{~m}$ para os grupos dinâmicos 3 e 4 e de $120 \mathrm{~m}$ para os grupos dinâmicos 1 e 2 .

Já a largura desta área deve ser de pelo menos o dobro da largura da pista de pouso e decolagem a ela associada. A norma recomenda que se utilize uma largura igual à da área preparada da faixa da pista de pouso e decolagem.

A RESA deve oferecer uma área limpa e nivelada para as aeronaves às quais a RW é destinada, no caso de uma aeronave realizar o toque antes de alcançar a cabeceira ou ultrapassar acidentalmente o fim da pista. A RESA não pode conter instalações que não sejam estritamente necessárias. 
O parágrafo 9.9 da ICAO Annex 14 (2004a) apresenta detalhes sobre equipamentos e instalações localizados na RESA.

Os parágrafos 3.5.8, 3.5.9 e 3.5.10 da ICAO Annex 14 (2004a) apresentam recomendações sobre as declividades longitudinais e transversais na RESA. O parágrafo 5.3.22 da ICAO Doc 9157 Parte 1 (2006a) apresenta informações sobre capacidade de suporte para uma RESA.

4.7.2.1 Relação entre a RESA e outros componentes, metodologias e considerações de projeto

A RESA guarda relação com a faixa da RW, pois se inicia no final desta. Como a faixa da RW é especificada com base em distância declaradas, a posição da RESA também está sujeita a distâncias declaradas.

\subsubsection{ESPECIFICAÇÕES DA FAA PARA A ROFA (RUNWAY OBJECT FREE AREA)}

A FAA AC 150/5300-13 (1989, p. 23) estabelece a ROFA como uma área livre de objetos, centrada na RW, na qual os objetos permitidos são: auxílios visuais, auxílios rádio à navegação aérea, equipamentos necessários à movimentação de aeronaves, além do táxi e espera de aeronaves. Objetos não essenciais à navegação ou movimentação não devem estar na ROFA. Isso inclui aeronaves estacionadas e operações agrícolas. A Tabela 4.7-1 apresenta as dimensões padrões da ROFA, sendo que $W$ representa a largura e $L$ representa o comprimento após o final da RW. Aconselha-se que o comprimento da ROFA seja aumentado, se possível.

Para o caso de distâncias declaradas (quando TORA, TODA, ASDA e LDA diferem entre si) ver o item 4.7.6 que discorre sobre o referencial para a distância $\mathrm{L}$.

\subsubsection{Relação entre a ROFA e outros componentes, metodologias e considerações de projeto}

A ROFA guarda relação com a RSA, pois seu comprimento nos finais de pista não pode exceder o comprimento desta área no final de pista. Guarda relação também com as distâncias declaradas. 
Tabela 4.7-1 - Padrão FAA para a ROFA

\begin{tabular}{c|cc|cc|cc}
\hline \multirow{2}{*}{$\begin{array}{c}\text { Grupo } \\
\text { geométrico }\end{array}$} & $\begin{array}{c}\text { RWs visuais ou RWs com } \\
\text { visibilidade de } \\
\text { aproximação não menor do } \\
\text { que 1.200m |b }\end{array}$ & $\begin{array}{c}\text { RWs com visibilidade de } \\
\text { aproximação menor do } \\
\text { que 1.200m |b }\end{array}$ & \multirow{2}{*}{ C e D } \\
\hline & W & L |c & W & L |c & W & L *b \\
\hline I|a & $75 \mathrm{~m}$ & $72 \mathrm{~m}$ & $240 \mathrm{~m}$ & $180 \mathrm{~m}$ & - & - \\
I & $120 \mathrm{~m}$ & $72 \mathrm{~m}$ & $240 \mathrm{~m}$ & $180 \mathrm{~m}$ & $240 \mathrm{~m}$ & $300 \mathrm{~m}$ \\
II & $150 \mathrm{~m}$ & $90 \mathrm{~m}$ & $240 \mathrm{~m}$ & $180 \mathrm{~m}$ & $240 \mathrm{~m}$ & $300 \mathrm{~m}$ \\
III & $240 \mathrm{~m}$ & $180 \mathrm{~m}$ & $240 \mathrm{~m}$ & $240 \mathrm{~m}$ & $240 \mathrm{~m}$ & $300 \mathrm{~m}$ \\
IV & $240 \mathrm{~m}$ & $300 \mathrm{~m}$ & $240 \mathrm{~m}$ & $300 \mathrm{~m}$ & $240 \mathrm{~m}$ & $300 \mathrm{~m}$ \\
V V & - & - & - & - & $240 \mathrm{~m}$ & $300 \mathrm{~m}$ \\
VI & - & - & - & - & $240 \mathrm{~m}$ & $300 \mathrm{~m}$ \\
\hline
\end{tabular}

a: somente aeronaves de pequeno porte.

$\mid \mathrm{b}$ : adotar as dimensões correspondentes à cabeceira com a menor visibilidade permitida. lc: O comprimento da ROFA não deve superar o comprimento da RSA.

FONTE: FAA AC 150/5300-13 (1989, p. de 25 até 26-1)

\subsubsection{ESPECIFICAÇÕES DA FAA PARA A RSA (RUNWAY SAFETY AREA)}

A FAA AC 150/5300-13 (1989, p. 21) estabelece a RSA como uma área de segurança centrada na pista de pouso e decolagem. Os seguintes critérios se aplicam à RSA:

- Deve ser limpa e nivelada, sem sulcos, protuberâncias, depressões ou outras variações de superfície;

- Drenada, seja por abaulamento, seja pelo uso de bocas de lobo, para evitar acúmulo de água;

- Capaz de suportar, sob condições secas, equipamento de remoção de neve, equipamentos de resgate e combate a incêndio e a passagem eventual de aeronaves sem induzir danos à mesma;

- Livre de objetos, exceto aqueles que precisarem estar na RSA devido à sua função. Objetos com mais de $7,6 \mathrm{~cm}$ devem estar montados sob bases frangíveis, com o ponto frangível a uma altura menor do que 7,6cm.

- A especificação P-152 da FAA AC 150/5370-10 apresenta informações sobre a compactação do solo de uma RSA.

As dimensões da RSA são mostradas na Tabela 4.7-2, onde $\mathrm{W}$ representa a sua largura, $\mathrm{L}_{1}$ o comprimento antes da cabeceira e $\mathrm{L}_{2}$, o comprimento depois do final da pista. 
Tabela 4.7-2 - Dimensões padrão da FAA para a RSA

\begin{tabular}{|c|c|c|c|c|c|c|c|c|c|}
\hline \multirow{3}{*}{$\begin{array}{c}\text { Grupo } \\
\text { geométrico }\end{array}$} & \multicolumn{6}{|c|}{$A$ e $B$} & & & \\
\hline & \multicolumn{3}{|c|}{$\begin{array}{l}\text { RWs de aproximação } \\
\text { visual ou RWs com } \\
\text { visibilidade de } \\
\text { aproximação não menor } \\
\text { do que } 1.200 \mathrm{~m} \mid \mathrm{b}\end{array}$} & \multicolumn{3}{|c|}{$\begin{array}{c}\text { RWs com visibilidade } \\
\text { de aproximação } \\
\text { menor do que } 1.200 \mathrm{~m} \\
\text { |b }\end{array}$} & \multicolumn{3}{|c|}{$C$ e D } \\
\hline & $W$ & $L_{1}$ & $L_{2}|\mathrm{c}| \mathrm{d}$ & $W$ & $L_{1}$ & $L_{2}|\mathrm{c}| \mathrm{d}$ & $w \mid \mathbf{e}$ & $L_{1}$ & $L_{2}|\mathrm{c}| \mathrm{d}$ \\
\hline $1 \mid a$ & $36 \mathrm{~m}$ & $72 \mathrm{~m}$ & $72 m$ & $90 \mathrm{~m}$ & $180 \mathrm{~m}$ & $180 \mathrm{~m}$ & - & - & - \\
\hline I & $36 m$ & $72 m$ & $72 m$ & $90 m$ & $180 \mathrm{~m}$ & $180 \mathrm{~m}$ & $150 \mathrm{~m}$ & $180 \mathrm{~m}$ & $300 \mathrm{~m}$ \\
\hline II & $45 \mathrm{~m}$ & $90 \mathrm{~m}$ & $90 \mathrm{~m}$ & $90 \mathrm{~m}$ & $180 \mathrm{~m}$ & $180 \mathrm{~m}$ & $150 \mathrm{~m}$ & $180 \mathrm{~m}$ & $300 \mathrm{~m}$ \\
\hline III & $90 \mathrm{~m}$ & $180 \mathrm{~m}$ & $180 \mathrm{~m}$ & $120 \mathrm{~m}$ & $180 m$ & $240 m$ & $150 \mathrm{~m}$ & $180 \mathrm{~m}$ & $300 \mathrm{~m}$ \\
\hline IV & $150 m$ & $180 m$ & $300 m$ & $150 m$ & $180 m$ & $300 m$ & $150 m$ & $180 m$ & $300 m$ \\
\hline V & - & - & - & - & - & - & $150 \mathrm{~m}$ & $180 m$ & $300 m$ \\
\hline VI & - & - & - & - & - & - & $150 \mathrm{~m}$ & $180 \mathrm{~m}$ & $300 \mathrm{~m}$ \\
\hline
\end{tabular}

a: aeronaves de pequeno porte.

|b: adotar as dimensões correspondentes à cabeceira com a menor visibilidade permitida.

|c: quando uma RW possui uma zona de parada (stopway - SWY) o comprimento é em relação ao final da SWY.

|d: o comprimento pode ser igualado àquele anterior à cabeceira, caso um EMAS (Enginnering Materials Arresting System) seja construído e caso seja oferecida orientação vertical (vertical guidance) por instrumentos ou visual, na direção oposta da RW. Ver AC 150/5220-22.

le: Para os ARCs C-I e C-Il uma largura de $120 \mathrm{~m}$ é permissível.

FONTE: FAA AC 150/5300-13 (1989, p. de 25 até 26-1)

O fato de a RSA apresentar aspectos fora dos padrões não deve ser entendido como uma possibilidade de flexibilização dos padrões. Ao contrário, devese continuamente melhorar uma RSA até que ela atenda a todas as especificações, incluindo o tratamento dado aos NAVAIDs (Navigational Aids).

Uma RSA com terreno acidentado pode levar à necessidade de torres reforçadas para acomodar luzes de aproximação, contidas na sua área. Ainda, se o terreno adjacente à RSA for mais baixo do que esta, pode haver a necessidade de alocação de equipamentos como o ILS na área da RSA. Ambos os aspectos justificam cuidados com o nivelamento do terreno, na RSA e nas suas adjacências.

Para o caso de distâncias declaradas (quando TORA, TODA, ASDA e LDA diferem entre si) ver o item 4.7.6 que discorre sobre o referencial para as distâncias $\mathrm{L}_{1}$ e $\mathrm{L}_{2}$.

\subsubsection{Relação entre a RSA e outros componentes, metodologias e considerações de projeto}

A RSA guarda relação com a ROFA, pois esta não pode excedê-la e também com as distâncias declaradas. 
Ainda, serve de critério para a separação entre uma RW e uma TW, por excluir aeronaves taxiando. Além disso, exclui aeronaves em espera, o que a torna um critério para a posição da BPRW.

\subsubsection{ESPECIFICAÇÕES DA FAA PARA A RPZ (RUNWAY PROTECTION ZONE)}

A FAA AC 150/5300-13 (1989, p. 13, 276) especifica dois tipos de RPZs: a RPZ de aproximação (approach RPZ) e a RPZ de saída (departure RPZ). Uma pista que opera pousos e decolagens terá duas RPZs em cada extremidade. Caso a cabeceira coincida com o final de pista, as RPZs estarão sobrepostas, iniciando a $60 \mathrm{~m}$ da cabeceira, ou a $60 \mathrm{~m}$ do final de pista. Estas dimensões são apresentadas na Tabela 4.7-3, e variam de acordo com o tipo de aeronave e o nível de visibilidade associado à extremidade da pista.

No entanto, para a RPZ de saída, dimensões diferentes são aplicáveis, conforme a Tabela 4.7-4, iniciando-se $60 \mathrm{~m}$ após o final da TORA.

A área central da RPZ possui a mesma largura da ROFA. Já a área de atividade controlada fica nas laterais, ou seja, entre as bordas da ROFA e da RPZ.

Tabela 4.7-3 - RPZ de aproximação e saída para RW utilizada em toda a extensão

\begin{tabular}{|c|c|c|c|c|c|}
\hline \multirow[b]{2}{*}{$\begin{array}{l}\text { Visibilidade } \\
\text { mínima de } \\
\text { aproximação }\end{array}$} & \multirow[b]{2}{*}{ Tipo de aeronave } & \multicolumn{4}{|c|}{ Dimensões } \\
\hline & & $\begin{array}{c}\text { Comprimento } \\
L \\
\end{array}$ & $\begin{array}{c}\text { Largura } \\
\text { interna } \\
W_{1}\end{array}$ & $\begin{array}{c}\text { Largura } \\
\text { externa } \\
W_{2}\end{array}$ & Área \\
\hline \multirow{3}{*}{$\begin{array}{c}\mathrm{RW} \text { de } \\
\text { aproximação visual } \\
\text { ou RW com } \\
\text { visibilidade não } \\
\text { menor do que } \\
1.600 \mathrm{~m}\end{array}$} & $\begin{array}{l}\text { Aeronaves de } \\
\text { pequeno porte }\end{array}$ & $300 m$ & $75 m$ & $135 \mathrm{~m}$ & $31.500 \mathrm{~m}^{2}$ \\
\hline & $\begin{array}{c}\text { Grupos dinâmicos } \\
\text { A e B }\end{array}$ & $300 m$ & $150 m$ & $210 \mathrm{~m}$ & $54.000 \mathrm{~m}^{2}$ \\
\hline & $\begin{array}{c}\text { Grupos dinâmicos } \\
\text { C e D }\end{array}$ & $510 m$ & $150 m$ & $303 m$ & $115.515 \mathrm{~m}^{2}$ \\
\hline $\begin{array}{c}\text { Visibilidade não } \\
\text { menor do que } \\
1.200 \mathrm{~m} \\
\end{array}$ & $\begin{array}{l}\text { Todas as } \\
\text { aeronaves }\end{array}$ & $510 m$ & $300 m$ & $453 m$ & $192.015 \mathrm{~m}^{2}$ \\
\hline $\begin{array}{l}\text { Visibilidade menor } \\
\text { do que } 1.200 \mathrm{~m}\end{array}$ & $\begin{array}{l}\text { Todas as } \\
\text { aeronaves }\end{array}$ & $750 m$ & $300 m$ & $525 m$ & $309.375 \mathrm{~m}^{2}$ \\
\hline
\end{tabular}

Apesar de ser desejável remover todos os objetos da RPZ, alguns usos desta área são permitidos, desde que não atraiam vida selvagem, estejam fora da ROFA e não interfiram com auxílios à navegação aérea. Estacionamentos de automóveis, apesar de desencorajados, são permitidos, desde que estas instalações estejam localizadas fora da área central da RPZ. Instalações de armazenamento de combustíveis não são permitidas na RPZ. 
Tabela 4.7-4 - RPZ de saída para distâncias declaradas

\begin{tabular}{|c|c|c|c|c|}
\hline Tipo de aeronave & $\begin{array}{c}\text { Comprimento } \\
L\end{array}$ & $\begin{array}{c}\text { Largura } \\
\text { interna } \\
W_{1}\end{array}$ & $\begin{array}{c}\text { Largura } \\
\text { externa } \\
W_{2}\end{array}$ & Área \\
\hline $\begin{array}{l}\text { Aeronaves de pequeno porte pertencendo } \\
\text { aos grupos dinâmicos A e B }\end{array}$ & $300 m$ & $75 m$ & $135 \mathrm{~m}$ & $31.500 \mathrm{~m}^{2}$ \\
\hline $\begin{array}{l}\text { Aeronaves de grande porte pertencendo } \\
\text { aos grupos dinâmicos } \mathrm{A} \text { e B }\end{array}$ & $300 m$ & $150 m$ & $210 \mathrm{~m}$ & $54.000 \mathrm{~m}^{2}$ \\
\hline $\begin{array}{l}\text { Aeronaves pertencendo aos grupos } \\
\text { dinâmicos C e D }\end{array}$ & $510 \mathrm{~m}$ & $150 m$ & $303 m$ & $115.515 m^{2}$ \\
\hline
\end{tabular}

FONTE: FAA AC 150/5300-13 (1989, p.276)

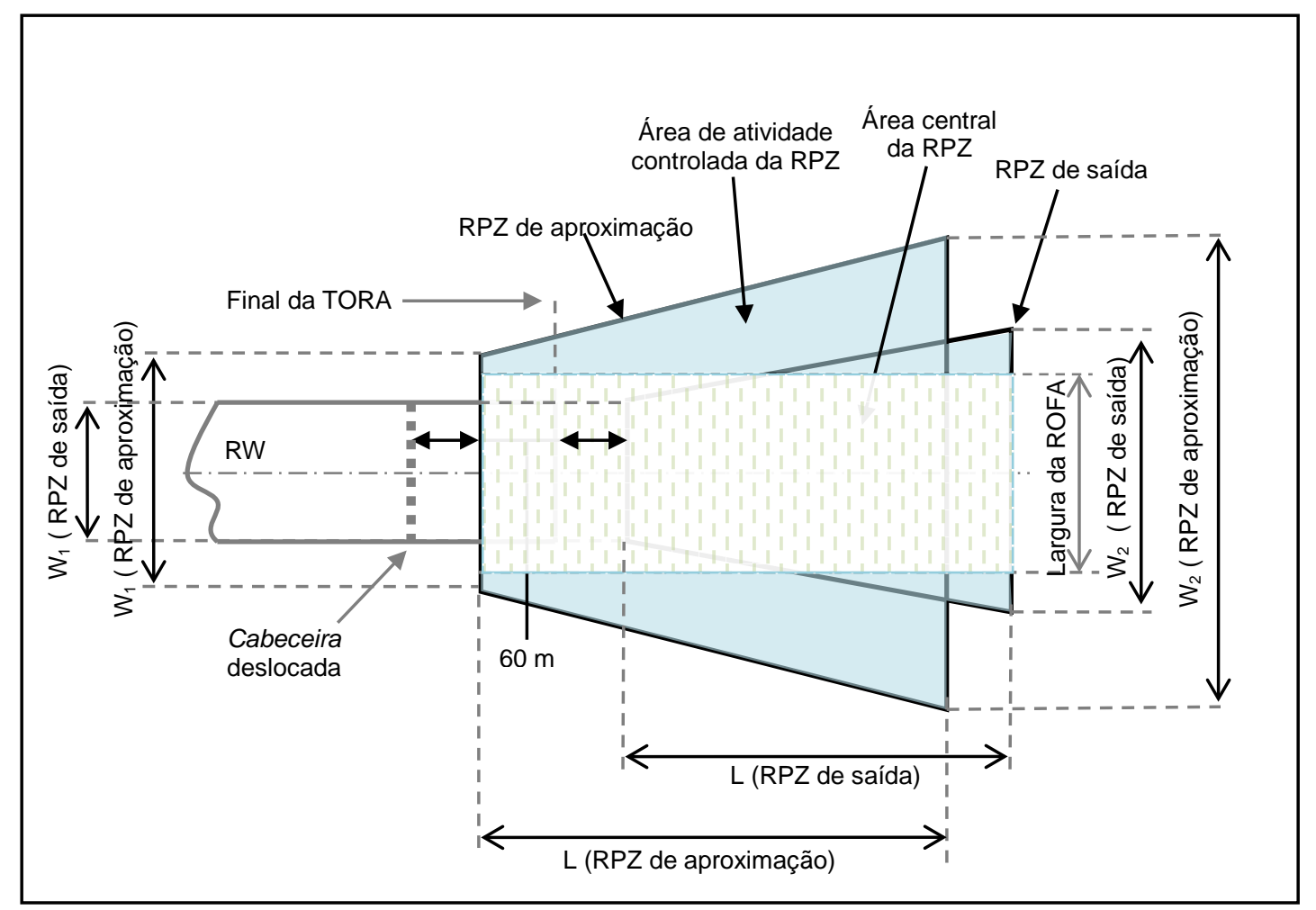

Figura 4.7-4- Geometria da RPZ. FONTE: Criado a partir das descrições da RPZ na FAA AC 150/5300-13 (1989)

Locais de aglomeração de pessoas (igrejas, escolas, hospitais, prédios comerciais, shopping centres, etc.) não são permitidos nesta área.

Quando não for possível controlar-se toda a área da RPZ, os padrões possuem caráter de recomendação para a porção de área que o aeroporto não domina.

\subsubsection{Relação entre a RPZ e outros componentes, metodologias e considerações de projeto}

A RPZ guarda relação com as distâncias declaradas. 


\subsubsection{USO DE DISTÂNCIAS DECLARADAS PARA ROFA E RSA}

Os seguintes critérios devem ser observados para a RSA e ROFA quanto à decolagem, lembrando-se que o comprimento de ambas é a soma de: uma distância prévia à cabeceira, o comprimento da RW e uma distância posterior ao final de pista.

- No início da RW: a RSA e a ROFA precisam se estender para trás do início da corrida de decolagem para continuar a OFA da taxiway de acesso à RW e prover proteção contra o jet blast. A porção de pista atrás deste inicio é indisponível para consideração na corrida de decolagem, distância de decolagem ou distância de aceleração e parada;

- No final da RW: o comprimento após o final de pista deve iniciar após o final da ASDA. A porção da RW depois do final da ASDA não pode ser considerada disponível nos cálculos de comprimento de distância de aceleração e parada.

Os seguintes critérios devem ser observados para a RSA e a ROFA quanto ao pouso:

No início da RW: o comprimento a considerar inicia na cabeceira, sendo a distância antes desta não computável como distância de pouso;

No final da RW: a distância deve iniciar no final da LDA. Distâncias após o final da LDA não são computáveis como distâncias de pouso.

\subsubsection{REFERENCIAL LONGITUDINAL DAS ÁREAS DE PROTEÇÃO DA RW}

As especificações da faixa da RW e da RESA levam em conta dois pontos de referência: i) a cabeceira; e ii) o final da RW ou o final da SWY (se disponível). A FAA, por sua, vez, utiliza quatro pontos de referência diferentes ao especificar a ROFA e a RSA, dependendo se a operação é de pouso ou decolagem: i) decolagem: distância anterior ao início da TORA e distância posterior ao final da ASDA; e ii) pouso: distância anterior à cabeceira e distância posterior ao final da LDA.

Admitindo-se que a faixa da RW, a RESA, a ROFA e a RSA cumprem funções similares $^{30}$, torna-se oportuna uma análise da posição relativa entre estas áreas, dada a complexidade introduzida pelo uso de referenciais diferentes para as

\footnotetext{
30 Ao oferecerem proteção contra riscos que incluem undershoots, overrruns, veering-offs e interferência nos auxílios rádio à navegação aérea.
} 
especificações. Essa complexidade é aumentada pela necessidade de avaliação da RW para os dois sentidos, caso as operações assim demandem.

A Figura 4.7-5 e a Tabela 4.7-5 esquematizam os referenciais em questão a partir das especificações da ICAO e da FAA. A Figura 4.7-5 mostra, para um caso genérico, os referenciais da faixa da RW, da RESA, da ROFA e da RSA, considerando-se operações de pouso e decolagem nos dois sentidos. Dada a variabilidade imposta pela base de especificação, a posição longitudinal de uma dada área está sujeita a um perfil de extensão e de distância desde o referencial. A Figura 4.7-5 mostra essa faixa de variação, bem como a sua configuração mínima, adotando-se as especificações mínimas. Para fins de exemplificação, cita-se o caso de uma operação de pouso efetuada da esquerda para a direita. O referencial para as áreas da ICAO (faixa da RW e RESA) e da FAA (ROFA e RSA) será a cabeceira.

- A faixa da $R \boldsymbol{W}$ deverá estender-se a uma distância que varia entre $30 \mathrm{~m}$ e $60 \mathrm{~m}$ da cabeceira, longitudinalmente para fora da RW. Neste caso a distância mínima será de $30 \mathrm{~m}$, ou seja, necessariamente qualquer ponto a menos do que $30 \mathrm{~m}$ da cabeceira, deve estar inserido na faixa da RW, independentemente das variáveis de especificação;

- A RESA inicia na borda da faixa da RW. Portanto, sua posição inicial, desde a cabeceira, varia entre $30 \mathrm{~m}$ e $60 \mathrm{~m}$. Como o seu comprimento varia entre $90 \mathrm{~m}$ e $240 \mathrm{~m}$, a posição final poderá ser de até $300 \mathrm{~m}$. Já a posição mínima está entre $60 \mathrm{~m}$ e $120 \mathrm{~m}$, ou seja, necessariamente qualquer ponto situado entre $60 \mathrm{~m}$ e $120 \mathrm{~m}$ da cabeceira, deve estar inserido na RESA, independentemente das variáveis de especificação;

- A ROFA é especificada somente para o final da RW ou LDA ou ASDA; e

- A RSA deverá estender-se a uma distância que varia entre $72 \mathrm{~m}$ e $180 \mathrm{~m}$ da cabeceira, longitudinalmente para fora da RW. Neste caso a distância mínima será de $72 \mathrm{~m}$, ou seja, necessariamente qualquer ponto a menos do que $72 \mathrm{~m}$ da cabeceira, deve estar inserido na RSA, independentemente das variáveis de especificação.

Por sua vez, a Tabela 4.7-5 mostra a faixa de variação e as variáveis associadas a cada especificação. Esta tabela também apresenta fórmulas para 0 cálculo do comprimento total da faixa da RW, da ROFA e da RSA. 
Cabe notar-se que, para a faixa da $R W$ e para a RESA, não existe uma especificação para a extremidade da RW onde inicia uma decolagem. No entanto, isso não causa estranheza, pois undershootings, overrunings, veering-offs e interferência nos auxílios rádio à navegação aérea não são riscos associados a esta extremidade, nesta situação. Ainda para ROFA e a RSA, na situação descrita, também não existem especificações, a não ser recomendações quanto ao atendimento à OFA da TW adjacente, e quanto aos riscos do jet blast.

As situações apresentadas na Figura 4.7-5 e na Tabela 4.7-5, implicam possível sobreposição entre as quatro áreas consideradas. Neste caso, deve-se considerar a combinação mais demandante de cada uma das áreas de proteção. 


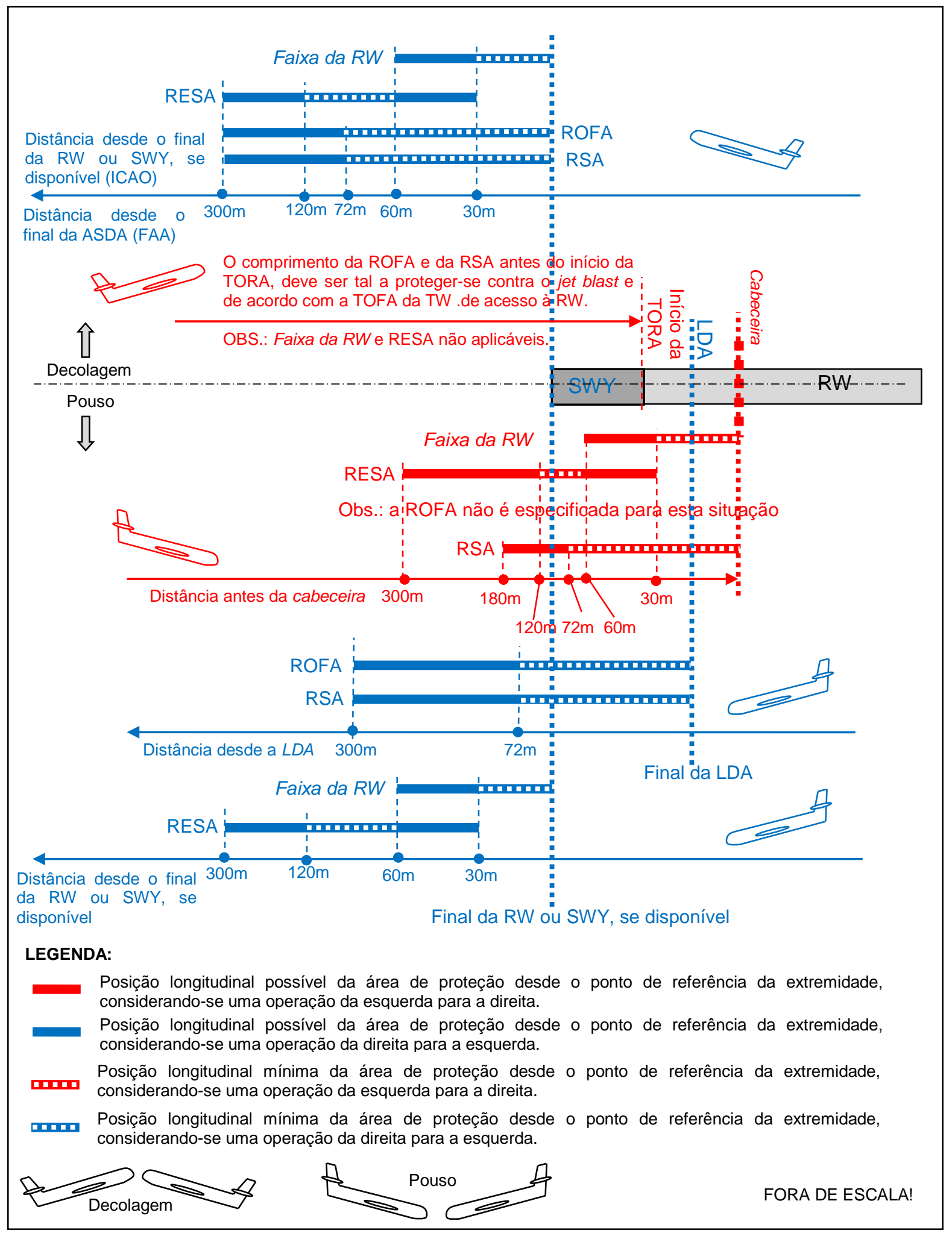

Figura 4.7-5 - Referencial longitudinal para as áreas de proteção da RW. FONTE: Adaptado a partir das especificações da ICAO Annex 14 (2004a) e da FAA AC 150/5300-13 (1989) 
Tabela 4.7-5 - Referencial longitudinal paras as áreas de proteção da RW

\begin{tabular}{|c|c|c|c|c|c|c|c|c|c|c|c|}
\hline Colunas & $\mathrm{C} 1$ & $\mathrm{C} 2$ & $\mathrm{C} 3$ & $\mathrm{C} 4$ & C5 & C6 & $\mathrm{C} 7$ & C8 & C9 & C10 & C11 \\
\hline \multirow{3}{*}{ Linhas } & \multirow{3}{*}{$\begin{array}{c}\text { Referência } \\
\text { na } \\
\text { extremidade } \\
\text { da RW }\end{array}$} & \multicolumn{2}{|c|}{ Faixa da RW } & \multicolumn{4}{|c|}{ RESA } & \multicolumn{2}{|c|}{ ROFA } & \multicolumn{2}{|r|}{ RSA } \\
\hline & & \multicolumn{2}{|c|}{ Comprimento } & \multicolumn{2}{|c|}{ Comprimento } & \multicolumn{2}{|c|}{ Posição } & \multicolumn{2}{|c|}{ Comprimento } & \multicolumn{2}{|c|}{ Comprimento } \\
\hline & & Variáveis & $\begin{array}{c}\text { Faixa de } \\
\text { variação }(\mathbf{m})\end{array}$ & Variáveis & $\begin{array}{l}\text { Faixa de } \\
\text { variação } \\
(\mathrm{m})\end{array}$ & Variáveis & $\begin{array}{c}\text { Faixa de } \\
\text { variação } \\
(\mathrm{m})\end{array}$ & Variáveis & $\begin{array}{c}\text { Faixa de } \\
\text { variação }(\mathrm{m})\end{array}$ & Variáveis & $\begin{array}{l}\text { Faixa de } \\
\text { variação }(m)\end{array}$ \\
\hline L1 & \begin{tabular}{|c|} 
Comprimento \\
anterior à \\
cabeceira |a
\end{tabular} & $\begin{array}{l}\text { TPICAO; } \\
\text { GDICAO }\end{array}$ & $30-60$ & - & - & \multicolumn{2}{|c|}{$\begin{array}{l}\text { Inicia na Faixa da } \\
\text { RW }\end{array}$} & $\begin{array}{l}T_{F A A} \\
G_{F A A} \\
G G_{F A A}\end{array}$ & $72-300$ & $\begin{array}{l}T_{F A A} \\
G_{F A A} \\
G G_{F A A}\end{array}$ & $72-180$ \\
\hline L2 & \begin{tabular}{|c|} 
Comprimento \\
anterior ao \\
início da \\
TORA |b \\
\end{tabular} & - & - & - & - & - & - & \multicolumn{4}{|c|}{$\begin{array}{l}\text { Deve ser de forma a proteger-se contra o jet blast e } \\
\text { de acordo com a TOFA da TW de acesso à RW. }\end{array}$} \\
\hline L3 & \begin{tabular}{|c|} 
Comprimento \\
posterior ao \\
final de pista \\
ou stopway \\
(se \\
disponível) \\
\end{tabular} & $\begin{array}{l}\text { TP } \\
\text { GCAO; } \\
\text { GD }\end{array}$ & $30-60$ & - & - & \multicolumn{2}{|c|}{$\begin{array}{l}\text { Inicia na Faixa da } \\
\qquad \text { RW }\end{array}$} & - & - & - & - \\
\hline L4 & $\begin{array}{c}\text { Comprimento } \\
\text { após a ASDA } \\
\mathbf{l b} \mid \mathbf{d}\end{array}$ & - & - & - & - & - & - & $\begin{array}{l}\mathrm{TP}_{\mathrm{FAA}} \\
\mathrm{GD}_{\mathrm{FAA}} \\
\mathrm{GG}_{\mathrm{FAA}}\end{array}$ & $72-300$ & $\begin{array}{l}\mathrm{TP}_{\mathrm{FAA}} \\
\mathrm{GD}_{\mathrm{FAA}} \\
\mathrm{GG}_{\mathrm{FAA}}\end{array}$ & $72-300$ \\
\hline L5 & $\begin{array}{c}\text { Comprimento } \\
\text { após a LDA } \\
\mathbf{| a} \mid \mathbf{d} \\
\end{array}$ & - & - & - & - & - & - & $\begin{array}{l}\text { TP } \\
\text { GAA } \\
\mathrm{GD}_{\mathrm{FAA}} \\
\mathrm{GG}_{\mathrm{FAA}}\end{array}$ & $72-300$ & $\begin{array}{l}\text { TP } \\
\text { GAA; } \\
\text { DDAA }_{\text {FAA }} \\
G_{F A A}\end{array}$ & $72-300$ \\
\hline L6 & $\begin{array}{c}\text { Comprimento } \\
\text { total }\end{array}$ & $\begin{array}{l}\text { TP }{ }_{\text {ICAO }} \\
\text { GD } \\
L_{\text {ICAO }} \\
\text { RW }\end{array}$ & $\mathrm{L} 1 \mathrm{C} 3+\mathrm{L}_{\mathrm{RW}}+\mathrm{L} 3 \mathrm{C} 3$ & $\begin{array}{l}\text { TP ICAO; } \\
\text { GDICAO }\end{array}$ & $90-240$ & - & - & $\begin{array}{c}\mathrm{TP}_{\mathrm{FAA}} ; \\
\mathrm{GD}_{\mathrm{FAA}} ; \\
\mathrm{GG}_{\mathrm{FAA}} ; \\
\mathrm{L}_{\mathrm{RW}}\end{array}$ & \begin{tabular}{|c|} 
(L1C9 ou \\
L2C9)+(L4C9 \\
ou \\
L5C9)+L \\
|c
\end{tabular} & $\begin{array}{l}\mathrm{TP}_{\mathrm{FAA}} \\
\mathrm{GD}_{\mathrm{FAA}} \\
\mathrm{GG}_{\mathrm{FAA}}\end{array}$ & $\begin{array}{c}\text { (L1C11 ou } \\
\text { L2C11)+(L4C11 } \\
\text { ou L5C11)+L } \\
\text { IC }\end{array}$ \\
\hline
\end{tabular}

FONTE: Compilado a partir das especificações contidas na ICAO Annex 14 (2004a) e na FAA AC 150/5300-13 (1989).

|a: aeronave que pousa. |b: aeronave que decola. |c: dependendo se a aeronave pousa ou decola. |d: o comprimento da ROFA além do final de pista não pode ser maior do que o comprimento da RSA. 


\section{8 ÁREAS DE PROTEÇÃO DA TW}

A ICAO estabelece a faixa da TW, conforme o item 4.8.1. Já a FAA exige a observação de duas áreas: a OFA da TW (TOFA) conforme o item 4.8.2, e a área de segurança da TW (taxiway safety area - TSA), conforme o item 4.8.3.

\subsubsection{ESPECIFICAÇÕES DA ICAO PARA A FAIXA DA TW}

A ICAO Annex 14 (2004a, p. 3-15) exige que as pistas de táxi estejam inseridas em uma faixa da pista de táxi. Esta exigência se aplica a pistas de táxi, com exceção das TLs e com inclusão das pistas de taxi do pátio.

Propõe-se nesta dissertação a separação da faixa da TW em duas áreas: área geral da faixa da TW; e área preparada da faixa da TW, com base nas diferenças de especificação entre estas duas porções da faixa da TW. A área geral da faixa da TW compreende a largura total prevista para esta faixa, contendo a área preparada da faixa da TW. Assim, a área preparada da faixa da TW está sujeita aos mesmos critérios da área geral da faixa da TW e também a critérios específicos. A Figura 4.8-1 ilustra a divisão proposta.

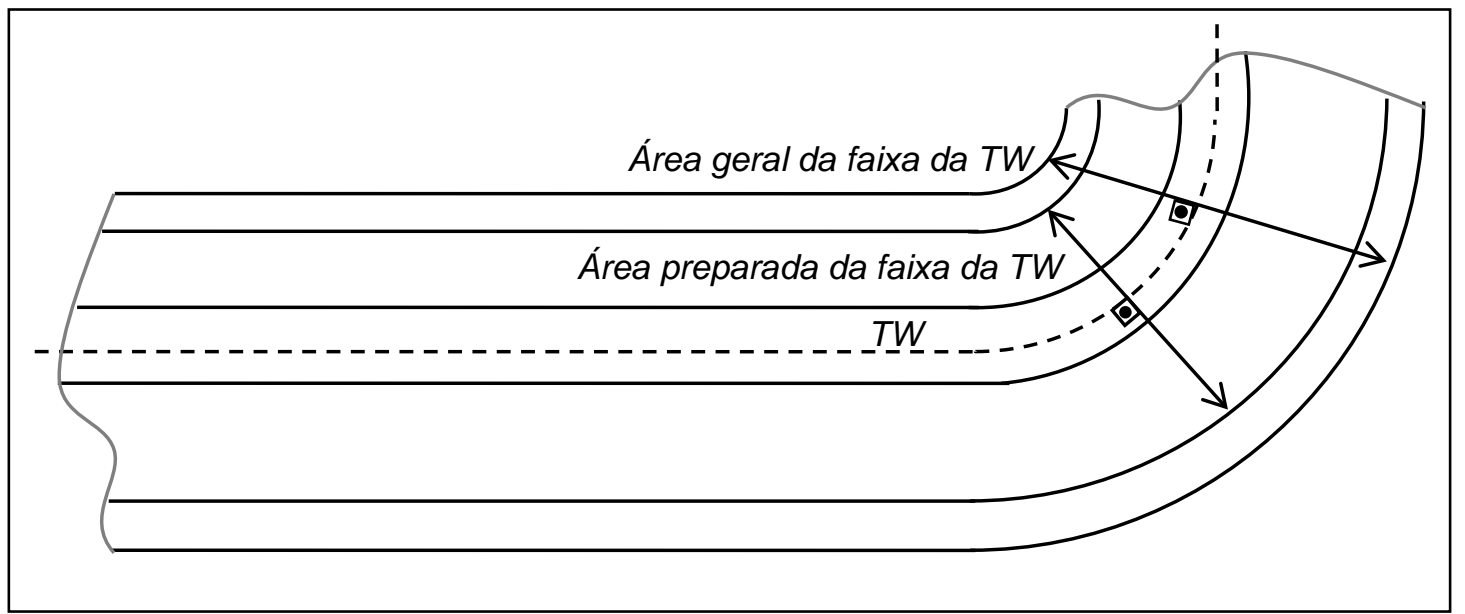

Figura 4.8-1 - Proposta de divisão da faixa da TW em duas áreas. FONTE: Proposto pelo autor

\subsubsection{1 Área geral da faixa da TW (AGFTW)}

A faixa da TW deve ser uma área livre de objetos que possam representar riscos às aeronaves que taxiam. O parágrafo 9.9 da ICAO Annex 14 (2004a) apresenta detalhes sobre a instalação de equipamentos na faixa da TW. Estruturas de drenagem devem ser adequadamente projetadas, de forma prevenir danos às aeronaves que acidentalmente saiam da pista (veering-off). A declividade transversal, medida desde a TW, não deve exceder 5\%. 
A norma recomenda que a largura da faixa da TW seja dobro dos valores V2, da Tabela 4.6-3, para cada um dos grupos geométricos especificados, garantindo-se dessa forma a distância mínima entre o eixo da pista de táxi e os objetos. Dessa forma, aeronaves estão excluídas da faixa da TW.

\subsubsection{2 Área preparada (graded area) da faixa da TW (APFTW)}

A área preparada da faixa da TW deve possuir a largura indicada na Tabela 4.8-1. A superfície da faixa da TW deve ser nivelada com a superfície da $T W$ ou acostamento, se disponível ${ }^{31}$.

O parágrafo 3.11.5 da ICAO Annex 14 (2004a) apresenta recomendações para os limites máximos das declividades transversais na área preparada da faixa da TW.

Tabela 4.8-1 - Largura padrão ICAO para a área preparada da faixa da TW

\begin{tabular}{l|ccccccc}
\hline \multirow{3}{*}{ Largura padrão } & \multicolumn{6}{|c}{ Grupo geométrico } \\
& A & B & C & D & E & F \\
\cline { 2 - 7 } & $22 \mathrm{~m}$ & $25 \mathrm{~m}$ & $25 \mathrm{~m}$ & $38 \mathrm{~m}$ & $44 \mathrm{~m}$ & $60 \mathrm{~m}$ \\
\hline
\end{tabular}

FONTE: ICAO Annex 14 (2004a, p. 3-16)

\subsubsection{Relação entre a faixa da TW e outros componentes, metodologias e considerações de projeto}

A área geral da faixa da TW exclui outras aeronaves, o que a torna um critério para a separação entre TWs e para a folga entre a aeronave e objetos.

A área preparada da faixa da TW serve de padrão para a largura mínima da área com capacidade plena de suporte para TWs sobre pontes.

\subsubsection{ESPECIFICAÇÕES DA FAA PARA A ÁREA LIVRE DE OBJETOS DA TW (TAXIWAY OBJECT FREE AREA - TOFA) E DA TL}

Na OFA da TW ou TL não podem estar localizadas vias de serviço, aeronaves estacionadas nem objetos acima do nível do solo, além daqueles necessários à navegação ou movimentação de aeronaves. Veículos podem operar dentro da OFA desde que mantenham separação adequada, dando passagem às aeronaves.

Quanto às dimensões, a FAA especifica duas OFAs diferentes: uma para a TWs e outra para as TLs.

A OFA da TW é centrada nas pistas de táxi e nas pistas de táxi do pátio, sendo sua largura apresentada na Tabela 4.8-2. Além disso, a FAA AC 150/5300-13

\footnotetext{
${ }^{31}$ Texto original: The surface of the strip should be flush at the edge of the taxiway or shoulder, if provided..(). Parágrafo 3.11 .5 da ICAO Annex 14 (2004a).
} 
(1989, p. 16) coloca que larguras diferentes podem ser estabelecidas para a OFA da TW, conforme a Equação 4.8-1, onde as distâncias são dadas em metros e $S$ representa a envergadura da aeronave crítica.

Tabela 4.8-2 - Largura padrão da OFA da TW

\begin{tabular}{c|cccccc}
\hline \multirow{2}{*}{ Item } & \multicolumn{5}{|c}{ Grupo geométrico } \\
& I & II & III & IV & V & VI \\
\hline Largura OFA da TW & $27 \mathrm{~m}$ & $40 \mathrm{~m}$ & $57 \mathrm{~m}$ & $79 \mathrm{~m}$ & $97 \mathrm{~m}$ & $118 \mathrm{~m}$ \\
\hline
\end{tabular}

FONTE: FAA AC 150/5300-13 (1989, p. 39)

$W_{O F A_{-} T W}=1,4 \times S+6$

Alternativamente, a OFA da TW pode ser provida com base em folgas de ponta de asa, como as mostradas na Tabela 4.8-3. Além disso, a FAA AC 150/530013 (1989, p. 16) coloca que folgas de ponta de asa diferentes podem ser estabelecidas para a OFA da TW, conforme a Equação 4.8-2, onde as distâncias são dadas em metros e $S$ representa a envergadura da aeronave crítica.

Tabela 4.8-3 - Padrão de folga OFA da TW

\begin{tabular}{c|cccccc}
\hline \multirow{2}{*}{ Item } & \multicolumn{5}{|c}{ Grupo geométrico } \\
& I & II & III & IV & V & VI \\
\hline Folga de ponta de asa da TW & $6 \mathrm{~m}$ & $8 \mathrm{~m}$ & $10,5 \mathrm{~m}$ & $13,5 \mathrm{~m}$ & $16 \mathrm{~m}$ & $19 \mathrm{~m}$ \\
\hline
\end{tabular}

FONTE: FAA AC 150/5300-13 (1989, p. 41)

$W_{\text {folga } \_W}=0,2 \times S+3$

No caso de curvas nas TWs, deve-se prover as folgas de ponta de asa da Tabela 4.8-3 ou da Equação 4.8-1, considerando a trajetória da ponta de asa. Para a análise da trajetória, ver item 4.5.

Em instalações existentes onde não seja possível o atendimento das folgas de ponta de asa, a FAA AC 150/5300-13 (1989, p. 34) permite, temporariamente, o deslocamento da linha guia para fora da curva (offsetting), através do uso de um raio mais amplo para o arco, conforme a Equação 4.8-3. Nesta equação R representa o raio atual e $\mathrm{d}$ o comprimento de referência da aeronave. Lembra-se que o aumento do raio do arco aumenta a folga no lado interno da curva, mas diminui a folga no lado externo. Por isso, deve-se verificar o atendimento das folgas de ponta de asa tanto no lado interno quanto externo da curva.

$R_{\text {novo }}=\sqrt{R^{2}+d^{2}}$ 
A OFA da TL, por sua vez é centrada nas TLs. A Tabela 4.8-4 apresenta os padrões de largura da OFA da TL e das folgas de ponta de asa. A Equação 4.8-4 e a Equação 4.8-5 podem ser usadas para o caso em que a aeronave crítica possui uma envergadura menor do que a máxima do grupo geométrico. Nestas equações S é a envergadura da aeronave crítica e a unidade é metros.

Tabela 4.8-4 - Largura padrão da OFA da TL (m)

\begin{tabular}{c|cccccc}
\hline \multirow{2}{*}{ Item } & \multicolumn{5}{|c}{ Grupo geométrico } \\
& I & II & III & IV & V & VI \\
\hline Largura OFA da TL & $24 \mathrm{~m}$ & $35 \mathrm{~m}$ & $49 \mathrm{~m}$ & $68 \mathrm{~m}$ & $84 \mathrm{~m}$ & $102 \mathrm{~m}$ \\
Folga de ponta de asa da TL & $4,5 \mathrm{~m}$ & $5,5 \mathrm{~m}$ & $6,5 \mathrm{~m}$ & $8 \mathrm{~m}$ & $9,5 \mathrm{~m}$ & $11 \mathrm{~m}$ \\
\hline
\end{tabular}

FONTE: FAA AC 150/5300-13 (1989, p.41)

$W_{\text {OFA_TL }}=1,2 \times S+6$

$W_{\text {folga_TL }}=0,1 \times S+3$

Caso existam duas TLs paralelas, a largura da OFA total será igual à:

$W_{O F A_{-} T L_{-} d u p l a}=2,3 \times S+9$

Nas curvas, deve-se prover as folgas da Tabela 4.8-4, tendo-se em vista a trajetória de ponta de asa, conforme a metodologia apresentada no item 4.5.

4.8.2.1 Relação entre a OFA da TW e da TL e outros componentes, metodologias e considerações de projeto

A OFA da TW e a OFA da TL são utilizadas como critério para separações em TWs e TLs, respectivamente, tanto para a distância entre estas áreas como para folga da aeronave em relação a objetos.

\subsubsection{ESPECIFICAÇÕES DA FAA PARA A ÁREA DE SEGURANÇA DA TW (TSA)}

Conforme a FAA AC 150/5300-13 (1989, p. 33) a TSA é centrada na TW e suas dimensões padrão são mostradas na Tabela 4.8-5.

Tabela 4.8-5 - Largura padrão da FAA para a TSA

\begin{tabular}{l|ccccccc}
\hline \multirow{3}{*}{ Largura da TSA } & \multicolumn{7}{|c}{ Grupo geométrico } \\
& I & II & III & IV & V & VI \\
\cline { 2 - 7 } & $15 \mathrm{~m}$ & $24 \mathrm{~m}$ & $36 \mathrm{~m}$ & $52 \mathrm{~m}$ & $65 \mathrm{~m}$ & $80 \mathrm{~m}$ \\
\hline
\end{tabular}

FONTE: FAA AC 150/5300-13 (1989, p. 33) 
A TSA deve ser:

- Livre de objetos e sem sulcos, elevações, depressões ou outras variações de superfície;

- Drenada, seja por abaulamento, seja por bocas de lobo, para prevenir acúmulo de água;

- Capaz de suportar, sob condições secas equipamentos de remoção de neve, resgate e combate a incêndio, bem como ser capaz de suportar a passagem eventual de aeronaves sem induzir-lhes danos;

- Livre de objetos, exceto aqueles que precisarem estar na TSA devido à sua função. Objetos com mais de 7,6cm devem estar montados sob bases frangíveis, com o ponto frangível a uma altura menor do que 7,6 cm; e

- A especificação P-152 da FAA AC 150/5370-10 apresenta informações sobre a compactação do solo de uma TSA.

Segundo a FAA AC 150/5300-13 (1989, p. 142), a TSA oferece espaço para resgate e combate a incêndio. Para tanto, sua largura deve ser, no mínimo, igual à envergadura da aeronave mais demandante.

\subsubsection{Relação entre a TSA e outros componentes, metodologias e considerações de projeto}

A TSA serve de padrão para a largura mínima da área com capacidade plena de suporte para TWs sobre pontes.

\subsection{OFZ}

De forma a proteger-se o espaço aéreo para as aeronaves que chegam e deixam um aeródromo, a ICAO e a FAA estabelecem uma série de superfícies delimitadoras de objetos, as quais formam uma geometria complexa, que se origina na vizinhança da pista de pouso e decolagem e se estende por quilômetros. A geometria definida por estes planos não pode ser infringida por objetos como árvores, antenas, linhas de transmissão, prédios ou quaisquer outros objetos oriundos de atividade humana ou natural. A delimitação de objetos através destas superfícies evita o aparecimento de obstáculos, que poderiam resultar em situações operacionais mais restritivas, como o estabelecimento de mínimos de visibilidade mais elevados. O Capítulo 4 da ICAO Annex 14 (2004a) apresenta os padrões e recomendações da ICAO para a proteção do espaço aéreo utilizado pelas 
aeronaves que chegam e deixam um aeródromo. A Parte 77 da EUA e-CFR Title 14 (2010), por sua vez, apresenta os padrões e recomendações da FAA para o assunto.

Conforme diminui a visibilidade mínima permitida, as RWs exigem uma proteção ainda mais restritiva, conhecida como obstacle free zone - OFZ, definida na vizinhança imediata de cada uma das RWs de um aeródromo. A OFZ é composta por um conjunto de superfícies, cuja altura aumenta com o distanciamento da RW e cuja proteção depende da exclusão de objetos fixos e móveis, com exceção de estruturas de baixa massa, montadas em bases frangíveis e indispensáveis à navegação aérea.

Como consequência da geometria e da posição da OFZ, esta é um critério chave para a posição de pistas de táxi, barras de parada da pista de pouso e decolagem, baías de espera e outras estruturas, em relação à RW.

O item 4.9.1 apresenta as especificações da ICAO e da FAA para a OFZ. Já o item 4.9.3 apresenta uma modelagem para uma superfície da OFZ em especial, que é a OFZ de transição interna, a qual é um critério chave para a posição de diversos componentes em relação à RW, como BPRWs, pistas de táxi e baías de espera.

\subsubsection{ESPECIFICAÇÕES DA ICAO E DA FAA PARA A OFZ}

O item 4.9.1.1 apresenta as especificações da ICAO e o item 4.9.1.2 apresenta as especificações da FAA.

\subsubsection{ESPECIFICAÇÕES DA ICAO PARA A OFZ}

Conforme os critérios da ICAO, a OFZ só é aplicável a pistas para aproximação de precisão, sendo construída pela união de até três superfícies: superfície de aproximação interna, superfície de transição interna e superfície de pouso interrompido. Juntas, as superfícies da OFZ protegem as aeronaves durante aproximações perdidas (missed approach), pousos interrompidos (balked landing) e pouso (landing). Estas superfícies são ilustradas na Figura 4.9-1. Os itens 4.9.1.1.1, 4.9.1.1.2 e 4.9.1.1.3, respectivamente, tratam cada uma dessas superfícies. 


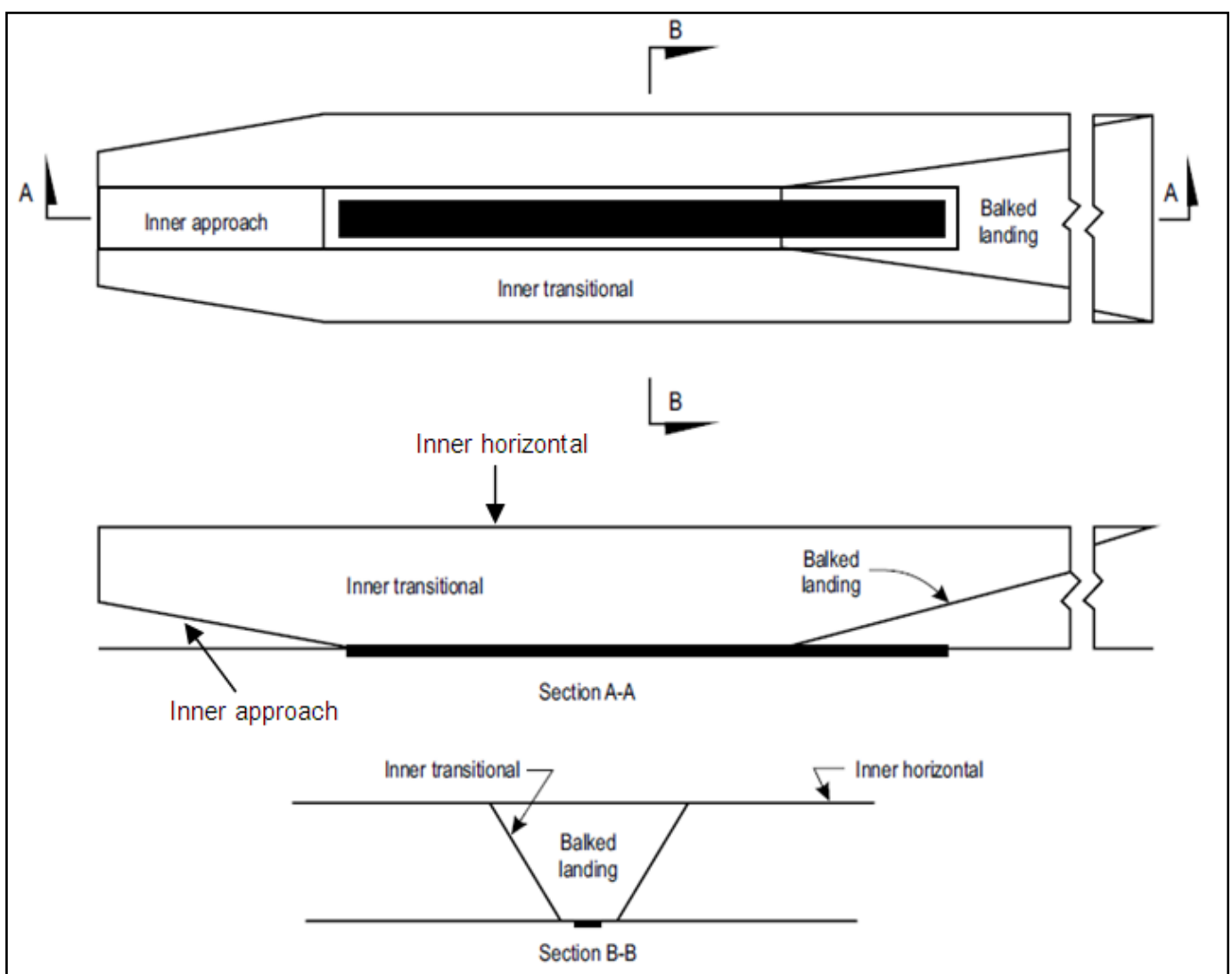

Figura 4.9-1 -Superfícies da OFZ conforme ICAO. FONTE: Adaptado a partir da ICAO Annex 14 (2004a, p. 4-3)

\subsection{SUPERFÍCIE DE APROXIMAÇÃO INTERNA}

A superfície de aproximação interna (inner approach surface) possui a forma de um retângulo inclinado. A ICAO Annex 14 (2004a, p. 4-3) descreve os limites de tal superfície:

- uma aresta interna coincidente com a aresta interna da superfície de aproximação ${ }^{32}$, porém com um comprimento próprio especificado;

- duas laterais que se originam nas extremidades da aresta interna e se estendem paralelamente ao plano vertical contendo a linha de centro da pista de pouso e decolagem; e

- uma aresta externa paralela à aresta interna.

Para dimensões ver Tabela 4.9-1.

\subsection{SUPERFÍCIE DE TRANSIÇÃO INTERNA}

Conforme a descrição da ICAO Annex 14 (2004a, p. 4-4), os limites da superfície de transição interna compreendem:

32 A posição desta aresta é especificada com base em uma distância da cabeceira, possuindo e mesma elevação do ponto central da cabeceira e sendo ortogonal ao eixo da RW. 
- uma aresta limítrofe inferior que inicia no final da superfície de aproximação interna e se estende para baixo da lateral da superfície de aproximação interna em direção à aresta inferior daquela superfície. A partir daí segue por todo o comprimento da faixa da pista de pouso e decolagem ${ }^{33}$, paralelamente à $\mathrm{RW}$, em direção à aresta inferior da superfície de pouso interrompida (balked landing surface) e então segue a lateral da superfície de pouso interrompida até o ponto onde a lateral intercepta a superfície horizontal interna ${ }^{34}$; e

- uma aresta delimitadora superior localizada no plano da superfície horizontal interna.

A elevação de um ponto na aresta limítrofe inferior deve ser:

a) ao longo da lateral da superfície de aproximação interna e da superfície de pouso interrompido - igual à elevação da superfície particular naquele ponto; e

b) ao longo da faixa da pista de pouso e decolagem - igual à elevação do ponto mais próximo no eixo da pista ou sua extensão.

Como consequência de b), a superfície de transição interna ao longo da faixa será curva caso o perfil da pista de pouso e decolagem seja curvo, ou uma linha reta caso o perfil da pista de pouso e decolagem seja uma linha reta. A intersecção da superfície de transição interna com a superfície horizontal interna também será curva ou reta dependo do perfil da pista de pouso e decolagem.

A declividade da superfície de transição interna deve ser medida em um plano vertical a ângulos retos com o eixo da pista de pouso de decolagem.

Para dimensões ver Tabela 4.9-1.

\subsection{SUPERFÍCIE DE POUSO INTERROMPIDO}

A superfície de pouso interrompido (balked landing surface) é um plano inclinado localizado a uma distância específica após a cabeceira, estendendo-se entre a superfície de transição interna. Seus limites são descritos na ICAO Annex 14 (2004a, p. 4-4):

- uma aresta interna horizontal e perpendicular ao eixo da pista de pouso e decolagem e localizada a uma distância específica após a cabeceira no sentido da operação de pouso;

\footnotetext{
${ }^{33}$ A largura da superfície de transição interna coincide com a largura da área restrita da faixa da RW.

${ }^{34}$ A superfície horizontal interna consiste de um plano horizontal situado a $45 \mathrm{~m}$ de altura, tomando-se como base a elevação de referência do aeródromo (datum elevation).
} 
- duas laterais originando-se nos extremos da aresta interna e divergindo uniformemente a uma razão específica a partir de um plano vertical contendo o eixo da pista; e

- uma aresta externa paralela à aresta interna e localizada no plano da superfície horizontal interna.

A elevação da aresta interna deve ser igual à elevação do eixo da RW no local da aresta interna.

A declividade da superfície de pouso interrompido deve ser medida no plano vertical contendo o eixo da pista de pouso e decolagem. Assim, a declividade, quando medida em um plano vertical ortogonal ao eixo da pista, será a mesma da superfície de transição interna.

Considerando-se que a declividade da superfície de pouso interrompido é maior do que a declividade da superfície de aproximação interna, a superfície de pouso interrompido oferecerá proteção somente caso inicie-se após a cabeceira da extremidade oposta. Para tanto, a cabeceira da extremidade oposta deve estar posicionada antes do final da pista e ainda, a menos do que $1.800 \mathrm{~m}$ da cabeceira de referência.

Para dimensões ver Tabela 4.9-1.

Tabela 4.9-1 - Padrões ICAO para as superfícies da OFZ

\begin{tabular}{|c|c|c|}
\hline \multirow{2}{*}{$\begin{array}{c}\text { Superfície e } \\
\text { Dimensões |a }\end{array}$} & \multicolumn{2}{|c|}{ Grupo dinâmico } \\
\hline & 1 e 2 & 3 e 4 \\
\hline $\begin{array}{l}\text { APROXIMAÇÃO } \\
\text { INTERNA }\end{array}$ & & \\
\hline Largura & $90 m$ & $120 \mathrm{~m} / d$ \\
\hline Distância da cabeceira & $60 m$ & $60 m$ \\
\hline Comprimento & $900 \mathrm{~m}$ & $900 \mathrm{~m}$ \\
\hline Declividade longitudinal & 1:40 (vertical:longitudinal) & 1:50 (vertical:longitudinal) \\
\hline \multicolumn{3}{|l|}{ TRANSIÇÃO INTERNA } \\
\hline Declividade transversal & $\begin{array}{c}1: 2,5 \\
\text { (vertical:transversal) }\end{array}$ & $\begin{array}{c}1: 3 \\
\text { (vertical:transversal) }\end{array}$ \\
\hline $\begin{array}{c}\text { POUSO } \\
\text { INTERROMPIDO }\end{array}$ & & \\
\hline $\begin{array}{l}\text { Comprimento da aresta } \\
\text { interna }\end{array}$ & $90 m$ & $120 \mathrm{~m} \mid \mathbf{d}$ \\
\hline Distância da cabeceira & |b & $1.800 \mathrm{~m} / \mathrm{c}$ \\
\hline $\begin{array}{l}\text { Divergência lateral } \\
\text { (cada lado) }\end{array}$ & $\begin{array}{c}1: 10 \\
\text { (transversal: longitudinal) }\end{array}$ & $\begin{array}{c}1: 10 \\
\text { (transversal: longitudinal) }\end{array}$ \\
\hline Declividade longitudinal & $\begin{array}{c}1: 25 \\
\text { (vertical:horizontal) }\end{array}$ & $\begin{array}{c}1: 30 \\
\text { (vertical:horizontal) }\end{array}$ \\
\hline
\end{tabular}


OBS.: Convenciona-se o sentido longitudinal como uma reta pertencente ao plano horizontal, paralela ao eixo da RW. Já o sentido transversal pertence ao plano horizontal e é ortogonal ao eixo da RW.

|a: todas as dimensões são medidas horizontalmente, a menos que outra especificação seja feita.

|b: distância até o final da faixa da pista de pouso e decolagem.

lc: ou o final da pista, vale o que for menor.

|d: onde o código é $F$, a largura é aumentada para $155 \mathrm{~m}$.

FONTE: ICAO Annex 14 (2004a, p.4-6)

\subsubsection{ESPECIFICAÇÕES DA FAA PARA A OFZ}

A FAA estabelece as seguintes superfícies delimitadoras, como parte da OFZ: ROFZ; OFZ de precisão; OFZ de aproximação interna; e OFZ de transição interna. Dependendo da visibilidade mínima permitida e de outros fatores operacionais, nem todas são necessárias. Os itens 4.9.1.2.1, 4.9.1.2.2, 4.9.1.2.3 e 4.9.1.2.4 descrevem cada uma das superfícies previstas, indicando também a situação na qual são necessárias. A Figura 4.9-2 ilustra uma OFZ destinada a aeronaves de grande porte, com visibilidade de aproximação menor do que 1.200 m em uma RW com cabeceira deslocada.

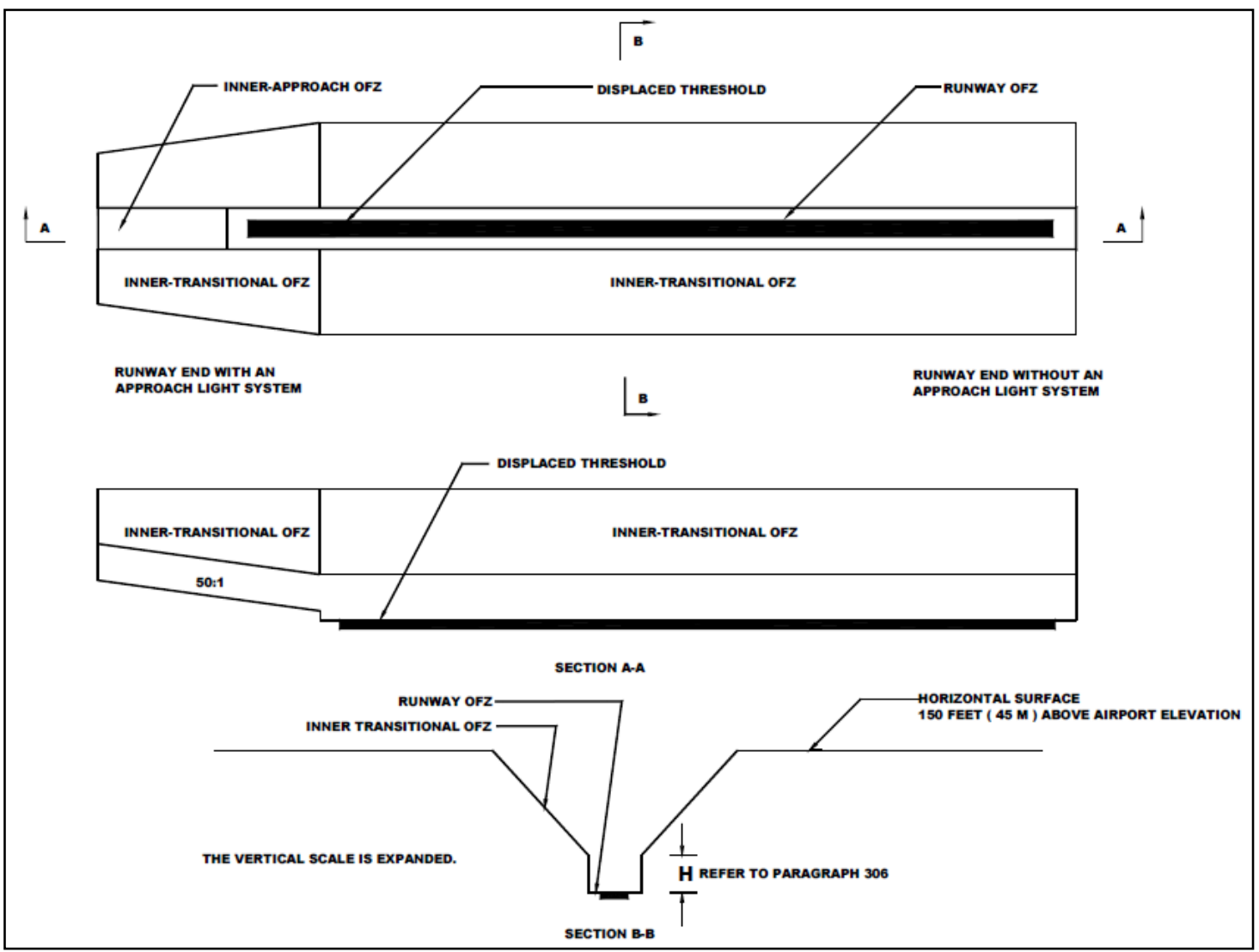

Figura 4.9-2 -Superfícies da OFZ conforme FAA, destinada a aeronaves de grande porte, com visibilidade de aproximação menor do que $1.200 \mathrm{~m}$ em uma RW com cabeceira deslocada. FONTE: FAA AC 150/5300-13 (1989, p. 31) 


\subsection{OFZ DA RW (RUNWAY OFZ - ROFZ)}

A FAA AC 150/5300-13 (1989, p. 22) estabelece a ROFZ como um volume de espaço aéreo centrado na pista de pouso e decolagem cuja elevação em qualquer ponto é a mesma elevação do ponto mais próximo na linha de centro da RW. A ROFZ se estende $60 m$ após cada final de pista.

Sua largura para RWs que servem somente aeronaves pequenas é de:

- $90 \mathrm{~m}$ para visibilidade mínima de aproximação menor do que $1.200 \mathrm{~m}$;

- 75m para visibilidade mínima de aproximação maior do que $1.200 \mathrm{~m}$, servindo aeronaves com velocidade de aproximação maior do que $93 \mathrm{~km} / \mathrm{h}$ (50nós);

- $36 m$ para visibilidade mínima de aproximação maior do que $1.200 m$, servindo aeronaves com velocidade de aproximação menor do que $93 \mathrm{~km} / \mathrm{h}$ (50nós);

Para RWs servindo aeronaves de grande porte a largura deve ser de $120 \mathrm{~m}$.

\subsection{OFZ DE APROXIMAÇÃO INTERNA (INNER-APPROACH OFZ)}

A FAA AC 150/5300-13 (1989, p. 22) estabelece a OFZ de aproximação interna como um volume de espaço aéreo centrado na área de aproximação, aplicável somente a RWs com sistema de iluminação.

A OFZ de aproximação interna começa a $60 \mathrm{~m}$ da cabeceira, na mesma elevação desta e se estende $60 \mathrm{~m}$ após a última luz do sistema de iluminação de pouso. Possui a mesma largura da ROFZ e sobe em um plano inclinado de 1(vertical): 50(longitudinal) por toda sua extensão.

\subsection{OFZ DE TRANSIÇÃO INTERNA (INNER-TRANSITIONAL OFZ)}

A FAA AC 150/5300-13 (1989, p. 22) estabelece a OFZ de transição interna como um volume de espaço aéreo ao longo das bordas da ROFZ e da OFZ de aproximação interna. Aplica-se somente a pistas com visibilidade mínima de aproximação menor do que $1.200 \mathrm{~m}$. Sua geometria depende do tipo de aeronave, como segue:

- Aeronaves de pequeno porte: sobe em um plano inclinado de 1(vertical): 3(transversal), na direção ortogonal ao centro da RW, a partir das bordas da ROFZ e da OFZ de aproximação interna até uma altura de $45 m$ sobre a elevação oficial do aeroporto. 
- Aeronaves de grande porte: neste caso a geometria depende do procedimento de aproximação, como segue:

- CAT I: inicia nas bordas da ROFZ e da OFZ de aproximação interna, então sobe verticalmente até uma altura $H_{1}$ definida pela Equação 4.9-1 (onde $S$ corresponde à envergadura mais demandante e $E$ representa a altitude da cabeceira. Nesta equação todas as variáveis estão em metros). A partir daí sobe em um plano inclinado 1(vertical): 6(transversal) até uma altura de $45 \mathrm{~m}$ sobre a elevação de referência do aeroporto.

$H_{1}=18,4-0,094 \times S-0,003 \times E$

- CAT II e III: inicia nas bordas da ROFZ e da OFZ de aproximação interna, então sobe verticalmente até uma altura $\mathrm{H}_{2}$ definida pela Equação 4.9-2 (onde $S$ corresponde à envergadura mais demandante e $E$ representa a altitude da cabeceira. Nesta equação todas as variáveis estão em metros). A partir daí sobe em um plano inclinado 1(vertical): 5(transversal) até uma distância $Y$ do centro da RW, definida pela Equação 4.9-3 (onde todas as variáveis estão em metros). A partir daí a $O F Z$ de transição interna é igual àquela da CAT I, subindo em um plano com inclinação 1(vertical): 6(transversal) até a altura de $45 \mathrm{~m}$ sobre a elevação de referência do aeroporto. Isso é ilustrado na Figura 4.9-3.

$$
\begin{aligned}
& H_{2}=16-0,13 \times S-0,0022 \times E \\
& Y=132+1,08 \times S-0,024 \times E
\end{aligned}
$$

Verificou-se que as equações para $Y$ e $\mathrm{H}$ são tais a produzir uma $O F Z$ de transição interna idêntica após a distância $Y$, para as categorias de aproximação CAT I e CAT II/III, em RWs servindo aeronaves de grande porte. A partir da Figura 4.9-3, verifica-se que as duas OFZs de transição interna irão coincidir após a distância $Y$ caso possuam a mesma altura neste ponto, o que implica:

$$
H_{1}+\frac{Y-w_{f}}{6}=H_{2}+\frac{Y-w_{f}}{5}
$$


Substituindo-se os valores de $\mathrm{H}_{1}, \mathrm{H}_{2}$ e Y pela Equação 4.9-1, pela Equação 4.9-2 e pela Equação 4.9-3, respectivamente, as variáveis envergadura e altitude se anulam, resultando $w_{f}=60$. Esta é justamente a semi-largura padrão da ROFZ para aeronaves de grande porte.

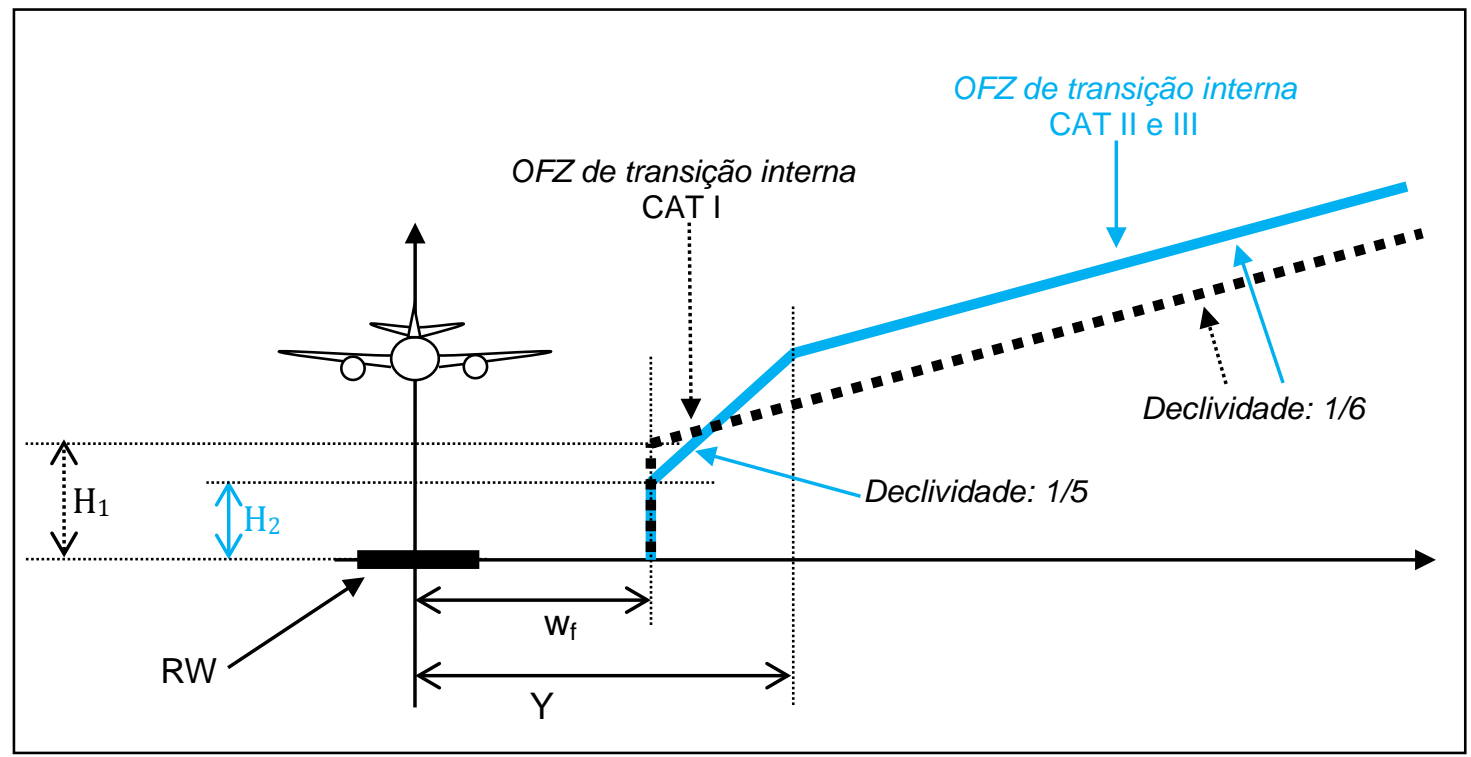

Figura 4.9-3 -Geometria da OFZ de transição interna da FAA. FONTE: Adaptado a partir de descrições da FAA AC 150/5300-13 (1989, p. 22)

\subsection{OFZ DE PRECISÃO (PRECISION OFZ - POFZ)}

A FAA AC 150/5300-13 (1989, p. 23) estabelece a POFZ como um volume de espaço aéreo sobre uma área que inicia na cabeceira da RW, na elevação da cabeceira, se estende por uma distância de $60 \mathrm{~m}$, antes da cabeceira, e possui $240 \mathrm{~m}$ de largura. A POFZ é centrada na RW e deve ser observada nas seguintes condições operacionais:

- Aproximação verticalmente guiada;

- Teto informado abaixo de 250pés e/ou visibilidade menor do que 3/4 de milha terrestre (ou RVR abaixo de 4.000pés).

- Uma aeronave em aproximação final mais perto do que 2 milhas da cabeceira.

Nestas condições, a asa de uma aeronave que espera na pista de táxi para entrar na RW pode penetrar na POFZ, porém nem a fuselagem nem o estabilizador podem infringi-la.

A POFZ é aplicável a todos os finais de pista, incluindo-se cabeceiras deslocadas. 


\subsubsection{RELAÇÃO ENTRE A OFZ E OUTROS COMPONENTES, METODOLOGIAS E CONSIDERAÇÕES DE PROJETO}

A OFZ é um critério chave para posição de RWs, BPRWs e pistas de táxi, em relação a uma $\mathrm{RW}$.

Para a ICAO, a especificação da OFZ está relacionada à área restrita da faixa da RW.

Ainda, a OFZ da ICAO e da FAA guardam relação com as distâncias declaradas.

\subsubsection{METODOLOGIA PARA ANÁLISE DA OFZ DE TRANSIÇÃO INTERNA}

Tanto para a ICAO quanto para a FAA, a OFZ de transição interna é formada por linhas retas, o que permite uma abordagem matemática comum às duas. $A$ modelagem consiste em relacionar um ponto de interesse da aeronave com a superfície da $O F Z$ de transição interna e com a posição da aeronave em relação à RW, admitindo-se a RW como origem do sistema cartesiano.

Na modelagem proposta, avalia-se a violação da OFZ de transição interna em duas situações: a aeronave espera para entrar na RW; e a aeronave deixa a RW, logo após o pouso. Para o primeiro caso, propõe-se que três pontos da aeronave sejam considerados: nariz; estabilizador; e ponta da asa. Para o segundo caso, não é necessário analisar-se a violação da OFZ de transição interna pelo nariz, pois o estabilizador e a asa serão mais críticos. A Figura 4.9-4 ilustra estas duas condições, os pontos de interesse para avaliação e as variáveis associadas a estes pontos e à posição da aeronave.

Conhecendo-se as coordenadas dos pontos de interesse, a OFZ de transição interna pode ser avaliada de duas formas: calculando-se a folga $(\Delta)$ estabelecida entre o ponto e a OFZ de transição interna, com base na coordenada desse ponto sobre o eixo y; e calculando-se a coordenada y associada a uma dada folga. Convenciona-se que tal folga deverá ser positiva para que a OFZ seja atendida. Caso a elevação do terreno sobre o qual a aeronave se situa for maior do que a elevação da cabeceira ${ }^{35}$, a folga deverá ser maior do que essa diferença de elevação. A Figura 4.9-5 ilustra a geometria e as variáveis que relacionam a coordenada y dos pontos com a folga.

\footnotetext{
${ }^{35}$ A OFZ é construída com base na altitude da cabeceira.
} 


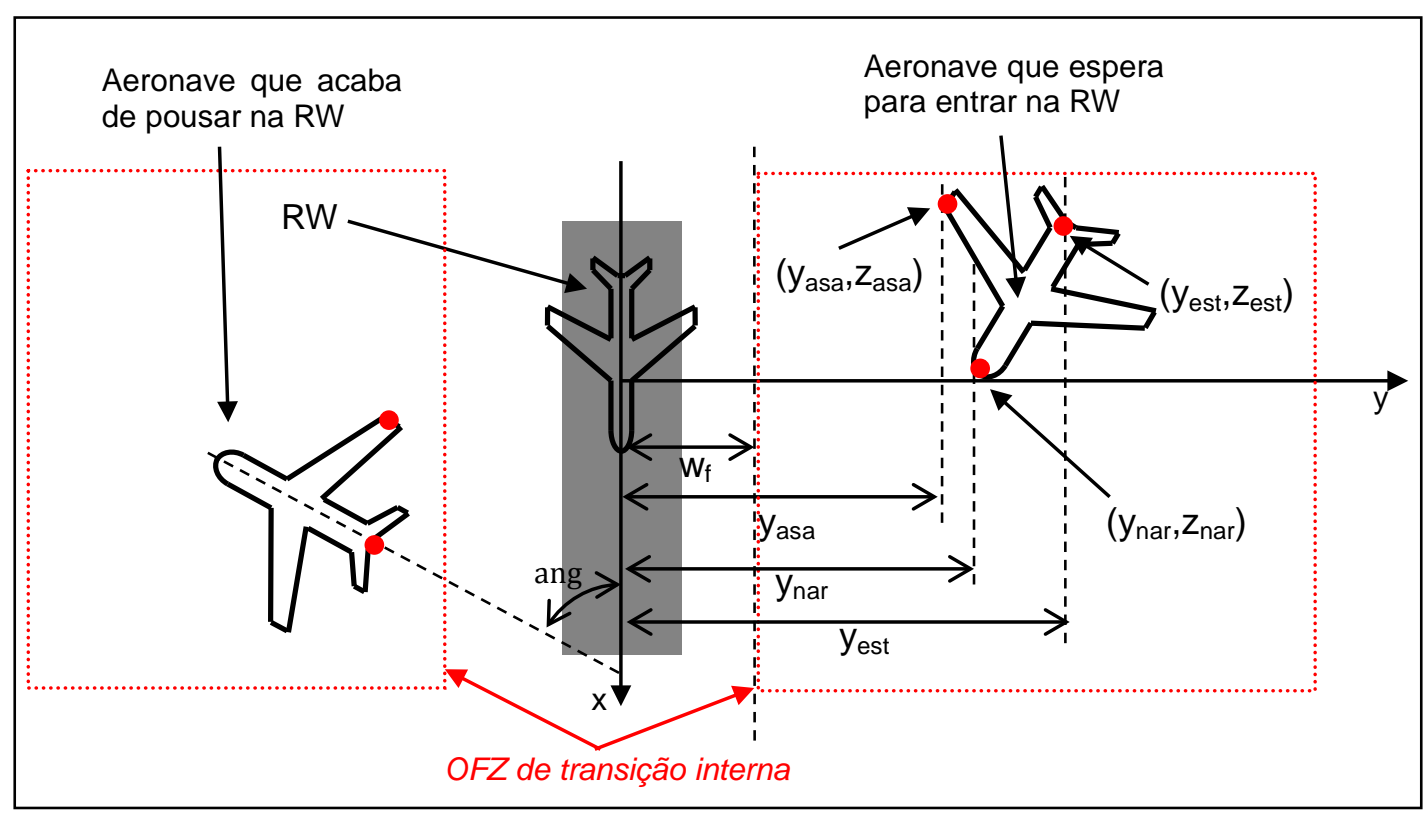

Figura 4.9-4 - Vista superior da geometria utilizada para modelagem da OFZ de transição interna. FONTE: Proposto pelo autor

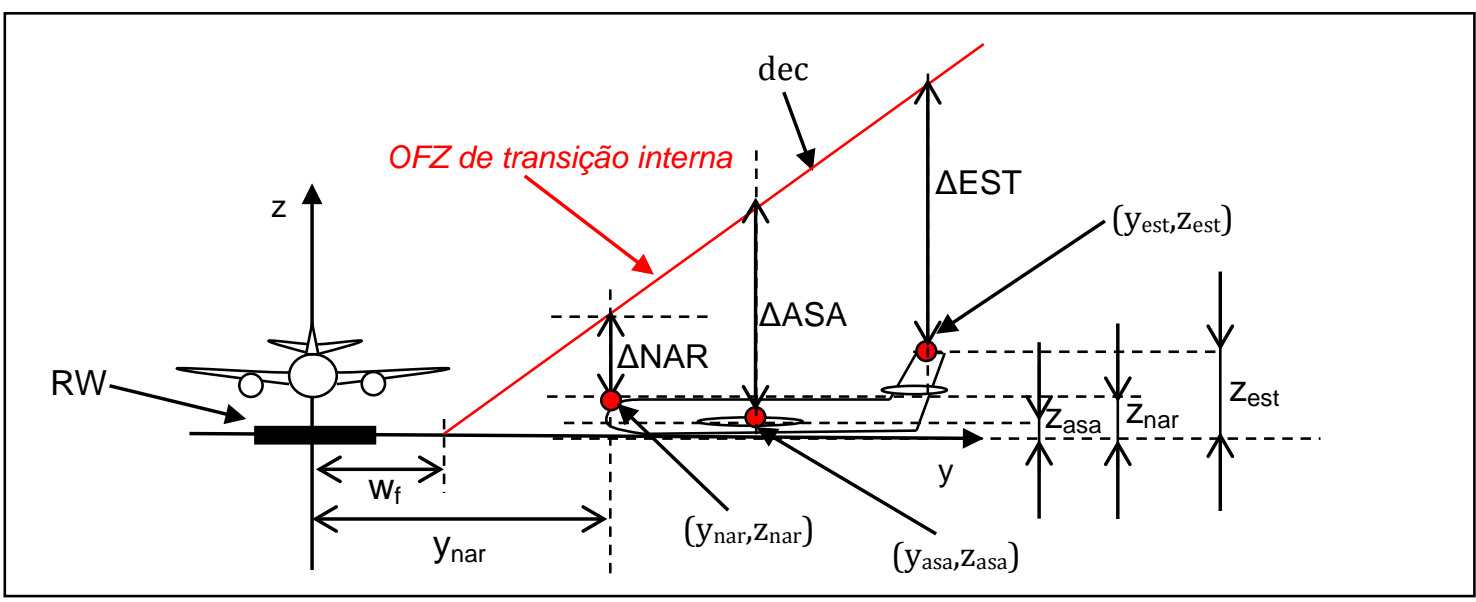

Figura 4.9-5 -OFZ de transição interna para uma aeronave que espera para entrar na RW. FONTE: Adaptado a partir de descrições da ICAO Annex 14 (2004a, p. 4-4) e da FAA AC 150/5300-13 (1989, p. 22)

Com base na Figura 4.9-5, é possível escrever-se:

$\Delta=\operatorname{dec} \times\left(P_{y}-w_{f}\right)-P_{z}$

Onde: $\Delta$ representa a folga entre a OFZ de transição interna e um dado ponto de interesse da aeronave; dec representa a declividade da OFZ de transição interna; $\mathrm{w}_{\mathrm{f}}$ representa a semi-largura da área próxima à $\mathrm{RW}^{36}$, a partir da qual inicia-se a OFZ de transição interna; e $\mathrm{y}_{\text {nar, }} \mathrm{y}_{\text {est }} \mathrm{e} \mathrm{y}_{\text {asa }} \mathrm{e} \mathrm{z}_{\text {nar, }} \mathrm{z}_{\text {est }} \mathrm{e} \mathrm{z}_{\text {asa }}$ denotam a posição dos pontos de interesse da aeronave sobre os eixos y e $z$, respectivamente.

${ }^{36}$ Para a ICAO esta área é a área restrita da faixa da RW e para a FAA é a ROFZ. 
Assim, o nariz será representado pelo ponto NAR $\left(y_{\text {nar }}, z_{\text {nar }}\right)$, sendo as duas coordenadas, dados de entrada.

O estabilizador será representado pelo ponto EST $\left(y_{\text {est }}, z_{\text {est }}\right)$, sendo $z_{\text {est }}$ um dado de entrada. Quando a aeronave analisada espera para entrar na RW, $y_{e s t}$ pode ser calculado por:

$y_{\text {est }}=y_{\text {nar }}+l_{\text {est }} \times \operatorname{sen}($ ang $)$

Onde lest é a distância entre o nariz da aeronave e o estabilizador, medida sobre o eixo longitudinal da aeronave.

E quando a aeronave analisada sai da RW, $y_{e s t}$ pode ser calculado por:

$y_{\text {est }}=y_{\text {nar }}-l_{\text {est }} \times \operatorname{sen}($ ang $)$

A ponta da asa será representada pelo ponto ASA $\left(y_{a s a}, z_{a s a}\right)$, sendo $z_{a s a}$ um dado de entrada. Quando a aeronave analisada espera para entrar na RW, $y_{\text {asa }}$ pode ser calculado por:

$y_{a s a}=y_{n a r}+l_{\text {asa }} \times \operatorname{sen}(a n g)-\frac{e n v}{2} \times \cos (a n g)$

Onde $\mathrm{l}_{\text {asa }}$ é a distância entre o nariz da aeronave e o a ponta da asa, medida sobre o eixo longitudinal da aeronave e onde env é a envergadura da aeronave.

E quando a aeronave analisada sai da RW, $y_{a s a}$ pode ser calculado por:

$y_{a s a}=y_{n a r}-l_{\text {asa }} \times \operatorname{sen}($ ang $)+\frac{e n v}{2} \times \cos ($ ang $)$

Conhecida a relação entre $y_{\text {nar, }}$, yest e yasa, pode-se obter diretamente o valor de $\Delta$ para cada um dos três pontos, a partir da Equação 4.9-5. Para o caso em que a aeronave espera para entrar na RW, o nariz é o ponto de referência padrão nas equações. Para o caso em que a aeronave sai da RW, utiliza-se diretamente a posição do estabilizador em relação à RW para avaliar a folga do estabilizador, e utiliza-se diretamente a posição da asa em relação à RW para avaliar a folga da asa.

As seguintes relações são aplicáveis ao caso em que a aeronave espera para entrar na RW, e fornecem, respectivamente, a folga no nariz, estabilizador ou ponta de asa, relacionada a um dado ynar:

$$
\begin{aligned}
& \triangle N A R=\operatorname{dec} \times\left(y_{\text {nar }}-w_{f}\right)-z_{\text {nar }} \\
& \triangle E S T=\operatorname{dec} \times\left(\left(y_{\text {nar }}+l_{\text {est }} \times \operatorname{sen}(\text { ang })\right)-w_{f}\right)-z_{\text {est }}
\end{aligned}
$$


$\Delta A S A=\operatorname{dec} \times\left(\left(y_{\text {nar }}+l_{\text {asa }} \times \operatorname{sen}(\right.\right.$ ang $\left.\left.)-\frac{e n v}{2} \times \cos (a n g)\right)-w_{f}\right)-z_{\text {asa }}$

Já o valor de $\Delta$ para o estabilizador e a ponta da asa, para a situação em que a aeronave deixa a RW, podem ser calculados por:

$\Delta E S T=\operatorname{dec} \times\left(y_{e s t}-w_{f}\right)-z_{e s t}$

$\Delta A S A=\operatorname{dec} \times\left(y_{a s a}-w_{f}\right)-z_{a s a}$

Alternativamente, poder-se-ia calcular a posição do nariz (ynar) que corresponda a um dado valor de $\Delta$. Isso é especialmente útil para a situação $\Delta=0$, de forma a obter-se o limite para um objeto para que não interfira na $O F Z$ de transição interna, tendo-se por base a folga do nariz, da ponta da asa ou do estabilizador, para uma aeronave que entra ou que sai da RW.

Para o caso das aeronaves que esperam para entrar na RW, as seguintes equações podem ser obtidas, respectivamente, a partir da Equação 4.9-10, da Equação 4.9-11 e da Equação 4.9-12, isolando-se ynar:

$$
\begin{aligned}
& y_{\text {nar }}=\frac{\left(z_{\text {nar }}+\Delta \mathrm{NAR}\right)}{d e c}+w_{f} \\
& y_{\text {nar }}=\frac{\Delta E S T+z_{\text {est }}}{\text { dec }}+w_{f}-l_{\text {est }} \times \operatorname{sen}(\text { ang }) \\
& y_{\text {nar }}=\frac{\Delta A S A+z_{\text {asa }}}{\text { dec }}+w_{f}-l_{\text {asa }} \times \operatorname{sen}(\text { ang })+\frac{e n v}{2} \times \cos (\text { ang })
\end{aligned}
$$

Já para o caso das aeronaves que deixam a RW, as seguintes equações podem ser obtidas, respectivamente, a partir da Equação 4.9-13 e da Equação 4.9-14:

$$
\begin{aligned}
& y_{\text {est }}=\frac{\Delta E S T+z_{\text {est }}}{\operatorname{dec}}+w_{f} \\
& y_{\text {asa }}=\frac{\Delta A S A+z_{a s a}}{\operatorname{dec}}+w_{f}
\end{aligned}
$$

A seguir apresenta-se separadamente o desenvolvimento da modelagem da OFZ de transição interna, de acordo com os padrões da ICAO e da FAA. 


\subsubsection{ICAO}

As equações anteriormente apresentadas são aplicáveis, sendo a variável dec dada conforme a Tabela 4.9-1. Já a dimensão $\mathrm{w}_{\mathrm{f}}$ corresponde à distância entre 0 eixo da RW e a borda da área restrita da faixa da RW, apresentada no item 4.7.1.3.

\subsubsection{FAA}

Para o caso da FAA, existem três geometrias diferentes para a $O F Z$ de transição interna: a) aeronaves de pequeno porte; b) aeronaves de grande porte, CAT I; e c) aeronaves de grande porte, CAT II e III. Lembra-se que as especificações da FAA para $\mathrm{w}_{\mathrm{f}}$ são mostradas no item 4.9.1.2.1 e que as especificações referentes à variável dec são mostradas no item 4.9.1.2.3.

Para o caso a, todas as equações comuns à ICAO são aplicáveis, embora wf e dec sejam diferentes. Para o caso $b$, cabe uma adaptação, pois na borda da ROFZ, a OFZ de transição interna sobe verticalmente até a altura $\mathrm{H}_{1}$, dada na Equação 4.9-1. Esta geometria é ilustrada na Figura 4.9-6.

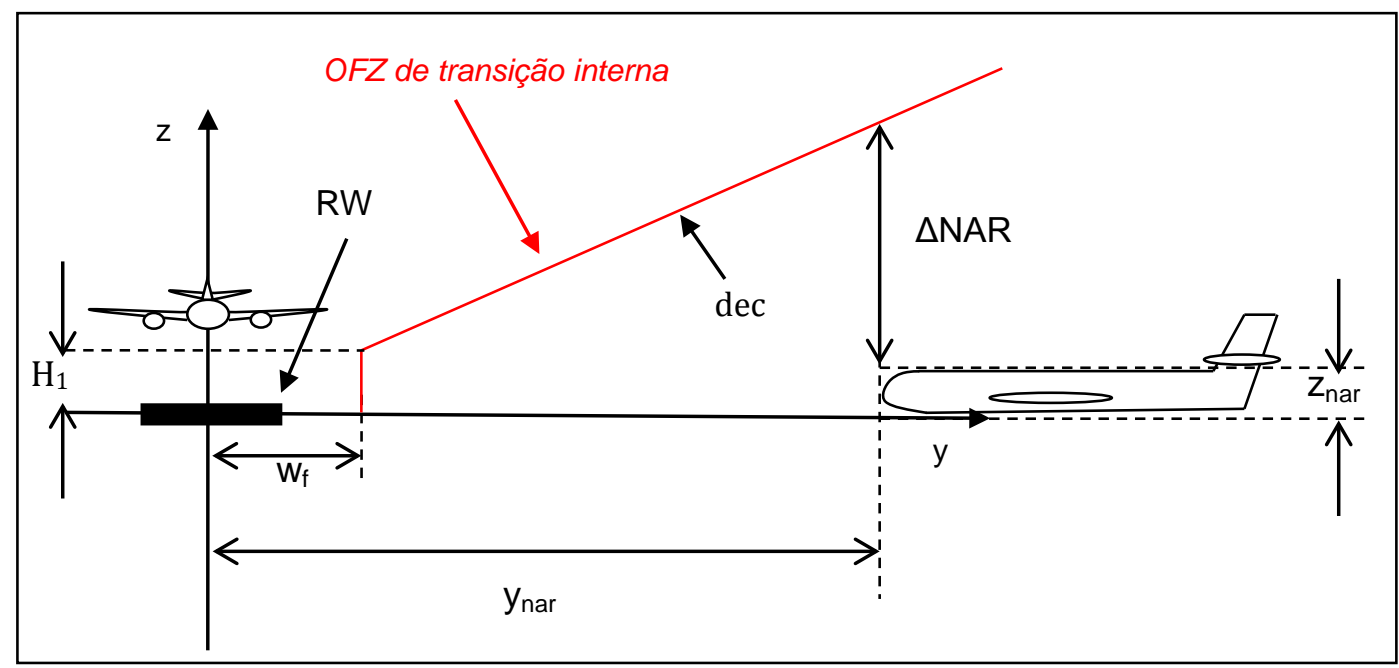

Figura 4.9-6 - Geometria da OFZ de transição interna, conforme FAA para condições CAT I. FONTE: Adaptado a partir de descrições da FAA AC 150/5300-13 (1989, p. 22)

As equações a seguir servem para o caso em que a aeronave espera para entrar na RW e foram adaptadas a partir da Equação 4.9-10, da Equação 4.9-11 e da Equação 4.9-12:

$$
\begin{aligned}
& \triangle N A R=\operatorname{dec} \times\left(y_{\text {nar }}-w_{f}\right)-z_{\text {nar }}+H_{1} \\
& \triangle E S T=\operatorname{dec} \times\left(\left(y_{\text {nar }}+l_{\text {est }} \times \operatorname{sen}(\text { ang })\right)-w_{f}\right)-z_{e s t}+H_{1}
\end{aligned}
$$


$\Delta A S A=\operatorname{dec} \times\left(\left(y_{n a r}+l_{\text {asa }} \times \operatorname{sen}(a n g)-\frac{e n v}{2} \times \cos (a n g)\right)-w_{f}\right)-z_{a s a}+H_{1}$

Quando isola-se ynar nestas equações obtém-se:

$$
\begin{aligned}
& y_{n a r}=\frac{\Delta \mathrm{NAR}+z_{n a r}-H_{1}}{d e c}+w_{f} \\
& y_{n a r}=\frac{\Delta E S T+z_{e s t}-H_{1}}{d e c}+w_{f}-l_{e s t} \times \operatorname{sen}(\text { ang }) \\
& y_{n a r}=\frac{\Delta A S A+z_{a s a}-H_{1}}{d e c}+w_{f}-l_{a s a} \times \operatorname{sen}(\text { ang })+\frac{e n v}{2} \times \cos (\text { ang })
\end{aligned}
$$

Cabe observar que nenhuma parte da aeronave deve ocupar a largura da ROFZ, o que faz com que os valores de ynar não devam ser menores do que $\mathrm{w}_{\mathrm{f}}$. Assim, caso o valor de $\mathrm{y}_{\mathrm{nar}}$ seja menor do que $\mathrm{w}_{\mathrm{f}}$, ynar deve assumir o valor de $\mathrm{w}_{\mathrm{f}}$.

Enquanto isso, as equações a seguir servem para o caso em que a aeronave sai da RW e foram adaptadas a partir da Equação 4.9-13 e da Equação 4.9-14:

$$
\begin{aligned}
& \Delta E S T=\operatorname{dec} \times\left(y_{e s t}-w_{f}\right)-z_{e s t}+H_{1} \\
& \Delta A S A=\operatorname{dec} \times\left(y_{a s a}-w_{f}\right)-z_{a s a}+H_{1}
\end{aligned}
$$

Quando isola-se y nestas equações obtém-se:

$$
\begin{aligned}
& y_{e s t}=\frac{\Delta E S T+z_{e s t}-H_{1}}{d e c}+w_{f} \\
& y_{n a r}=\frac{\Delta A S A+z_{a s a}-H_{1}}{\operatorname{dec}}+w_{f}
\end{aligned}
$$

Como nenhuma parte da aeronave deve ocupar a ROFZ, yest e yasa não podem ser menores do que wf, o que exige um teste lógico para a utilização destas equações. Já o caso c possui uma geometria mais complexa, ilustrada na Figura 4.9-7.

Para este caso, a OFZ de transição interna consiste em: uma reta vertical de altura $\mathrm{H}_{2}$, definida pela Equação 4.9-2, desde a ROFZ; uma reta com declividade dec1 (1(vertical):5(horizontal)) até uma distância Y, desde o centro da RW, definida 
pela Equação 4.9-3; e uma reta com declividade dec2 (1(vertical):6(horizontal)) até uma elevação de $45 \mathrm{~m}$ sobre a cabeceira.

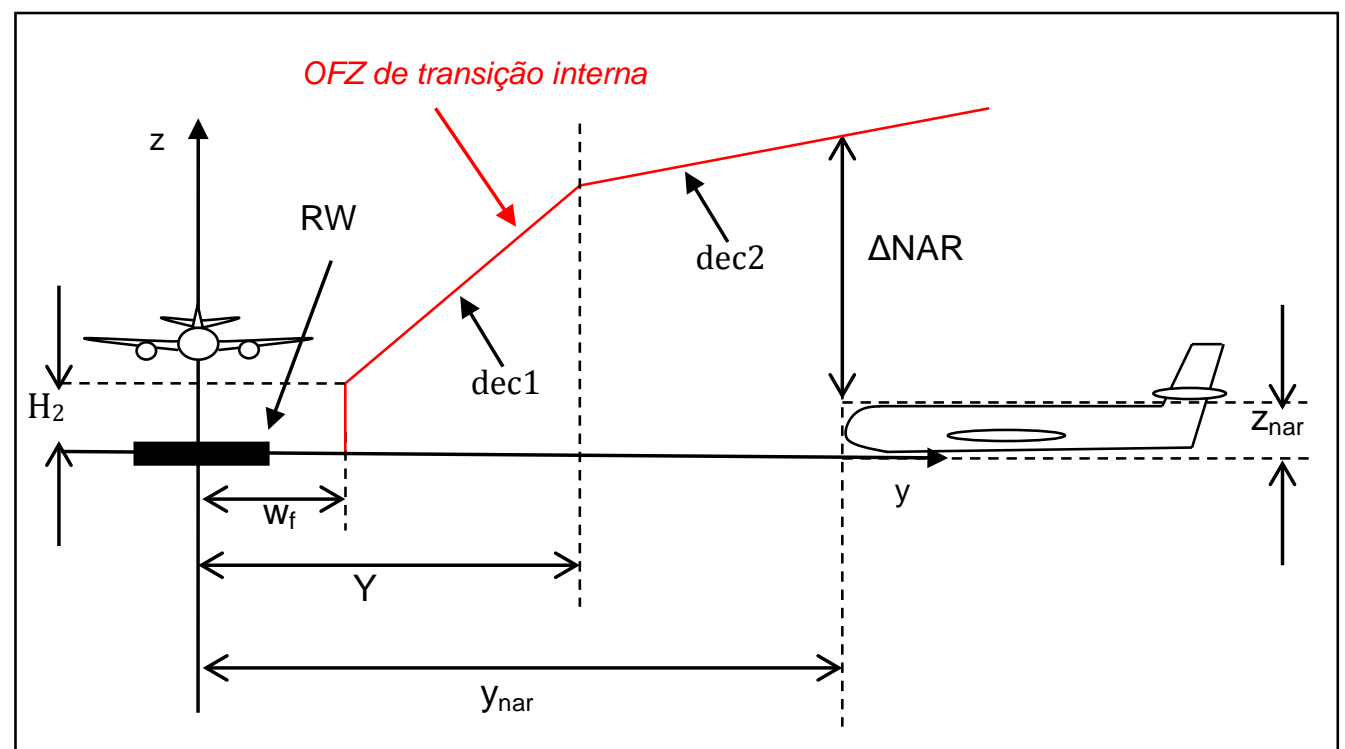

Figura 4.9-7 - Geometria da OFZ de transição interna, conforme FAA para condições CAT II e III. FONTE: Adaptado a partir de descrições da FAA AC 150/5300-13 (1989, p. 22)

Para tanto, dois conjuntos de equações são necessários, dependendo se o ponto de interesse da aeronave ( $\mathrm{y}_{\text {nar }}$ ou y yst ou yasa) está posicionado a uma distância menor (caso c.I) ou maior (caso c.ii) do que Y, desde o centro da RW.

Para o caso c.i, pode-se utilizar o intervalo de equações que vai desde a Equação 4.9-20 até a Equação 4.9-29, desde que as especificações apropriadas sejam utilizadas para dec, $\mathrm{w}_{\mathrm{f}}$ e $\mathrm{H}_{2}$.

Para o caso c.ii, é preciso transformar-se estas equações, como segue, para o caso em que a aeronave espera para entrar na RW:

$$
\begin{aligned}
& \triangle N A R=\operatorname{dec} 1 \times\left(Y-w_{f}\right)+\operatorname{dec} 2 \times\left(y_{\text {nar }}-Y\right)+H_{2}-z_{\text {nar }} \\
& \triangle E S T=\operatorname{dec} 1 \times\left(Y-w_{f}\right)+\operatorname{dec} 2 \times\left(y_{\text {nar }}+l_{\text {est }} \times \operatorname{sen}(\text { ang })-Y\right)+H_{2}-z_{\text {est }} \\
& \triangle A S A=\operatorname{dec} 1 \times\left(Y-w_{f}\right)+\operatorname{dec} 2 \times\left(y_{\text {nar }}+l_{\text {asa }} \times \operatorname{sen}(\text { ang })-\frac{e n v}{2} \times \cos (\text { ang })-Y\right)+H_{2}-z_{\text {asa }}(4 .
\end{aligned}
$$

Também para o caso c.ii, considerando-se agora a situação em que a aeronave espera para sair da RW, as seguintes equações são aplicáveis:

$$
\begin{aligned}
& \Delta E S T=\operatorname{dec} 1 \times\left(Y-w_{f}\right)+\operatorname{dec} 2 \times\left(y_{\text {est }}-Y\right)-z_{e s t}+H_{2} \\
& \Delta A S A=\operatorname{dec} 1 \times\left(Y-w_{f}\right)+\operatorname{dec} 2 \times\left(y_{\text {asa }}-Y\right)-z_{\text {asa }}+H_{2}
\end{aligned}
$$


Isolando-se a variável ynar e considerando-se o caso em que a aeronave espera para entrar na RW, tem-se:

$$
\begin{aligned}
& y_{n a r}=\frac{\Delta N A R+z_{n a r}-H_{2}-\operatorname{dec} 1 \times\left(Y-w_{f}\right)}{\operatorname{dec} 2}+\mathrm{Y} \\
& y_{n a r}=\frac{\Delta E S T+z_{e s t}-H_{2}-\operatorname{dec} 1 \times\left(Y-w_{f}\right)}{\operatorname{dec} 2}-l_{\text {est }} \times \operatorname{sen}(\text { ang })+Y \\
& y_{n a r}=\frac{\Delta A S A+z_{a s a}-H_{2}-\operatorname{dec} 1 \times\left(Y-w_{f}\right)}{\operatorname{dec} 2}-l_{\text {asa }} \times \operatorname{sen}(\text { ang })+\frac{e n v}{2} \times \cos (\text { ang })+Y
\end{aligned}
$$

E isolando-se a variável ynar para o caso em que a aeronave espera para sair da RW, tem-se:

$$
\begin{aligned}
& y_{e s t}=\frac{\Delta E S T+z_{e s t}-H_{2}-\operatorname{dec} 1 \times\left(Y-w_{f}\right)}{\operatorname{dec} 2}+Y \\
& y_{a s a}=\frac{\Delta A S A+z_{a s a}-H_{2}-\operatorname{dec} 1 \times\left(Y-w_{f}\right)}{\operatorname{dec} 2}+Y
\end{aligned}
$$

As equações apresentadas para a modelagem da OFZ de transição interna são resumidas na Tabela 4.9-2, onde cada linha, apresenta um critério de avaliação, codificado por uma letra. As colunas, por sua vez, apresentam as equações

\begin{tabular}{|c|c|c|c|c|c|c|}
\hline \multirow{2}{*}{ Critério (CR) } & \multicolumn{3}{|c|}{$\begin{array}{c}\text { Aeronave que espera para } \\
\text { entrar }\end{array}$} & \multicolumn{3}{|c|}{$\begin{array}{l}\text { Aeronave que acaba de } \\
\text { pousar }\end{array}$} \\
\hline & $\begin{array}{l}\text { ICAO e } \\
\text { FAA |a }\end{array}$ & $\begin{array}{l}\text { FAA, } \\
\text { CAT I }\end{array}$ & $\begin{array}{c}\text { FAA, } \\
\text { CAT II e } \\
\text { III }\end{array}$ & $\begin{array}{l}\text { ICAO e } \\
\text { FAA |a }\end{array}$ & $\begin{array}{l}\text { FAA, } \\
\text { CAT I }\end{array}$ & $\begin{array}{c}\text { FAA, } \\
\text { CAT II e } \\
\text { III }\end{array}$ \\
\hline $\begin{array}{l}\text { CR A) Posição do estabilizador } \\
\text { sobre o eixo y, que corresponde } \\
\text { a uma dada posição do nariz } \\
\text { sobre o eixo y }\end{array}$ & \multicolumn{3}{|c|}{ Equação 4.9-6 } & \multicolumn{3}{|c|}{ Equação 4.9-7 } \\
\hline $\begin{array}{l}\text { CR B) Posição da ponta da asa } \\
\text { sobre o eixo y, que corresponde } \\
\text { a uma dada posição do nariz } \\
\text { sobre o eixo y }\end{array}$ & \multicolumn{3}{|c|}{ Equação 4.9-8 } & \multicolumn{3}{|c|}{ Equação 4.9-9 } \\
\hline
\end{tabular}
equivalentes para a avaliação de um dado critério para os padrões da ICAO e da FAA, tendo-se em vista o caso em que a aeronave espera para entrar na RW e o caso no qual a aeronave deixa a RW.

Tabela 4.9-2 - Resumo das equações utilizadas para modelagem da OFZ de transição interna 


\begin{tabular}{l|c|c|c|c|c|c}
\hline \multirow{2}{*}{ Critério (CR) } & \multicolumn{3}{|c|}{ Aeronave que espera para } \\
entrar
\end{tabular}

|a: aeronaves de pequeno porte.

|b: caso o ponto no qual se avalia a OFZ de transição interna estiver a uma distância menor do que Y do eixo da RW, deve-se utilizar as equações da coluna FAA, CAT I,porém com as especificações referentes às condições CAT II/III.

|c: a posição de qualquer parte da aeronave não deve resultar menor do que a semi-largura da ROFZ $\left(\mathrm{w}_{\mathrm{f}}\right)$, o que exige um teste lógico para utilização do resultado destas equações.

FONTE: Proposto pelo autor

\subsection{CONCLUSÕES DO CAPÍTULO}

Este capítulo resume os padrões e recomendações da ICAO e da FAA quanto ao projeto geométrico de aeródromos, para um conjunto selecionado de critérios, metodologias e considerações de projeto. Isso é atingido através da consulta aos documentos emitidos por estas instituições.

Para cada critério, metodologia ou consideração de projeto, aponta-se a relação que estes guardam com outros critérios, metodologias ou considerações de projeto. Verificou-se que tais inter-relações podem ser apontadas em todos os casos analisados. A investigação dos princípios de projeto poderia permitir um aprofundamento da demonstração destas inter-relações.

Verifica-se que as normas da ICAO e da FAA apresentam padrões e recomendações para a maioria dos critérios, metodologias ou considerações de 
projeto. A exceção fica por conta das áreas de proteção de RWs e TWs, onde a nomenclatura utilizada, as exigências e especificações variam entre as normas.

Ainda, verifica-se um caráter complementar entre as normas da ICAO e da FAA, em relação ao nível de profundidade da abordagem aos diferentes critérios, metodologias ou considerações de projeto.

De maneira mais pontual chama atenção o fato de que a $O F Z$ de transição interna estabelecida pela FAA para condições CAT I e para condições CAT II/III coincidem após a distância Y.

Verifica-se também que a metodologia para avaliação do jet blast não trata os contornos de velocidade acima de $35 \mathrm{mph}$.

Finalmente, este capítulo dá suporte aos Capítulos 5 e 7 desta dissertação, nos quais os padrões da ICAO são, respectivamente, comparados e aplicados ao caso do Aeroporto Internacional de São Paulo/Guarulhos. 


\section{CAPÍTULO 5 - COMPARAÇÃO ENTRE OS PADRÕES E RECOMENDAÇÕES DA ICAO E FAA}

Este capítulo apresenta uma série de comparações entre os padrões e recomendações da ICAO e da FAA para um conjunto de critérios, metodologias e considerações de projeto, distribuídos na mesma ordem apresentada nos Capítulos 4 e 7. Quando a base de especificação coincide, estas comparações podem ser feitas diretamente. Para os demais casos, utiliza-se um conjunto de aeronaves para as quais as características pertencentes à base de especificação são conhecidas.

Ainda, propõe-se uma estruturação à consideração dos efeitos do jet blast e do FOD (Foreign Object Damage).

\subsection{CÓDIGO DE REFERÊNCIA DO AERÓDROMO (ARC)}

O ARC (código de referência do aeródromo) é uma forma simplificada de relacionar-se as características de uma aeronave com a estrutura necessária para acomodá-la em um aeródromo. Tanto a ICAO quanto a FAA se utilizam de tal codificação como base de especificação dos seus padrões de projeto. Como característica comum entre os ARCs da ICAO e da FAA está a utilização de dois termos, sendo o primeiro termo relacionado às características dinâmicas da aeronave e o segundo, às características geométricas.

Para o grupo dinâmico, a ICAO utiliza o CBP (Comprimento Básico de Pista da aeronave) e a FAA utiliza a velocidade de aproximação. Para o grupo geométrico, as duas instituições utilizam duas características das aeronaves, sendo a envergadura utilizada em ambas, o wheel span no caso da ICAO e altura do estabilizador no caso da FAA.

Como os padrões e recomendações de projeto são baseados no ARC, é necessário estabelecer-se uma correspondência entre a codificação da ICAO e da FAA para compará-los. Quanto ao grupo dinâmico nenhuma comparação direta é possível, dado o fato de que a ICAO e a FAA utilizam características distintas para a classificação. Quanto ao grupo geométrico, das duas características utilizadas, apenas uma coincide. 
Tabela 5.1-1 - Dados utilizados como base de especificação pela ICAO e pela FAA relativos a um conjunto de aeronaves selecionadas

\begin{tabular}{|c|c|c|c|c|c|c|c|c|c|c|c|c|}
\hline $\begin{array}{l}N^{\circ} \\
\text { le }\end{array}$ & Fabricante & Modelo & $\begin{array}{l}\text { env } \\
\text { (m) }\end{array}$ & $\begin{array}{l}\text { WS } \\
(\mathrm{m})\end{array}$ & $\begin{array}{l}Z_{\text {est }} \\
(\mathrm{m})\end{array}$ & CBP & $\begin{array}{l}V_{\mathrm{ap}} \\
\text { (nós) }\end{array}$ & $\begin{array}{l}\text { MTOW } \\
(\mathrm{kg})\end{array}$ & $\begin{array}{l}I_{\text {est }} \\
(\mathrm{m})\end{array}$ & $\begin{array}{c}\mathbf{z}_{\text {nar }} \text { ou } \\
\mathbf{z}_{\text {asa }} \\
\text { (m) } \\
|\mathrm{a}| \mathrm{i}\end{array}$ & $\begin{array}{l}\text { ARC } \\
\text { ICAO }\end{array}$ & $\begin{array}{l}\text { ARC } \\
\text { FAA }\end{array}$ \\
\hline 1 & ATR & $42-600 \mid c$ & 24,6 & 4,1 & 7,6 & 1.165 & 104 & 18.600 & 22,7 & 5,8 & $2-C$ & B-III \\
\hline 2 & Embraer & 135ER & $20,0 \mid a$ & $4,8 \mid a$ & $6,8 \mid a$ & $1.640 \mid b$ & $111 \mid c$ & $19.600 \mathrm{la}$ & 26,3 la & 3,8 & $3-B$ & B-II \\
\hline 3 & Embraer & 140ER & $20,0 \mid a$ & $4,8 \mid a$ & $6,8 \mid a$ & $1.580 \mid b$ & $129 \mid c$ & 20.100 la & 28,5 la & 3,8 & $3-B$ & C-II \\
\hline 4 & Bombardier & $\begin{array}{c}\text { CRJ700 Next } \\
\text { Gen ER }\end{array}$ & 23,2 |b & $5,0 \mid a$ & 7,6 |b & $1.724 \mid b$ & $135 \mid a$ & 34.019 |b & 32,3 |b & 4,5 & $3-B$ & C-II \\
\hline 5 & ATR & $72-600 \mid c$ & 27,1 & 4,1 & 7,7 & 1.333 & 113 & 22.800 & 27,2 & 5,8 & $3-C$ & B-III \\
\hline 6 & Embraer & 170 standard & 26,0 la & 6,2 |a & $9,9 \mid a$ & $1.483 \mid b$ & 124 |c & 35.990 la & 29,9 |a & 4,6 & $3-C$ & C-III \\
\hline 7 & Embraer & 175 standard & 26,0 la & 6,2 |a & $9,8 \mid a$ & $1.612 \mid b$ & $126 \mid c$ & $37.500 \mathrm{la}$ & 31,7 |a & 4,6 & $3-C$ & C-III \\
\hline 8 & Embraer & 190 standard & 28,7 |a & $7,3 \mid a$ & $10,6 \mid a$ & $1.598 \mid b$ & $123 \mid c$ & $47.790 \mathrm{la}$ & 36,2 la & 5,3 & $3-C$ & C-III \\
\hline 9 & Embraer & 195 standard & $28,7 \mathrm{la}$ & $7,3 \mid \mathrm{a}$ & 10,6 |a & $1.742 \mathrm{bb}$ & $126 \mid c$ & 48.790 la & 38,7 |a & 5,2 & $3-C$ & C-III \\
\hline 10 & Boeing & 737-700 |f |h & $35,8 \mid b$ & $7,0 \mid a$ & $12,5 \mid b$ & $1.600 \mid c$ & $130 \mid c$ & 70.080 |b & $33,6 \mid b$ & 6,6 & $3-C$ & C-III \\
\hline 11 & Airbus & $318-100$ & $34,1 \mid b$ & $8,7 \mid a$ & $12,5 \mid b$ & $1.750 \mathrm{a}$ & $138 \mid \mathrm{a}$ & 68.000 la & $31,4 \mid b$ & 5,9 & $3-C$ & C-III \\
\hline 12 & Embraer & 145LR & 20,0 la & $4,8 \mid a$ & $6,8 \mid a$ & $2.270 \mid b$ & 129 |c & 20.600 la & 29,9 |a & 3,8 & $4-B$ & C-II \\
\hline 13 & Bombardier & $\begin{array}{c}\text { CRJ900 Next } \\
\text { Gen LR }\end{array}$ & 24,9 |b & $5,0 \mid a$ & 7,5 lb & $1.954 \mid b$ & $138 \mid a$ & $38.330 \mid b$ & $36,2 \mid b$ & 4,5 & $4-C$ & C-III \\
\hline 14 & Embraer & 195AR & 28,7 |a & $7,3 \mid a$ & 10,6 |a & $2.179 \mid b$ & $127 \mid c$ & 52.290 la & 38,7 |a & 5,1 & $4-C$ & C-III \\
\hline 15 & Airbus & 319 & $34,1 \mid b$ & $8,7 \mid a$ & $11,8 \mid b$ & $2.100 \mathrm{la}$ & 138 |a & $75.500 \mathrm{la}$ & $33,8 \mid b$ & 6,0 & $4-C$ & C-III \\
\hline 16 & Airbus & 320 & 34,1 la & $8,7 \mid a$ & $11,8 \mid a$ & $2.058 \mid d$ & 138 |a & 78.000 la & $37,6 \mid b$ & 5,9 & $4-C$ & C-III \\
\hline 17 & Airbus & 321 & $34,1 \mid b$ & $8,7 \mid a$ & $11,8 \mid b$ & $2.200 \mid \mathrm{a}$ & $138 \mid a$ & 89.000 la & $44,5 \mid b$ & 6,0 & $4-C$ & C-III \\
\hline 18 & Boeing & $737-800$ lf $\mid \mathrm{h}$ & $35,8 \mid b$ & $7,0 \mid a$ & $12,5 \mid b$ & $2.010 \mid c$ & 142 |c & $79.010 \mid b$ & 39,5 |b & 6,8 & $4-C$ & D-III \\
\hline 19 & Boeing & 737-900ER |f |h & $35,7 \mid b$ & $7,0 \mid \mathrm{a}$ & $12,5 \mid b$ & 2.470 |c & 141 |c & $85.130 \mid b$ & 42,1 |b & 6,8 & $4-C$ & D-III \\
\hline
\end{tabular}




\begin{tabular}{|c|c|c|c|c|c|c|c|c|c|c|c|c|}
\hline $\begin{array}{l}N^{\circ} \\
\mid \mathrm{e}\end{array}$ & Fabricante & Modelo & $\begin{array}{l}\text { env } \\
\text { (m) }\end{array}$ & $\begin{array}{l}\text { WS } \\
\text { (m) }\end{array}$ & $\begin{array}{l}Z_{\text {est }} \\
(\mathrm{m})\end{array}$ & CBP & $\begin{array}{c}V_{\mathrm{ap}} \\
\text { (nós) }\end{array}$ & $\begin{array}{c}\text { MTOW } \\
\text { (kg) }\end{array}$ & $\begin{array}{l}I_{\text {est }} \\
\text { (m) }\end{array}$ & $\begin{array}{c}\mathrm{z}_{\text {nar }} \text { ou } \\
\mathrm{z}_{\text {asa }} \\
(\mathrm{m}) \\
|\mathrm{a}| \mathbf{i}\end{array}$ & $\begin{array}{l}\text { ARC } \\
\text { ICAO }\end{array}$ & $\begin{array}{l}\text { ARC } \\
\text { FAA }\end{array}$ \\
\hline 20 & Boeing & 767-300ER |f & 47,6 lb & 10,9 |c & $15,8 \mid b$ & $2.540 \mid c$ & 145 |c & $186.880 \mathrm{lb}$ & $54,9 \mid b$ & 7,5 & $4-D$ & D-IV \\
\hline 21 & Boeing & $787-8$ |f & 60,0 lb & 11,6 |a & $17,0 \mid b$ & $2.660 \mid \mathrm{c}$ & 140 lc lg & $227.930 \mathrm{lb}$ & $57,0 \mathrm{lb}$ & 7,7 & $4-E$ & $\mathrm{C}-\mathrm{V}$ \\
\hline 22 & Airbus & $330-200$ & 60,3 lb & 12,3 la & 17,4 |b & $2.713 \mid d$ & $140 \mid a$ & $238.000 \mid \mathrm{a}$ & $58,4 \mid a$ & 7,8 & $4-E$ & $\mathrm{C}-\mathrm{V}$ \\
\hline 23 & Airbus & $330-300$ & $60,3 \mid b$ & 12,3 |a & $16,8 \mid b$ & $2.560 \mid d$ & $140 \mid a$ & $233.000 \mathrm{la}$ & $63,7 \mid \mathrm{a}$ & 7,7 & $4-E$ & $\mathrm{C}-\mathrm{V}$ \\
\hline 24 & Boeing & 777-200ER |f & 60,9 lb & 12,9 |c & 18,5 lb & $2.890 \mid c$ & $139 \mid c$ & $297.550 \mathrm{lb}$ & $63,7 \mid b$ & 8,7 & $4-E$ & $\mathrm{C}-\mathrm{V}$ \\
\hline 25 & Boeing & $777-200 L R$ |f & 64,8 lb & 12,9 |c & $18,6 \mid b$ & $3.390 \mid c$ & $140 \mid c$ & $347.452 \mathrm{la}$ & $63,7 \mid b$ & 8,7 & $4-E$ & $\mathrm{C}-\mathrm{V}$ \\
\hline 26 & Boeing & 777-300ER |f & 64,8 lb & 12,9 |c & 18,5 |b & 3.060 lc & $149 \mid c$ & 351.535 |a & $73,9 \mathrm{lb}$ & 8,8 & $4-E$ & $D-V$ \\
\hline 27 & Airbus & $330-200 F$ & 60,3 lb & 12,3 la & 17,4 |b & $3.400 \mathrm{la}$ & 142 |a & 233.000 la & $58,4 \mid a$ & 8,1 & $4-E$ & D-V \\
\hline 28 & Airbus & $340-500$ & $63,5 \mid b$ & $12,6 \mathrm{la}$ & $17,3 \mid b$ & $3.275 \mid d$ & 144 |a & 380.000 la & 67,9 |b & 8,0 & $4-E$ & D-V \\
\hline 29 & Boeing & $747-8$ |f & $68,5 \mid b$ & 12,7 |a & 19,4 lb & $3.070 \mathrm{lc} \mathrm{lg}$ & 150 |c lg & $442.250 \mathrm{lb}$ & $76,3 \mid b$ & 9,8 & $4-F$ & $\mathrm{D}-\mathrm{VI}$ \\
\hline 30 & Boeing & $747-8 \mathrm{~F}$ |f & $68,5 \mid b$ & $12,7 \mathrm{la}$ & $19,4 \mid b$ & $3.070 \mathrm{lc} \mathrm{lg}$ & 159 lc lg & $442.250 \mathrm{lb}$ & 76,3 |b & 9,8 & $4-F$ & $\mathrm{D}-\mathrm{VI}$ \\
\hline 31 & Airbus & $380-800$ & 79,7 |b & 14,2 la & 24,1 lb & $3.350 \mid d$ & 145 |a & $560.000 \mathrm{la}$ & $72,7 \mathrm{lb}$ & 11,0 & $4-F$ & $\mathrm{D}-\mathrm{VI}$ \\
\hline
\end{tabular}

FONTE: Os dados foram obtidos de diversas fontes, conforme as seguintes notas:

|a: APM das aeronaves: Airbus 2007, 2008, 2011a, 2011b, 2011c, 2011d; ATR, 2011; Boeing 2002, 2005a, 2005b, 2008a, 2008b, 2009, 2010; Bombardier 2010a, 2010b; Embraer 2005, 2007, 2008a, 2008b, 2008c, 2008d.

lb: Website do fabricante.

|c: Material complementar obtido do fabricante por e-mail.

|d: Obtido da Tabela 2.1-2 da CASA Part 139 (2011).

OUTRAS NOTAS:

|e: Número de sequência das aeronaves, classificadas por: $1^{\circ}$ ) Ordem crescente do grupo dinâmico ICAO; $2^{\circ}$ ) Ordem crescente do grupo geométrico ICAO; e $3^{\circ}$ ) Ordem crescente do grupo dinâmico FAA.

|f: Os dados de CBP da Boeing correspondem aos modelos que resultam no menor CBP. |g: Dados preliminares.|h: Com winglets |i: Foi coletada somente a dimensão mais demandante. 
Com base nos dados da Tabela 4.1-1 e da Tabela 4.1-2, verifica-se que 0 número de classes coincide entre ICAO e FAA, sendo a envergadura um critério comum entre ambas, apresentando limites idênticos para as seis classes. Enquanto isso, a segunda característica geométrica utilizada difere entre as instituições: a ICAO utiliza o wheel span e a FAA utiliza a altura do estabilizador. Lembra-se que para efeitos de classificação de uma aeronave vale a característica que corresponde à classe mais demandante ${ }^{37}$.

Dadas as dificuldades de comparação direta entre os grupos dinâmicos e geométricos, efetuou-se uma comparação com base nas aeronaves da Tabela 5.1-1 Os resultados dessas comparações são mostrados nos itens 5.1.1 e 5.1.2.

Na Tabela 5.1-1, representa-se: a envergadura por env, o wheel span por WS, a altura do estabilizador por $\mathrm{z}_{\mathrm{est}}$, o comprimento básico de pista por CBP, a velocidade de aproximação por $\mathrm{V}_{\mathrm{ap}}$, o peso máximo de decolagem por MTOW, o comprimento da aeronave por l $\mathrm{l}_{\mathrm{est}}$, a altura do nariz por $\mathrm{z}_{\text {nar }}$ e a altura da ponta da asa por $\mathrm{z}_{\text {asa }}$.

\subsubsection{COMPARAÇÃO ENTRE OS GRUPOS DINÂMICOS}

A Tabela 5.1-2 resume a classificação das aeronaves da Tabela 5.1-1 quanto aos grupos dinâmicos da ICAO e da FAA.

Tabela 5.1-2 -Grupos dinâmicos da ICAO e da FAA para as aeronaves da Tabela 5.1-1

\begin{tabular}{|c|c|c|c|c|c|}
\hline \multirow{2}{*}{ ICAO } & \multicolumn{4}{|c|}{ FAA } & \multirow{2}{*}{ TOTAL } \\
\hline & A & B & C & D & \\
\hline 1 & - & - & - & - & - \\
\hline 2 & - & 1 & - & - & 1 \\
\hline 3 & - & 2 & 8 & - & 10 \\
\hline 4 & - & - & 11 & 9 & 20 \\
\hline TOTAL & - & 3 & 19 & 9 & 31 \\
\hline
\end{tabular}

FONTE: Preparado a partir das especificações da ICAO e da FAA e das aeronaves da Tabela 5.1-1

A partir destes dados, verifica-se que as grupos dinâmicos da ICAO e da FAA não guardam necessariamente uma correspondência entre si. Esse fato impede comparações entre padrões e recomendações da ICAO e da FAA quando o grupo dinâmico faz parte da base de especificação.

\footnotetext{
${ }^{37} \mathrm{~A}$ é menos demandante do que $\mathrm{B}$, enquanto $\mathrm{B}$ é menos demandante do que $\mathrm{C}$ e assim por diante. Da mesma forma I é menos demandante do que II, enquanto II é menos demandante do que III e assim por diante. Isso porque as respectivas especificações associadas a estes grupos geométricos aumentam nessa mesma ordem.
} 


\subsubsection{COMPARAÇÃO ENTRE OS GRUPOS GEOMÉTRICOS}

A Tabela 5.1-3 resume a classificação das aeronaves da Tabela 5.1-1 quanto aos grupos geométricos da ICAO e da FAA.

Tabela 5.1-3 -Grupos geométricos da ICAO e da FAA para as aeronaves da Tabela 5.1-1

\begin{tabular}{|c|c|c|c|c|c|c|c|}
\hline \multirow{2}{*}{ ICAO } & \multicolumn{6}{|c|}{ FAA } & \multirow[b]{2}{*}{ TOTAL } \\
\hline & $\mathbf{I}$ & II & III & IV & v & VI & \\
\hline A & - & - & - & - & - & - & 0 \\
\hline B & - & 4 & - & - & - & - & 4 \\
\hline C & - & - & 15 & - & - & - & 15 \\
\hline D & - & - & - & 1 & - & - & 1 \\
\hline E & - & - & - & - & 8 & - & 8 \\
\hline $\mathrm{F}$ & - & - & - & - & - & 3 & 3 \\
\hline TOTAL & - & 4 & 15 & 1 & 8 & 3 & 31 \\
\hline
\end{tabular}

FONTE: Preparado a partir das especificações da ICAO e da FAA e das aeronaves da Tabela 5.1-1.

A partir destes dados verifica-se que todas as aeronaves analisadas encontram-se na diagonal principal e, a partir dos dados da Tabela 5.1-1, verifica-se que esta correspondência entre os grupos geométricos é mantida aeronave por aeronave.

Resta saber qual o papel de cada um dos critérios utilizados para a classificação das aeronaves segundo os grupos geométricos da ICAO e da FAA. Isso é feito avaliando-se qual o critério que resulta na classificação mais demandante, conforme demonstra a Tabela 5.1-4.

Como ambos os grupos geométricos possuem dois critérios geométricos, avalia-se a relação de dominância entre eles. Nesta tabela representa-se: envergadura por env, wheel span por WS e altura do estabilizador por $Z_{\text {est }}$.

Tabela 5.1-4 -Dominância entre os dois critérios do grupo geométrico da ICAO e da FAA para as aeronaves da Tabela 5.1-1

\begin{tabular}{c|ccc|ccc}
\hline $\begin{array}{c}\text { Grupo } \\
\text { geométrico }\end{array}$ & \multicolumn{3}{|c|}{ ICAO } & \multicolumn{3}{c}{ FAA } \\
env $>w s$ & $\boldsymbol{e n v}=\boldsymbol{w s}$ & $\boldsymbol{e n \boldsymbol { v } < w s}$ & $\boldsymbol{e n v}>z_{\text {est }}$ & $\boldsymbol{e n v}=z_{\text {est }}$ & $\boldsymbol{e n v}<z_{\text {est }}$ \\
\hline $1^{\circ}$ & - & - & - & - & - & - \\
$2^{\circ}$ & - & 4 & - & - & 4 & - \\
$3^{\circ}$ & 3 & 12 & - & 3 & 12 & - \\
$4^{\circ}$ & - & 1 & - & - & 1 & - \\
$5^{\circ}$ & 8 & - & - & 5 & 3 & - \\
$6^{\circ}$ & 2 & 1 & - & 2 & 1 & - \\
\hline
\end{tabular}

FONTE: Preparado a partir das especificações da ICAO e da FAA e das aeronaves da Tabela 5.1-1 
Percebe-se que a utilização da envergadura como único critério resultaria em uma classificação idêntica das aeronaves nas duas normas. Ainda com respeito à dominância entre os critérios geométricos de classificação e com base na Tabela 5.1-1, chama atenção o fato de que para 28 das 31 aeronaves, a classificação de acordo com o segundo critério geométrico (wheel span e altura do estabilizador) são idênticas. Isso contribui para que a classificação das aeronaves segundo o grupo geométrico apresente correspondência entre as duas normas mesmo no caso em que a envergadura não seja o critério dominante para a classificação. Os três modelos de aeronaves que apresentam uma relação de dominância diferente são variações da família Boeing 777.

Do ponto de vista das comparações entre padrões e recomendações da ICAO e da FAA, quando o grupo geométrico compõe a base de especificação, as comparações podem ser feitas diretamente para todas as aeronaves analisadas e para qualquer aeronave desde que o segundo critério geométrico não seja dominante.

Para finalizar, cabe mencionar que a comparação entre os padrões $e$ recomendações da ICAO e da FAA, mesmo para grupos geométricos correspondentes, deve considerar o fato de que um ARC não limita o wheel span e o outro não limita a altura do estabilizador.

\subsection{CONSIDERAÇÕES DE PROJETO}

Esta seção apresenta a comparação entre os critérios da ICAO e da FAA quanto ao vento de través de projeto e quanto ao jet blast.

\subsubsection{VENTO DE TRAVÉS}

A Figura 5.2-1 apresenta graficamente os dados referentes aos critérios da ICAO e da FAA para o vento de través de projeto para cada aeronave.

Verifica-se que os valores diferem para todas as aeronaves narrowbodies, em até 7nós, e são idênticos para todas as aeronaves widebodies. 


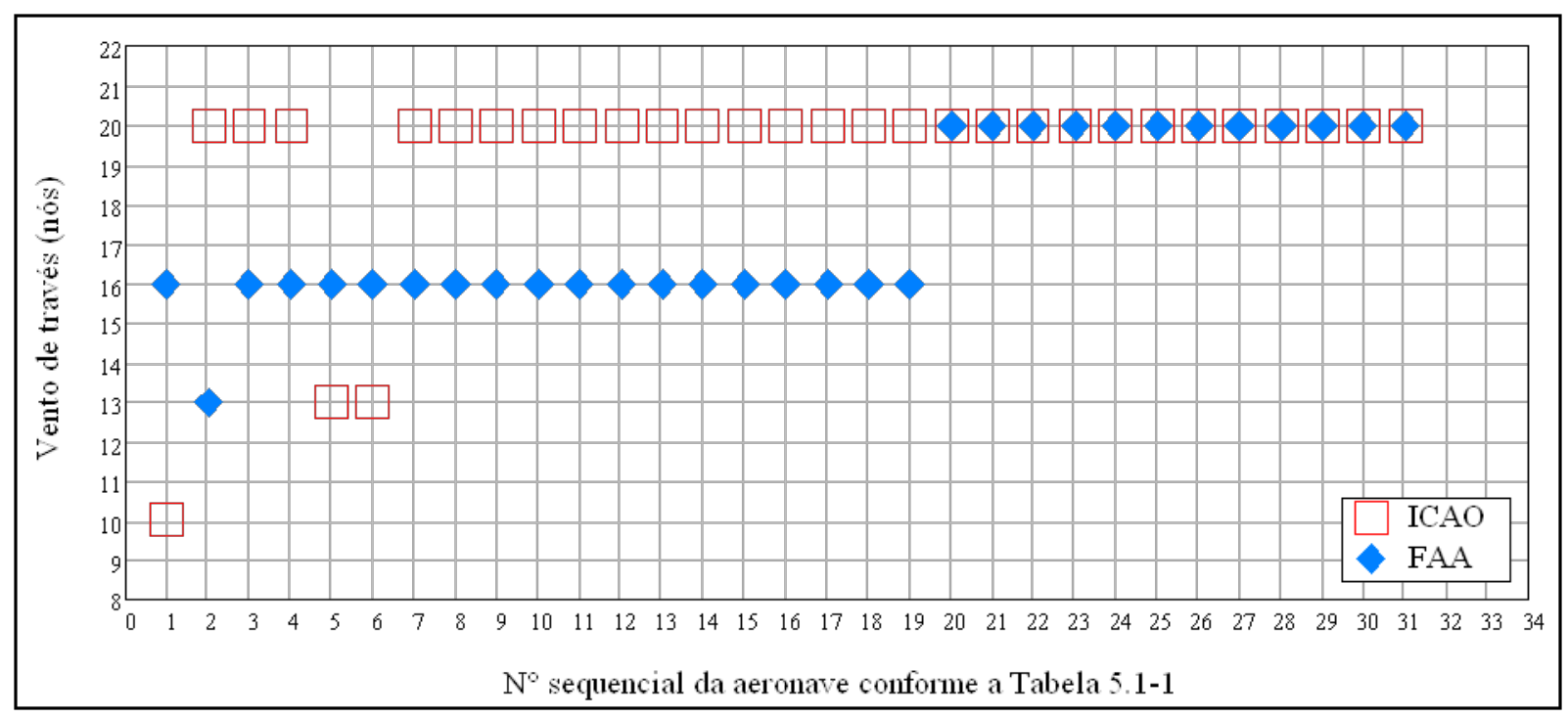

Figura 5.2-1- Comparação dos critérios da ICAO e da FAA para o vento de través. FONTE: Preparado a partir dos dados das aeronaves da Tabela 5.1-1 e das especificações da ICAO e da FAA

\subsubsection{JET BLAST E FOD}

Os efeitos gerados pelo funcionamento das turbinas influenciam diretamente 0 projeto de acostamentos, blast pads e também as distâncias permissíveis para a localização de outras aeronaves, veículos, pessoal e objetos, conforme o nível de empuxo considerado em cada parte do aeródromo. A seguir o assunto é discutido através de uma estruturação proposta.

\subsubsection{Considerações gerais}

O funcionamento das turbinas, além do ruído, gera três implicações sobre o ambiente vizinho: sucção do ar à frente das turbinas; velocidade elevada do fluxo de ar na parte posterior das mesmas; e temperaturas elevadas também na parte posterior das turbinas. O ruído não é tratado nesta dissertação. Já a temperatura dos gases de escape tende a ser menos crítica do que a velocidade do fluxo na parte posterior da turbina, pois a temperatura decai de forma mais acentuada em relação à distância do que decai a velocidade. Por sua vez, a sucção do ar a frente das turbinas e a velocidade do fluxo de ar delas oriundo foram abordadas nesta dissertação, sendo estes dois aspectos referidos respectivamente como FOD (Foreign Object Damage) e jet blast.

O potencial acontecimento de um evento FOD depende da altura da turbina em relação ao solo, da posição da mesma em relação à borda do pavimento e das características do fluxo.

Já para a análise dos efeitos do jet blast propõe-se a seguinte estruturação: 
- Efeitos do fluxo de ar (EFA) sobre

- I: pessoas;

- II: veículos e equipamentos;

- III: outras aeronaves; e

- IV: estruturas;

- Efeitos da erosão (EE) sobre

- I: áreas adjacentes ao pátio;

- II: pistas de táxi e baías de espera; e

- III: pista de pouso e decolagem;

- Efeito do arremesso de materiais (EAM).

Lembra-se que os três efeitos citados acima podem ser aumentados por condições ambientais, como o vento, por exemplo. Além disso, é preciso considerarse os efeitos do jet blast dentro e fora do aeródromo.

Os perigos relacionados aos EFAs decorrem, basicamente, da pressão e da vibração induzida pelo fluxo que atua sobre os quatro grupos citados, bem como da possibilidade de arremesso de materiais, incluindo poeira, areia, pedras e objetos indevidamente abandonados no aeródromo ou que se desprendam da superfície. Sobre cada um dos grupos é de se esperar que os efeitos sejam diferentes. Sobre pessoas, além da segurança, é necessário prover-se um nível mínimo de conforto. O mesmo vale para as áreas destinadas a veículos, já que muitos destes são abertos. Também, deve-se avaliar questões como a estabilidade dos veículos e equipamentos permitidos em cada parte do aeródromo. Tanto para aeronaves como veículos em movimento, a estabilidade é uma questão crítica, especialmente em relação às rajadas. Para as estruturas, deve-se considerar as cargas do jet blast, quanto à pressão e vibração.

Já os EEs decorrem principalmente das forças que o fluxo exerce sobre a superfície, desgastando, arrastando e levantando os materiais que a constituem. Esta erosão é indesejável por desgastar a superfície, por criar degraus na borda dos pavimentos, e por levantar, arremessar e dispersar materiais como poeira e pedras pelo aeródromo.

Os EAMs decorrem da possibilidade de o jet blast levantar objetos e arremessá-los a distâncias maiores do que os contornos de velocidade considerados perigosos. Embora tal fenômeno não seja explicitamente considerado nas normas, ele é substanciado pela seguinte afirmação: "Velocidades do jet blast maiores do que $30 \mathrm{mph}(48 \mathrm{~km} / \mathrm{h})$ podem fazer com que materiais soltos no pavimento se tornem projéteis, capazes de causar ferimentos em pessoas situadas a uma distância 
considerável atrás da aeronave. ${ }^{38 "}$ (FAA, 1983, p. 77). A menos que hipóteses simplificadoras possam ser aplicadas, a modelagem dos perigos oriundos dos EAMs é complexa, pois depende das condições iniciais do arremesso do objeto, da distribuição de velocidade do jet blast e da geometria e massa do objeto arremessado.

\subsubsection{Mitigação dos efeitos}

Os riscos de eventos FOD os efeitos do jet blast são mitigados através da aplicação de critérios de projeto e da especificação de procedimentos operacionais.

Os possíveis riscos oriundos da sucção de objetos estranhos (FOD) são mitigados a partir do provimento de superfícies especialmente preparadas na proximidade das turbinas, como é o caso dos acostamentos. Como nas duas normas a largura da RW e dos acostamentos é especificada de acordo com o grupo geométrico, é necessário avaliar, de forma caso a caso, a posição da turbina em relação à borda do pavimento.

A mitigação de EFAs, EEs e EAMs pode ser feita através do provimento de separações suficientes para o decaimento da velocidade, bem como pelo uso de blast fences especialmente projetadas para este fim. Outra mitigação possível é o aproveitamento do relevo do aeródromo e o uso de cercas vivas.

A mitigação dos EEs é feita também através do provimento de superfícies pavimentadas ou estabilizadas como acostamentos e blast pads.

Os efeitos do jet blast e dos eventos FOD podem também ser mitigados através de procedimentos operacionais, entre os quais: o estabelecimento do nível máximo de empuxo permitido em cada área do aeródromo; a sinalização, para alertar pessoas e operadores de veículos; o desligamento dos motores externos de aviões quadrimotores em determinados trechos das TWs, para evitar FOD; a demarcação de áreas a serem evitadas por veículos durante as operações; e provimento de instruções ao tráfego coordenadas com o ATC; uso de equipamentos automáticos de detecção de objetos na superfície ${ }^{39}$; e uso de dispositivos, de forma

\footnotetext{
${ }^{38}$ Texto original: "Blast velocities greater than $30 \mathrm{mph}(48 \mathrm{~km} / \mathrm{h})$ can cause loose objects on the pavement to become missiles capable of causing injury to personnel who may be at considerable distance behind the airplane." (FAA, 1983, p. 77).

${ }^{39}$ A FAA AC 150/5220-24 (2009) apresenta especificações mínimas de funcionamento para sistemas automáticos de detecção de FODs, os quais podem ser baseados em sensores móveis ou fixos. Exemplos de sistemas fixos: Stratech iFerret (http://www.stratechsystems.com/iv iferret.asp), Qinetiq Tarsier (http://www2.qinetiq.com/home tarsier.html) e Xsight FODetect (http://www.xsightsys.com/fodetect.htm). Exemplo de sistema móvel, montado sobre um veículo de inspeção: Trex FOD Finder (http://www.fodfinder.com/).
} 
a limpar-se os pneus dos veículos antes de estes entrarem nas áreas de movimento.

\subsubsection{Especificações e métodos}

Verificou-se que as normas, apesar de fazerem inúmeras considerações em relação aos riscos de FOD e do jet blast, não especificam critérios de projeto, a não ser para a velocidade máxima permitida sobre pessoas e veículos, que é de $35 \mathrm{mph}(56 \mathrm{~km} / \mathrm{h})$ para a ICAO e de $30 \mathrm{mph}(48 \mathrm{~km} / \mathrm{h})$ para a FAA. Ainda a FAA especifica que a velocidade média de $20 \mathrm{mph}(31 \mathrm{~km} / \mathrm{h})$ seja utilizada como limite para a consideração de rajadas que atuam sobre veículos e aeronaves em movimento. Tais especificações servem na melhor das hipóteses, ao propósito de avaliação dos efeitos do tipo EFAI, EFAll e EFAIII.

Para a análise dos efeitos do tipo EFAIV deve-se levar em conta os custos adicionais de construção necessários à adoção de limites de velocidade mais altos.

Para a análise dos EEs seria necessário o estabelecimento de velocidades limite que considerem a resistência das superfícies quanto às forças aerodinâmicas e quanto ao desgaste. Tal categorização poderia ser feita para diferentes tipos de superfícies, incluindo as pavimentadas e as estabilizadas. Para o caso da análise de introdução de new large aircrafts (NLAs) em aeroportos existentes, que não atendem os padrões do $6^{\circ}$ grupo geométrico, poder-se-ia pensar na comparação entre os contornos de velocidade laterais e longitudinais das novas aeronaves com aeronaves de quatro turbinas existentes (como o B747 e o A340).

Para a análise dos EAMs uma possível solução é a adoção de simplificações baseadas na velocidade do contorno de jet blast, com o uso de fatores de segurança de distância a serem aplicados nestes contornos.

Por fim, é necessário mencionar-se que a análise dos efeitos do jet blast, deve considerar a natureza multifatorial das mitigações possíveis. Por exemplo, os acostamentos, além de protegerem contra FOD e EEs, são destinados a acomodar desvios eventuais das rodas das aeronaves e a operação de veículos de emergência e serviços.

\section{3 ÁREAS PAVIMENTADAS PRINCIPAIS}

Nesta seção apresenta-se a comparação entre os padrões e recomendações da ICAO e da FAA quanto à: largura da pista de pouso e decolagem (RW), largura combinada entre a RW e os acostamentos, dimensões de blast pads, largura de uma pista de táxi (TW), largura combinada entre TWs e acostamentos, pistas de táxi de saída rápida (PTSRs), e TWs sobre pontes. 


\subsubsection{LARGURA DA PISTA DE POUSO E DECOLAGEM}

As especificações da ICAO são feitas com base nos dois elementos do ARC e no tipo de pista (pista para aproximação de precisão ou pista para aproximação visual). Já as especificações da FAA se baseiam nos dois elementos do ARC e na visibilidade mínima de operação, existindo ainda exceções com base no MTOW. Considerando-se essas questões, recorre-se às aeronaves da Tabela 5.1-1 para as comparações, criando-se dois cenários com base no tipo de pista/visibilidade: Cenário 1) englobando RWs para aproximação de precisão (especificações da ICAO) e RWs com visibilidade de aproximação menor do que $1.200 \mathrm{~m}$ (especificações da FAA); e Cenário 2) englobando RWs de não precisão e visuais (especificações da ICAO) e RWs com visibilidade de aproximação maior ou igual a 1.200m (especificações da FAA). Os resultados são ilustrados na Figura 5.3-1 e disponibilizados no ANEXO A. Verifica-se que, para a $12^{\circ}$ aeronave da lista (ERJ 145LR) não existe nenhuma especificação padrão da ICAO, uma vez que o ARC desta aeronave é 4-B.

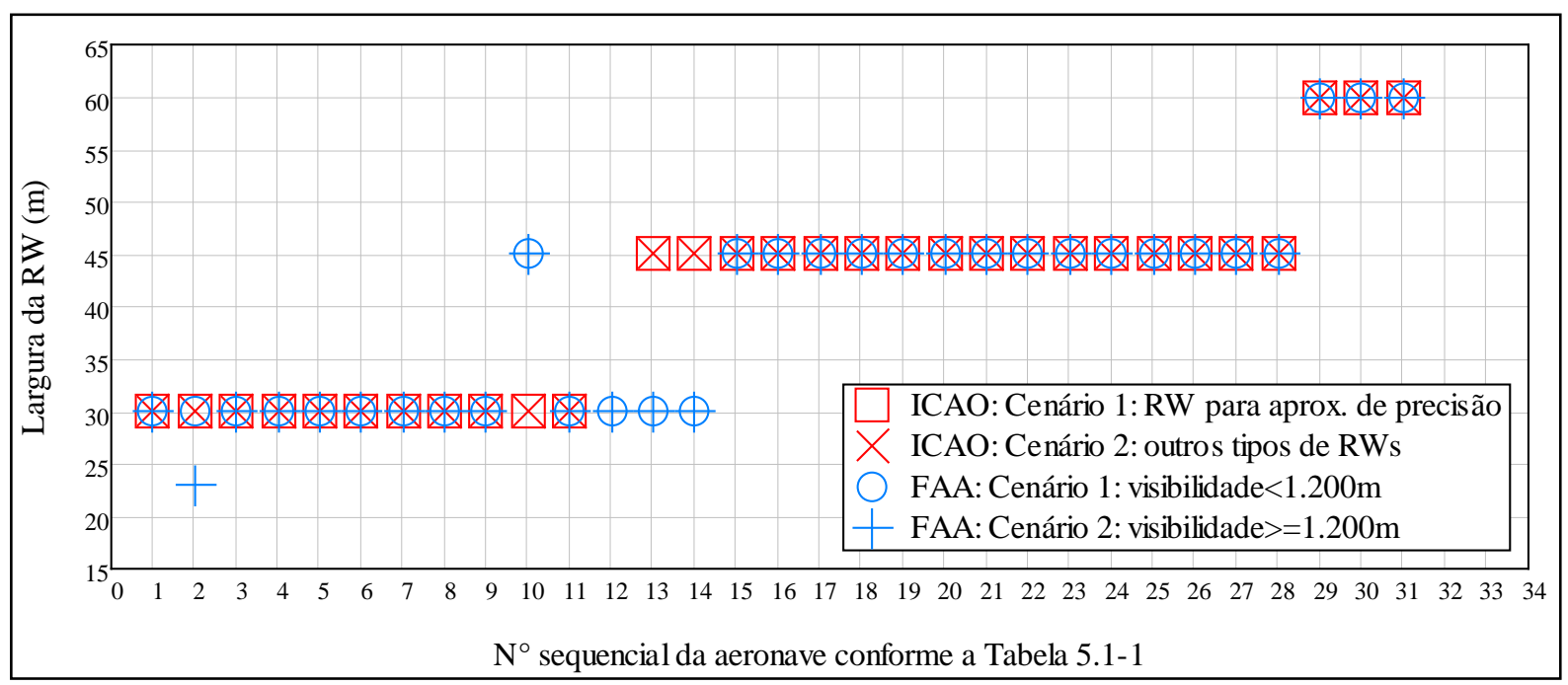

Figura 5.3-1- Comparação dos critérios da ICAO e da FAA para a largura da RW. Dados disponíveis no ANEXO A. FONTE: Preparado a partir dos dados das aeronaves da Tabela 5.1-1 e das especificações da ICAO e da FAA

\subsubsection{ACOSTAMENTOS DA PISTA DE POUSO E DECOLAGEM}

A ICAO especifica uma largura mínima combinada entre a RW e seus acostamentos, ao invés de especificar a largura dos acostamentos de forma direta. Ainda, tais especificações existem somente para $04^{\circ}$, o $5^{\circ}$ e $06^{\circ}$ grupos geométricos, sendo baseadas no segundo termo do ARC (grupo geométrico). A FAA, por sua vez, especifica acostamentos para todos os grupos geométricos, com base nos dois elementos do ARC, na visibilidade e no MTOW. 
Os resultados são mostrados na Figura 5.3-2 e os dados são disponibilizados no ANEXO B.

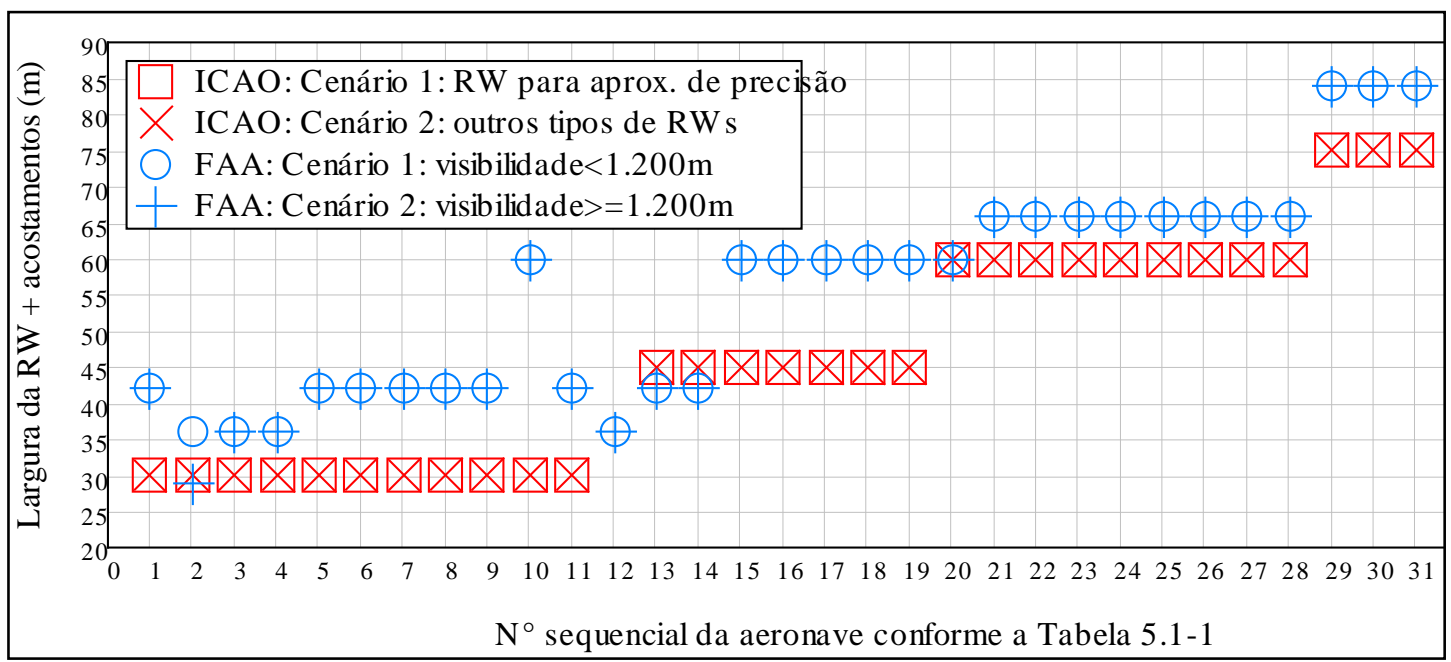

Figura 5.3-2- Comparação dos critérios da ICAO e da FAA para a largura combinada entre a RW e seus acostamentos. Dados disponíveis no ANEXO B. FONTE: Preparado a partir dos dados das aeronaves da Tabela 5.1-1 e das especificações da ICAO e da FAA

Verifica-se, como padrão geral, que a largura combinada entre RW e acostamentos é maior segundo as especificações da FAA para a maior parte dos casos, sendo que a diferença chega a ser de até 30m no caso do E-195 standard. Nos casos em que a ICAO é mais demandante (13 a $14^{\mathrm{a}}$ aeronaves - CRJ 900 Next Gen LR e E195AR) a diferença não passa de três metros.

\subsubsection{BLAST PADS}

Trata-se aqui da largura e do comprimento de uma blast pad. Devido à diferença na forma como as especificações da ICAO e da FAA são feitas, recorre-se às aeronaves da Tabela 5.1-1. As comparações quanto à largura de uma blast pad podem ser conferidas no gráfico da Figura 5.3-2, uma vez que, tanto para a ICAO como para a FAA, a largura de uma blast pad é igual à largura combinada entre a RW e seus acostamentos.

Já em relação ao comprimento, os resultados são mostrados na Figura 5.3-3 e os dados são disponibilizados no ANEXO C.

Verifica-se que o comprimento varia para 12 das 31 aeronaves analisadas, com diferenças de até $60 \mathrm{~m}$ entre as normas. Essa diferença tão elevada acontece para as aeronaves widebody, com exceção do B767-300ER, para as quais a FAA especifica $120 \mathrm{~m}$ de comprimento para a blast pad. Enquanto isso, a ICAO especifica $60 \mathrm{~m}$ de comprimento da blast pad para estas aeronaves, com exceção do A380-800 e B747-8, para os quais a ICAO também especifica $120 \mathrm{~m}$. 


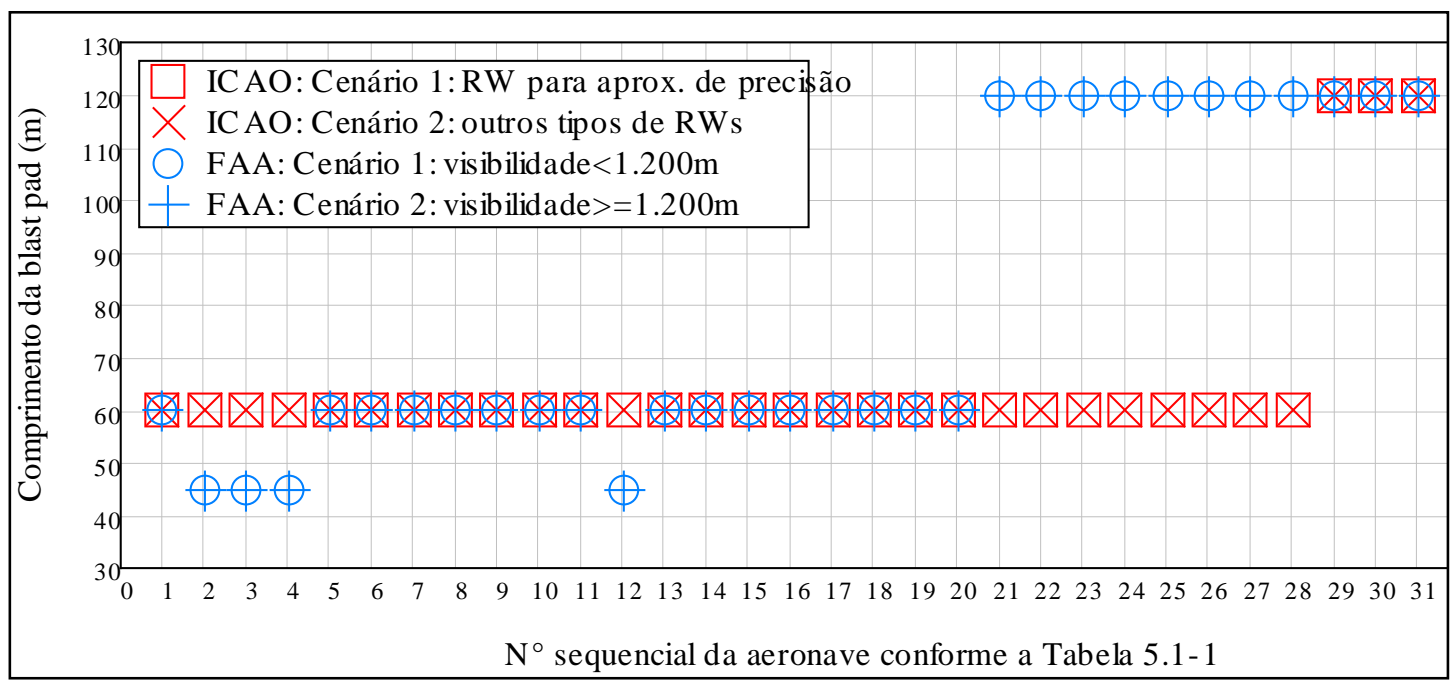

Figura 5.3-3- Comparação dos critérios da ICAO e da FAA para o comprimento de blast pads. Dados Disponíveis no ANEXO C. FONTE: Preparado a partir dos dados das aeronaves da Tabela 5.1-1 e das especificações da ICAO e da FAA

\subsubsection{LARGURA DAS PISTAS DE TÁXI}

Em relação à largura de uma pista de táxi em um trecho retilíneo, A ICAO e a FAA especificam larguras padrão e também folgas, a serem observadas entre a borda externa da roda e a borda do pavimento (folga do pavimento). Nos trechos curvos, é preciso considerar-se também o desvio das rodas, mantendo-se a folga do pavimento. ${ }^{40}$

Para a especificação da largura da TW e também da borda do pavimento, a ICAO utiliza o grupo geométrico, o wheel span e a base de rodas. A FAA utiliza o grupo geométrico e o wheel span.

As larguras especificadas pela ICAO para a TW correspondem à soma entre 0 wheel span máximo do grupo geométrico e o dobro da folga do pavimento. A FAA, no entanto, não considera o wheel span para classificar as aeronaves segundo grupos geométricos. Portanto a utilização da largura padrão da TW especificada pela FAA não garante o atendimento da folga do pavimento.

Ainda é preciso dizer-se que tanto a ICAO quanto a FAA permitem a utilização de dimensões menores do que largura padrão da TW, mas a folga do pavimento é considerada um princípio de projeto.

\footnotetext{
${ }^{40}$ Isso é tratado no item 4.5.
} 
De forma a comparar-se os valores das larguras e das folgas, foi criada a Tabela 5.3-1:

Tabela 5.3-1 - Comparação entre os padrões da ICAO e da FAA para largura da pista de táxi e para a folga do pavimento

\begin{tabular}{c|c|c|c|c}
\hline \multirow{2}{*}{ Grupo geométrico } & \multicolumn{3}{|c|}{ Folga do pavimento } & \multicolumn{2}{c}{ Largura da pista de táxi } \\
& \multicolumn{1}{|c|}{ ICAO } & FAA & \multicolumn{1}{c}{ ICAO } & \multicolumn{1}{c}{ FAA } \\
\hline $1^{\circ}$ & $1,5 \mathrm{~m}$ & $1,5 \mathrm{~m}$ & $7,5 \mathrm{~m}$ & $7,5 \mathrm{~m}$ \\
$2^{\circ}$ & $2,25 \mathrm{~m}$ & $2,25 \mathrm{~m}$ & $10,5 \mathrm{~m}$ & $10,5 \mathrm{~m}$ \\
$3^{\circ}$, com base de rodas menor do que 18m & $3 \mathrm{~m}$ & $3 \mathrm{~m}$ & $15 \mathrm{~m}$ & $15 \mathrm{~m}$ \\
$3^{\circ}$, com base de rodas igual ou maior a 18m & $4,5 \mathrm{~m}$ & $4,5 \mathrm{~m}$ & $18 \mathrm{~m}$ & $18 \mathrm{~m}$ \\
$4^{\circ}$,com wheel span menor do que 9m & $4,5 \mathrm{~m}$ & $4,5 \mathrm{~m} \mid \mathbf{b}$ & $18 \mathrm{~m}$ & $23 \mathrm{~m} \mid \mathbf{b}$ \\
$4^{\circ}$, com wheel span maior ou igual a 9m & $4,5 \mathrm{~m}$ & $4,5 \mathrm{~m} \mid \mathbf{b}$ & $23 \mathrm{~m}$ & $23 \mathrm{~m} \mid \mathbf{b}$ \\
$5^{\circ}$ & $4,5 \mathrm{~m}$ & $4,5 \mathrm{~m}$ & $23 \mathrm{~m}$ & $23 \mathrm{~m}$ \\
$6^{\circ}$ & $4,5 \mathrm{~m} \mid \mathbf{a}$ & $6 \mathrm{~m}$ & $25 \mathrm{~m} \mid \mathbf{a}$ & $30 \mathrm{~m}$ \\
\hline
\end{tabular}

|a: Para aeronaves do grupo geométrico $F$, em condições de tráfego elevado, a adoção de uma folga do pavimento maior torna-se interessante para permitir velocidades maiores de taxiamento, à medida que isso influencia o comportamento dos pilotos.

|b: Esta classe é fictícia, pois a FAA não considera o wheel span como base de especificação.

FONTE: ICAO Annex 14 (2004a, p.3-11) e FAA AC 150/5300-13 (1989, p.38).

Desta tabela percebe-se que a folga do pavimento é igual para todos os grupos geométricos, com exceção do $6^{\circ}$. Já a largura padrão da TW varia para o $6^{\circ}$ e para 0 $4^{\circ}$ grupo geométrico.

\subsubsection{ACOSTAMENTOS DA TW}

A ICAO apresenta padrões para a largura combinada entre a TW e seus acostamentos. A FAA por sua vez, especifica larguras para os acostamentos diretamente. Para comparar-se estes padrões preparou-se a Tabela 5.3-2, onde:

- as larguras dos acostamentos para a ICAO foram calculadas a partir do: i) padrão para a largura combinada entre a TW e seus acostamentos; e ii) padrão de largura da TW; e

- as larguras combinadas entre a TW e os acostamentos para a FAA foram obtidas a partir de: i) padrão de largura da TW; e ii) padrão de largura dos acostamentos.

A partir da Tabela 5.3-2, verificam-se diferenças expressivas entre as larguras combinadas entre TWs e acostamentos, com exceção do $4^{\circ}$ e do $5^{\circ}$ grupo geométrico, no qual as especificações coincidem. 
Tabela 5.3-2 - Comparação dos padrões de largura combinada entre a TW e seus acostamentos, para a ICAO e para a FAA $(\mathrm{m})$

\begin{tabular}{c|ccccccccc}
\hline \multirow{2}{*}{ Padrão } & \multicolumn{7}{|c}{ Grupo geométrico } \\
& $\mathbf{1}^{\circ}$ & $\mathbf{2}^{\circ}$ & $\mathbf{3}^{\circ} \mid \mathbf{a}$ & $\mathbf{3}^{\circ} \mid \mathbf{b}$ & $\mathbf{4}^{\circ} \mid \mathbf{c}$ & $\mathbf{4}^{\circ} \mid \mathbf{d}$ & $\mathbf{5}^{\circ}$ & $\mathbf{6}^{\circ}$ \\
\hline Padrão de largura da TW (ICAO) & 7,5 & 10,5 & 15 & 18 & 18 & 23 & 23 & 25 \\
\hline $\begin{array}{c}\text { Largura do acostamento da TW } \\
\text { (ICAO) }\end{array}$ & $\mathbf{| e}$ & $\mathbf{| e}$ & 5 & 3,5 & 10 & 7,5 & 10,5 & 17,5 \\
\hline $\begin{array}{c}\text { Padrão de largura da TW (FAA) } \\
\text { Padrão de largura do acostamento } \\
\text { da TW (FAA) }\end{array}$ & 7,5 & 10,5 & 15 & 18 & 23 & 23 & 23 & 30 \\
\hline $\begin{array}{c}\text { Padrão de largura combinada entre } \\
\text { TW e acostamentos (ICAO) }\end{array}$ & 7,5 & 10,5 & 25 & 25 & 38 & 38 & 44 & 60 \\
\hline $\begin{array}{c}\text { Largura combinada entre TW e } \\
\text { acostamentos (FAA) }\end{array}$ & 13,5 & 16,5 & 27 & 30 & 38 & 38 & 44 & 54 \\
\hline
\end{tabular}

a: base de rodas menor do que $18 \mathrm{~m}$. Esta nota é feita pela ICAO e pela FAA.

lb: base de rodas maior ou igual a $18 \mathrm{~m}$. Esta nota é feita pela ICAO e pela FAA.

|c: wheel span menor do que $9 \mathrm{~m}$. Esta nota é exclusiva da ICAO. Para a FAA faz-se a duplicação da coluna do $4^{\circ}$ grupo geométrico para fins de comparação.

|d: wheel span maior ou igual a $9 \mathrm{~m}$. Esta nota é exclusiva da ICAO. Para a FAA faz-se a duplicação da coluna do $4^{\circ}$ grupo geométrico para fins de comparação.

le: a ICAO não especifica acostamentos para estes grupos geométricos.

FONTE: Adaptado a partir de ICAO Annex 14 (2004a, p.3-11, 3-15) e FAA AC 150/5300-13 (1989)

\subsubsection{PISTAS DE TÁXI DE SAÍDA RÁPIDA (PTSRS)}

A ICAO apresenta duas geometrias padrão para PTSRs, sendo: uma para os grupos dinâmicos 1 e 2, com um raio da curva de saída de $275 \mathrm{~m}$ e um ângulo de intersecção de $45^{\circ} \mathrm{com}$ a RW; e outra para os grupos dinâmicos 3 e 4, com um raio da curva de saída de 550m e um ângulo de intersecção de $30^{\circ} \mathrm{com}$ a RW. Enquanto isso, a FAA apresenta apenas uma PTSR padrão, com um raio da curva de saída de $410 \mathrm{~m}$ e um ângulo de intersecção de $30^{\circ}$ com a RW.

Para o projeto de PTSRs diferentes daquelas apresentadas como padrão, a ICAO estabelece três critérios de projeto: i) raio da curva de turn-off, que depende da velocidade de turn-off; ii) ângulo de intersecção entre a PTSR e a RW; e iii) padrões de desaceleração na PTSR a serem observados no dimensionamento do comprimento desta, de forma a garantir-se que a aeronave pare antes de qualquer intersecção com uma TW ou RW. Para o cálculo da velocidade de turn-off, a ICAO apresenta uma metodologia conhecida como Three Segment Method. Além disso, a norma aconselha o aumento das sobrelarguras da PTSR em relação ao padrão de folga do pavimento. 


\subsubsection{PISTAS DE TÁXI SOBRE PONTES}

Além de várias considerações de projeto, a ICAO e a FAA estabelecem padrões para a largura da área pavimentada com capacidade plena de suporte para TWs em pontes. Para a ICAO a largura padrão corresponde à área preparada da faixa da TW e para a FAA a largura padrão é da TSA. No item 5.8 são comparadas as larguras padrão das áreas de proteção das TWs. As duas normas permitem redução deste padrão mediante o uso de restrição lateral, embora não encorajem a redução da largura da ponte.

Em relação ao comprimento, a ICAO apresenta comprimentos mínimos, antes e depois da ponte, dentro dos quais o eixo da TW deve estar alinhado ao eixo da ponte. A FAA, por sua vez, não especifica estas distâncias mínimas.

\subsection{DISTÂNCIAS DECLARADAS}

Neste tópico tratam-se as clearways (CWYs) e as stopways (SWYs). Os conceitos associados às distâncias declaradas (TORA, TODA, ASDA e LDA) para a ICAO e para a FAA são equivalentes.

\subsubsection{ZONA DESIMPEDIDA (CLEARWAY - CWY)}

As especificações da ICAO e da FAA são equivalentes com exceção de que o comprimento máximo estabelecido pela ICAO para a CWY é a metade do comprimento da TORA, enquanto a FAA coloca $300 \mathrm{~m}$ como limite prático.

\subsubsection{ZONA DE PARADA (STOPWAY - SWY)}

As especificações da ICAO e da FAA são equivalentes.

\subsection{CURVAS E INTERSECÇÕES}

A ICAO apresenta uma metodologia detalhada para a trajetória de uma aeronave quando sua cabine de comando segue uma linha reta ou o arco de um círculo. A metodologia é embasada por um modelo matemático, que culmina em equações, que podem ser aplicadas ao cálculo da trajetória. A norma apresenta também um método alternativo, baseado em ábacos.

Para o dimensionamento das sobrelarguras, a ICAO apresenta três métodos: método ótimo; o método arco e tangente; e uma variação deste (arc and tangent variant). O método ótimo requer o cálculo da trajetória da aeronave, seja pelas equações ou pelos ábacos. O método arco e tangente e o método arc and tangent 
variant baseiam em equações e ábacos simplificados, dispensando-se o cálculo da trajetória da aeronave.

A FAA apresenta equações simplificadas para o cálculo da trajetória da aeronave, aplicáveis ao caso que o ponto de referência da aeronave segue uma reta ou um arco de círculo. Para o dimensionamento de sobrelarguras, a norma apresenta padrões para a construção de uma geometria simples, similar ao método arco e tangente, definida por um raio (r) e um comprimento linear L. Estes padrões podem ser aplicados diretamente desde que a relação wheel base/wheel span da aeronave de projeto se encaixe em certos limites. Para os demais casos, equações simplificadas são apresentadas, para a construção da mesma geometria. Ainda, a FAA apresenta equações para o cálculo da trajetória de partes da aeronave, como pontas de asa, nariz e estabilizadores, a qual foi adaptada pelo autor no item 4.5.2.3.

\subsection{SEPARAÇÕES}

\subsubsection{SEPARAÇÃO ENTRE RWs PARALELAS}

A ICAO apresenta separações padrão para dois grandes grupos: i) pistas para aproximação visual; e ii) pistas para aproximação por instrumentos. A FAA também apresenta suas especificações com base em dois grupos, a saber: I) pistas para operações VFR (Visual Flight Rules); e II) pistas para operações IFR (Instrument Flight Rules). As comparações apresentadas a seguir assumem que pistas para aproximação visual operem sob regras VFR e que pistas para aproximação por instrumentos operem sob regras IFR.

\subsubsection{RWs para aproximação visual}

Neste caso a menor separação lateral é compensada por uma maior separação longitudinal, que pode ser mantida pelo piloto mediante uma visibilidade maior do que 5.000m. Os padrões da ICAO variam conforme o grupo dinâmico e os padrões da FAA variam conforme o grupo geométrico. Tomando-se por base as aeronaves da Tabela 5.1-1, pode-se construir o gráfico da Figura 5.6-1, cujos dados constam no Anexo I.

Verifica-se que as especificações praticamente coincidem (diferença máxima de $4 \mathrm{~m}$ ) para 19 das 31 aeronaves analisadas. As maiores diferenças são encontradas entre as aeronaves widebody, com exceção do B767-300ER, cuja especificação praticamente coincide entre as normas. Para as demais aeronaves widebody, a ICAO especifica $210 \mathrm{~m}$ de separação enquanto a FAA especifica $366 \mathrm{~m}$. 
Também chama a atenção a aeronave ATR 42-600 para a qual a especificação da ICAO é de $150 \mathrm{~m}$ e a especificação da FAA é de $214 \mathrm{~m}$.

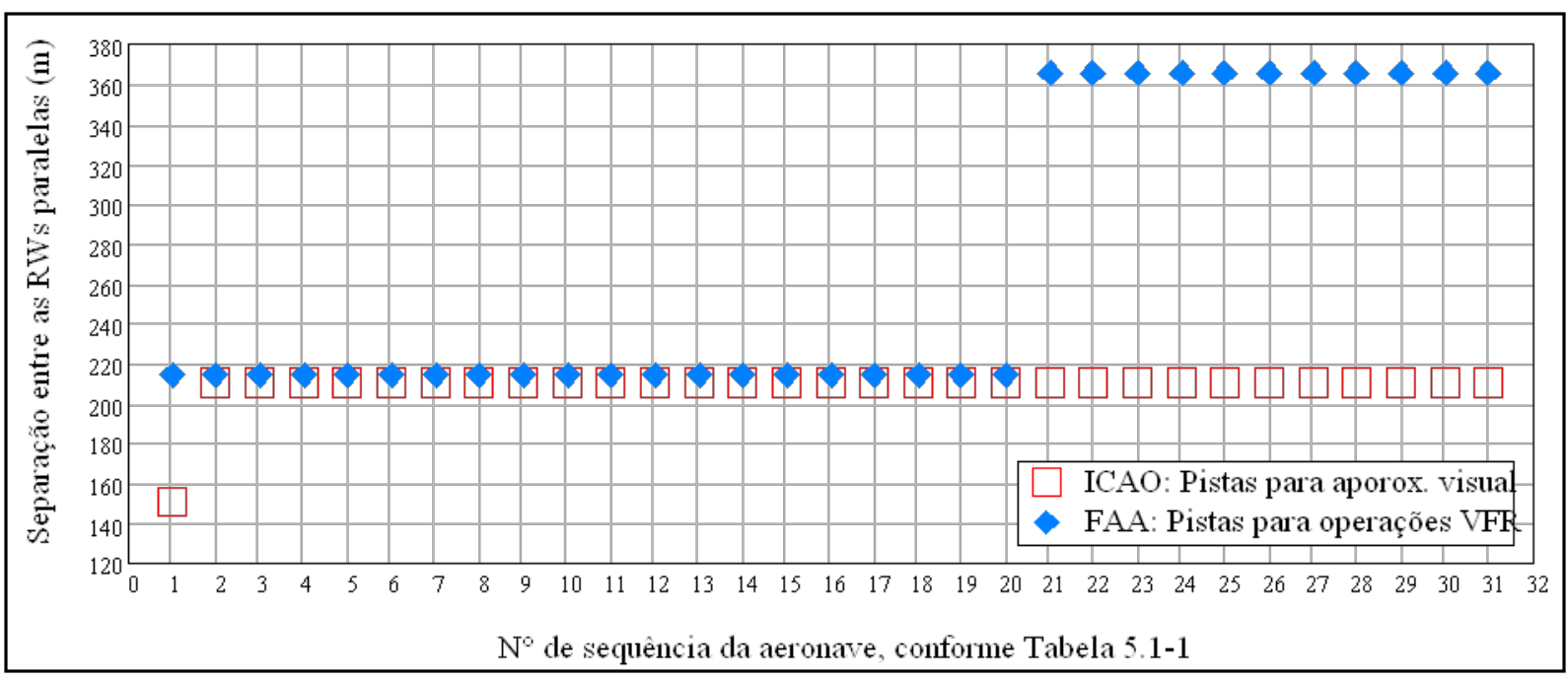

Figura 5.6-1- Comparação entre as especificações da ICAO e da a FAA para a separação entre RWs paralelas, em pistas para aproximação visual, com base nas aeronaves da Tabela 5.1-1. Dados disponíveis no ANEXO I. FONTE: Preparado a partir dos dados das aeronaves e das especificações da ICAO e da FAA

\subsubsection{RWs para aproximação por instrumentos}

Neste caso os padrões de separação não dependem de características das aeronaves, a não ser a separação mínima especificada pela FAA para pistas paralelas sujeitas a operações segregadas quando suas extremidades possuem uma decalagem favorável.

Para operações independentes, a ICAO especifica $1.035 \mathrm{~m}$, enquanto a FAA especifica $1.525 \mathrm{~m}$ como separação padrão. A FAA permite que esse valor seja reduzido até $915 \mathrm{~m}$, mediante sistemas de controle e monitoração mais sofisticados. A ICAO também permite uma separação mínima de $915 \mathrm{~m}$, no caso de aproximações simultâneas dependentes.

Para o caso de duas saídas simultâneas a ICAO especifica uma separação mínima de $760 \mathrm{~m}$, enquanto para a FAA esse padrão vale $762 \mathrm{~m}$.

Esses mesmos padrões valem para operações paralelas segregadas. Porém a ICAO e a FAA fazem concessões ou exigências, com base na decalagem (stagger) entre as extremidades da RW. Para decalagem favorável, o padrão de separação da ICAO e da FAA pode ser diminuído em $30 \mathrm{~m}$ para cada $150 \mathrm{~m}$ de decalagem favorável. No entanto, para a ICAO, a separação nunca pode ser menor do que $300 \mathrm{~m}$. Para a FAA a separação mínima é de 305m para aeronaves cujo grupo geométrico é I, II , III ou IV e de $366 \mathrm{~m}$ para os grupos geométricos $\mathrm{V}$ e VI. 
Para o caso de decalagem desfavorável, as exigências da ICAO e da FAA variam levemente: a ICAO exige um aumento de $30 \mathrm{~m}$ para cada $150 \mathrm{~m}$ de decalagem desfavorável, enquanto para a FAA essa proporção é de $30 \mathrm{~m}$ para cada $152 \mathrm{~m}$.

\subsubsection{SEPARAÇÃO ENTRE RWS e TWS PARALELAS}

Os padrões de separação apresentados pela ICAO consideram a semienvergadura da aeronave crítica a taxiar e a largura geral da faixa da $R W$, de forma a protegê-la. Já os padrões da FAA se baseiam no atendimento à $O F Z$ de transição interna e à RSA.

O atendimento a estes padrões, no entanto, não garante que a separação seja suficiente para: atendimento da OFZ; acomodação de aeronaves em espera entre a RW e a TW; e acomodação de PTSRs entre a RW e a TW. O item 4.6.2 apresenta uma série de recomendações relacionadas a estes fatores.

Tendo-se em vista a função principal que cumpre a separação entre RWs e TWs, qual seja proteger as aeronaves que pousam, decolam e taxiam, as comparações aqui apresentadas levam em conta os padrões de separação entre RWs e TWs e a OFZ de transição interna.

Verificou-se que a Tabela 4.6-1, não apresenta especificações para alguns ARCs. Com isso, para algumas das aeronaves da Tabela 5.1-1 foi necessário o cálculo da separação padrão a partir da área geral da faixa da RW e da semienvergadura máxima do grupo geométrico.

Devido às diferenças entre as bases de especificação dos padrões de separação e da OFZ de transição interna, utilizou-se os cenários apresentados na Tabela 5.6-1 para as comparações.

Tabela 5.6-1 - Cenários para comparação entre os padrões da ICAO e da FAA quanto à separação entre RWs e TWs

\begin{tabular}{|c|c|c|c|c|c|c|c|}
\hline \multirow{2}{*}{\multicolumn{4}{|c|}{ Cenários (dados de entrada) }} & \multicolumn{4}{|c|}{ Cenários que produzem especificações iguais } \\
\hline & & & & \multicolumn{2}{|c|}{ ICAO } & \multicolumn{2}{|c|}{ FAA } \\
\hline Cenário & Visibilidade (m) & Altitude & CAT & $\begin{array}{c}\text { Separação } \\
\text { RW/TW }\end{array}$ & $\begin{array}{c}\text { OFZ de } \\
\text { trans. Int. }\end{array}$ & $\begin{array}{c}\text { Separação } \\
\text { RW/TW }\end{array}$ & $\begin{array}{c}\text { OFZ de } \\
\text { trans. Int. }\end{array}$ \\
\hline $\mathrm{C} 1$ & $\leq 800$ & 0 & I & \multirow{4}{*}{$\begin{array}{l}\text { C1= } \\
\text { C2= } \\
\text { C3= } \\
\text { C4 }\end{array}$} & \multirow{4}{*}{$\begin{array}{l}\text { C1= } \\
\text { C2= } \\
\text { C3= } \\
\text { C4 }\end{array}$} & C1 & $\mathrm{C} 1$ \\
\hline $\mathrm{C} 2$ & $\leq 800$ & 3.500 & 1 & & & $\mathrm{C} 2$ & $\mathrm{C} 2$ \\
\hline C3 & $\leq 800$ & 0 & II/III & & & C3 & C3 \\
\hline C4 & $\leq 800$ & 3.500 & II/III & & & C4 & C4 \\
\hline $\mathrm{C5}$ & $\geq 5.000$ & 0 & - & \multirow{2}{*}{$\begin{array}{l}\mathrm{C} 5= \\
\mathrm{C} 6\end{array}$} & - & C5 & - \\
\hline C6 & $\geq 5.000$ & 3.500 & - & & - & C6 & - \\
\hline
\end{tabular}

FONTE: Proposto pelo autor 
Os dados oriundos das comparações com base nestes cenários, nas especificações da ICAO e da FAA e nas aeronaves da Tabela 5.1-1 são mostrados nos gráficos da Figura 5.6-2, da Figura 5.6-3 e da Figura 5.6-4. Os dados completos estão disponíveis nos ANEXOS J, K e L, respectivamente.

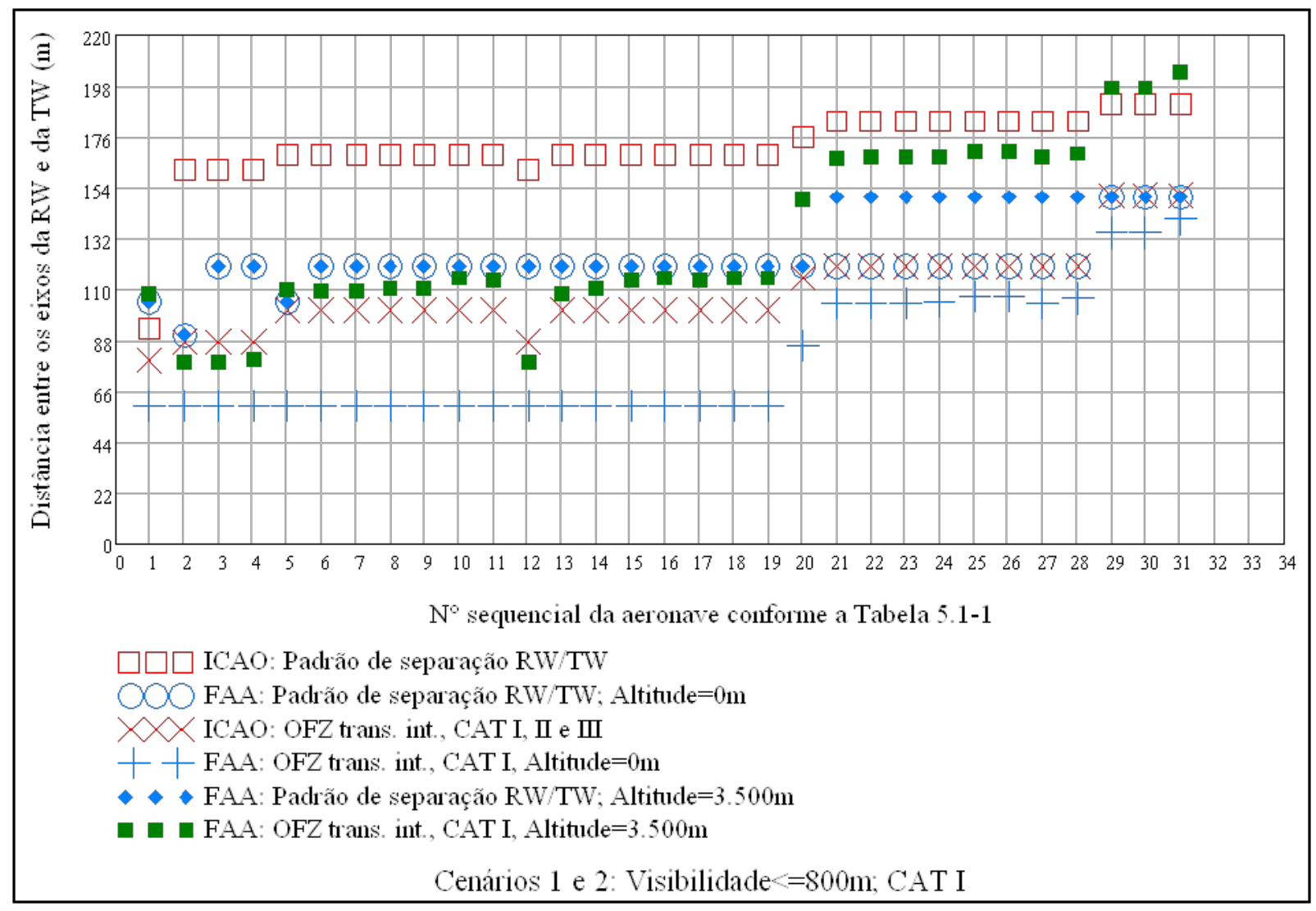

Figura 5.6-2- Comparação entre as especificações da ICAO e da a FAA para separação entre RWs e TWs paralelas com base nas aeronaves da Tabela 5.1-1. Cenários 1 e 2 para o caso em que a aeronave espera para entrar na RW. Dados disponíveis no ANEXO J. FONTE: Preparado a partir dos dados das aeronaves e das especificações da ICAO e da FAA

A partir da Figura 5.6-2, para pistas para aproximação por instrumentos, verifica-se que os padrões de separação da ICAO são suficientes para atender-se à OFZ de transição interna, independentemente da altitude. O mesmo vale para os padrões da FAA ao nível do mar. No entanto, como o aumento da altitude para $3.500 \mathrm{~m}$, a OFZ de transição interna exige aumento da separação entre RWs e TWs para os critérios da FAA. Comparando-se as separações mínimas entre RWs e TWs, com base nos dois critérios analisados (padrão de separação e $O F Z$ de transição interna), ao nível do mar os padrões da ICAO são mais demandantes para todas as aeronaves, com exceção da $1^{\text {a }}$ aeronave (ATR 42-600). Quando a altitude aumenta para $3.500 \mathrm{~m}$, os padrões da ICAO continuam mais demandantes, com exceção da $1^{\mathrm{a}}$ aeronave (ATR 42-600) e das aeronaves A380-800 e B747-8 (29a a $31^{\mathrm{a}}$ aeronaves). 


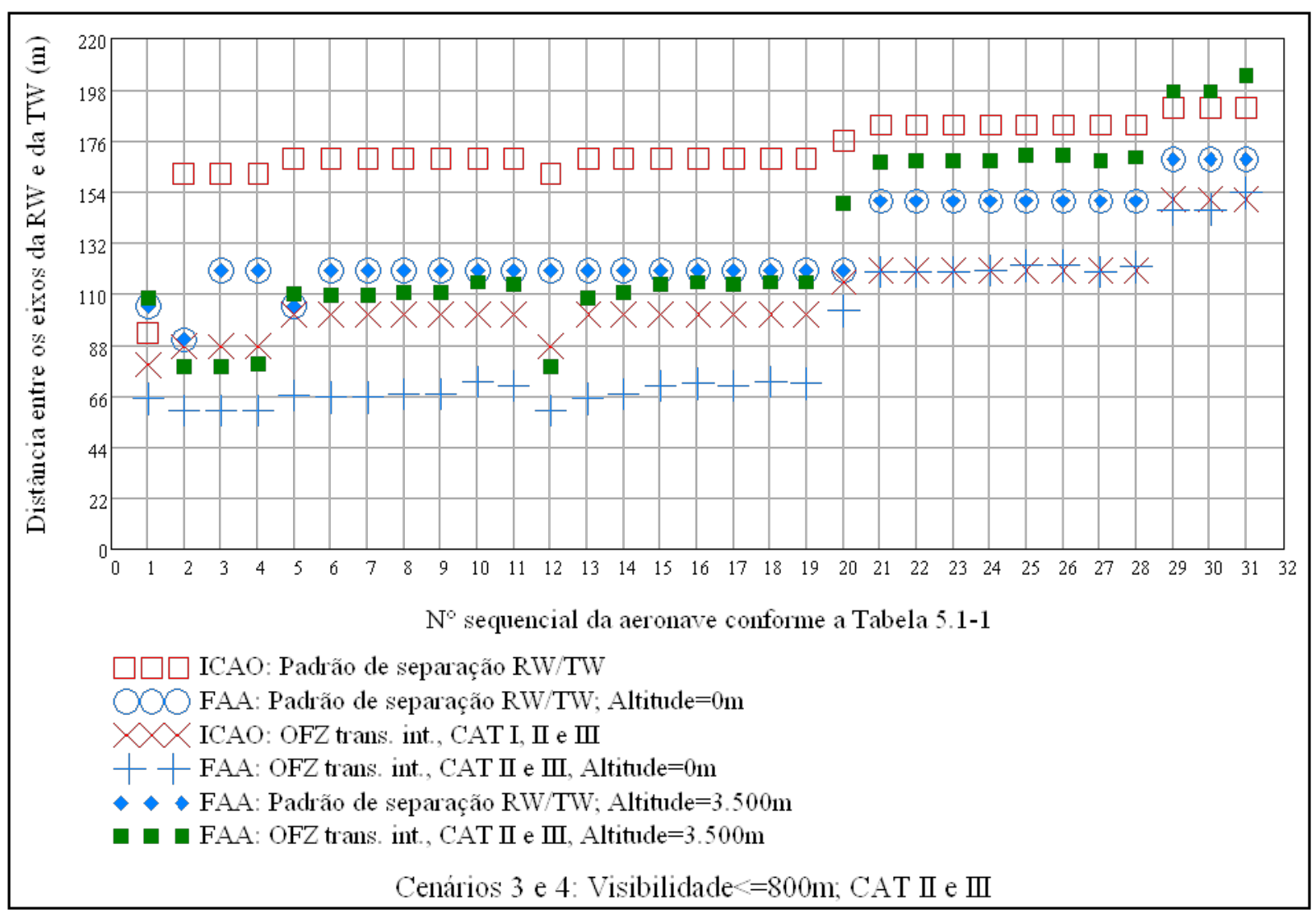

Figura 5.6-3- Comparação entre as especificações da ICAO e da a FAA para separação entre RWs e TWs paralelas com base nas aeronaves da Tabela 5.1-1. Cenários 3 e 4 para o caso em que a aeronave espera para entrar na RW. Dados disponíveis no ANEXO K. FONTE: Preparado a partir dos dados das aeronaves e das especificações da ICAO e da FAA

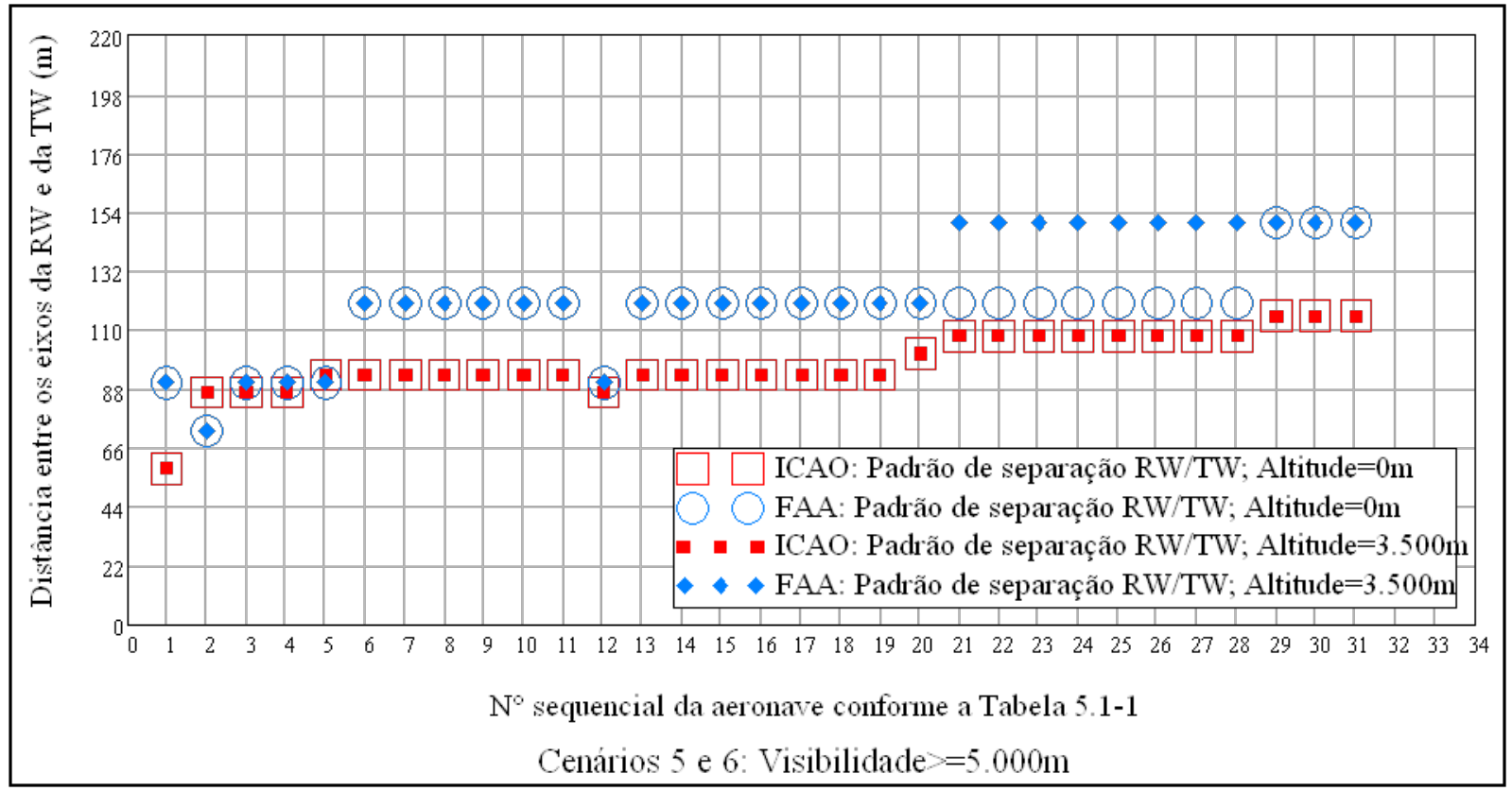

Figura 5.6-4- Comparação entre as especificações da ICAO e da a FAA para separação entre RWs e TWs paralelas, com base nas aeronaves da Tabela 5.1-1. Cenários 5 e 6 para o caso em que a aeronave espera para entrar na RW. Dados disponíveis no ANEXO L. FONTE: Preparado a partir dos dados das aeronaves e das especificações da ICAO e da FAA 
A partir da Figura 5.6-3 verifica-se que as conclusões válidas para condições CAT I são também válidas para condições CAT II/III.

Para pistas para aproximação visual, conforme a Figura 5.6-4, verifica-se que para 29 das 31 aeronaves analisadas os critérios da FAA são mais demandantes. No caso da ICAO a altitude não influencia o padrão, o que é garantido pelas especificações. Já para a FAA, a altitude compõe a base de especificação. Verificouse que, para 23 das 31 aeronaves analisadas, a altitude não influencia o padrão de separação.

\subsubsection{SEPARAÇÕES EM TWs e TLs}

Os padrões para separações TWs/TWs, TWs/TLs, TLs/TLs, TWs/objetos e TLs/objetos da ICAO e da FAA são especificados com base no grupo geométrico.

\subsubsection{SEPARAÇÕES TWITW E TWIOBJETOS}

A Tabela 5.6-2 compara as separações padrão da ICAO e da FAA referentes a pistas de táxi.

Tabela 5.6-2 - Comparação entre os padrões da ICAO e da FAA quanto a separações em TWs

\begin{tabular}{c|c|c|c|c|c|c}
\hline \multirow{2}{*}{ Padrão } & \multicolumn{7}{c}{ Grupo geométrico } & $\mathbf{4}^{\circ}$ & $\mathbf{5}^{\circ}$ & $\mathbf{6}^{\circ}$ \\
\cline { 2 - 7 } & $\mathbf{1}^{\circ}$ & $\mathbf{2}^{\circ}$ & $\mathbf{3}^{\circ}$ & $\mathbf{6}$ & $\mathbf{9}$ \\
\hline $\begin{array}{c}\text { Padrão da ICAO para a } \\
\text { separação TW/TW }\end{array}$ & $23,75 \mathrm{~m}$ & $33,5 \mathrm{~m}$ & $44 \mathrm{~m}$ & $66,5 \mathrm{~m}$ & $80 \mathrm{~m}$ & $97,5 \mathrm{~m}$ \\
\hline $\begin{array}{c}\text { Padrão da FAA para a } \\
\text { separação TW/TW }\end{array}$ & $21 \mathrm{~m}$ & $34,8 \mathrm{~m}$ & $46,2 \mathrm{~m}$ & $65,4 \mathrm{~m}$ & $81 \mathrm{~m}$ & $99 \mathrm{~m}$ \\
\hline $\begin{array}{c}\text { Padrão ICAO para a folga de } \\
\text { ponta de asa para TW }\end{array}$ & $8,75 \mathrm{~m}$ & $9,5 \mathrm{~m}$ & $8 \mathrm{~m}$ & $14,5 \mathrm{~m}$ & $15 \mathrm{~m}$ & $17,5 \mathrm{~m}$ \\
\hline $\begin{array}{c}\text { Padrão FAA para a folga de } \\
\text { ponta de asa para TW }\end{array}$ & $6 \mathrm{~m}$ & $10,8 \mathrm{~m}$ & $10,2 \mathrm{~m}$ & $13,4 \mathrm{~m}$ & $16 \mathrm{~m}$ & $19 \mathrm{~m}$ \\
\hline
\end{tabular}

FONTE: ICAO Doc 9157 Parte 2 (2005a, p. 1-11) e FAA AC 150/5300-13 (1989, p.de 39 a 41)

Chama atenção o fato de as folgas da ICAO apresentarem declínio até o $3^{\circ}$ grupo geométrico e depois aumentarem. A explicação para esta situação está no fato de a folga ser determinada com base na largura da área geral da faixa da TW (AGFTW). Assim, o aumento da envergadura máxima do grupo geométrico a uma razão maior do que a largura da AGFTW exige uma diminuição da folga.

A variação máxima entre as folgas de cada grupo é de $2,75 \mathrm{~m}$.

\subsubsection{SEPARAÇÕES TL/TL E TL/OBJETOS}

A partir da Tabela 5.6-3 verifica-se que a variação máxima entre as folgas de cada grupo é de $2 \mathrm{~m}$. 
Tabela 5.6-3 - Comparação entre os padrões da ICAO e da FAA quanto separações em TLs

\begin{tabular}{c|c|c|c|c|c|c}
\hline \multirow{2}{*}{ Padrão } & \multicolumn{7}{|c}{ Grupo geométrico } \\
\cline { 2 - 7 } & $\mathbf{1}^{\circ}$ & $\mathbf{2}^{\circ}$ & $\mathbf{3}^{\circ}$ & $\mathbf{4}^{\circ}$ & $\mathbf{5}^{\circ}$ & $\mathbf{6}^{\circ}$ \\
\hline $\begin{array}{c}\text { Padrão da ICAO para a } \\
\text { separação TL/TL }\end{array}$ & $19,5 \mathrm{~m}$ & $28,5 \mathrm{~m}$ & $42,5 \mathrm{~m}$ & $62 \mathrm{~m}$ & $75 \mathrm{~m}$ & $90,5 \mathrm{~m}$ \\
\hline $\begin{array}{c}\text { Padrão da FAA para a } \\
\text { separação TL/TL }\end{array}$ & $19,5 \mathrm{~m}$ & $29,5 \mathrm{~m}$ & $42,5 \mathrm{~m}$ & $60 \mathrm{~m}$ & $74,5 \mathrm{~m}$ & $91 \mathrm{~m}$ \\
\hline $\begin{array}{c}\text { Padrão ICAO para a folga de } \\
\text { ponta de asa para TL }\end{array}$ & $4,5 \mathrm{~m}$ & $4,5 \mathrm{~m}$ & $6,5 \mathrm{~m}$ & $10 \mathrm{~m}$ & $10 \mathrm{~m}$ & $10,5 \mathrm{~m}$ \\
\hline $\begin{array}{c}\text { Padrão FAA para a folga de } \\
\text { ponta de asa para TL }\end{array}$ & $4,5 \mathrm{~m}$ & $5,5 \mathrm{~m}$ & $6,5 \mathrm{~m}$ & $8 \mathrm{~m}$ & $9,5 \mathrm{~m}$ & $11 \mathrm{~m}$ \\
\hline
\end{tabular}

FONTE: ICAO Doc 9157 Parte 2 (2005a, p. 1-11) e FAA AC 150/5300-13 (1989, p.de 39 a 41)

\subsubsection{SEPARAÇÕES NAS POSIÇÕES DE ESTACIONAMENTO}

A ICAO apresenta um único tipo de separação para a área de estacionamento, especificado com base no grupo geométrico, a ser observada entre a aeronave e: outras aeronaves; prédios; e outros objetos fixos.

A FAA, por sua vez, especifica quatro tipos de separações: i) separação nariz/terminal para posições do tipo nose-in; ii) separação entre o terminal e a cauda (nose to tail clearance), para os casos em que a aeronave perfaz auto-manobra; iii) separação entre as extremidades da aeronave e prédios; e iv) separação entre as pontas das asas.

A Tabela 5.6-4 resume as recomendações para separações no pátio. Chama atenção que a separação entre o nariz e terminal, recomendada pela FAA diminui na direção dos grupos geométricos mais demandantes. Essa diminuição se deve ao maior espaço que sobra para o trator de manobra na área abaixo da aeronave.

Tabela 5.6-4 - Comparação entre as separações padrão da ICAO e da FAA para o pátio de aeronaves $(\mathrm{m})$

\begin{tabular}{|c|c|c|c|c|c|c|c|c|}
\hline \multirow[b]{2}{*}{ Agência } & \multirow[b]{2}{*}{ Separação } & \multicolumn{7}{|c|}{ Grupo geométrico } \\
\hline & & $1^{\circ}$ & $2^{\circ}$ & $3^{\circ}$ & $\begin{array}{c}4^{\circ}, \\
\text { comprimento } \\
\text { da } \\
\text { fuselagem } \\
\text { menor do } \\
\text { que } 49 \mathrm{~m}\end{array}$ & $\begin{array}{c}4^{\circ}, \\
\text { comprimento } \\
\text { da } \\
\text { fuselagem } \\
\text { maior do que } \\
49 \mathrm{~m}\end{array}$ & $5^{\circ}$ & $6^{\circ}$ \\
\hline ICAO & $\begin{array}{l}\text { Entre a aeronave e: } \\
\text { outras aeronaves; } \\
\text { prédios; e outros } \\
\text { objetos fixos }\end{array}$ & 3 & 3 & 4,5 & \multicolumn{2}{|c|}{7,5} & 7,5 & 7,5 \\
\hline FAA & $\begin{array}{c}\text { Entre o nariz e o } \\
\text { terminal na posição de } \\
\text { estacionamento nose-in }\end{array}$ & - & - & 9 & 6 & 6 & 4,5 & - \\
\hline
\end{tabular}




\begin{tabular}{|c|c|c|c|c|c|c|c|c|c|}
\hline \multirow[b]{2}{*}{ Agência } & \multirow{2}{*}{\multicolumn{2}{|c|}{ Separação }} & \multicolumn{7}{|c|}{ Grupo geométrico } \\
\hline & & & $1^{\circ}$ & $2^{\circ}$ & $3^{\circ}$ & $\begin{array}{c}4^{\circ}, \\
\text { comprimento } \\
\text { da } \\
\text { fuselagem } \\
\text { menor do } \\
\text { que } 49 \mathrm{~m}\end{array}$ & $\begin{array}{c}4^{\circ} \\
\text { comprimento } \\
\text { da } \\
\text { fuselagem } \\
\text { maior do que } \\
49 \mathrm{~m}\end{array}$ & $5^{\circ}$ & $6^{\circ}$ \\
\hline \multirow{4}{*}{ FAA } & \multicolumn{2}{|c|}{$\begin{array}{l}\text { Entre a cauda e o } \\
\text { terminal, para os casos } \\
\text { em que a aeronave } \\
\text { perfaz auto-manobra }\end{array}$} & - & - & 37 & 37 & 113 & 149 & - \\
\hline & \multirow{2}{*}{$\begin{array}{c}\text { Entre as } \\
\text { extremidades } \\
\text { da aeronave e } \\
\text { prédios }\end{array}$} & $\begin{array}{l}\text { Exceto } \\
\text { pier } \\
\text { gates }\end{array}$ & - & - & 6 & 6 & 6 & 6 & - \\
\hline & & $\begin{array}{l}\text { Pier } \\
\text { gates }\end{array}$ & - & - & 14 & 14 & 14 & 14 & - \\
\hline & $\begin{array}{l}\text { Entre pontas } \\
\text { de asa }\end{array}$ & & - & - & $\begin{array}{l}6 \mathrm{a} \\
7,5\end{array}$ & 6 a 7,5 & 6 a 7,5 & $\begin{array}{l}6 \mathrm{a} \\
7,5\end{array}$ & - \\
\hline
\end{tabular}

FONTE: ICAO e FAA

\subsubsection{POSIÇÃO DAS BARRAS DE PARADA DA RW (BPRWS)}

A base de especificação dos padrões da ICAO e da FAA para BPRWs varia bastante, o que dificulta comparações diretas. Assim, para as comparações são utilizadas as aeronaves da Tabela 5.1-1 e um conjunto de cenários para a elevação do aeródromo e para a elevação relativa entre a BPRW e a cabeceira.

Considerou-se que a posição de uma BPRW deve atender a dois critérios: posição padrão de uma BPRW; e OFZ de transição interna.

As comparações entre os padrões da ICAO e da FAA foram realizadas com base nas aeronaves da Tabela 5.1-1 e com base em alguns cenários para o tipo de pista, categoria de aproximação, altitude e para a diferença de elevação entre a BPRW e a cabeceira. As aeronaves consideradas possuem os seguintes dados que fazem parte da base de especificação de BPRWs e OFZs: grupo dinâmico; grupo geométrico; MTOW, velocidade de aproximação e características geométricas. Já os cenários foram construídos pela combinação dos seguintes parâmetros:

- Visibilidade: i) maior ou igual a 1.200m (englobando as especificações da ICAO para RWs para aproximação visual e as especificações da FAA para RWs com visibilidade maior ou igual a $1.200 \mathrm{~m}$ ); e ii) menor do que $1.200 \mathrm{~m}$ (englobando as especificações da ICAO para RWs para aproximação de 
precisão e as especificações da FAA para RWs com visibilidade menor do que $1.200 \mathrm{~m}$, CAT, I, II e III);

- Categoria de aproximação: i) CAT I; e ii) CAT II e III;

- Altitude da cabeceira: i) 0m; e ii) $3.500 \mathrm{~m}$;

- Diferença de altitude entre a cabeceira e a BPRW: i) 0m; e ii) a BPRW está 2,25m acima da cabeceira;

Dessa forma, são desconsiderados os seguintes tipos de pista: i) RWs exclusivas de decolagem, as quais não são especificadas pela FAA; e ii) RWs para aproximação de não precisão, na falta de um limite único para a visibilidade mínima permitida neste tipo de operação.

A Tabela 4.6-5 apresenta os cenários propostos para as comparações, cabendo-se afirmar que alguns deles resultam em especificações comuns. Exemplo: a OFZ de transição interna, segundo os critérios da ICAO, será igual, para uma dada aeronave, para os cenários 5, 6, 7 e 8. Porém, nota-se que cada cenário produz um único grupo de especificações combinadas resultantes.

Os padrões relativos às BPRWs podem ser consultados no item 4.6.5. Já a análise da $O F Z$ de transição interna, exige um pouco mais de discussão, conforme os parágrafos seguintes.

Para a análise da OFZ de transição interna utilizou-se a modelagem proposta no item 4.9.3, considerando-se dois casos: i) o caso em que a aeronave espera para entrar na RW e; ii) o caso em a aeronave deixa a RW. Estes dois casos foram tratados separadamente em função de as especificações para BPRWs considerarem somente o primeiro caso. No entanto, a análise do segundo caso está de acordo com as especificações sobre controle de tráfego aéreo, apontadas no item 4.6.5. Assim, deixa-se para o leitor a opção de que condição se deve levar em conta.

Tabela 5.6-5 - Cenários para as comparações entre os padrões da ICAO e da FAA quanto a BPRWs e OFZs de transição interna

\begin{tabular}{|c|c|c|c|c|c|c|c|c|}
\hline \multicolumn{5}{|c|}{ Cenários (dados de entrada) } & \multicolumn{4}{|c|}{ Especificações resultantes } \\
\hline \multirow[b]{2}{*}{ Cenário } & \multirow[b]{2}{*}{$\begin{array}{l}\text { Visibilidade } \\
\text { (m) }\end{array}$} & \multirow[b]{2}{*}{ CAT } & \multirow[b]{2}{*}{$\begin{array}{c}\text { Altitude } \\
\text { (m) }\end{array}$} & \multirow{2}{*}{$\begin{array}{c}\text { Diferença de } \\
\text { elevação entre } \\
\text { a cabeceira e a } \\
\text { BPRW }\end{array}$} & \multicolumn{2}{|c|}{ ICAO } & \multicolumn{2}{|c|}{ FAA } \\
\hline & & & & & BPRW & $\begin{array}{c}\text { OFZ } \\
\text { trans. } \\
\text { int. }\end{array}$ & BPRW & $\begin{array}{c}\text { OFZ } \\
\text { trans. } \\
\text { int. }\end{array}$ \\
\hline $\mathrm{C1}$ & $\leq 800 m$ & I & 0 & 0 & \multirow{2}{*}{$\mathrm{C} 1=\mathrm{C} 2$} & \multirow{4}{*}{$\begin{array}{l}\text { C1= } \\
\text { C2 }= \\
\text { C3 }= \\
\text { C4 }\end{array}$} & \multirow{2}{*}{$\begin{array}{c}\text { C1= } \\
\text { C2 }= \\
\text { C5 }= \\
\text { C6 }\end{array}$} & C1 \\
\hline $\mathrm{C} 2$ & $\leq 800 \mathrm{~m}$ & II e III & 0 & 0 & & & & $\mathrm{C} 2$ \\
\hline C3 & $\leq 800 \mathrm{~m}$ & I & 3.500 & 0 & \multirow{2}{*}{$\mathrm{C} 3=\mathrm{C} 4$} & & \multirow{2}{*}{$\begin{array}{l}\text { C3= } \\
\text { C4= } \\
\text { C7= } \\
\text { C8 }\end{array}$} & C3 \\
\hline C4 & $\leq 800 \mathrm{~m}$ & II e III & 3.500 & 0 & & & & C4 \\
\hline
\end{tabular}




\begin{tabular}{|c|c|c|c|c|c|c|c|c|}
\hline \multicolumn{5}{|c|}{ Cenários (dados de entrada) } & \multicolumn{4}{|c|}{ Especificações resultantes } \\
\hline \multirow[b]{2}{*}{ Cenário } & \multirow[b]{2}{*}{$\begin{array}{l}\text { Visibilidade } \\
\text { (m) }\end{array}$} & \multirow[b]{2}{*}{ CAT } & \multirow[b]{2}{*}{$\begin{array}{c}\text { Altitude } \\
\text { (m) }\end{array}$} & \multirow{2}{*}{$\begin{array}{c}\text { Diferença de } \\
\text { elevação entre } \\
\text { a cabeceira e a } \\
\text { BPRW }\end{array}$} & \multicolumn{2}{|c|}{ ICAO } & \multicolumn{2}{|c|}{ FAA } \\
\hline & & & & & BPRW & $\begin{array}{c}\text { OFZ } \\
\text { trans. } \\
\text { int. }\end{array}$ & BPRW & $\begin{array}{c}\text { OFZ } \\
\text { trans. } \\
\text { int. }\end{array}$ \\
\hline C5 & $\leq 800 m$ & I & 0 & $2,25 \mathrm{~m}$ & \multirow{2}{*}{$\mathrm{C} 5=\mathrm{C} 6$} & \multirow{4}{*}{$\begin{array}{l}\mathrm{C} 5= \\
\mathrm{C} 6= \\
\mathrm{C} 7= \\
\mathrm{C} 8\end{array}$} & \multirow{2}{*}{$\begin{array}{l}\mathrm{C} 1= \\
\mathrm{C} 2= \\
\mathrm{C} 5= \\
\mathrm{C} 6\end{array}$} & C5 \\
\hline C6 & $\leq 800 m$ & II e III & 0 & $2,25 \mathrm{~m}$ & & & & C6 \\
\hline $\mathrm{C7}$ & $\leq 800 \mathrm{~m}$ & I & 3.500 & $2,25 \mathrm{~m}$ & \multirow{2}{*}{$\mathrm{C} 7=\mathrm{C} 8$} & & \multirow{2}{*}{$\begin{array}{l}\text { C3 }= \\
\text { C4= } \\
\text { C7 }= \\
\text { C8 }\end{array}$} & C7 \\
\hline C8 & $\leq 800 \mathrm{~m}$ & II e III & 3.500 & $2,25 \mathrm{~m}$ & & & & C8 \\
\hline C9 & $\geq 5.000 \mathrm{~m}$ & - & 0 & 0 & C9 & & \multirow{2}{*}{$\begin{array}{l}\mathrm{C} 9= \\
\mathrm{C} 10\end{array}$} & \\
\hline C10 & $\geq 5.000 \mathrm{~m}$ & - & 0 & $2,25 \mathrm{~m}$ & C10 & & & \\
\hline C11 & $\geq 5.000 \mathrm{~m}$ & - & 3.500 & 0 & C11 & & \multirow{2}{*}{$\begin{array}{l}\text { C11= } \\
\text { C12 }\end{array}$} & \\
\hline C12 & $\geq 5.000 \mathrm{~m}$ & - & 3.500 & $2,25 m$ & $\mathrm{C} 12$ & & & \\
\hline
\end{tabular}

FONTE: Proposto pelo autor com base nas especificações da ICAO e da FAA para BPRWs e OFZs de transição interna.

Sobre os dados, cabe lembrar que:

Para aeronaves que esperam para entrar na RW: foram utilizados os critérios $F$ e $G$ da Tabela 4.9-2. O critério $H$ não foi utilizado em função de simplificações, assumindo-se que a ponta da asa não fique à frente do nariz e assumindo-se $\mathrm{z}_{\text {nar }}$ como a altura máxima de dois pontos: nariz e asa. Ainda por simplificação, para a variável lest utiliza-se o comprimento máximo da aeronave. Já ang vale $45^{\circ}$.

Para aeronaves que acabam de deixar a RW: Foi utilizado o critério G da Tabela 4.9-2. Não considerou-se nas análises a ponta da asa (critério $\mathrm{H}$ ), assumindo-se a hipótese simplificadora de que a ponta da asa não estará mais perto do centro da RW do que o estabilizador.

Cabe lembrar que se atribuiu à folga $\Delta$ a diferença de elevação entre a cabeceira e a RW.

$\mathrm{Na}$ Tabela 5.6-6 analisam-se os casos em que o padrão para a posição da BPRW não é suficiente para atendimento da OFZ de transição interna. Os dados que dão suporte às análises podem ser vistos nos ANEXOS D, E, F, G e H. 
Tabela 5.6-6 - Comparação entre os padrões da ICAO e da FAA para BPRWs e OFZs de transição interna

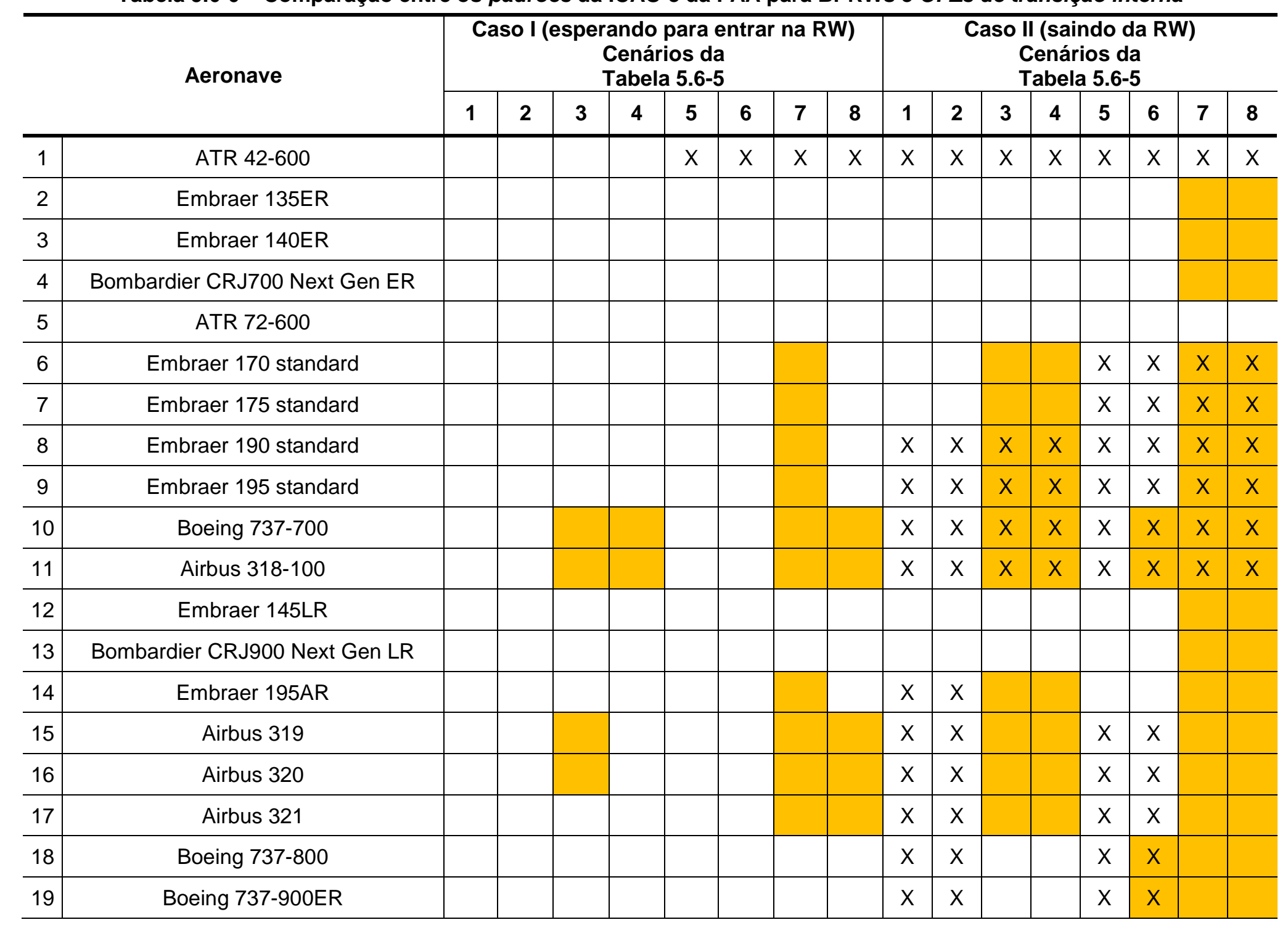




\begin{tabular}{|c|c|c|c|c|c|c|c|c|}
\hline & \multirow[t]{2}{*}{ Aeronave } & \multicolumn{5}{|c|}{$\begin{array}{c}\text { Caso I (esperando para entrar na RW) } \\
\text { Cenários da } \\
\text { Tabela 5.6-5 } \\
\end{array}$} & \multicolumn{2}{|c|}{$\begin{array}{c}\text { Caso II (saindo da RW) } \\
\text { Cenários da } \\
\text { Tabela 5.6-5 } \\
\end{array}$} \\
\hline & & 1 & 2 & 3 & 4 & 5 & 7 & 8 \\
\hline 20 & Boeing 767-300ER & & & & & & & \\
\hline 21 & Boeing 787-8 & & & & & & & \\
\hline 22 & Airbus 330-200 & & & & & & & \\
\hline 23 & Airbus $330-300$ & & & & & & & \\
\hline 24 & Boeing 777-200ER & & & & & & & \\
\hline 25 & Boeing 777-200LR & & & & & & & \\
\hline 26 & Boeing 777-300ER & & & & & & & \\
\hline 27 & Airbus 330-200F & & & & & & & \\
\hline 28 & Airbus 340-500 & & & & & & & \\
\hline 29 & Boeing 747-8 & & & & & $>$ & $x$ & $x$ \\
\hline 30 & Boeing 747-8F & & & & & $>$ & $x$ & $x$ \\
\hline 31 & Airbus 380-800 & $\mathrm{X}$ & $\mathrm{x}$ & $x$ & $x$ & $>$ & $\mathrm{X}$ & $x$ \\
\hline
\end{tabular}

FONTE: Adaptado a partir dos dados da Tabela 5.1-1 e das especificações da ICAO e da FAA para BPRWs e para OFZs de transição interna.

\section{LEGENDA:}

$\mathrm{X}$ A especificação da ICAO para a BPRW não é suficiente para garantir o atendimento à OFZ de transição interna da ICAO.

A especificação da FAA para a BPRW não é suficiente para garantir o atendimento à OFZ de transição interna da FAA. 
A partir desta tabela e dos dados apresentados nos ANEXOS D, E, F, G e H, verifica-se que:

- O atendimento da $O F Z$ de transição interna não é garantido pelo padrão de posição da BPRW para nenhum dos cenários, nem para o caso I, nem para o caso II;

- No entanto, excluindo-se a aeronave A380-800, o padrão da FAA para BPRWs garante a OFZ ao nível do mar para o caso I; e

- Os padrões para BPRWs da ICAO e da FAA diferem em muitas situações, atingindo as seguintes diferenças máximas: i) para o cenário 7, aeronave 12 , o padrão da ICAO supera o padrão da FAA em 61,7m; e ii) para o cenário 11 , aeronave 29 , o padrão da FAA supera o padrão da ICAO em $45 \mathrm{~m}$.

\section{7 ÁREAS DE PROTEÇÃO DA RW}

De forma a proteger-se as operações em RWs quanto a riscos que incluem veering-offs, undershootings, overrunnings e interferência com auxílios rádio à navegação aérea, a ICAO estabelece a faixa da RW e a RESA. Com objetivo similar, a FAA estabelece a ROFA e a RSA. A FAA estabelece também a RPZ, que é uma área destinada à proteção de pessoas e bens no solo. A ICAO não estabelece nenhuma área com esta função. ${ }^{41}$

Estas áreas são aqui comparadas com base em dois tipos de especificações: especificações dimensionais e especificações de preparação e uso. As especificações dimensionais, como o próprio nome sugere, definem a extensão e a posição das áreas em relação à RW. Já as especificações não dimensionais definem basicamente critérios de preparação do terreno e de controle de objetos. As comparações aqui propostas também estão divididas entre comparação dimensional e comparação quanto ao uso e preparação.

\subsubsection{COMPARAÇÃO DIMENSIONAL}

As especificações para as três áreas da faixa da $R W$, para a RESA, para a ROFA e para a RSA dependem do ARC da aeronave e do tipo de pista. No caso da ICAO, os tipos de pista previstos são: pista para aproximação de precisão; pista para aproximação de não precisão e pista para aproximação visual. No caso da FAA o

\footnotetext{
${ }^{41}$ Embora a RESA se estenda na extremidade da RW, suas dimensões são muito inferiores às da RPZ, sendo similares às da ROFA.
} 
tipo de pista depende da visibilidade de aproximação, que pode ser maior ou igual a $1.200 \mathrm{~m}$ e menor do que esse valor. De forma a fazer-se comparações em condições equivalentes, considera-se apenas dois tipos de pistas: Cenário 1) com visibilidade menor ou igual a $800 \mathrm{~m}$; Cenário 2) com visibilidade maior ou igual a $5.000 \mathrm{~m}$. Assim, não entram nas comparações as especificações da ICAO referentes a pistas para aproximação de não precisão. Devido à diferença de especificação de ARCs entre a ICAO e a FAA, utilizam-se as aeronaves da Tabela 5.1-1.

Os dados referentes à largura de cada uma das áreas em estudo deram origem aos gráficos da Figura 5.7-1 e da Figura 5.7-2 e estão disponíveis nos Anexos M e $\mathrm{N}$, respectivamente. Admite-se para a RESA a largura da área preparada da faixa da $R W$ (APFRW), conforme a recomendação da ICAO, o que elimina a necessidade de representação desse dado separadamente.

Já os dados referentes ao comprimento de cada uma das áreas em estudo deram origem aos gráficos da Figura 5.7-3 e da Figura 5.7-4 e estão disponíveis nos ANEXOS M e N, respectivamente. Nestes gráficos, apresenta-se: o comprimento da faixa da RW (desde a cabeceira ou final da RW); a posição do final da RESA (desde a cabeceira ou final da RW, o qual inicia no limite da faixa da RW); a ROFA (desde a ASDA ou LDA ou final da RW); e a RSA. Para esta última, apresentam-se as distâncias $\mathrm{L}_{1}$ (desde a cabeceira) e $\mathrm{L}_{2}$ (desde a ASDA ou LDA ou final da RW).

Os resultados são discutidos a seguir.

Em relação à largura, para as aeronaves avaliadas, em pistas para aproximação de precisão, a área geral da faixa da RW (AGFRW) é a área mais larga, com 300m de largura, seguida pela ROFA, com 240m de largura. Já a área preparada da faixa da $R W$ (APFRW), a área restrita da faixa da $R W$ (ARFRW) e a RSA se alternam com larguras entre $80 \mathrm{~m}$ e $150 \mathrm{~m}$.

Ainda em relação à largura, para as aeronaves avaliadas, em pistas para aproximação visual, a ROFA é a área mais larga, com 240m, seguida pela AGFRW, com $150 \mathrm{~m}$, a não ser para $1^{\mathrm{a}}$ aeronave (ATR 42-600) para a qual a AGFRW possui $80 \mathrm{~m}$ de largura. A APFRW coincide com a AGFRW para todos os casos. Já a largura da RSA varia entre $90 \mathrm{~m}$ e $150 \mathrm{~m}$. 


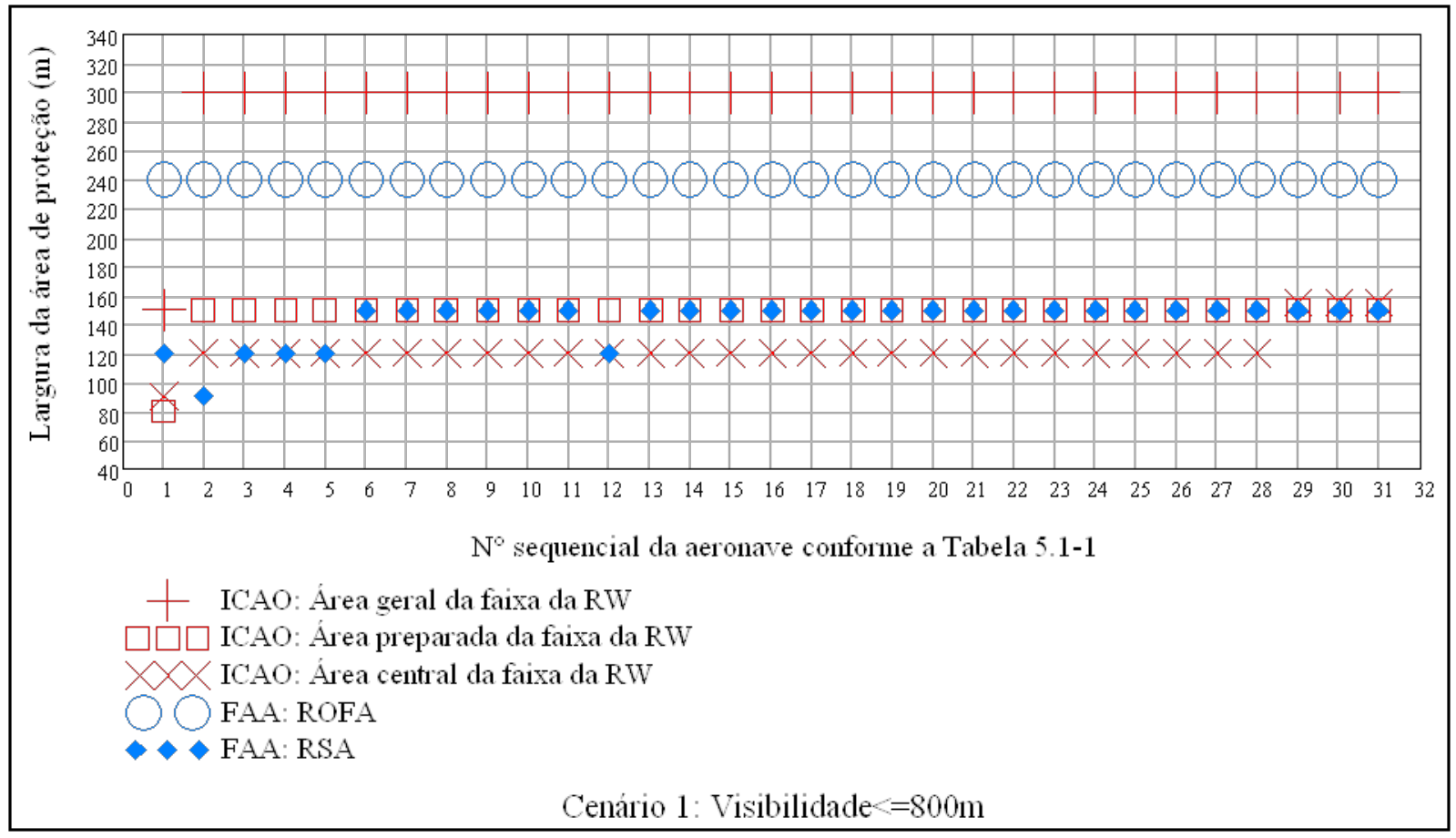

Figura 5.7-1- Comparação entre as especificações da ICAO e da a FAA para a largura das áreas de proteção da RW, com base nas aeronaves da Tabela 5.1-1. Cenário 1. Dados disponíveis no ANEXO M. FONTE: Preparado a partir dos dados das aeronaves e das especificações da ICAO e da FAA

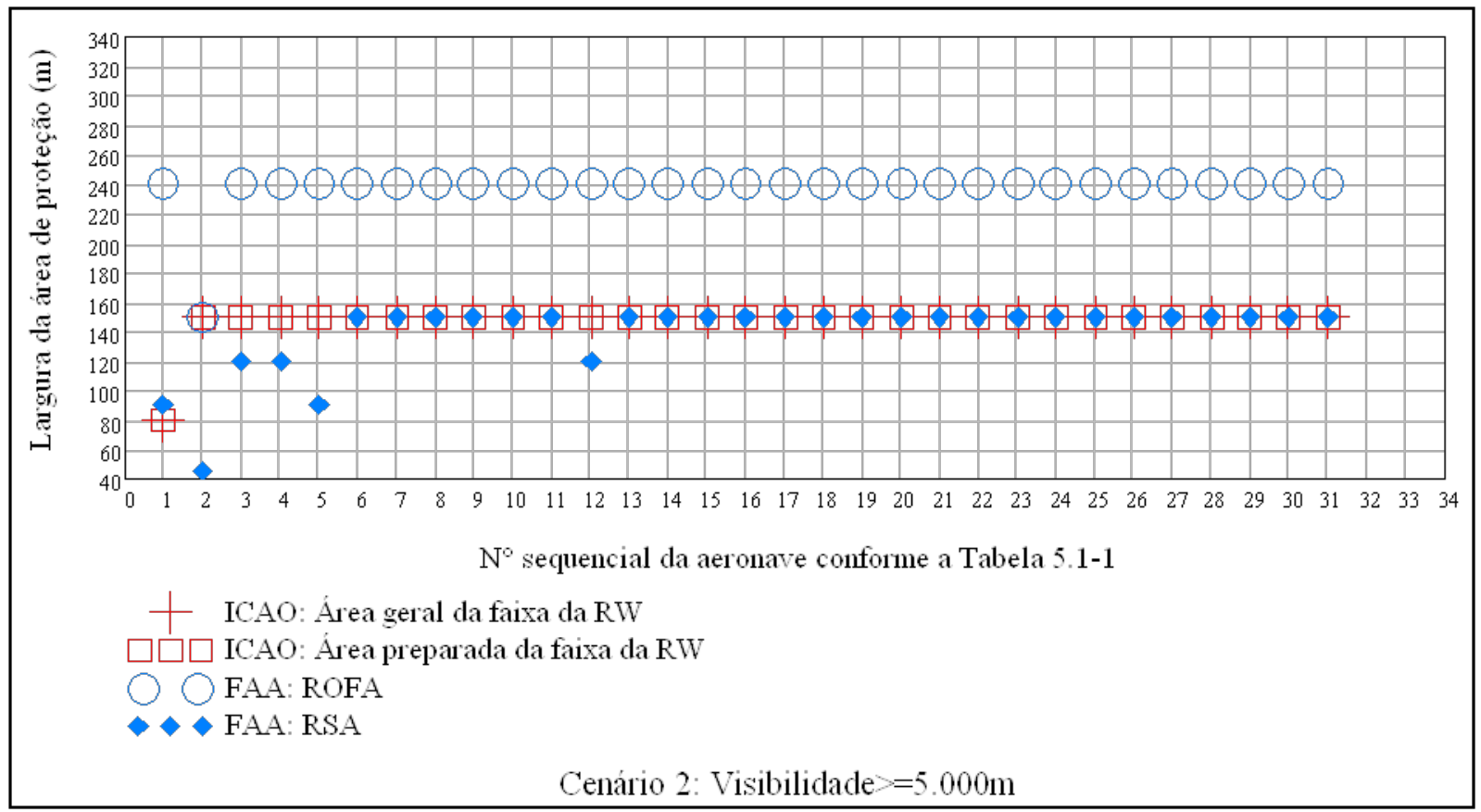

Figura 5.7-2- Comparação entre as especificações da ICAO e da FAA para a largura das áreas de proteção da RW, com base nas aeronaves da Tabela 5.1-1. Cenário 2. Dados disponíveis no ANEXO N. FONTE: Preparado a partir dos dados das aeronaves e das especificações da ICAO e da FAA 


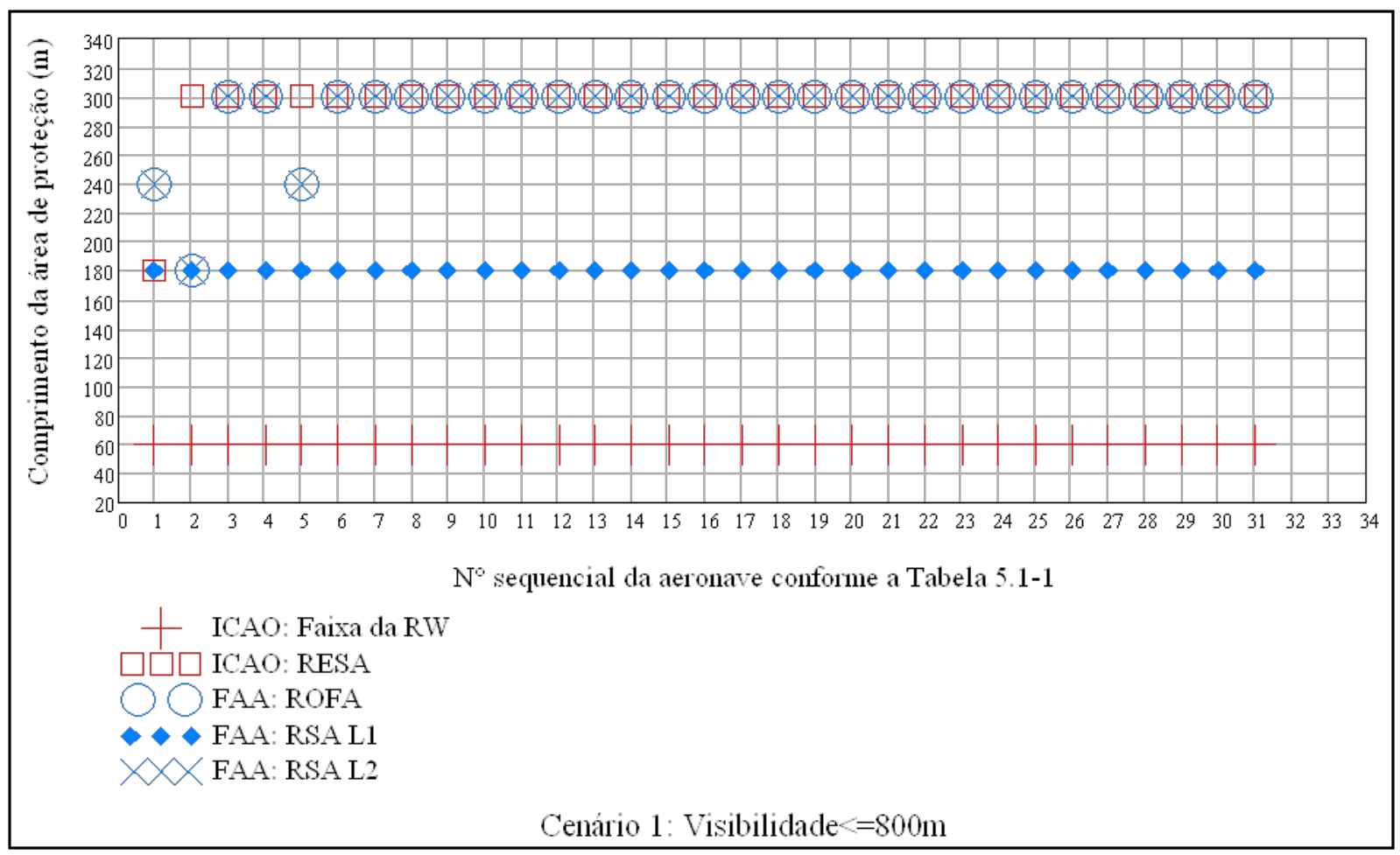

Figura 5.7-3- Comparação entre as especificações da ICAO e da FAA para o comprimento das áreas de proteção da RW desde o final da RW, com base nas aeronaves da Tabela 5.1-1. Cenário 1. Dados disponíveis no ANEXO M. FONTE: Preparado a partir dos dados das aeronaves e das especificações da ICAO e da FAA

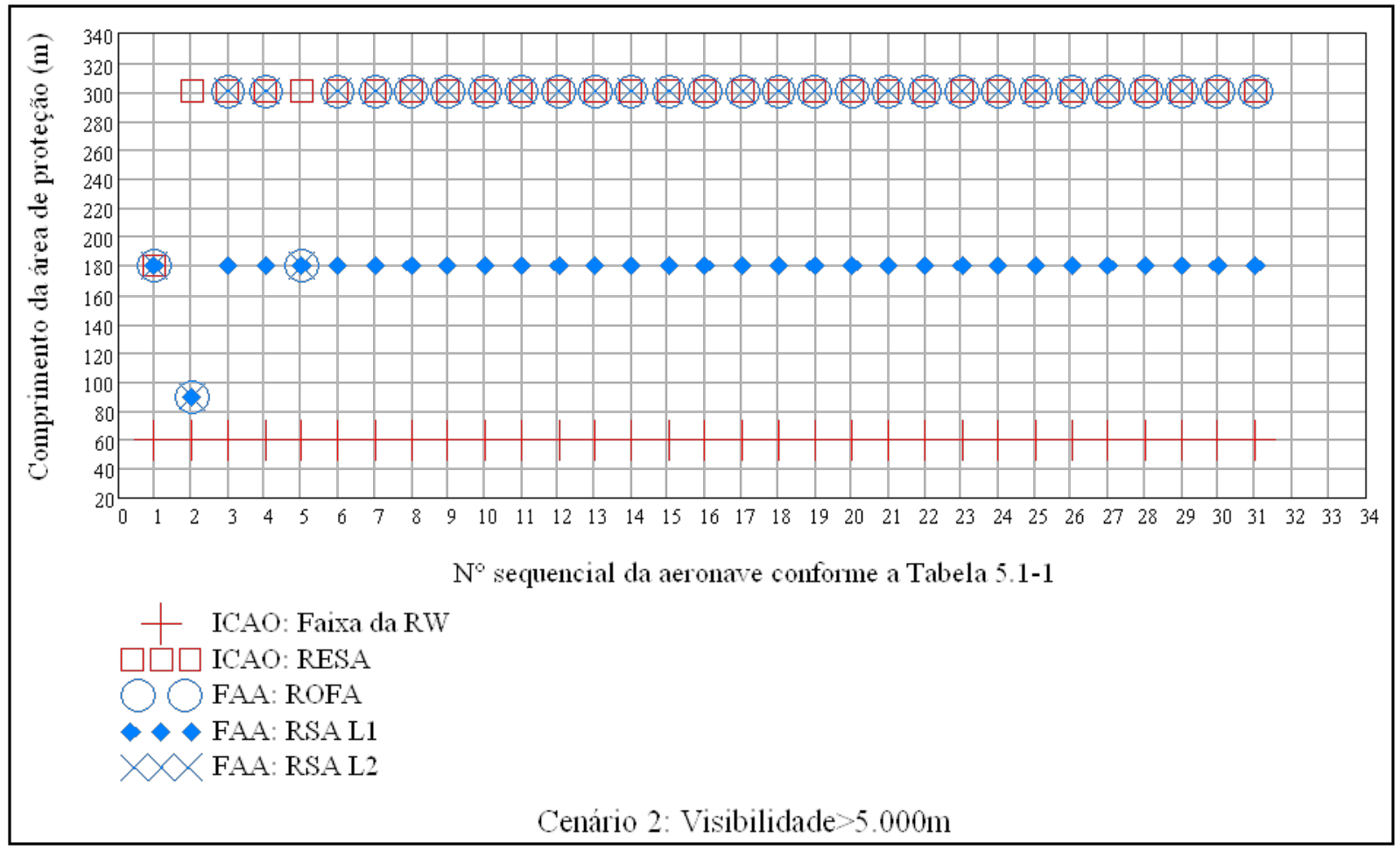

Figura 5.7-4- Comparação entre as especificações da ICAO e da FAA para o comprimento das áreas de proteção da RW desde o final da RW, com base nas aeronaves da Tabela 5.1-1. Cenário 2. Dados disponíveis no ANEXO N. FONTE: Preparado a partir dos dados das aeronaves e das especificações da ICAO e da FAA 
Em relação ao comprimento, em pistas não sujeitas a distâncias declaradas, para as aeronaves avaliadas, em pistas para aproximação de precisão, com exceção das aeronaves 1, 2 e 5, o final da RESA, da ROFA e da RSA coincidem $300 \mathrm{~m}$ além dos finais de pista. Já no caso de distâncias declaradas muitas diferenças são esperadas, a partir dos diferentes referenciais para estas áreas.

Ainda em relação ao comprimento, em pistas não sujeitas a distâncias declaradas, para as aeronaves avaliadas, em pistas para aproximação visual, as conclusões encontradas são iguais às das pistas para aproximação de precisão.

\subsubsection{COMPARAÇÃO QUANTO AO USO E PREPARAÇÃO}

A comparação quanto ao uso e preparação é feita através da Tabela 5.7-1, que apresenta as especificações da ICAO e da FAA sobre estas áreas com respeito ao controle de objetos (presença de aeronaves, objetos e equipamentos) e quanto à preparação da superfície. Nessa tabela, os critérios mencionados pelas normas são classificados em exigido, excluído e permitido. Utiliza-se um contraste de cores de fundo e fonte para melhor visualização.

Nota-se um certo padrão de semelhança entre as áreas da ICAO e da FAA, embora critérios em relação a objetos e preparação não sejam idênticos. Serve de exemplo a ARFRW e a RSA que excluem aeronaves taxiando, em espera e estacionadas, o que impede que estas áreas contenham pistas de táxi e barras de parada da RW (BPRW). Já a APFRW guarda relação com a RSA, haja vista a exigência de que estas áreas devem possuir capacidade de suporte tal a permitir a desaceleração das aeronaves sem induzir-lhes danos. No sentido de servir como critério para a separação entre RWs e TWs, são equivalentes a AGFRW e a RSA. Dessas áreas, percebe-se que a ROFA é a menos demandante em termos de critérios de controle de objetos e preparação. 
Tabela 5.7-1 - Comparação quanto ao uso e preparação das áreas de proteção da RW

\begin{tabular}{|c|c|c|c|c|c|c|c|}
\hline \multirow{3}{*}{\multicolumn{2}{|c|}{ Critérios }} & \multicolumn{4}{|c|}{ ICAO } & \multicolumn{2}{|c|}{ FAA } \\
\hline & & \multicolumn{3}{|c|}{ Faixa da RW } & \multirow{2}{*}{ RESA } & \multirow{2}{*}{ ROFA } & \multirow{2}{*}{ RSA } \\
\hline & & AGFRW & APFRW & ARFRW & & & \\
\hline \multirow{3}{*}{ Aeronaves } & Em espera & permitido & permitido & excluído & & permitido & excluído \\
\hline & Taxiando & excluído & excluído & excluído & & permitido & excluído \\
\hline & Estacionadas & excluído & excluído & excluído & & excluído & excluído \\
\hline Objetos & $\begin{array}{l}\text { Objetos que não sejam estritamente necessários às } \\
\text { operações }\end{array}$ & excluído & excluído & excluído & excluído & excluído & excluído \\
\hline \multirow{2}{*}{ Equipamentos } & $\begin{array}{l}\begin{array}{l}\text { Equipamentos necessários à movimentação de } \\
\text { aeronaves }\end{array} \\
\end{array}$ & excluído & excluído & excluído & & permitido & excluído \\
\hline & $\begin{array}{l}\text { Equipamento indispensáveis devem ser montados sore } \\
\text { bases frangíveis }\end{array}$ & exigido & exigido & exigido & exigido & & exigido \\
\hline \multirow{7}{*}{ Preparação } & $\begin{array}{l}\text { Uso de chanfros } 30 \mathrm{~cm} \text { abaixo do nível solo, para proteger } \\
\text { aeronaves que saíram da RW e cujas rodas afundaram } \\
\text { no solo }\end{array}$ & exigido & exigido & exigido & & & \\
\hline & $\begin{array}{l}\text { Capacidade de suporte suficiente para desacelerar as } \\
\text { aeronaves sem causar-Ihes danos }\end{array}$ & & exigido & exigido & exigido & & exigido \\
\hline & $\begin{array}{l}\text { A área situada a } 30 \mathrm{~m} \text { da cabeceira deve ser protegida } \\
\text { contra erosão }\end{array}$ & exigido & exigido & exigido & & & \\
\hline & Declividades longitudinais e transversais especificadas & & exigido & exigido & exigido & & \\
\hline & $\begin{array}{l}\text { Deve ser limpa e nivelada, sem sulcos, protuberâncias, } \\
\text { depressões ou outras variações de superfície. }\end{array}$ & & & & & & exigido \\
\hline & $\begin{array}{l}\text { Drenada, seja por abaulamento, seja pelo uso de bocas } \\
\text { de lobo, para evitar acúmulo de água. }\end{array}$ & & & & & & exigido \\
\hline & $\begin{array}{l}\text { Capaz de suportar, sob condições secas, equipamento de } \\
\text { remoção de neve, equipamentos de resgate e combate a } \\
\text { incêndio e a passagem eventual de aeronaves sem } \\
\text { induzir a danos à mesma. }\end{array}$ & & & & exigido & & exigido \\
\hline
\end{tabular}

FONTE: Compilado a partir das especificações contidas na ICAO Annex 14 (2004a) e na FAA AC 150/5300-13 (1989). 


\section{8 ÁREAS DE PROTEÇÃO DA TW}

As áreas de proteção da TW são a faixa da TW (ICAO), a OFA da TW (FAA) e a TSA (FAA). A Figura 5.8-1 compara a largura destas áreas.

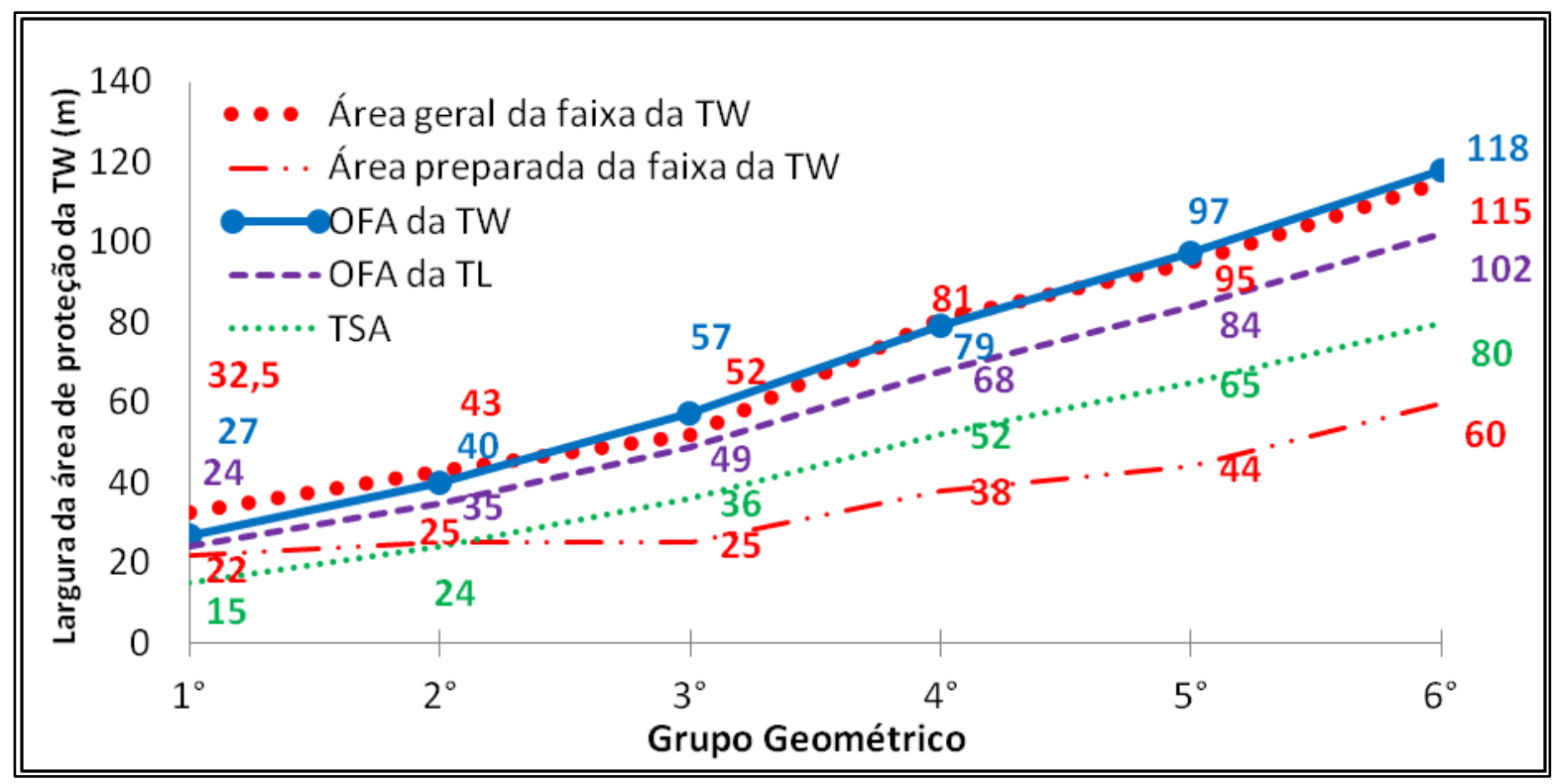

Figura 5.8-1- Comparação entre as especificações da ICAO e da FAA para a largura das áreas de proteção da TW. FONTE: Preparado a partir das especificações da ICAO e da FAA

Em relação à largura, diretamente a partir das especificações, percebe-se três grupos, discutidos a seguir.

A área geral da faixa da TW (AGFTW) e a OFA da TW são as áreas mais largas, sendo que a diferença máxima nas especificações entre os grupos geométricos varia entre $2,1 \%$ e $12,5 \%$.

Em seguida vem a OFA da TL.

Por último, tem-se a TSA e a área preparada da faixa da TW (APFTW), entre as quais a diferença máxima de largura entre os grupos geométricos varia entre $4,1 \%$ e $47,7 \%$.

Já a Tabela 5.8-1 compara as especificações para estas áreas quanto à presença de aeronaves, objetos, equipamentos, vias de serviço e quanto à preparação. Nessa tabela, os critérios mencionados pelas normas são classificados em exigido, excluído e permitido. Utiliza-se um contraste de cores de fundo e fonte para melhor visualização. 
Tabela 5.8-1 - Comparação das especificações quanto ao uso e preparação das áreas de proteção da TW

\begin{tabular}{|c|c|c|c|c|c|c|}
\hline & \multirow{3}{*}{ Critérios } & \multicolumn{3}{|c|}{ ICAO } & \multicolumn{2}{|c|}{ FAA } \\
\hline & & \multicolumn{2}{|c|}{ Faixa da TW } & \multirow{2}{*}{$\begin{array}{l}\text { OFA da } \\
\text { TW }\end{array}$} & \multirow{2}{*}{$\begin{array}{l}\text { OFA da } \\
\text { TL }\end{array}$} & \multirow{2}{*}{ TSA } \\
\hline & & AGFTW & APFTW & & & \\
\hline \multirow{3}{*}{ Aeronaves } & Em espera & excluído & excluído & excluído & excluído & \\
\hline & Taxiando & excluído & excluído & excluído & excluído & \\
\hline & Estacionadas & excluído & excluído & excluído & excluído & \\
\hline \multirow{2}{*}{ Objetos } & Livre de objetos que possam oferecer risco às aeronaves que taxiam & exigido & exigido & & & \\
\hline & Veículos, desde que dando passagem às aeronaves & & & permitido & permitido & \\
\hline Equipamentos & Equipamentos necessários à movimentação de aeronaves & & & permitido & & \\
\hline Vias de serviço & Vias de serviço & & & excluído & excluído & excluído \\
\hline \multirow{8}{*}{ Preparação } & Equipamentos indispensáveis devem ser montados sore bases frangíveis & exigido & exigido & & & exigido \\
\hline & $\begin{array}{l}\text { Estruturas de drenagem devem ser adequadamente projetadas, de forma } \\
\text { prevenir danos às aeronaves que acidentalmente saiam da pista (veering- } \\
\text { off) }\end{array}$ & exigido & exigido & & & \\
\hline & $\begin{array}{c}\text { Capacidade de suporte suficiente para os veículos que utilizam a área, } \\
\text { incluindo-se veículos de emergência }\end{array}$ & exigido & exigido & & & exigido \\
\hline & Declividades longitudinais e/ou transversais especificadas & exigido & exigido & & & \\
\hline & Especificações de compactação & & & & & exigido \\
\hline & $\begin{array}{c}\text { Deve ser limpa e nivelada, sem sulcos, protuberâncias, depressões ou } \\
\text { outras variações de superfície. }\end{array}$ & & exigido & & & exigido \\
\hline & $\begin{array}{l}\text { Drenada, seja por abaulamento, seja pelo uso de bocas de lobo, para evitar } \\
\text { acúmulo de água. }\end{array}$ & & & & & exigido \\
\hline & $\begin{array}{c}\text { Capaz de suportar, sob condições secas, equipamento de remoção de neve, } \\
\text { equipamentos de resgate e combate a incêndio e a passagem eventual de } \\
\text { aeronaves sem induzir a danos à mesma. }\end{array}$ & & & & & exigido \\
\hline
\end{tabular}


Em relação aos critérios de controle de obstáculos e preparação, verifica-se que as áreas AGFTW, OFA da TW e OFA da TL estão mais relacionadas ao controle de obstáculos, enquanto a APFTW e a TSA apresentam exigência quanto à capacidade de suporte de forma a não danificar as aeronaves durante veering-offs.

\subsection{OFZ}

Para a ICAO, a OFZ (Object Free Zone) só é exigida em pistas para aproximações de precisão, sendo composta por três superfícies: superfície de aproximação interna, superfície de transição interna e superfície de pouso interrompido ${ }^{42}$. Ainda, a área restrita da faixa da RW (Pista de pouso e decolagem) é similar à OFZ quanto à presença de objetos e, além disso, as especificações das três superfícies da OFZ são atreladas a ela, dependendo do grupo dinâmico e do grupo geométrico.

Já para a FAA, a OFZ é composta por até quatro superfícies: ROFZ (Runway Object Free Zone); OFZ de precisão (POFZ); OFZ de aproximação interna; e OFZ de transição interna. A ROFZ é exigida para qualquer tipo de pista. A POFZ é exigida quando as três situações seguintes coincidem: aproximação verticalmente guiada; teto informado abaixo de 250pés e/ou visibilidade menor do que 3/4 de milha terrestre (ou RVR abaixo de 4.000pés); e uma aeronave encontra-se em aproximação final a menos do que 2 milhas da cabeceira. A OFZ de aproximação interna é exigida somente a RWs com sistema de iluminação. E a OFZ de transição interna é exigida somente para pistas com visibilidade de aproximação menor do que $1.200 \mathrm{~m}$. As especificações dependem do MTOW (Maximum Take-off Weight), da velocidade de aproximação, da envergadura da aeronave crítica e da elevação do aeródromo.

Tomando-se por base a posição das superfícies da OFZ, identificam-se alguns grupos, ilustrados na Figura 5.9-1.

Superfícies no solo: são a área restrita da faixa da RW (ARFRW); a ROFZ; e a POFZ. A ARFRW e a ROFZ prolongam-se $60 \mathrm{~m}$ a partir das extremidades da RW, considerando-se pistas para aproximação de precisão. A largura da ROFZ varia entre $90 \mathrm{~m}$ e $120 \mathrm{~m}$, dependendo se a aeronave é uma aeronave de pequeno porte ou uma aeronave de grande porte, respectivamente. A largura da área restrita da faixa da $R W$ varia entre $90 \mathrm{~m}$ e $155 \mathrm{~m}$, dependendo do ARC e da categoria de

\footnotetext{
${ }^{42}$ Para aproximações menos demandantes do que CAT II/III, estas superfícies não são obrigatórias, embora sejam recomendadas.
} 
aproximação. A POFZ também forma um retângulo centrado na RW, com 240m de largura e 60m de comprimento, anterior à cabeceira. Portanto, a POFZ está longitudinalmente contida na ROFZ, embora, lateralmente, supere a ROFZ e a ARFRW $^{43}$;

Superfícies de aproximação: a superfície interna de aproximação da ICAO e da FAA iniciam-se a $60 \mathrm{~m}$ da cabeceira e se estendem para fora da RW, ao longo do seu eixo estendido. Para a ICAO a largura é mesma da ARFRW (variando entre 90m e $155 \mathrm{~m}$ ). Para a FAA a largura é a mesma da ROFZ (variando entre 90m e 120m). Para a ICAO, a declividade varia entre 1:40 e 1:50 (vertical:longitudinal). Para a FAA, a declividade é de 1:50 (vertical:longitudinal).

Superfície de pouso perdido (balked landing surface): é especificada somente pela ICAO, sendo similar a uma superfície de aproximação interna. A sua largura é a mesma da ARFRW (que varia entre $90 \mathrm{~m}$ e $155 \mathrm{~m}$ ). A declividade longitudinal varia entre 1:25 e 1:30 (vertical:longitudinal). Lateralmente, desde o seu início, a superfície de pouso interrompido tem a mesma declividade do que a superfície de transição interna. Logo, a superfície de pouso interrompido não terá função caso seja provida uma superfície de aproximação interna na cabeceira da extremidade oposta da RW localizada à sua frente. Como a FAA não especifica uma superfície de pouso interrompido, esta função poderá ser desempenhada pela superfície de aproximação da cabeceira da extremidade oposta da RW, desde que esteja posicionada a uma distância suficiente da cabeceira na qual é feita a aproximação.

Superfície de transição interna: para a ICAO e para a FAA, estas superfícies se iniciam respectivamente na ARFRW (cuja semi-largura varia entre $45 \mathrm{~m}$ e 77,5m) e na ROFZ (cuja largura é de $60 \mathrm{~m}$, para aeronaves de grande porte). A geometria e as especificações da ICAO e da FAA variam com base no ARC das aeronaves, na envergadura e elevação do aeródromo. A Figura 5.9-2 mostra uma comparação entre as OFZs de transição interna da ICAO e da FAA. Conforme as especificações, a ICAO só possui três geometrias possíveis. Já a FAA coloca a envergadura da aeronave e a altitude do aeródromo como variáveis contínuas para a especificação dessa superfície. Nas comparações, para a FAA, admite-se somente o caso de aeronaves de grande porte, adotando-se quatro combinações de envergadura e altitude.

\footnotetext{
${ }^{43}$ Estas conclusões são válidas para pistas não sujeitas a distâncias declaradas.
} 
A partir da Figura 5.9-2, verifica-se que OFZ de transição interna da FAA é mais restritiva do que qualquer reta da ICAO após uma distância de cerca de 195m do centro da RW.

Como a declividade das retas da ICAO é maior do que a declividade das retas da FAA, a partir do ponto de cruzamento entre as duas retas, os critérios da FAA serão mais demandantes. A seguir, compara-se cada uma das retas da ICAO com todas as retas da FAA.

Tomando-se a reta da ICAO associada aos grupos dinâmicos 1 e 2, ela é menos demandante do que qualquer reta da FAA para uma distância entre $45 \mathrm{~m}$ e $60 \mathrm{~m}$ desde o centro da RW. No entanto, a partir de $60 \mathrm{~m}$, desde o centro da RW, a relação entre as retas depende muito da envergadura e da altitude. A reta da FAA associada à envergadura de $15 \mathrm{~m}$ e altitude de $0 \mathrm{~m}$ será ultrapassada verticalmente pela reta da ICAO a cerca de $105 \mathrm{~m}$ do centro da RW. No caso mais restritivo da FAA (env $=80 \mathrm{~m}$ e alt $=3.500 \mathrm{~m}$ ) o cruzamento já ocorrerá a $60 \mathrm{~m}$ do centro da RW.

Já a reta intermediária da ICAO (grupos dinâmicos 3 e 4) parte do mesmo ponto que as retas da FAA (60m desde o centro da RW), ultrapassando verticalmente a reta mais demandante da FAA nesse mesmo ponto e a menos demandante a cerca de $165 \mathrm{~m}$ desde o centro da RW.

Por fim, a reta mais demandante da ICAO (grupos dinâmicos 3 e 4, grupo geométrico F)) será mais demandante do que qualquer reta da FAA até uma distância de cerca de $90 \mathrm{~m}$, desde o centro da RW. A reta da ICAO ultrapassará verticalmente a reta menos demandante da FAA a cerca de $195 \mathrm{~m}$ do centro da RW.

Cabe colocar-se que a não utilização das variáveis envergadura, altitude e categoria de aproximação pela ICAO, faz com que as suas OFZs de transição interna possuam características intermediárias entre aquelas especificadas pela FAA. Essa conclusão é válida para o envelope, indicado na Figura 5.9-2, criado pela combinação das seguintes situações: i) distância do centro da RW maior do que $85 \mathrm{~m}$; ii) altura da OFZ menor do que $22 \mathrm{~m}$, para aeronaves dos grupos dinâmicos $1 \mathrm{e}$ 2; altura da OFZ menor do que $35 \mathrm{~m}$, para aeronaves dos grupos dinâmicos 3 e 4; altura da OFZ menor do que $40 \mathrm{~m}$, para aeronaves de ARCs 3-F e 4-F; envergadura entre $15 \mathrm{~m}$ e $80 \mathrm{~m}$; altitude entre $0 \mathrm{~m}$ e $3.500 \mathrm{~m}$; e em condições CAT I, II ou III. 


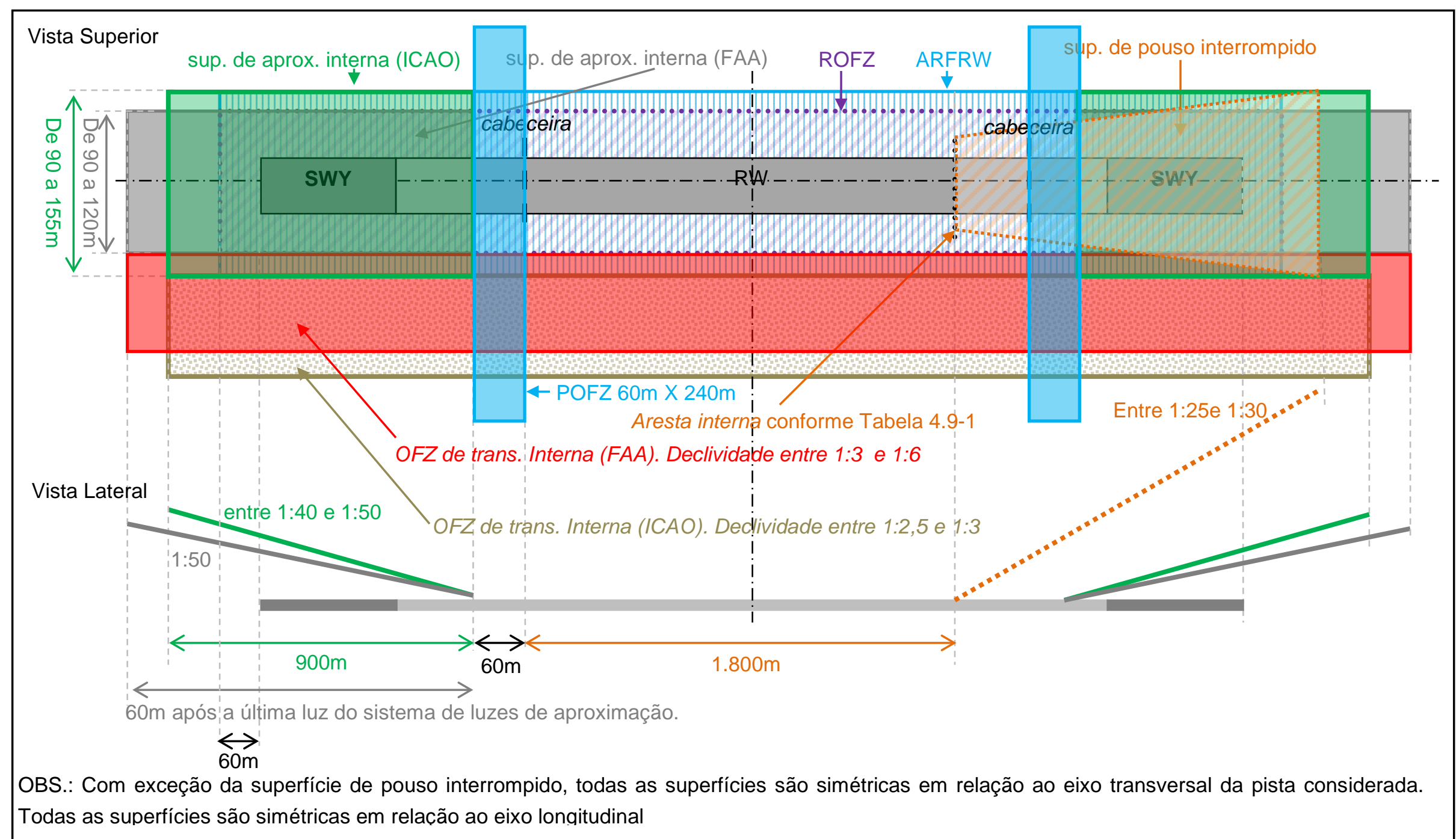

Figura 5.9-1- Comparação entre as especificações da ICAO e da FAA para as superfícies da OFZ. FONTE: Preparado a partir das especificações da ICAO e da FAA 


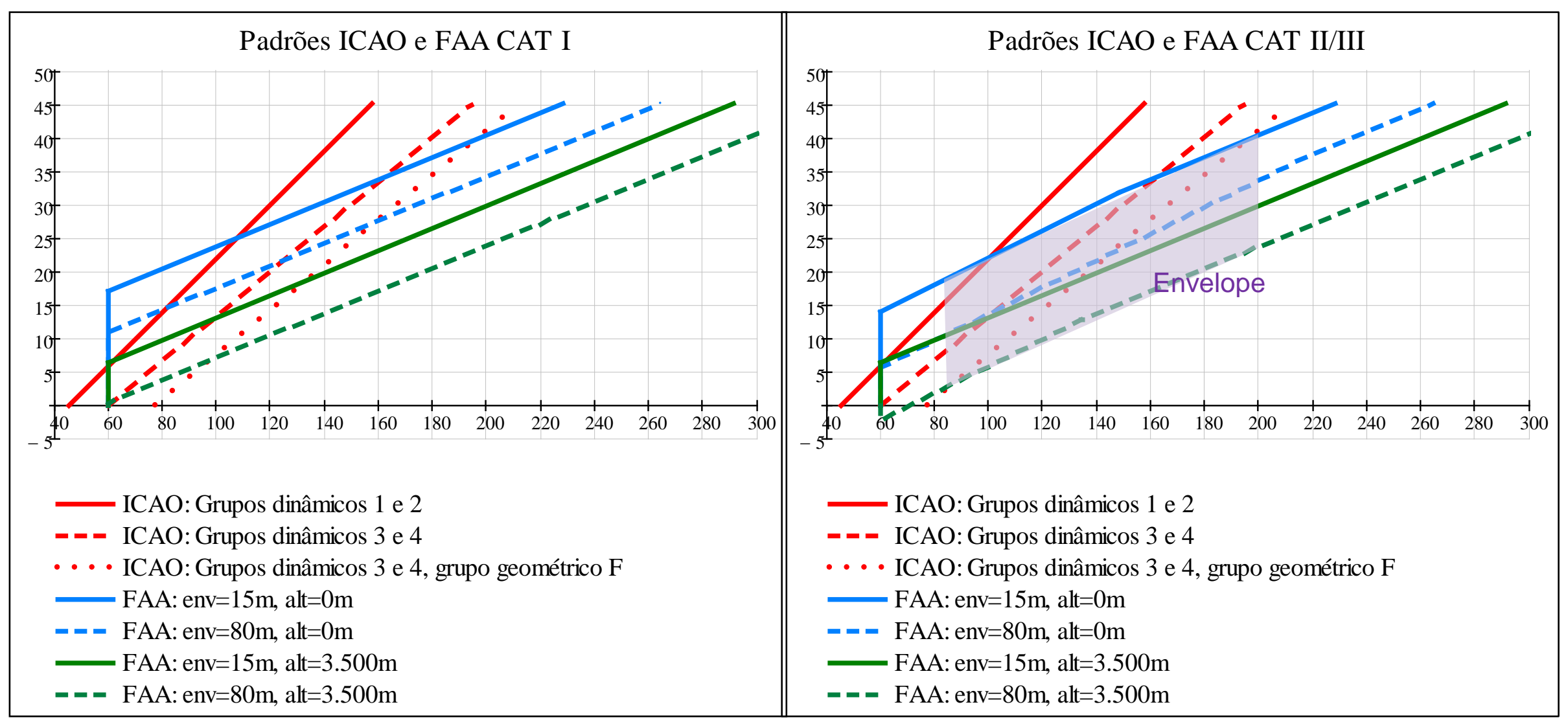

Figura 5.9-2- Comparação entre as especificações da ICAO e da FAA para OFZs de transição interna. FONTE: Preparado a partir das especificações da ICAO e da FAA 


\subsection{CONCLUSÕES DO CAPÍTULO}

Este Capítulo apresentou uma série de comparações entre os critérios da ICAO e da FAA. Algumas destas comparações são feitas diretamente, a partir das especificações das normas. Isso foi possível nos casos em que a base de especificação das duas normas coincide. Para os demais casos, recorre-se a um grupo de 31 aeronaves, comparando-se as especificações associadas a cada aeronave, em cada norma. A seguir são apresentados alguns apontamentos relacionados às comparações entre os diversos critérios, metodologias $e$ considerações de projeto tratados na pesquisa.

Em relação ao ARC (Airport Reference Code), demonstrou-se que os grupos geométricos da ICAO e da FAA são equivalentes para o grupo de 31 aeronaves consideradas e que os grupos dinâmicos diferem bastante entre si. Isso tem consequências diretas sobre os critérios de projeto especificados com base nestes dois grupos.

Em relação ao vento de través de projeto, verificam-se diferenças de até 7nós entre as duas normas para uma mesma aeronave, embora para as aeronaves widebodies analisadas as exigências sejam iguais.

Para a análise dos efeitos do jet blast propõe-se uma estruturação, a partir da categorização dos efeitos do fluxo de ar (EFAs), dos efeitos de erosão (EEs) e dos efeitos do arremesso de materiais (EAMs). A partir dessa categorização evidencia-se a falta de metodologias e critérios adequados para a consideração dos efeitos do jet blast.

Quanto à largura da RW, dos acostamentos e quanto às dimensões de uma blast pad, evidenciam-se as diferenças entre as normas através da apresentação dos padrões exigidos para as 31 aeronaves. No entanto, tal análise não conseguiu apontar uma predominância sistemática das especificações de uma norma em relação às especificações da outra, sendo que os dados parecem variar mais entre as aeronaves do que entre as normas.

A partir das especificações, percebe-se que a folga do pavimento é igual para todos os grupos geométricos, com exceção do $6^{\circ}$ grupo geométrico. Já a largura padrão da TW varia para o $4^{\circ}$ e para o $6^{\circ}$ grupos geométricos. Já as especificações para os acostamentos e para as larguras combinadas entre TWs e acostamentos 
levam a diferenças expressivas entre as normas para todos os grupos geométricos, com exceção do $4^{\circ}$ e do $5^{\circ}$, nos quais as especificações coincidem.

Quanto às pistas de táxi de saída rápida, verifica-se que a ICAO e a FAA apresentam geometrias padrão e que a ICAO apresenta também metodologias e princípios de projeto.

Em relação a pistas de táxi sobre pontes, para a ICAO a largura padrão corresponde à área preparada da faixa da TW e para a FAA a largura padrão é a da TSA. Como a largura destas áreas de proteção varia entre as normas, as mesmas diferenças se aplicam para a largura da área de uma pista de táxi sobre ponte com capacidade plena de suporte.

Em relação a distâncias declaradas, verifica-se uma equivalência entre os conceitos TORA, TODA, ASDA e LDA e também entre as especificações associadas a stopways e clearways.

Em relação a curvas e intersecções, verifica-se que ambas as normas apresentam fórmulas simplificadas para a avaliação da trajetória de uma aeronave em uma curva e para o desenho de sobrelarguras. No entanto, a ICAO apresenta também uma abordagem analítica ao tema.

Em relação às separações entre pistas de pouso e decolagem paralelas, a partir das comparações entre as 31 aeronaves, não foi possível apontar-se uma predominância sistemática das especificações de uma norma em relação às especificações da outra. O mesmo pode ser dito para as separações entre pistas de pouso e decolagem e pistas de táxi paralelas.

Em relação à posição de uma barra de parada da pista de pouso e decolagem, verificou-se que os padrões estabelecidos pela ICAO e pela FAA não são suficientes para o atendimento da OFZ (Object Free Zone), nem mesmo ao nível do mar, para todas as aeronaves analisadas.

Em relação às áreas de proteção da pista de pouso e decolagem, verifica-se que as dimensões e as exigências quanto ao uso e preparação variam entre as normas, sendo que a ICAO especifica a faixa da RW e a FAA especifica duas áreas: a ROFA (Runway Object Free Area) e a RSA (Runway Safety Area). O mesmo se pode dizer em relação às áreas de proteção de pistas de táxi, sendo que a ICAO especifica a faixa da pista de táxi e a FAA especifica a TOFA (Taxiway Object Free Area) e a TSA (Taxiway Safety Area). Já para pistas de táxi de acesso ao estacionamento de aeronaves (taxilanes - TLs), a ICAO especifica apenas folgas 
entre a aeronave e objetos, enquanto a FAA especifica a taxiway object free area como área de proteção.

Já quanto à OFZ (Object Free Zone), verifica-se que as superfícies da ICAO, que utilizam menos variáveis para sua especificação, são geometricamente contidas pelas superfícies da FAA, tendo-se em vista o envelope proposto para a altitude, para a geometria da aeronave e para a OFZ. 


\section{CAPÍTULO 6 - ACOMODAÇÃO DE AERONAVES DO $6^{\circ}$ GRUPO GEOMÉTRICO EM AEROPORTOS EXISTENTES}

Este capítulo trata da acomodação de aeronaves dos grupos geométricos ICAO F e FAA VI em aeroportos existentes que não atendem aos requisitos destes grupos.

A introdução de aeronaves como o A380 e o B747-8, ambos dos $6^{\circ}$ grupo geométrico, em aeroportos de código ICAO E ou FAA V, tem motivado uma série de flexibilizações dos padrões de projeto. Isso porque, pode-se atingir o TLS (Target Level of Safety) com a utilização de critérios menos demandantes. Tanto a ICAO quanto a FAA permitem a modificação dos padrões mediante a condução de estudos que demonstrem o atendimento dos níveis de segurança estabelecidos. As flexibilizações são justificadas por argumentos geométricos e pelas características de táxi e vôo de uma determinada aeronave.

Os argumentos geométricos, em geral, são utilizados para os casos em que a envergadura, wheel span ou altura do estabilizador, de uma dada aeronave, é menor do que o limite previsto para o $6^{\circ}$ grupo geométrico. Assim, é possível demonstrar-se diretamente que uma separação menor não implica a violação de uma área de proteção (como uma RPZ, OFA, RSA, TSA, faixa da RW, faixa da TW), de uma OFZ, ou na deterioração de uma margem de segurança (como folga do pavimento, folga de ponta de asa, folga em relação a objetos).

As características de táxi e voo, que justificam a flexibilização dos padrões, podem ser tanto observadas quanto esperadas, a partir de modelos matemáticos e computacionais, e a partir de observações de aeronaves similares.

Uma solução alternativa para a acomodação de aeronaves como o A380 e o B747-8 em aeroportos que não atendem aos requisitos do $6^{\circ}$ grupo geométrico, é o estabelecimento de restrições operacionais. No entanto, esta solução tem o inconveniente de impactar negativamente sobre a capacidade e os atrasos no aeroporto.

Em geral, os aeroportos recorrem a alternativas que mesclam obras de infraestrutura nos componentes críticos, modificações de padrões de projeto e restrições operacionais, avaliando-se os custos das obras e os transtornos operacionais delas advindos.

Este capítulo está organizado da seguinte forma: o item 6.1 trata da flexibilização dos padrões da ICAO para o $6^{\circ}$ grupo geométrico, apresentando 
também um conjunto de documentos relacionados, oriundos de alguns países europeus; e o item 6.2 apresenta aspectos de flexibilização dos padrões da FAA, além de citar as modificações aprovadas pela FAA em diversos aeroportos dos EUA para acomodar as aeronaves A380 e o B747-8.

\subsection{FLEXIBILIZAÇÃO DE PADRÕES DA ICAO}

O NLA Forum ${ }^{44}$ disponibiliza uma série de documentos relacionados à flexibilização de padrões da ICAO para a operação das aeronaves A380 e o B747-8 em aeroportos existentes. Tais documentos não têm validade normativa, mas servem de base para que os Estados autorizem flexibilizações dos padrões de projeto, bem como a operação destas aeronaves em condições não conformes com os padrões da ICAO.

\subsubsection{A380 COMMON AGREEMENT DOCUMENT - AACG}

O A380 Common Agreement Document é um documento que reúne a posição comum da indústria sobre a flexibilização de padrões de projeto para a operação do A380-800 em aeroportos existentes. Estas flexibilizações são:

- Largura da RW: $45 m$ ao invés de $60 m$, com base na certificação da aeronave para esta largura da RW;

- Largura dos acostamentos RW: introduz a ideia de inner shoulder, que consiste em uma parcela do acostamento, adjacente à RW com capacidade de suporte adequada à aeronave crítica; ${ }^{45}$

- Largura da TW: $23 m$ ao invés de $25 m$, com base nos desvios da aeronave em relação à linha de centro, largura do trem principal e visibilidade a partir da cabine de comando;

- Separação entre a RW e uma TW paralela: o padrão de $190 \mathrm{~m}$ é considerado conservador quanto ao risco de colisão, com base na análise de dados de acidentes/incidentes;

- Separação entre duas TWs paralelas: $91 \mathrm{~m}$ ou $11 \mathrm{~m}$ de folga de ponta de asa (inclusive para trechos curvos), com base: i) na ICAO Doc 7754 (2001b) - a mesma margem de $11 \mathrm{~m}$ do 747-400; ii) estudos de desvio da linha de centro da TW; e iii) visão a partir da cabine de comando da aeronave.

\footnotetext{
${ }^{44}$ NLA Forum (2008). Disponível em: https://www.ecac-ceac.org/nla-forum/. Acesso: agosto de 2010.

${ }^{45}$ O AACG não define as características do inner shoulder. Mas com base nos EBs da FAA, pode-se intuir que são um tipo de pavimento com uma capacidade de suporte menor do que aquela da RW.
} 
- Separação entre TWs e objetos: $49 \mathrm{~m}$ ou $9 \mathrm{~m}$ de folga de ponta de asa (inclusive para trechos curvos), com base: i) na ICAO Doc 7754 (2001b) (a mesma margem de $9 \mathrm{~m}$ do 747-400); ii) estudos de desvio da linha de centro da TW; e iii) visão a partir da cabine de comando da aeronave.

- Separação entre TLs e objetos, incluindo vias de serviço: 47,5m ou 7,5m de folga de ponta de asa (inclusive para trechos curvos), com base: i) na ICAO Doc 7754 (2001b) - a mesma margem de 7,5m do B747-400; ii) estudos de desvio da linha de centro da TL; e iii) visão a partir da cabine de comando da aeronave;

- Largura da ponte em uma TW: mínimo de $49 \mathrm{~m}$ para a parte capaz de suportar o A380 e operações de emergência e mínimo de $60 \mathrm{~m}$ por questões de jet blast. Fatores que suportam a flexibilização: i) comparação com o B747 operando em uma ponte de código E; ii) envergadura da aeronave e posição dos motores; e iii) contornos de velocidade e temperatura durante o táxi.

\subsubsection{B747-8 COMMON AGREEMENT DOCUMENT - BACG}

O B747-8 Common Agreement Document é um documento que reúne a posição comum da indústria sobre a flexibilização de padrões de projeto para a operação do B747-8 em aeroportos existentes. O documento segue o modelo apresentado na ICAO Cir 301 (2005b): Identificação de riscos, análise causal, análise de consequências e medidas mitigatórias.

As flexibilizações apontadas são:

- Largura da RW: $45 m$ ao invés de $60 m$;

- Largura dos acostamentos da RW: permite a largura RW+acostamentos de $60 \mathrm{~m}$, ao invés de $75 \mathrm{~m}$, com base em: i) a distância entre os motores externos do B747-8 é mesma do B747-400; e ii) a velocidade de $56 \mathrm{~km} / \mathrm{h}$ (35mph) (contorno do jet blast na potência de decolagem) fica confinada a uma largura de 58,5m, pouco a mais que o B747-400ER, cuja largura é de $56,1 \mathrm{~m}$. Portanto a nova aeronave não ultrapassa o limite de $60 \mathrm{~m}$;

- Largura de uma TW: $23 m$ ao invés de $25 m$, com base na largura do trem de pouso e em estudos que demonstram que a margem de 4,5m é adequada;

- Largura dos acostamentos da TW: permite a largura TW+acostamentos de $44 \mathrm{~m}$, ao invés de $60 \mathrm{~m}$, com base em: i) a distância entre os motores externos do B747-8 é mesma do 747-400ER; ii) a velocidade de $56 \mathrm{~km} / \mathrm{h}$ 
(contorno do jet blast na potência de partida) fica confinada a uma largura de 46,9m, a mesma do B747-400ER; e iii) a altura do centro de empuxo do motor mais externo do B747-8 é levemente maior do que a do B747-400ER;

- Separação entre a RW e uma TW paralela: $182,5 \mathrm{~m}$ ao invés de $190 \mathrm{~m}$ para pistas de aproximação por instrumentos, com base: i) na tendência declinante de saídas de RW de aeronaves B747; ii) crescimento de semienvergadura de somente $1,7 \mathrm{~m}$; iii) a separação baseada na OFZ é de $118,8 \mathrm{~m}$; e iv) a separação baseada na proteção da área preparada da faixa da $R W$, em relação a um B747-8 que taxia, é de 139,2m. No entanto são necessários estudos específicos no aeroporto para avaliação da interferência ILS. Neste caso colabora o fato de a altura do estabilizador da nova aeronave ser a mesma do B747-400;

- OFZ: aeronaves do grupo geométrico F podem operar de forma segura na OFZ do grupo E, conforme exposto no item 6.1.3 desta dissertação;

- Distância da linha de espera: $90 \mathrm{~m}$ ao invés de 107,5m do padrão, com base em: i) aplicabilidade da OFZ do código E; ii) $90 \mathrm{~m}$ é o padrão do grupo $\mathrm{E}$, com base na mesma altura do estabilizador das aeronaves B747-8 e B747-400; e iii) menor risco de colisão pois a fuselagem é mais longa, o que põe o estabilizador a uma distância maior do centro da RW. No entanto são necessários estudos específicos no aeroporto para avaliação da interferência ILS. Neste caso colabora o fato de a altura do estabilizador da nova aeronave ser a mesma do B747-400;

- Separação entre duas TWs: folga entre pontas de asas mínima de $11 \mathrm{~m}$, para duas aeronaves alinhadas com o centro de TWs paralelas, ou em curva seguindo a linha guia. Suportam essa flexibilização: i) recomendações da ICAO Doc 7754 (2001b); ii) estudos estatísticos de desvios na TW; iii) conclusão do AACG permite a utilização desta separação para o A380, desde que luzes sejam providas no centro da RW ou que orientação equivalente seja fornecida. Em condições de baixa visibilidade deve ser provida iluminação da linha guia ou orientação equivalente (marshaller, por exemplo)

- Separação entre uma TW e um objeto: folga de ponta de asa mínima de $9 \mathrm{~m}$ contra o padrão de 17,5m. Mesmas justificativas apresentadas na separação entre duas TWs.

- Separação entre uma TL e um objeto: margem mínima de 7,5m contra 0 padrão de $10,5 m$ considerando movimentos retilíneos ou quando a linha guia 
é seguida (cockpit over centerline). Mesmas justificativas apresentadas na separação entre duas TWs.

- Largura da ponte em uma TW: mínimo de $44 m$ para a parte capaz de suportar o B747-8 e operações de emergência e por questões de jet blast. Os fatores que suportam a flexibilização: i) mesmo wheel span do B747; ii) mesma distância entre os motores externos do B747; e iii) contornos de velocidade durante o táxi similares ao B747-400;

- RESA: largura mínima de $90 \mathrm{~m}$ com base no dobro da largura da RW, baseando em: i) previsão de aprovação de uso de RWs de $45 \mathrm{~m}$ pela EASA e FAA; ii) histórico satisfatório da operação do B747 em RWs de $45 \mathrm{~m}$ de largura; e iii) saídas da RW diminuíram significativamente durante o período de serviço do B747.

Os anexos do referido documento obedecem à seguinte descrição:

- Anexo A: Análise de riscos para os componentes do lado aéreo seguindo o modelo apresentado na ICAO Cir 301 (2005b): identificação de riscos; análise causal; análise de consequências e medidas mitigatórias;

- Anexo B: Características físicas e desempenho da aeronave B747-8;

- Anexo C: Lista de estudos e referências relacionados aos padrões e recomendações da ICAO Annex14 (2004a);

- Anexo D: Separações em TWs - AOPG $^{46}$ (747-400) versus AACG (A380800);

- Anexo E: uma parte da ICAO Doc 7754 (2001b);

- Anexo F: dados de separações entre RWs e TWs de diversos aeroportos mundiais;

- Anexo G: padrão da FAA para a separação entre RWs e TWs;

- Anexo H: processo para a aprovação da modificação de padrões de projeto na FAA;

- Anexo I: situação atual da aprovação da operação da aeronave B747-8 em RWs com $45 m$ de largura junto à FAA.

\subsubsection{FLEXIBILIZAÇÃO DA OFZ CONFORME ICAO CIR301 (2005b)}

Esta seção apresenta informações contidas na ICAO Cir 301 (2005b). O propósito do documento é fornecer informações operacionais aos Estados que desejam introduzir aeronaves NLAs em aeroportos existentes com pistas para

\footnotetext{
${ }^{46}$ AOPG - Aerodrome Operations Planning Group. Desenvolveu as exigências operacionais para o 747-400, contidas na ICAO Doc 7754 (2001b)
} 
aproximação de precisão de categorias I, II e III. As informações são baseadas nos resultados de um estudo aeronáutico conduzido pela FAA, o qual investiga a probabilidade de colisão durante um pouso interrompido (balked landing), para uma aeronave de categoria $F$, operando em um aeródromo cujo grupo geométrico é $E$.

As avaliações foram realizadas tanto para o caso de uso de piloto automático como no caso de uso de flight director. Trata-se de um estudo bastante amplo, com a descrição dos cenários, dos métodos de simulação e do tratamento dos dados.

As informações apresentadas a seguir foram extraídas do Capítulo 3 da Parte I da ICAO Cir 301 (2005b), fornecendo informações sobre como implementar os resultados do estudo em aeroportos de categoria $E$ que esperam acomodar aeronaves do grupo geométrico $F$. O estudo sugere que as dimensões da OFZ de pouso interrompido, associada ao grupo geométrico $E$ poderiam ser adequadas para proteger-se uma aeronave abaixo da altura de decisão desde que o piloto automático ou o flight director esteja sendo usado e desde que a função ground track hold esteja em uso.

Especificamente, a OFZ do código $E$ pode ser usada para aeronaves do tipo NLA com estas capacidades. Caso se pretenda operar aterrissagem automática (autoland), é importante que haja proteção adequada aos sinais ILS.

O estudo apontou que $155 \mathrm{~m}$ é um valor adequado e até conservador para a largura da OFZ faixa da pista de pouso e decolagem ${ }^{47}$, para aeronaves cujo grupo geométrico é $F$.

Para aeródromos de código $E$ a largura total da OFZ da faixa da pista de pouso e decolagem é de $120 \mathrm{~m}$. O estudo mostra que uma aeronave do grupo geométrico $F$ equipada com piloto automático ou flight director e track hold guidance fica contida dentro da OFZ do código E. Consequentemente a superfície de pouso interrompido do grupo geométrico $E$ pode ser usada para aeronaves do grupo geométrico $F$.

Tanto a largura total de $120 \mathrm{~m}$ quanto a declividade de 1:3 foram consideradas adequadas.

\footnotetext{
${ }^{47}$ Diferentemente da FAA, a ICAO não prescreve uma OFZ no nível da RW (ROFZ- runway object free zone). No entanto esta área fica subentendida à partir da descrição da superfície de transição interna do item 4.9.1.1.2 . E a distância que a superfície de transição interna se encontra a partir do eixo da RW corresponde à área restrita da faixa da RW, descrita no item 4.7.1.3.
} 


\subsubsection{METODOLOGIA PARA ESTUDOS QUE SUPORTAM FLEXIBILIZAÇÕES CONFORME ICAO CIR305 (2004c)}

Esta seção apresenta a ICAO Cir 305 (2004c), que trata da compatibilização de aeronaves de categoria $F$ em aeródromos de categoria $E$, discutindo relações entre os padrões de projeto e características das novas aeronaves da categoria $F$. Além disso, as informações apresentadas são úteis para a compatibilização de aeronaves, que mesmo pertencendo à categoria $E$, possuem fuselagem e base de rodas bastante avantajadas, impactando em certos componentes do aeródromo. O documento apresenta também informações sobre como realizar estudos aeronáuticos relacionados, e coloca que a responsabilidade pela flexibilização de qualquer padrão é do Estado que a autoriza.

\subsubsection{Impactos de NLAs sobre um aeródromo}

Esta seção relaciona o impacto que as características NLAs podem exercer sobre certos componentes de aeródromos existentes que não cumprem os requisitos da categoria $F$.

- Comprimento da fuselagem: pátio; baías de espera; instalações de manutenção e serviços; instalações anti-congelamento; posições de estacionamento; folga na traseira da aeronave; categoria de resgate e combate a incêndio; portões de embarque;

- Largura da fuselagem: categoria para resgate e combate a incêndio;

- Altura da fuselagem: instalações de manutenção e serviços; posição da barra de parada; OFZ; portões de embarque;

- Envergadura: largura dos acostamentos; pátio; baías de espera; instalações de manutenção e serviços; posições de estacionamento, posição da barra de parada; OFZ; separação entre uma RW e uma TW; separação entre TWs e TWs e objetos; esteira de turbulência; escolha do portão; serviços de manutenção do aeródromo (ex.: remoção de neve); equipamentos de reboque; veículos de serviço e equipamentos de remoção;

- Distância entre a ponta da asa e o chão: separação entre TWs e objetos; separação entre o pátio/baías de espera e objetos; altura e posição da sinalização do lado aéreo; serviços de manutenção do aeródromo (ex.; remoção de neve);

- Altura do estabilizador: instalações de manutenção e serviços; instalações anti-congelamento; posição da barra de parada; área de estacionamento de aeronaves; áreas sensíveis do sistema ILS; OFZ; 
- Distância entre o centro da cabine de comando e a roda da bequilha: pátio; baías de espera; sobrelarguras; áreas de giro; posições de estacionamento;

- Base de rodas: pátio; baías de espera; sobrelarguras; áreas de giro; posições de estacionamento;

- Wheel span: pátio; baías de espera; sobrelarguras; áreas de giro;

- Capacidade máxima de passageiros e carga: terminal de passageiros; sistema de armazenamento e distribuição de combustíveis; plano de emergência do aeródromo; categoria de resgate e combate à incêndio; portões de embarque;

- Peso máximo da aeronave: esteira de turbulência; equipamentos de reboque, veículos de serviços e equipamentos de remoção; projeto de pavimentos e fundações; limitação de operação sobre estruturas como pontes, túneis e galerias;

- Pressão dos pneus, geometria do trem de pouso e parâmetro $\mathrm{ACN}$ : largura dos acostamentos; projeto de pavimentos e fundações;

- Quantidade e posição dos motores: largura dos acostamentos; largura das pontes que comportam pistas de táxi; luzes da borda das RWs e TWs; altura e posição da sinalização do lado aéreo; serviços de manutenção do aeródromo (ex: veículos de remoção de neve); dimensões e localização de blast fences;

- Jet blast: largura dos acostamentos; largura das pontes que comportam pistas de táxi; áreas de giro; blast pads; distância mínima entre uma aeronave com motores ligados e veículos e pessoal em solo; resistência mecânica da sinalização; características das luzes das RWs e TWs; altura e posição da sinalização do lado aéreo; serviços de manutenção do aeródromo; dimensão e localização das blast fences;

- Sistema reversor: largura da pista de pouso e decolagem; largura dos acostamentos;

- Sistema de direção do trem: pátio; baías de espera; áreas de giro;

- Aterrissagem (modo manual e automático): largura da RW; OFZ; separação entre uma RW e uma TW; referência visual da RW; sinalização e iluminação da RW, TW, pátio e baías de espera; esteira de turbulência;

- Visão a partir da cabine de comando: sobrelarguras; sinalização e iluminação da RW, TW, pátio e baías de espera; altura e posição da sinalização do lado aéreo; distâncias de visão; 
- Evolução tecnológica: largura da pista de pouso e decolagem; largura da pista de táxi; largura dos acostamentos; posição da barra de parada; OFZ; área de estacionamento de aeronaves; aspectos ambientais.

\subsubsection{Metodologia para estudos aeronáuticos}

O documento ICAO Annex 14 (2004a) permite que, mediante um estudo aeronáutico, alguns critérios de projeto sejam flexibilizados. Os seguintes aspectos de segurança devem ser avaliados em estudos aeronáuticos:

- Probabilidade de colisão;

- Probabilidade de saída de uma área pavimentada;

- Risco de ingestão de objetos estranhos pelos motores.

A segurança quanto a estes riscos pode ser avaliada com base em parâmetros como:

- Distância entre as linhas de centro de uma RW e de uma TW;

- Distância entre as linhas de centro de duas TWs paralelas;

- Distância entre a linha de centro de uma TW e um objeto;

- Distância entre a linha de centro de uma TL e um objeto;

- Dimensões da RW, das TWs e dos seus acostamentos;

- Proteção dos motores contra a ingestão de material estranho.

O estudo deve iniciar apontando o nível de conformidade do aeródromo com os critérios do grupo geométrico $F$ e as não conformidades devem ser identificadas. A análise dos riscos deve levantar possíveis eventos indesejáveis, com base na experiência e em julgamento operacional. Tal análise deve cobrir:

- Os fatores causais e os eventos críticos baseados em uma análise causal a partir de dados disponíveis sobre acidentes e incidentes;

- Da mesma forma, deve-se analisar a gravidade das consequências do acidente.

O nível de gravidade (minor, major, hazardous e catastrophic) pode ser deduzido a partir das consequências aos ocupantes e à aeronave. $O$ apêndice $B$ da ICAO Cir 305 (2004c) contém informações que esclarecem o nível de gravidade (severity level), que é ilustrado pela Figura 6.1-1. 


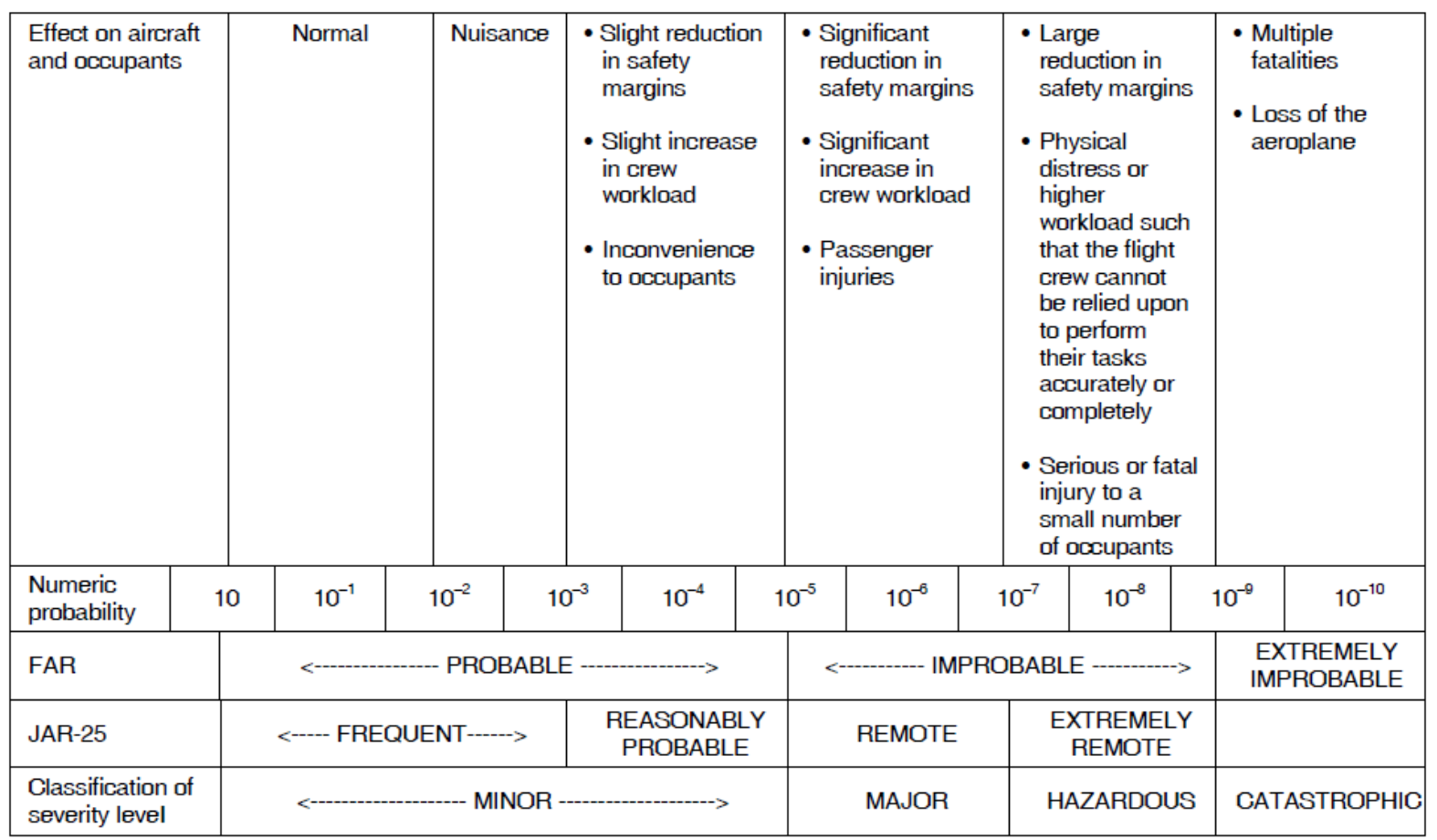

Figura 6.1-1- Nível de gravidade (severity level). FONTE: ICAO Cir 305 (2004c)

A análise de risco pode ser quantitativa ou qualitativa, neste caso tendo por base a comparação com uma situação existente. Dependendo da natureza do risco, três métodos podem ser utilizados para avaliar se o mesmo está ou não sob controle:

- Método A: Para certos perigos, a avaliação de riscos depende das características de desempenho e manobrabilidade da aeronave e da infraestrutura. A avaliação de riscos, portanto, pode se basear no projeto da aeronave, certificação, resultados de simulação e análise de acidentes;

- Método B: em outras situações a avaliação de risco não está diretamente associada às características de desempenho e manobrabilidade da aeronave. Neste caso a análise de riscos pode ser baseada em estatísticas (desvios, por exemplo) de aviões existentes ou em dados de acidentes. Modelos quantitativos de risco podem se adaptar bem a este tipo de avaliação;

- Método C: Nesse caso um "estudo de avaliação de riscos" não é necessário. Um simples argumento geométrico pode ser suficiente para calcular as necessidades de infraestrutura de uma aeronave NLA.

O entendimento dos riscos é a base para a subsequente avaliação de medidas alternativas, procedimentos operacionais e restrições operacionais para a acomodação de uma aeronave NLA em um aeródromo existente. 
O Capítulo 4 da ICAO Cir 305 (2004c) apresenta uma série de critérios a serem avaliados para a flexibilização dos padrões de projeto de vários componentes do aeródromo.

\subsubsection{ESTUDOS SOBRE MODIFICAÇÕES DE PADRÕES DA ICAO}

Os documentos enumerados a seguir apresentam estudos que, ou fazem parte da base de avaliação para a elaboração dos Common Agreement Documents para o A380 e o B747-8, ou se baseiam nestes documentos e podem ser obtidos do website NLA Forum. ${ }^{48}$

- Aeropuertos Españoles y Navegación Aérea (2005);

- Aéroports de Paris (2008a);

- Aéroports de Paris (2008b);

- Diréction générale de l'Aviation Civile (2008); e

- Norwegian Civil Aviation Authority (2008).

\subsection{FLEXIBILIZAÇÃO DE PADRÕES DA FAA}

A FAA tem emitido um conjunto de documentos que tratam da flexibilização de padrões do $6^{\circ}$ grupo geométrico para acomodação das aeronaves $A 380-800 \mathrm{e}$ B747-8 em aeroportos existentes. A Tabela 6.2-1 apresenta uma série de EBs emitida para pistas de pouso e decolagem e pistas de táxi. Os EBs são referências para modificações nos padrões de projeto (MoSs), quando não é possível que um dado aeroporto atenda aos padrões.

Tabela 6.2-1 - EBs da FAA relacionados à acomodação das aeronaves A380 e B747-8

\begin{tabular}{|c|c|c|}
\hline$N^{\circ}$ do EB & FONTE & Conteúdo \\
\hline $63 B$ & $\begin{array}{l}\text { FAA EB Nº } \\
63 B(2007 a)\end{array}$ & $\begin{array}{l}\text { Operação do A380 em TWs de } 23 m \text { de largura sem a utilização de } \\
\text { câmeras de auxílio (on-board taxi-camera system). }\end{array}$ \\
\hline $65 A$ & $\begin{array}{l}\text { FAA EB Nº } \\
65 A(2007 c)\end{array}$ & $\begin{array}{l}\text { Operação do A380 em RWs de } 45 \mathrm{~m} \text { de largura. A largura total entre } \\
\text { a RW e os acostamentos deve somar } 75 \mathrm{~m} \text {. No caso de RWs com } \\
45 \mathrm{~m} \text { de largura e acostamentos menores do que } 15 \mathrm{~m} \text { em cada lado, } \\
\text { a FAA pode autorizar operações temporárias, sujeitas a } \\
\text { procedimentos especiais que incluem a inspeção de objetos } \\
\text { estranhos (debris) entre as operações. }\end{array}$ \\
\hline 73 & $\begin{array}{l}\text { FAA EB N } \\
73(2007 b)\end{array}$ & $\begin{array}{l}\text { Operação do B747-8 em TWs de } 23 m \text { de largura com a utilização de } \\
\text { acostamentos de } 35 p \text { és }(\sim 10,5 m) \text {. }\end{array}$ \\
\hline 74 & $\begin{array}{l}\text { FAA EB N } \\
74(2008)\end{array}$ & $\begin{array}{l}\text { Operação do B747-8 em RWs de } 45 \mathrm{~m} \text { de largura, com a utilização } \\
\text { de acostamentos de resistência maior do que a usual (inner shoulder } \\
\text { com } 7,5 \mathrm{~m} \text { de largura em cada lado) e acostamentos de } 12 \mathrm{~m} \text {, }\end{array}$ \\
\hline
\end{tabular}

\footnotetext{
${ }^{48}$ Em geral estes estudos foram elaborados antes da entrada em operação da aeronave A380, sendo
} baseados, portanto, em previsões das características desta aeronave. 


\begin{tabular}{c|c|l}
\hline No do EB & FONTE & \multicolumn{1}{c}{ Conteúdo } \\
\hline & & $\begin{array}{l}\text { também em cada lado. O inner shoulder é um tipo de pavimento de } \\
\text { resistência menor do que o da RW e está situado em um local onde } \\
\text { substitui o acostamento antigo. Este EB especifica padrões de } \\
\text { carregamento a serem considerados. Trata-se de uma aprovação de } \\
\text { modificação temporária, prevista para um período máximo de 5 anos. } \\
\text { É uma alternativa que permite aos aeroportos terem um maior tempo } \\
\text { para planejar a construção de RWs que atendam aos padrões. Como } \\
\text { se vê este EB é mais restritivo do que aquele referente ao A380 } \\
\text { (EB65A). Isso porque a aeronave da Airbus já demonstrou em testes } \\
\text { uma dispersão compatível com uma RW de 45m. Trata-se de um } \\
\text { aspecto de certificação. O B747-8, por sua vez, ainda não existia na } \\
\text { época em que este EB foi emitido. }\end{array}$ \\
\hline 80 & $\begin{array}{l}\text { FAA EB No } \\
80 \text { (2010b) }\end{array}$ & $\begin{array}{l}\text { Utilização de folga do pavimento de 4,5m para aeronaves do grupo } \\
\text { geométrico VI. }\end{array}$ \\
\hline FAA EB No & $\begin{array}{l}\text { Utilização dos padrões separação (entre RW e TW paralelas) do } \\
\text { grupo V para o B747-8. }\end{array}$ \\
\hline
\end{tabular}

FONTE: Compilado com base nas informações dos EBs

Em adição aos EBs, o website da FAA apresenta uma série de modificações de padrões de projeto (MoSs) ${ }^{49}$ autorizadas em aeroportos dos EUA para a introdução de NLAs. É possível fazer o download destes documentos que apresentam croquis e desenhos em escala de diversos aeroportos onde MoOs foram autorizados. De uma maneira geral, estas flexibilizações se baseiam nos EBs. A sub-seção a seguir apresenta uma análise de jet blast utilizada para a aprovação de uma TOFA (taxiway object free area) fora dos padrões.

\subsubsection{MOS PARA A LARGURA DA TOFA}

Para o aeroporto de Anchorage, no Alaska, um documento ${ }^{50}$ disponibilizado pela FAA no seu sítio eletrônico compara os contornos de velocidade do jet blast do B747-400ER e do A380F, sem no entanto, especificar os motores. Os contornos foram obtidos a partir do software Pathplanner, em quatro cenários construídos a partir da variação de dois parâmetros: velocidade de táxi (20mph e 30mph) e dois tipos de operação (deslocamento contínuo e deslocamento com parada e arrancada). A partir dos quatro cenários propostos, verifica-se que a dispersão lateral dos contornos de velocidade do jet blast de $35 \mathrm{mph}$ das duas aeronaves

49 FAA - $\quad$ Modification of Standards. Disponível em: $<$ http://www.faa.gov/airports/engineering/nla_mos/>. Acesso em setembro de 2010.

${ }^{50}$ Rationale for Conditional Approval of a Módification of Standards for Taxiway CL to Fixed/Movable Object Separation at ANC for Airbus A380. Disponível em: < http://www.faa.gov/airports/engineering/nla mos/media/ANC rationale twy cl mos1 20040614.pdf> 
praticamente se sobrepõem. A análise demonstrada se restringe à avaliação da dispersão lateral do jet blast, para efeitos de avaliação da largura disponível no aeroporto para a TOFA (taxiway object free area).

Tal análise foi realizada para avaliar-se o nível de segurança de uma TOFA fora dos padrões da FAA. O aeroporto em questão solicitou a utilização de uma semi-largura de 174pés $(53 \mathrm{~m})$, enquanto o padrão para a semi-largura da TOFA para o grupo geométrico VI é de 190pés $(118 m / 2=58 m)$ e o padrão para o grupo geométrico $V$ é de 160 pés $(98 \mathrm{~m} / 2=49 \mathrm{~m})$. O pedido feito pelo aeroporto foi aceito pela FAA com base nas análises descritas no parágrafo anterior.

Chama atenção o fato de que o documento da FAA cita o limite de velocidade de jet blast estipulado pela ICAO, que é ligeiramente superior, uma vez que a agência americana estabelece $30 \mathrm{mph}$ como velocidade limite.

\subsection{CONCLUSÕES DO CAPÍTULO}

Este capítulo trata da acomodação das aeronaves A380 e B747-8 em aeroportos existentes nos quais não é possível atender-se aos requisitos dos grupos geométricos ICAO F ou FAA VI. Para tanto, são apresentadas as principais conclusões dos documentos A380 Common Agreement Document e B747-8 Common Agreement Document, no caso da ICAO, e de Engineering Briefs relacionados ao tema, no caso da FAA. Além disso, cita-se um conjunto de estudos e documentos técnicos relacionados.

Verifica-se que uma série de flexibilizações dos padrões de projeto tem sido propostas e implantadas, visando à acomodação destas aeronaves do $6^{\circ}$ grupo geométrico. Diante disso, análise de acomodação destas aeronaves em aeroportos existentes deve considerar tais flexibilizações, sempre que não for possível atender aos padrões estabelecidos pelas normas. 


\section{CAPÍTULO 7 - ANÁLISE DO LADO AÉREO DO AEROPORTO DE GUARULHOS QUANTO À OPERAÇÃO DO A380-800 E DO B747-8}

Neste capítulo apresenta-se uma análise da possibilidade de operação das aeronaves A380-800 e B747-8 no Aeroporto Internacional de São Paulo/Guarulhos. Tal análise é realizada com base nos critérios, metodologias e considerações de projeto apresentados no Capítulos 4 e nas flexibilizações dos padrões, conforme o Capítulo 6. De forma preferencial utilizam-se os padrões e recomendações da ICAO, embora padrões da FAA também sejam utilizados, com o intuito de servir como justificativa para eventuais adoções de flexibilizações.

O aeroporto de São Paulo/Guarulhos foi selecionado para esta análise tendose em vista o interesse apresentado por algumas companhias aéreas em operar o A380-800 e o B747-8 neste aeroporto.

\subsection{ARC}

O A380-800 apresenta todas as características do $6^{\circ}$ grupo geométrico, tanto para o ARC da ICAO, como da FAA, possuindo: uma envergadura muito próxima do $6^{\circ}$ grupo geométrico da ICAO e da FAA; um wheel span que se encaixa no grupo geométrico ICAO $F$ e uma altura de estabilizador igual à altura máxima do grupo geométrico FAA VI.

O B747-8 também se encaixa no $6^{\circ}$ grupo geométrico das duas normas, em função de sua envergadura, que ultrapassa em pouco mais de três metros o limite do $5^{\circ}$ grupo geométrico. Quanto ao wheel span e à altura do estabilizador, o B747-8 possui características do $5^{\circ}$ grupo geométrico em ambas as normas.

Quanto ao elemento dinâmico do ARC, as duas aeronaves se encaixam nos grupos ICAO 4 e FAA $D$, coincidindo com a classificação do B747-400 nas duas normas.

Considerando-se a classificação das aeronaves nos quesitos envergadura, wheel span e altura do estabilizador, é de se esperar que o B747-8 seja mais fácil de acomodar do que o A380-800.

\subsection{CRITÉRIOS DE PROJETO}

Nesta seção analisa-se o vento de través de projeto e o jet blast. 


\subsubsection{VENTO DE TRAVÉS}

Considerando-se os padrões de projeto do Capítulo 4, para as duas aeronaves sob análise, o vento de través máximo é de 20nós, para os critérios da ICAO e da FAA. Esse é o mesmo limite estabelecido para o B747-400, nas duas normas. Lembra-se que estes padrões servem como recomendação para a orientação da RW durante as fases de planejamento e projeto do aeródromo, não regulando a operação.

Do ponto de vista da operação, não é incomum que as aeronaves operem sob limites mais elevados para o vento de través. Os próprios AFMs (Aircraft Flight Manuals) apresentam o vento de través máximo encontrado durante os vôos de certificação (demonstrated crosswind), ao invés de fixarem um limite. Conforme informações da Boeing, operadores da região Ártica operam em ventos de través superiores a 45 nós.

\subsubsection{JET BLAST E FOD}

Como discutido no item 5.2.2, as normas da ICAO e da FAA não apresentam uma metodologia consistente e ampla para a avaliação dos efeitos do jet blast, apesar de ressaltarem sua importância no projeto e na operação de aeródromos. Por outro lado, cabe mencionar-se que alguns efeitos do jet blast estão implicitamente considerados nos critérios de projeto referentes a separações e áreas pavimentadas. Disso, se pode intuir que $o$ atendimento aos padrões $e$ recomendações gera um certo nível de proteção contra os efeitos do jet blast. Portanto, quando flexibilizações dos padrões são propostas, é necessária a devida consideração.

Verificou-se que a FAA utiliza métodos comparativos para a aprovação de modificações dos padrões de projeto ${ }^{51}$ relacionados ao jet blast, e o padrão de comparação é a aeronave B747-400 (ver item 6.2.1). Por isso, e pela falta de uma metodologia mais sofisticada para a análise dos efeitos do jet blast, optou-se, neste trabalho, por métodos comparativos.

Tal abordagem consiste na comparação entre as curvas de velocidade do jet blast das aeronaves B747-8 e A380-800 e das aeronaves B747-400 e A340-600. Estas duas últimas aeronaves pertencem ao $5^{\circ}$ grupo geométrico e foram escolhidas por serem as aeronaves mais críticas, quanto à posição dos motores, atualmente em operação no aeródromo sob análise. A partir dos APMs (Airport Planning Manuals)

\footnotetext{
${ }^{51}$ MOSs - modification of standards
} 
foram extraídas três informações: distância máxima lateral da área de sucção da turbina desde a linha de centro da aeronave; dispersão máxima lateral de um dado contorno de velocidade, também em relação à linha de centro da aeronave; e distância máxima longitudinal de um dado contorno de velocidade desde a cauda e desde a bequilha.

\subsubsection{Análise de FOD}

As análises de sucção foram realizadas somente para as aeronaves Airbus, uma vez, que para as demais, tal informação não consta nos APMs.

A Tabela 7.2-1 mostra a distância lateral da área de sucção desde a linha de centro da aeronave para três níveis de empuxo. Mostra também os padrões para a largura combinada entre um acostamento e a semi-largura da RW e da TW. Nestas semi-larguras considera-se também o desvio da aeronave em relação à linha de centro da RW ou TW. Para as RWs o desvio assumido é de 9,1m, conforme a FAA FAR 25.149 (2002), utilizada para certificação de aeronaves de transporte (Transport Category Airplanes). Para TWs, o desvio considerado é tal que a aeronave não viole a folga do pavimento, conforme a semi-largura $L$, obtida pela Equação 7.2-1, onde: $\mathrm{L}_{\mathrm{TW}}$ representa a largura da RW; $\mathrm{L}_{\text {acostamento }}$ representa a largura do acostamento; WS representa o wheel span; e M, a folga do pavimento:

$L=\frac{L_{T W}}{2}+\frac{L_{\text {acostamento }}}{2}-\left(\frac{L_{T W}}{2}-\left(\frac{W S}{2}+M\right)\right)=\frac{L_{\text {acostamento }}}{2}+\frac{W S}{2}+M$

Ainda, a Tabela 7.2-1 apresenta a distância entre o centro da turbina mais externa e o eixo longitudinal da aeronave, medida ortogonalmente a este.

Organizando-se os dados da Tabela 7.2-1, é possível obter-se a Tabela 7.2-2, onde o atendimento dos critérios propostos é avaliado para: o A340-600, tendo-se em vista os padrões do $5^{\circ}$ grupo geométrico para RWs e TWs; o A380-800, tendo-se em vista os padrões do $6^{\circ}$ grupo geométrico para RWs e TWs; e o A380-800, tendose em vista os padrões do $5^{\circ}$ grupo geométrico para RWs e TWs. Nesta tabela, apresentam-se as folgas para o atendimento de cada critério, utilizando-se um contraste de fonte e fundo para as células.

Se for admitido que o A380-800 deve, no mínimo, atender aos critérios que o A340-600 atende, as seguintes observações podem ser feitas:

- Os padrões da ICAO para o $6^{\circ}$ grupo geométrico são suficientes para que o A380-800 atenda aos mesmos critérios atendidos pelo A340-600, ou seja, CR1, CR2, CR3, CR4 e CR7. 
- Já os padrões do $5^{\circ}$ grupo geométrico fazem com que o A380-800 viole alguns dos critérios que o A340-600 atende, ou seja, CR1, CR2, CR4 e CR7.

Tabela 7.2-1 - Distâncias laterais de sucção, semi-larguras padrão das RWs e TWs e posição do centro das turbinas, tomando-se como referência o eixo longitudinal da aeronave

\begin{tabular}{|c|c|c|c|c|}
\hline \multirow{2}{*}{\multicolumn{3}{|c|}{$\begin{array}{c}\text { Padrões de projeto e características das } \\
\text { aeronaves }\end{array}$}} & \multicolumn{2}{|c|}{ Aeronaves } \\
\hline & & & \multirow{2}{*}{$\begin{array}{c}\text { A340-600 le } \\
\left(5^{\circ} \text { grupo }\right. \\
\text { geométrico) }\end{array}$} & \multirow{2}{*}{$\begin{array}{l}\text { A380-800 le } \\
\left(6^{\circ} \text { grupo }\right. \\
\text { geométrico) } \\
30 \mathrm{~m}\end{array}$} \\
\hline \multirow{8}{*}{$\begin{array}{l}\text { Semi-larguras } \\
\text { das áreas } \\
\text { pavimentadas }\end{array}$} & \multirow{2}{*}{$\begin{array}{l}\text { Semi-largura padrão para } \\
\text { a TW + acostamento }\end{array}$} & ICAO & & \\
\hline & & FAA & $22 \mathrm{~m}$ & $27 \mathrm{~m}$ \\
\hline & \multirow{2}{*}{$\begin{array}{c}\text { Semi-largura padrão para } \\
\text { a TW + acostamento - } \\
\text { desvio (L), conforme } \\
\text { Equação } 7.2-1 \\
\end{array}$} & ICAO & $21 \mathrm{~m} \mid \mathrm{a}$ & 29,1m |b \\
\hline & & FAA & $21 \mathrm{~m} \mid \mathrm{c}$ & 23,6m |d \\
\hline & \multirow{2}{*}{$\begin{array}{l}\text { Semi-largura padrão para } \\
\text { a RW + acostamento }\end{array}$} & ICAO & $30 \mathrm{~m}$ & $37,5 \mathrm{~m}$ \\
\hline & & FAA & $33 m$ & $42 m$ \\
\hline & \multirow{2}{*}{$\begin{array}{c}\text { Semi-largura padrão para } \\
\text { a RW + acostamento - } \\
\text { desvio previsto no } \\
\text { parágrafo } 25.149 \text { da ANAC } \\
\text { RBAC } 25 \text { (2009b) }\end{array}$} & ICAO & $20,9 m$ & $28,4 \mathrm{~m}$ \\
\hline & & FAA & $23,9 m$ & $32,9 m$ \\
\hline \multirow{3}{*}{$\begin{array}{c}\text { Distância o } \\
\text { contorno de } \\
\text { sucção, desde } \\
\text { a linha de } \\
\text { centro } \\
\text { longitudinal da } \\
\text { aeronave |f }\end{array}$} & \multicolumn{2}{|l|}{ Idle thrust } & $27 m$ & $30 m$ \\
\hline & \multicolumn{2}{|l|}{ Breakaway thrust } & $27 m$ & $32 \mathrm{~m}$ \\
\hline & \multicolumn{2}{|l|}{ Take-off thrust } & $27 m$ & $35 m$ \\
\hline \multicolumn{3}{|c|}{$\begin{array}{l}\text { Posição da linha de centro da turbina mais externa } \\
\text { em relação ao eixo longitudinal da aeronave }\end{array}$} & $19 m$ & $26 m$ \\
\hline
\end{tabular}

FONTE: Preparado a partir dos APMs das aeronaves e dos padrões da ICAO e da FAA para RWs e TWs.

|a: $L_{\text {acostamento }}=10,5 \mathrm{~m} ; W S=12 \mathrm{~m}$ e $M=4,5 \mathrm{~m}$. |b: $L_{\text {acostamento }}=17,5 \mathrm{~m} ; W S=14,2 \mathrm{~m}$ e $M=4,5 \mathrm{~m}$. |c: $L_{\text {acostamento }}=10,5 \mathrm{~m} ; \mathrm{WS}=12 \mathrm{~m}$ e $M=4,5 \mathrm{~m}$. |d: $\mathrm{L}_{\text {acostamento }}=12 \mathrm{~m} ; \mathrm{WS}=14,2 \mathrm{~m}$ e $\mathrm{M}=4,5 \mathrm{~m}$. |e: A340-600 com motor TRENT 500 e A380-800 com motor TRENT 900.

|f: Dados obtidos do APM, a partir de um desenho em escala.

Já o B747-8 tem um importante argumento a seu favor para que esta aeronave seja autorizada a operar nas mesmas RWs e TWs (considerando-se a largura combinada entre estas e os acostamentos) que o B747-400: a distância entre o centro da turbina mais externa fica à mesma distância do centro da fuselagem para as duas aeronaves. Além disso, na nova aeronave a turbina mais externa fica a uma altura maior do chão, na ordem de $1 \mathrm{~m}$. A própria Boeing utiliza estes aspectos geométricos como justificativa para operação do B747-8 em RWs e TWs que comportam o B747-400, considerando-se os efeitos de sucção gerados pela turbina. 
Tabela 7.2-2 - Folgas quanto à distância de sucção e quanto à posição da turbina desde a linha de centro longitudinal da aeronave $(m)$

\begin{tabular}{|c|c|c|c|c|c|c|c|c|c|c|c|}
\hline \multirow{2}{*}{\multicolumn{3}{|c|}{ Critérios }} & \multicolumn{3}{|c|}{$\begin{array}{c}\text { A340-600 } \\
\text { (padrões do } 5^{\circ} \\
\text { grupo } \\
\text { geométrico) la }\end{array}$} & \multicolumn{3}{|c|}{$\begin{array}{c}\text { A380-800 } \\
\text { (padrões do } 6^{\circ} \\
\text { grupo } \\
\text { geométrico) la }\end{array}$} & \multicolumn{3}{|c|}{$\begin{array}{c}\text { A380-800 } \\
\text { (padrões do } 5^{\circ} \\
\text { grupo } \\
\text { geométrico) |a }\end{array}$} \\
\hline & & & I & $B$ & $T$ & I & $B$ & $T$ & I & $B$ & $T$ \\
\hline \multirow{8}{*}{$\begin{array}{c}\text { Abrigo do } \\
\text { centro da } \\
\text { turbina mais } \\
\text { externa na } \\
\text { área } \\
\text { pavimentada } \\
\text { formada } \\
\text { entre o } \\
\text { acostamento } \\
\text { e a: }\end{array}$} & \multirow{2}{*}{$\begin{array}{c}\text { TW, } \\
\text { sem } \\
\text { desvio } \\
\text { (CR1) }\end{array}$} & ICAO & \multicolumn{3}{|c|}{2,8} & \multicolumn{3}{|c|}{4,3} & \multicolumn{3}{|c|}{$-3,7$} \\
\hline & & FAA & \multicolumn{3}{|c|}{2,8} & \multicolumn{3}{|c|}{1,3} & \multicolumn{3}{|c|}{$-3,7$} \\
\hline & $\begin{array}{l}\mathrm{RW} \\
\text { com }\end{array}$ & ICAO & \multicolumn{3}{|c|}{1,8} & \multicolumn{3}{|c|}{3,4} & \multicolumn{3}{|c|}{$-4,7$} \\
\hline & $\begin{array}{l}\text { desvio } \\
\text { (CR2) }\end{array}$ & FAA & \multicolumn{3}{|c|}{1,8} & \multicolumn{3}{|c|}{$-2,1$} & \multicolumn{3}{|c|}{$-4,7$} \\
\hline & $\begin{array}{l}\text { RW, } \\
\text { sem }\end{array}$ & ICAO & \multicolumn{3}{|c|}{10,8} & \multicolumn{3}{|c|}{11,8} & \multicolumn{3}{|c|}{4,3} \\
\hline & $\begin{array}{l}\text { desvio } \\
\text { (CR3) }\end{array}$ & FAA & \multicolumn{3}{|c|}{13,8} & \multicolumn{3}{|c|}{16,3} & \multicolumn{3}{|c|}{7,3} \\
\hline & $\begin{array}{l}\mathrm{RW} \\
\text { com }\end{array}$ & ICAO & \multicolumn{3}{|c|}{1,7} & \multicolumn{3}{|c|}{2,7} & \multicolumn{3}{|c|}{$-4,8$} \\
\hline & $\begin{array}{l}\text { desvio } \\
\text { (CR4) }\end{array}$ & FAA & \multicolumn{3}{|c|}{4,7} & \multicolumn{3}{|c|}{7,2} & \multicolumn{3}{|c|}{$-1,8$} \\
\hline \multirow{6}{*}{$\begin{array}{l}\text { Abrigo do } \\
\text { contorno } \\
\text { lateral de } \\
\text { sucção na } \\
\text { área } \\
\text { pavimentada } \\
\text { formada } \\
\text { entre o } \\
\text { acostamento } \\
\text { e a: }\end{array}$} & \multirow{2}{*}{$\begin{array}{c}\text { TW, } \\
\text { sem } \\
\text { desvio } \\
\text { (CR1) }\end{array}$} & ICAO & -5 & -5 & -5 & 0 & -2 & -5 & -8 & -10 & -13 \\
\hline & & FAA & -5 & -5 & -5 & -3 & -5 & -8 & -8 & -10 & -13 \\
\hline & \multirow{2}{*}{$\begin{array}{c}\text { RW, } \\
\text { com } \\
\text { desvio } \\
\text { (CR2) }\end{array}$} & ICAO & -6 & -6 & -6 & -1 & -3 & -5 & -9 & -11 & -14 \\
\hline & & FAA & -6 & -6 & -6 & -6 & -8 & -11 & -9 & -11 & -14 \\
\hline & \multirow{2}{*}{$\begin{array}{c}\text { RW, } \\
\text { sem } \\
\text { desvio } \\
\text { (CR3) }\end{array}$} & ICAO & 3 & 3 & 3 & 7 & 5 & 3 & $-0,2$ & $-1,7$ & $-4,6$ \\
\hline & & FAA & 6 & 6 & 6 & 12 & 10 & 7 & 3 & 1 & $-1,6$ \\
\hline lb & $\begin{array}{l}\text { RW, } \\
\text { com }\end{array}$ & ICAO & -6 & -6 & -6 & -2 & -3 & -6 & -9 & -11 & -14 \\
\hline & $\begin{array}{l}\text { desvio } \\
\text { (CR4) }\end{array}$ & FAA & -3 & -3 & -3 & 3 & 1 & -2 & -6 & -8 & -11 \\
\hline
\end{tabular}

FONTE: Preparado a partir dos APMs das aeronaves e dos padrões da ICAO e da FAA para RWs e TWs.

a: |I: Idle Thrust. |B: Breakaway Thrust. |T: Take-off Thrust.

b: Dados obtidos do APM, a partir de um desenho em escala.

\subsection{Análise da dispersão lateral do contorno de 35mph}

A dispersão máxima do contorno de $35 \mathrm{mph}$ é mostrada na Figura 7.2-1, de onde se confirma a tendência esperada, de que, o contorno de velocidade se afasta da linha de centro da aeronave conforme aumenta o nível de empuxo. Os mesmos dados foram utilizados para a construção da Tabela 7.2-3. Desta tabela nota-se que a aeronave $\mathrm{B} 747-8$ possui acréscimos muito pequenos em relação às aeronaves B747-400 e A340-600 e decréscimos mais substanciais. Já o A380-800 merece 
atenção, à medida que apresenta acréscimos consideráveis em relação às duas aeronaves.

Tabela 7.2-3 - Variação entre a dispersão lateral máxima do contorno jet blast a 35mph

\begin{tabular}{c|cc|cc|cc}
\hline $\begin{array}{c}\text { Nível de empuxo } \\
\text { Aeronaves }\end{array}$ & \multicolumn{3}{|c|}{ Idle Thrust } & \multicolumn{2}{c|}{ Breakaway Thrust } & \multicolumn{2}{c}{ Take-off Thrust } \\
& A380-800 & B747-8 & A380-800 & B747-8 & A380-800 & B747-8 \\
\hline A340-600 & $5 \mathrm{~m}$ & $-1 \mathrm{~m}$ & $12 \mathrm{~m}$ & $1 \mathrm{~m}$ & $20 \mathrm{~m}$ & $1 \mathrm{~m}$ \\
B747-400 & $7 \mathrm{~m}$ & $1 \mathrm{~m}$ & $8 \mathrm{~m}$ & $-4 \mathrm{~m}$ & $10 \mathrm{~m}$ & $-9 \mathrm{~m}$ \\
\hline
\end{tabular}

FONTE: Adaptado a partir do APMs das aeronaves

|a: com base na motorização que gera o contorno mais demandante.

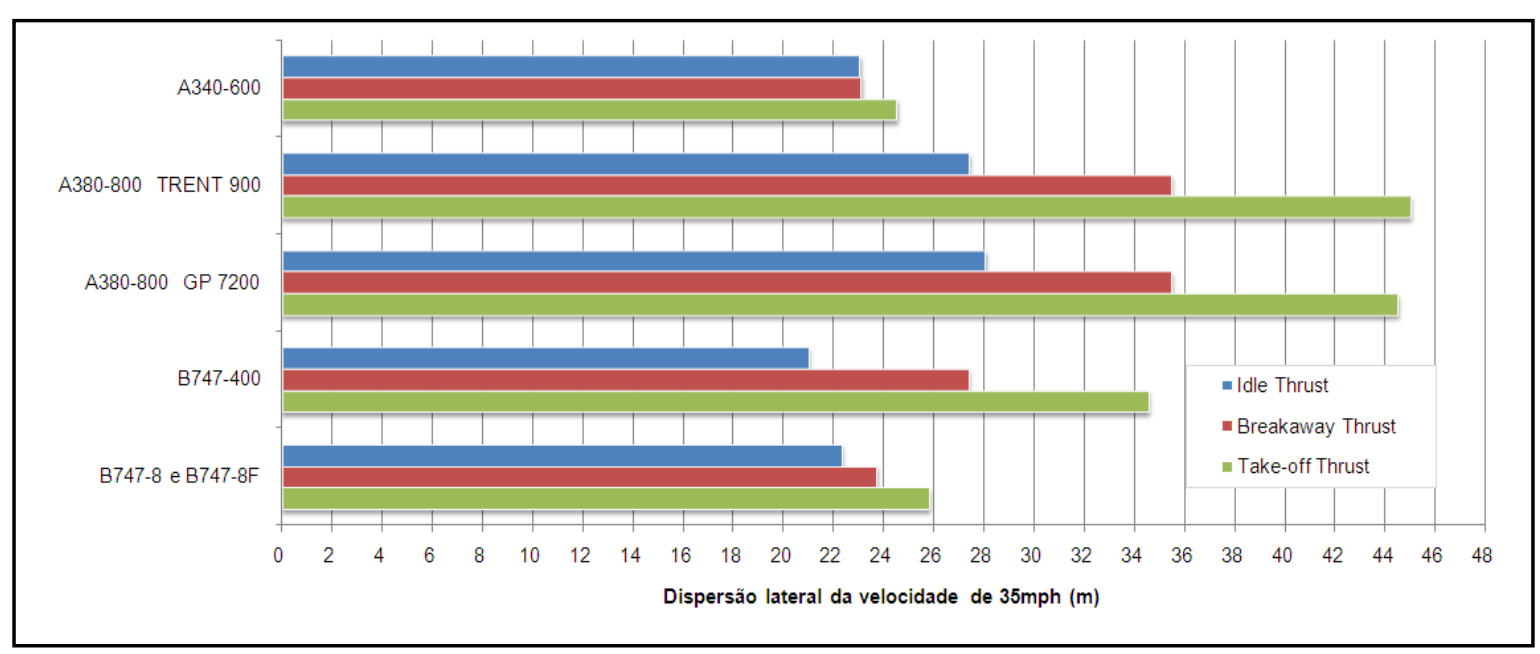

Figura 7.2-1 - Dispersão lateral máxima do jet blast de 35mph. FONTE: Adaptado dos APMs das aeronaves

\subsection{Análise da dispersão longitudinal do contorno de 35mph}

A Figura 7.2-2 e a Figura 7.2-3 apresentam a distâncias máximas longitudinais do jet blast a $35 \mathrm{mph}$ desde a bequilha e desde a cauda, respectivamente. Para o nível de empuxo de decolagem a dispersão mais alta é do B747-8, que supera em $155 \mathrm{~m}$ o segundo colocado que é o B747-400. Este aumento pode exigir um distanciamento maior de pessoas e veículos da cabeceira da RW no momento em que um B747-8 pousa ou decola. Já para o nível de empuxo de partida (breakaway) o B747-400 é a aeronave crítica. Já para o menor nível de empuxo as duas novas aeronaves apresentam um acréscimo da ordem de dezenas de metros em relação ao B747-400. Isso pode exigir um distanciamento maior de pessoas e veículos no pátio, quando o A380-800 ou o B747-8 estão com os motores ligados. 


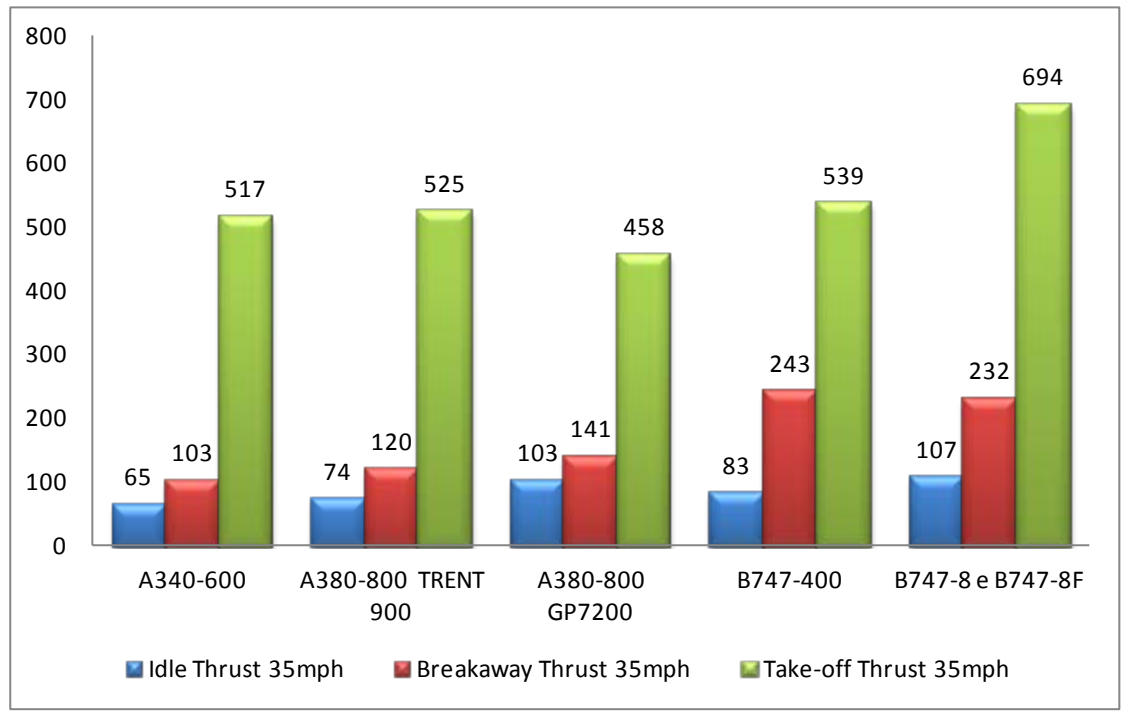

Figura 7.2-2 - Dispersão longitudinal máxima do jet blast a $35 \mathrm{mph}$, desde a bequilha. FONTE: Adaptado a partir dos APMs das aeronaves

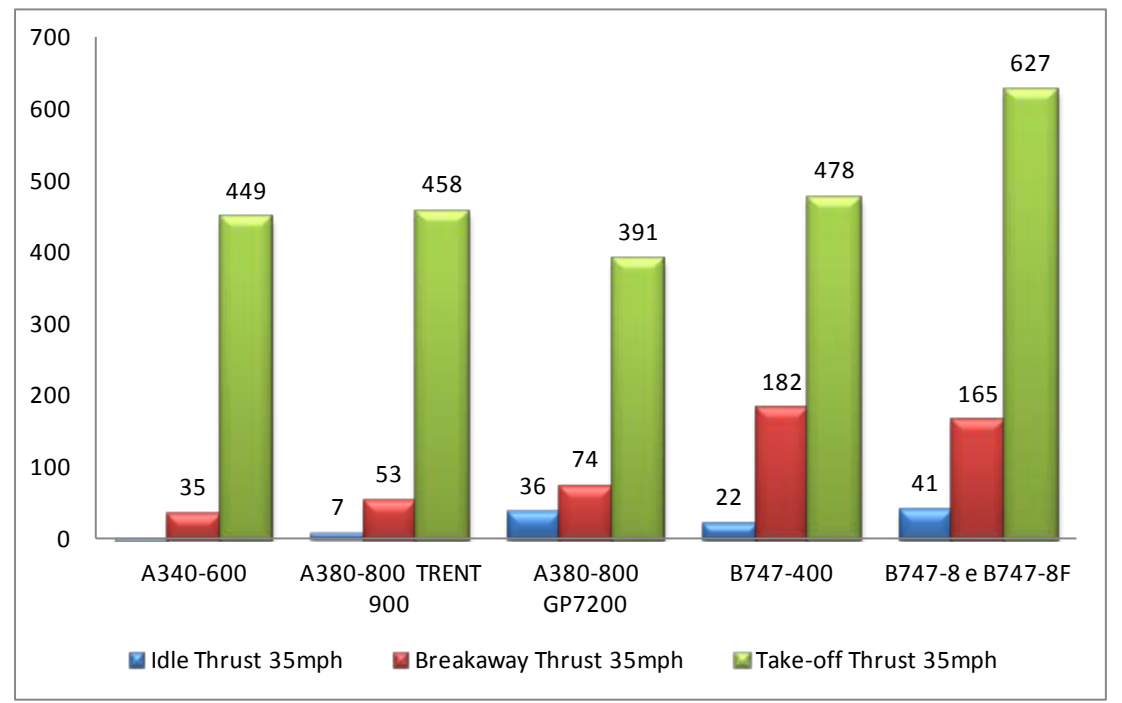

Figura 7.2-3 - Dispersão longitudinal máxima do jet blast a 35mph, desde a cauda. FONTE: Adaptado a partir dos APMs das aeronaves

\subsection{Análise da dispersão de velocidades maiores do que 35mph}

Para velocidades do jet blast maiores do que 35mph não foi possível a realização de comparações entre todas as velocidades e aeronaves, à medida que não existe uma padronização das velocidades utilizadas nos APMs. Mesmo assim, algumas afirmações podem ser feitas com base na Tabela 7.2-4. Estas velocidades, acima de 35mph, são importantes para a consideração de EFAs (Efeitos do Fluxo de Ar) sobre equipamentos, estruturas e prédios, bem como EEs (Efeitos de Erosão) e EAMs (Efeitos do Arremesso de Materiais), conforme discutido no item 5.2.2.

Sobre a dispersão lateral, O A380-800 apresenta aumento nos contornos de velocidade na ordem de $4 m, 8 m$ e $14 m$ para cada nível de empuxo, do menor para o 
maior, respectivamente. Já os dados referentes aos níveis de empuxo de partida e decolagem, mostram que o B747-8 apresenta variações bem menores e quase todas negativas, para a dispersão lateral dos contornos de velocidade, em relação às aeronaves A340-600 e B747-400.

Sobre a dispersão longitudinal, verifica-se que, nos dois níveis menores de empuxo, o A380-800 possui variações muito pequenas, enquanto a variação do B747-8 é mais importante. No nível de empuxo de decolagem os dados podem ser separados em três grupos:

- O A380-800 e o B747-8 apresentam aumentos da ordem de $100 \mathrm{~m}$ em relação ao A340-600 para as velocidades de 50, 60 e $100 \mathrm{mph}$ e em relação ao B747-400 para a velocidade de $50 \mathrm{mph}$;

- O A380-800 e o B747-8 apresentam aumentos pequenos em relação ao B747-400 na velocidade de 100mph; e

- O B747-8 apresenta uma redução de cerca de $40 \mathrm{~m}$ para o contorno de $150 \mathrm{mph}$ do B747-400.

Tabela 7.2-4 - Variação da dispersão lateral e longitudinal do jet blast: A380-800 e B747-8 versus $A 340-600$ e $B 747-400$

\begin{tabular}{|c|c|c|c|c|c|c|c|c|}
\hline \multirow{2}{*}{ Parâmetro } & \multirow{2}{*}{ Aeronave } & \multirow{2}{*}{$\begin{array}{l}\text { Velocidade } \\
\text { (mph) }\end{array}$} & \multicolumn{2}{|c|}{ Idle Thrust } & \multicolumn{2}{|c|}{$\begin{array}{c}\text { Breakaway } \\
\text { Thrust }\end{array}$} & \multicolumn{2}{|c|}{ Take-off Thrust } \\
\hline & & & B747-8 & $\begin{array}{c}\text { A380- } \\
800\end{array}$ & B747-8 & $\begin{array}{l}\text { A380- } \\
800\end{array}$ & B747-8 & $\begin{array}{c}\text { A380- } \\
800\end{array}$ \\
\hline \multirow{5}{*}{$\begin{array}{c}\text { Dispersão } \\
\text { lateral }\end{array}$} & \multirow{2}{*}{ A340-600 } & 68 & - & $5 m$ & - & $8 m$ & - & $15 \mathrm{~m}$ \\
\hline & & 100 & - & $4 m$ & $-1 m$ & $8 m$ & $2 m$ & $14 \mathrm{~m}$ \\
\hline & \multirow{3}{*}{ B747-400 } & 50 & - & - & $-4 m$ & - & $-6 m$ & - \\
\hline & & 100 & - & - & - & - & $-2 m$ & $10 \mathrm{~m}$ \\
\hline & & 150 & - & - & - & - & $-1 m$ & - \\
\hline \multirow{5}{*}{$\begin{array}{l}\text { Dispersão } \\
\text { longitudinal }\end{array}$} & \multirow{2}{*}{ A340-600 } & 68 & - & $4 \mathrm{~m}$ & - & $4 m$ & - & $111 \mathrm{~m}$ \\
\hline & & 100 & - & $3 m$ & $21 \mathrm{~m}$ & $2 m$ & $104 m$ & $88 m$ \\
\hline & \multirow{3}{*}{ B747-400 } & 50 & - & - & & - & $99 m$ & - \\
\hline & & 100 & - & - & - & - & $19 m$ & $2 m$ \\
\hline & & 150 & - & - & - & - & $-43 m$ & - \\
\hline
\end{tabular}

FONTE: Adaptado a partir do APMs das aeronaves

\section{3 ÁREAS PAVIMENTADAS PRINCIPAIS}

\subsubsection{LARGURA DA PISTA DE POUSO E DECOLAGEM}

As duas pistas do SBGR possuem $45 \mathrm{~m}$ de largura, ou seja, menos do que o padrão do $6^{\circ}$ grupo geométrico, que é de $60 \mathrm{~m}$, nas duas normas. No entanto, as flexibilizações aos padrões que constam no AACG, no BACG e nos EBs, permitem a 
utilização de $45 \mathrm{~m}$, para as duas aeronaves em questão, guardadas algumas condições.

Para o A380-800, o AACG permite a utilização de pistas de $45 \mathrm{~m}$ de largura, porém o documento cita o provimento de inner shoulders, de forma a completar-se $60 \mathrm{~m}$ de largura, indicando que tal pavimento adicional deveria oferecer pelo menos uma capacidade de suporte para desvios eventuais. Já a FAA EB65A (2007c), com base na certificação da aeronave, permite que a mesma opere em pistas com um mínimo de $45 m$ de largura.

Para o B747-8, o BACG também permite a utilização de pistas de $45 \mathrm{~m}$ de largura, mas deixa aos Estados a responsabilidade de avaliar a necessidade de utilização de acostamentos com pavimento de maior capacidade de suporte (inner shoulder). Já a FAA EB74 (2008a) ${ }^{52}$ permite a utilização de pistas de $45 \mathrm{~m}$ de largura, desde que sejam providos acostamentos de 7,5m de largura em cada lado, com uma capacidade de suporte mínima especificada. Ainda, este EB limita em um prazo de cinco anos a utilização da flexibilização, de forma a dar prazo para a construção de uma RW em conformidade com os requisitos do grupo geométrico VI.

\subsubsection{ACOSTAMENTOS DA PISTA DE POUSO E DECOLAGEM}

Como visto no item anterior, as modificações nos acostamentos dependem das modificações da RW. Atualmente os acostamentos das duas RWs possuem uma largura na ordem de 7,5m, o que resulta em uma largura total de $60 \mathrm{~m}(45 \mathrm{~m}+2 \times$ $7,5 m$ ). Isso está conforme com o padrão da ICAO para o $5^{\circ}$ grupo geométrico. Já para $06^{\circ}$ grupo geométrico é exigida uma largura combinada de $75 \mathrm{~m}$ pelos padrões da ICAO e de $84 \mathrm{~m}$ pelos padrões da FAA.

Para o A380-800, conforme o AACG, seria necessário prover-se uma largura mínima da área pavimentada/estabilizada de 75m. A FAA EB65A (2007c) também especifica 75m como largura mínima da área pavimentada para o A380-800.

Para o B747-8 o BACG permite uma largura mínima de $60 \mathrm{~m}$, o que torna adequada a atual largura combinada entre RW e acostamentos. A FAA EB74 $(2008 a)^{53}$, coloca a necessidade de inner shoulders com capacidade de suporte suficiente para acomodar desvios eventuais da aeronave e acostamentos adicionais de $12 \mathrm{~m}$ em cada lado. Com isso a largura total do pavimento atinge a especificação padrão para o grupo geométrico VI, que é de $84 \mathrm{~m}$. Ainda, este EB limita em prazo de

\footnotetext{
${ }^{52}$ Este EB foi publicado em uma data anterior à certificação do B747-8.
}

${ }^{53}$ Este EB foi publicado em uma data anterior à certificação do B747-8. 
cinco anos o uso desta flexibilização. Após este período é necessário o atendimento aos critérios do grupo geométrico $\mathrm{VI}$.

\subsubsection{BLAST PADS}

Os quatro finais de pista possuem uma área pavimentada de $60 \mathrm{~m}$ de comprimento e a mesma largura da área combinada entre a RW e os acostamentos. Uma vez que as SWYs não são utilizadas para cálculo da TORA, então as quatro SWYs servem ao propósito de blast pads.

Conforme os padrões da ICAO, o comprimento atual das blast pads está de acordo para aeronaves menores do que o B747. Para atender-se a aeronaves como o A380-800, o B747-8 e o próprio B747-400, seria necessário aumentar-se o comprimento das blast pads para $120 \mathrm{~m}$. Seriam necessárias também correções para dar às blast pads a mesma largura do conjunto $R W+$ acostamentos. Estas modificações podem não ser necessárias nas duas RWs, dependo da utilização destas pelas três aeronaves recém citadas.

\subsubsection{LARGURA DAS PISTAS DE TÁXI}

Nos trechos retilíneos as TWs possuem uma largura de $23 \mathrm{~m}$. Isso está de acordo com os padrões da ICAO e da FAA para aeronaves do $5^{\circ}$ grupo geométrico. Mas está dois metros abaixo do padrão de largura do $6^{\circ}$ grupo geométrico da ICAO, e $7 \mathrm{~m}$ aquém do padrão FAA para aeronaves do $6^{\circ}$ grupo geométrico.

Por outro lado, deve-se considerar que a largura da TW se baseia na folga do pavimento, que é de 4,5m nos padrões da ICAO e da FAA ${ }^{54}$. Nesse sentido,o B7478 já atende a esta folga, pois seu wheel span é muito próximo ao do B747-400. Já o A380-800 fere esta margem em apenas $0,3 m(14,3 m+2 \times 4,5 m)$. Tanto o AACG (A380-800) quanto o BACG (B747-8) permitem a utilização de uma largura de $23 m$ para as TWs. Na mesma linha, a FAA EB N 63B (2007a) e a FAA EB Nº 73 (2007b) permitem a utilização de uma largura de $23 m$ para o A380 e o B747-8, respectivamente.

\subsubsection{ACOSTAMENTOS DA TW}

Os acostamentos das TWs possuem 10,5m de largura, formando, com as TWs de $23 \mathrm{~m}$ de largura, uma área pavimentada de $44 \mathrm{~m}$ de largura.

\footnotetext{
${ }^{54}$ Pelo padrão da FAA a folga do pavimento é de $6 \mathrm{~m}$, mas a FAA EB $\mathrm{N}^{\circ} 80$ (2010b) permite a utilização de 4,5m, mediante uma flexibilização de padrão de projeto.
} 
Isso está de acordo com o padrão da ICAO, para o grupo geométrico E, enquanto para o grupo $\mathrm{F}$ o padrão da ICAO seria de $60 \mathrm{~m}$.

Os padrões da FAA resultam em uma largura combinada entre a TW e os acostamentos de $44 \mathrm{~m}$ para $05^{\circ}$ grupo geométrico e de $54 \mathrm{~m}$ para $06^{\circ}$.

Assim, os padrões da ICAO e da FAA exigem aumento dos acostamentos para o A380-800 e o B747-8.

No entanto, considerando-se as flexibilizações, o BACG permite a utilização de $44 m$ para o B747-8. Na mesma linha, A FAA EB N ${ }^{\circ} 73$ (2007b) permite a utilização de acostamentos de $10,5 \mathrm{~m}$ quando para o $\mathrm{B} 747-8$, mesmo quando a TW possui $23 \mathrm{~m}$ de largura.

Para a aeronave A380-800 não existem flexibilizações previstas quanto a este critério.

\subsubsection{PISTAS DE TÁXI DE SAÍDA RÁPIDA (PTSRs)}

Componente não avaliado.

\subsubsection{PISTAS DE TÁXI SOBRE PONTES}

Não aplicável ao aeródromo em estudo.

\subsection{DISTÂNCIAS DECLARADAS}

\subsubsection{ZONA DESIMPEDIDA (CLEARWAY-CWY)}

Componente não avaliado, por depender das características de desempenho das aeronaves nas condições locais.

\subsubsection{ZONA DE PARADA (STOPWAY-SWY)}

A largura da SWY deve ter, no mínimo, a mesma da RW. As normas não apresentam informações sobre a necessidade de se prover acostamentos para SWYs. No entanto, devido à dupla função das SWYs, como discutido no item 7.3.3, as larguras totais destas áreas pavimentadas, deverão considerar o critério de largura total das blast pads

\subsection{CURVAS E INTERSECÇÕES}

O fator de carga lateral, limitado a 0,133g é um critério que limita o raio mínimo de uma dada curva no sistema de pistas de táxi, tendo-se em vista uma velocidade mínima de táxi. Se for admitido que este mesmo limite possa ser adotado 
para o A380-800 e para o B747-8, então não se espera uma queda na velocidade de táxi devido a este fator.

Quando ao ângulo de esterçamento da aeronave $(\beta)$, este cresce na razão direta do comprimento de referência da aeronave (d) e na razão inversa do raio da curva. Assim, para um dado raio, o maior ângulo de esterçamento ocorrerá para a aeronave com maior comprimento d. Admite-se d como a distância entre o centro da cabine de comando $(\mathrm{N})$ e o centro geométrico das rodas do trem principal sem capacidade de esterçamento. Já o ângulo de esterçamento da bequilha ( $\beta \mathrm{beq}$ ) cresce na razão direta das variáveis $\beta$ e $d_{\text {beq }}$, o que é equivalente a dizer-se que este cresce na razão direta das variáveis $\mathrm{d}$ e $\mathrm{d}_{\text {beq }}$. Portanto, uma análise comparativa entre as variáveis $d$ e $d_{\text {beq }}$, é suficiente para entender-se qual aeronave é mais crítica quanto ao critério ângulo de esterçamento da bequilha, dado um raio. A Tabela 7.5-1 mostra estas dimensões e permite concluir que o ângulo de esterçamento da bequilha é mais crítico para as aeronaves A340-600 e B777-300ER do que para o A380-800 e para o B747-8.

Tabela 7.5-1 - Dimensões WS, $\mathrm{d}_{\text {beq }}$ e $\mathrm{d}$ de aeronaves selecionadas

\begin{tabular}{c|c|c|c}
\hline Aeronave & Wheel span & $\begin{array}{c}\text { Distância entre o centro do } \\
\text { cockpit e a bequilha }\left(\boldsymbol{d}_{\text {beq }}\right)\end{array}$ & $\begin{array}{c}\text { Comprimento de referência | } \\
(\boldsymbol{d}) \mathbf{~ | a}\end{array}$ \\
\hline A340-600 & $12,6 \mathrm{~m}$ & $4,2 \mathrm{~m}$ & $37,4 \mathrm{~m}$ \\
B777-300ER & $12,9 \mathrm{~m}$ & $3,6 \mathrm{~m}$ & $34,2 \mathrm{~m}$ \\
B747-400ER & $12,6 \mathrm{~m}$ & $2,3 \mathrm{~m}$ & $26,4 \mathrm{~m}$ \\
A380-800 & $14,3 \mathrm{~m}$ & $2,1 \mathrm{~m}$ & $31,9 \mathrm{~m}$ \\
B747-8 & $12,7 \mathrm{~m}$ & $2,4 \mathrm{~m}$ & $30,5 \mathrm{~m}$ \\
\hline
\end{tabular}

FONTE: The Boeing Company. 747-8 Airport Compatibility ACI-NA. DFW, 6 de outubro de 2008. Disponível em: http://www.boeing.com/commercial/aeromagazine/articles/2010 q3/3/.

|a: Distância entre o centro da cabine de comando e o centro do trem principal.

Embora as aeronaves A380-800 e o B747-8 apresentem um d menor, a geometria dessas aeronaves (posição do nariz, pontas de asa, trem de pouso, estabilizador) são mais demandantes, o que obriga a realização de análises ao longo do caminho de táxi e também nas posições de estacionamento, de forma a verificar-se o atendimento às folgas de projeto (folga do pavimento, TSA, OFA da TW e TL, faixa da TW, folga de ponta de asa, entre outros). Na falta de dados precisos sobre os raios ao longo do caminho de táxi, limita-se a análise da trajetória de pontos de interesse ao trem central. Esta análise também é comparativa, tendose por base aeronaves que já utilizam o SBGR.

Tendo-se em vista a trajetória do trem de pouso, a aeronave B747-8 possui características menos demandantes do que o A340-600 e do que o B777-300ER, 
conforme os dados da Tabela 7.5-1. No entanto para o A380-800 uma análise mais detalhada se faz necessária. Esta análise é feita para três situações: i) o ponto N segue uma linha guia retilínea; ii) o ponto $\mathrm{N}$ segue o arco de um círculo, iniciando a manobra com o ponto $U$ deslocado para fora do arco; e iii) o ponto $\mathrm{N}$ segue o arco de um círculo, iniciando a manobra com o ponto U deslocado para dentro do arco. Nas análises a seguir, considerou-se a folga do pavimento, com base em coordenadas obtidas pela Equação 4.5-3 e pela Equação 4.5-4, utilizando-se para a variável $\mathrm{d}_{\mathrm{y}}$ a soma entre a metade do wheel span e a folga do pavimento. O ângulo $\beta$ foi obtido com base na metodologia apresentada no Apêndice 1 da ICAO Doc 9157 Parte 2 (2005a).

A Figura 7.5-1 analisa o caso $i$. O ângulo $\beta$ inicia em $90^{\circ}$ e termina em aproximadamente $1^{\circ}$, tendo o ponto $N$ percorrido $150 \mathrm{~m}$. Através desta figura, conclui-se que o A340-600 é mais demandante do que o A380-800, quanto à trajetória do trem de pouso, quando a cabine de comando segue uma trajetória retilínea.

A manobra associada ao caso ii é mostrada na Figura 7.5-2, na qual a linha guia é um círculo centrado na origem e o ponto $\mathrm{N}$ percorre a linha guia, do ângulo polar $0^{\circ}$ até $270^{\circ}$. No início da manobra o ângulo $\beta$ vale $0^{\circ}$ atingindo um $\beta \_m a x$ indicado no quadro superior da figura. No mesmo quadro apresenta-se o ângulo máximo da bequilha ( $\beta$ _beq_max). O gráfico da esquerda considera um raio $(\mathrm{R})$ de $50 \mathrm{~m}$, sendo que ele é crítico para a manobra da aeronave A340-600, pois sua bequilha chega a ultrapassar o limite de $50^{\circ}$ de esterçamento. Como fica claro neste gráfico, o A380-800 é menos demandante do que a do A340-600. Já o raio de $75 \mathrm{~m}$ foi escolhido para ilustrar o que acontece em raios maiores: a trajetória avaliada (WS/2 + folga do pavimento) das duas aeronaves se aproximam. O gráfico da direita contém ilustrações adicionais sobre a manobra analisada. Percebe-se, pela Figura 7.5-2, que a aeronave A340-600 é mais demandante neste tipo de manobra do que o $\mathrm{A} 380-800$.

Já a manobra associada ao caso iii é ilustrada na Figura 7.5-3. O raio de $55 \mathrm{~m}$ foi escolhido por ser um limite inferior para o A340-600, à medida que o ângulo de esterçamento da bequilha supera ligeiramente o limite de $50^{\circ}$. No lado esquerdo da Figura 7.5-3 as duas aeronaves iniciam a manobra com um ângulo $\beta$ de $50^{\circ}$ e no gráfico da direita este ângulo é de aproximadamente $45^{\circ}$, também para as duas aeronaves. 
Percebe-se que um pavimento que acomode o A340 -600 nesta situação, acomodará também um A380-800. Como o aumento do raio para 75m, esta situação se mantém.

A partir das análises realizadas, percebe-se que sobrelarguras suficientes para acomodar a aeronave A340-600 serão adequadas para as aeronaves A380800. Na mesma linha, sobrelarguras suficientes para acomodar as aeronaves A340600 e B777-300ER serão suficientes para acomodar-se o B747-8.

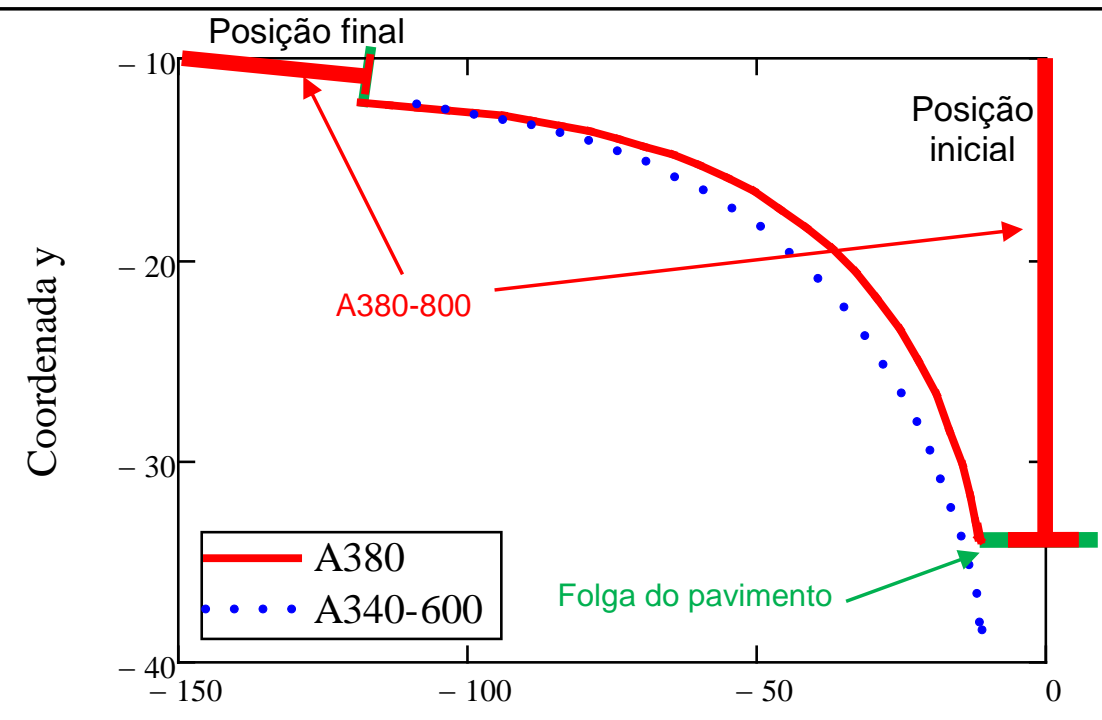

Coordenada $\mathrm{x}$

FORA DE ESCALA!

Figura 7.5-1 - Comparação entre as aeronaves A380-800 e A340-600 quando estas encontramse inicialmente desviadas em $90^{\circ}$ em relação a uma linha guia retilínea. FONTE: Calculado a partir dos dados do APMs e da metodologia da ICAO para análise da trajetória
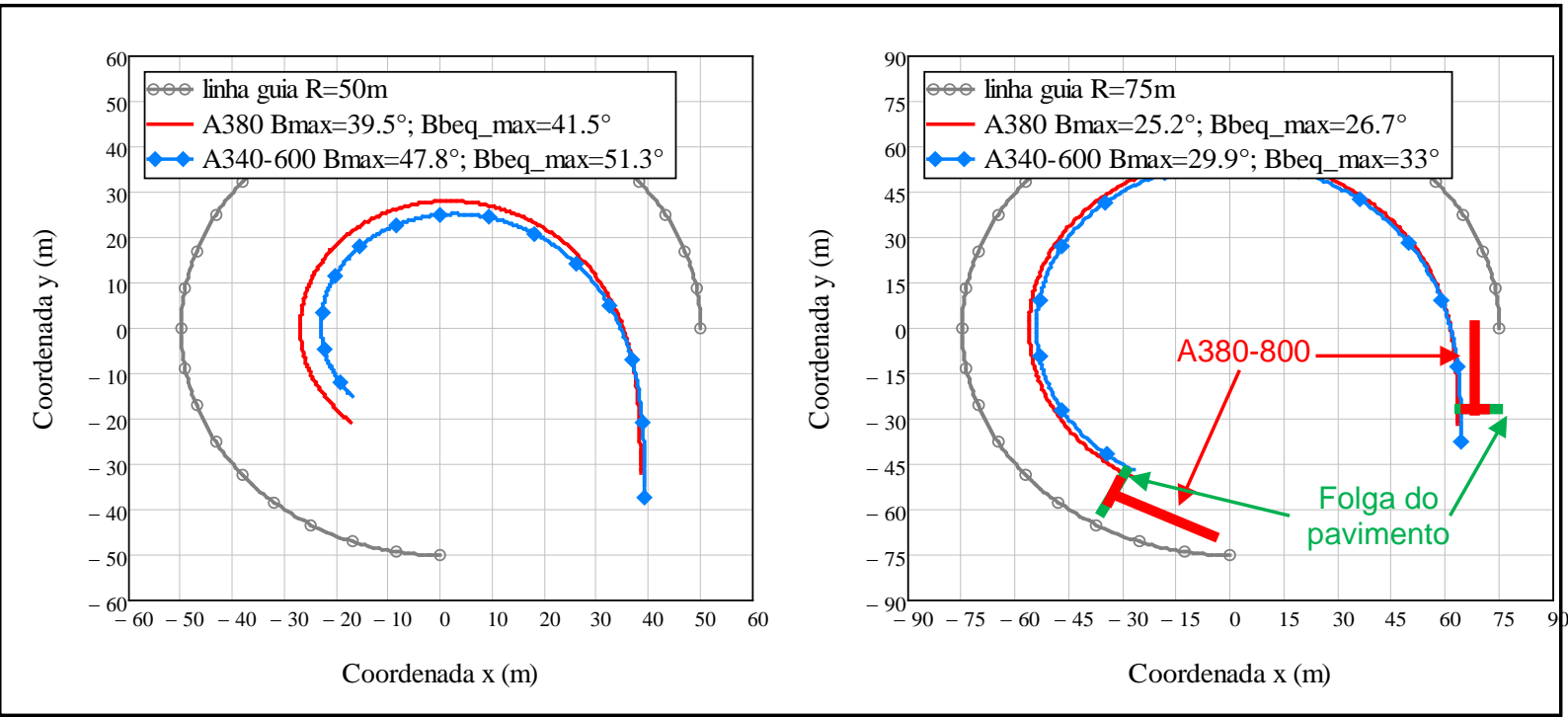

Figura 7.5-2 -Trajetória para as aeronaves A340-600 e A380-800 durante manobra associada ao caso ii . FONTE: Calculado a partir dos dados do APMs e da metodologia da ICAO para análise da trajetória 


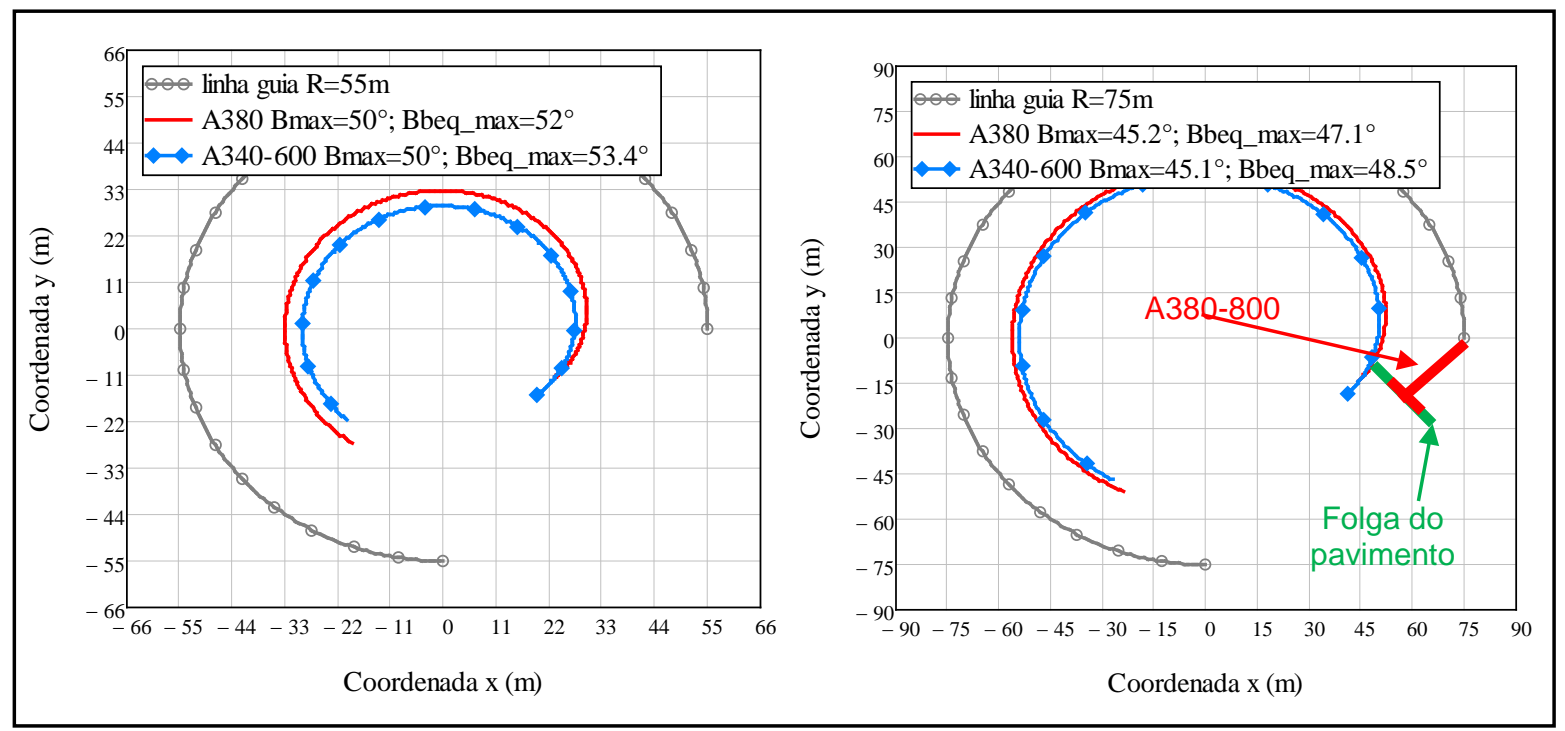

Figura 7.5-3 - Trajetória para as aeronaves A340-600 e A380-800 durante manobra associada ao caso iii . FONTE: Autor

\subsection{SEPARAÇÕES}

\subsubsection{SEPARAÇÃO ENTRE RWs PARALELAS}

A separação entre as duas RWs, que é de aproximadamente $375 \mathrm{~m}$, não permite operações paralelas. Porém, atualmente, enquanto uma RW é utilizada para pousos, a outra é utilizada para decolagens. Assim, uma aeronave pode estar posicionada sobre o eixo da RW durante uma aproximação na RW paralela. Isso traz a necessidade de avaliação da OFZ de transição interna, o que é feito no item 7.9.1. Através de tal análise se conclui que a separação é suficiente para a não violação da OFZ quando um A380-800 ocupa uma das RWs e uma aproximação de precisão é efetuada na RW paralela.

\subsubsection{SEPARAÇÃO ENTRE RWs E TWS PARALELAS}

Avalia-se a separação entre a RW 09L/27R e a TW B a partir de três aspectos: i) se esta separação é suficiente para acomodar aeronaves do grupo geométrico $F$, taxiando na TW B; ii) se a separação é suficiente para acomodar a espera de aeronaves entre a RW e a TW B; e iii) se a OFZ de transição interna da RW 09L/27R não é violada por uma aeronave taxiando na TW B. Os itens seguintes apresentam estas análises, nas quais assume-se que a RW é utilizada por aeronaves do grupo dinâmico 4.

\subsubsection{Análise da separação entre os eixos da RW e da TW}

A separação entre a RW 09L/27R e a TW B é de $184 m$, enquanto o padrão é de $190 \mathrm{~m}$. Este padrão, por sua vez, baseia-se na premissa de que a aeronave que 
taxia na TW não pode infringir a faixa da $R W$ paralela. Como a largura da faixa da $R W$ é de $300 m$ e a envergadura do A380-800 é de cerca de $80 m$, o padrão deve ser atingido para garantir-se a proteção da faixa da $R W$, pois $190=300 / 2+80 / 2$.

Como a envergadura do B747-8 é de $68,4 m$, esta premissa de projeto poderia ser atendida com uma separação mínima de $184,2 \mathrm{~m}$. Portanto, salva uma diferença de 0,2m, a separação existente é suficiente para a aeronave B747-8.

Tendo-se em vista as flexibilizações aos padrões de projeto, o AACG considera que $190 \mathrm{~m}$ é uma distância conservadora para a aeronave A380-800. Na mesma linha, o BACG aprova uma utilização de 182,5m para o B747-8, embora aconselhe a avaliação do sítio quanto à interferência da aeronave que taxia sobre o sistema ILS da RW. A FAA aprova para o B747-8, a partir do EB 81 (2010a), a utilização de separações do grupo geométrico $V$, que é de $168 \mathrm{~m}$, considerando visibilidade menor do que $800 \mathrm{~m}$. Esta separação padrão da FAA, pode necessitar de aumento para atender-se à $O F Z$ de transição interna.

\subsubsection{Espera entre a RW e a TW}

O táxi na TW B, quando uma aeronave espera entre esta e a RW 09L/27R, só será possível se a separação entre a RW e a TW for maior ou igual à soma entre: i) distância da RW 09L/27R até a barra de parada; ii) comprimento da aeronave que espera; e iii) folga entre esta aeronave e aquela que taxia na TW B. Esta situação é ilustrada na Figura 4.6-1. Dependendo de qual aeronave espera para entrar na RW 09L/27R e de qual taxia na TW B, pode-se calcular a distância máxima permissível entre a barra de parada e a RW 09L/27R.

Para tal avaliação utilizam-se algumas das aeronaves da Tabela 5.1-1, de forma que o valor de cada combinação é obtido pela expressão:

valor $=$ separação $-e n v_{\text {taxia }}-f o l g a_{\text {taxia }}-l_{\text {espera }}$

Onde: a separação representa a distância entre o eixo da RW 09L/27R e o eixo da TW B, assumida em 184m; env taxia representa a envergadura da aeronave que taxia na TW B; folga taxia representa a folga de ponta de asa da aeronave que taxia na TW B, conforme a soma X2+Z2 da Tabela 4.6-3; e lespera representa o comprimento da aeronave que espera, assumido igual ao comprimento $l_{\text {est }}$ da Tabela 5.1-1.

Os valores são mostrados na Tabela 7.6-1, onde nas linhas estão as aeronaves que taxiam na TW $B$ e nas colunas, as aeronaves que esperam entre a TW B e a RW 09L/27R. 
Tabela 7.6-1 - Distância máxima possível entre a RW 09L/27R e a BPRW que lhe dá acesso desde a TW B

\begin{tabular}{|c|c|c|c|c|c|c|c|c|c|c|c|c|c|c|c|c|c|c|}
\hline \multirow[b]{2}{*}{$\begin{array}{l}\text { Aeronave } \\
\text { que taxia } \\
\text { na TW B }\end{array}$} & \multicolumn{18}{|c|}{ Aeronave que espera entre a TW B e a RW 09L/27R } \\
\hline & $\begin{array}{l}\hat{N} \\
\dot{0} \\
8\end{array}$ & $\begin{array}{l}\text { 点 } \\
\text { 䍙 }\end{array}$ & 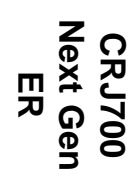 & $\begin{array}{l}\text { Ñ } \\
\dot{\alpha} \\
\text { \& }\end{array}$ & $\begin{array}{l}\frac{0}{0} \\
\frac{2}{2} \\
\frac{0}{2} \\
\frac{2}{2}\end{array}$ & 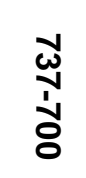 & $\begin{array}{l}\stackrel{\omega}{\omega} \\
\stackrel{0}{0} \\
\stackrel{1}{8}\end{array}$ & $\begin{array}{l}\text { 点 } \\
\text { 另 }\end{array}$ & $\begin{array}{l}\qquad \\
0 \\
0 \\
D\end{array}$ & $\underset{N}{\omega}$ & 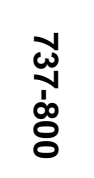 & $\begin{array}{l}\omega \\
\text { ơ } \\
\text { 耑 }\end{array}$ & 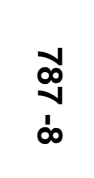 & $\begin{array}{l}\mathscr{\omega}^{w} \\
\dot{\omega} \\
\stackrel{\omega}{0}\end{array}$ & 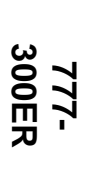 & $\begin{array}{l}\omega \\
\text { ô } \\
\text { ஸे } \\
8\end{array}$ & $\begin{array}{l}N \\
\infty \\
\infty\end{array}$ & $\begin{array}{l}\omega \\
\infty \\
0 \\
0 \\
0 \\
\delta\end{array}$ \\
\hline $42-600$ & 141 & 135 & 131 & 137 & 134 & 130 & 132 & 134 & 125 & 126 & 124 & 109 & 107 & 100 & 90 & 96 & 87 & 91 \\
\hline 140ER & 142 & 136 & 132 & 137 & 135 & 131 & 133 & 135 & 126 & 127 & 125 & 110 & 108 & 101 & 91 & 97 & 88 & 92 \\
\hline $\begin{array}{c}\text { CRJ700 } \\
\text { Next Gen } \\
\text { ER }\end{array}$ & 140 & 134 & 131 & 136 & 133 & 129 & 132 & 133 & 124 & 125 & 123 & 108 & 106 & 99 & 89 & 95 & 87 & 90 \\
\hline $72-600$ & 140 & 134 & 130 & 135 & 133 & 129 & 131 & 133 & 124 & 125 & 123 & 108 & 105 & 99 & 89 & 95 & 86 & 90 \\
\hline $\begin{array}{c}170 \\
\text { standard }\end{array}$ & 140 & 135 & 131 & 136 & 133 & 129 & 132 & 133 & 124 & 125 & 124 & 108 & 106 & 99 & 89 & 95 & 87 & 90 \\
\hline $737-700$ & 135 & 130 & 126 & 131 & 128 & 125 & 127 & 128 & 119 & 121 & 119 & 103 & 101 & 94 & 84 & 90 & 82 & 85 \\
\hline $318-100$ & 136 & 130 & 127 & 132 & 129 & 125 & 128 & 129 & 120 & 121 & 119 & 104 & 102 & 95 & 85 & 91 & 83 & 86 \\
\hline 145LR & 142 & 136 & 132 & 137 & 135 & 131 & 133 & 135 & 126 & 127 & 125 & 110 & 108 & 101 & 91 & 97 & 88 & 92 \\
\hline 195AR & 139 & 133 & 129 & 134 & 132 & 128 & 130 & 132 & 123 & 124 & 122 & 107 & 105 & 98 & 88 & 94 & 85 & 89 \\
\hline 320 & 136 & 130 & 127 & 132 & 129 & 125 & 128 & 129 & 120 & 121 & 119 & 104 & 102 & 95 & 85 & 91 & 83 & 86 \\
\hline $737-800$ & 135 & 130 & 126 & 131 & 128 & 125 & 127 & 128 & 119 & 121 & 119 & 103 & 101 & 94 & 84 & 90 & 82 & 85 \\
\hline $\begin{array}{c}767- \\
\text { 300ER }\end{array}$ & 123 & 117 & 113 & 119 & 116 & 112 & 114 & 116 & 107 & 108 & 106 & 91 & 89 & 82 & 72 & 78 & 69 & 73 \\
\hline $787-8$ & 116 & 111 & 107 & 112 & 109 & 105 & 108 & 109 & 100 & 101 & 100 & 84 & 82 & 75 & 65 & 71 & 63 & 66 \\
\hline $330-300$ & 116 & 110 & 107 & 112 & 109 & 105 & 107 & 109 & 100 & 101 & 99 & 84 & 82 & 75 & 65 & 71 & 63 & 66 \\
\hline $\begin{array}{c}777- \\
300 E R\end{array}$ & 114 & 108 & 104 & 109 & 107 & 103 & 105 & 107 & 98 & 99 & 97 & 82 & 80 & 73 & 63 & 69 & 60 & 64 \\
\hline $340-500$ & 115 & 109 & 105 & 110 & 107 & 104 & 106 & 107 & 99 & 100 & 98 & 82 & 80 & 74 & 63 & 69 & 61 & 65 \\
\hline $747-8$ & 110 & 104 & 100 & 105 & 102 & 99 & 101 & 102 & 94 & 95 & 93 & 77 & 75 & 69 & 58 & 64 & 56 & 60 \\
\hline $380-800$ & 104 & 98 & 94 & 99 & 97 & 93 & 95 & 97 & 88 & 89 & 87 & 72 & 70 & 63 & 53 & 59 & 50 & 54 \\
\hline
\end{tabular}

FONTE: Calculado a partir das especificações contidas na ICAO Annex 14 (2004a) e dos dados das aeronaves 
As células com fundo escuro representam combinações que atendem aos requisitos de BPRWs para RWs exclusivas de decolagem. As células com fonte clara representam combinações que permitem uma distância maior ou igual a $125 \mathrm{~m}$ para a BPRW, tendo-se em vista que este é o valor da distância da BPRW mais distanciada em todo o sistema de RWs.

\subsubsection{OFZ de transição interna}

Pelos critérios da ICAO e da FAA a separação entre a RW 09L/27R e a TW B do SBBR é suficiente para que uma aeronave A380-800 taxie sobre a TW B, enquanto uma aproximação de precisão CAT I, II ou III é realizada na RW 09L/27R por uma outra aeronave A380-800. As mesmas conclusões são válidas o B747-8. Os cálculos são apresentados no item 7.9.3.

\subsubsection{SEPARAÇÃO ENTRE TWs PARALELAS}

A separação entre as TWs B e A é de $90 \mathrm{~m}$, ao passo que o padrão ICAO é de $97,5 \mathrm{~m}$ para aeronaves do grupo geométrico $F$. Tendo-se em vista a folga de ponta de asa de $17,5 \mathrm{~m}$ e a semi-envergadura do A380-800, a máxima envergadura a ser permitida em uma TW paralela a outra TW na qual taxia esta aeronave será de $65 \mathrm{~m}$ (2×(90-40-17,5)). Assim, qualquer aeronave do grupo geométrico $E$, ou menos demandante, poderá taxiar na TW A enquanto o A380-800 ocupa a TW B, ou viceversa. Se a flexibilização prevista pelo AACG for considerada, pode-se utilizar uma folga de ponta de asa de $11 \mathrm{~m}$. Isso permite que uma aeronave com envergadura de até $78 m(2 \times(90-40-11))$ taxie paralelamente a um A380-800, considerando-se a geometria das TWs A e B.

Caso o B747-8 ocupe a TW B, qualquer aeronave com menos de 76,6m (2×(9068,4/2-17,5) ) poderá taxiar na TW A, ou vice-versa. Considerando-se a flexibilização do BACG, esta envergadura máxima passa a ser de 89,6m $(2 \times(90$ 68,4/2-11) ).

\subsubsection{SEPARAÇÕES NAS POSIÇÕES DE ESTACIONAMENTO}

Conforme a INFRAERO, o estudo preliminar do novo terminal de passageiros, o TPS3, a ser localizado na direção leste do atual TPS2 leva em conta o provimento de posições de estacionamento para o A380-800, através de pontes de embarque. 


\subsubsection{POSIÇÃO DAS BARRAS DE PARADA DA RW (BPRWs)}

A Figura 7.6-1 e a Tabela 7.6-2 mostram as barras de parada das RWs, numeradas sequencialmente.

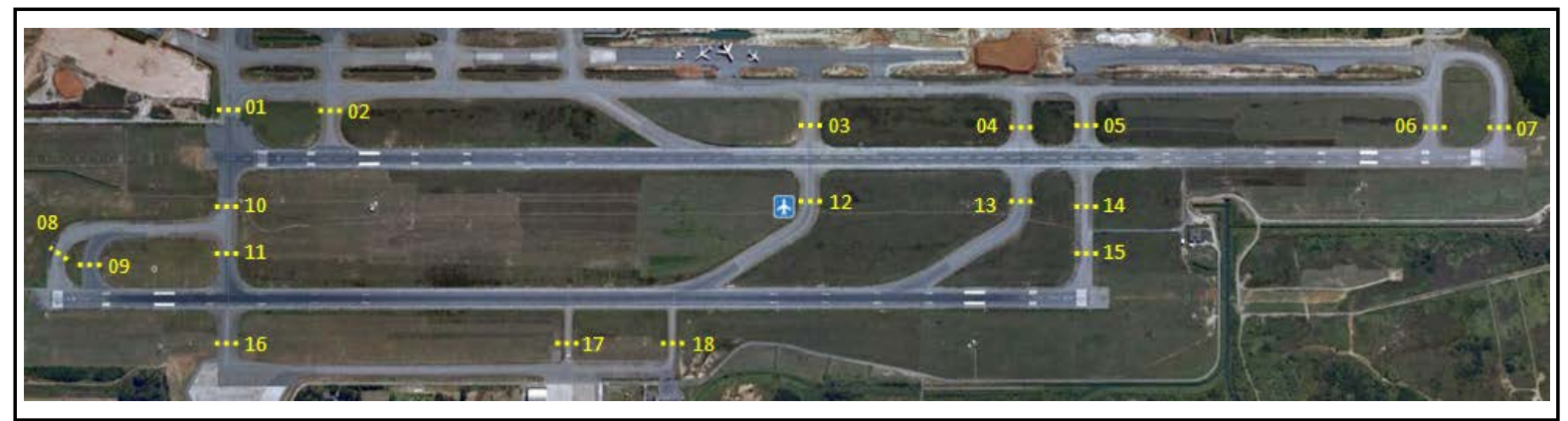

Figura 7.6-1 - Posição das barras de parada. FONTE: Adaptado a partir do Google Earth

Tabela 7.6-2 - Posição das barras de parada (m)

\begin{tabular}{c|c|c}
\hline BPRW & RW 09R/27L & RW 09L/27R \\
\hline 1 & - & 123 \\
2 & - & 123 \\
3 & - & 76 \\
4 & - & 83 \\
5 & - & 83 \\
6 & - & 77 \\
7 & - & 77 \\
8 & 121 & - \\
9 & 90 & - \\
10 & - & 124 \\
11 & 120 & - \\
12 & - & 122 \\
13 & - & 122 \\
14 & - & 124 \\
15 & 123 & - \\
16 & 123 & - \\
17 & 121 & - \\
18 & 122 & - \\
\hline
\end{tabular}

FONTE: Google Earth (Data das imagens: 15/12/2008).

Considerando-se que atualmente a RW 09L/27R é utilizada somente para decolagens, faz sentido analisar-se o atendimento aos padrões de uma pista exclusiva de decolagem, para a qual a ICAO faz especificações próprias. Como visto no item 4.6.5.3, para aeronaves de ARC ICAO 4-F, a BPRW deve estar posicionada 
a uma distância mínima de 77,5m. Essa distância é atendida por todas as BPRWs, com exceção das BPRWs 3, 6 e 7, cuja posição é ligeiramente inferior a 77,5m.

Já para o caso de as duas pistas serem utilizadas para aproximações de precisão, é necessário analisar-se os padrões para BPRWs conjuntamente com o atendimento à $O F Z$ de transição interna.

Conforme os critérios da ICAO, a separação entre a BPRW e o centro da RW deve ser de 107,5m para aeronaves do grupo geométrico F. Esta distância deve aumentar em $1 \mathrm{~m}$ para cada $100 \mathrm{~m}$ acima do nível do mar, caso a altitude seja menor do que $2.000 \mathrm{~m}$. Assim, para a altitude do aeroporto que é de $749,5 \mathrm{~m}$, a separação padrão deve ser de $107,5 \mathrm{~m}$ mais $7,5 \mathrm{~m}$, totalizando $115 \mathrm{~m}$. Portanto, as BPRWs $1,2,8,10,11,12,13,14,15,16,17$, e 18 comportam, pelos padrões da ICAO, aeronaves como o A380-800 e o B747-8 em espera durante aproximações de precisão. Devese considerar ainda que a ICAO exige que, para cada metro que a cabeceira estiver abaixo do nível da BPRW, a separação deve aumentar em $5 \mathrm{~m}$. Assim, uma análise mais detalhada seria necessária, tendo-se em mãos os valores das diferenças de elevação entre as cabeceiras e as BPRWs.

Já a FAA exige uma separação mínima de 92,5m $\left(85 m+7,5 m^{55}\right)$ entre a RW e a BPRW para aeronaves de ARC D-VI. Esta exigência resulta na mesma conclusão criada pelos padrões da ICAO, com exceção da BPRW 9, cuja separação é suficiente para aeronaves D-VI, embora situe-se no limiar da especificação.

No entanto, quando os padrões para a OFZ de transição interna são levados em conta, um número menor de BPRWs pode ser utilizado.

A Tabela 7.9-1 mostra quais BPRWs podem ser utilizadas e em que condições, tendo-se em vista a OFZ de transição interna.

\section{7 ÁREAS DE PROTEÇÃO DA RW}

Analisam-se somente as áreas de proteção previstas pela ICAO, ou seja, a faixa da RW e a RESA.

\subsubsection{FAIXA DA RW}

Os critérios para a área geral da faixa da RW, para a largura da área preparada da faixa da $R W$ e para o comprimento da mesma dependem do grupo dinâmico e do fato de as operações serem ou não de precisão. A RW 09L/27R e a RW 09L/27R já

\footnotetext{
${ }^{55}$ Correção para altitude.
} 
atendem aos padrões: $3.940 m \times 300 m$ e $3.240 m \times 300 m$, respectivamente, conforme DECEA (2010a).

No entanto, os padrões para a área restrita da faixa da $R W$ variam entre os ARCs 4-E e 4-F. A largura desta área é de $120 \mathrm{~m}$ para aeronaves com ARC 4-E e de $155 \mathrm{~m}$ para aeronaves $4-F$. Portanto, seria necessária a obtenção de dados mais detalhados para tal análise.

\subsubsection{RESA}

As dimensões da RESA não constam em DECEA (2010a). Como as recomendações para a RESA dependem do grupo dinâmico de as operações serem ou não de precisão, pode-se afirmar que uma RESA que atenda ao ARC 4-E, em aproximações de precisão, atenderá também ao ARC 4-F, na mesma condição.

\section{8 ÁREAS DE PROTEÇÃO DA TW}

Para a ICAO esta área é a faixa da TW, recomendando-se uma área geral da faixa da TW, que exclui objetos, e uma área preparada da faixa da TW. As especificações destas duas larguras dependem do grupo geométrico. Em relação ao grupo geométrico $E$, o grupo geométrico $F$ exige um aumento de $20 \mathrm{~m}$ para a largura total e de $16 \mathrm{~m}$ para a área preparada da faixa da TW.

\section{$7.9 \mathrm{OFZ}$}

As dimensões especificadas para as três superfícies da OFZ são mais restritivas para aeronaves do grupo geométrico $F$. No entanto, considerando-se que não existem pistas de táxi além das cabeceiras por uma largura maior do que a especificada para as superfícies da OFZ, a superfície de aproximação interna e a superfície de pouso interrompido não causam restrições, a não ser por obstruções do terreno ou equipamentos de auxílio à navegação aérea.

Avaliou-se a violação da OFZ de transição interna para as seguintes situações: um A380-800 ou B747-8 encontra-se sobre uma das RWs durante uma aproximação de precisão na RW paralela; um A380-800 ou B747-8 encontra-se esperando em uma das BPRWs, ou saindo da pista e tendo passado por essas BPRWs; e um A380-800 ou B747-8 taxia na TW B e um A380-800 ou B747-8 perfaz uma aproximação de precisão na RW 09L/27R. 


\subsubsection{UM A380-800 OU B747-8 ENCONTRA-SE SOBRE UMA DAS RWS DURANTE APROXIMAÇÃO DE PRECISÃO NA RW PARALELA}

A separação entre as RWs é de cerca de $375 \mathrm{~m}$.

Pelos critérios da ICAO, para aeronaves do grupo geométrico $\mathrm{F}$, utilizando-se a Equação 4.9-11, verifica-se a folga do estabilizador em relação à $O F Z$ de transição interna:

$\Delta E S T=1 / 3 \times((375+72,7 \times \operatorname{sen}(0))-77,5)-24,4=74,76 m$

Já pelas especificações da FAA, para aeronaves de grande porte em condições CAT II/III, deve-se calcular $Y$, através da Equação 4.9-3, resultando:

$Y=132+1,08 \times 79,7-0,024 \times 749,5=200 m$

$E \mathrm{H}_{2}$, através da Equação 4.9-2:

$H_{2}=16-0,13 \times 79,7-0,0022 \times 749,5=4 m$

Como a separação entre as RWs é maior do $\mathrm{Y}$, deve-se utilizar a Equação 4.9-31:

$\Delta E S T=\frac{1}{5} \times(200-60)+\frac{1}{6} \times(375+72,7 \times \operatorname{sen}(0)-200)+4-24,4=29,8 m$

Portanto, pelos critérios da ICAO e da FAA a separação entre as RWs do SBBR é suficiente para que uma aeronave A380-800 ocupe uma RW, enquanto uma aproximação de precisão CAT II ou III é realizada na RW paralela por outra aeronave A380-800. Como o B747-8 é menos demandante nesse critério, a mesma conclusão é válida para esta aeronave. Estas conclusões se apoiam na ideia de que as folgas apontadas sejam suficientes frente a possíveis diferenças de elevação entre a cabeceira e o solo sobre o qual se encontra a aeronave.

\subsubsection{POSIÇÃO DAS BPRWS}

Tendo-se em vista a numeração proposta na Figura 7.6-1 para as BPRWs, avalia-se a OFZ de transição interna quando a aeronave espera para entrar na RW e quando a aeronave se encontra deixando a RW, já tendo passado completamente pela BPRW. Para o caso em que a aeronave espera, avalia-se somente o nariz e o estabilizador, com a aeronave posicionada a $45^{\circ}$ em relação à RW. Para o caso em que a aeronave deixa a RW, avalia-se a violação da $O F Z$ de transição interna apenas pelo estabilizador. As equações utilizadas estão de acordo com os critérios 
C e D da Tabela 4.9-2. As análises propostas consistem no cálculo da folga entre o nariz e o estabilizador da aeronave e a OFZ de transição interna. Valores negativos indicam violação. Já a folga, pode ser entendida como uma margem para acomodar diferenças de altura entre a cabeceira e o solo sobre o qual se encontra a aeronave.

Como discutido no item 6.1.3, pelos critérios da ICAO, existe a possibilidade de que aeronaves do grupo geométrico $F$ utilizem uma $O F Z$ de transição interna projetada para o grupo geométrico E. A FAA, no entanto, não apresenta uma concessão de tal tipo.

As folgas para a $O F Z$ de transição interna padrão são mostradas na Tabela 7.9-1 e no ANEXO O, com um contraste de fonte e fundo para as situações em que a OFZ de transição interna é atendida ou violada.

Já as folgas para a OFZ de transição interna, com dimensões do grupo geométrico E são mostradas na Tabela 7.9-1 e no ANEXO P. Os dados referentes à FAA são idênticos nos ANEXO O e P.

As células marcadas na Tabela 7.9-1 representam as BPRWs para as quais a folga entre a OFZ de transição interna e o nariz ou estabilizador das aeronaves A380-800 e B747-8 é maior do que zero, considerando-se os padrões e flexibilizações da ICAO e os padrões da FAA. Portanto, as células marcadas indicam BPRWs que podem ser utilizadas pelas aeronaves, desde que as folgas apontadas nos ANEXOS O e $P$ sejam suficientes frente a possíveis diferenças de elevação entre a cabeceira e o solo sobre o qual se encontra a aeronave. ${ }^{56}$

Tabela 7.9-1 - Avaliação da OFZ de transição interna nas BPRWs do SBGR

\begin{tabular}{|c|c|c|c|c|c|c|c|c|c|c|c|c|c|c|c|c|c|c|c|}
\hline \multirow{2}{*}{\multicolumn{2}{|c|}{ Condição }} & \multicolumn{18}{|c|}{ BPRW, numeração conforme a Tabela 7.6-2 } \\
\hline & & 1 & 2 & 3 & 4 & 5 & 6 & 7 & 8 & 9 & 10 & 11 & 12 & 13 & 14 & 15 & 16 & 17 & 18 \\
\hline \multirow{2}{*}{$\begin{array}{c}\text { ICAO, } \\
\text { padrões do } \\
\text { grupo } \\
\text { geométrico F }\end{array}$} & $\begin{array}{l}\text { Esperando } \\
\text { para entrar }\end{array}$ & $x$ & $X$ & & & & & & X & & $X$ & $X$ & $X$ & $x$ & $X$ & $X$ & $\mathrm{x}$ & $X$ & $\mathrm{X}$ \\
\hline & $\begin{array}{c}\text { Saindo da } \\
\text { RW }\end{array}$ & & & & & & & & & & & & & & & & & & \\
\hline \multirow{2}{*}{$\begin{array}{c}\text { ICAO, } \\
\text { flexibilização } \\
\text { para utilizar } \\
\text { os padrões } \\
\text { do grupo } \\
\text { geométrico E }\end{array}$} & $\begin{array}{l}\text { Esperando } \\
\text { para entrar }\end{array}$ & $x$ & $\mathrm{X}$ & & & & & & $X$ & & $X$ & $\mathrm{X}$ & $X$ & $\mathrm{X}$ & $x$ & $x$ & $x$ & $x$ & $X$ \\
\hline & $\begin{array}{c}\text { Saindo da } \\
\text { RW }\end{array}$ & & & & & & & & & & & & & & & & & & \\
\hline
\end{tabular}

${ }^{56}$ No caso da ICAO, a dimensão padrão de uma BPRW pode necessitar de aumento, com base na elevação da cabeceira, conforme apresentado no item 4.6.5.1. No entanto este aumento não será necessário caso a OFZ já exija um determinado aumento em relação ao padrão. 


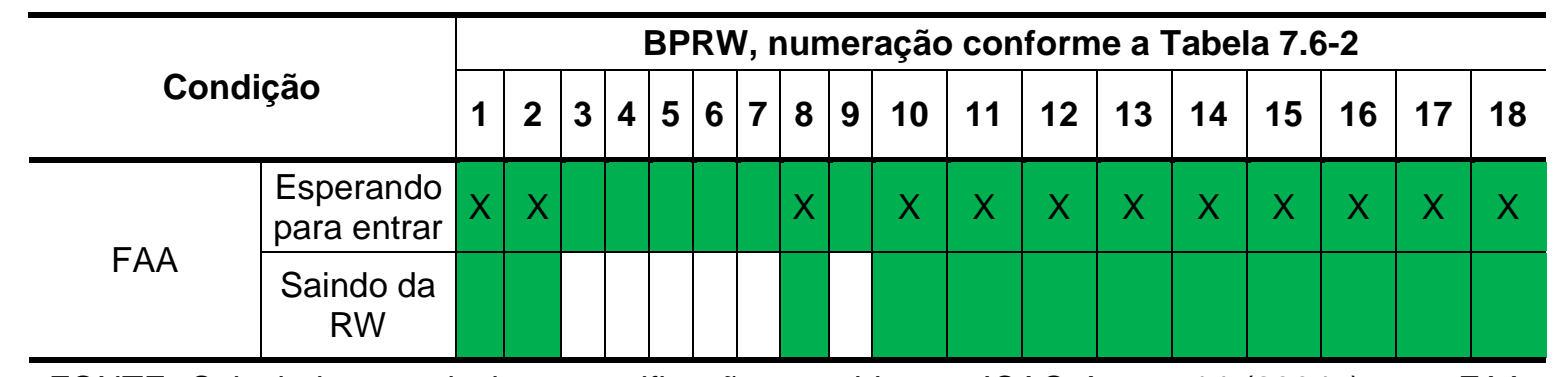

FONTE: Calculado a partir das especificações contidas na ICAO Annex 14 (2004a) e na FAA AC 150/5300-13 (1989) e dos dados das aeronaves. Os dados constam nos ANEXOS O e P
Legenda: $x$ A380-800
B747-8

OBS.: As informações referentes à FAA são aquelas relacionadas a condições CAT II/III.

\subsubsection{UM A380-800 OU UM B747-8 TAXIA NA TW B E UM A380-800 OU UM B747-8 PERFAZ UMA APROXIMAÇÃO DE PRECISÃO NA RW 09L/27R}

A separação entre a TW B e a RW 09L/27R é de aproximadamente 184m.

Pelos critérios da ICAO, utilizando-se a Equação 4.9-11, verifica-se a folga do estabilizador em relação à $O F Z$ de transição interna, considerando-se que um A380800 encontra-se parado sobre o eixo da TW:

$\Delta E S T=1 / 3 \times((184+72,7 \times \operatorname{sen}(0))-77,5)-24,4=11,1 m$

Para o B747-8 esta folga será ainda maior:

$\Delta E S T=1 / 3 \times((184+76,3 \times \operatorname{sen}(0))-77,5)-19,4=16,1 m$

Agora para o A380-800, pelas especificações da FAA, para condições CAT II/III deve-se calcular $Y$, através da Equação 4.9-3, resultando:

$Y=132+1,08 \times 79,7-0,024 \times 749,5=200 m$

$E \mathrm{H}_{2}$, através da Equação 4.9-2:

$H_{2}=16-0,13 \times 79,7-0,0022 \times 749,5=4 m$

Como a separação entre RW e a TW é menor do que $\mathrm{Y}$, deve-se utilizar a Equação 4.9-31:

$\Delta E S T=\frac{1}{6} \times(184+72,7 \times \operatorname{sen}(0)-60)+4-24,4=0,3 m$

Agora para o B747-8, pelas especificações da FAA, deve-se calcular $Y$, através da Equação 4.9-3, resultando:

$Y=132+1,08 \times 68,5-0,024 \times 749,5=188 m$ 
$\mathrm{E} \mathrm{H}$ 2, através da Equação 4.9-2:

$H_{2}=16-0,094 \times 68,5-0,0022 \times 749,5=5,4 m$

Como a separação entre RW e a TW é menor do que $\mathrm{Y}$,deve-se utilizar a Equação 4.9-31:

$\Delta E S T=\frac{1}{6} \times(184+68,5 \times \operatorname{sen}(0)-60)+5,4-19,4=6,6 m$

Pelos critérios da ICAO e da FAA a separação entre a RW e a TW B do SBBR é suficiente para que uma aeronave A380-800 taxie sobre a TW $B$, enquanto uma aproximação de precisão CAT II ou III é realizada na RW 09L/27R por outra aeronave A380-800. As mesmas conclusões são válidas o B747-8. Estas conclusões se apoiam na ideia de que as folgas apontadas sejam suficientes frente a possíveis diferenças de elevação entre a cabeceira e o solo sobre o qual se encontra a aeronave.

\subsection{CONCLUSÕES DO CAPÍTULO}

Este Capítulo apresentou uma análise do lado aéreo do aeroporto de São Paulo/Guarulhos quanto à introdução das aeronaves A380-800 e B747-8, à luz dos critérios apresentados no Capítulo 4 e das flexibilizações apresentadas no Capítulo 6. Disso, apontaram-se as conformidades e não conformidades, colocando-se as flexibilizações como uma facilitação à acomodação dessas novas aeronaves. A seguir apresentam-se as principais conclusões.

Os seguintes critérios de projeto podem ser considerados conformes, tendo-se em vista seu estado atual ou flexibilizações de projeto:

- A largura atual da pista de pouso e decolagem, que é de $45 \mathrm{~m}$, pode ser utilizada para as duas novas aeronaves, mediante a adoção de flexibilizações dos padrões. Flexibilizações também podem justificar a utilização dos acostamentos atuais das pistas de pouso e decolagem e das pistas de táxi no caso do B747-8.

- A largura de $23 \mathrm{~m}$ das pistas de táxi também pode ser utilizada pelas duas novas aeronaves, mediante flexibilizações.

- O caminho de táxi utilizado pela aeronave A340-600 também pode ser utilizado pelas duas novas aeronaves, tendo-se em vista as sobrelarguras. Ainda, o B747-8, que é menos demandante que o A380-800 neste aspecto, pode seguir também o mesmo caminho de táxi que um B777-300ER. 
- A OFZ de transição interna de uma das pistas de pouso e decolagem do aeródromo não é violada, quando um A380-800 ou B747-8 ocupa a pista de pouso e decolagem paralela.

- A separação entre a RW 09L/27R e a TW B, apesar de ser menor do que o padrão de $190 \mathrm{~m}$ imposto pela ICAO para o $6^{\circ}$ grupo geométrico, pode ser considerada suficiente, mediante a flexibilização do padrão, ou restringindose a envergadura das aeronaves que operam de forma concomitante a um A380-800 ou B747-8.

- Os padrões para a faixa da RW e para a RESA não diferem entre os grupos geométricos $E$ e $F$. Se for considerado que estas estruturas já atendem aos padrões exigidos para as aeronaves que atualmente operam no aeródromo, nenhuma modificação será necessária para acomodar-se o A380-800 e o B747-8.

Já os seguintes critérios e considerações de projeto podem exigir adequação da infraestrutura ou adoção de restrições operacionais:

- A largura combinada entre os acostamentos e as pistas de pouso e decolagem não é suficiente para atender aos critérios exigidos para a aeronave A380-800, nem mesmo recorrendo-se a flexibilizações. O mesmo pode ser dito para a largura combinada entre os acostamentos e as pistas de táxi.

- Quanto à área de sucção lateral, a aeronave A380-800 apresenta um acréscimo em relação ao A340-600. Já para as aeronaves Boeing nenhuma análise foi realizada, pois estes dados não constam nos APMs.

- O A380-800 também foi verificado mais demandante em relação à dispersão lateral do contorno de velocidade de $35 \mathrm{mph}$. O B747-8, por sua vez, tende a ser menos crítico neste aspecto, apresentando acréscimos muito pequenos e até decréscimos, dependendo da aeronave com a qual a comparação é feita e dependendo também do nível de empuxo avaliado.

- Quanto à dispersão longitudinal dos contornos de 35mph, o A380-800 e o B747-8 apresentam acréscimos razoáveis dependendo do nível de empuxo avaliado. O mesmo pode ser dito para a dispersão lateral e longitudinal das velocidades maiores do que $35 \mathrm{mph}$.

- O comprimento das blast pads atuais, que é de $60 \mathrm{~m}$, não atende nem mesmo à recomendação para aeronaves como o B747-400, que seria de $120 \mathrm{~m}$. Já a largura de uma blast pad deve ser igual à largura combinada entre a pista de pouso e decolagem e os acostamentos, o que exigiria 
intervenções no caso do A380-800. Para o B747-8, no entanto, flexibilizações podem ser utilizadas para justificar a não intervenção sobre a largura das blast pads, tendo-se em vista a possibilidade de flexibilizar-se a largura combinada entre a pista de pouso e decolagem e os acostamentos.

- A separação entre as TWs A e B exige limitação da envergadura das aeronaves que taxiam na TW paralela àquela ocupada por um A380-800 ou B747-8.

- Verificou-se que a envergadura máxima permitida na TW B está condicionada ao comprimento da aeronave que espera entre a TW B e a RW 09L/27R.

- A posição de algumas BPRWs é insuficiente para que as novas aeronaves nelas aguardem a liberação da pista de pouso e decolagem. Ainda, verificouse que nenhuma das BPRWs possui uma separação suficiente para a proteção da OFZ de transição interna no caso de um A380-800 deixar a pista de pouso e decolagem, devido à maior altura do estabilizador desta aeronave.

- Em relação à faixa da pista de táxi, esta pode exigir melhorias, uma vez que os padrões associados ao grupo geométrico $F$ são mais demandantes do que os padrões do grupo geométrico $E$. 


\section{CAPÍTULO 8 - CONCLUSÕES E RECOMENDAÇÕES}

Esta dissertação trata do projeto geométrico de aeródromos a partir das normas da ICAO e da FAA. Propõe-se uma estrutura de critérios de projeto, na qual os padrões e recomendações são agrupados por função. Conforme esta estrutura proposta, apresenta-se uma revisão dos padrões e recomendações de cada norma. Estes padrões são então comparados, demonstrando-se os pontos de concordância e divergência entre as duas normas, bem como as diferenças na forma como cada norma especifica os padrões relacionados a um dado critério de projeto. Apresentase também uma série de flexibilizações dos padrões de projeto, visando à acomodação das aeronaves A380-800 e B747-8 em aeroportos existentes. E, com base nos padrões e flexibilizações apresentados, analisa-se o lado aéreo do Aeroporto Internacional de Guarulhos quanto à operação das aeronaves A380-800 e B747-8.

\subsection{CONCLUSÕES}

No Capítulo 4 apresentam-se os padrões e recomendações da ICAO e da FAA para o projeto geométrico de aeródromos através de uma estrutura proposta de critérios, metodologias e considerações de projeto. Esta estrutura tem por base a semelhança funcional entre os critérios, metodologias e considerações de projeto. Esta estrutura serve de base às comparações, feitas no Capítulo 5 e à avaliação da operação das aeronaves A380-800 e B747-8 no Aeroporto Internacional de São Paulo/Guarulhos, feita no Capítulo 7. Ao longo do Capítulo 4 são propostos termos e siglas que facilitam a referenciação ao longo do texto. Propõe-se ainda, uma divisão da faixa da $R W$ em sub-partes, que são a área geral da faixa da $R W$, a área preparada da faixa da $R W$ e a área restrita da faixa da $R W$. De forma similar, propõe-se a divisão da faixa da TW em área geral da faixa da TW e área preparada da faixa da TW. Estas divisões também se justificam pelas diferenças de função e pelas diferenças de especificação a elas associadas.

Também, no Capítulo 4 demonstram-se as relações que os diversos critérios, metodologias e considerações de projeto guardam entre si. Ainda, propõe-se uma modelagem da OFZ de transição interna, motivada pela complexidade geométrica desse critério de projeto.

No Capítulo 5 comparam-se os padrões e recomendações da ICAO e da FAA, demonstrando-se as diferenças nas especificações e também na forma como as especificações são feitas por cada norma. Quando comparações diretas não são 
possíveis, utilizou-se um conjunto de aeronaves, sendo as especificações obtidas a partir de suas características.

Dentre as muitas conclusões pontuais obtidas a partir das aeronaves analisadas, merecem destaque aquelas relacionadas aos seguintes critérios:

- os grupos dinâmicos da ICAO e da FAA não são equivalentes;

- os grupos geométricos da ICAO e da FAA são exatamente iguais, sendo a envergadura a característica geométrica mais importante para definí-los;

- o vento de través de projeto varia entre as aeronaves narrowbodies e é igual para as widebodies;

- a largura combinada entre a pista de pouso e decolagem e os acostamentos resulta maior em até $30 \mathrm{~m}$ pelos critérios da FAA;

- o comprimento de uma blast pad resulta maior em até $60 \mathrm{~m}$ pelos critérios da FAA;

- a separação entre os eixos de RWs paralelas em pistas para aproximação visual difere em até 74\%; e

- o atendimento à $O F Z$ de transição interna não é garantido pelo padrão de posição da BPRW, nem para o nível do mar nas normas da ICAO e da FAA.

E ainda, diretamente a partir de comparações, o Capítulo 5 permite uma série de conclusões pontuais, entre as quais cabe destacar:

- a folga do pavimento é igual para todos os grupos geométricos, com exceção do $6^{\circ}$. Já a largura padrão da TW varia para o $6^{\circ}$ e para o $4^{\circ}$ grupos geométricos;

- as folgas de ponta de asa da ICAO em pistas de táxi sofrem declínio do $1^{\circ}$ ao $3^{\circ}$ grupos geométricos e depois voltam a subir;

- para o $4^{\circ}$ e para o $5^{\circ}$ grupos geométricos as especificações da ICAO e da FAA para a largura combinada entre pistas de táxi e acostamentos coincidem; e

- sobre as superfícies da OFZ, verifica-se que as normas têm em comum três tipos básicos de superfícies: superfícies no solo, superfícies de aproximação e superfícies de transição interna.

No Capítulo 5 apresenta-se também uma proposta de estruturação aos efeitos do jet blast.

Já o Capítulo 6 resume uma série de flexibilizações aos padrões de projeto para acomodação do A380-800 e do B747-8 em aeroportos existentes. Estas flexibilizações provém da própria FAA e de outras autoridades aeronáuticas, o que 
ressalta a importância de considerá-las quando não for possível atender-se aos padrões de projeto.

Já o Capítulo 7 apresenta uma análise da operação das aeronaves A380-800 e B747-8 no Aeroporto Internacional de São Paulo/Guarulhos, demonstrando-se, entre os componentes analisados, as conformidades e não conformidades com os padrões da ICAO. Para as não conformidades, apresenta-se também as considerações pertinentes aos critérios e da FAA e às flexibilizações dos padrões de projeto.

De forma geral, o B747-8 é mais fácil de acomodar, devido à sua envergadura menos demandante do que a do A380-800, e devido às diversas semelhanças com o B747-400, apesar de pertencer ao $6^{\circ}$ grupo geométrico. Entre as muitas conclusões pontuais em relação aos critérios de projeto, cabe destacar:

- a largura da pista de pouso e decolagem, que é de $45 \mathrm{~m}$ tende a ser suficiente paras as duas aeronaves, mediante flexibilizações dos padrões de projeto;

- a largura atual combinada entre a pista de pouso e decolagem e os acostamentos, que é de $60 \mathrm{~m}$, mediante flexibilizações, poderia ser utilizada pelo B747-8, mas o A380-800 exigiria aumentos;

- as blast pads atuais não atendem nem mesmo aos critérios do B747-400, devendo ser aumentadas para $120 \mathrm{~m}$ para as duas novas aeronaves;

- a largura das pistas de táxi atual, que é de 23m, mediante flexibilizações, poderia ser utilizada para as duas aeronaves;

- a largura atual combinada entre a pista de táxi e os acostamentos, que é de $44 \mathrm{~m}$, mediante flexibilizações, poderia ser utilizada pelo B747-8, mas o A380-800 exigiria aumentos;

- em relação às sobrelarguras, a aeronave B747-8 é menos demandante do que as aeronaves A340-600 e B777-300ER, o que permite que a nova aeronave perfaça o mesmo caminho de táxi que estas duas aeronaves que atualmente operam no aeródromo. Já o A380-800 é menos demandante que a aeronave A340-600, podendo perfazer o mesmo caminho de táxi desta aeronave;

- as separações entre as pistas de pouso e decolagem e entre estas e a pista de táxi paralela (TW B) não levam à violação da OFZ de transição interna quando uma aeronave A380-800 ou B747-8 se encontra sobre o eixo da RW ou TW; 
- a separação entre as pistas de táxi B e A são suficientes para as duas novas aeronaves, desde que a envergadura da aeronave que taxia na outra pista de táxi seja limitada a $65 \mathrm{~m}$ no caso do $A 380-800$ e a $76,6 \mathrm{~m}$ no caso do B747-8. Flexibilizações poderiam ser utilizadas para diminuir estas restrições de envergadura;

- a possibilidade de espera entre a RW 09L/27R e a TW B é condicionada à combinação entre: a aeronave que taxia na TW $B$, o comprimento da aeronave que espera e o tipo de operação permitida na RW 09L/27R (somente decolagem ou aproximação de precisão o que influencia o padrão para a posição da barra de parada da RW);

- caso alguma das RWs seja considerada exclusiva de decolagem, todas as barras de parada da RW são adequadas às duas novas aeronaves. Já para aproximações de precisão, restrições de utilização são aplicáveis, com base nos padrões para barras de parada e nos padrões para a OFZ de transição interna;

- a faixa da RW e a RESA tendem a ser adequadas para as duas novas aeronaves, pois os padrões a elas associados não são mais demandantes do que para outras aeronaves que já operam no aeródromo. Uma exceção fica por conta da área restrita da faixa da $R W$, que é mais demandante para aeronaves do $6^{\circ}$ grupo geométrico.

\subsection{RECOMENDAÇÕES PARA PESQUISAS FUTURAS}

A comparação entre as normas da ICAO e da FAA demonstra especificações, por vezes, bastante discrepantes para um mesmo critério de projeto. Com base em informações como procedimentos operacionais, exigências de certificação das aeronaves e dados de acidentes/incidentes, poder-se-ia explorar como as diferenças nas especificações levam a níveis de segurança igualmente aceitáveis em ambas as normas.

Outra possibilidade de pesquisa diz respeito aos fundamentos de cada critério de projeto, dos padrões a ele especificados e da própria forma como as especificações são feitas. Para subsidiar esta pesquisa, seria necessária a consulta à ICAO e à FAA, bem como outros órgãos afins, para a obtenção dos relatórios técnicos que suportam as normas. A confrontação entre estes critérios e as características das novas aeronaves poderia levar a uma reavaliação das normas atuais. Nesse sentido, seria fundamental a consideração das flexibilizações dos padrões de projeto, bem como das novas tecnologias disponíveis, em termos de posicionamento, monitoração etc. 
Seguindo-se uma linha mais prática, poder-se-ia expandir as avaliações do Capítulo 7, a partir da obtenção de dados mais detalhados sobre o Aeroporto Internacional de São Paulo/Guarulhos, incluindo-se os aspectos operacionais. Com isso, poder-se-ia explorar os trade-offs entre custos de infraestrutura, interrupções operacionais necessárias para as obras, e medidas de capacidade e atraso. 


\section{REFERÊNCIAS}

AÉROPORTS DE PARIS. Aeronautical Study from Aeroports de Paris (ADP) on Runway and Shoulder Width: A380 Accommodation at Paris Charles de Gaulle Airport (CDG) on Runway 1 (09R/27L) and Runway 2 (08L/26R). Paris, 2008a.

AÉROPORTS DE PARIS. ILS Study at Paris Charles-De-Gaulle International Airport (CDG): A380 Effect on Localizer Beam and Potential Consequences on the Size of the Associated Sensitive Area. Paris, 2008b.

AEROPUERTOS ESPAÑOLES Y NAVEGACIÓN AÉREA. Operación de Aeronaves A380 en Aeropuertos Alternativos y de Forma Esporádica. Dirección de Operaciones e Sistemas de Red - EXA34. Madri, 2005.

ANAC. Agência Nacional de Aviação Civil. Regulamento Brasileiro de Aviação Civil RBAC 154 - Emenda 00. Brasília, 2009a. . Requisitos de Aeronavegabilidade: Aviões Categoria Transporte - RBAC 25

- Emenda 128. Brasília, 2009b.

AIRBUS. A319 Airplane Characteristics for Airport Planning. Blagnac, 2007.

AIRBUS. A320 Airplane Characteristics for Airport Planning. Blagnac, 2011a.

AIRBUS. A321 Airplane Characteristics for Airport Planning. Blagnac, 2011b.

AIRBUS. A330 Airplane Characteristics for Airport Planning. Blagnac, 2011c.

AIRBUS. A340-500/-600 Airplane Characteristics for Airport Planning. Blagnac, 2011d.

AIRBUS. A380 Airplane Characteristics for Airport Planning. Blagnac, 2008.

ATR. ATR Family. Blagnac, 2011.

BOEING. 737 Airplane Characteristics for Airport Planning. 2005a. 
BOEING. 747-8 Airplane Characteristics for Airport Planning. 2008a.

BOEING. 767 Airplane Characteristics for Airport Planning. 2005b.

BOEING. 777-200/300 Airplane Characteristics for Airport Planning. 2008b.

BOEING. 777-200LR/300ER/Freighter Airplane Characteristics for Airport Planning. 2009.

BOEING. 787 Airplane Characteristics for Airport Planning. 2010.

BOEING. 747-400 Airplane Characteristics for Airport Planning. 2002.

BOMBARDIER. CRJ 700. Airport Planning Manual. Toronto, 2010a.

BOMBARDIER. CRJ 900. Airport Planning Manual. Toronto, $2010 \mathrm{~b}$.

CASA. Civil Aviation Safety Authority. Manual of Standards Part 139 - Aerodromes. Versão 1.6. Canberra, 2011.

DIRECTION GÉNÉRALE DE L'AVIATION CIVILE. A380 Resistance of elevated runway edge lights to jet blast: Report of 3 studies. Paris, 2008.

DECEA. Departamento de Controle do Espaço Aéreo: ADC - SBGR (DATA: 3 de junho de 2010). AIS - Serviço de informação Aeronáutica. Disponível em: < http://www.aisweb.aer.mil.br/ inc/carta-download.cfm?carta=5837E0D6-17364A94-AC31FD106C1A94FDed=tela>. Acesso em setembro de 2010.

EMBRAER. EMB 135 Airport Planning Manual. 2008a.

EMBRAER. EMB 140 Airport Planning Manual. 2005.

EMBRAER. EMB 1405LR Airport Planning Manual. 2007.

EMBRAER. EMB 170 Airport Planning Manual. 2008b. 
EMBRAER. EMB 190 Airport Planning Manual. 2008c.

EMBRAER. EMB 195 Airport Planning Manual. 2008d.

EUA. Electronic Code of Federal Regulations: Title 14-Aeronautics and Space. GPO Access. Disponível em: < http://ecfr.gpoaccess.gov/cgi/t/text/textidx?c=ecfretpl=/index.tpl>. Acesso em 23 de fevereiro de 2010.

FAA. Federal Aviation Administration. Aircraft Weight and Balance Control: AC 12027E. Washington, 2005a.

Airport Capacity and Delay: AC 150/5060-5. Washington, 1983.

. Airport Design: Advisory Circular 150/5300-13 - Incorporates changes 1 thru 15. Washington, 1989.

Airport Foreign Object Debris: Advisory Circular 150/5220-24. Washington, 2009.

. Minimum Requirements to Widen Existing 150-Foot Wide Runways for Boeing 747-8 Operations: Engineering Brief $N^{0}$ 74. Washington, 2008.

. Planning and Design Guidelines for Airport Terminal Facilities: Advisory Circular 150/5360-13 - Incorporates change 1. Washington, 1988.

. Runway Length Requirements for Airport Design: Advisory Circular 150/5325-4B. Washington, 2005b.

. Taxiways for Airbus A380 Taxiing Operations: Engineering Brief $\mathrm{N}^{0} 63 \mathrm{~B}$. Washington, 2007a.

. United States Standard for Terminal Instrument Procedures - TERPS: Order 8260.3B. Washington, 1976a. 
Centerline Separation For Boeing 747-8: Engineering Brief $\mathrm{N}^{0}$ 81. Washington, 2010a.

. Use of Interim Taxiway Edge Safety Margin Clearance for Airplane Design Group VI: Engineering Brief $N^{0} 80$. Washington, 2010b.

. Use of Non-Standard 75-Foot Wide Straight Taxiway Sections for Boeing 747-8 Taxiing Operations: Engineering Brief $\mathrm{N}^{0}$ 73. Washington, 2007b.

. Use of 150-Foot-(45-M) Wide Runways for Airbus A380 Operations: Engineering Brief $\mathrm{N}^{\circ}$ 65A. Washington, 2007c.

KAZDA, A.; CAVES, R. E. Airport Design and Operation. $2^{\mathrm{a}}$ Edição. Bingley, 2008.

HORONJEFF, R.; MCKELVEY, F. X. Planning and Design of Airports. $4^{\mathrm{a}}$ Edição. Nova lorque, 1994.

ICAO. International Civil Aviation Organization. Aerodrome Design Manual: Parte 1 Runways - Doc 9157. $3^{a}$ Edição. Montreal, 2006a.

. Aerodrome Design Manual: Parte 2 - Taxiways, Aprons and Holding Bays Doc 9157. 4ª Edição. Montreal, 2005a.

Airport Services Manual: Parte 6 - Control of Obstacles - Doc 9137. $2^{\mathrm{a}}$ Edição. Montreal, 1983a.

Annex 6 to the Convention on International Civil Aviation: Operation of Aircraft, Part 1: International Commercial Air Transport - Aeroplanes. $8^{a}$ Edição. Montreal, 2001a.

Annex 10 to the Convention on International Civil Aviation: Aerodromes, Volume I - Radio Navigation Aids. 6ª Edição. Montreal, 2006b.

. Annex 14 to the Convention on International Civil Aviation: Aerodromes, Volume I - Design and Operation. 4ª Edição. Montreal, 2004a.

European Region Air Navigation Plan: Volume I, Basic ANP - Doc 7754. $1^{\mathrm{a}}$ Edição. Montreal, 2001b. 
. Manual de Planificación de Aeropuertos: Parte 1 - Planificación General Doc 9184-AN/902. 2a Edição. Montreal, 1987.

. Manual on the Use of the Collision Risk Model (CRM) for ILS Operations Doc 9274. 1ª Edição. Montreal,1980.

. Manual sobre operaciones simultáneas en pistas de vuelo por instrumentos paralelas o casi paralelas - Doc 9643. $1^{\mathrm{a}}$ Edição. Montreal, 2004b.

. New Larger Aeroplanes - Infringement of Obstacle Free Zone: Operational Measures and Aeronautical Study - Cir 301. Montreal, 2005b.

Operation of New Larger Aeroplanes at Existing Aerodromes - Cir 305. Montreal, 2004c.

Procedures for Air Navigation Services: Aircraft Operations - Volume I: Flight Procedures - Doc 8168. 5ª Edição. Montreal, 2006c.

- Procedures for Air Navigation Services: Aircraft Operations - Volume II: Construction of Visual and Instrument Flight Procedures - Doc 8168. $5^{a}$ Edição. Montreal, 2006d.

Procedures for Air Navigation Services: Air Traffic Management - Doc 4444. $15^{a}$ Edição. Montreal, 2007.

NORWEGIAN CIVIL AVIATION AUTHORITY. Final Report on the Risk Analysis in Support of Aerodrome Design Rules. Bodø, 2008.

WEISSMANN, A. J. Estudo da Influência da Dispersão do Tráfego nas Características das Pistas de Pouso Aeroportuárias. 1983. 225 p. v.1. Dissertação (Mestrado) - Escola Politécnica, Universidade de São Paulo, 1983. 


\section{GLOSSÁRIO}

O glossário está dividido em três partes. A primeira parte apresenta definições utilizadas pela ICAO e também aquelas utilizadas no trabalho de forma geral. A segunda parte do glossário é específica para a FAA, sendo utilizada exclusivamente no Capítulo 5 , e não repetindo os termos da primeira parte do glossário comuns às duas instituições. A terceira parte cita termos utilizados pela ICAO e pela FAA que possuem significados diferentes entre si.

\section{I) Glossário comum à ICAO e FAA}

Acostamento (shoulder): Área adjacente à borda de um pavimento, preparada de modo a oferecer uma transição entre o pavimento e a superfície adjacente.

Aeródromo: uma área definida sobre terra ou água (incluindo quaisquer prédios, instalações e equipamentos) destinada total ou parcialmente para a chegada, partida e movimento em superfície de aeronaves.

Alcance visual de pista (runway visual range - RVR): distância na qual o piloto de uma aeronave, que se encontra no eixo de uma pista de pouso e decolagem, pode ver a sinalização horizontal na superfície da pista, as luzes que a delineiam ou as que identificam seu eixo.

Altitude livre de objetos (obstacle clearance altitude or height - OCA/H): a altitude ou altura mínima sobre a elevação mais relevante da cabeceira da pista de pouso e decolagem, ou sobre a elevação do aeródromo, como aplicável, usada para estabelecer adequação com critérios apropriados de distância em relação a objetos.

Altura de decisão (decision height - DH): uma altura especificada, durante uma aproximação de precisão ou aproximação verticalmente guiada, abaixo da qual, o piloto só pode descer caso estabeleça a referência visual especificada. 
Ângulo de esterçamento da aeronave (aircraft steering angle): ângulo formado entre uma linha tangente à linha guia e o eixo longitudinal da aeronave no ponto de referência. Este ponto é simbolizado por $S$ nos padrões da ICAO e por $N$ nos padrões da FAA.

Ângulo de esterçamento da bequilha (nose wheel steering angle): ângulo formado entre o eixo longitudinal da aeronave e a direção de deslocamento da roda da bequilha.

Área de manobras (manoeuvring area): parte do aeródromo utilizada para a decolagem, pouso e táxi de aeronaves, excluindo-se os pátios de aeronaves.

Área de movimento (movement area): parte do aeródromo a ser utilizada para decolagem, pouso e táxi de aeronaves, consistindo da área de manobras e dos pátios de aeronaves.

Área de giro da pista de pouso e decolagem: uma área definida em um aeródromo terrestre, adjacente a uma pista de pouso e decolagem, com o propósito de permitir a uma aeronave completar uma curva de $180^{\circ}$ sobre a pista de pouso e decolagem.

Área de segurança de fim de pista (runway end safety área - RESA): área simétrica ao longo do prolongamento do eixo da pista de pouso e decolagem e adjacente ao fim da faixa de pista, utilizada primordialmente para reduzir o risco de danos a aeronaves que realizem o toque antes de alcançar a cabeceira (undershooting) ou que ultrapassem acidentalmente o fim da pista de pouso e decolagem (overruning).

Aproximações paralelas dependentes (dependent parallel approaches): Aproximações simultâneas em pistas paralelas, ou quase paralelas, por instrumento, onde são prescritas as separações radar mínimas entre aeronaves nos prolongamentos dos eixos de pistas adjacentes. 
Aproximações paralelas independentes (independent parallel approaches): aproximações simultâneas em pistas paralelas, ou quase paralelas, por instrumento, onde não são prescritas as separações radar mínimas entre aeronaves nos prolongamentos dos eixos de pistas adjacentes.

Auto-manobra (self-manoeuvring) a aeronave utiliza sua própria propulsão para se aproximar ou deixar o terminal.

Baía de espera (holding bay): Área definida onde uma aeronave pode esperar ou ser ultrapassada, de modo a facilitar o movimento eficiente de aeronaves na superfície.

Barra de parada (holdline): posição estabelecida visando proteger uma pista de pouso e decolagem, superfície limitadora de obstáculos ou área crítica/sensível de um equipamento de aproximação de precisão, na qual uma aeronave taxiando ou um veículo deve parar e esperar, a menos que autorizados a prosseguir pelo órgão de controle de tráfego aéreo do aeródromo.

Base de rodas (wheel base): distância entre a bequilha e o centro do trem principal.

Blast pad: uma superfície posicionada no início da pista destinada a proteger o solo contra a erosão devida ao sopro do sistema propulsor das aeronaves.

Borda mínima do pavimento: a borda mínima do pavimento de uma superfície, normalmente uma pista de táxi, capaz de acomodar: a largura do trem principal; o desvio deste durante uma curva; e a folga do pavimento.

Cabeceira (threshold): O início da parcela da pista de pouso e decolagem destinada ao pouso.

Cabeceira deslocada (displaced threshold): Uma cabeceira não localizada na extremidade da pista de pouso/decolagem. 
Circling approach: Quando a aproximação é realizada conforme uma direção não coincidente com o eixo da pista, exigindo alinhamento da aeronave quando esta se encontra próxima do pouso.

Código de referência do aeródromo (aerodrome reference code - ARC): Tratase de um código de dois elementos que objetiva relacionar as características das aeronaves com os diversos componentes de um aeródromo.

Comprimento básico de pista da aeronave (aeroplane reference field length CBP): o comprimento de pista mínimo necessário para a decolagem com o peso máximo certificado para decolagem, ao nível do mar, sob condições atmosféricas padrão, com ventos nulos e gradiente de pista nulo, de acordo com o manual de vôo, aprovado pela autoridade certificadora ou dado equivalente a partir do fabricante da aeronave. O comprimento de pista (field length) neste caso, é o comprimento de pista balanceado (balanced field length), se aplicável, ou distância de decolagem.

Consideração de projeto: se refere a aspectos cuja observação é essencial, ou pelo menos relevante, para a segurança e economia das operações, podendo ser composto por um mais critérios de projeto.

Critério de projeto: é cada um dos critérios cuja observação é essencial, ou pelo menos relevante, para a segurança e economia das operações.

Cut-off angle: está relacionado à visão dos pilotos para baixo e para frente a partir da cabine de comando.

Decalagem (stagger): É a distância longitudinal entre as cabeceiras de mesma orientação (heading) de duas pistas paralelas.

Decalagem desfavorável: Quando a decalagem de duas RWs aumenta a separação longitudinal entre as aeronaves durante operações segregadas. 
Decalagem favorável: Quando a decalagem de duas RWs diminui a separação longitudinal entre as aeronaves durante operações segregadas.

Declividade da pista de pouso e decolagem (runway slope): é o quociente entre a diferença de elevação das extremidades da pista de pouso e decolagem e o comprimento desta.

Decolagens paralelas independentes (independent parallel departures): decolagens simultâneas a partir de pistas paralelas ou quase paralelas operando por instrumentos.

Distância (ou Pista) disponível para corrida de decolagem (take-off run available - TORA): O comprimento de pista declarado disponível e adequado para a corrida em solo de uma aeronave que decola.

Distância disponível para decolagem (take-off distance available - TODA): comprimento da TORA mais o comprimento da clearway se esta estiver disponível.

Distância disponível para aceleração e parada (accelerate-stop distance available - ASDA): Comprimento da pista disponível para corrida de decolagem (TORA), somado ao comprimento da Zona de Parada (Stopway), se existente.

Distância disponível para pouso (landing distance available - LDA): Comprimento declarado de pista disponível para o procedimento de pouso de uma aeronave.

Dominado: termo adotado nesta dissertação para o caso em que um objeto situa-se a uma distância tal de um obstáculo que o princípio de shielding pode ser aplicado.

Elevação do aeródromo (aerodrome elevation): a altitude do ponto mais alto da área de pouso. 
Engine blast: fluxo de ar que sai dos motores, representando risco à pessoas, veículos, estruturas e objetos. É um termo mais geral para jet blast, englobando todos os tipos de motores.

Faixa da pista de pouso e decolagem (runway strip): área definida no aeródromo, que inclui a pista de pouso e decolagem e as zonas de parada, se disponíveis, destinada a proteger a aeronave durante as operações de pouso e decolagem e a reduzir o risco de danos à aeronave, em caso desta sair dos limites da pista.

Faixa da pista de táxi (taxiway strip): Uma área que inclui uma pista de táxi com o propósito de proteger uma aeronave em operação na pista de táxi e reduzir o risco de danos a uma aeronave que saia acidentalmente da pista de táxi.

Fator de utilização (usability factor): A porcentagem de tempo durante o qual uma pista de pouso e decolagem ou um sistema de pistas não tem sua utilização limitada devido ao componente de vento de través.

Folga do pavimento (wheel-to-edge clearance): a distância entre a borda externa da roda e a borda do pavimento com capacidade de suporte plena. Vale tanto para o trem central como para a bequilha.

Folga de ponta de asa (wingtip clearance): a distância mínima permissível entre a ponta da asa e um objeto.

Folga entre pontas de asa (wingtip-to-wingtip clearance): a distância mínima permissível entre as pontas das asas de duas aeronaves.

Foreign Object Damage (FOD): dano devido a um objeto estranho.A mesma sigla é utilizada para referência ao objeto estranho através da expressão foreign object debris.

Gear width: a distância lateral entre os centros das rodas do trem principal. 
Grupo dinâmico (runway group): agrupamento de aeronaves segundo suas características geométricas formando o primeiro elemento do código de referência do aeródromo da ICAO. A ICAO utiliza o termo code letter, traduzido pela ANAC, na RBAC 154 como número do código. Nesta dissertação adotou-se o termo grupo dinâmico.

Grupo geométrico (design group): agrupamento de aeronaves segundo suas características geométricas formando o segundo elemento do código de referência do aeródromo (ICAO) / código de referência do aeroporto (FAA). Este termo é utilizado pela FAA, mas a ICAO utiliza o termo code letter, traduzido pela ANAC, na RBAC 154 como letra do código. Nesta dissertação adotou-se o termo grupo geométrico.

Intersecção de pistas de táxi (taxiway intersection): junção de duas ou mais pistas de táxi.

Jet blast: é o sopro emanado pelas turbinas de uma aeronave, constituindo risco para pessoas, veículos, outras aeronaves, construções, pavimentos, sinalização e outros objetos suficientemente próximos. O jet blast é um fluxo instável que induz estruturas à vibração, podendo ter seus efeitos agravados pelo vento ambiente. Outro fator de especial preocupação é a temperatura dos gases de escape.

Lado aéreo (airside): compreende os componentes de um aeródromo nos quais a aeronave pousa, decola, taxia e estaciona, como: pistas de pouso e decolagem, pistas de táxi, baías de espera, áreas de giro, blast pads, pátio e áreas afins.

Lado terrestre (landside): compreende os componentes de um aeródromo utilizados por passageiros e carga, como: terminais de passageiros, terminais de cargas, áreas de movimentação de bagagem, áreas de estacionamento, meios de acesso ao aeroporto e demais áreas afins.

Largura do trem principal (wheel span): a distância entre as bordas externas das rodas mais externas do trem principal. Difere do termo gear width que a FAA utiliza para designar a distância lateral entre os centros das rodas do trem principal. 
Linha de restrição predial (building restriction line): delimita as áreas de um aeródromo onde a construção de prédios é ou não permitida.

Linha do trem principal: é uma linha que passa pelo centro geométrico do trem principal, pelo centro de giro da aeronave e é perpendicular à linha longitudinal da mesma.

Manobra assistida por trator (tractor assisted manoeuvre): a aeronave entra e/ou sai da posição de estacionamento com o auxílio de um trator.

Marshaller: Pessoa que guia as aeronaves no pátio através de sinais.

Metodologia de projeto: é uma metodologia utilizada para o projeto de algum componente ou para avaliação de algum critério de projeto.

Não padrão (nonstandard): uma característica não conforme com a especificação (padrão).

Número de classificação da aeronave (aircraft classification number - $A C N$ ): Número que expressa o efeito relativo de uma aeronave sobre um pavimento para uma categoria padrão de subleito especificada.

Número de classificação do pavimento (pavement classification number $P C N$ ): número que expressa a capacidade de suporte de um pavimento para operações sem restrição.

Objeto frangível (frangible object): Um objeto de pouca massa que deve quebrarse, distorcer-se ou ceder mediante impacto, de modo a minimizar os danos à aeronave. 
Obstáculo (obstacle): todo objeto fixo (de forma temporária ou permanente) ou móvel, ou qualquer parte do mesmo que esteja localizado em uma área destinada à movimentação de aeronaves no solo ou que se estenda acima de uma superfície destinada à proteção de aeronaves em vôo.

Operações paralelas segregadas (segregated parallel operations): operações simultâneas, em pistas de operação por instrumento paralelas ou quase paralelas, nas quais uma pista é utilizada exclusivamente para aproximações e a outra pista é utilizada exclusivamente para decolagens.

Orientação da pista de pouso e decolagem (runway heading): É o ângulo formado entre uma pista de pouso e decolagem e o norte magnético. Esta orientação está sinalizada em cada cabeceira da pista na forma de código.

Overruning: contato entre a aeronave e o solo na região posterior ao final da pista de pouso e decolagem.

Padrão (standard): qualquer especificação para características físicas, configuração, material, desempenho, pessoal ou procedimento, cuja aplicação uniforme é reconhecida como necessária para segurança ou regularidade da navegação aérea internacional. Os Estados signatários se comprometem a seguir esta especificação e na impossibilidade de conformidade, a notificação ao Conselho (Council) é compulsória de acordo com o Artigo 38 (Article 38).

Pista de decolagem (take-off runway): pista destinada exclusivamente para decolagens.

Pista de pouso e decolagem (runway): Área retangular, definida em um aeródromo em terra, preparada para pousos e decolagens de aeronaves.

Pista de táxi (taxiway): trajetória definida em um aeródromo em terra, estabelecida para táxi de aeronaves e com a função de oferecer uma ligação entre as partes do aeródromo, incluindo: 
- Pista de táxi de acesso ao estacionamento de aeronaves (aircraft stand taxilane): parcela de um pátio de aeronaves designada como uma pista de táxi e com o propósito único de oferecer acesso às posições de estacionamento de aeronaves; e

- Pista de táxi de pátio (apron taxiway): parcela de um sistema de pistas de táxi localizada em um pátio de aeronaves com a função de oferecer uma circulação completa de táxi através do pátio de aeronaves.

Pista de Táxi de Saída Rápida (rapid exit taxiway-PTSR): pista de táxi conectada a uma pista de pouso e decolagem em um ângulo agudo, projetada para permitir que aeronaves que pousem saiam da pista em velocidades mais altas do que em outras pistas de táxi de saída. Desta forma, diminui-se o tempo de ocupação da pista de pouso e decolagem.

Pista para aproximação por instrumentos (instrument runway): Pista de pouso e decolagem habilitada para procedimento de aproximação por instrumentos, podendo ser classificada da seguinte forma:

- Pista de aproximação de não precisão (non-precision approach runway): pista para operação por instrumento provida de auxílios visuais e não-visuais à navegação, que fornecem, no mínimo, orientação direcional adequada para a aproximação direta.

- Pista para aproximação de precisão, categoria I (precision approach runway, category I): Pista para operação por instrumentos provida de ILS e/ou MLS e auxílios visuais para operações com uma altitude de decisão não inferior a $60 \mathrm{~m}(200 \mathrm{ft}$ ) e com visibilidade não inferior a $800 \mathrm{~m}$ ou alcance visual de pista (RVR ) não inferior a $550 \mathrm{~m}$.

- Pista para aproximação de precisão, categoria II (precision approach runway, category II): Pista para operação por instrumentos provida de ILS e/ou MLS e auxílios visuais para operações com uma altitude de decisão inferior a $60 \mathrm{~m}$ (200pés) mas não inferior a 30m (100 ft) e alcance visual de pista (RVR) não inferior a $350 \mathrm{~m}$.

- Pista para aproximação de precisão, categoria III (precision approach runway, category III): Pista para operação por instrumento provida de ILS e/ou MLS para a superfície e ao longo da superfície da pista é: 
- A: prevista para operações com altitude de decisão não inferior a $30 \mathrm{~m}$ (100 pés), ou sem altitude de decisão, e com um alcance visual de pista (RVR) não inferior a $200 \mathrm{~m}$;

- B: prevista para operações com altitude de decisão inferior a $15 \mathrm{~m}$ (50pés), ou sem nenhuma altitude de decisão, e com um alcance visual de pista (RVR) inferior a $200 \mathrm{~m}$, mas não inferior a $50 \mathrm{~m}$;

- C: prevista para operações sem altitude de decisão e sem limitações de alcance visual de pista (RVR).

Pista para aproximação visual (non-instrument runway): pista de pouso e decolagem para a operação de aeronaves utilizando procedimentos de aproximação visual.

Pista(s) principal(is) (primary runway): Pista(s) de pouso e decolagem utilizada(s) preferencialmente às outras, sempre que as condições permitirem.

Pistas quase paralelas (near-parallel runways): Pistas de pouso e decolagem que não se interceptam e cujos prolongamentos de seus eixos perfazem um ângulo de convergência/divergência menor ou igual a $15^{\circ}$.

Ponto de referência do aeródromo (aerodrome reference point): localização geográfica designada de um aeródromo.

Posição de espera na via de serviço (road holding position): posição designada na qual os veículos podem ser solicitados a esperar.

Posição de estacionamento (aircraft stand): uma área do pátio (apron) destinada ao estacionamento de aeronaves.

Rampa ou pátio de aeronaves (apron): uma área definida em um aeródromo construído sobre o solo (land aerodrome), destinada à acomodação de aeronaves com o propósito de carga e descarga de passageiros, mala postal ou carga, reabastecimento, estacionamento ou manutenção. 
Recomendação (recommended practice): qualquer especificação para características físicas, configuração, material, desempenho, pessoal ou procedimento, cuja aplicação uniforme é reconhecida como desejável para segurança, regularidade ou eficiência da navegação aérea internacional. Os Estados signatários devem se esforçar para seguir esta especificação.

Run-off: a saída de uma área designada para corrida em solo de uma aeronave. Veering-offs, undershootings e overrunnings são exemplos de run-offs.

Semi-envergadura (semispan): metade da envergadura da asa.

Semi-largura: metade da largura.

Shielding: princípio pelo qual um objeto que penetra em um plano de proteção não precisa ser removido, à medida que outro objeto irremovível constitui um obstáculo dominante.

Sobrelargura (fillet): um alargamento necessário para a garantia de alguma folga de projeto no caso em que a aeronave percorre um trecho curvo da pista de táxi. Em geral se aplica ao alargamento do pavimento, mas pode também se referir a uma folga em relação a objetos.

Temperatura de referência do aeródromo (aerodrome reference temperature): média diária das temperaturas máximas do mês mais quente do ano. O mês mais quente do ano é aquele com maior temperatura mensal média.

Via de serviço (road): uma rota de superfície estabelecida para uso exclusivo de veículos.

Zona desimpedida (clearway - CWY): uma área retangular definida sobre solo ou água, controlada pela respectiva autoridade, a qual é selecionada ou preparada para que uma aeronave possa perfazer uma parte de sua subida de decolagem até uma dada altura. 
Zona livre de obstáculos (obstacle free zone - OFZ): espaço aéreo acima da superfície de aproximação interna, superfícies de transição internas, superfície de pouso interrompido e da porção da faixa de pista ligada por essas superfícies, o qual não é penetrado por nenhum obstáculo móvel. Objetos fixos também são excluídos a não ser aqueles de baixa massa e montados sobre suporte frangível, necessários para fins de navegação aérea.

Zona de parada (stopway - SWY): área retangular definida no terreno, situada no prolongamento do eixo da pista no sentido da decolagem, destinada e preparada como zona adequada à parada de aeronaves.

Zona de toque (touchdown zone): a parte de uma pista de pouso e decolagem, após a cabeceira, onde se espera que as aeronaves pousando façam o primeiro contato com o solo.

\section{II) GLOSSÁRIO ESPECÍFICO PARA A FAA}

Aeronave de grande porte (large aircraft): uma aeronave com peso máximo certificado de decolagem maior do que 12.500 libras $(5.670 \mathrm{~kg})$.

Aeronave de pequeno porte (small aircraft): uma aeronave com peso máximo certificado de decolagem de 12.500 libras $(5.670 \mathrm{~kg})$ ou menos.

Área de movimento (movement area): as pistas de pouso e decolagem, pistas de táxi, e outras áreas de um aeroporto que são utilizadas para o táxi, decolagem, e pouso de aeronaves, com exceção das áreas de embarque do pátio e áreas de estacionamento.

Declividade da pista de pouso e decolagem (runway slope): é o quociente entre: i) a diferença de elevação do ponto mais baixo e do ponto mais elevado da pista de pouso e decolagem; e ii) o comprimento desta. 
Pista de pouso e decolagem utilitária (utility runway): uma pista de pouso e decolagem destinada a aeronaves propelidas a hélice com peso bruto menor do que 12.500 libras $(\sim 5.670 \mathrm{~kg})$.

Temperatura de referência do aeródromo (airport reference temperature): média diária das temperaturas máximas do mês mais quente do ano. O mês mais quente do ano é aquele com maior temperatura mensal média.

Undershooting: contato entre a aeronave e o solo na região anterior à cabeceira.

Velocidade de aproximação: é definida como 1,3 vezes a velocidade de estol, na configuração de pouso, com os flapes na configuração máxima certificada e máximo peso de aterrissagem em condições atmosféricas padrão, ao nível do mar. Esta definição serve para o primeiro termo do ARC formando grupos chamados de aircraft approach category.

\section{III) TERMOS CONFLITUOSOS ENTRE ICAO E FAA:}

Área de movimento (movement area): equivalente à área de manobras da ICAO (manoeuvring area).

Declividade da pista de pouso e decolagem (runway slope): a ICAO se baseia nas diferenças de elevação entre extremidades da pista e a FAA na maior diferença de elevação.

Pista de aproximação de precisão (CAT I): para o caso em que a RW atende a critérios específicos de sinalização (operative touchdown zone and runway centerline lights) o alcance visual da vista (RVR) das duas normas é igual, ou seja, 1.800pés $(\sim 550 \mathrm{~m})$. Para o caso de a RW não atender a estes critérios, o RVR mínimo especificado é de 2.400 pés $(\sim 730 \mathrm{~m})$, no caso da FAA. 


\section{ANEXO A - DADOS RELATIVOS À LARGURA DA RW}

\begin{tabular}{|c|c|c|c|c|c|}
\hline \multirow{2}{*}{$\begin{array}{c}\mathrm{N}^{\circ} \\
\text { Sequencial }\end{array}$} & \multirow{2}{*}{ Modelo } & \multicolumn{2}{|c|}{ ICAO } & \multicolumn{2}{|c|}{ FAA } \\
\hline & & Cenário 1 & Cenário 2 & Cenário 1 & Cenário 2 \\
\hline 1 & $42-600$ & 30 & 30 & 30 & 30 \\
\hline 2 & 135ER & 30 & 30 & 30 & 23 \\
\hline 3 & 140ER & 30 & 30 & 30 & 30 \\
\hline 4 & CRJ700 Next Gen ER & 30 & 30 & 30 & 30 \\
\hline 5 & $72-600$ & 30 & 30 & 30 & 30 \\
\hline 6 & 170 standard & 30 & 30 & 30 & 30 \\
\hline 7 & 175 standard & 30 & 30 & 30 & 30 \\
\hline 8 & 190 standard & 30 & 30 & 30 & 30 \\
\hline 9 & 195 standard & 30 & 30 & 30 & 30 \\
\hline 10 & $737-700$ & 30 & 30 & 45 & 45 \\
\hline 11 & $318-100$ & 30 & 30 & 30 & 30 \\
\hline 12 & 145LR & 0 & 0 & 30 & 30 \\
\hline 13 & CRJ900 Next Gen LR & 45 & 45 & 30 & 30 \\
\hline 14 & 195AR & 45 & 45 & 30 & 30 \\
\hline 15 & 319 & 45 & 45 & 45 & 45 \\
\hline 16 & 320 & 45 & 45 & 45 & 45 \\
\hline 17 & 321 & 45 & 45 & 45 & 45 \\
\hline 18 & $737-800$ & 45 & 45 & 45 & 45 \\
\hline 19 & 737-900ER & 45 & 45 & 45 & 45 \\
\hline 20 & 767-300ER & 45 & 45 & 45 & 45 \\
\hline 21 & $787-8$ & 45 & 45 & 45 & 45 \\
\hline 22 & $330-200$ & 45 & 45 & 45 & 45 \\
\hline 23 & $330-300$ & 45 & 45 & 45 & 45 \\
\hline 24 & 777-200ER & 45 & 45 & 45 & 45 \\
\hline 25 & $777-200 L R$ & 45 & 45 & 45 & 45 \\
\hline 26 & 777-300ER & 45 & 45 & 45 & 45 \\
\hline 27 & $330-200 F$ & 45 & 45 & 45 & 45 \\
\hline 28 & $340-500$ & 45 & 45 & 45 & 45 \\
\hline 29 & 747-8 & 60 & 60 & 60 & 60 \\
\hline 30 & $747-8 F$ & 60 & 60 & 60 & 60 \\
\hline 31 & $380-800$ & 60 & 60 & 60 & 60 \\
\hline
\end{tabular}

FONTE: Calculado a partir dos dados da aeronave (Tabela 5.1-1) e das especificações da ICAO e da FAA.

Obs.: Dimensões em metros. 


\section{ANEXO B - DADOS RELATIVOS À LARGURA COMBINADA ENTRE RW E ACOSTAMENTOS}

\begin{tabular}{|c|c|c|c|c|c|}
\hline \multirow{2}{*}{$\begin{array}{c}\mathrm{N}^{\circ} \\
\text { Sequencial }\end{array}$} & \multirow{2}{*}{ Modelo } & \multicolumn{2}{|c|}{ ICAO } & \multicolumn{2}{|c|}{ FAA } \\
\hline & & Cenário 1 & Cenário 2 & Cenário 1 & Cenário 2 \\
\hline 1 & $42-600$ & 30 & 30 & 42 & 42 \\
\hline 2 & 135ER & 30 & 30 & 36 & 29 \\
\hline 3 & 140ER & 30 & 30 & 36 & 36 \\
\hline 4 & CRJ700 Next Gen ER & 30 & 30 & 36 & 36 \\
\hline 5 & $72-600$ & 30 & 30 & 42 & 42 \\
\hline 6 & 170 standard & 30 & 30 & 42 & 42 \\
\hline 7 & 175 standard & 30 & 30 & 42 & 42 \\
\hline 8 & 190 standard & 30 & 30 & 42 & 42 \\
\hline 9 & 195 standard & 30 & 30 & 42 & 42 \\
\hline 10 & $737-700$ & 30 & 30 & 60 & 60 \\
\hline 11 & $318-100$ & 30 & 30 & 42 & 42 \\
\hline 12 & 145LR & 0 & 0 & 36 & 36 \\
\hline 13 & CRJ900 Next Gen LR & 45 & 45 & 42 & 42 \\
\hline 14 & 195AR & 45 & 45 & 42 & 42 \\
\hline 15 & 319 & 45 & 45 & 60 & 60 \\
\hline 16 & 320 & 45 & 45 & 60 & 60 \\
\hline 17 & 321 & 45 & 45 & 60 & 60 \\
\hline 18 & $737-800$ & 45 & 45 & 60 & 60 \\
\hline 19 & 737-900ER & 45 & 45 & 60 & 60 \\
\hline 20 & 767-300ER & 60 & 60 & 60 & 60 \\
\hline 21 & 787-8 & 60 & 60 & 66 & 66 \\
\hline 22 & $330-200$ & 60 & 60 & 66 & 66 \\
\hline 23 & $330-300$ & 60 & 60 & 66 & 66 \\
\hline 24 & 777-200ER & 60 & 60 & 66 & 66 \\
\hline 25 & 777-200LR & 60 & 60 & 66 & 66 \\
\hline 26 & 777-300ER & 60 & 60 & 66 & 66 \\
\hline 27 & $330-200 \mathrm{~F}$ & 60 & 60 & 66 & 66 \\
\hline 28 & $340-500$ & 60 & 60 & 66 & 66 \\
\hline 29 & $747-8$ & 75 & 75 & 84 & 84 \\
\hline 30 & $747-8 \mathrm{~F}$ & 75 & 75 & 84 & 84 \\
\hline 31 & $380-800$ & 75 & 75 & 84 & 84 \\
\hline
\end{tabular}

FONTE: Calculado a partir dos dados da aeronave (Tabela 5.1-1) e das especificações da ICAO e da FAA.

Obs.: Dimensões em metros. 


\section{ANEXO C - DADOS RELATIVOS AO COMPRIMENTO DA BLAST $P A D$}

\begin{tabular}{|c|c|c|c|c|c|}
\hline \multirow{2}{*}{$\begin{array}{c}N^{\circ} \\
\text { Sequencial }\end{array}$} & \multirow{2}{*}{ Modelo } & \multicolumn{2}{|c|}{ ICAO } & \multicolumn{2}{|c|}{ FAA } \\
\hline & & Cenário 1 & Cenário 2 & Cenário 1 & Cenário 2 \\
\hline 1 & $42-600$ & 60 & 60 & 60 & 60 \\
\hline 2 & 135ER & 60 & 60 & 45 & 45 \\
\hline 3 & 140ER & 60 & 60 & 45 & 45 \\
\hline 4 & CRJ700 Next Gen ER & 60 & 60 & 45 & 45 \\
\hline 5 & $72-600$ & 60 & 60 & 60 & 60 \\
\hline 6 & 170 standard & 60 & 60 & 60 & 60 \\
\hline 7 & 175 standard & 60 & 60 & 60 & 60 \\
\hline 8 & 190 standard & 60 & 60 & 60 & 60 \\
\hline 9 & 195 standard & 60 & 60 & 60 & 60 \\
\hline 10 & $737-700$ & 60 & 60 & 60 & 60 \\
\hline 11 & $318-100$ & 60 & 60 & 60 & 60 \\
\hline 12 & 145LR & 60 & 60 & 45 & 45 \\
\hline 13 & CRJ900 Next Gen LR & 60 & 60 & 60 & 60 \\
\hline 14 & 195AR & 60 & 60 & 60 & 60 \\
\hline 15 & 319 & 60 & 60 & 60 & 60 \\
\hline 16 & 320 & 60 & 60 & 60 & 60 \\
\hline 17 & 321 & 60 & 60 & 60 & 60 \\
\hline 18 & 737-800 & 60 & 60 & 60 & 60 \\
\hline 19 & 737-900ER & 60 & 60 & 60 & 60 \\
\hline 20 & 767-300ER & 60 & 60 & 60 & 60 \\
\hline 21 & $787-8$ & 60 & 60 & 120 & 120 \\
\hline 22 & $330-200$ & 60 & 60 & 120 & 120 \\
\hline 23 & $330-300$ & 60 & 60 & 120 & 120 \\
\hline 24 & 777-200ER & 60 & 60 & 120 & 120 \\
\hline 25 & 777-200LR & 60 & 60 & 120 & 120 \\
\hline 26 & 777-300ER & 60 & 60 & 120 & 120 \\
\hline 27 & $330-200 F$ & 60 & 60 & 120 & 120 \\
\hline 28 & $340-500$ & 60 & 60 & 120 & 120 \\
\hline 29 & $747-8$ & 120 & 120 & 120 & 120 \\
\hline 30 & $747-8 F$ & 120 & 120 & 120 & 120 \\
\hline 31 & $380-800$ & 120 & 120 & 120 & 120 \\
\hline
\end{tabular}

FONTE: Calculado a partir dos dados da aeronave (Tabela 5.1-1) e das especificações da ICAO e da FAA.

Obs.: Dimensões em metros. 
ANEXO D - DADOS RELATIVOS AOS CENÁRIOS 1 E 2 PARA AVALIAÇÃO DOS PADRÕES DAS BPRWS E DA OFZ DE TRANSIÇÃO INTERNA

\begin{tabular}{|c|c|c|c|c|c|c|c|c|c|}
\hline \multirow{4}{*}{$\begin{array}{c}\mathbf{N}^{\circ} \\
\text { Sequencial }\end{array}$} & \multirow{4}{*}{ Modelo } & \multirow{2}{*}{\multicolumn{2}{|c|}{ Padrão BPRW }} & \multirow{2}{*}{\multicolumn{3}{|c|}{$\begin{array}{c}\text { Aeronave que espera para } \\
\text { entrar na RW } \\
\text { OFZ de trans. Interna }\end{array}$}} & \multirow{2}{*}{\multicolumn{3}{|c|}{$\begin{array}{c}\text { Aeronave que acaba de sair } \\
\text { da RW } \\
\text { OFZ de trans. Interna }\end{array}$}} \\
\hline & & & & & & & & & \\
\hline & & \multirow{2}{*}{\begin{tabular}{|c|} 
ICAO \\
Cenários \\
1 e 2 \\
\end{tabular}} & \multirow{2}{*}{\begin{tabular}{|c|} 
FAA \\
Cenários \\
1 e 2 \\
\end{tabular}} & \multirow{2}{*}{$\begin{array}{c}\text { ICAO } \\
\text { Cenários } \\
1 \text { e } 2\end{array}$} & \multicolumn{2}{|c|}{ FAA } & \multirow{2}{*}{\begin{tabular}{|c|} 
ICAO \\
Cenários \\
1 e 2 \\
\end{tabular}} & \multicolumn{2}{|c|}{ FAA } \\
\hline & & & & & $\begin{array}{c}\text { Cenário } \\
1\end{array}$ & $\begin{array}{c}\text { Cenário } \\
2\end{array}$ & & $\begin{array}{c}\text { Cenário } \\
1\end{array}$ & $\begin{array}{c}\text { Cenário } \\
2\end{array}$ \\
\hline 2 & 135ER & 90,0 & 75,0 & 71,5 & 60,0 & 71,5 & 80,3 & 60,0 & 60,0 \\
\hline 3 & 140ER & 90,0 & 75,0 & 71,5 & 60,0 & 71,5 & 80,3 & 60,0 & 60,0 \\
\hline 4 & CRJ700 Next Gen ER & 90,0 & 75,0 & 73,4 & 60,0 & 73,4 & 82,8 & 60,0 & 60,0 \\
\hline 5 & $72-600$ & 90,0 & 75,0 & 77,5 & 60,0 & 77,5 & 83,0 & 60,0 & 60,0 \\
\hline 6 & 170 standard & 90,0 & 75,0 & 73,9 & 60,0 & 73,9 & 89,6 & 60,0 & 60,0 \\
\hline 10 & $737-700$ & 90,0 & 75,0 & 79,9 & 60,0 & 79,9 & 97,5 & 60,0 & 65,8 \\
\hline 11 & $318-100$ & 90,0 & 75,0 & 77,8 & 60,0 & 77,8 & 97,5 & 60,0 & 64,7 \\
\hline 12 & 145LR & 90,0 & 75,0 & 71,5 & 60,0 & 71,5 & 80,3 & 60,0 & 60,0 \\
\hline 13 & CRJ900 Next Gen LR & 90,0 & 75,0 & 73,4 & 60,0 & 73,4 & 82,5 & 60,0 & 60,0 \\
\hline 14 & 195AR & 90,0 & 75,0 & 75,3 & 60,0 & 75,3 & 91,7 & 60,0 & 60,0 \\
\hline 15 & 319 & 90,0 & 75,0 & 78,0 & 60,0 & 78,0 & 95,4 & 60,0 & 61,2 \\
\hline 16 & 320 & 90,0 & 75,0 & 77,7 & 60,0 & 77,7 & 95,4 & 60,0 & 62,1 \\
\hline 17 & 321 & 90,0 & 75,0 & 77,9 & 60,0 & 77,9 & 95,4 & 60,0 & 61,2 \\
\hline 18 & $737-800$ & 90,0 & 75,0 & 80,3 & 60,0 & 80,3 & 97,5 & 60,0 & 65,8 \\
\hline 19 & 737-900ER & 90,0 & 75,0 & 80,3 & 60,0 & 80,3 & 97,5 & 60,0 & 65,7 \\
\hline
\end{tabular}




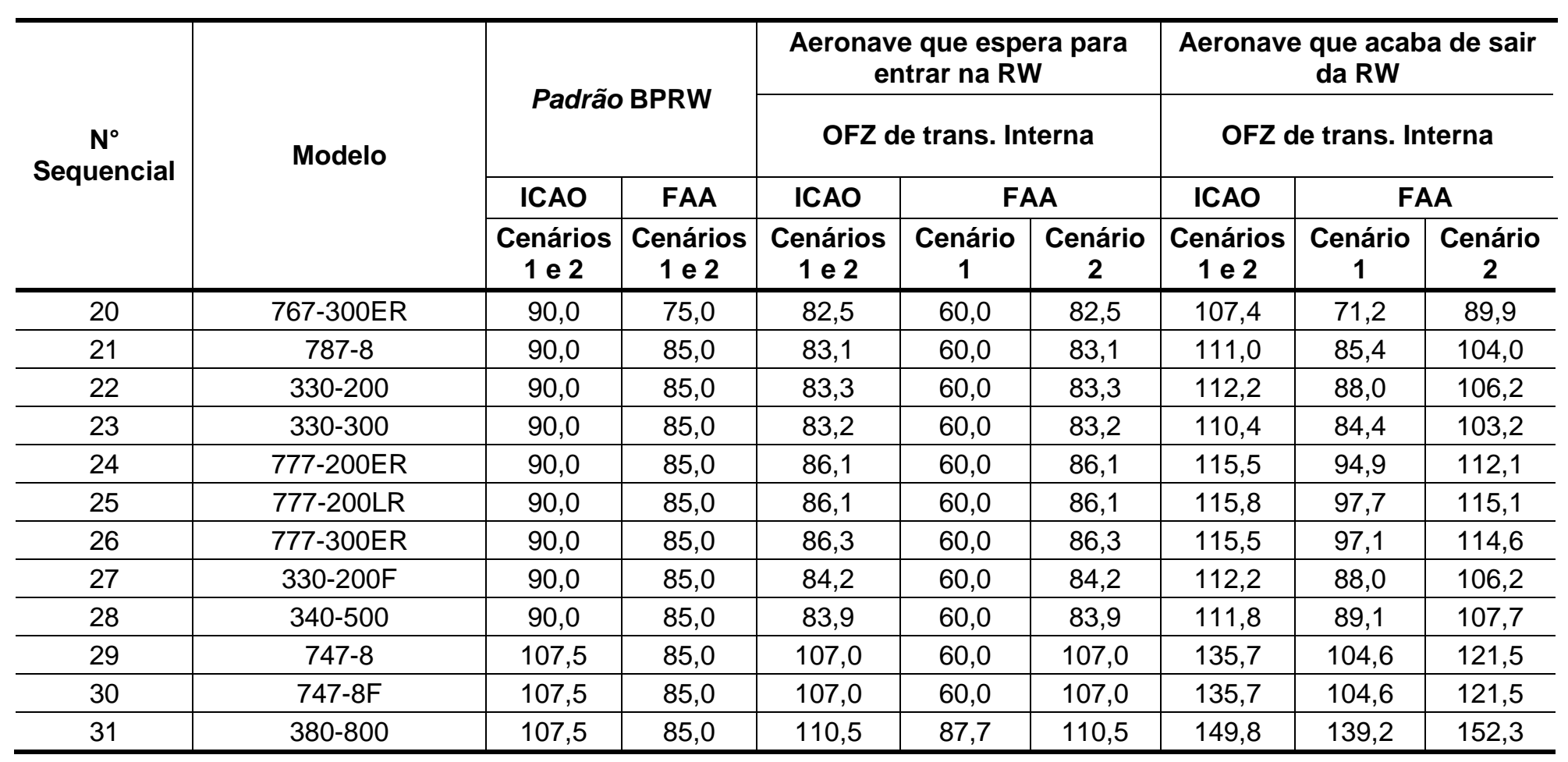

FONTE: Adaptado a partir dos dados da Tabela 5.1-1 e das especificações da ICAO e da FAA 
ANEXO E - DADOS RELATIVOS AOS CENÁRIOS 3 E 4 PARA AVALIAÇÃO DOS PADRÕES DAS BPRWS E DA OFZ DE TRANSIÇÃO INTERNA

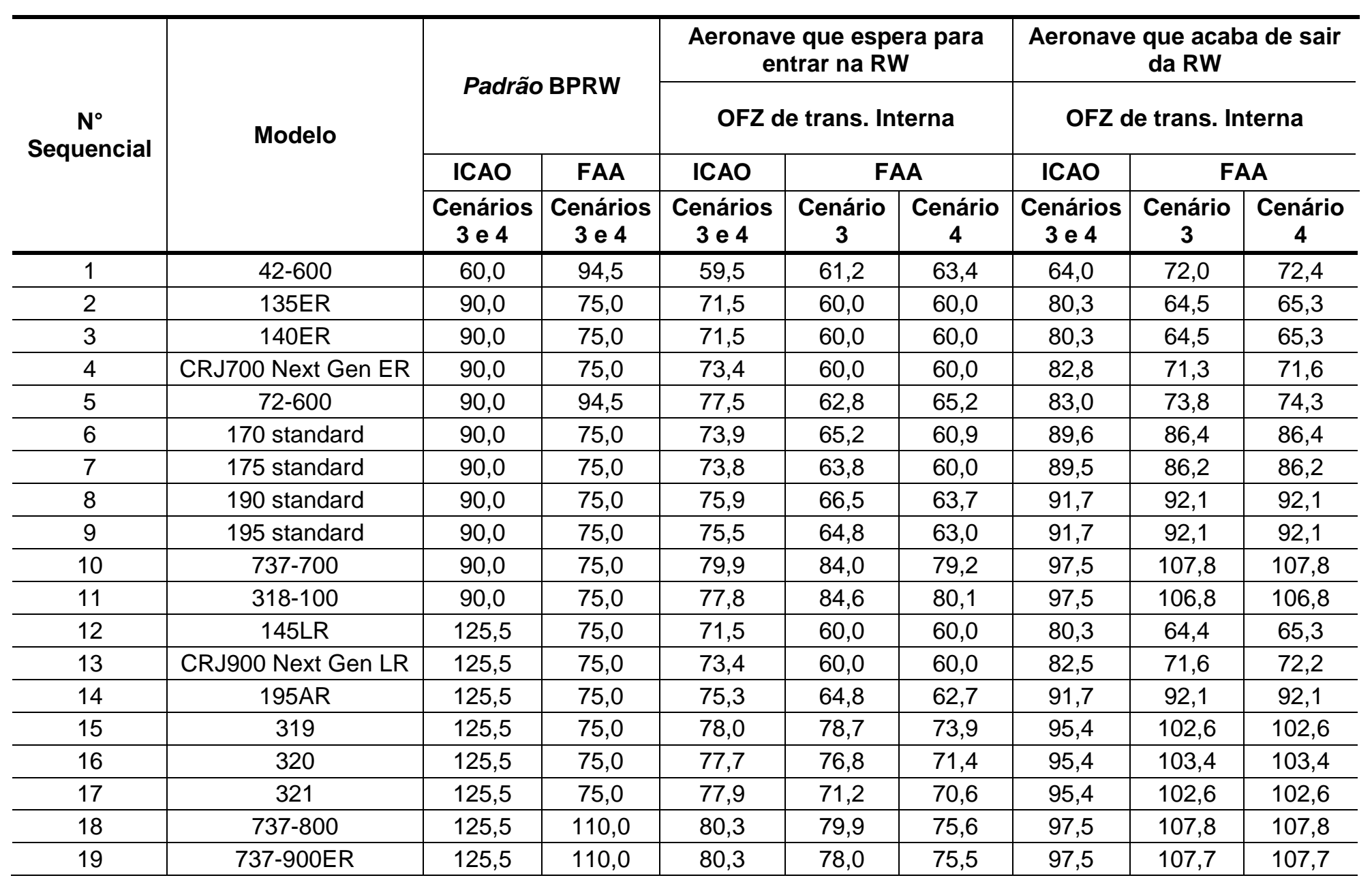




\begin{tabular}{|c|c|c|c|c|c|c|c|c|c|}
\hline \multirow{4}{*}{$\begin{array}{c}\mathbf{N}^{\circ} \\
\text { Sequencial }\end{array}$} & \multirow{4}{*}{ Modelo } & \multirow{2}{*}{\multicolumn{2}{|c|}{ Padrão BPRW }} & \multirow{2}{*}{\multicolumn{3}{|c|}{$\begin{array}{c}\text { Aeronave que espera para } \\
\text { entrar na RW } \\
\text { OFZ de trans. Interna }\end{array}$}} & \multirow{2}{*}{\multicolumn{3}{|c|}{$\begin{array}{c}\text { Aeronave que acaba de sai } \\
\text { da RW } \\
\text { OFZ de trans. Interna }\end{array}$}} \\
\hline & & & & & & & & & \\
\hline & & \multirow{2}{*}{\begin{tabular}{|c|} 
ICAO \\
Cenários \\
3 e 4 \\
\end{tabular}} & \multirow{2}{*}{\begin{tabular}{|c|} 
FAA \\
Cenários \\
3 e 4 \\
\end{tabular}} & \multirow{2}{*}{$\begin{array}{c}\text { ICAO } \\
\text { Cenários } \\
3 \text { e } 4\end{array}$} & \multicolumn{2}{|c|}{ FAA } & \multirow{2}{*}{\begin{tabular}{|c|} 
ICAO \\
Cenários \\
3 e 4 \\
\end{tabular}} & \multicolumn{2}{|c|}{ FAA } \\
\hline & & & & & $\begin{array}{c}\text { Cenário } \\
3\end{array}$ & $\begin{array}{c}\text { Cenário } \\
4\end{array}$ & & $\begin{array}{c}\text { Cenário } \\
3\end{array}$ & $\begin{array}{c}\text { Cenário } \\
4\end{array}$ \\
\hline 21 & $787-8$ & 125,5 & 120,0 & 83,1 & 108,1 & 99,9 & 111,0 & 148,4 & 148,4 \\
\hline 22 & $330-200$ & 125,5 & 120,0 & 83,3 & 109,7 & 101,3 & 112,2 & 151,0 & 151,0 \\
\hline 23 & $330-300$ & 125,5 & 120,0 & 83,2 & 102,4 & 96,4 & 110,4 & 147,4 & 147,4 \\
\hline 24 & 777-200ER & 125,5 & 120,0 & 86,1 & 112,9 & 103,7 & 115,5 & 157,9 & 157,9 \\
\hline 25 & 777-200LR & 125,5 & 120,0 & 86,1 & 115,7 & 106,5 & 115,8 & 160,7 & 160,7 \\
\hline 29 & $747-8$ & 143,0 & 120,0 & 107,0 & 113,7 & 112,2 & 135,7 & 167,6 & 167,6 \\
\hline 30 & $747-8 \mathrm{~F}$ & 143,0 & 120,0 & 107,0 & 113,7 & 112,2 & 135,7 & 167,6 & 167,6 \\
\hline 31 & $380-800$ & 143,0 & 120,0 & 110,5 & 150,7 & 140,3 & 149,8 & 202,2 & 202,2 \\
\hline
\end{tabular}

FONTE: Adaptado a partir dos dados da Tabela 5.1-1 e das especificações da ICAO e da FAA 
ANEXO F - DADOS RELATIVOS AOS CENÁRIOS 5 E 6 PARA AVALIAÇÃO DOS PADRÕES DAS BPRWS

E DA OFZ DE TRANSIÇÃO INTERNA

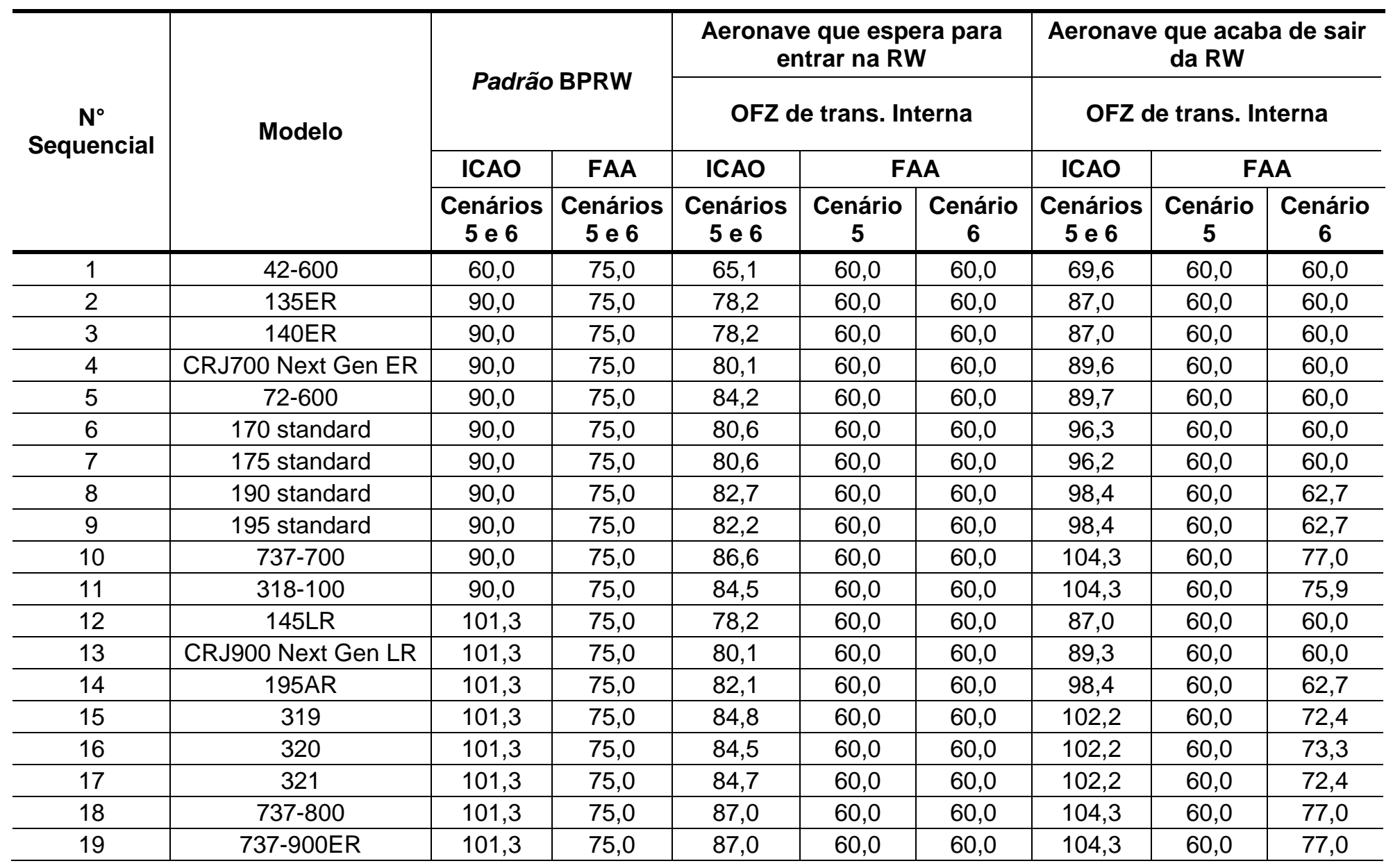




\begin{tabular}{|c|c|c|c|c|c|c|c|c|c|}
\hline \multirow{4}{*}{$\begin{array}{c}\mathbf{N}^{\circ} \\
\text { Sequencial }\end{array}$} & \multirow{4}{*}{ Modelo } & \multirow{2}{*}{\multicolumn{2}{|c|}{ Padrão BPRW }} & \multirow{2}{*}{\multicolumn{3}{|c|}{$\begin{array}{c}\text { Aeronave que espera para } \\
\text { entrar na RW } \\
\text { OFZ de trans. Interna }\end{array}$}} & \multirow{2}{*}{\multicolumn{3}{|c|}{$\begin{array}{c}\text { Aeronave que acaba de sair } \\
\text { da RW } \\
\text { OFZ de trans. Interna }\end{array}$}} \\
\hline & & & & & & & & & \\
\hline & & \multirow{2}{*}{\begin{tabular}{|c|} 
ICAO \\
Cenários \\
5 e 6 \\
\end{tabular}} & \multirow{2}{*}{\begin{tabular}{|c|} 
FAA \\
Cenários \\
5 e 6
\end{tabular}} & \multirow{2}{*}{\begin{tabular}{|c|} 
ICAO \\
Cenários \\
5 e 6 \\
\end{tabular}} & \multicolumn{2}{|c|}{ FAA } & \multirow{2}{*}{\begin{tabular}{|c|} 
ICAO \\
Cenários \\
5 e 6 \\
\end{tabular}} & \multicolumn{2}{|c|}{ FAA } \\
\hline & & & & & $\begin{array}{c}\text { Cenário } \\
5\end{array}$ & $\begin{array}{c}\text { Cenário } \\
6\end{array}$ & & $\begin{array}{c}\text { Cenário } \\
5\end{array}$ & $\begin{array}{c}\text { Cenário } \\
6\end{array}$ \\
\hline 21 & $787-8$ & 101,3 & 85,0 & 89,9 & 60,0 & 74,9 & 117,8 & 98,9 & 115,3 \\
\hline 22 & $330-200$ & 101,3 & 85,0 & 90,0 & 60,2 & 76,1 & 119,0 & 101,5 & 117,4 \\
\hline 23 & $330-300$ & 101,3 & 85,0 & 90,0 & 60,0 & 69,4 & 117,2 & 97,9 & 114,4 \\
\hline 24 & 777-200ER & 101,3 & 85,0 & 92,9 & 63,4 & 78,3 & 122,3 & 108,4 & 123,3 \\
\hline 25 & 777-200LR & 101,3 & 85,0 & 92,9 & 66,2 & 81,3 & 122,6 & 111,2 & 126,4 \\
\hline 26 & 777-300ER & 101,3 & 85,0 & 93,1 & 60,0 & 77,3 & 122,3 & 110,6 & 125,9 \\
\hline 31 & $380-800$ & 107,5 & 85,0 & 117,3 & 101,2 & 112,1 & 156,6 & 152,7 & 163,6 \\
\hline
\end{tabular}

FONTE: Adaptado a partir dos dados da Tabela 5.1-1 e das especificações da ICAO e da FAA 
ANEXO G - DADOS RELATIVOS AOS CENÁRIOS 7 E 8 PARA AVALIAÇÃO DOS PADRÕES DAS BPRWS E DA OFZ DE TRANSIÇÃO INTERNA

\begin{tabular}{|c|c|c|c|c|c|c|c|c|c|}
\hline \multirow{4}{*}{$N^{\circ}$ Sequencial } & \multirow{4}{*}{ Modelo } & \multirow{2}{*}{\multicolumn{2}{|c|}{ Padrão BPRW }} & \multirow{2}{*}{\multicolumn{3}{|c|}{$\begin{array}{c}\text { Aeronave que espera para } \\
\text { entrar na RW } \\
\text { OFZ de trans. Interna }\end{array}$}} & \multirow{2}{*}{\multicolumn{3}{|c|}{$\begin{array}{c}\text { Aeronave que acaba de sair } \\
\text { da RW } \\
\text { OFZ de trans. Interna }\end{array}$}} \\
\hline & & & & & & & & & \\
\hline & & \multirow{2}{*}{\begin{tabular}{|c|} 
ICAO \\
Cenários \\
7 e 8 \\
\end{tabular}} & \multirow{2}{*}{\begin{tabular}{|c|} 
FAA \\
Cenários \\
7 e 8 \\
\end{tabular}} & \multirow{2}{*}{\begin{tabular}{|c|} 
ICAO \\
Cenários \\
7 e 8 \\
\end{tabular}} & \multicolumn{2}{|c|}{ FAA } & \multirow{2}{*}{\begin{tabular}{|c|} 
ICAO \\
Cenários \\
7 e 8 \\
\end{tabular}} & \multicolumn{2}{|c|}{ FAA } \\
\hline & & & & & $\begin{array}{c}\text { Cenário } \\
7\end{array}$ & $\begin{array}{c}\text { Cenário } \\
8\end{array}$ & & $\begin{array}{c}\text { Cenário } \\
7\end{array}$ & $\begin{array}{c}\text { Cenário } \\
8\end{array}$ \\
\hline 1 & $42-600$ & 60,0 & 94,5 & 65,1 & 74,7 & 74,7 & 69,6 & 85,5 & 85,5 \\
\hline 2 & 135ER & 90,0 & 75,0 & 78,2 & 60,3 & 61,9 & 87,0 & 78,0 & 78,0 \\
\hline 3 & 140ER & 90,0 & 75,0 & 78,2 & 60,3 & 61,9 & 87,0 & 78,0 & 78,0 \\
\hline 4 & CRJ700 Next Gen ER & 90,0 & 75,0 & 80,1 & 65,9 & 67,1 & 89,6 & 84,8 & 84,8 \\
\hline 5 & $72-600$ & 90,0 & 94,5 & 84,2 & 76,3 & 76,5 & 89,7 & 87,3 & 87,3 \\
\hline 6 & 170 standard & 90,0 & 75,0 & 80,6 & 78,7 & 74,4 & 96,3 & 99,9 & 99,9 \\
\hline 7 & 175 standard & 90,0 & 75,0 & 80,6 & 77,3 & 72,7 & 96,2 & 99,7 & 99,7 \\
\hline 8 & 190 standard & 90,0 & 75,0 & 82,7 & 80,0 & 74,9 & 98,4 & 105,6 & 105,6 \\
\hline 9 & 195 standard & 90,0 & 75,0 & 82,2 & 78,3 & 74,2 & 98,4 & 105,6 & 105,6 \\
\hline 10 & $737-700$ & 90,0 & 75,0 & 86,6 & 97,5 & 92,7 & 104,3 & 121,3 & 121,3 \\
\hline 11 & $318-100$ & 90,0 & 75,0 & 84,5 & 98,1 & 93,6 & 104,3 & 120,3 & 120,3 \\
\hline 12 & 145LR & 136,8 & 75,0 & 78,2 & 60,4 & 61,9 & 87,0 & 77,9 & 77,9 \\
\hline 13 & CRJ900 Next Gen LR & 136,8 & 75,0 & 80,1 & 66,9 & 68,2 & 89,3 & 85,1 & 85,1 \\
\hline 14 & 195AR & 136,8 & 75,0 & 82,1 & 78,3 & 73,9 & 98,4 & 105,6 & 105,6 \\
\hline 15 & 319 & 136,8 & 75,0 & 84,8 & 92,2 & 87,4 & 102,2 & 116,1 & 116,1 \\
\hline 16 & 320 & 136,8 & 75,0 & 84,5 & 90,3 & 84,9 & 102,2 & 116,9 & 116,9 \\
\hline 17 & 321 & 136,8 & 75,0 & 84,7 & 84,7 & 81,8 & 102,2 & 116,1 & 116,1 \\
\hline 18 & $737-800$ & 136,8 & 110,0 & 87,0 & 93,4 & 87,7 & 104,3 & 121,3 & 121,3 \\
\hline 19 & 737-900ER & 136,8 & 110,0 & 87,0 & 91,5 & 86,8 & 104,3 & 121,2 & 121,2 \\
\hline
\end{tabular}




\begin{tabular}{|c|c|c|c|c|c|c|c|c|c|}
\hline \multirow{4}{*}{$N^{\circ}$ Sequencial } & \multirow{4}{*}{ Modelo } & \multirow{2}{*}{\multicolumn{2}{|c|}{ Padrão BPRW }} & \multirow{2}{*}{\multicolumn{3}{|c|}{$\begin{array}{c}\text { Aeronave que espera para } \\
\text { entrar na RW } \\
\text { OFZ de trans. Interna }\end{array}$}} & \multirow{2}{*}{\multicolumn{3}{|c|}{$\begin{array}{c}\text { Aeronave que acaba de sair } \\
\text { da RW } \\
\text { OFZ de trans. Interna }\end{array}$}} \\
\hline & & & & & & & & & \\
\hline & & \multirow{2}{*}{\begin{tabular}{|c|} 
ICAO \\
Cenários \\
7 e 8 \\
\end{tabular}} & \multirow{2}{*}{\begin{tabular}{|c|} 
FAA \\
Cenários \\
7 e 8 \\
\end{tabular}} & \multirow{2}{*}{\begin{tabular}{|c|} 
ICAO \\
Cenários \\
7 e 8 \\
\end{tabular}} & \multicolumn{2}{|c|}{ FAA } & \multirow{2}{*}{\begin{tabular}{c|} 
ICAO \\
Cenários \\
7 e 8 \\
\end{tabular}} & \multicolumn{2}{|c|}{ FAA } \\
\hline & & & & & $\begin{array}{c}\text { Cenário } \\
7\end{array}$ & $\begin{array}{c}\text { Cenário } \\
8\end{array}$ & & $\begin{array}{c}\text { Cenário } \\
7\end{array}$ & $\begin{array}{c}\text { Cenário } \\
8\end{array}$ \\
\hline 20 & 767-300ER & 136,8 & 110,0 & 89,2 & 108,9 & 101,0 & 114,2 & 147,7 & 147,7 \\
\hline 21 & $787-8$ & 136,8 & 120,0 & 89,9 & 121,6 & 113,4 & 117,8 & 161,9 & 161,9 \\
\hline 22 & $330-200$ & 136,8 & 120,0 & 90,0 & 123,2 & 114,8 & 119,0 & 164,5 & 164,5 \\
\hline 23 & $330-300$ & 136,8 & 120,0 & 90,0 & 115,9 & 107,6 & 117,2 & 160,9 & 160,9 \\
\hline 24 & 777-200ER & 136,8 & 120,0 & 92,9 & 126,4 & 117,2 & 122,3 & 171,4 & 171,4 \\
\hline 25 & 777-200LR & 136,8 & 120,0 & 92,9 & 129,2 & 120,0 & 122,6 & 174,2 & 174,2 \\
\hline 26 & 777-300ER & 136,8 & 120,0 & 93,1 & 121,4 & 115,8 & 122,3 & 173,6 & 173,6 \\
\hline 27 & $330-200 \mathrm{~F}$ & 136,8 & 120,0 & 90,9 & 123,2 & 114,8 & 119,0 & 164,5 & 164,5 \\
\hline 28 & $340-500$ & 136,8 & 120,0 & 90,6 & 117,6 & 110,8 & 118,6 & 165,6 & 165,6 \\
\hline 29 & $747-8$ & 143,0 & 120,0 & 113,7 & 127,2 & 123,7 & 142,5 & 181,1 & 181,1 \\
\hline 30 & $747-8 \mathrm{~F}$ & 143,0 & 120,0 & 113,7 & 127,2 & 123,7 & 142,5 & 181,1 & 181,1 \\
\hline 31 & $380-800$ & 143,0 & 120,0 & 117,3 & 164,2 & 153,8 & 156,6 & 215,7 & 215,7 \\
\hline
\end{tabular}

FONTE: Adaptado a partir dos dados da Tabela 5.1-1 e das especificações da ICAO e da FAA 
ANEXO H - DADOS RELATIVOS AOS CENÁRIOS 9, 10, 11 e 12 PARA AVALIAÇÃO DOS PADRÕES DAS BPRWS

\begin{tabular}{c|c|c|c|c|c|c|c}
\hline \multirow{2}{*}{$\mathbf{N}^{\circ}$ Sequencial } & \multirow{2}{*}{ Modelo } & \multicolumn{4}{|c|}{ ICAO } & \multicolumn{2}{c}{ FAA } \\
\cline { 3 - 8 } & & $\begin{array}{c}\text { Cenário } \\
\mathbf{9}\end{array}$ & $\begin{array}{c}\text { Cenário } \\
\mathbf{1 0}\end{array}$ & $\begin{array}{c}\text { Cenário } \\
\mathbf{1 1}\end{array}$ & $\begin{array}{c}\text { Cenário } \\
\mathbf{1 2}\end{array}$ & $\begin{array}{c}\text { Cenários } \\
\mathbf{9} \text { e 10 }\end{array}$ & $\begin{array}{c}\text { Cenários } \\
\mathbf{1 1} \text { e 12 }\end{array}$ \\
\hline 1 & $42-600$ & 40,0 & 40,0 & 40 & 40 & 60 & 79,455 \\
\hline 2 & $135 E R$ & 75,0 & 75,0 & 75 & 75 & 60 & 60 \\
\hline 3 & $140 E R$ & 75,0 & 75,0 & 75 & 75 & 75 & 75 \\
\hline 4 & CRJ700 Next Gen ER & 75,0 & 75,0 & 75 & 75 & 75 & 75 \\
\hline 5 & $72-600$ & 75,0 & 75,0 & 75 & 75 & 60 & 79,455 \\
\hline 6 & 170 standard & 75,0 & 75,0 & 75 & 75 & 75 & 75 \\
\hline 7 & 175 standard & 75,0 & 75,0 & 75 & 75 & 75 & 75 \\
\hline 8 & 190 standard & 75,0 & 75,0 & 75 & 75 & 75 & 75 \\
\hline 9 & 195 standard & 75,0 & 75,0 & 75 & 75 & 75 & 75 \\
\hline 10 & $737-700$ & 75,0 & 75,0 & 75 & 75 & 75 & 75 \\
\hline 11 & $318-100$ & 75,0 & 75,0 & 75 & 75 & 75 & 75 \\
\hline 12 & 145 LR & 75,0 & 86,3 & 110,5 & 121,75 & 75 & 75 \\
\hline 13 & CRJ900 Next Gen LR & 75,0 & 86,3 & 110,5 & 121,75 & 75 & 75 \\
\hline 14 & $195 A R$ & 75,0 & 86,3 & 110,5 & 121,75 & 75 & 75 \\
\hline 15 & 319 & 75,0 & 86,3 & 110,5 & 121,75 & 75 & 75 \\
\hline 16 & 320 & 75,0 & 86,3 & 110,5 & 121,75 & 75 & 75 \\
\hline 17 & 321 & 75,0 & 86,3 & 110,5 & 121,75 & 75 & 75 \\
\hline 18 & $737-800$ & 75,0 & 86,3 & 110,5 & 121,75 & 75 & 110 \\
\hline 19 & $737-900 E R$ & 75,0 & 86,3 & 110,5 & 121,75 & 75 & 110 \\
\hline
\end{tabular}




\begin{tabular}{|c|c|c|c|c|c|c|c|}
\hline \multirow{2}{*}{$N^{\circ}$ Sequencial } & \multirow{2}{*}{ Modelo } & \multicolumn{4}{|c|}{ ICAO } & \multicolumn{2}{|c|}{ FAA } \\
\hline & & $\begin{array}{c}\text { Cenário } \\
9\end{array}$ & $\begin{array}{c}\text { Cenário } \\
10\end{array}$ & $\begin{array}{c}\text { Cenário } \\
11\end{array}$ & $\begin{array}{c}\text { Cenário } \\
12\end{array}$ & $\begin{array}{c}\text { Cenários } \\
9 \text { e } 10\end{array}$ & $\begin{array}{c}\text { Cenários } \\
11 \text { e } 12\end{array}$ \\
\hline 20 & 767-300ER & 75,0 & 86,3 & 110,5 & 121,75 & 75 & 110 \\
\hline 21 & $787-8$ & 75,0 & 86,3 & 110,5 & 121,75 & 75 & 110 \\
\hline 22 & $330-200$ & 75,0 & 86,3 & 110,5 & 121,75 & 75 & 110 \\
\hline 23 & $330-300$ & 75,0 & 86,3 & 110,5 & 121,75 & 75 & 110 \\
\hline 24 & 777-200ER & 75,0 & 86,3 & 110,5 & 121,75 & 75 & 110 \\
\hline 25 & 777-200LR & 75,0 & 86,3 & 110,5 & 121,75 & 75 & 110 \\
\hline 26 & 777-300ER & 75,0 & 86,3 & 110,5 & 121,75 & 75 & 110 \\
\hline 27 & $330-200 \mathrm{~F}$ & 75,0 & 86,3 & 110,5 & 121,75 & 75 & 110 \\
\hline 28 & $340-500$ & 75,0 & 86,3 & 110,5 & 121,75 & 75 & 110 \\
\hline 29 & $747-8$ & 75,0 & 75,0 & 110,5 & 110,5 & 85 & 120 \\
\hline 30 & $747-8 \mathrm{~F}$ & 75,0 & 75,0 & 110,5 & 110,5 & 85 & 120 \\
\hline 31 & $380-800$ & 75,0 & 75,0 & 110,5 & 110,5 & 85 & 120 \\
\hline
\end{tabular}

FONTE: Adaptado a partir dos dados da Tabela 5.1-1 e das especificações da ICAO e da FAA 


\section{ANEXO I - DADOS RELATIVOS À SEPARAÇÃO ENTRE RWS PARALELAS}

\begin{tabular}{|c|c|c|c|}
\hline \multirow[t]{2}{*}{$\begin{array}{c}\mathbf{N}^{\circ} \\
\text { Sequencial }\end{array}$} & \multirow[t]{2}{*}{ Modelo } & \multicolumn{2}{|c|}{$\begin{array}{c}\text { Padrão de } \\
\text { separação entre } \\
\text { RWs para } \\
\text { aproximação } \\
\text { visual } \\
\end{array}$} \\
\hline & & ICAO & FAA \\
\hline 1 & $42-600$ & 150,0 & 214,0 \\
\hline 2 & 135ER & 210,0 & 214,0 \\
\hline 3 & 140ER & 210,0 & 214,0 \\
\hline 4 & CRJ700 Next Gen ER & 210,0 & 214,0 \\
\hline 5 & $72-600$ & 210,0 & 214,0 \\
\hline 6 & 170 standard & 210,0 & 214,0 \\
\hline 7 & 175 standard & 210,0 & 214,0 \\
\hline 8 & 190 standard & 210,0 & 214,0 \\
\hline 9 & 195 standard & 210,0 & 214,0 \\
\hline 10 & $737-700$ & 210,0 & 214,0 \\
\hline 11 & $318-100$ & 210,0 & 214,0 \\
\hline 12 & 145LR & 210,0 & 214,0 \\
\hline 13 & CRJ900 Next Gen LR & 210,0 & 214,0 \\
\hline 14 & 195AR & 210,0 & 214,0 \\
\hline 15 & 319 & 210,0 & 214,0 \\
\hline 16 & 320 & 210,0 & 214,0 \\
\hline 17 & 321 & 210,0 & 214,0 \\
\hline 18 & $737-800$ & 210,0 & 214,0 \\
\hline 19 & 737-900ER & 210,0 & 214,0 \\
\hline 20 & 767-300ER & 210,0 & 214,0 \\
\hline 21 & $787-8$ & 210,0 & 366,0 \\
\hline 22 & $330-200$ & 210,0 & 366,0 \\
\hline 23 & $330-300$ & 210,0 & 366,0 \\
\hline 24 & 777-200ER & 210,0 & 366,0 \\
\hline 25 & 777-200LR & 210,0 & 366,0 \\
\hline 26 & 777-300ER & 210,0 & 366,0 \\
\hline 27 & $330-200 \mathrm{~F}$ & 210,0 & 366,0 \\
\hline 28 & $340-500$ & 210,0 & 366,0 \\
\hline 29 & $747-8$ & 210,0 & 366,0 \\
\hline 30 & $747-8 \mathrm{~F}$ & 210,0 & 366,0 \\
\hline 31 & $380-800$ & 210,0 & 366,0 \\
\hline
\end{tabular}

FONTE: Adaptado a partir dos dados da Tabela 5.1-1 e das especificações da ICAO e da FAA 
ANEXO J - DADOS RELATIVOS À SEPARAÇÃO ENTRE RWS E TWS PARALELAS PARA OS CENÁRIOS 1 E 2

\begin{tabular}{|c|c|c|c|c|c|c|c|}
\hline \multirow{3}{*}{$\begin{array}{c}\mathbf{N}^{\circ} \\
\text { Sequencial }\end{array}$} & \multirow{3}{*}{ Modelo } & \multicolumn{3}{|c|}{$\begin{array}{c}\text { Padrão de separação } \\
\text { RW/TW }\end{array}$} & \multicolumn{3}{|c|}{$\begin{array}{l}\text { Separação para atendimento } \\
\text { à OFZ de transição interna }\end{array}$} \\
\hline & & \multirow{2}{*}{$\begin{array}{c}\text { ICAO } \\
\text { Cenários } \\
1 \text { e } 2 \\
\end{array}$} & \multicolumn{2}{|c|}{ FAA } & \multirow{2}{*}{\begin{tabular}{|c|} 
ICAO \\
Cenários \\
1 e 2 \\
\end{tabular}} & \multicolumn{2}{|c|}{ FAA } \\
\hline & & & \begin{tabular}{|c|} 
Cenário \\
1
\end{tabular} & \begin{tabular}{|c|} 
Cenário \\
2 \\
\end{tabular} & & $\begin{array}{c}\text { Cenário } \\
1\end{array}$ & $\begin{array}{c}\text { Cenário } \\
2 \\
\end{array}$ \\
\hline 1 & $42-600$ & 93,0 & 105,0 & 105,0 & 79,3 & 60,0 & 108,7 \\
\hline 2 & 135ER & 162,0 & 90,0 & 90,0 & 87,3 & 60,0 & 78,5 \\
\hline 3 & 140ER & 162,0 & 120,0 & 120,0 & 87,3 & 60,0 & 78,5 \\
\hline 4 & $\begin{array}{c}\text { CRJ700 Next Gen } \\
\text { ER }\end{array}$ & 162,0 & 120,0 & 120,0 & 87,3 & 60,0 & 80,3 \\
\hline 5 & $72-600$ & 168,0 & 105,0 & 105,0 & 101,1 & 60,0 & 110,1 \\
\hline 6 & 170 standard & 168,0 & 120,0 & 120,0 & 101,1 & 60,0 & 109,5 \\
\hline 7 & 175 standard & 168,0 & 120,0 & 120,0 & 101,1 & 60,0 & 109,5 \\
\hline 8 & 190 standard & 168,0 & 120,0 & 120,0 & 101,1 & 60,0 & 111,0 \\
\hline 9 & 195 standard & 168,0 & 120,0 & 120,0 & 101,1 & 60,0 & 111,0 \\
\hline 10 & $737-700$ & 168,0 & 120,0 & 120,0 & 101,1 & 60,0 & 115,0 \\
\hline 11 & $318-100$ & 168,0 & 120,0 & 120,0 & 101,1 & 60,0 & 114,0 \\
\hline 12 & 145LR & 162,0 & 120,0 & 120,0 & 87,3 & 60,0 & 78,5 \\
\hline 13 & $\begin{array}{c}\text { CRJ900 Next Gen } \\
\text { LR }\end{array}$ & 168,0 & 120,0 & 120,0 & 101,1 & 60,0 & 108,8 \\
\hline 14 & 195AR & 168,0 & 120,0 & 120,0 & 101,1 & 60,0 & 111,0 \\
\hline 15 & 319 & 168,0 & 120,0 & 120,0 & 101,1 & 60,0 & 114,0 \\
\hline 16 & 320 & 168,0 & 120,0 & 120,0 & 101,1 & 60,0 & 114,8 \\
\hline 17 & 321 & 168,0 & 120,0 & 120,0 & 101,1 & 60,0 & 114,0 \\
\hline 18 & $737-800$ & 168,0 & 120,0 & 120,0 & 101,1 & 60,0 & 115,0 \\
\hline 19 & $737-900 E R$ & 168,0 & 120,0 & 120,0 & 101,1 & 60,0 & 114,9 \\
\hline 20 & 767-300ER & 176,0 & 120,0 & 120,0 & 114,9 & 86,2 & 149,2 \\
\hline 21 & $787-8$ & 182,5 & 120,0 & 150,0 & 120,3 & 104,0 & 167,0 \\
\hline 22 & $330-200$ & 182,5 & 120,0 & 150,0 & 120,3 & 104,2 & 167,2 \\
\hline 23 & $330-300$ & 182,5 & 120,0 & 150,0 & 120,3 & 104,2 & 167,2 \\
\hline 24 & 777-200ER & 182,5 & 120,0 & 150,0 & 120,3 & 104,5 & 167,5 \\
\hline 25 & 777-200LR & 182,5 & 120,0 & 150,0 & 120,3 & 106,7 & 169,7 \\
\hline 26 & 777-300ER & 182,5 & 120,0 & 150,0 & 120,3 & 106,7 & 169,7 \\
\hline 27 & $330-200 \mathrm{~F}$ & 182,5 & 120,0 & 150,0 & 120,3 & 104,2 & 167,2 \\
\hline 28 & $340-500$ & 182,5 & 120,0 & 150,0 & 120,3 & 106,0 & 169,0 \\
\hline 29 & $747-8$ & 190,0 & 150,0 & 150,0 & 150,7 & 134,6 & 197,6 \\
\hline 30 & $747-8 \mathrm{~F}$ & 190,0 & 150,0 & 150,0 & 150,7 & 134,6 & 197,6 \\
\hline 31 & $380-800$ & 190,0 & 150,0 & 150,0 & 150,7 & 141,0 & 204,0 \\
\hline
\end{tabular}

FONTE: Adaptado a partir dos dados da Tabela 5.1-1 e das especificações da ICAO e da FAA 


\section{ANEXO K - DADOS RELATIVOS À SEPARAÇÃO ENTRE RWS E TWS PARALELAS PARA OS CENÁRIOS 3 E 4}

\begin{tabular}{|c|c|c|c|c|c|c|c|}
\hline \multirow{3}{*}{$\begin{array}{c}\mathrm{N}^{\circ} \\
\text { Sequencial }\end{array}$} & \multirow{3}{*}{ Modelo } & \multicolumn{3}{|c|}{$\begin{array}{c}\text { Padrão de separação } \\
\text { RW/TW }\end{array}$} & \multicolumn{3}{|c|}{$\begin{array}{l}\text { Separação para atendimento } \\
\text { à OFZ de transição interna }\end{array}$} \\
\hline & & \multirow{2}{*}{$\begin{array}{c}\text { ICAO } \\
\text { Cenários } \\
3 \text { e } 4\end{array}$} & \multicolumn{2}{|c|}{ FAA } & \multirow{2}{*}{\begin{tabular}{|c|} 
ICAO \\
Cenários \\
3 e 4 \\
\end{tabular}} & \multicolumn{2}{|c|}{ FAA } \\
\hline & & & $\begin{array}{c}\text { Cenário } \\
3\end{array}$ & \begin{tabular}{|c|} 
Cenário \\
4
\end{tabular} & & $\begin{array}{c}\text { Cenário } \\
3\end{array}$ & $\begin{array}{c}\text { Cenário } \\
4\end{array}$ \\
\hline 1 & $42-600$ & 93,0 & 105,0 & 105,0 & 79,3 & 64,5 & 108,7 \\
\hline 2 & 135ER & 162,0 & 90,0 & 90,0 & 87,3 & 60,0 & 78,5 \\
\hline 3 & 140ER & 162,0 & 120,0 & 120,0 & 87,3 & 60,0 & 78,5 \\
\hline 4 & $\begin{array}{c}\text { CRJ700 Next Gen } \\
\text { ER }\end{array}$ & 162,0 & 120,0 & 120,0 & 87,3 & 60,0 & 80,3 \\
\hline 5 & $72-600$ & 168,0 & 105,0 & 105,0 & 101,1 & 66,1 & 110,1 \\
\hline 6 & 170 standard & 168,0 & 120,0 & 120,0 & 101,1 & 65,4 & 109,5 \\
\hline 7 & 175 standard & 168,0 & 120,0 & 120,0 & 101,1 & 65,4 & 109,5 \\
\hline 8 & 190 standard & 168,0 & 120,0 & 120,0 & 101,1 & 67,2 & 111,0 \\
\hline 9 & 195 standard & 168,0 & 120,0 & 120,0 & 101,1 & 67,2 & 111,0 \\
\hline 10 & $737-700$ & 168,0 & 120,0 & 120,0 & 101,1 & 71,8 & 115,0 \\
\hline 11 & $318-100$ & 168,0 & 120,0 & 120,0 & 101,1 & 70,7 & 114,0 \\
\hline 12 & 145LR & 162,0 & 120,0 & 120,0 & 87,3 & 60,0 & 78,5 \\
\hline 13 & $\begin{array}{c}\text { CRJ900 Next Gen } \\
\text { LR }\end{array}$ & 168,0 & 120,0 & 120,0 & 101,1 & 64,7 & 108,8 \\
\hline 14 & 195AR & 168,0 & 120,0 & 120,0 & 101,1 & 67,2 & 111,0 \\
\hline 15 & 319 & 168,0 & 120,0 & 120,0 & 101,1 & 70,7 & 114,0 \\
\hline 16 & 320 & 168,0 & 120,0 & 120,0 & 101,1 & 71,6 & 114,8 \\
\hline 17 & 321 & 168,0 & 120,0 & 120,0 & 101,1 & 70,7 & 114,0 \\
\hline 18 & $737-800$ & 168,0 & 120,0 & 120,0 & 101,1 & 71,8 & 115,0 \\
\hline 19 & 737-900ER & 168,0 & 120,0 & 120,0 & 101,1 & 71,7 & 114,9 \\
\hline 20 & 767-300ER & 176,0 & 120,0 & 120,0 & 114,9 & 102,4 & 149,2 \\
\hline 21 & 787-8 & 182,5 & 150,0 & 150,0 & 120,3 & 119,5 & 167,0 \\
\hline 22 & $330-200$ & 182,5 & 150,0 & 150,0 & 120,3 & 119,7 & 167,2 \\
\hline 23 & $330-300$ & 182,5 & 150,0 & 150,0 & 120,3 & 119,7 & 167,2 \\
\hline 24 & 777-200ER & 182,5 & 150,0 & 150,0 & 120,3 & 120,1 & 167,5 \\
\hline 25 & 777-200LR & 182,5 & 150,0 & 150,0 & 120,3 & 122,6 & 169,7 \\
\hline 26 & 777-300ER & 182,5 & 150,0 & 150,0 & 120,3 & 122,6 & 169,7 \\
\hline 27 & $330-200 F$ & 182,5 & 150,0 & 150,0 & 120,3 & 119,7 & 167,2 \\
\hline 28 & $340-500$ & 182,5 & 150,0 & 150,0 & 120,3 & 121,8 & 169,0 \\
\hline 29 & $747-8$ & 190,0 & 168,0 & 168,0 & 150,7 & 146,5 & 197,6 \\
\hline 30 & $747-8 F$ & 190,0 & 168,0 & 168,0 & 150,7 & 146,5 & 197,6 \\
\hline 31 & $380-800$ & 190,0 & 168,0 & 168,0 & 150,7 & 153,8 & 204,0 \\
\hline
\end{tabular}

FONTE: Adaptado a partir dos dados da Tabela 5.1-1 e das especificações da ICAO e da FAA 


\section{ANEXO L - DADOS RELATIVOS À SEPARAÇÃO ENTRE RWS E TWS PARALELAS PARA OS CENÁRIOS 5 E 6}

\begin{tabular}{|c|c|c|c|c|}
\hline \multirow{3}{*}{$\begin{array}{c}\mathrm{N}^{\circ} \\
\text { Sequencial }\end{array}$} & \multirow{3}{*}{ Modelo } & \multicolumn{3}{|c|}{$\begin{array}{c}\text { Padrão de separação } \\
\text { RWITW }\end{array}$} \\
\hline & & \multirow{2}{*}{\begin{tabular}{|c|} 
ICAO \\
Cenários \\
5 e 6
\end{tabular}} & \multicolumn{2}{|c|}{ FAA } \\
\hline & & & $\begin{array}{c}\text { Cenário } \\
5\end{array}$ & $\begin{array}{c}\text { Cenário } \\
6\end{array}$ \\
\hline 1 & $42-600$ & 58,0 & 90,0 & 90,0 \\
\hline 2 & 135ER & 87,0 & 72,0 & 72,0 \\
\hline 3 & 140ER & 87,0 & 90,0 & 90,0 \\
\hline 4 & CRJ700 Next Gen ER & 87,0 & 90,0 & 90,0 \\
\hline 5 & $72-600$ & 93,0 & 90,0 & 90,0 \\
\hline 6 & 170 standard & 93,0 & 120,0 & 120,0 \\
\hline 7 & 175 standard & 93,0 & 120,0 & 120,0 \\
\hline 8 & 190 standard & 93,0 & 120,0 & 120,0 \\
\hline 9 & 195 standard & 93,0 & 120,0 & 120,0 \\
\hline 10 & $737-700$ & 93,0 & 120,0 & 120,0 \\
\hline 11 & $318-100$ & 93,0 & 120,0 & 120,0 \\
\hline 12 & 145LR & 87,0 & 90,0 & 90,0 \\
\hline 13 & CRJ900 Next Gen LR & 93,0 & 120,0 & 120,0 \\
\hline 14 & 195AR & 93,0 & 120,0 & 120,0 \\
\hline 15 & 319 & 93,0 & 120,0 & 120,0 \\
\hline 16 & 320 & 93,0 & 120,0 & 120,0 \\
\hline 17 & 321 & 93,0 & 120,0 & 120,0 \\
\hline 18 & $737-800$ & 93,0 & 120,0 & 120,0 \\
\hline 19 & 737-900ER & 93,0 & 120,0 & 120,0 \\
\hline 20 & 767-300ER & 101,0 & 120,0 & 120,0 \\
\hline 21 & $787-8$ & 107,5 & 120,0 & 150,0 \\
\hline 22 & $330-200$ & 107,5 & 120,0 & 150,0 \\
\hline 23 & $330-300$ & 107,5 & 120,0 & 150,0 \\
\hline 24 & 777-200ER & 107,5 & 120,0 & 150,0 \\
\hline 25 & 777-200LR & 107,5 & 120,0 & 150,0 \\
\hline 26 & 777-300ER & 107,5 & 120,0 & 150,0 \\
\hline 27 & $330-200 \mathrm{~F}$ & 107,5 & 120,0 & 150,0 \\
\hline 28 & $340-500$ & 107,5 & 120,0 & 150,0 \\
\hline 29 & $747-8$ & 115,0 & 150,0 & 150,0 \\
\hline 30 & $747-8 \mathrm{~F}$ & 115,0 & 150,0 & 150,0 \\
\hline 31 & $380-800$ & 115,0 & 150,0 & 150,0 \\
\hline
\end{tabular}

FONTE: Adaptado a partir dos dados da Tabela 5.1-1 e das especificações da ICAO e da FAA 
ANEXO L - DADOS RELATIVOS ÀS ÁREAS DE PROTEÇÃO DA RW, CENÁRIO 1

\begin{tabular}{|c|c|c|c|c|c|c|c|c|c|c|c|}
\hline \multirow{3}{*}{$\begin{array}{c}\mathbf{N}^{\circ} \\
\text { Sequencial }\end{array}$} & \multirow{3}{*}{ Modelo } & \multicolumn{5}{|c|}{ Largura } & \multicolumn{5}{|c|}{ Comprimento } \\
\hline & & \multicolumn{3}{|c|}{ ICAO } & \multicolumn{2}{|c|}{ FAA } & \multicolumn{2}{|c|}{ ICAO } & \multicolumn{3}{|c|}{ FAA } \\
\hline & & AGFRW & APFRW & ARFRW & ROFA & RSA & $\begin{array}{c}\text { Faixa } \\
\text { da RW }\end{array}$ & RESA & ROFA & $\begin{array}{l}\text { RSA } \\
\text { (L1) }\end{array}$ & $\begin{array}{l}\text { RSA } \\
\text { (L2) }\end{array}$ \\
\hline 1 & $42-600$ & 150,0 & 80,0 & 90,0 & 240 & 120 & 60 & 180 & 240 & 180 & 240 \\
\hline 2 & 135ER & 300,0 & 150,0 & 120,0 & 240 & 90 & 60 & 300 & 180 & 180 & 180 \\
\hline 3 & 140ER & 300,0 & 150,0 & 120,0 & 240 & 120 & 60 & 300 & 300 & 180 & 300 \\
\hline 4 & CRJ700 Next Gen ER & 300,0 & 150,0 & 120,0 & 240 & 120 & 60 & 300 & 300 & 180 & 300 \\
\hline 5 & $72-600$ & 300,0 & 150,0 & 120,0 & 240 & 120 & 60 & 300 & 240 & 180 & 240 \\
\hline 6 & 170 standard & 300,0 & 150,0 & 120,0 & 240 & 150 & 60 & 300 & 300 & 180 & 300 \\
\hline 7 & 175 standard & 300,0 & 150,0 & 120,0 & 240 & 150 & 60 & 300 & 300 & 180 & 300 \\
\hline 8 & 190 standard & 300,0 & 150,0 & 120,0 & 240 & 150 & 60 & 300 & 300 & 180 & 300 \\
\hline 9 & 195 standard & 300,0 & 150,0 & 120,0 & 240 & 150 & 60 & 300 & 300 & 180 & 300 \\
\hline 10 & $737-700$ & 300,0 & 150,0 & 120,0 & 240 & 150 & 60 & 300 & 300 & 180 & 300 \\
\hline 11 & $318-100$ & 300,0 & 150,0 & 120,0 & 240 & 150 & 60 & 300 & 300 & 180 & 300 \\
\hline 12 & 145LR & 300,0 & 150,0 & 120,0 & 240 & 120 & 60 & 300 & 300 & 180 & 300 \\
\hline 13 & CRJ900 Next Gen LR & 300,0 & 150,0 & 120,0 & 240 & 150 & 60 & 300 & 300 & 180 & 300 \\
\hline 14 & 195AR & 300,0 & 150,0 & 120,0 & 240 & 150 & 60 & 300 & 300 & 180 & 300 \\
\hline 15 & 319 & 300,0 & 150,0 & 120,0 & 240 & 150 & 60 & 300 & 300 & 180 & 300 \\
\hline 16 & 320 & 300,0 & 150,0 & 120,0 & 240 & 150 & 60 & 300 & 300 & 180 & 300 \\
\hline 17 & 321 & 300,0 & 150,0 & 120,0 & 240 & 150 & 60 & 300 & 300 & 180 & 300 \\
\hline 18 & $737-800$ & 300,0 & 150,0 & 120,0 & 240 & 150 & 60 & 300 & 300 & 180 & 300 \\
\hline 19 & 737-900ER & 300,0 & 150,0 & 120,0 & 240 & 150 & 60 & 300 & 300 & 180 & 300 \\
\hline 20 & 767-300ER & 300,0 & 150,0 & 120,0 & 240 & 150 & 60 & 300 & 300 & 180 & 300 \\
\hline 21 & $787-8$ & 300,0 & 150,0 & 120,0 & 240 & 150 & 60 & 300 & 300 & 180 & 300 \\
\hline
\end{tabular}




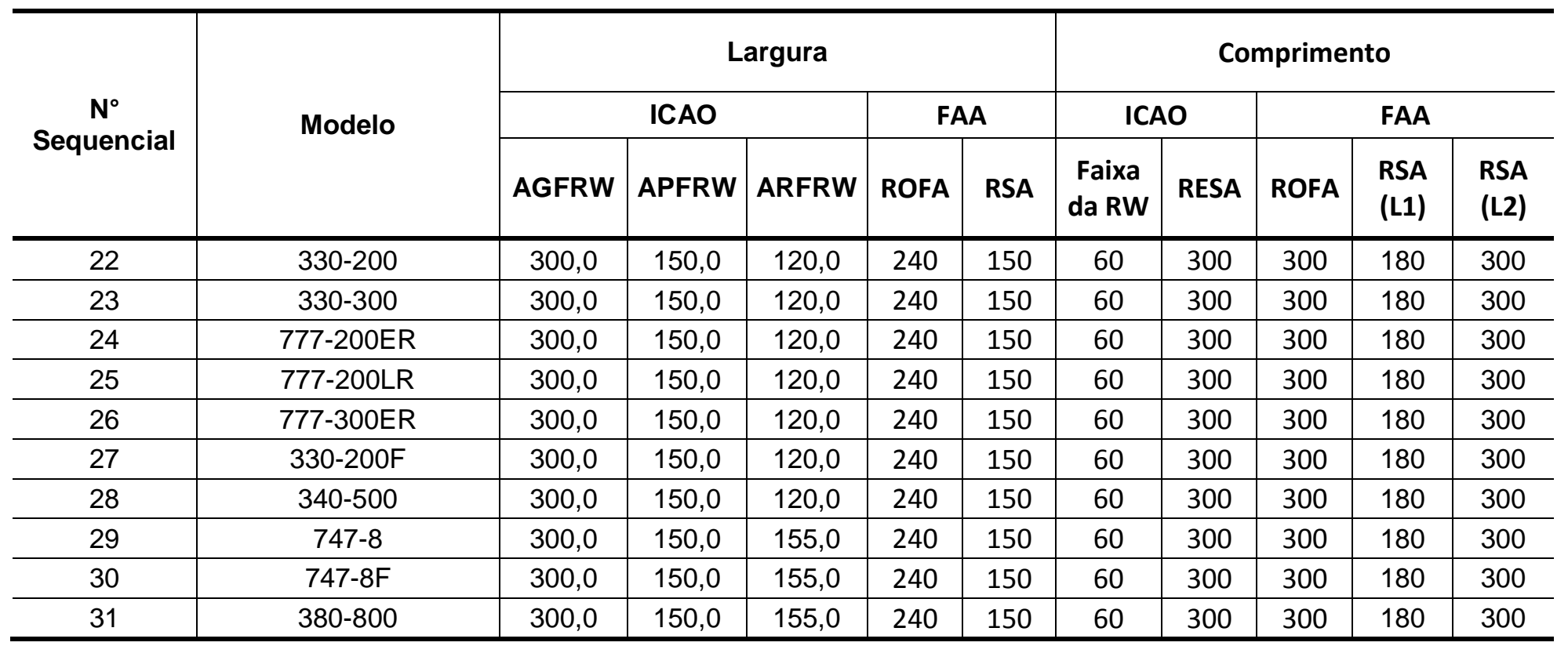

FONTE: Adaptado a partir dos dados da Tabela 5.1-1 e das especificações da ICAO e da FAA 


\section{ANEXO N - DADOS RELATIVOS ÀS ÁREAS DE PROTEÇÃO DA RW, CENÁRIO 2}

\begin{tabular}{|c|c|c|c|c|c|c|c|c|c|c|}
\hline \multirow{3}{*}{$\begin{array}{c}\mathrm{N}^{\circ} \\
\text { Sequencial }\end{array}$} & \multirow{3}{*}{ Modelo } & \multicolumn{4}{|c|}{ Largura } & \multicolumn{5}{|c|}{ Comprimento } \\
\hline & & \multicolumn{2}{|c|}{ ICAO } & \multicolumn{2}{|c|}{ FAA } & \multicolumn{2}{|c|}{ ICAO } & \multicolumn{3}{|c|}{ FAA } \\
\hline & & AGFRW & APFRW & ROFA & RSA & $\begin{array}{l}\text { Faixa } \\
\text { da RW }\end{array}$ & RESA & ROFA & $\begin{array}{l}\text { RSA } \\
\text { (L1) }\end{array}$ & $\begin{array}{l}\text { RSA } \\
\text { (L2) }\end{array}$ \\
\hline 1 & $42-600$ & 80,0 & 80,0 & 240 & 90 & 60 & 180 & 180 & 180 & 180 \\
\hline 2 & 135ER & 150,0 & 150,0 & 150 & 45 & 60 & 300 & 90 & 90 & 90 \\
\hline 3 & 140ER & 150,0 & 150,0 & 240 & 120 & 60 & 300 & 300 & 180 & 300 \\
\hline 4 & $\begin{array}{c}\text { CRJ700 Next Gen } \\
\text { ER }\end{array}$ & 150,0 & 150,0 & 240 & 120 & 60 & 300 & 300 & 180 & 300 \\
\hline 5 & $72-600$ & 150,0 & 150,0 & 240 & 90 & 60 & 300 & 180 & 180 & 180 \\
\hline 6 & 170 standard & 150,0 & 150,0 & 240 & 150 & 60 & 300 & 300 & 180 & 300 \\
\hline 7 & 175 standard & 150,0 & 150,0 & 240 & 150 & 60 & 300 & 300 & 180 & 300 \\
\hline 8 & 190 standard & 150,0 & 150,0 & 240 & 150 & 60 & 300 & 300 & 180 & 300 \\
\hline 9 & 195 standard & 150,0 & 150,0 & 240 & 150 & 60 & 300 & 300 & 180 & 300 \\
\hline 10 & $737-700$ & 150,0 & 150,0 & 240 & 150 & 60 & 300 & 300 & 180 & 300 \\
\hline 11 & $318-100$ & 150,0 & 150,0 & 240 & 150 & 60 & 300 & 300 & 180 & 300 \\
\hline 12 & 145LR & 150,0 & 150,0 & 240 & 120 & 60 & 300 & 300 & 180 & 300 \\
\hline 13 & $\begin{array}{c}\text { CRJ900 Next Gen } \\
\text { LR }\end{array}$ & 150,0 & 150,0 & 240 & 150 & 60 & 300 & 300 & 180 & 300 \\
\hline 14 & 195AR & 150,0 & 150,0 & 240 & 150 & 60 & 300 & 300 & 180 & 300 \\
\hline 15 & 319 & 150,0 & 150,0 & 240 & 150 & 60 & 300 & 300 & 180 & 300 \\
\hline 16 & 320 & 150,0 & 150,0 & 240 & 150 & 60 & 300 & 300 & 180 & 300 \\
\hline 17 & 321 & 150,0 & 150,0 & 240 & 150 & 60 & 300 & 300 & 180 & 300 \\
\hline 18 & $737-800$ & 150,0 & 150,0 & 240 & 150 & 60 & 300 & 300 & 180 & 300 \\
\hline 19 & 737-900ER & 150,0 & 150,0 & 240 & 150 & 60 & 300 & 300 & 180 & 300 \\
\hline
\end{tabular}




\begin{tabular}{|c|c|c|c|c|c|c|c|c|c|c|}
\hline \multirow{3}{*}{$\begin{array}{c}\mathbf{N}^{\circ} \\
\text { Sequencial }\end{array}$} & \multirow{3}{*}{ Modelo } & \multicolumn{4}{|c|}{ Largura } & \multicolumn{5}{|c|}{ Comprimento } \\
\hline & & \multicolumn{2}{|c|}{ ICAO } & \multicolumn{2}{|c|}{ FAA } & \multicolumn{2}{|c|}{ ICAO } & \multicolumn{3}{|c|}{ FAA } \\
\hline & & AGFRW & APFRW & ROFA & RSA & $\begin{array}{c}\text { Faixa } \\
\text { da } R W\end{array}$ & RESA & ROFA & $\begin{array}{l}\text { RSA } \\
\text { (L1) }\end{array}$ & $\begin{array}{l}\text { RSA } \\
\text { (L2) }\end{array}$ \\
\hline 20 & 767-300ER & 150,0 & 150,0 & 240 & 150 & 60 & 300 & 300 & 180 & 300 \\
\hline 21 & $787-8$ & 150,0 & 150,0 & 240 & 150 & 60 & 300 & 300 & 180 & 300 \\
\hline 22 & $330-200$ & 150,0 & 150,0 & 240 & 150 & 60 & 300 & 300 & 180 & 300 \\
\hline 23 & $330-300$ & 150,0 & 150,0 & 240 & 150 & 60 & 300 & 300 & 180 & 300 \\
\hline 24 & 777-200ER & 150,0 & 150,0 & 240 & 150 & 60 & 300 & 300 & 180 & 300 \\
\hline 25 & 777-200LR & 150,0 & 150,0 & 240 & 150 & 60 & 300 & 300 & 180 & 300 \\
\hline 26 & 777-300ER & 150,0 & 150,0 & 240 & 150 & 60 & 300 & 300 & 180 & 300 \\
\hline 27 & $330-200 F$ & 150,0 & 150,0 & 240 & 150 & 60 & 300 & 300 & 180 & 300 \\
\hline 28 & $340-500$ & 150,0 & 150,0 & 240 & 150 & 60 & 300 & 300 & 180 & 300 \\
\hline 29 & $747-8$ & 150,0 & 150,0 & 240 & 150 & 60 & 300 & 300 & 180 & 300 \\
\hline 30 & $747-8 F$ & 150,0 & 150,0 & 240 & 150 & 60 & 300 & 300 & 180 & 300 \\
\hline 31 & $380-800$ & 150,0 & 150,0 & 240 & 150 & 60 & 300 & 300 & 180 & 300 \\
\hline
\end{tabular}

FONTE: Adaptado a partir dos dados da Tabela 5.1-1 e das especificações da ICAO e da FAA 
ANEXO O - DADOS RELATIVOS À AVALIAÇÃO DA OFZ DE TRANSIÇÃO INTERNA NAS BPRWS DO SBGR COM BASE NOS PADRÕES DO GRUPO GEOMÉTRICO F PARA ICAO E NOS PADRÕES CAT II/III PARA AERONAVES DE GRANDE PORTE NO CASO DA FAA

\begin{tabular}{|c|c|c|c|c|c|c|c|c|c|c|c|c|c|}
\hline \multirow{4}{*}{ BPRW } & \multirow{4}{*}{$\begin{array}{c}\text { Posição } \\
\text { (m) }\end{array}$} & \multicolumn{8}{|c|}{ Estabilizador } & \multirow{2}{*}{\multicolumn{4}{|c|}{$\begin{array}{c}\text { Nariz } \\
\text { Esperando para entrar }\end{array}$}} \\
\hline & & \multicolumn{4}{|c|}{ Esperando para entrar } & \multicolumn{4}{|c|}{ Saindo da RW } & & & & \\
\hline & & \multicolumn{2}{|c|}{ Folga ICAO } & \multicolumn{2}{|c|}{ Folga FAA } & \multicolumn{2}{|c|}{ Folga ICAO } & \multicolumn{2}{|c|}{ Folga FAA } & \multicolumn{2}{|c|}{ Folga ICAO } & \multicolumn{2}{|c|}{ Folga FAA } \\
\hline & & A380-800 & B747-8 & A380-800 & B747-8 & A380-800 & B747-8 & $\begin{array}{c}\text { A380- } \\
800\end{array}$ & B747-8 & $\begin{array}{c}\text { A380- } \\
800\end{array}$ & B747-8 & $\begin{array}{c}\text { A380- } \\
800\end{array}$ & B747-8 \\
\hline 1 & 123 & 8,2 & 13,8 & 3,6 & 9,8 & $-8,9$ & $-4,2$ & $-4,9$ & 0,8 & 4,2 & 5,3 & 8,2 & 10,4 \\
\hline 2 & 123 & 8,2 & 13,8 & 3,6 & 9,8 & $-8,9$ & $-4,2$ & $-4,9$ & 0,8 & 4,2 & 5,3 & 8,2 & 10,4 \\
\hline 3 & 76 & $-7,5$ & $-1,9$ & $-4,2$ & 2,0 & $-24,6$ & $-19,9$ & $-12,8$ & $-7,0$ & $-11,5$ & $-10,3$ & 0,3 & 2,5 \\
\hline 4 & 83 & $-5,1$ & 0,4 & $-3,0$ & 3,1 & $-22,3$ & $-17,6$ & $-11,6$ & $-5,9$ & $-9,2$ & $-8,0$ & 1,5 & 3,7 \\
\hline 5 & 83 & $-5,1$ & 0,4 & $-3,0$ & 3,1 & $-22,3$ & $-17,6$ & $-11,6$ & $-5,9$ & $-9,2$ & $-8,0$ & 1,5 & 3,7 \\
\hline 6 & 77 & $-7,1$ & $-1,6$ & $-4,0$ & 2,1 & $-24,3$ & $-19,6$ & $-12,6$ & $-6,9$ & $-11,2$ & $-10,0$ & 0,5 & 2,7 \\
\hline 7 & 77 & $-7,1$ & $-1,6$ & $-4,0$ & 2,1 & $-24,3$ & $-19,6$ & $-12,6$ & $-6,9$ & $-11,2$ & $-10,0$ & 0,5 & 2,7 \\
\hline 8 & 121 & 7,5 & 13,1 & 3,3 & 9,5 & $-9,6$ & $-4,9$ & $-5,3$ & 0,5 & 3,5 & 4,7 & 7,8 & 10,0 \\
\hline 9 & 90 & $-2,8$ & 2,8 & $-1,9$ & 4,3 & $-19,9$ & $-15,2$ & $-10,4$ & $-4,7$ & $-6,8$ & $-5,7$ & 2,7 & 4,9 \\
\hline 10 & 124 & 8,5 & 14,1 & 3,8 & 10,0 & $-8,6$ & $-3,9$ & $-4,8$ & 1,0 & 4,5 & 5,7 & 8,3 & 10,5 \\
\hline 11 & 120 & 7,2 & 12,8 & 3,1 & 9,3 & $-9,9$ & $-5,2$ & $-5,4$ & 0,3 & 3,2 & 4,3 & 7,7 & 9,9 \\
\hline 12 & 122 & 7,9 & 13,4 & 3,5 & 9,6 & $-9,3$ & $-4,6$ & $-5,1$ & 0,6 & 3,8 & 5,0 & 8,0 & 10,2 \\
\hline 13 & 122 & 7,9 & 13,4 & 3,5 & 9,6 & $-9,3$ & $-4,6$ & $-5,1$ & 0,6 & 3,8 & 5,0 & 8,0 & 10,2 \\
\hline 14 & 124 & 8,5 & 14,1 & 3,8 & 10,0 & $-8,6$ & $-3,9$ & $-4,8$ & 1,0 & 4,5 & 5,7 & 8,3 & 10,5 \\
\hline 15 & 123 & 8,2 & 13,8 & 3,6 & 9,8 & $-8,9$ & $-4,2$ & $-4,9$ & 0,8 & 4,2 & 5,3 & 8,2 & 10,4 \\
\hline 16 & 123 & 8,2 & 13,8 & 3,6 & 9,8 & $-8,9$ & $-4,2$ & $-4,9$ & 0,8 & 4,2 & 5,3 & 8,2 & 10,4 \\
\hline 17 & 121 & 7,5 & 13,1 & 3,3 & 9,5 & $-9,6$ & $-4,9$ & $-5,3$ & 0,5 & 3,5 & 4,7 & 7,8 & 10,0 \\
\hline 18 & 122 & 7,9 & 13,4 & 3,5 & 9,6 & $-9,3$ & $-4,6$ & $-5,1$ & 0,6 & 3,8 & 5,0 & 8,0 & 10,2 \\
\hline
\end{tabular}

FONTE: Calculado a partir das especificações contidas na ICAO Annex 14 (2004a) e na FAA AC 150/5300-13 (1989) e dos dados das aeronaves

|a: Dimensões em metros 
ANEXO P - DADOS RELATIVOS À AVALIAÇÃO DA OFZ DE TRANSIÇÃO INTERNA NAS BPRWS DO SBGR COM BASE NOS PADRÕES DO GRUPO GEOMÉTRICO E PARA ICAO E NOS PADRÕES CAT II/III PARA AERONAVES DE GRANDE PORTE NO CASO DA FAA

\begin{tabular}{|c|c|c|c|c|c|c|c|c|c|c|c|c|c|}
\hline \multirow{4}{*}{ BPRW } & \multirow{4}{*}{$\begin{array}{c}\text { Posição } \\
\text { (m) }\end{array}$} & \multicolumn{8}{|c|}{ Estabilizador } & \multirow{2}{*}{\multicolumn{4}{|c|}{$\begin{array}{c}\text { Nariz } \\
\text { Esperando para entrar }\end{array}$}} \\
\hline & & \multicolumn{4}{|c|}{ Esperando para entrar } & \multicolumn{4}{|c|}{ Saindo da RW } & & & & \\
\hline & & \multicolumn{2}{|c|}{ Folga ICAO } & \multicolumn{2}{|c|}{ Folga FAA } & \multicolumn{2}{|c|}{ Folga ICAO } & \multicolumn{2}{|c|}{ Folga FAA } & \multicolumn{2}{|c|}{ Folga ICAO } & \multicolumn{2}{|c|}{ Folga FAA } \\
\hline & & A380-800 & B747-8 & A380-800 & B747-8 & A380-800 & B747-8 & $\begin{array}{c}\text { A380- } \\
800\end{array}$ & B747-8 & $\begin{array}{c}\text { A380- } \\
800 \\
\end{array}$ & B747-8 & $\begin{array}{c}\text { A380- } \\
800 \\
\end{array}$ & B747-8 \\
\hline 1 & 123 & 14,0 & 19,6 & 3,6 & 9,8 & $-3,1$ & 1,6 & $-4,9$ & 0,8 & 10,0 & 11,2 & 8,2 & 10,4 \\
\hline 2 & 123 & 14,0 & 19,6 & 3,6 & 9,8 & $-3,1$ & 1,6 & $-4,9$ & 0,8 & 10,0 & 11,2 & 8,2 & 10,4 \\
\hline 3 & 76 & $-1,6$ & 3,9 & $-4,2$ & 2,0 & $-18,8$ & $-14,1$ & $-12,8$ & $-7,0$ & $-5,7$ & $-4,5$ & 0,3 & 2,5 \\
\hline 4 & 83 & 0,7 & 6,3 & $-3,0$ & 3,1 & $-16,4$ & $-11,7$ & $-11,6$ & $-5,9$ & $-3,3$ & $-2,2$ & 1,5 & 3,7 \\
\hline 5 & 83 & 0,7 & 6,3 & $-3,0$ & 3,1 & $-16,4$ & $-11,7$ & $-11,6$ & $-5,9$ & $-3,3$ & $-2,2$ & 1,5 & 3,7 \\
\hline 6 & 77 & $-1,3$ & 4,3 & $-4,0$ & 2,1 & $-18,4$ & $-13,7$ & $-12,6$ & $-6,9$ & $-5,3$ & $-4,2$ & 0,5 & 2,7 \\
\hline 7 & 77 & $-1,3$ & 4,3 & $-4,0$ & 2,1 & $-18,4$ & $-13,7$ & $-12,6$ & $-6,9$ & $-5,3$ & $-4,2$ & 0,5 & 2,7 \\
\hline 8 & 121 & 13,4 & 18,9 & 3,3 & 9,5 & $-3,8$ & 0,9 & $-5,3$ & 0,5 & 9,3 & 10,5 & 7,8 & 10,0 \\
\hline 9 & 90 & 3,0 & 8,6 & $-1,9$ & 4,3 & $-14,1$ & $-9,4$ & $-10,4$ & $-4,7$ & $-1,0$ & 0,2 & 2,7 & 4,9 \\
\hline 10 & 124 & 14,4 & 19,9 & 3,8 & 10,0 & $-2,8$ & 1,9 & $-4,8$ & 1,0 & 10,3 & 11,5 & 8,3 & 10,5 \\
\hline 11 & 120 & 13,0 & 18,6 & 3,1 & 9,3 & $-4,1$ & 0,6 & $-5,4$ & 0,3 & 9,0 & 10,2 & 7,7 & 9,9 \\
\hline 12 & 122 & 13,7 & 19,3 & 3,5 & 9,6 & $-3,4$ & 1,3 & $-5,1$ & 0,6 & 9,7 & 10,8 & 8,0 & 10,2 \\
\hline 13 & 122 & 13,7 & 19,3 & 3,5 & 9,6 & $-3,4$ & 1,3 & $-5,1$ & 0,6 & 9,7 & 10,8 & 8,0 & 10,2 \\
\hline 14 & 124 & 14,4 & 19,9 & 3,8 & 10,0 & $-2,8$ & 1,9 & $-4,8$ & 1,0 & 10,3 & 11,5 & 8,3 & 10,5 \\
\hline 15 & 123 & 14,0 & 19,6 & 3,6 & 9,8 & $-3,1$ & 1,6 & $-4,9$ & 0,8 & 10,0 & 11,2 & 8,2 & 10,4 \\
\hline 16 & 123 & 14,0 & 19,6 & 3,6 & 9,8 & $-3,1$ & 1,6 & $-4,9$ & 0,8 & 10,0 & 11,2 & 8,2 & 10,4 \\
\hline 17 & 121 & 13,4 & 18,9 & 3,3 & 9,5 & $-3,8$ & 0,9 & $-5,3$ & 0,5 & 9,3 & 10,5 & 7,8 & 10,0 \\
\hline 18 & 122 & 13,7 & 19,3 & 3,5 & 9,6 & $-3,4$ & 1,3 & $-5,1$ & 0,6 & 9,7 & 10,8 & 8,0 & 10,2 \\
\hline
\end{tabular}

FONTE: Calculado a partir das especificações contidas na ICAO Annex 14 (2004a) e na FAA AC 150/5300-13 (1989) e dos dados das aeronaves a: Dimensões em metro 
